University of Arkansas, Fayetteville

ScholarWorks@UARK

Graduate Theses and Dissertations

$5-2012$

\title{
Slope Stability Monitoring Using Remote Sensing Techniques
}

Omar Alberto Conte Robles

University of Arkansas, Fayetteville

Follow this and additional works at: https://scholarworks.uark.edu/etd

Part of the Construction Engineering and Management Commons, Geotechnical Engineering Commons, Remote Sensing Commons, and the Structural Engineering Commons

Citation

Conte Robles, O. A. (2012). Slope Stability Monitoring Using Remote Sensing Techniques. Graduate Theses and Dissertations Retrieved from https://scholarworks.uark.edu/etd/392

This Thesis is brought to you for free and open access by ScholarWorks@UARK. It has been accepted for inclusion in Graduate Theses and Dissertations by an authorized administrator of ScholarWorks@UARK. For more information, please contact scholar@uark.edu. 
SLOPE STABILITY MONITORING USING REMOTE SENSING TECHNIQUES 


\section{SLOPE STABILITY MONITORING USING REMOTE SENSING TECHNIQUES}

A thesis submitted in partial fulfillment of the requirements for the degree of Master of Science in Civil Engineering

By

Omar A. Conte Robles

Missouri University of Science \& Technology

Bachelor of Science in Civil Engineering, 2010

May 2012

University of Arkansas 


\begin{abstract}
During the past six years the Arkansas State Highway and Transportation Department (AHTD) has spent over nine million dollars repairing slope failures that have occurred in the state of Arkansas. Specifically, higher than average precipitation in 2004 and 2008 led to large quantities of slides, all of which were repaired. Two highways, within the state of Arkansas, with known historical movements along or across the highways are being monitored using traditional surveying techniques and advanced remote sensing techniques. These slides, both of which are located in fill slopes. One a 500-foot long slide located north of Chester, Arkansas, within the median of Interstate I-540. The other site is a 1200-foot long slide located east of Malvern, Arkansas, cutting across all four-lanes of Interstate I-30, have visible evidence of movement (tension cracks, traverse cracks, head scarps, flank displacement, etc.)
\end{abstract}

A ground portable RADAR interferometer (GPRI-II) constructed by Gamma Remote Sensing is the first device in the United States being used to remotely monitor slopes. Surveying monuments (2.5-inch diameter aluminum monuments placed on 24-inch long, 1/2-inch diameter rebar encased in 6-inches of concrete) were installed inside and outside of the sliding mass at each site (29 monuments at the calibration site in Chester, Arkansas site and 54 monuments at the validation site in Malvern, Arkansas), and are being monitored using traditional surveying techniques (using a Nikon DTM-520 total station) to identify the movement of each monument as detected from two observation points. The GPRI-II and a Leica C-10 LIDAR are also being used to identify the movement of the slopes. Inclinometers have been also installed at the validation site near Malvern, Arkansas to compare the displacements obtained by remote sensing techniques with standard borehole slope monitoring methods. The results of the movements observed using in-situ instrumentation, total station, RADAR, and LIDAR are discussed. 
A full geotechnical subsurface investigation was perform at the validation site in Malvern, Arkansas during the summer of 2011. The drilling and sampling investigation provided the necessary soil and rock samples for laboratory testing. The results from the laboratory tests permitted the displacement rates to be inspected in the light of the shear strength of the soil strata and the depth to the shear failure plane. Since December 2010, site visits have been conducted every two weeks for the Chester site and every month for the Malvern site. During each visit total station, RADAR, and LIDAR observations were conducted. 
This thesis is approved for

Recommendation to the

Graduate Council

Thesis Director:

Dr. Richard A. Coffman, P.E., P.L.S.

Thesis Committee:

Dr. Norman D. Dennis, P.E.

Dr. Brady R. Cox, P.E. 


\section{Thesis Duplication Release}

I hereby authorize the University of Arkansas Libraries to duplicate this thesis when needed for research and/or scholarship.

Agreed

Omar A. Conte Robles

Disagreed

Omar A. Conte Robles 


\section{Acknowledgments}

This research project would have not been possible without the support of various agencies and persons. I would like to acknowledge all the persons that in what way or another contributed with this research project presented in this thesis document.

- The Arkansas Highway and Transportation Department (AHTD) for funding the project research.

- Dr. Richard Coffman for his patience, guidance and mentoring in all the aspects throughout this research project.

- Dr. Cox and Dr. Dennis for their suggestions and availability to provide assistance while analyzing the data acquired.

- All the Geotechnical Graduate Students (G-I GSO) from the University of Arkansas for their continuous help and motivation.

- Mr. Greenwood from the Research Division of AHTD for his unconditional field support in both sites studied during this research project.

- Mr. Hall and Mr. Arnold from the Surveying Division of AHTD for acquiring all the LIDAR data utilized in this study.

- The University of Arkansas Civil Engineering Department and staff. 


\section{Dedication}

This thesis document is dedicated first of all to my parents for their absolute support and motivation during all the years of my academic career.

\section{ENILDA ROBLES DE CONTE OMAR CONTE SUCRE}

To my grandfather that with his behavior became a role model for me and provided the first engineering skills during my childhood.

\section{GONZALO ROBLES TAPIA "TALO”}

To all my family and friends that in what way or another helped me throughout this journey. 


\section{Table of Contents}

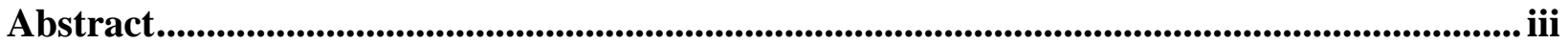

Acknowledgments ............................................................................................................. vii

Dedication .................................................................................................................................... viii

Table of Contents .......................................................................................................................... ix

List of Figures.............................................................................................................

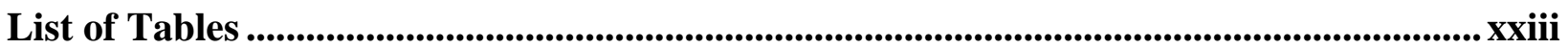

List of Equations ............................................................................................................................... $\mathrm{xxV}$

Chapter 1 . Introduction .................................................................................................................................. 1

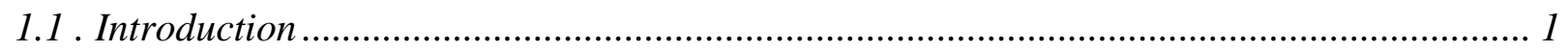

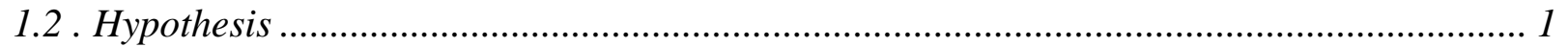

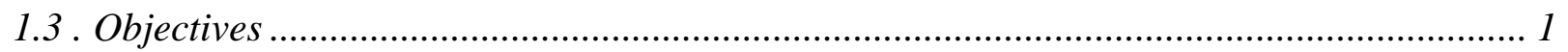

1.4 . Problem Statement t...................................................................................................... 2

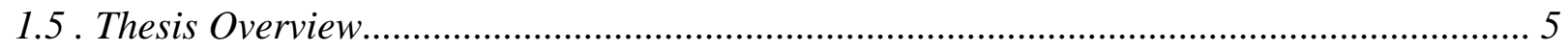

Chapter 2 . Literature Review ............................................................................................................. 6

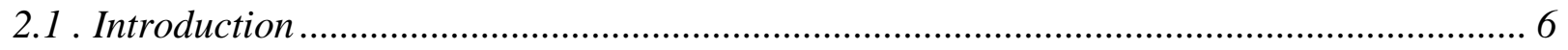

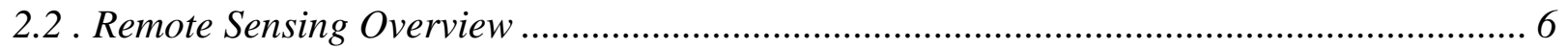

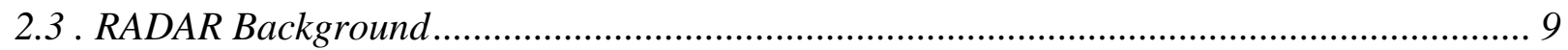

2.3.1 . Ground Based RADAR Equipment ……………................................................ 14

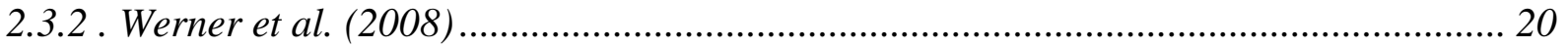

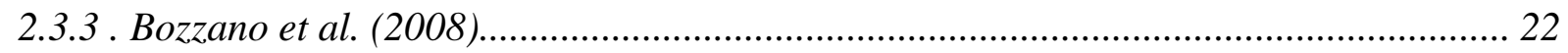

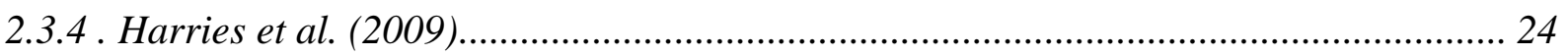

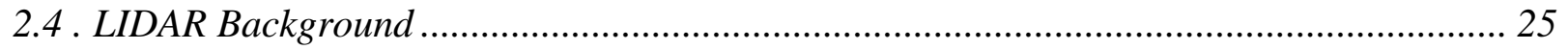

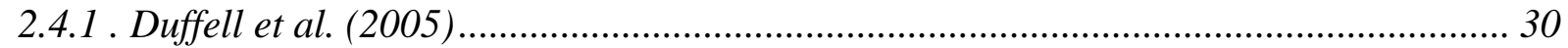

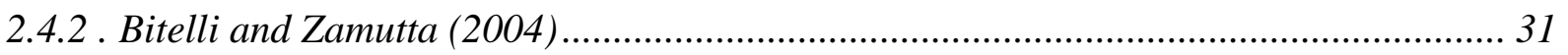

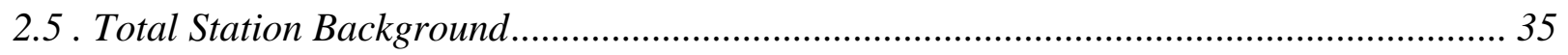

2.5.1 . Barla et al. (2010) .................................................................................................. 36

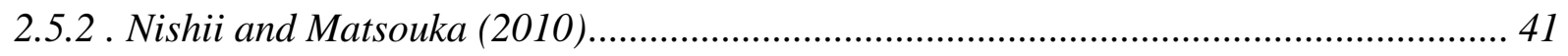

2.6 . Other Non-Remote Sensing Techniques used for Landslide Monitoring ........................... 43

2.6.1 . Dowding and Connor (2000) .................................................................................... 44

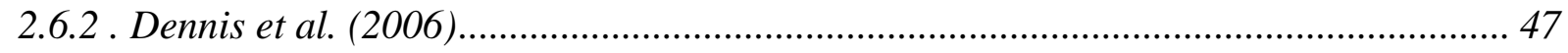




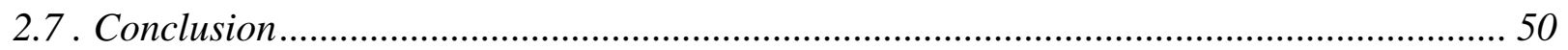

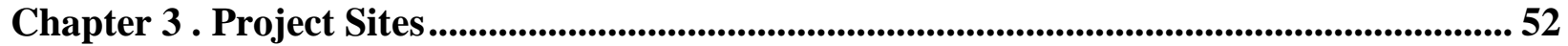

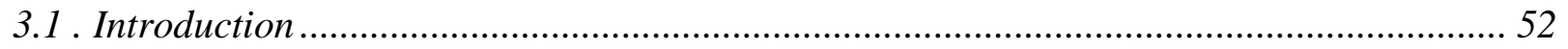

3.2 . Calibration Site - Chester, Arkansas..................................................................... 52

3.2.1 . Calibration Site Information ................................................................................... 53

3.2.2 . Three Dimensional Topographic Model ............................................................ 61

3.2.3 . Site Slope Stability Model for the Calibration Site (Chester, Arkansas) ..................... 64

3.3 . Validation Site - Malvern, Arkansas........................................................................ 66

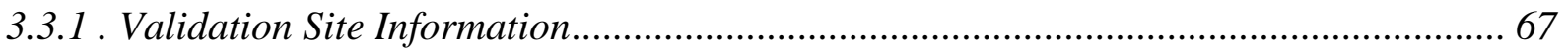

3.3.2 . Three Dimensional Topographic Model ........................................................... 74

3.3.3 . Validation Site Slope Stability Model .................................................................. 77

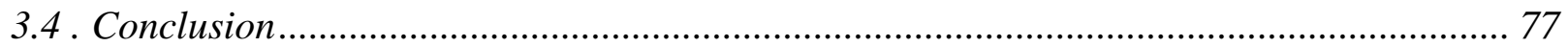

Chapter 4 . Field Instrumentation and Data Acquisition ...................................................... 79

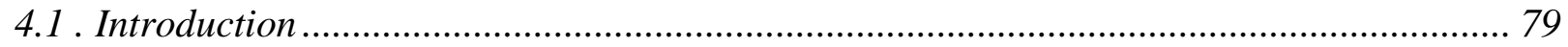

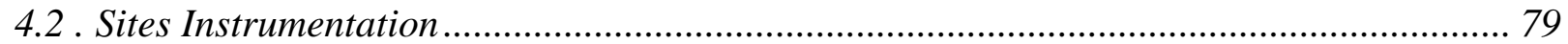

4.2.1 . Instrumentation at Calibration Site (Chester, Arkansas) ........................................ 81

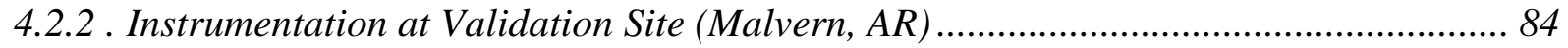

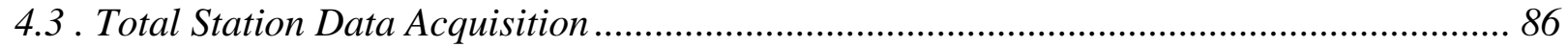

4.3.1 . Setup Procedure and Image Acquisition ............................................................... 88

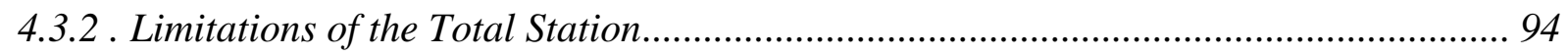

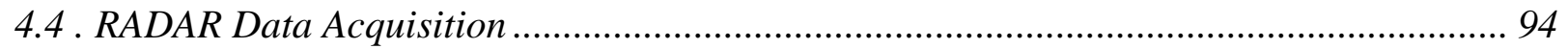

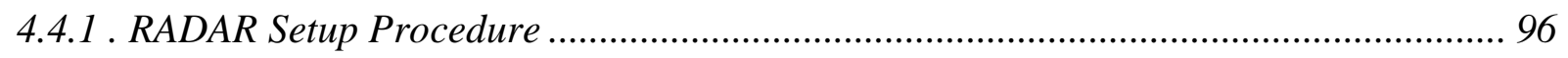

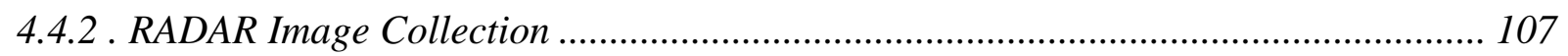

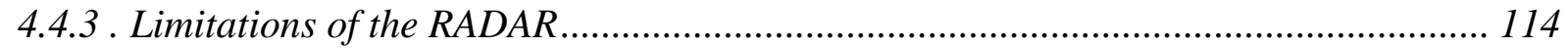

4.5 . LIDAR Data Acquisition............................................................................... 115

4.5.1 . LIDAR Setup Procedures ................................................................................. 115

4.5.2 . LIDAR Point Cloud Acquisition ........................................................................... 117

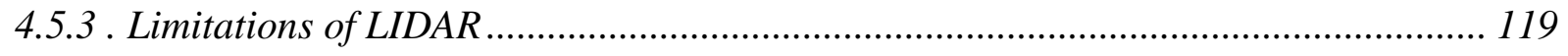

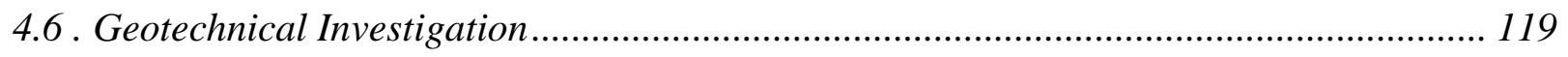

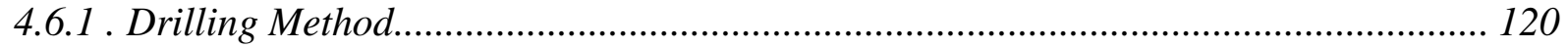

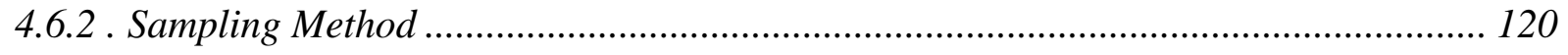




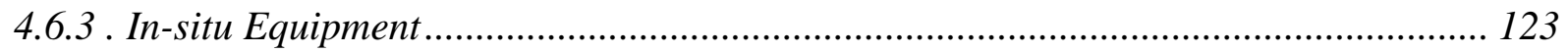

4.6.4 . Cone Penetrometer Testing (CPT) ................................................................... 128

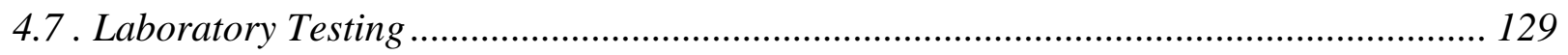

4.7.1 . Water Content and Index Properties................................................................ 130

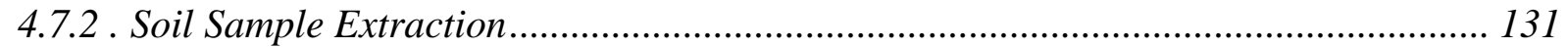

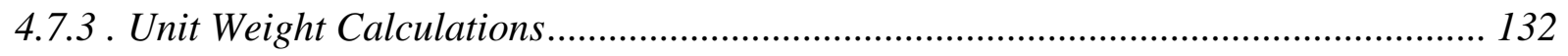

4.7.4 . Unconsolidated Undrained (UU) Triaxial Test ....................................................... 133

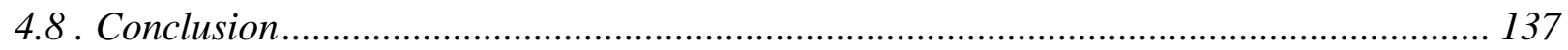

Chapter 5 . Data Reduction and Interpretation.................................................................................. 138

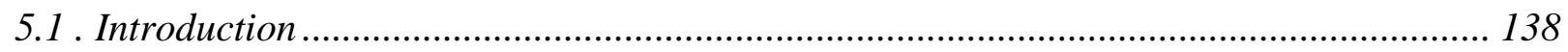

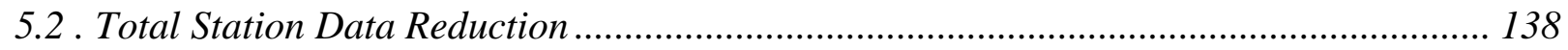

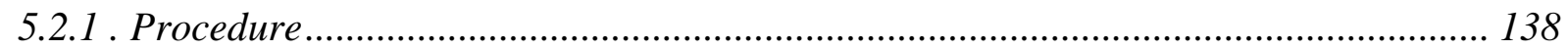

5.2.2 Analysis ............................................................................................................ 139

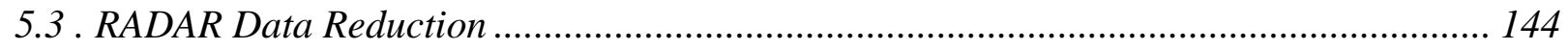

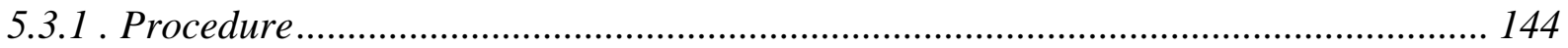

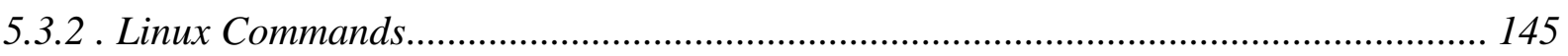

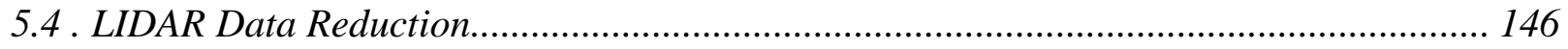

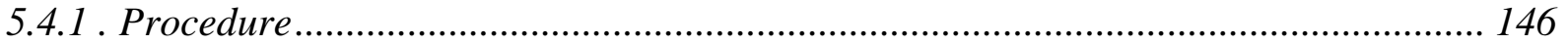

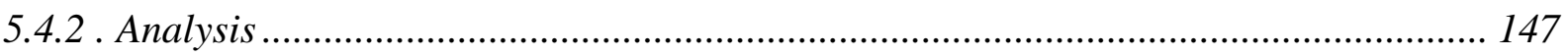

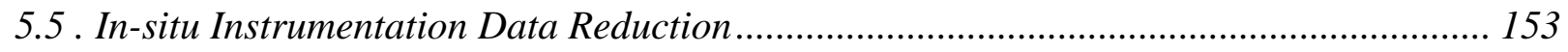

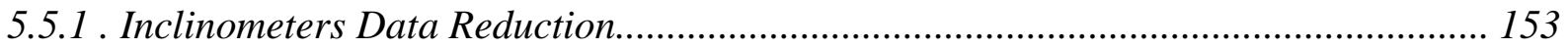

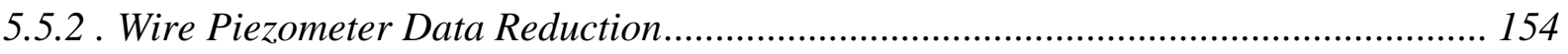

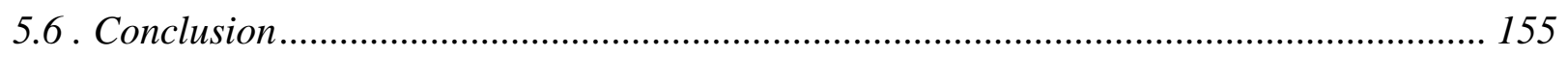

Chapter 6 . Results and Discussion ................................................................................................ 156

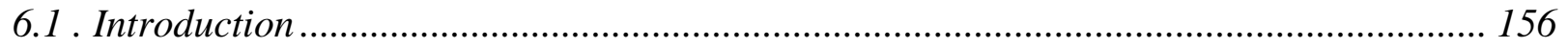

6.2 . Subsurface Exploration Results at the Validation Site (Malvern, Arkansas).................. 156

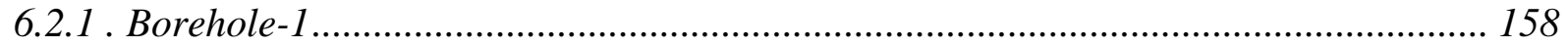

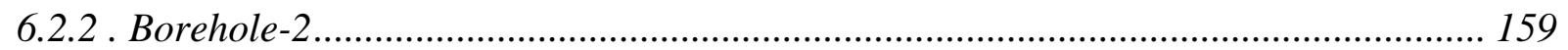

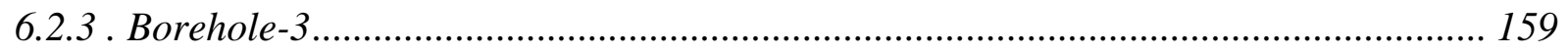

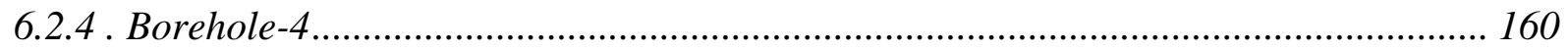

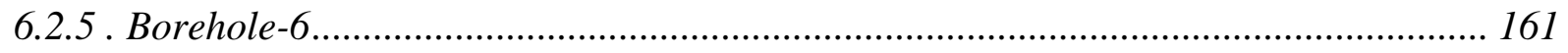


6.3 . Laboratory Testing Results............................................................................... 162

6.3.1 . Moisture Content and Index Properties............................................................... 162

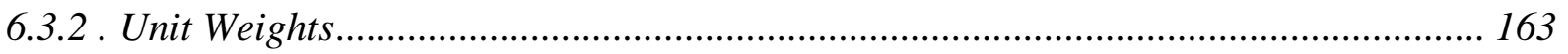

6.3.3 . Unconsolidated Undrained (UU) Triaxial Test .................................................. 166

6.4 . Preliminary Slope Stability Analyses ..................................................................... 170

6.4.1 . Preliminary Slope Stability Analysis at the Calibration Site (Chester, Arkansas).... 171

6.4.2 . Preliminary Slope Stability Analysis at the Validation Site (Malvern, Arkansas)...... 173

6.5 . Refined Slope Stability Analysis at the Validation Site (Malvern, Arkansas) ................. 173

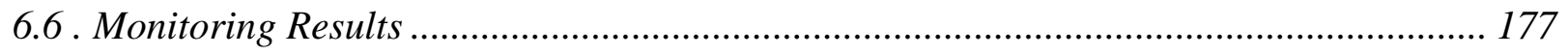

6.6.1 . Monitoring Results at the Calibration Site (Chester, Arkansas) ............................ 177

6.6.2 . Monitoring Results at the Validation Site (Malvern, Arkansas) .............................. 197

6.7 . Discussion of Results............................................................................................. 220

6.7.1 . Comparison of Monitoring Results at the Calibration Site (Chester, Arkansas) ....... 222

6.7.2 . Comparison of Monitoring Results at the Validation Site (Malvern, Arkansas)........ 224

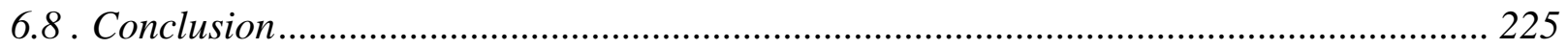

Chapter 7 . Conclusion and Recommendations ............................................................. 226

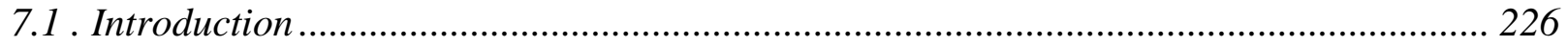

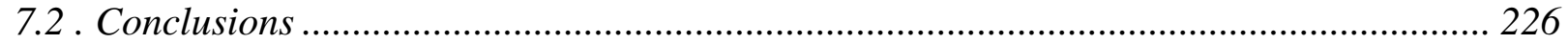

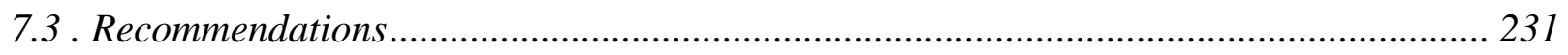

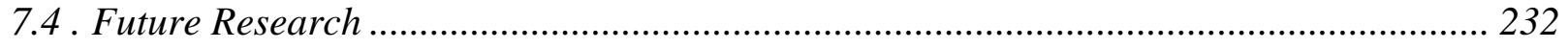

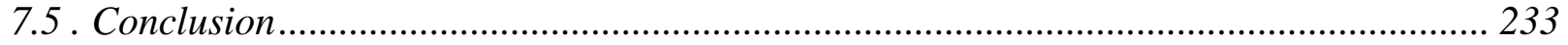

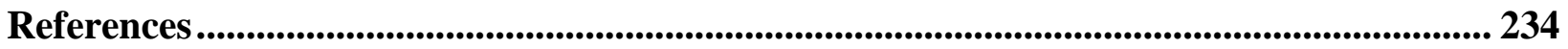




\section{List of Figures}

Figure 2.1. Schematic of the remote sensing process (from Jensen, 2007)................................. 7

Figure 2.2. Penetration of RADAR waves due to wavelength being larger than atmospheric

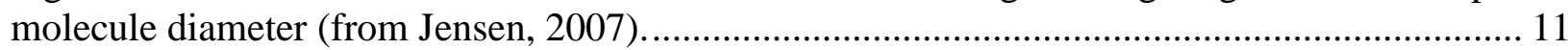

Figure 2.3. Wavelengths of commonly used microwave frequencies (from Jensen, 2007)......... 12

Figure 2.4. Schematic showing satellite based synthetic aperture RADAR concept (from Jensen,

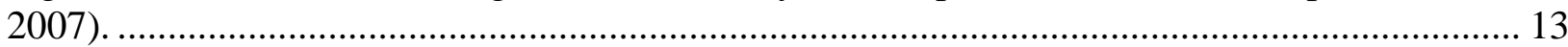

Figure 2.5. GPRI-II acquiring images of a mountain near Gumligen, Switzerland on October 31, 2010 (from GAMMA Remote Sensing AG, 2011). ………………………………………..... 16

Figure 2.6. (a) Photograph of GPRI-I with antennas and wave-pattern geometry, (b) differential interferogram of the Tessina landslide (modified from Wiesmann, 2008). 16

Figure 2.7. IBIS-L system at the Tessina landslide site (modified from Ingegneria Dei Sistem

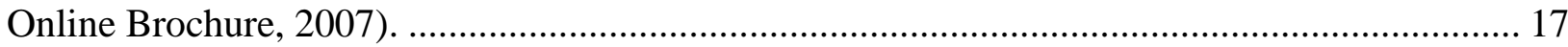

Figure 2.8.a) IBIS-L RADAR system: rail, sensor module, and computer/power component (from (Jungner, 2009), b) IBIS-L sensor module composed of receiver and transmitter antennas (from Ingegneria Dei Sistem Website, 2012) .......................................................................... 18

Figure 2.9. a) Photograph of the trailer mounted GroundProbe SSR acquiring data, and b) detailed photograph of the SSR parabolic dish antenna (from GroundProbe, 2012). .................. 19

Figure 2.10. a) GPRI-I acquiring images at the Rhône glacier, and b) RADAR image developed after data acquisition at Rhône glacier in October 2007 (from Werner et al., 2008).................... 21

Figure 2.11. a) LOS deformation map as developed from GPRI-I data collected at the Rhône glacier, and b) a DEM obtained from data collected in the two receiving antennas with a baseline of $15 \mathrm{~cm}$ (from Werner et al., 2008). ...................................................................................... 21

Figure 2.12. Segmented photographs of the platform and landslide site. Note the ongoing road work at the toe of the landslide (from Bozzano et al., 2008)...................................................... 23

Figure 2.13. a) Photograph of the exterior of IBIS-L platform enclosure, and b) photograph of the interior of the platform enclosure including the IBIS-L system (from Bozzano et al., 2008)...... 23

Figure 2.14. GroundProbe SSR deployed at Thompson Creek Mine, and b) wedge failure located in the central portion of the north highwall (from Harries et al., 2009). ..................................... 25

Figure 2.15. Diagram of an airborne laser scanning (ALS) LIDAR (from Jensen, 2009). .......... 27

Figure 2.16. Idealized schematic of terrestrial laser scanner (TLS) LIDAR principles showing multiple return geometries (from Jaboyedoff, 2010). 27 
Figure 2.17. Digital Elevation model created from ALS LIDAR, with locations of slip along the M25 London Orbtal Motorway shown in circles (from Duffell et al., 2005)..

Figure 2.18. Results from comparison of surfaces obtain using ALS LIDAR and surveys from a year apart (from Duffell et al., 2005) [in color]..... 31

Figure 2.19. a) Three dimensional digital elevation model created from aerial photogrammetric survey in 2000, b) Riegl LMS-Z210 on site in 2001, c) Riegl LMS-Z420i on site in 2004 (from Bitelli and Zamutta, 2004). .... 33

Figure 2.20. a) Different cross-sections shown in the original point cloud, b) LIDAR crosssection before filtering, c) LIDAR cross-section after filtering and vegetation removal, d) comparison of the 2000-2001 DTMs, e) comparison of the 2000-2004 DTMs, f) comparison 2001-2004 DTMs (from Bitelli and Zamutta, 2004). .......................................................... 34

Figure 2.21. EDM mounted on a theodolite; the first total station (from Wolf, 2002)............... 36

Figure 2.22. Monitor systems installed at the BDSGSD site (modified from Barla et al., 2010). 38

Figure 2.23. Photograph of BDSGSD site (from Valle d' Aosta Website, 2012)..................... 38

Figure 2.24. Comparison between displacements obtained with total station and GBInSAR for targets K1, K4, K13 and K19 (modified from Barla et al., 2010). ........................................ 40

Figure 2.25. Site layout and target positions (from Nishii and Matsouka, 2010)..................... 42

Figure 2.26. a) Scarp formed after the failure of 2004, b) overview of the monitored area (from

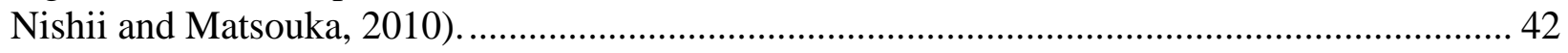

Figure 2.27. TDR waveforms and inclinometer profile against depth for case 1 (from Dowding

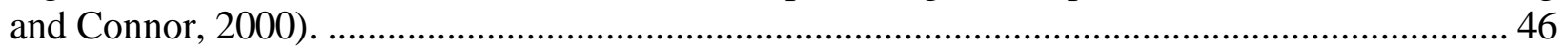

Figure 2.28. TDR waveforms compared to inclinometer profile for case 3 (from Dowding and Connor, 2000). 47

Figure 2.29. Cross-section of the test area along Highway 167 with instrumentation used (from

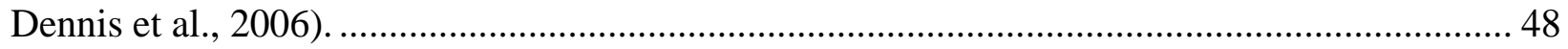

Figure 2.30. Inclinometers displacements obtained by the inclinometers on the Highway 167 project site (from Dennis et al., 2006).

Figure 2.31. Monitoring results obtained by TDR on the Highway 167 project site (from Dennis et al., 2006).

Figure 3.1. Location of calibration site along Interstate 540, near Log Mile 36.4 North of

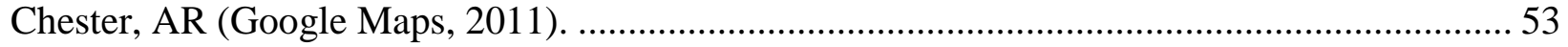

Figure 3.2. Photograph obtained while looking northeast across southbound lane of I-540 at calibration site near Chester, Arkansas. 
Figure 3.3. Looking north to the main scarp at the calibration site near Chester, Arkansas in May 2010 (from AHTD, 2010).

Figure 3.4. Looking southeast to the main scarp at the calibration site near Chester, Arkansas.. 56

Figure 3.5. a) Looking north, the main scarp at the calibration site located in Chester, Arkansas, and b) tension crack observed in the median of I-540. 56

Figure 3.6. a) Cracking in the edge of northbound lane, b) separation between the shoulder and the road on the I-540 northbound lane, and c) separation of approximately 5 inches observed during September 2010. 57

Figure 3.7. Traffic passing next to the main scarp in calibration site near Chester, Arkansas..... 58

Figure 3.8. Map of the bedrock geology near the calibration site (indicated by white star) along Interstate 540, near Log Mile 36.4 near Chester, Arkansas (USGS, 2011). 60

Figure 3.9. a) Optima 30mm prism, b) flat shoe for prism pole, and c) pointed shoe on the prim pole.

Figure 3.10. Researchers from the UofA a) preparing the total station for data acquisition, and b) acquiring topographic data at the calibration site near Chester, Arkansas.

Figure 3.11. Screenshot of the 3D model created for the calibration site (AutoCAD, 2011)...... 63

Figure 3.12. Typical 2D cross-section extracted from the 3D model (AutoCAD, 2011)........... 63

Figure 3.13. Values used to develop the UARK correlation for NWA soils (Ritchey, 1999)..... 65

Figure 3.14. Location of project site located at Log Mile 95.7 on Interstate 30 near Malvern, Arkansas. Anticipated slide area shaded in red (Google Maps, 2011). 68

Figure 3.15. a) Looking southwest from the hillside between Highway 84 and I-30, and b) looking west towards I-30 at the validation site near Malvern, Arkansas in December 2010. .... 68

Figure 3.16. Position of inclinometers and piezometers installed between 2004 and 2006 in validation site near Malvern, Arkansas (modified from Westerman, 2006)......

Figure 3.17. a) Tension cracking in the shoulder of the eastbound lane of Highway 84, and b) lane cracking and settlement failure in Highway 84. 71

Figure 3.18. a) Crack observed in the shoulder of the westbound lane of I-30, and b) crack in the westbound lane of I-30 in December 2010. 71

Figure 3.19. Geology map of validation site along Interstate 540, near Log Mile 36.4 at Chester, AR 73

Figure 3.20. Validation site statigraphy and underlying geology near Malvern, Arkansas (from Westerman, 2006). 74 
Figure 3.21.a) University personnel acquiring points for topographic model, b) looking South to the total station set up point in validation site near Malvern, Arkansas. .................................. 75

Figure 3.22. Topographic 3D model of the validation site near Malvern, Arkansas.................. 76

Figure 3.23. Profile view (vertical exaggeration $=4.0$ ) of the validation site near Malvern,

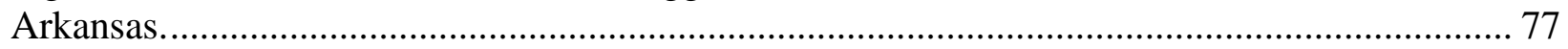

Figure 4.1. View of main scarp at the (calibration site) looking North from the median of I-540 near Chester, Arkansas. 81

Figure 4.2. Relative positioning of survey monument lines at the calibration site (Chester, Arkansas) looking east from the Southbound lane of I-540. 82

Figure 4.3. Plan view of calibration near Chester, Arkansas; the locations of survey monuments are illustrated. 82

Figure 4.4. a) Hole augured for monument installation, b) placing Quickcrete ${ }^{\circledR}$ in the hole, c) steel bar placed in the ground, and d) survey monument installed. 83

Figure 4.5. a) Installation of survey monument in the ground by UofA and AHTD personnel, and b) survey monument installed in the ground using Quickcrete®. 84

Figure 4.6. Plan view of survey monument positions installed in validation site near Malvern, Arkansas. 85

Figure 4.7. Alignments of installed survey monuments at the validation site near Malvern, Arkansas (modified Google Maps, 2011). 85

Figure 4.8. a) Nikon DTM-520 (Nikon Positioning Website, 2012), and b) Leica total station tripod utilized during this project. 87

Figure 4.9. a) 30mm Optima prism with bipod legs on a Sokkia prism pole with bipod legs, and b) Carlson Explorer 600+ data collector. 87

Figure 4.10. Nikon DTM-520 (Nikon Positioning Website, 2012)...................................... 89

Figure 4.11. Total station setup and backsight at the calibration site near Chester, Arkansas..... 91

Figure 4.12. Total station deployed at Survey Monument 1000 in Line 4 of the monuments at the validation site. 94

Figure 4.13. GPRI-II features (from GAMMA Remote Sensing AG, 2011). 95

Figure 4.14. a) tripod for GPRI-II anchored to footings, b) tripod's bubble level (from GAMMA Remote Sensing AG, 2011). 96 
Figure 4.15. a) Measurement of tripod leg, b) motor bubble level, c) antenna holder with elevation angles, and d) scope mounted on GPRI-II frame used for alignment ( $a, b$, and c from GAMMA Remote Sensing AG, 2011). 98

Figure 4.16. RADAR viewpoints locations at look directions at the calibration site near Chester, Arkansas (modified from Google Maps, 2011). 100

Figure 4.17. a) Southbound viewpoint, and b) Overlook viewpoint. 100

Figure 4.18. a) Placing concrete footings for GPRI-II at the Southbound viewpoint at the calibration site, and b) tripod of GPRI-II anchored at the Southbound viewpoint near Chester, Arkansas. 101

Figure 4.19. a) Anchoring tripod to rock at the Overlook viewpoint, and b) PK nail in rock used to center the GPRI-II at the Overlook viewpoint near Chester, Arkansas. 102

Figure 4.20. Location of the locations of the GPRI-II at the validation site near Malvern, Arkansas (modified from Google Maps, 2011). 103

Figure 4.21. a) GPRI-II scanning at the NE viewpoint, b) GPRI-II scanning at the SW viewpoint. c) deployment of the GPRI-II at night at the NE viewpoint, and d) nighttime RADAR deployment at the SW viewpoint. 104

Figure 4.22. a) Tripod of the GPRI-II anchored to the asphalt pavement in northeast viewpoint, b) location of northeast viewpoint in validation site near Malvern, Arkansas, and c) scope aligned to corner of storage facility before image acquisition. 106

Figure 4.23. a) Concrete footings placed at the southwest viewpoint in validation site, and b) looking east from the southwest viewpoint. 107

Figure 4.24. GPRI-II acquiring data during fog in overlook viewpoint (calibration site) near Chester, Arkansas. 109

Figure 4.25. a) Photograph of GPRI-II acquiring images at the Southbound viewpoint, and b) waiting for a window in the traffic flow to acquire images at the Southbound viewpoint. 110

Figure 4.26. a) Viewing geometry of the GPRI-II at overlook viewpoint, and b) University researcher acquiring data with GPRI-II. 111

Figure 4.27. a) GPRI-II acquiring data at the NE viewpoint, and b) viewing geometry of the GPRI-II at the NE in validation site. 113

Figure 4.28. GPRI-II ready for data acquisition (at night) from the SW viewpoint near Malvern, Arkansas. 114

Figure 4.29. a) RADAR and LIDAR Southbound viewpoint, and b) LIDAR deployed at Point 2010 . 116 
Figure 4.30. a) LIDAR being deployed at the NE viewpoint, and b) LIDAR acquiring data at the SW viewpoint. 117

Figure 4.31. LIDAR target positioned at the Southbound Total Station viewpoint at the calibration site near Chester, Arkansas. 118

Figure 4.32. (a) AHTD drill truck used for geotechnical exploration, (b) view of AHTD rotary wash method used for sample collection near Malvern, Arkansas. 120

Figure 4.33. Geotechnical investigation borehole locations at the validation site (modified from Google Maps, 2011) 121

Figure 4.34. a) Torvane test being performed on a tube, b) index test locations. 122

Figure 4.35. Core rock sample box from sampling operations at validation site in Malvern, Arkansas. 123

Figure 4.36. a) Sections of inclinometer casing, b) installation of inclinometer casing, c) preparing grout mix, and d) grout connection between tremie and grout pump..... 125

Figure 4.37. a) AHTD personnel installing nested vibrating wire piezometer in borehole B-2, and b) saturating transducers prior to placement in the hole. 126

Figure 4.38. a) Post-installation view of Inclinometer B-3, and b) nested vibrating wire piezometer installed in B-2. 126

Figure 4.39. a) Lowering probe into inclinometer casing at B-4, and b) recording slope inclinometer data using the readout box. 128

Figure 4.40. a) Obtaining readings of the different pore pressure transducers installed at different depths, and b) vibrating wire piezometer data readout box. 128

Figure 4.41. a) Cone penetrometer test being performed at the CPT-1 location, and b) cone penetrometer rig conducting the test at CPT-2 location. 129

Figure 4.42. Moisture contents being obtained at a facility nearby the validation site. 130

Figure 4.43. a) Central Machinery band saw cutting Shelby tube sample for UU test, and b) six inches Shelby tube specimen for UU test. . 131

Figure 4.44. a) Shelby tube sample wrapped to prevent moisture change, b) circular hand saw used to start splitting the Shelby tubes specimen, c) final cuts with the Dremel before splitting the Shelby tube specimen, d) Shelby tube specimen with seam parallel to tube, e) retrieving soil specimen for UU test, and f) UU test specimen after Shelby tube extraction. 132

Figure 4.45. a) Height measurement of UU test soil specimen, b) measuring diameter of UU soil specimen using Pi tape, and c) scale utilized to obtain weight of the soil specimen. 133 
Figure 4.46. a) Soil specimen being level to prevent concentration of stresses, b) placing membrane around the sample, and c) securing o-ring to seal the UU triaxial cell................... 134

Figure 4.47. a) UU triaxial apparatus, and b) UU test being conducted in a soil specimen obtained from validation site near Malvern, Arkansas. 135

Figure 4.48. Soil specimen B-2 ST2 after UU triaxial test, sample ready for post-test moisture content. 136

Figure 4.49. a) Rock sample obtained from coring operations at validation site, and b) wet saw used to cut rock samples. 137

Figure 5.1. Diagram with an illustration of the procedures followed for the angle method....... 141

Figure 5.2. Graph obtained from Microsoft Excel® after the angles method was performed for Check 4 site visit at the validation site in Malvern, Arkansas. 142

Figure 5.3. a) Plan view of the validation site while tangent method was attempted, and b) zoomed view of the intersection between the two circles developed during the tangent method using AutoCAD Civil 3D®. 143

Figure 5.4. a) Cyclone ${ }^{\circledR}$ screenshot after polyline method was finished, and b) plan view of the ground polylines at validation site in Malvern, Arkansas [in color] ..................................... 148

Figure 5.5. Classified point cloud as a non-vegetative layer and a vegetation layer................. 151

Figure 5.6. Point cloud after bare earth correction method. ............................................. 152

Figure 6.1. Soil strata cross-section containing boreholes B-1, B-3 and B-6 in validation site near Malvern, Arkansas. 157

Figure 6.2. a) Auguring first 20 feet at B-1, and b) rotary wash method being performed at B-1. 158

Figure 6.3. a) Rock sample obtained coring at B-2 (validation site), and b) post-drilling conditions at B-2. 159

Figure 6.4. a) Drilling operations at B-3, and b) measuring RQD of rock sample obtained from B-3....... 160

Figure 6.5. a) Pre-drilling conditions at B-4, and b) torvane test being performed in Shelby tube soil sample. 161

Figure 6.6. a) Changing to rotary wash method at B-6, and b) rock sample obtained from B-6.162 Figure 6.7. Soil index properties for recovered samples from the validation site as determined by Atterberg Limit tests. 163

Figure 6.8. Design moisture content, unit weight and Atterberg Limits profile. 165 
Figure 6.9. Normalized stress-strain graph of UU test for B-2 specimens at validation site...... 167

Figure 6.10. Design strength profile for validation site near Malvern, Arkansas..................... 169

Figure 6.11. Slope stability analysis using the UARK correlation for the calibration site........ 172

Figure 6.12. Slope stability analysis using the UU test residual values site [in color]............. 177

Figure 6.13. Plan view of total station Check 15 at calibration site near Chester, Arkansas. .... 179

Figure 6.14. Horizontal displacements measured and precipitation data for calibration site..... 181

Figure 6.15. Elevation differences measured and precipitation data for calibration site........... 181

Figure 6.16. Displacements after four Checks performed at the calibration site [in color]....... 183

Figure 6.17. Displacements of the last five Checks conducted at calibration site [in color]..... 184

Figure 6.18. Maximum displacement rates (horizontal) and cumulative precipitation data with time for calibration site near Chester, Arkansas. .............................................................. 185

Figure 6.19. Elevation differences rates (vertical) and cumulative precipitation data with time for calibration site near Chester, Arkansas........................................................................ 186

Figure 6.20. Displacement areas for the calibration site; red zone represents largest movements, orange zone represents medium movements, and yellow areas low to zero movement [in color]. 187

Figure 6.21. Zones of vertical movements for the calibration site; red zone represents largest down movements, orange zone represents down medium movements, yellow areas low to zero down movement, and blue areas represent uplift movement [in color].... 188

Figure 6.22. a) Surface developed using polylines method, and b) Surface developed using bare earth correction method [in color]. 189

Figure 6.23 a) Volume surface 03/17/11-06/08/11 (obtained using polylines method) where maximum elevation difference on the main scarp was observed, and b) zoomed view to the main scarp where progressive movement was observed from 05/17/11 to 06/08/11 [in color]. 191

Figure 6.24. a) Volume surface 03/17/11-06/08/11 (obtained using bare earth correction method) where maximum elevation difference on the main scarp was observed, and b) zoomed view to the main scarp where progressive movement was observed from 05/17/11 to 06/08/11 [in color].

Figure 6.25. a) MLI RADAR image obained from southbound viewpoint in polar corrdinates using 500ms chirp, and b) MLI RADAR image obained from southbound viewpoint in rectangular corrdinates using 500ms chirp. 194 
Figure 6.26. a) MLI RADAR image obained from southbound viewpoint in polar corrdinates using 250ms chirp, and b) MLI RADAR image obained from southbound viewpoint in rectangular corrdinates using $250 \mathrm{~ms}$ chirp. 195

Figure 6.27. MLI RADAR image obained from overlook viewpoint in polar corrdinates using $4 \mathrm{~ms}$ chirp. 196

Figure 6.28. MLI RADAR image obained from overlook viewpoint in polar corrdinates using $4 \mathrm{~ms}$ chirp. 197

Figure 6.29. Recorded displacement (at the monuments) and digital elevation model of the validation site obtained using the total station. 199

Figure 6.30. Horizontal displacements measured and precipitation data for validation site..... 201

Figure 6.31. Elevation differences measured and precipitation data for validation site............ 201

Figure 6.32. Displacements recorded on four checks on validation site [in color]................. 203

Figure 6.33. Displacements recorded on the last four checks on validation site [in color]....... 204

Figure 6.34. Movement areas based on survey monument displacements obtain with total station at validation site [in color]. 204

Figure 6.35. Comparison of displacements obtained from control point 1000 and control point 1029 for validation site near Malvern, Arkansas. 207

Figure 6.36. Volume surface (050311-120211) obtained using polylines method at the validation site [in color]. 208

Figure 6.37. Volume surface (050311-120211) obtained using bare earth correction method at the validation site [in color] ...... 209

Figure 6.38. a) Volume surface (062711-080111) using bare earth correction method, and b) volume surface (062711-120211) using bare earth correction method [in color]. 209

Figure 6.39. a) MLI RADAR image obained from Northeast viewpoint in polar corrdinates using 250ms chirp, and b) MLI RADAR image obained from Northeast viewpoint in polar corrdinates using 250ms chirp. 211

Figure 6.40. MLI RADAR image obained from Southwest viewpoint in polar corrdinates using $500 \mathrm{~ms}$ chirp, and b) MLI RADAR image obained from Southwest viewpoint in polar corrdinates using 500ms chirp. 212

Figure 6.41. Profile of the slope inclinometer installed at B-1 location for the site visits to the validation site, and b) Profile of the slope inclinometers casing installed at the B-3 location for the site visits to the validation site. 215 
Figure 6.42. Profile of the slope inclinometer installed at B-4 location for the site visits to the validation site, and b) Profile of the slope inclinometers casing installed at the B-6 location for

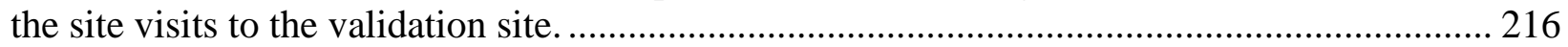

Figure 6.43. Sliding surface as recorded by slope inclinometers installed at validation site [in

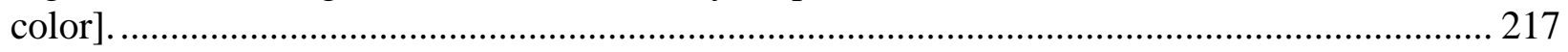

Figure 6.44. Pressure obtained from the nested vibrating wire piezometer [in color].............. 220 


\section{List of Tables}

Table 1.1. Methods used for determining stability of slopes (from Coffman, 2010)................. 4

Table 2.1. Properties of most common slope monitoring techniques compared to RADAR........ 9

Table 2.2. List of commercially available satellites and their attributes (from Coffman, 2009).. 10

Table 2.3. RADAR band wavelengths and frequencies (from Coffman, 2009)....................... 12

Table 2.4. Summary of major features of the main ground based RADARs. ........................... 20

Table 3.1. Summary of soil parameters used in the slope stability analysis for calibration site .. 66

Table 3.2. Location and depth of piezometers installed at the validation site between 2004 and 2006 (modified from Westerman, 2006).

Table 3.3. Location, depth, installation date, and observed cumulative movement of validation site inclinometers at the validation site 2004 and 2006 (from Westerman, 2006). ................... 70

Table 3.4. Summary of soil parameters utilized of the initial slope stability analysis for the validation site. 77

Table 4.1. Dates, corresponding deltas, and comments for the calibration site acquisition located near Chester, AR. 91

Table 4.2. Dates, corresponding deltas, and comments for the calibration site acquisition located

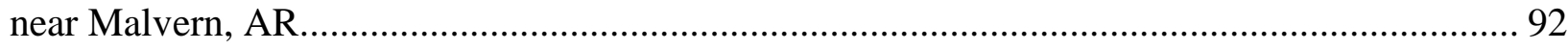

Table 4.3. Observation schedule for the calibration site near Chester, Arkansas...................... 99

Table 4.4. Observation schedule for the calibration site near Chester, Arkansas..................... 105

Table 4.5. Values utilized for data acquisition in southbound viewpoint near Chester, Arkansas. 110

Table 4.6. Values utilized for data acquisition in overlook viewpoint near Chester, Arkansas. 111

Table 4.7. Summarized values utilized in the NE viewpoint near Malvern, Arkansas 112

Table 4.8. Summary of values utilized during GPRI-II data acquisition near SW viewpoint in Malvern, Arkansas. 113

Table 4.9. Observations schedule for LIDAR data acquisition at the calibration site near Chester, Arkansas. 118

Table 4.10. Observation schedule for LIDAR data acquisition at validation site near Malvern, Arkansas. 119 
Table 4.11. Summary of samples from geotechnical exploration.

Table 4.12. Summary of inclinometer installation details.

Table 5.1. Summary of displacements (horizontal) and elevation differences for the four first monuments after Check 12 at the calibration site near Malvern, AR.

Table 5.2. Summary of relevant data reduction Linux commands 146

Table 6.1. Summary of rock sample tested in confined compression test. 170

Table 6.2. Summary of unconfined compression test results performed in rock samples. 170

Table 6.3. Summary of factors of safety obtained using different SPT- $\mathrm{S}_{\mathrm{u}}$ correlation methods for calibration site.... 172

Table 6.4. Summary of results for the preliminary slope stability analysis of the validation site. 173

Table 6.5. Summary of soil parameters used in the refined slope stability analysis at the validation site near Malvern, Arkansas. 174

Table 6.6. Summary of factors of safety obtained after refined slope stability analysis for the validation site. 175

Table 6.7. Summary of precipitation data for October 2010 to January, 2012 at calibration site near Chester, Arkansas (from National Oceanic and Atmospheric Administration, 2012)....... 180

Table 6.8. Summary of maximum and minimum displacements and elevation differences for calibration site. 183

Table 6.9. Summary of precipitation data for validation site near Malvern, Arkansas (modified from National Oceanic and Atmospheric Administration, 2012). 200

Table 6.10. Summary of maximum and minimum displacements and elevation differences for validation site. 202

Table 6.11. Summary of results for inclinometers installed at validation site. 214

Table 6.12. Summary of data and results obtained from the nested VWP. 219 


\section{List of Equations}

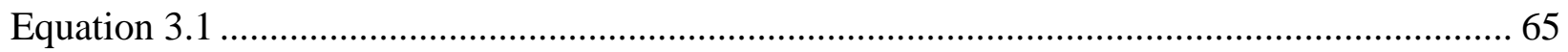

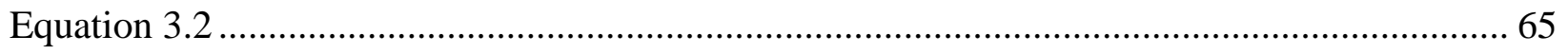

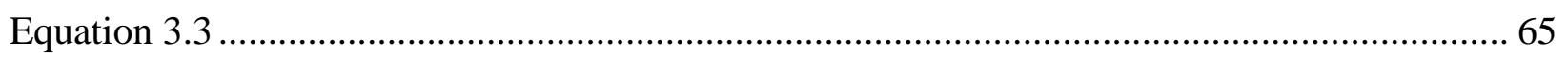

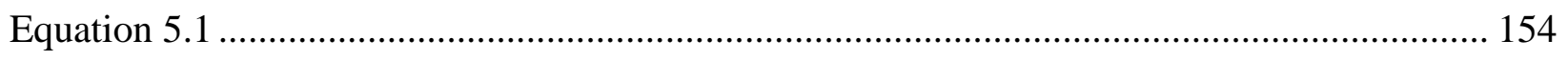

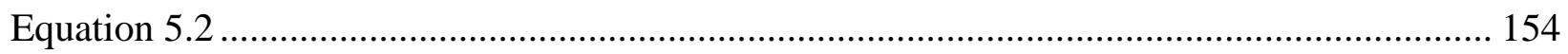




\section{Chapter 1. Introduction}

\subsection{Introduction}

An overview of this research project (Arkansas State Highway and Transportation Department [AHTD] Transportation Research Committee [TRC] Project Number 1102, commonly referred to as AHTD TRC-1102) is described in this chapter. The hypotheses investigated through the AHTD TRC-1102 research project are described; followed by a description of the objectives that the research was designed to accomplish. An overview of this thesis document is also presented outlining subsequent chapters.

\subsection{Hypothesis}

The surface extents, movement rates, vertical displacements, and direction of movements of a given landslide can be quantitatively identified using advanced remote sensing techniques. Specifically, the Gamma Portable RADAR Interferometer (GPRI-II) and a Leica C-10 Light Detection and Ranging (LIDAR) scanner are suitable for landslide monitoring applications. Furthermore, the movement obtained using advance remote sensing techniques (LIDAR and GPRI) are more precise than the commonly employed traditional surveying techniques and comparable to the results obtained using standard monitoring techniques such as slope inclinometers.

\subsection{Objectives}

The objectives of this research project were to: 1) validate the use of the GPRI-II and the LIDAR as tools to monitor slope stability failures to determine the extent of sliding masses within the State of Arkansas, 2) verify that the GPRI-II or LIDAR can define, to a high level of confidence, the limits, extents, and rate of movement within a sliding mass, and 3) compare the results obtained using the GPRI-II and LIDAR with other techniques currently used for landslide 
monitoring, such as traditional surveying techniques and slope inclinometers. These objectives were evaluated through:

1) reviewing of the relevant literature about slope monitoring using remote sensing technologies;

2) conducting laboratory testing on soil and rock samples recovered during on-site investigation (the results from the laboratory tests were used to determine the onsite soil properties, which were then used in computer modeling software programs);

3) measuring soil displacement and depth to water table measurements obtained from inclinometers and piezometers installed;

4) monitoring slopes with known movement using traditional surveying equipment (total station), the GPRI-II, and LIDAR;

5) comparing the collected data to determine which technique(s) shall be used for slope monitoring; and,

6) providing documentation to the AHTD with the necessary information regarding the implementation of the techniques for monitoring landslides.

\subsection{Problem Statement}

While individual slope failures are not as spectacular or costly as other natural disasters such as earthquakes, major floods, and tornadoes; slope failures are more widespread. In aggregate, the total financial loss due to slope failures is probably greater than that for any other single geologic hazard (Griffiths et al., 1999). In fact, seismically induced landslides (either directly through horizontal or vertical acceleration or indirectly through increased hydrostatic pore pressure) are a primary damage mechanism in many earthquakes. In addition to the significant economic damage inflicted on infrastructure by landslides every year, such slope failures may 
also directly threaten human safety through structural collapse or the severance of transportation routes during an emergency. The ability to precisely identify the extents of landslide, and to monitor and pre-emptively mitigate potential landslide disasters can help save money and ensure slope remediation is properly performed. The use remote sensing techniques saves labor time and equipment cost when used on numerous projects relative to the current state of practice (inclinometers, piezometers, traditional survey). For example, when inclinometers are installed they require the mobilization and deployment of a drilling crew for installation and only provide limited (point wise) data regarding the sliding mass. While some site instrumentation must be used, even with remote sensing techniques, the quantity of inclinometers and piezometers is greatly reduced allowing for reduction in project cost and project time. Furthermore, all of the methods used to determine the stability of slopes require knowledge of both the slope and the sliding surface geometries. The slope geometry is commonly unknown; however, remote sensing will aid in identifying the geometry. A list of typically employed methods to determine the stability of a slope is presented in Table 1.1.

Due to its proximity to the University of Arkansas (UofA), the active failure occurring near Chester, Arkansas, along Interstate 540, at Log Mile 36.4, was chosen as a calibration site. The active failure occurring near Malvern, Arkansas, along Interstate 30, at Log Mile 95.7, was selected as a validation site for this project. Contained in this document is documentation to aid the AHTD in determining the most appropriate method of monitoring. Specifically, the primary goal of this research project (AHTD TRC-1102) was to validate the use of remote sensing technology, specifically the GRPI-II and LIDAR, to monitor slopes in the state of Arkansas. 
Table 1.1. Methods used for determining stability of slopes (from Coffman, 2010).

\begin{tabular}{|c|c|c|}
\hline Method & Procedure & Identification \\
\hline \multirow{4}{*}{ Limit Equilibrium } & $\begin{array}{l}\text { Single free-body } \\
\text { Procedures }\end{array}$ & $\begin{array}{c}\text { Infinite Slope } \\
\text { Logarithmic Spiral Procedure } \\
\text { Swedish Circle } / \Phi=0 \text { Method }\end{array}$ \\
\hline & $\begin{array}{l}\text { Procedure of Slices: } \\
\text { Circular Slip Surface }\end{array}$ & $\begin{array}{c}\text { Ordinary Method of Slices Simplified Bishop } \\
\text { Procedure } \\
\text { Inclusion of Known and Unknown Forces } \\
\text { Complete Bishop Procedure }\end{array}$ \\
\hline & $\begin{array}{l}\text { Procedure of Slices: } \\
\text { Noncircular Slip } \\
\text { Surfaces }\end{array}$ & $\begin{array}{c}\text { Lowe and Karafiath } \\
\text { Simplified Jambu } \\
\text { U.S.A.C.E modified Swedish Method } \\
\text { Jambu's Generalized Procedure of Slices } \\
\end{array}$ \\
\hline & $\begin{array}{l}\text { Complete } \\
\text { Equilibrium } \\
\text { Procedures }\end{array}$ & $\begin{array}{l}\text { Spencer } \\
\text { Morgenstern and Price } \\
\text { Chen and Morgenster }\end{array}$ \\
\hline Charts & & $\begin{array}{l}\text { Fellenius } \\
\text { Taylor } \\
\text { Jambu }\end{array}$ \\
\hline Finite Element & $\begin{array}{l}\text { Computer } \\
\text { Program }\end{array}$ & $\begin{array}{l}\text { SV- Dynamic } \\
\text { Phase-2 } \\
\text { GFA-2D }\end{array}$ \\
\hline Finite Difference & Computer Program & FLAC/Slope \\
\hline
\end{tabular}

Finally, using the GPRI-II or LIDAR will provide more information of different slope scenarios throughout the state of Arkansas. Comparisons of these sites will ultimately determine mechanisms (present precipitation events, past precipitation events, hydrostatic water level in soil mass) that trigger landslides, increasing the understanding of this phenomenon. Correlating periods of large rates of movement and accelerated displacements with the time of the year or weather conditions will allow AHTD to anticipate mitigation techniques and reduce road closures or failures. Ultimately, the knowledge gained from this project should be used in the state of Arkansas and other states also to determine the efficacy of remediation measures used to prevent future slope movement. 


\subsection{Thesis Overview}

A summary of all the information acquired, computations, analysis, and results obtained during the research project (TRC-1102) are presented in this thesis. This document is organized and divided in seven chapters in order to document. The first chapter (Introduction) is an overview of the project including the hypotheses and objectives that motivated the research. Background information about the different techniques implemented to monitor the selected slopes failures, and a literature review of the research conducted by other researches on this topic are presented in the second chapter (Literature Review). A detail description of the location, geology, and history of each site is detailed in the third chapter (Project Sites).

A detailed description of the methodology used, and remote sensing or other monitoring techniques tested during the research study are discussed in Chapters 4-6. Specifically, the site instrumentation, procedures implemented, process for data acquisition of the three remote sensing techniques, and limitations of each technique are presented in the fourth chapter (Methods and Procedures). In the fifth chapter (Data Reduction) an explanation of steps followed to reduce the data obtained in the field is presented, along with the discussions about the software used for analysis. In the sixth chapter (Results and Discussion), the findings of the research are discussed. An explanation of each result is presented for a better understanding of the reasons that led to the findings.

The conclusions obtained from this research study and recommendation for future research are listed and discussed in the seventh chapter (Conclusion and Recommendations). Specifically, the need for further research is identified to provide a guide for the next steps associated with continued research on this topic. Appendices are also provided with specific step-by-step information that was to verbose to be discussed in the individual chapters. 


\section{Chapter 2. Literature Review}

\subsection{Introduction}

Research has been conducted by previous researchers regarding the development and use of remote sensing as applied to engineering applications. Specifically, most of the research discussed in the literature involves the use of remote sensing for the investigation, characterization, and quantification of landslides. Details of the previous work involving the use of three remote sensing techniques (RADAR, LIDAR, and Total Station) are described in this chapter in Sections 2.3, 2.4, and 2.5, respectively. Seven case studies, as presented in the literature, are also discussed in the aforementioned Sections to illustrate the use of these remote sensing techniques for engineering applications.

The use of inclinometers and time domain reflectometry (in-situ non-remote sensing measurements) for landslide monitoring are discussed and explained in this chapter (Section 2.6) for comparison with the remote sensing techniques. A comparison of the results obtained using inclinometers and time domain reflectometry are presented through discussion of two case histories. The key findings from the literature review are summarized in Section 2.7.

\subsection{Remote Sensing Overview}

Data collection is an important aspect of any research project. Specifically, the data collection method must provide sufficient temporal and special resolution to provide researchers with an understanding of the phenomenon of interest. Using remote sensing, researchers collect data about a source of interest from a remote distance enabling faster data collection without accessing or disturbing the study area. Therefore, remote sensing allows for the collection of data without an invasive onsite presence. Although, some on-site study may need to be performed in addition to remote sensing (for calibration and validation purposes), the amount of on-site work 
is minimal when compared to traditional in-situ techniques. Remote sensing data-collection and analysis procedures are often implemented in a systematic way, developed from the scientific method (Jensen, 2007). A typical (or idealized) remote sensing process used for extracting information from remotely sensed data is presented in Figure 2.1.

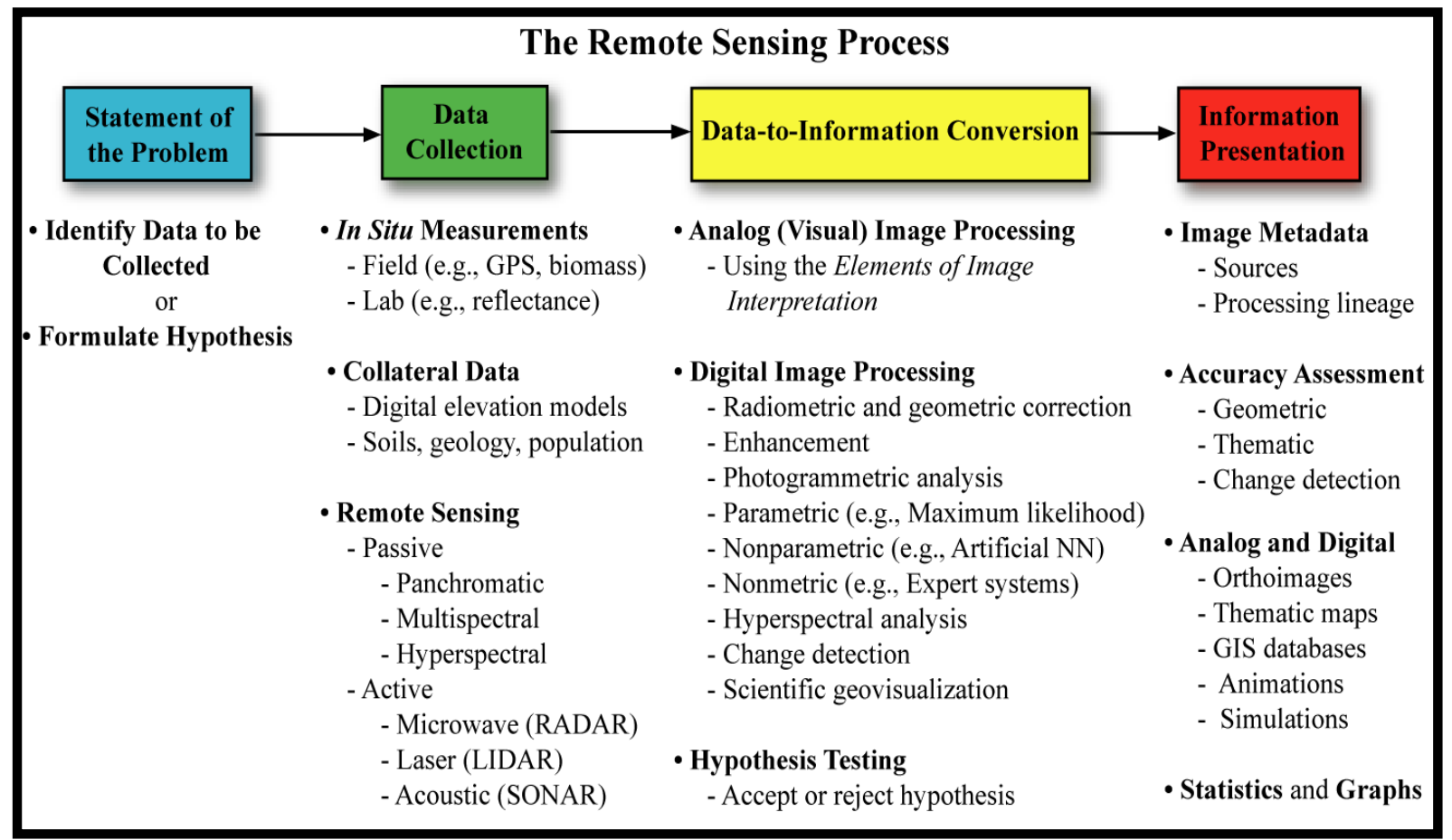

Figure 2.1. Schematic of the remote sensing process (from Jensen, 2007).

As with any field measurements technique there are limitations to the use of remote sensing techniques. Remote sensing cannot provide a complete solution for all engineering applications. Also, remote sensing instruments may become uncalibrated, leading to incorrect sensor data. Weather, vegetation and other factors that may affect remote sensing must be identified, characterized, and quantified before, during and after data collection and when analyzing results.

Unlike traditional surveying techniques (total station), remotely sensed data provide higher spatial resolution (millions of points versus tens or hundreds of points) which provide a more complete description of the characteristics of a large geographical area. Another principal 
advantage of remote sensing is that it causes minimal or no disturbance to the object or area of interest. Furthermore, data is gathered using remote sensing techniques by collecting backscattered energy from another source or by collecting energy that was emitted from the sensor and backscattered back to the sensor.

There are two types of remote sensing (passive and active). For passive remote sensing systems, the sensor records the amount of electromagnetic energy reflected (from the sun or other source) or emitted from the point of interest. The Landsat, multispectral satellites series are examples of passive remote sensing sensors. For active remote sensing systems, the sensor is not dependent on the Sun's electromagnetic energy or thermal properties of the Earth. Active remote sensors emit electromagnetic energy; this energy is transmitted from the sensor toward the terrain to "illuminate" the target and then received by the sensor after the energy has been reflected by the target. The type of emitted energy is dependent on the sensor platform, and is typically electromagnetic (e.g. Total Station, LIDAR, RADAR) although acoustic sensors do exist (Sound Navigation and Ranging [SONAR]). The most widely used active remote sensing systems for landslide monitoring include:

- RADAR, which uses long-wavelength microwaves (e.g., $3-25 \mathrm{~cm}$ ),

- LIDAR which uses green laser light in the visible spectrum (e.g., 532nm), and

- Total Station which uses red laser light in the visible spectrum (e.g. 630-680nm).

Globally, the most common landslide monitoring techniques used in geotechnical engineering are traditional surveying techniques. More recently, LIDAR has been employed to monitor landslide movements. Some advantages of using RADAR relative to traditional surveying and LIDAR techniques are summarized in Table 2.1. 
Table 2.1. Properties of most common slope monitoring techniques compared to RADAR.

\begin{tabular}{|c|c|c|c|}
\hline & RADAR & $\begin{array}{c}\text { Traditional } \\
\text { Surveying } \\
\text { (Total Station) }\end{array}$ & LIDAR \\
\hline Spatial Resolution & Great & Poor & Reasonable \\
\hline Wavelength & Microwave & Laser & Laser \\
\hline $\begin{array}{c}\text { Length of } \\
\text { Performance }\end{array}$ & New Technology & Proven/Standard & New Technology \\
\hline $\begin{array}{l}\text { Remote Control } \\
\text { Capability }\end{array}$ & $\begin{array}{l}\text { Remote control } \\
\text { capability }\end{array}$ & $\begin{array}{l}\text { Remote control } \\
\text { capability (not as } \\
\text { common) }\end{array}$ & $\begin{array}{l}\text { Remote control } \\
\text { capability }\end{array}$ \\
\hline $\begin{array}{c}\text { Night Time Data } \\
\text { Collection } \\
\text { Capability }\end{array}$ & $\begin{array}{c}\text { Night data collection } \\
\text { capability }\end{array}$ & $\begin{array}{l}\text { Illumination } \\
\text { necessary for night } \\
\text { data collection for } \\
\text { traditional device }\end{array}$ & $\begin{array}{c}\text { Night data collection } \\
\text { capability }\end{array}$ \\
\hline Data Reduction & $\begin{array}{l}\text { Complex data/data } \\
\text { reduction }\end{array}$ & $\begin{array}{l}\text { Simple data } \\
\text { reduction }\end{array}$ & $\begin{array}{l}\text { Complex data } \\
\text { reduction }\end{array}$ \\
\hline
\end{tabular}

\subsection{RADAR Background}

The principles and applications of electromagnetic (EM) radiation and propagation have been researched since the late 1800s. Significant contributions to the development of EM technologies were made by Clerk Maxwell (1879) and Heinrich Hertz (1893), among others. RADAR as we know it today was first investigated by A. H. Taylor and L. C. Young in 1922 (Jensen, 2007). However, the militaries of Great Britain, Japan, the United States of America, and Germany became interested in RADAR to determine the location of ships and planes prior to the Second World War.

There are two types of RADARs: real aperture RADAR (RAR) and synthetic aperture RADAR (SAR). Real aperture RADARs use an antenna of fixed length, e.g. $1-2$ meter. Whereas, synthetic aperture RADARs use a $1-2$ meter physical antenna, but synthesize a much larger antenna by observing targets from different locations while traveling in the azimuth direction to achieve higher resolution (Jensen, 2007). The use of RADAR on satellites for 
commercial purposes of remote sensing began in 1978 with the launch of the first orbital SAR, named SeaSAT by NASA (Coffman, 2009). Many other SAR satellites have been launched by many countries since 1978 with the purpose of terrestrial data collection. A summary of the main SAR platforms is presented in Table 2.2.

Table 2.2. List of commercially available satellites and their attributes (from Coffman, 2009).

\begin{tabular}{|c|c|c|c|c|c|}
\hline Name & SAR Polarization & $\begin{array}{l}\text { Altitude } \\
\quad(\mathbf{k m})\end{array}$ & Band & $\begin{array}{c}\text { Date } \\
\text { Launched }\end{array}$ & $\begin{array}{c}\text { Temporal } \\
\text { Resolution } \\
\text { (days) }\end{array}$ \\
\hline ERS-1 & VV & 782 & $\mathrm{C}$ & 07/17/1991 & 35 \\
\hline ERS-2 & VV & 782 & $\mathrm{C}$ & $04 / 21 / 1995$ & 35 \\
\hline ENVISAT-1 & $\mathrm{VV} / \mathrm{HH}$ & 785 & $\mathrm{C}$ & $03 / 01 / 2002$ & 35 \\
\hline RADARSAT-1 & $\mathrm{HH}$ & 798 & $\mathrm{C}$ & $11 / 04 / 1995$ & 24 \\
\hline RADARSAT-2 & Quad-Pol & 798 & $\mathrm{C}$ & $03 / 01 / 2002$ & 24 \\
\hline SRTM & $\begin{array}{c}\text { Quad-Pol (C) } \\
\text { VV (X) }\end{array}$ & 223 & $\mathrm{C} / \mathrm{X}$ & $02 / 11 / 2000$ & 0 \\
\hline Sea-SAT & $\mathrm{HH}$ & 791 & $\mathrm{~L}$ & $06 / 26 / 1978$ & $17 / 3$ \\
\hline SAR-LUPE 1 & Unknown & 500 & $X$ & $12 / 19 / 2006$ & Unknown \\
\hline SAR-LUPE 2 & Unknown & 500 & $X$ & $07 / 02 / 2007$ & Unknown \\
\hline SAR-LUPE 3 & Unknown & 500 & $X$ & $11 / 01 / 2007$ & Unknown \\
\hline SAR-LUPE 4 & Unknown & 500 & $\mathrm{X}$ & $03 / 27 / 2008$ & Unknown \\
\hline SAR-LUPE 5 & Unknown & 500 & $\mathrm{X}$ & $07 / 22 / 2008$ & Unknown \\
\hline TERRASAR-X & VV/HH & 514 & $\mathrm{X}$ & $06 / 15 / 2007$ & 11 \\
\hline JERS-1 & $\mathrm{HH}$ & 570 & $\mathrm{~L}$ & $02 / 11 / 1992$ & 44 \\
\hline COSMO-SkyMed-1 & $\begin{array}{c}\mathrm{HH}, \mathrm{HV}, \mathrm{VH}, \\
\mathrm{VV}\end{array}$ & 619 & $X$ & 06/08/2007 & $16(1)$ \\
\hline COSMO-SkyMed-2 & $\begin{array}{c}\mathrm{HH}, \mathrm{HV}, \mathrm{VH} \text {, } \\
\text { VV }\end{array}$ & 619 & $X$ & $12 / 09 / 2007$ & $16(1)$ \\
\hline COSMO-SkyMed-3 & $\begin{array}{c}\mathrm{HH}, \mathrm{HV}, \mathrm{VH}, \\
\text { VV }\end{array}$ & 619 & $X$ & $10 / 25 / 2008$ & $16(1)$ \\
\hline SIR-A & $\mathrm{HH}$ & 222 & $\mathrm{~L}$ & $11 / 12 / 1981$ & - \\
\hline SIR-B & $\mathrm{HH}$ & $352 / 272 / 225$ & $\mathrm{~L}$ & $10 / 05 / 1984$ & - \\
\hline SIR-C/X-SAR & $\begin{array}{c}\text { Quad-Pol }(\mathrm{L}, \mathrm{C}) \\
\text { VV }(\mathrm{X})\end{array}$ & $\begin{array}{l}215 \\
215 \\
\end{array}$ & $\begin{array}{l}\mathrm{L} / \mathrm{C} / \mathrm{X} \\
\mathrm{L} / \mathrm{C} / \mathrm{X}\end{array}$ & $\begin{array}{l}04 / 09 / 1994 \\
09 / 30 / 1994 \\
\end{array}$ & $\begin{array}{c}- \\
17-10,174\end{array}$ \\
\hline ALOS PALSAR & $\mathrm{VV} / \mathrm{HH}$ & 692 & $\mathrm{~L}$ & $01 / 24 / 2006$ & 46 \\
\hline
\end{tabular}

As stated previously, RADAR and other active sensors emit their own energy and do not depend on other sources of energy. This allows for day and night data collection in all weather conditions. In fact, RADAR sensors emit and receive microwaves which have longer 
wavelengths in comparison to the other wavelengths used in remote sensing. These longer wavelengths are larger than most atmospheric molecules and gases, which allow the signal to penetrate the atmosphere, illuminate the target, and then return to the sensor without suffering excessive scattering of the emission and subsequent loss of signal intensity. As presented in Figure 2.2, the type of scattering is a function of the wavelength of the incident radiant energy and the gas molecule, dust particle, and or water vapor molecule encountered (Jensen, 2007). Different microwave wavelengths and frequencies commonly employed by RADAR are displayed in Figure 2.3 and tabulated in Table 2.3.

\section{Atmospheric Scattering}

\section{Rayleigh Scattering}

a. $\mathrm{O}$ Gas molecule

b.

Mie Scattering

b. $\stackrel{\text { diameter }}{\longrightarrow}$ Smoke, dust

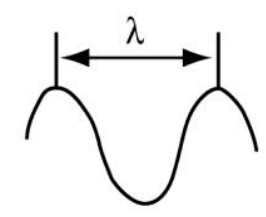

Nonselective Scattering

Photon of electromagnetic

energy modeled as a wave

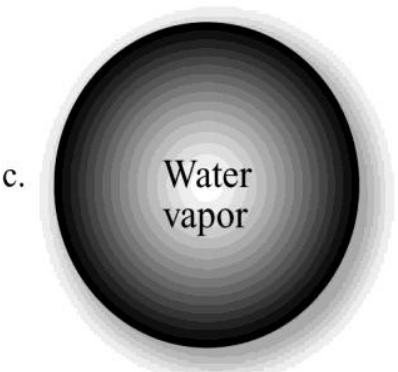

Figure 2.2. Penetration of RADAR waves due to wavelength being larger than atmospheric molecule diameter (from Jensen, 2007). 


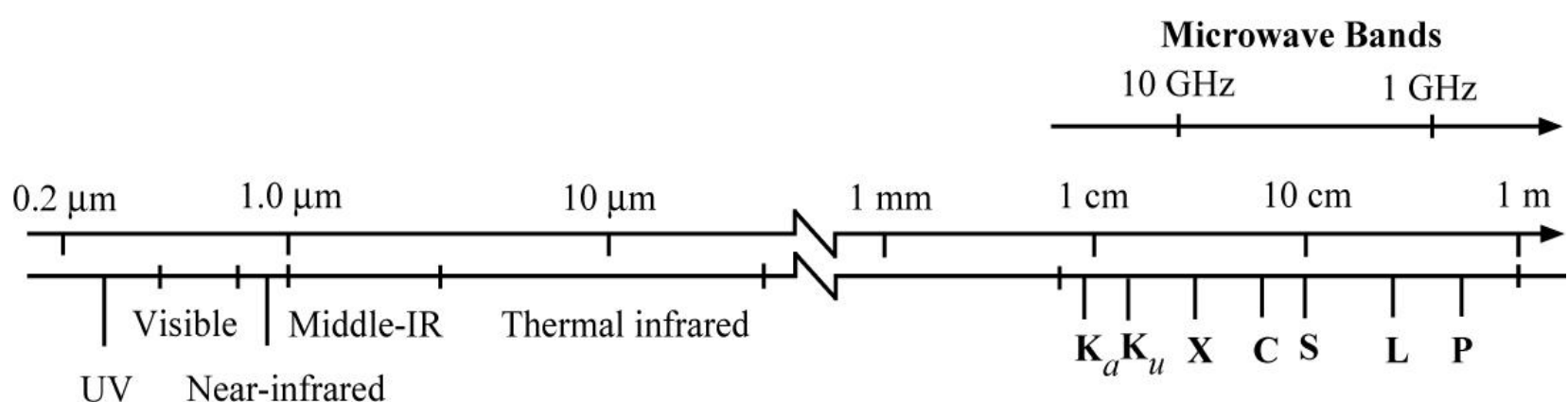

Figure 2.3. Wavelengths of commonly used microwave frequencies (from Jensen, 2007).

Table 2.3. RADAR band wavelengths and frequencies (from Coffman, 2009).

\begin{tabular}{|c|c|c|}
\hline Microwave Band Name & Wavelength $(\mathbf{c m})$ & Frequency $(\mathbf{G H z})$ \\
\hline $\mathrm{Ka}$ & $0.75-1.18$ & $26.5-40.0$ \\
\hline $\mathrm{K}$ & $1.18-1.67$ & $18.0-26.5$ \\
\hline $\mathrm{Ku}$ & $1.67-2.40$ & $12.5-18.0$ \\
\hline $\mathrm{X}$ & $2.40-3.80$ & $8.0-12.5$ \\
\hline $\mathrm{C}$ & $3.80-7.50$ & $4.0-8.0$ \\
\hline $\mathrm{S}$ & $7.50-15.0$ & $2.0-4.0$ \\
\hline $\mathrm{L}$ & $15.0-30.0$ & $1.0-2.0$ \\
\hline $\mathrm{P}$ & $30.0-100.0$ & $0.3-1.0$ \\
\hline
\end{tabular}

Images developed by orbital or aerial based remote sensor platforms, are produced by sending and receiving the emitted pulses while flying a fixed direction (azimuth). While the sensor is moving in this azimuth direction, it is also swathing the ground in the range direction (Figure 2.4). During the data analysis, digital elevation models and filters are used to remove effects attributable to topography and noise, respectively. After removing these effects the lineof-sight deformation is obtained. Sub-centimeters deformation measurements for individual pixels $\left(8 \mathrm{~m}^{2}-20 \mathrm{~m}^{2}\right.$ spatial resolution) can be achieved using differential interferometry processing techniques (Coffman, 2010).

RADAR technology has been extensively employed and investigated in wide ranging scientific and industrial applications. Examples of RADAR technology can be found in aerospace, automotive, marine, weather prediction, among others. As previously discussed since the deployment of the first orbital SAR sensor platform in 1979 (Coffman, 2009), the use of 
satellite based remote sensing for academic, governmental, and commercial purposes has increased substantially.

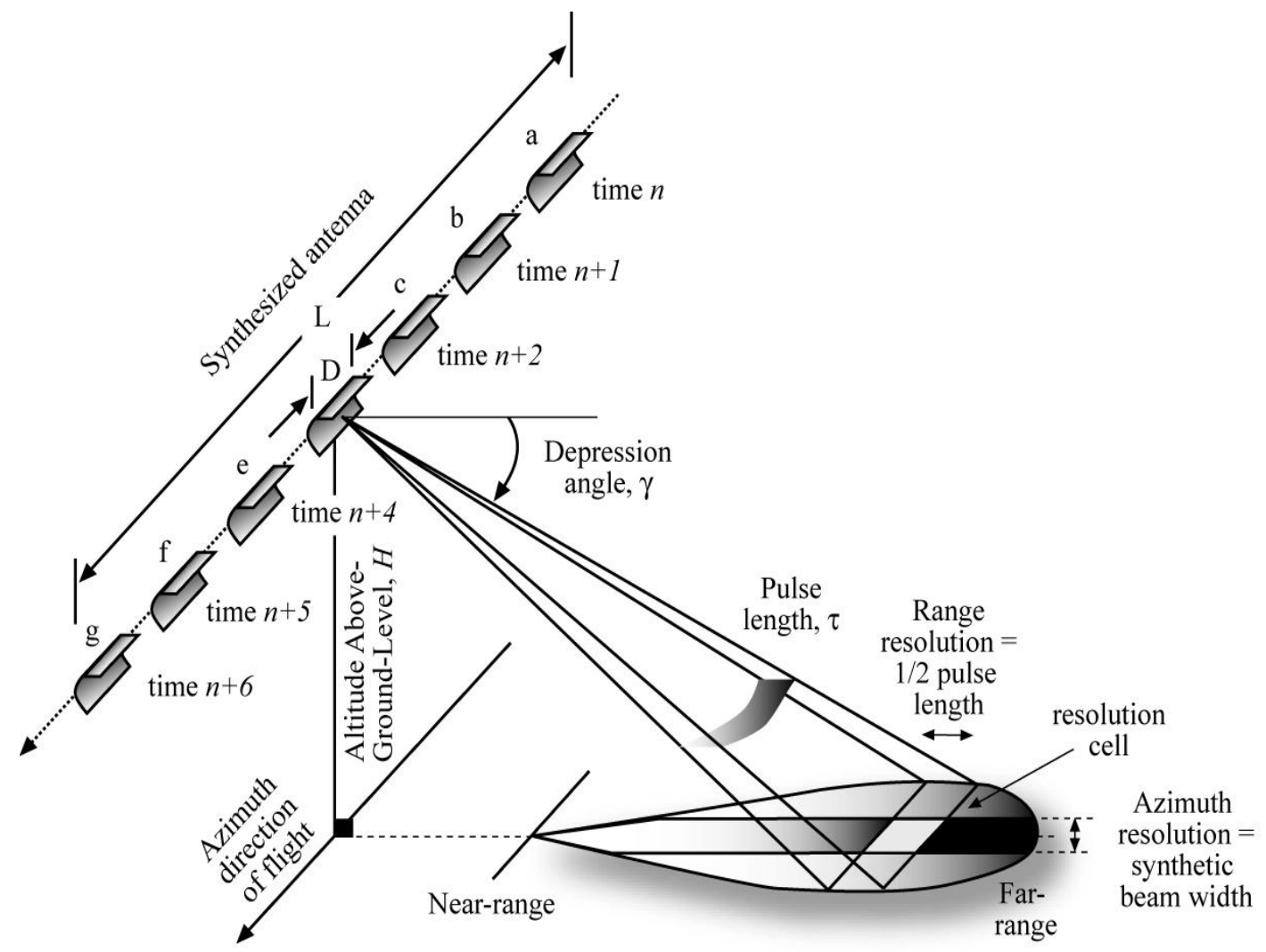

Figure 2.4. Schematic showing satellite based synthetic aperture RADAR concept (from Jensen, 2007).

The main limitation of the use of orbital based SAR for a landslide detection and monitoring application is the poor temporal resolution and large spatial resolution. Common spatial resolution and temporal resolution for satellite based RADARs are on the order of $8 \mathrm{~m}^{2}-$ $20 \mathrm{~m}^{2}$ and $11-46$ days, respectively (Coffman, 2010). The main reason that synthetic aperture RADARs are used on satellites is because it is not feasible to take a large real aperture (required for high spatial resolution) to the space. Real aperture RADARs eliminate the necessity of synthesizing, or viewing the same location from multiple vantage points as required when using a small antenna and SAR based methods. Real aperture RADARs also eliminate any error that 
may be incurred during synthesis of images taken from different locations along the flight (or orbit) line. This synthesis error may lead to a false "displacement" being observed.

\subsubsection{Ground Based RADAR Equipment}

Space-borne RADAR systems have been used to monitor slope movements; however, as previously mentioned, the low spatial resolution and low temporal resolution inherent to these systems has hampered the use for this application. Furthermore, the delay in obtaining data and limitations related to SAR imaging (signal decorrelation and other problems) make this technique unreliable as a landslide or rock fall warning system (Werner et al., 2008). A highly deployable (e.g. not preset timing of overhead passes) RADAR system capable of conducting observations regardless of meteorological conditions is ideal for slope monitoring.

In order to overcome the aforementioned limitations, various manufactures have created ground based RADAR interferometers which provide better temporal resolution (less than a day) and spatial resolution (less than $10 \mathrm{~m}^{2}$ ). These include: the GAMMA Remote Sensing developed GAMMA Portable RADAR Interferometer I and II (GPRI-I and GPRI-II), the Ingegneria Dei Sistem (IDS) developed Image By Interferometric Survey - L (IBIS-L), and the GroundProbe developed Slope Stability RADAR (SSR). The GPRI-I, GPRI-II, and the SSR are real aperture RADARs while the IBIS-L is a synthetic aperture RADAR. The GPRI-I was developed in 2005 (GAMMA Remote Sensing AG, 2012), while the IBIS-L and the SSR were developed in 2002 (McHugh et al., 2006) and 2006 (Ingegneria Dei Sistem, 2012), respectively. The GPRI-II is a refinement of the GPRI-I and is capable of acquiring data more rapidly; the GPRI-II also contains an integrated onboard GPS. This new GPRI (the GPRI-II) was completed in February 2011 (GAMMA Remote Sensing AG, 2011). The GPRI system, unlike previous ground based RADAR instruments (the IBIS-L), does not require aperture synthesis to achieve similar azimuthal spatial resolution (less than $8 \mathrm{~m}$ resolution at $1 \mathrm{~km}$ offset from the instrument) and is 
capable of being deployed in remote locations (unlike the SSR). The GPRI-II, IBIS-L, and SSR systems are discussed in Sections 2.3.1.1 through 2.3.1.3 and a comparison of the systems is presented in Section 2.3.1.4.

\subsubsection{GAMMA Portable RADAR Interferometer II (GPRI-II)}

The GPRI-II system utilizes three real-aperture antennas; two of the antennas are used to emit signals while one antenna is used to receive signals. The vertical separation between the two receiving antennas $(25 \mathrm{~cm})$ provides different viewing geometries allowing for topography measurements to be obtained. A picture of the GPRI-II acquiring data in Switzerland in October, 2010 is presented in Figure 2.5. The high frequency of the RADAR (17.2GHz) corresponding to a long wavelength $(1.74 \mathrm{~cm})$ allows the system to emit waves which travel through the atmosphere while also obtaining high sensitivity (sub-centimeter deformation) in the line-ofsight (LOS) direction. As stated before, the instrument is portable and is easily deployed with a minimal crew. The typical set up time for a two member crew is between 30 minutes and one hour. After the RADAR is deployed individual measurements are acquired in less than thirty-six seconds for a 360 degree field of view (Figure 2.6) to operational distances of 0.1 to 4 kilometers (GAMMA Remote Sensing AG, 2011).

The system is comprised of: the antennas $(2.7 \mathrm{~kg}$ each), the tower $(8 \mathrm{~kg})$, the $\mathrm{RF}$ electronics (4kg), tribrach/stepper motor $(10 \mathrm{~kg})$, tripod $(4 \mathrm{~kg})$, and field computer/controller located with a pelican case $(14 \mathrm{~kg})$, and a generator $(25 \mathrm{~kg})$. The approximate total weight of all of the equipment is $73 \mathrm{~kg}$. The device is conveniently transported in three pelican boxes and a transport bag, specifically: the RF assembly and field computer are stored in one box, the tower and tribrach/stepper motor are stored in one box, the three antennas are stored in one box, and the tripod is stored in the transport bag. 


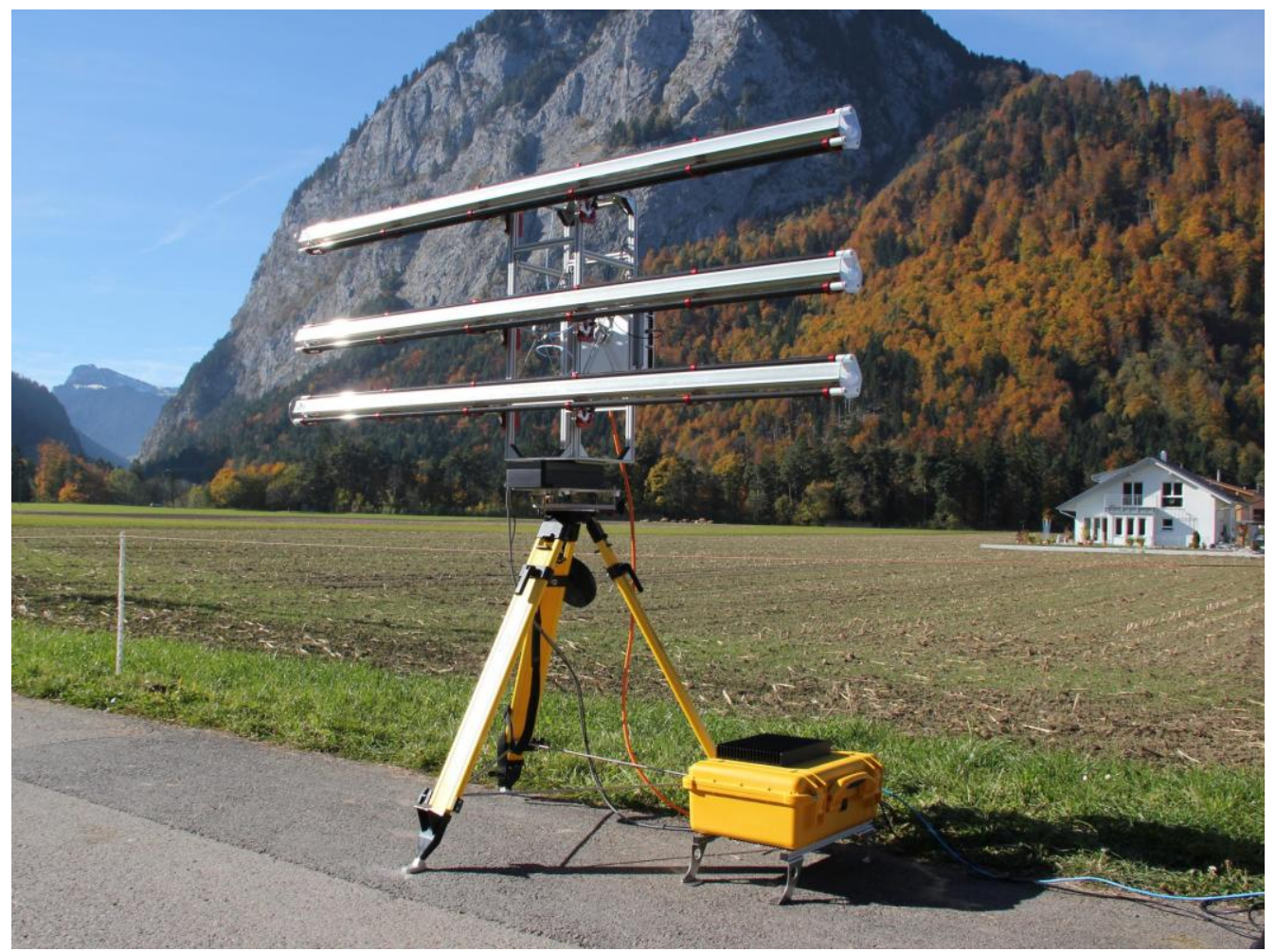

Figure 2.5. GPRI-II acquiring images of a mountain near Gumligen, Switzerland on October 31, 2010 (from GAMMA Remote Sensing AG, 2011).

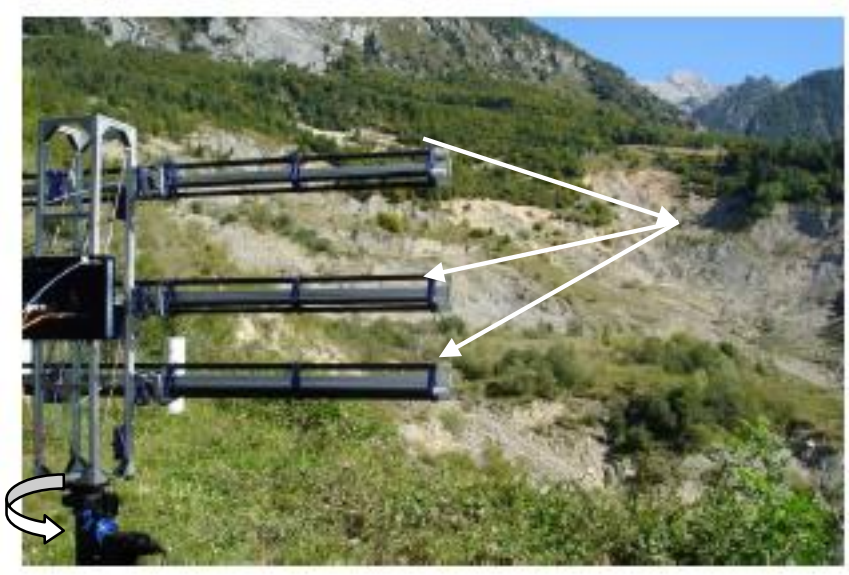

(a)

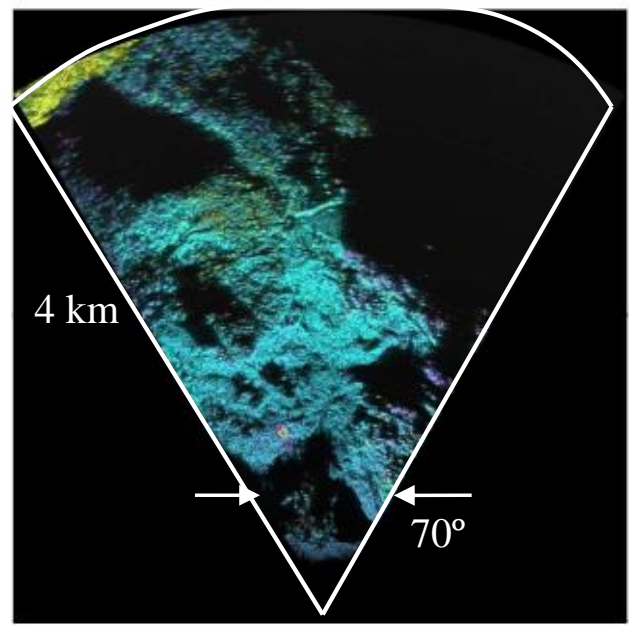

(b)

Figure 2.6. (a) Photograph of GPRI-I with antennas and wave-pattern geometry, (b) differential interferogram of the Tessina landslide (modified from Wiesmann, 2008).

\subsubsection{IDS Image By Interferometric Survey - Landslide (IBIS-L)}

During the last decade, researchers in Europe began using ground based synthetic aperture RADARs (Rudolf et al., 1999). The IBIS-L synthetic aperture RADAR utilizes horn antennas moving along a rail perpendicular to the observation direction. This synthetic aperture 
RADAR is commonly placed within or next to a weather shelter (Figure 2.7) and is specifically intended for monitoring displacements of slopes and structures.

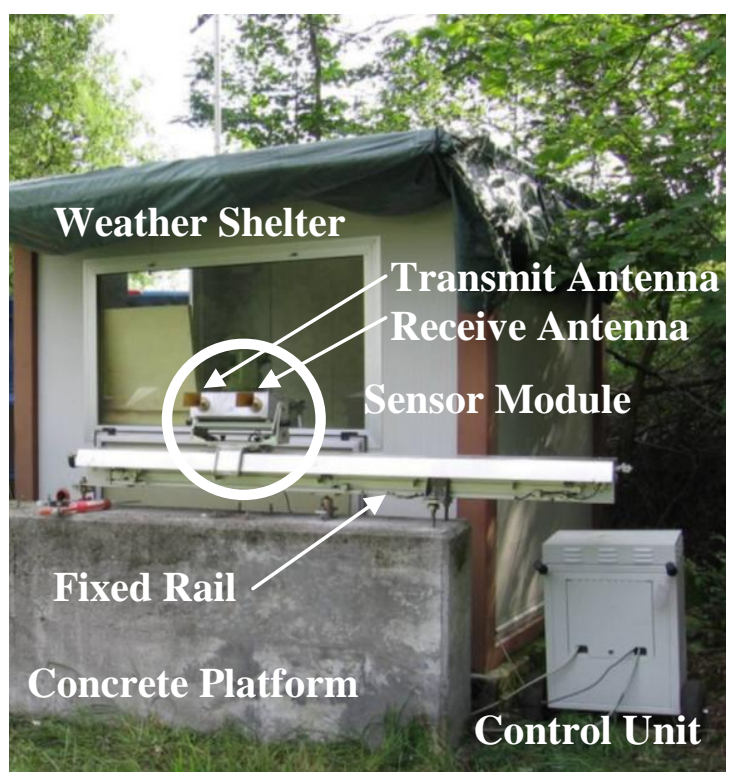

Figure 2.7. IBIS-L system at the Tessina landslide site (modified from Ingegneria Dei Sistem Online Brochure, 2007).

As shown previously in Figure 2.7, the IDS IBIS-L uses a 2.5m long fixed rail bolted to a concrete platform or into bedrock. The sensor module, consisting of two horn antennas (one transmitter and one receiver) moves along the rail to acquire data (Jungner, 2009). The IBIS-L control unit is comprised of a computer with the software necessary to control this RADAR system and a battery pack necessary for powering the device. Power for the RADAR is supply by two $12 \mathrm{~V}$ car batteries which also provides power to the computer and other external components (Jungner, 2009). A range resolution of $0.5 \mathrm{~m}$ is obtained by sampling at a frequency of $17.1 \mathrm{GHz}\left(\mathrm{K}_{\mathrm{u}}-\right.$ band), corresponding to a wavelength of $1.8 \mathrm{~cm}$. At this frequency and power, the maximum range for this system is $4.0 \mathrm{~km}$ and data is collected for approximately five minutes to collect an image. According to Junger, 2009, this RADAR system weights approximately $170 \mathrm{~kg}$ total (10kg sensor module, $54 \mathrm{~kg}$ baseline rail, and $89 \mathrm{~kg}$ power supply with computer). 
In a similar fashion to satellite based sensors, the IBIS-L uses SAR technology for image acquisition and interferogram computations. The small antennas synthesize to become a $2 \mathrm{~m}$ antenna when the system moves along the rail. The wavelength and antenna length of the IBISL system results in a cross range resolution of 4.5mrad (Ingegneria Dei Sistem Online Brochure, 2007). Photographs of the IBIS-L system are presented in Figure 2.8.

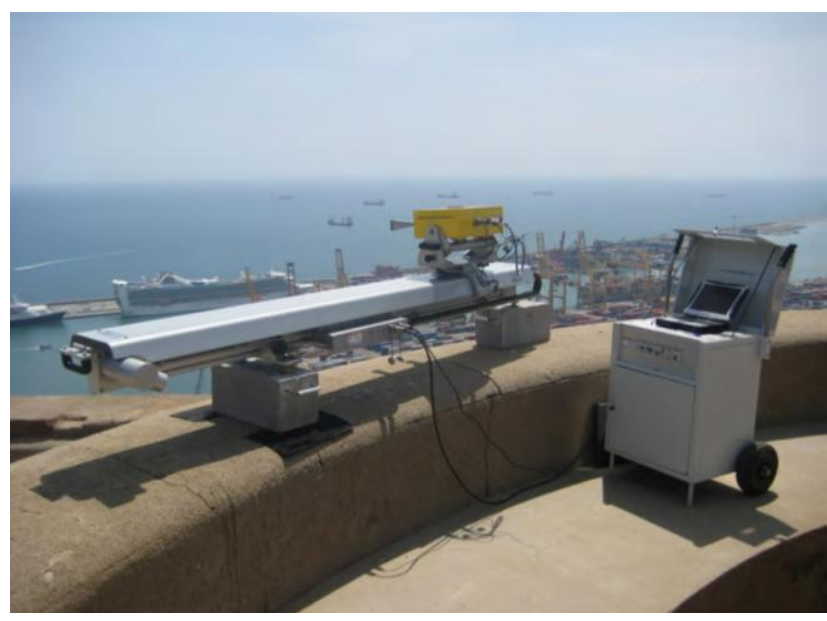

(a)

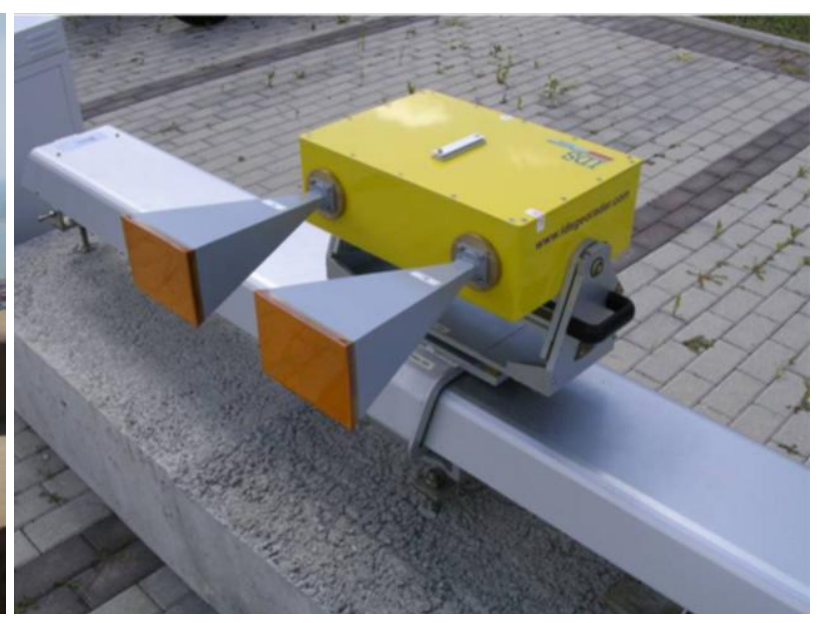

(b)

Figure 2.8.a) IBIS-L RADAR system: rail, sensor module, and computer/power component (from (Jungner, 2009), b) IBIS-L sensor module composed of receiver and transmitter antennas (from Ingegneria Dei Sistem Website, 2012)

\subsubsection{GroundProbe Slope Stability RADAR (SSR)}

The SSR, as developed specifically for monitoring of mine slopes by researchers at the University of Queensland, Australia in 2002, uses differential interferometry to detect and measure rock face movements and landslides (McHugh et al., 2006). This utilizes a X-band and RADAR is oriented towards the area of interest to perform scans using at a frequency of 9.55GHz using a narrow beam antenna in two directions (Noon, 2012; Metzger, 2012; Harries et al., 2006). A 2-degree beam-width RADAR (mounted in a $0.92 \mathrm{~m}$ diameter parabolic dish antenna or $1.8 \mathrm{~m}$ diameter parabolic dish antenna) for vertically (height) and horizontally (azimuth) monitoring of slopes. The SSR has a scanning rate of 10 degrees/sec, a range of 
motion from positive to negative 60 degrees (from horizontal) in the vertical direction, and a range of motion from zero to 340 degrees in the horizontal direction (McHugh et al., 2006).

The SSR has been proven to work under extreme environmental conditions. The deployment time for the SSR is approximately 20 minutes and a typical scan repeat time is 15 minutes (GroundProbe, 2012). The maximum range is $3500 \mathrm{~m}$ from the source of interest, measuring displacements to $\pm 0.2 \mathrm{~mm}$ without the use of reflectors (McHugh et al., 2006). Photographs of the SSR system are presented in Figure 2.9.

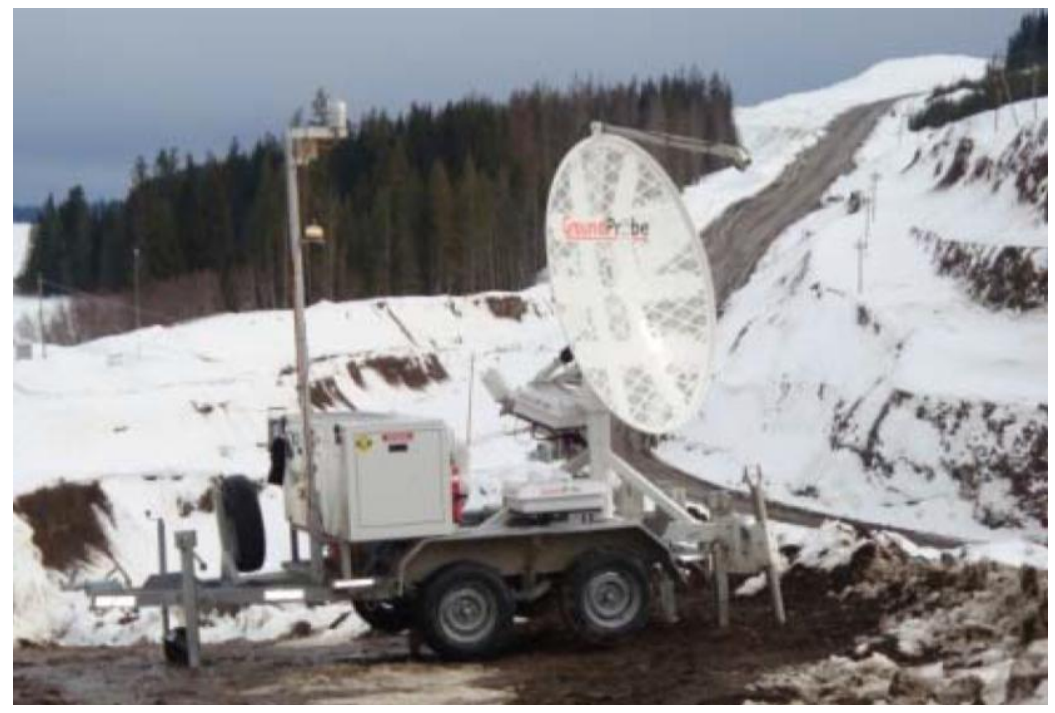

(a)

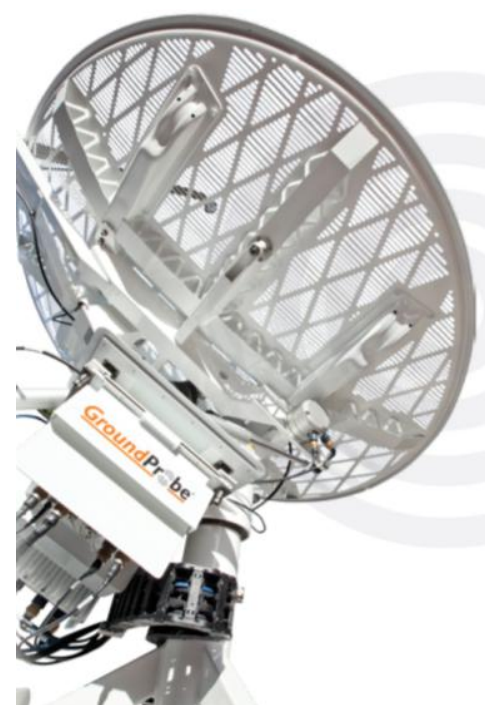

(b)

Figure 2.9. a) Photograph of the trailer mounted GroundProbe SSR acquiring data, and b) detailed photograph of the SSR parabolic dish antenna (from GroundProbe, 2012).

\subsubsection{Comparison of Ground Based Methods}

Synthetic aperture ground based RADARs, such as IBIS-L, require that the antennas move along a rail perpendicular to the observation direction, which are difficult to construct in a remote area. The IBIS-L also requires greater acquisition times than the GPRI-II and the SSR. These longer acquisition times may lead to decorrelation during each observation. Also, the IBIS-L and SSR ground based RADARs are not as portable as the GPRI-II due to mounting 
constraints and weight limitations. The SSR has proven useful for mine applications, but there has been limited research on monitoring landslides in vegetative environments.

Each of the different ground based RADARs possess advantages and disadvantages. Various features of each RADAR system have to be analyzed in order to best accomplish the required objective. The principal features of each system presented in the aforementioned sections are presented in Table 2.4 .

Table 2.4. Summary of major features of the main ground based RADARs.

\begin{tabular}{|c|c|c|c|}
\hline RADAR System & GPRI-II & IBIS-L & SSR \\
\hline Operational Range & $50 \mathrm{~m}$ to $10 \mathrm{~km}$ & up to $4 \mathrm{~km}$ & $50 \mathrm{~m}$ to $3.5 \mathrm{~km}$ \\
\hline Frequency Range & 17.1 to $17.3 \mathrm{GHz}$ & $17.1 \mathrm{GHz}$ & $9.55 \mathrm{GHz}$ \\
\hline Wavelength & $1.74 \mathrm{~cm}$ & $1.8 \mathrm{~cm}$ & $3.14 \mathrm{~cm}$ \\
\hline Azimuth Resolution & $8 \mathrm{~m} @ 1 \mathrm{~km}$ & $4.5 \mathrm{~km} @ 1 \mathrm{~km}$ & $1.2 \mathrm{degrees}$ \\
\hline Range Resolution & $1 \mathrm{~m}$ & $0.5 \mathrm{~m}$ & $1.5 \mathrm{~m}$ \\
\hline Scan Time & $10^{\circ} / \mathrm{sec}$ & $0.04^{\circ} / \mathrm{sec}$ & $10^{\circ} / \mathrm{sec}$ \\
\hline $\begin{array}{c}\text { Angular Rotation } \\
\text { Capability }\end{array}$ & $360^{\circ}$ & $35^{\circ}$ & $340^{\circ}$ \\
\hline Portability & Easy & Hard & Medium \\
\hline Deployment Time & $\sim 30 \mathrm{minutes}$ & Very Variable & $\sim 20 \mathrm{minutes}$ \\
\hline Approximate Weight & $70 \mathrm{~kg}$ & $170 \mathrm{~kg}$ & $1500 \mathrm{~kg}$ \\
\hline Developed/Refined & $2005 / 2012$ & 2006 & 2002 \\
\hline
\end{tabular}

\subsubsection{Werner et al. (2008)}

The previously mentioned GPRI-I was used for the study described in this section. In October, 2007, the GPRI-I RADAR was deployed to monitor the Rhône glacier located in the Valais region of Switzerland. Multiple images with sub-sampled $2 \mathrm{~m}$ pixel spacing covering $2.15 \mathrm{~km}$ in range direction and an angular field-of-view of 70 degrees were obtained (Werner et al., 2008). The average velocity of the glacier in the line-of-sight (LOS) direction, as observed with the GPRI-I, was approximately $4 \mathrm{~mm} /$ hour (35m/year). Post processing of the acquired data permitted the operator to stack multiple images to develop temporal deformation maps. A photograph of GPRI-I at the Rhône glacier and a backscatter intensity image are presented in Figure 2.10. The amount of deformation that occurred during the 80 minute observation period 
and a digital elevation model (DEM) of the glacier as developed by unwrapping an interferogram obtained by comparing the data collected from each of the two receive antennas are presented in Figure 2.11.

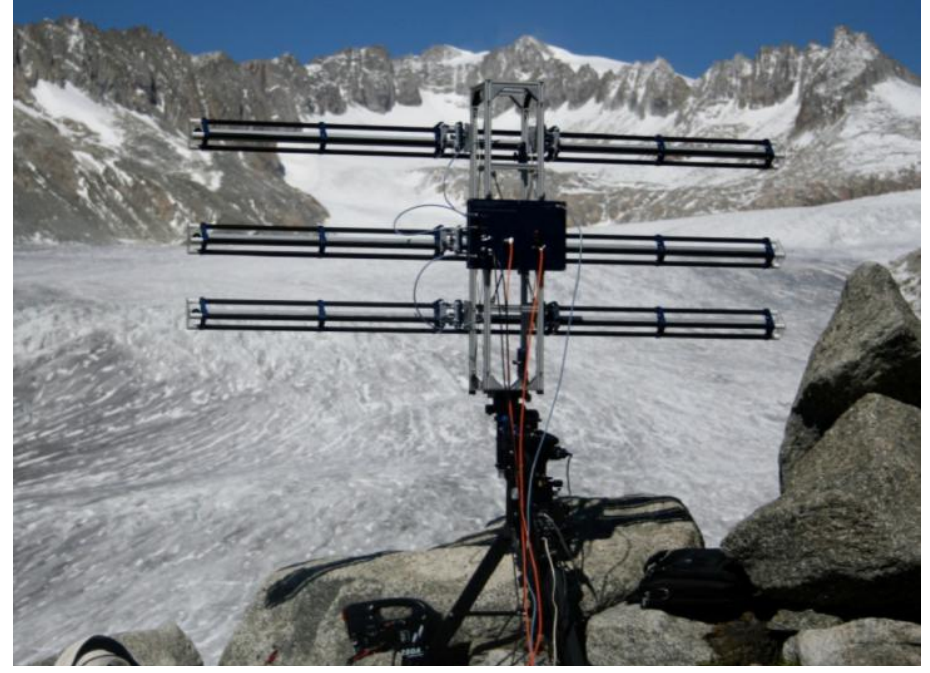

(a)

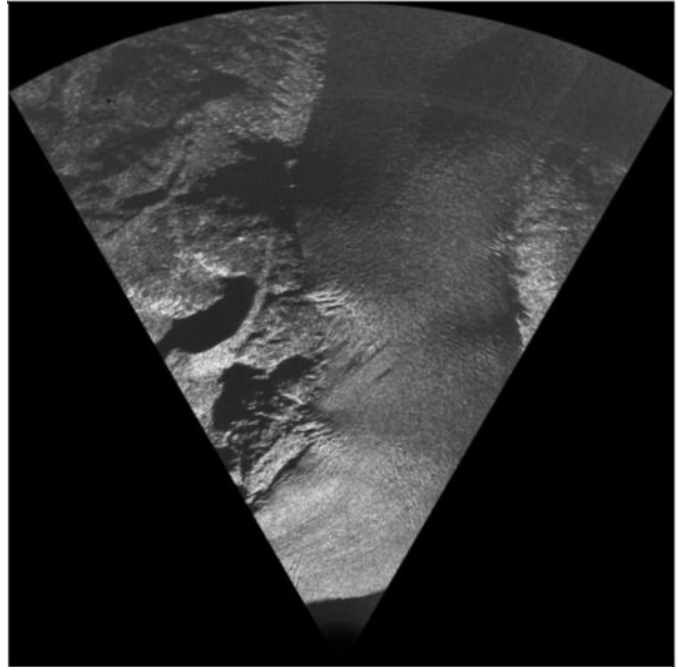

(b)

Figure 2.10. a) GPRI-I acquiring images at the Rhône glacier, and b) RADAR image developed after data acquisition at Rhône glacier in October 2007 (from Werner et al., 2008).

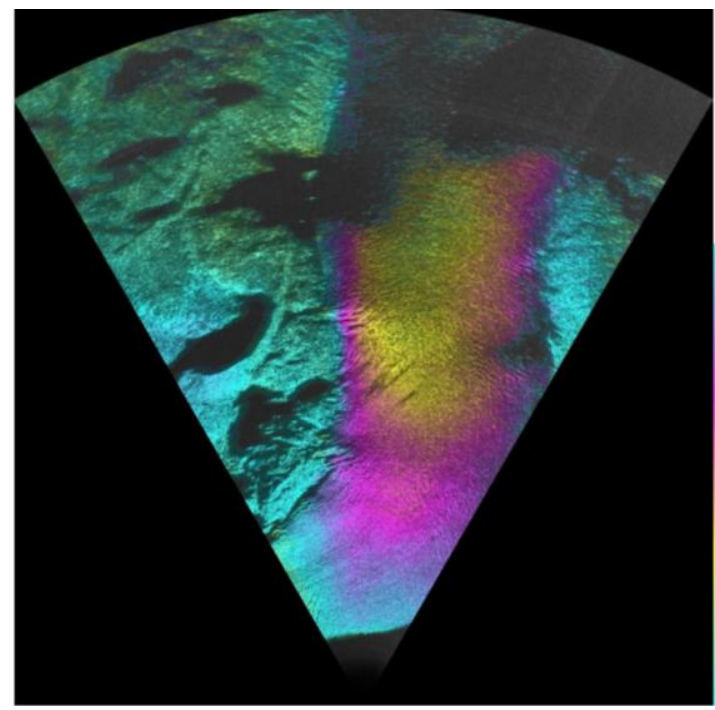

(a)

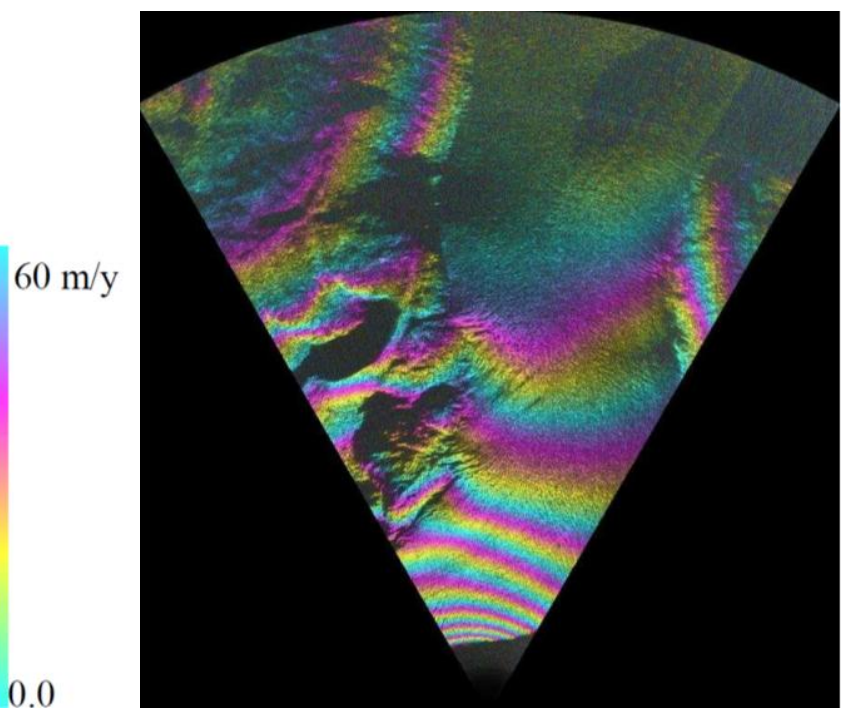

(b)

Figure 2.11. a) LOS deformation map as developed from GPRI-I data collected at the Rhône glacier, and b) a DEM obtained from data collected in the two receiving antennas with a baseline of $15 \mathrm{~cm}$ (from Werner et al., 2008). 


\subsubsection{Bozzano et al. (2008)}

An unstable slope in Italy, located next to a major road that was undergoing construction work, was monitored using a ground based remote sensing platform as described in Bozzano et al., 2008. The platform consisted of a ground-based interferometric SAR (the IBIS-L), a weather station, and an automatic acquisition camera. During September 20 through October 2, 2006 and December 14, 2006 through February 29, 2007, the system was used to continuously monitor the landslide. Correlations were developed between the obtained displacements and construction and weather events under almost all weather conditions. The IBIS-L system was to: i) monitor the landslide, ii) determine the displacement rates and extents of the moving mass, and iii) serve as an emergency control system to predict critical conditions/imminent failure. Specifically, the platform provided a warning system to protect project personnel during construction activities (Bozzano et al., 2008).

The geology of the site consisted of sandy marine deposits with some sandy colluvial deposits on top of fractured and weathered rock. The landslide was known to have experienced a deep rotational slide with a main sliding surface in the past. This deep rotation movement and the other observed small translational movements necessitated the need for this research (Bozzano et al., 2008). A picture of the platform used in this research and the observed landslide site are presented in Figure 2.12. The exterior and interior views of the platform enclosure are presented in Figure 2.13. 


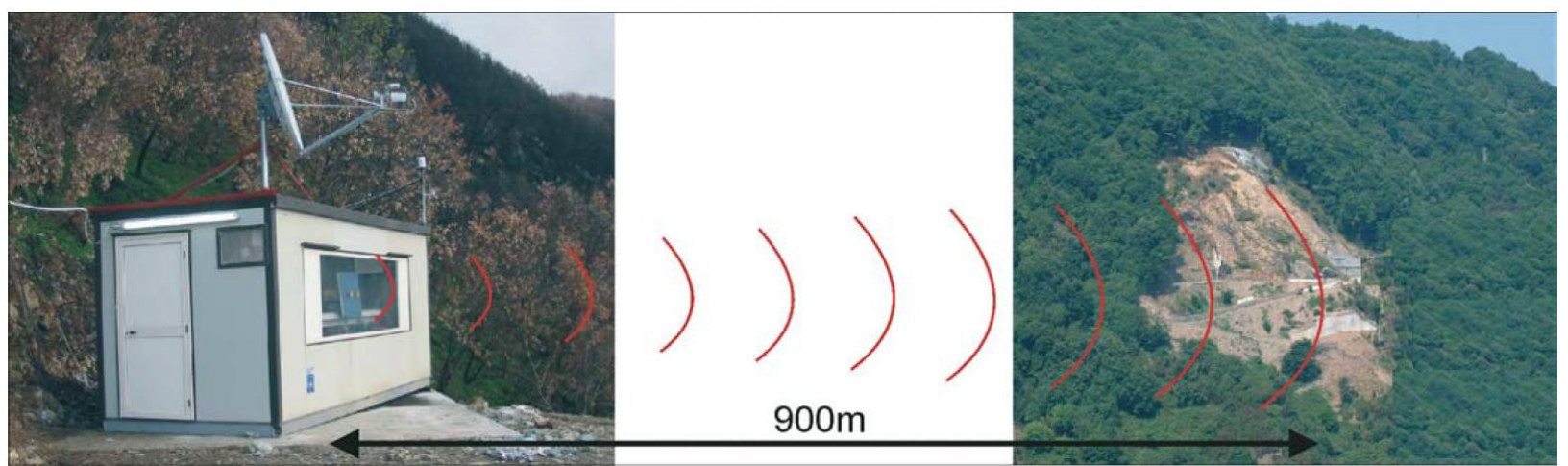

Figure 2.12. Segmented photographs of the platform and landslide site. Note the ongoing road work at the toe of the landslide (from Bozzano et al., 2008).

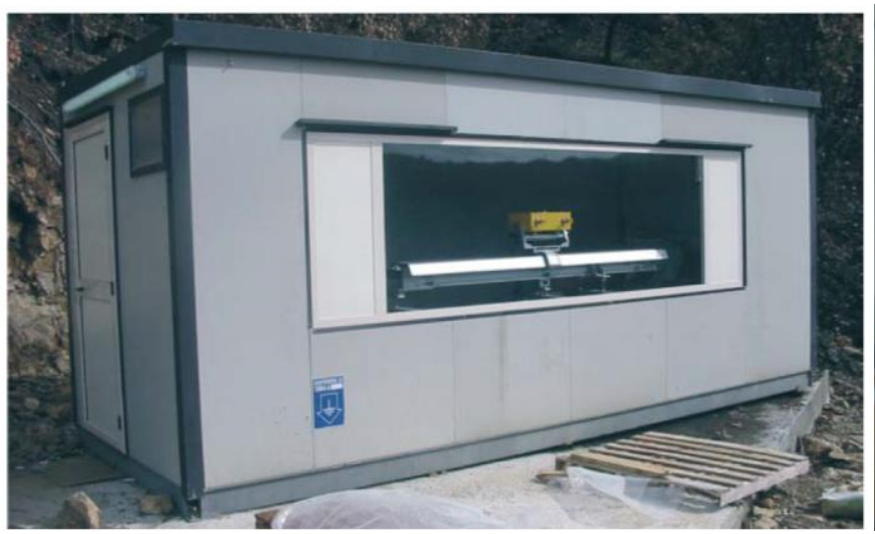

(a)

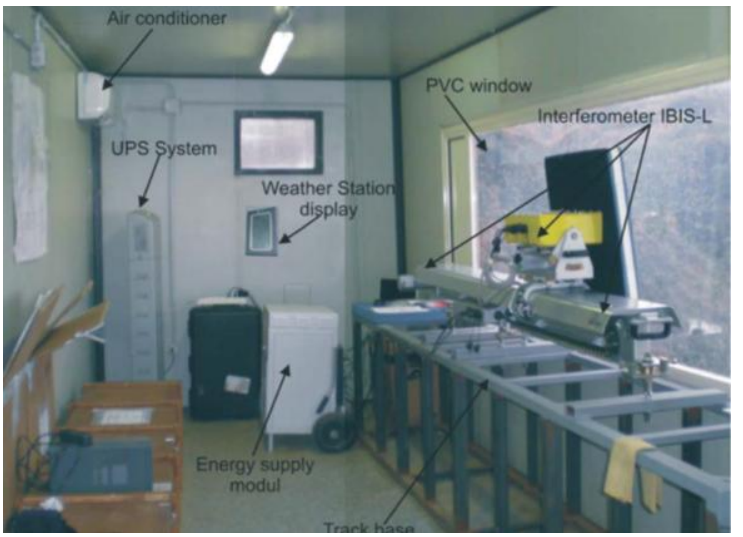

(b)

Figure 2.13. a) Photograph of the exterior of IBIS-L platform enclosure, and b) photograph of the interior of the platform enclosure including the IBIS-L system (from Bozzano et al., 2008).

Two dimensional maps of displacements versus time were one of the principal products of this monitoring study. The time-displacement maps permitted the identification of the portions of the slope sectors that moved at the same rate within the moving mass. Corner reflectors were also installed at specific locations within the landslide to allow the researchers to develop time series of displacements for individual pixels. Data was retrieved remotely on a daily basis from the platform. The authors reported that this systems guarantees high performance and enabled the user to process the data sufficiently fast to allow for real time decision making. 


\subsubsection{Harries et al. (2009)}

Engineers monitored a unstable slope using a GroundProbe SSR in the Thompson Creek Mine, a molybdenum mine located in central Idaho. Although the mine has been in operation since 1982, a failure began occurring in the central section of the north highwall (as detected using prisms and extensometers) in January 2008 (Harries et al., 2009). Althoguh the traditional monitoring system (prisms and extensometers) was working, the personnel at the Thompson Creek decided to improve the monitoring system by acquiring a GroundProbe SSR in November 2008.

Several slope accelerations, within the wedge failure, were detected using the SSR. On October 30, 2008 a significant acceleration event was recorded. For safety reasons the all personnel and equipment were cleared from the area. Four days later, on November 3rd, failure occurred. The catastrophic failure discharged about 70,000tons of material (Harries et al., 2009). Because of the use of remote sensing techniques, and the decisions made based on the data obtained from the remote sensing device, no injuries or equipment loss occurred during the failure. A picture of the SSR acquiring data at the open pit mine and the active failure wedge are presented in Figure 2.14. 


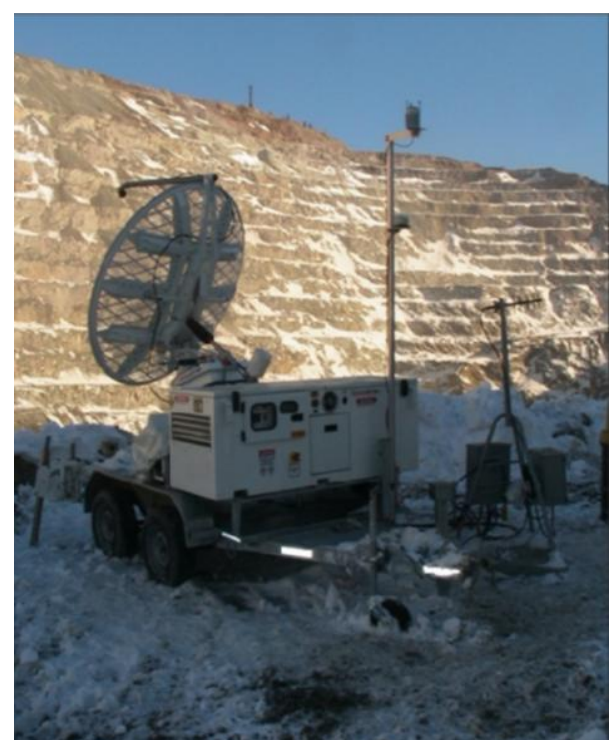

(a)

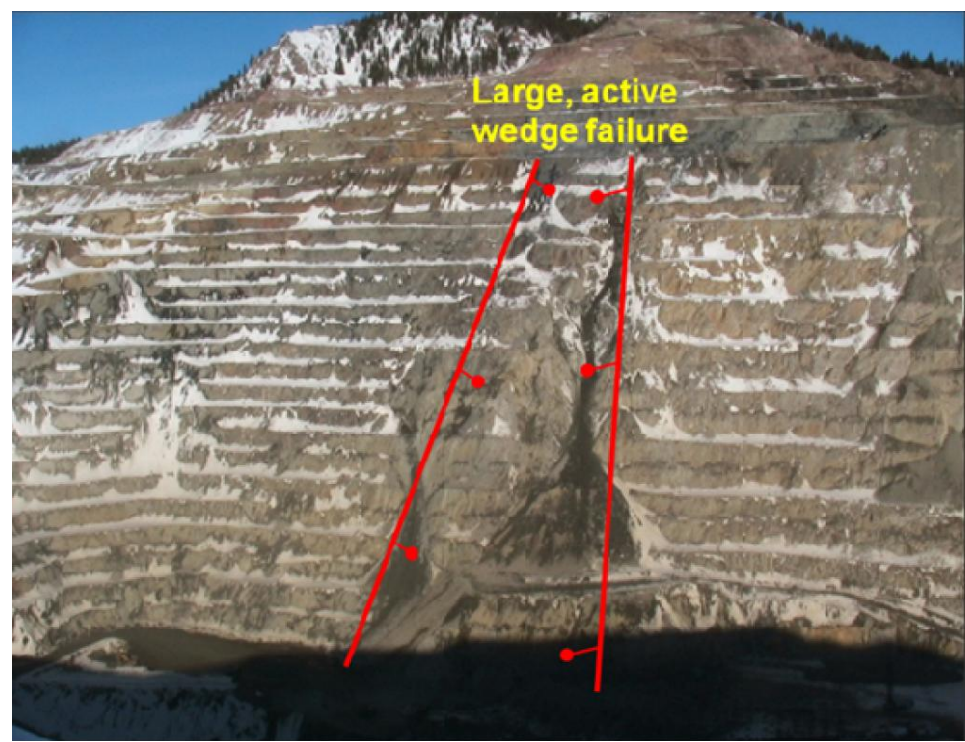

(b)

Figure 2.14. GroundProbe SSR deployed at Thompson Creek Mine, and b) wedge failure located in the central portion of the north highwall (from Harries et al., 2009).

\subsection{LIDAR Background}

Light detection and ranging (LIDAR) development followed the development of the total station, which followed the development of the electronic distance meter (EDM). The EDM, developed during the 1950s and 1960s, was a one-dimensional device that allowed for precise one dimensional measurement when coupled with a reflector (Dallaire, 1974). In the 1980s devices such as the total station were developed which were capable of measuring the threedimensional $(\mathrm{x}, \mathrm{y}, \mathrm{z})$ coordinates of multiple points (as discussed in Section 2.5). In the 1990s, terrestrial and aircraft mounted LIDAR systems were developed. These devices do not require reflectors and provide the three-dimensional coordinates and the backscattered intensity $(\mathrm{x}, \mathrm{y}, \mathrm{z}, \mathrm{i})$ of thousands of points collected during one scan.

LIDAR technology was developed and driven by the necessity to acquire surface data sets of the Earth for topographic mapping purposes (Krabill et al., 1984). The first LIDAR systems were mounted on aircraft for aerial topographic surveys using airborne laser scanning (ALS) techniques. One of the first applications of ALS was to determine topographical changes 
in the Greenland ice sheet (Kabrill et al., 1995). According to Heritage and Large (2009) and Jaboyedoff et al. (2010), at the end of the 1990s a terrestrial LIDAR version was created to conduct simplified terrestrial laser scanning (TLS). Both techniques (ALS and TLS) may be combined and used at the same time for the same project to mitigate problems such as shadow areas created by objects blocking the line-of-sight (LOS).

Both ALS and TLS LIDAR sensors work by sending laser pulses, from an oscillating and rotating device, that interact with various objects (trees, man-made structures, ground surface, etc.) and recording the energy that is returned to the sensor. Specifically, the sensors record the two-way travel time for each laser pulse as it travels away from the sensor and then back to the sensor (Figure 2.15 for ALS and Figure 2.16 for TLS). The two-way travel time is then used to calculate distance to, and relative elevation of objects in the LOS of the instrument. There are commonly two types of TLS systems: single return and multiple return systems. The defining feature of a multi-return LIDAR system is the capability of sending a pulse and recording multiple returns from that same pulse. The presence of multiple returns allows the system operator to detect if there are multiple objects in the same direction, but at different distances away from the sensor. 


\section{LIDAR Data Collection}

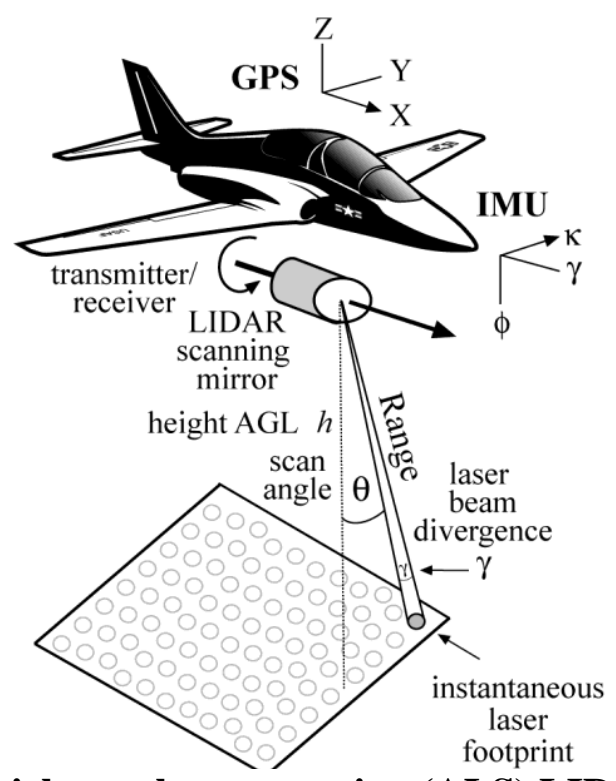

Figure 2.15. Diagram of an airborne laser scanning (ALS) LIDAR (from Jensen, 2009).

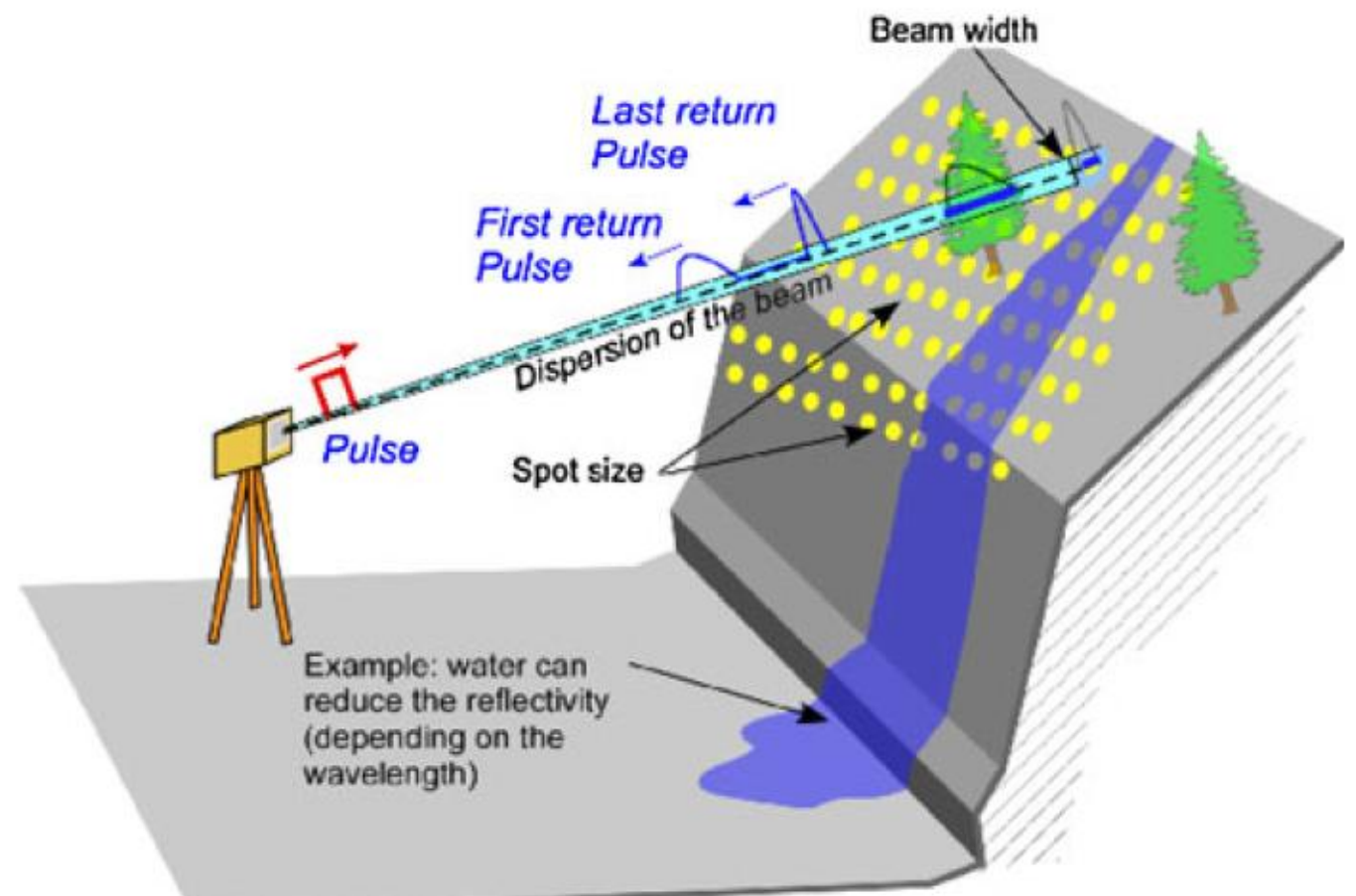

Figure 2.16. Idealized schematic of terrestrial laser scanner (TLS) LIDAR principles showing multiple return geometries (from Jaboyedoff, 2010).

Because of the increased distance from the instrument to the point of interest (longer travel times and more atmospheric and meteorological interference), ALS systems have a lower 
resolution than terrestrial systems. For example, for ALS sensors the average resolutions (instantaneous laser footprint as per Figure 2.15) range from meters to tens of meters, and for TLS sensors the average resolutions (spot size as per Figure 2.16) range from millimeters to centimeters (Shan and Toth, 2008).

ALS systems are best employed in applications where a terrestrial LIDAR may be difficult to use due to rough terrain or shadows caused by objects, or where a large geographical region is to be surveyed. Depending on the application (slope movement, bridge movement, or building movement) the LOS to the area of interest may dictate the use of the ALS or TLS system. All of the aforementioned factors must be taken into account when selecting the LIDAR system to use for a certain project.

While the accuracy of laser scanners can be impacted by various factors, the typical accuracy is $\pm 1.5 \mathrm{~cm}$ and maximum distances of about 800 - 1000m (Manetti and Steinmann, 2007). The real accuracy is lower due to weather (temperature, fog, rain, wind, etc.) or other conditions (earth curvature, barometric pressure, topographic relief). The quantity of points or density of points varies between ALS or TLS sensors. The point density for ALS systems range between 0.5 to 100 points $/ \mathrm{m}^{2}$; the point density for TLS systems range between 50 to 10000 points $/ \mathrm{m}^{2}$ (Jaboyedoff et al., 2010). As shown previously (in Figure 2.15 and Figure 2.16), the level of detail that may be achieved by the point density depends on the resolution of the laser sensor. Although not shown in Figure 2.15 and Figure 2.16, the resolution of LIDAR systems varies across the image. Specifically, the range resolution and angular resolution vary with distance from the instrument. The intensity of the reflected signal acquired depends on the beam wavelength, the type of material, roughness, soil moisture and angle of incidence (Ingensand, 2006). 
The ability to acquire three-dimensional terrain data with high accuracy and high spatial resolution using LIDAR has created new ways of studying and analyzing landslides and other types of earth movements. Specifically, the use of LIDAR has been demonstrated for: identification, mapping, modeling, and monitoring of landslides. A critical aspect when processing LIDAR data for landslide applications is the removal of vegetation either by automatic or manual methods. This is typically completed during data processing or by using a multi-return sensor in which the last returned pulse is identified as the pulse which made contact with the ground. However, when using ALS the vegetation may too dense and the laser beam will not reach the ground (even when using a multi-return sensor). Literature is limited on the use of TLS systems for landslide applications; however TLS scanners have proven to be useful in understanding the failure mechanism of a specific landslide, in determining the limits of the moving mass, and in estimating volumes of the moving mass (Sturzenegger et al., 2007).

Historically the principle method employed to detect, monitor and quantify landslides, prior to the development and implementation of remote sensing techniques, were based on single point measurements such as GPS or total station. A critical shortcoming of single-point measurement techniques is the difficulty in obtaining sufficient spatial coverage to accurately detect the extents of the moving mass. Acquiring an accurate measurement of the complete area of displacement is an important factor in understanding the specific landslide kinematics (Teza et al., 2008) and failure mechanism. Other advantages of the TLS LIDAR techniques are the fast data acquisition of three-dimensional point coordinates, relatively easy setup, portability, high spatial resolution, and ability to acquire measurements from a distance (as might be necessary around highly unstable or hazardous sites). Despite the considerable advantages of TLS (compared to traditional surveying techniques), some drawbacks of the technique include: line- 
of-sight restrictions (i.e. significant areas of interest may be shadowed by vegetation, structures, or topography), extensive data processing for filtering and cleaning point clouds, large data sets, and alignment and registration errors when several viewing from multiple geometries. Several of these advantages and disadvantages are discussed using the following case studies (Duffell et al, 2005 in Section 2.4.1; Bitelli and Zamutta, 2004 in Section 2.4.2).

\subsubsection{Duffell et al. (2005)}

Airborne LIDAR was utilized by the Department for Transport Highways Agency (HA) in the United Kingdom to qualitatively and quantitatively identify the change in profile of slopes alongside highways. The HA created a database by cataloging pertinent information from all the known slope failures along highways, in order to develop a more comprehensive way to understand the failure mechanisms and to increase maintenance efficiency of unstable slopes. According to Duffell et al., 2005 the HA has spent over 12 million English Pounds ( 23 million US Dollars [in 2011 inflation adjusted dollars]) per year repairing failures of slopes, mostly on clays soils, due to changes in strength and pore pressures. ALS LIDAR was selected by the HA because the data was provided rapidly with minimal initial ground support over a large geographic area without requiring additional ground personnel (Duffell et al., 2005).

Duffell et al. (2005) discussed how the HA relied on the high positional accuracy of the LIDAR to obtain surveys of the same area over a large temporal ranges (months to years). More specifically, the HA conducted two helicopter based LIDAR surveys over a trial area of the M25 London Orbtal Motorway one year apart. The point clouds obtained by the LIDAR surveys were used to create Digital Topographic Models (DTM) of the area of interest (Figure 2.17). The DTMs were then used to determine the change in elevation between surfaces via an "automated change detection routine". Structures, trees, vegetation and other site features were removed to uncover the ground surface. The comparison between the 2001 and 2002 surveys resulted in the 
identification of zones of settlement, rise, and slope repair zones (Duffell et al., 2005). The results of the comparison are presented in Figure 2.18, where cyan zones represent locations of slope repair, red zones represent rise, and green zones represent settlement. Based on this data it appears as if the toe is rising and the crest is lowering (indicative of a rotation failure mechanism).
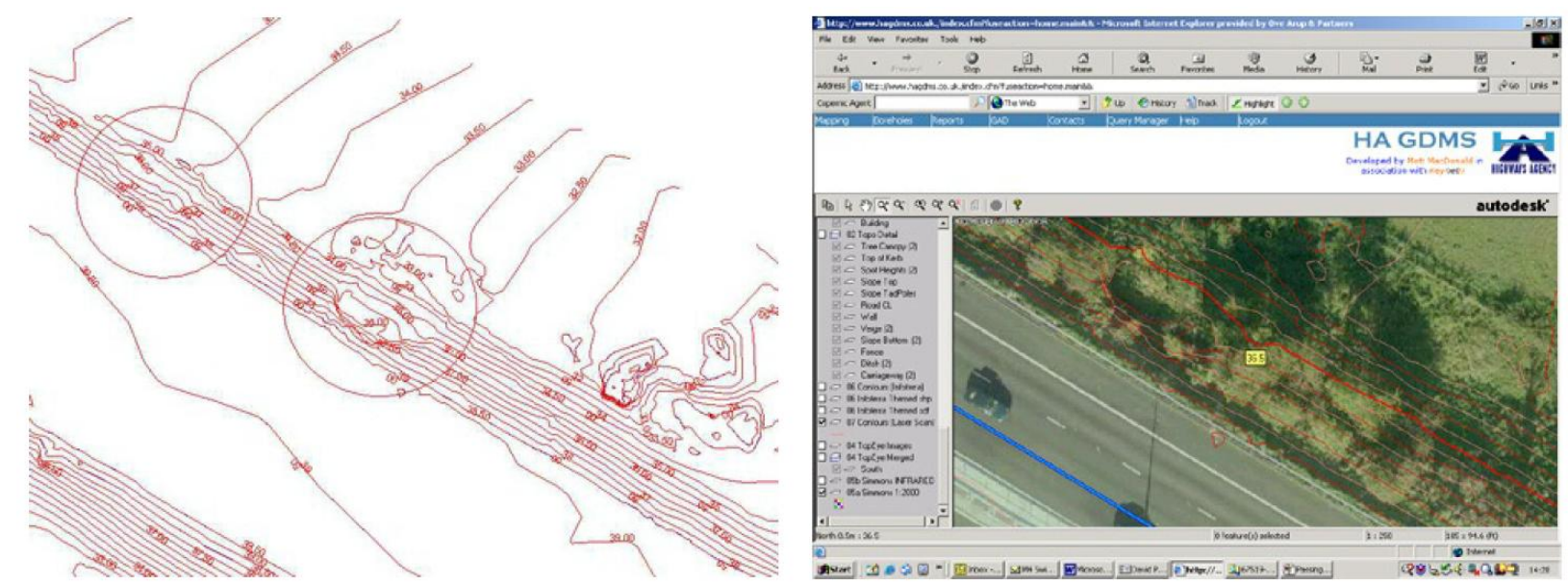

Figure 2.17. Digital Elevation model created from ALS LIDAR, with locations of slip along the M25 London Orbtal Motorway shown in circles (from Duffell et al., 2005).
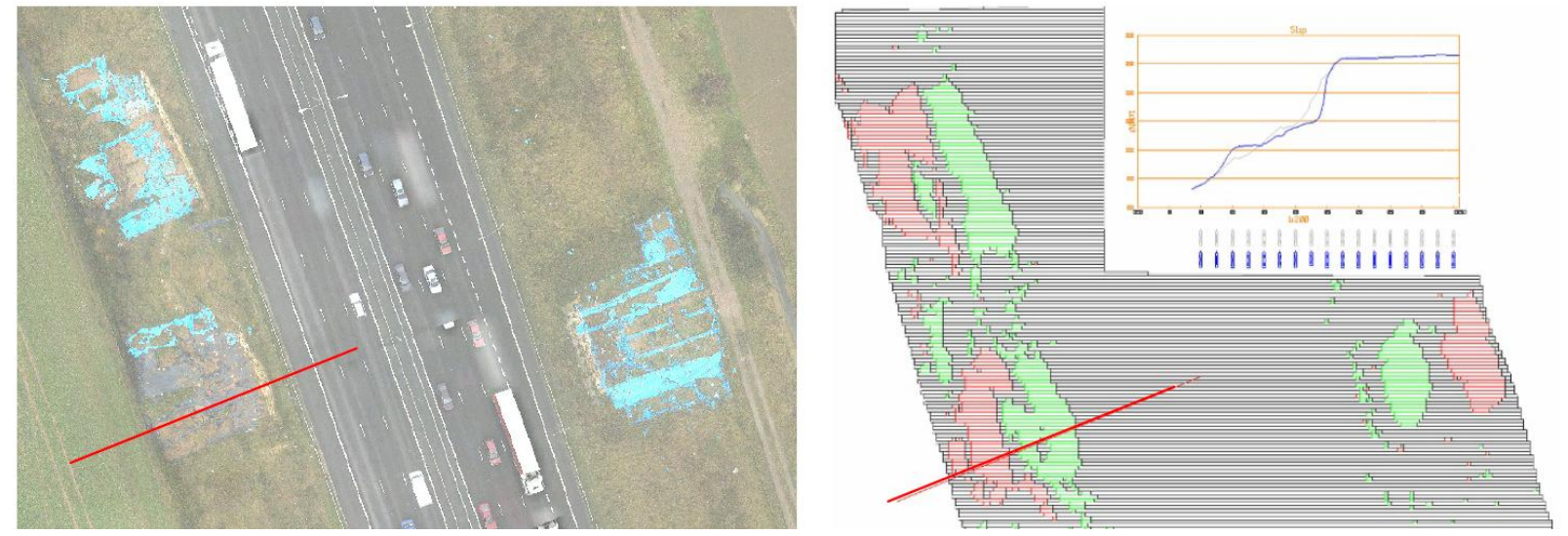

Figure 2.18. Results from comparison of surfaces obtain using ALS LIDAR and surveys from a year apart (from Duffell et al., 2005) [in color].

\subsubsection{Bitelli and Zamutta (2004)}

An example of TLS LIDAR systems being used for landslide monitoring was published by Bitelli and Zamutta (2004). A small landslide body located in the Northern Apennines near 
Bologna, in Northern Italy was studied. This landslide was selected by the authors for the following reasons (Bitelli and Zamutta, 2004):

- the landslide had been monitored using GPS systems, which had recorded movements on the order of 1-2 cm/month (Mora et al., 2003),

- the landslide was located in region with low vegetation, resulting in less data processing and filtering, and

- historical data was available.

As part of this research project a large photogrammetric survey was conducted in 2000 and two TLS surveys were conducted in 2001 and 2004. An initial three dimensional view of the slope under study was developed from the 2000 photogrammetric survey (Figure 2.19). The slide was monitored using two different TLS systems for the 2001 and 2004 surveys, a Riegl LMSZ210 system and a Riegl LMS-Z420i system, respectively (Figure 2.19). These multi-echo scanners were used to record the last returned pulse. This allowed the researchers to obtain a more clear point cloud, although more filtering of the point cloud was required. 


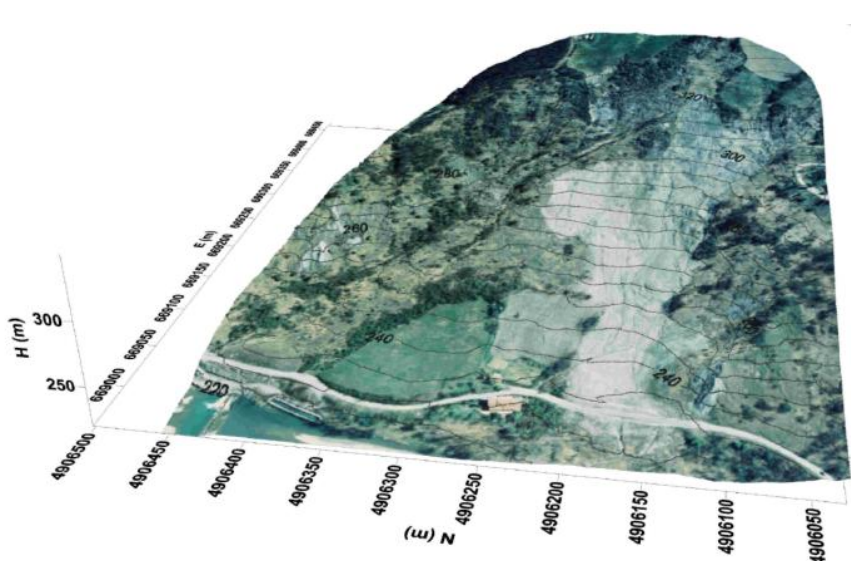

(a)

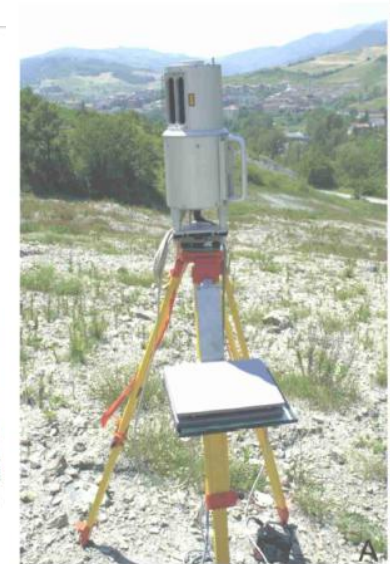

(b)

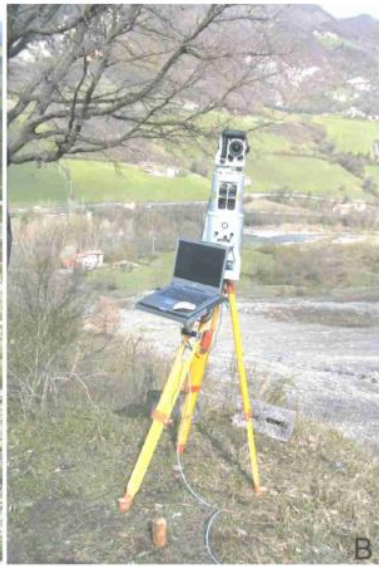

(c)

Figure 2.19. a) Three dimensional digital elevation model created from aerial photogrammetric survey in 2000, b) Riegl LMS-Z210 on site in 2001, c) Riegl LMS-Z420i on site in 2004 (from Bitelli and Zamutta, 2004).

The differences between the Digital Terrain Models (DTMs) obtained from the 2000 photogrammetric survey and the 2001 LIDAR survey were negligible. Some minor movement was observed in distinct areas, but this was attributed to effects of vegetation growth which was not properly filtered out during image processing. Conversely, significant elevation changes were observed when comparing the first two surfaces with the surface obtained from the 2004 LIDAR survey. The 2001-2004 DTM comparison revealed the greatest movements. Negative values (indicating downward movement) were located in the scarps of the landslide, as expected; however, positive values (uplifts zones) were not located at the foot of the landslide, as expected by the researchers. Cross-sections of the LIDAR point cloud before and after filtering, and comparison surfaces obtained from the three surveys are presented in Figure 2.20. 


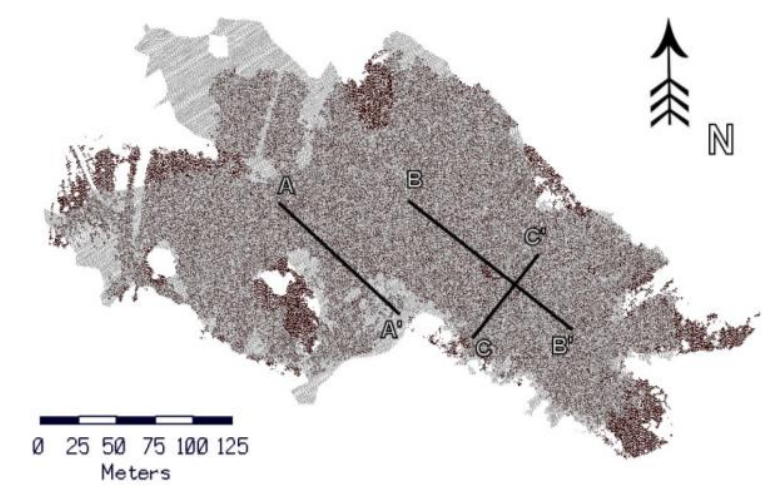

(a)

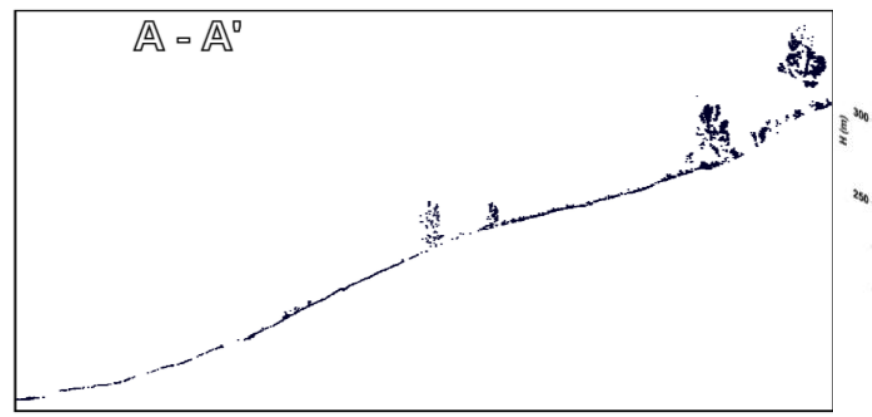

(b)

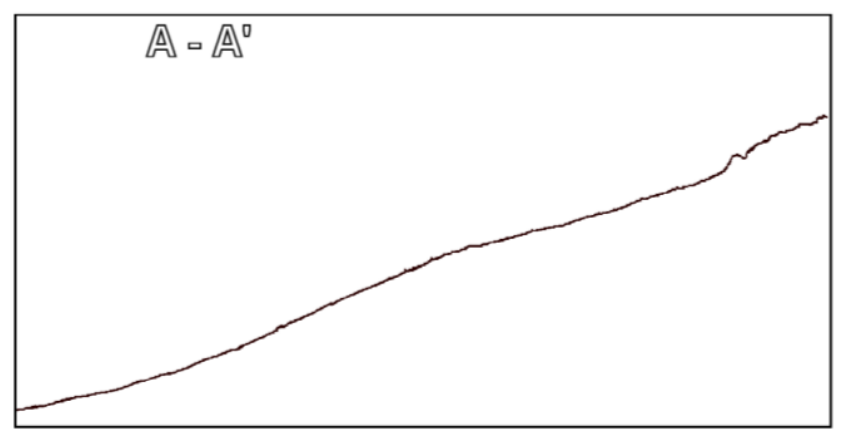

(c)

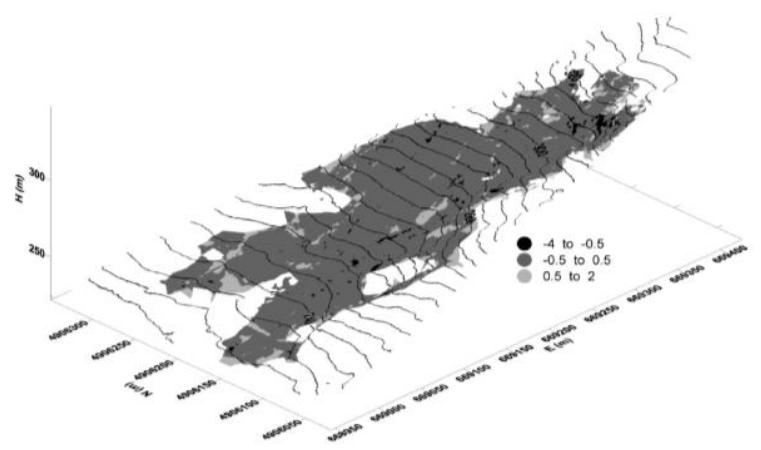

(d)

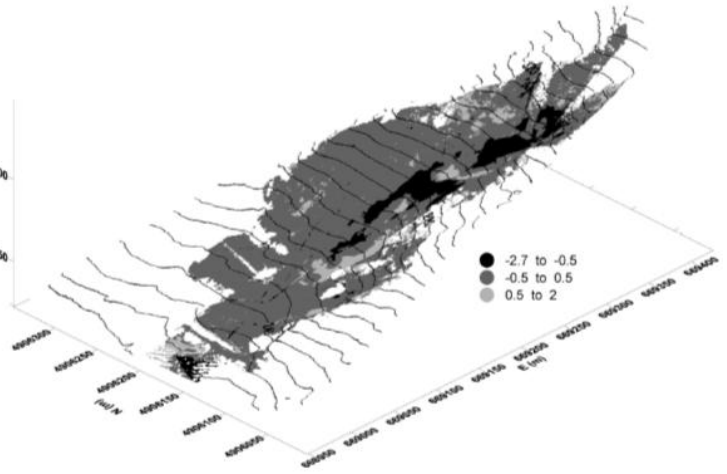

(e)

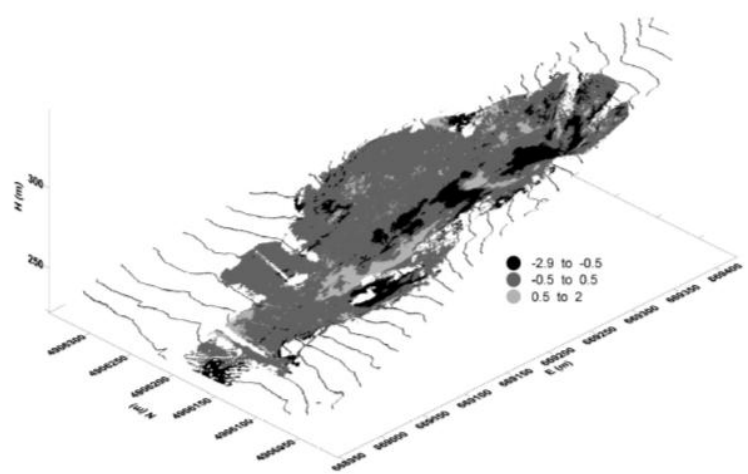

(f)

Figure 2.20. a) Different cross-sections shown in the original point cloud, b) LIDAR crosssection before filtering, c) LIDAR cross-section after filtering and vegetation removal, d) comparison of the 2000-2001 DTMs, e) comparison of the 2000-2004 DTMs, f) comparison 2001-2004 DTMs (from Bitelli and Zamutta, 2004).

Bitelli and Zamutta (2004) concluded that TLS systems provided an accurate, economical, and rapid means of monitoring and characterizing landslide bodies. The authors also stressed that the removal of vegetation is crucial when using LIDAR systems for ground investigations. Furthermore, the authors described automatic procedures used in software, but also suggested that manual interpretation and filtration by an operator is required for a precise 
DTM creation. The technique used in this study utilized the DTMs created from each point cloud to create a comparison surface where the movements are illustrated by different color intervals measured in meters.

\subsection{Total Station Background}

Total stations have been employed for decades as surveying and mapping tools. The first total station was created in 1980 when the first Electronic Distance Meter (EDM) was first attached to a theodolite (Figure 2.21) to create the total station (Wolf, 2002). Angular measurements in both, the vertical and horizontal planes are obtained using a total station device. The total station emits an active electromagnetic pulse (laser); the pulse is then reflected back to the total station from a target located at the point of inquiry. The two-way travel time (source target - sensor) of the emitted pulse is then used to calculate the distance between the total station and the targets. This distance measurement is then used in conjunction with the measured horizontal and vertical angles to determine the real time location of the target in three dimensions. Since their development, total stations have replaced older surveying tools (e.g. theodolites, stand-alone EDMs, and transits) in commercial and industrial practice (Wolf, 2002).

More recently, new total stations have been equipped with servo-drive mechanisms and built-in radio communication system (Wolf, 2002). These new devices are known as robotic total stations. These newer total stations are able to automatically follow a special type of target (prism). This feature allows the robotic total stations to repeatedly measure the coordinates of a point $(\mathrm{x}, \mathrm{y}, \mathrm{z})$ or pre-positioned targets independent of an operator. One of the limitations of the total station device is that a clear line-of-sight (LOS) between the instrument and the target is required. Another drawback of total stations systems when compared to more advanced remote sensing systems like LIDAR, is that total station systems acquire a limited number of points 
because a target or multiple targets are required. LIDAR systems on the other hand are capable of acquiring millions of points ( $\mathrm{x}, \mathrm{y}, \mathrm{z}$, intensity) during individual scans because targets are not required.

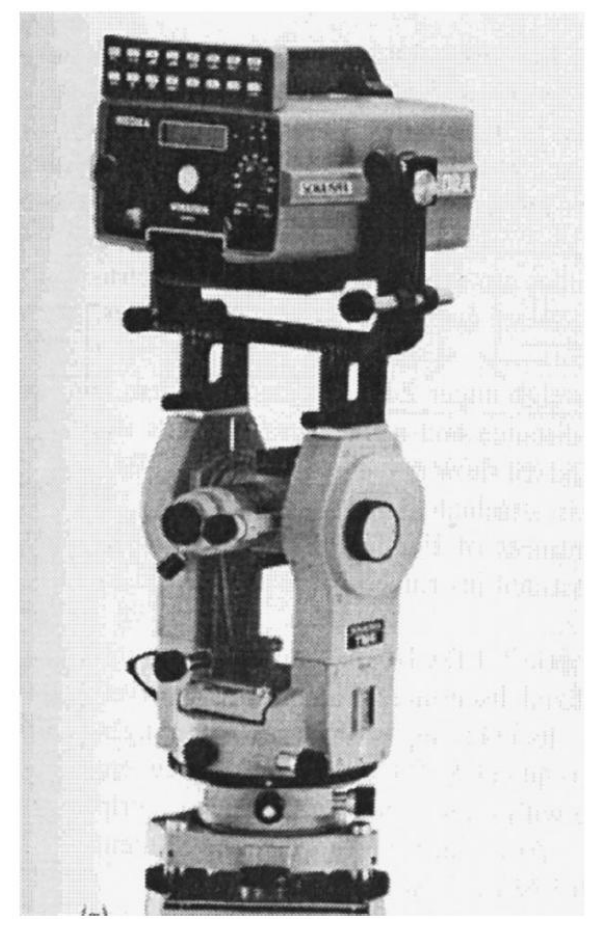

Figure 2.21. EDM mounted on a theodolite; the first total station (from Wolf, 2002).

While total station systems are constantly being upgraded, an angular resolution of \pm 0.15 miligon (mgon) and distance accuracy of approximately $\pm 1 \mathrm{~mm}+1$ parts per million (ppm) to a range of 3500m are obtained using these systems (Savvaidis, 2003). The accuracy and precision of total station systems are affected by atmospheric conditions, water molecules (as described in Section 2.2), and the wavelength of laser light used by the sensor. Therefore, total stations cannot be used in all weather conditions, as opposed to other remote sensing systems such as RADAR.

\subsubsection{Barla et al. (2010)}

Research was performed to monitor the Beauregard Deep Seated Gravitational Slope Deformation (BDSGSD) landslide located in Aosta Valley, Italy, which was compromising a $132 \mathrm{~m}$ high concrete arch-gravity dam. In the interest of public safety, proper monitoring and 
understanding of the behavior of the moving mass was of critical importance to researchers (Barla et al., 2010). The landslide site has been intermittently monitored since 1951, prior to completion of construction of the dam in 1954. The recent availability of new technology made it possible to employ a ground-based RADAR system (GBInSAR) to validate the new technology via comparison with the movements obtained using an automatic total station.

The landslide was divided into two parts or slopes, referred to as the south-eastern slope and the north-western slope. The two parts of the landslide consisted of the same rock lithology and formation. The primary difference between the two slopes was that the south-eastern slope exhibited good to excellent quality, while the north-western slope was highly weathered (Barla et al., 2010). Glacio-fluvial sediments were also found while excavating for the dam abutment. The discovery of these sediments, during construction of the dam in 1951, created serious concerns about water flow control and dam stability.

Multiple instruments used for monitoring (inclinometers, GPS, extensometers) were implemented between the completion of dam construction and the commencement of the research project. In 2003, a robotic total station was installed on the south-eastern (right) slope (considered to be stable) to monitor 19 targets located in the north-western (left) slope (known to be unstable). Daily measurements were acquired at night to obtain the coordinates $(\mathrm{x}, \mathrm{y}, \mathrm{z})$ of each point. The GBInSAR system was installed in 2008, and was also located on the southeastern (right) slope. RADAR image acquisitions were conducted every 20 minutes for a period of four months (from June 2008 to October 2008) with a spatial resolution of $0.5 \mathrm{~m}$ (Barla et al., 2010). All of the monitoring systems installed at the BDSGSD site are illustrated in Figure 2.22. A picture of the site and Beauregard dam is presented in Figure 2.23. 


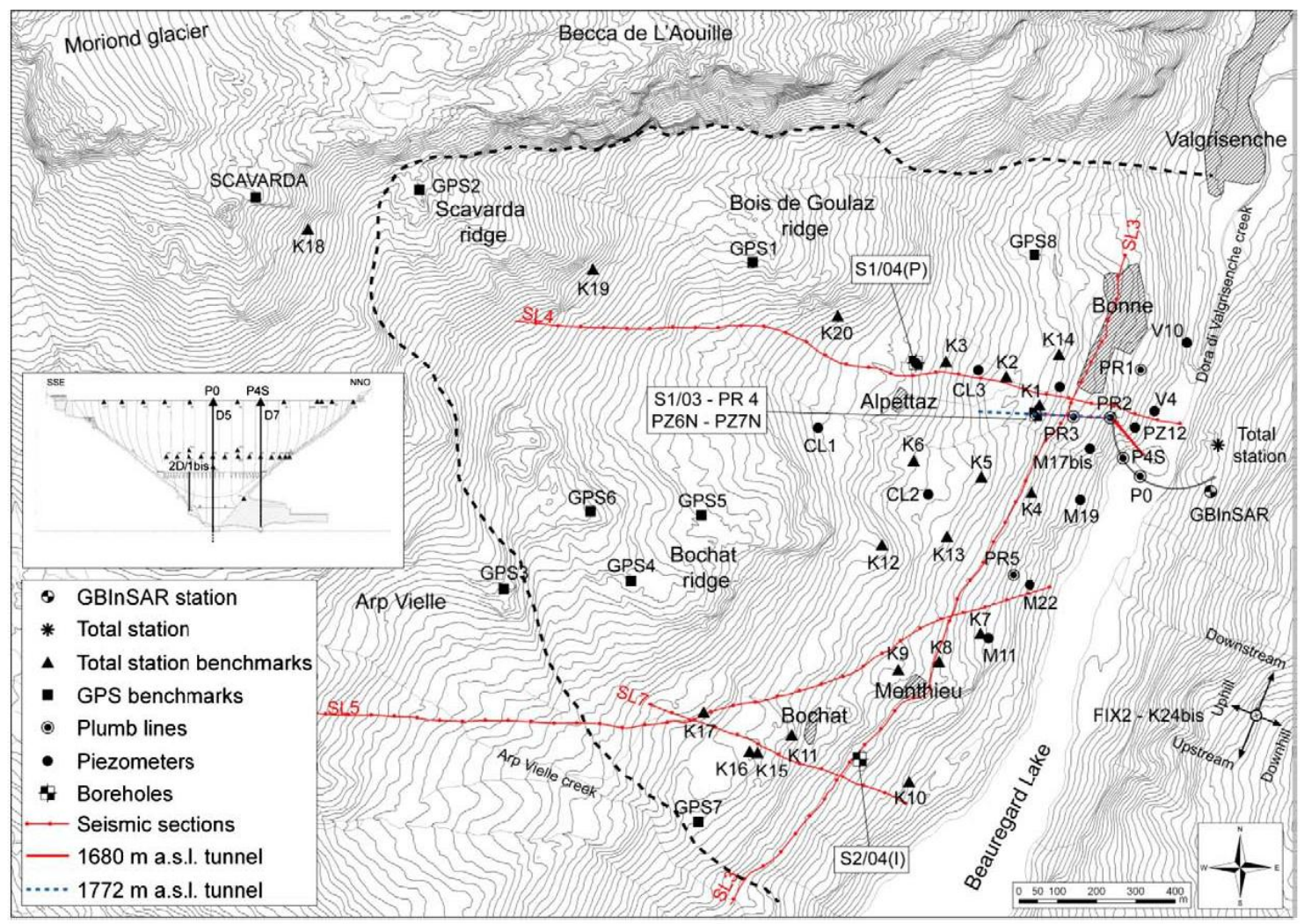

Figure 2.22. Monitor systems installed at the BDSGSD site (modified from Barla et al., 2010).

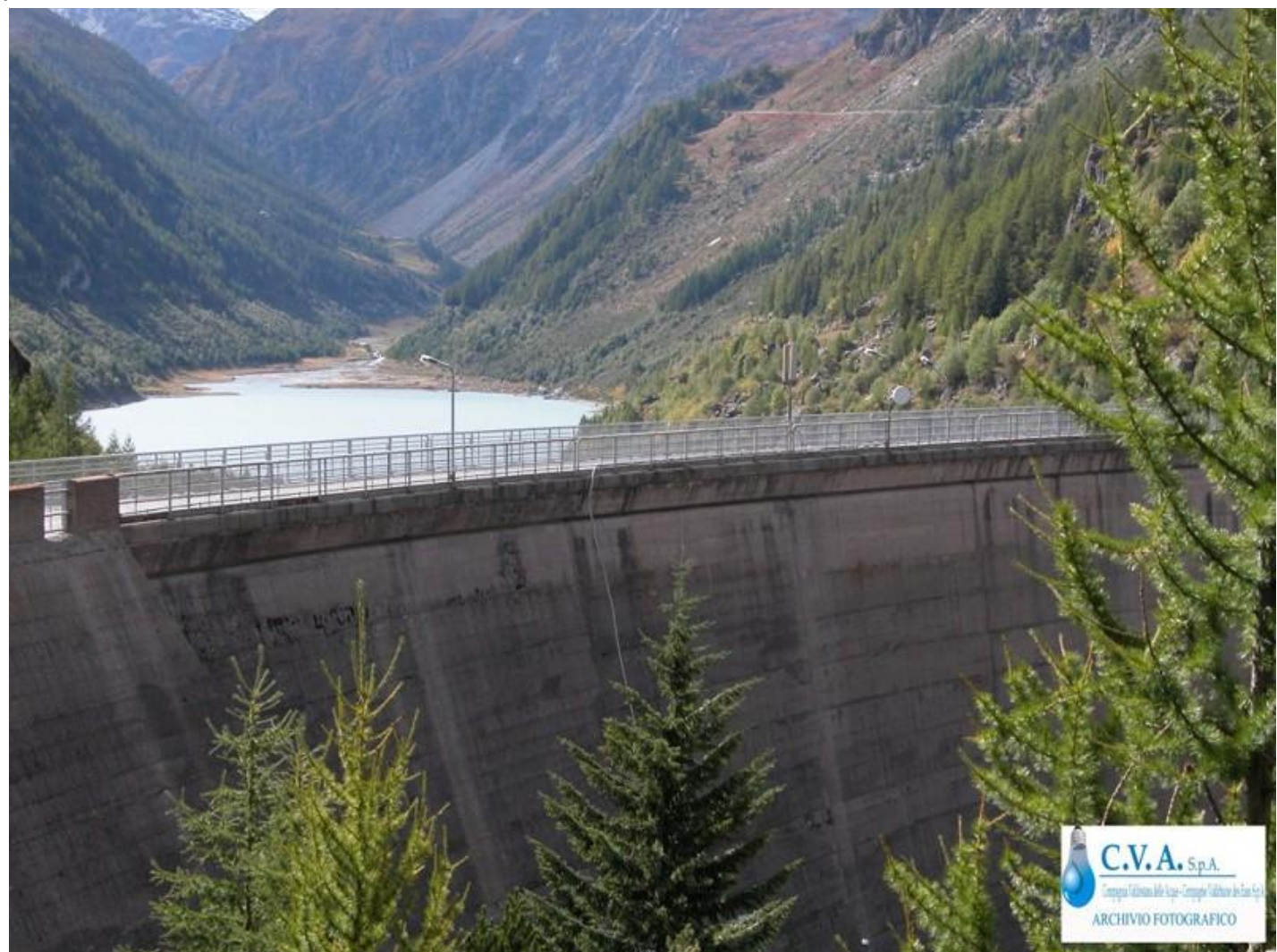

Figure 2.23. Photograph of BDSGSD site (from Valle d' Aosta Website, 2012). 
Comparisons between the RADAR displacements and the total station displacements were only possible in the areas where coherent RADAR backscattering was obtained. Therefore, movements from four targets were compared: K1, K4, K13, and K19 (Barla et al., 2010). The displacement records of the pixels corresponding to each target, as measured using the total station and RADAR measurements, were directly compared. Results within the expected range were obtained for three (K1, K4, K13) of the four targets. Measurement differences range from 2.0mm for $\mathrm{K} 4,2.4 \mathrm{~mm}$ for $\mathrm{K} 13$, and $3.7 \mathrm{~mm}$ for $\mathrm{K} 1$. However, differences between the RADAR and total station measurement for the K19 target were 10.5mm (Barla et al., 2010). The authors state that this difference is explained by the distance between the sensor and the targets. The K19 target was located on the upper part of the slope, $1.7 \mathrm{~km}$ away from the total station; hence large distance may lead to the large difference between sensors. The results obtained from the four targets, and associated weather data are presented in Figure 2.24.

The weather data was collected on the daily basis and correlated to monitoring results. Based on the results the authors determined that the optical system was more sensitive to weather conditions and dielectric effects than the RADAR system. Furthermore, Bara et al. (2010) concluded that the results obtained with total station are less reliable than GBInSAR for distances greater than $1.5 \mathrm{~km}$. 

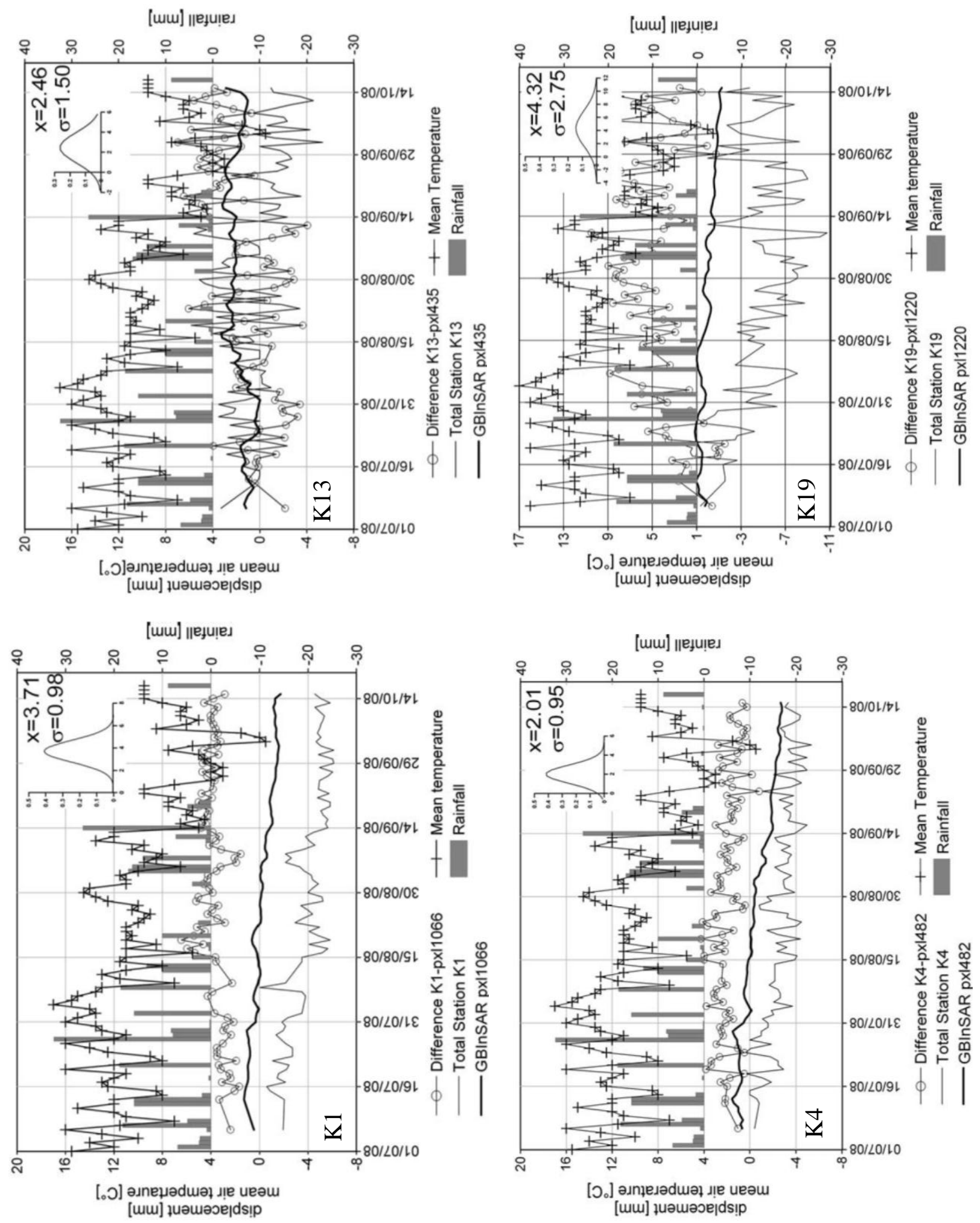

Figure 2.24. Comparison between displacements obtained with total station and GBInSAR for targets K1, K4, K13 and K19 (modified from Barla et al., 2010). 


\subsubsection{Nishii and Matsouka (2010)}

Remote sensing techniques are often employed for monitoring landslides in areas that are otherwise difficult to access for geographic reasons. Nishii and Matsouka (2010) conducted research to identify the progressive deformation in the Aresawa rockslide (part of the eastern slope of Mt. Aindake) in the Japanese Alps (Nishii and Matsouka, 2010).

The rock stratum was composed of shale and sandstone. Seasonal frost and snow covered the site periodically causing freeze and thaw cycles that were believed to be a major contributor to the instability of the site. In May 2004, a partial collapse produced new tension cracks around the old head scarp (located between the "upper" and "lower" slope); this collapse led to monitoring by Nishii and Matsouka, 2010. The site was monitored using a prism-type total station (Leica RC405) and a non-prism type ultra-total station (Leica TCR 405). The first system was used for the majority of the study until it was replaced by the non-prism system for safety reasons. Fifteen (15) inspections were conducted using the monitoring equipment between 2006 and 2008 (Nishii and Matsouka, 2010). The total stations were located approximately 100m away from the sliding mass, anchored to bedrock that was considered to be stable. Fifteen targets were anchored to the ground within the sliding mass; however, the targets were removed during the winter season of each year. Nine targets were placed in the upper slope and six targets were placed in the lower slope. Air temperature was recorded hourly, while precipitation and ground surface temperature were recorded in 6 hours intervals at a weather station that was located about $200 \mathrm{~m}$ south of Mt. Ainodake. A diagram of the site is presented in Figure 2.25. The division between the upper slope and lower slope and the head scarp are presented using photographs in Figure 2.26. 


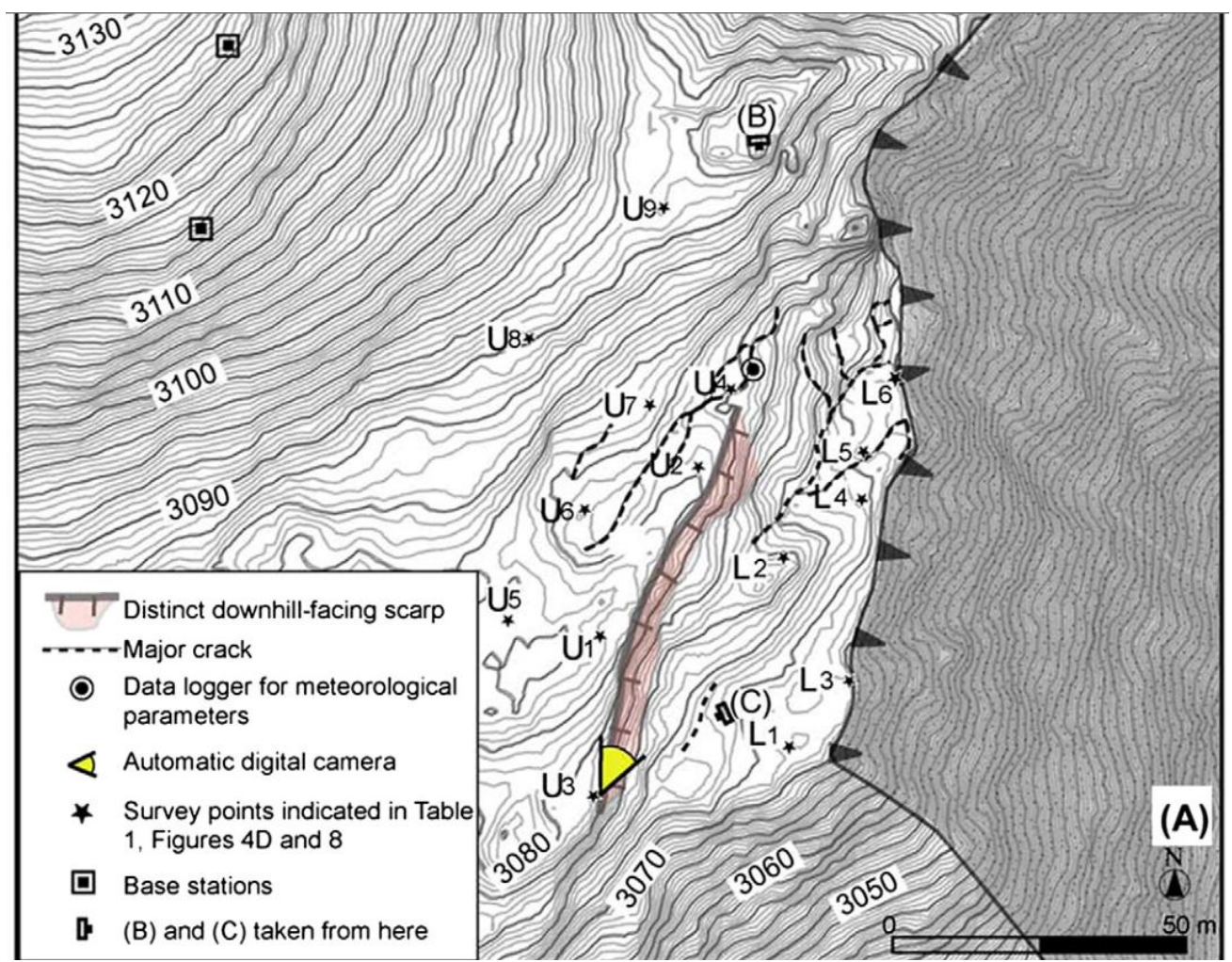

Figure 2.25. Site layout and target positions (from Nishii and Matsouka, 2010).

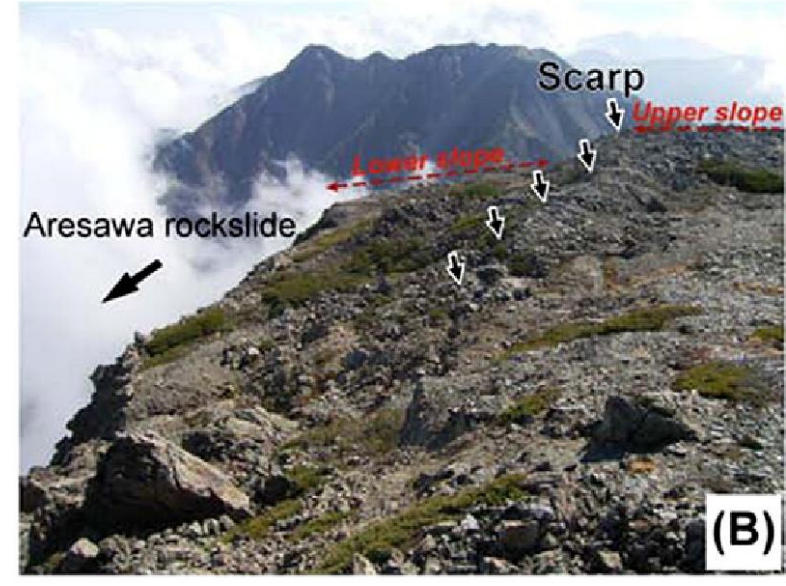

(a)

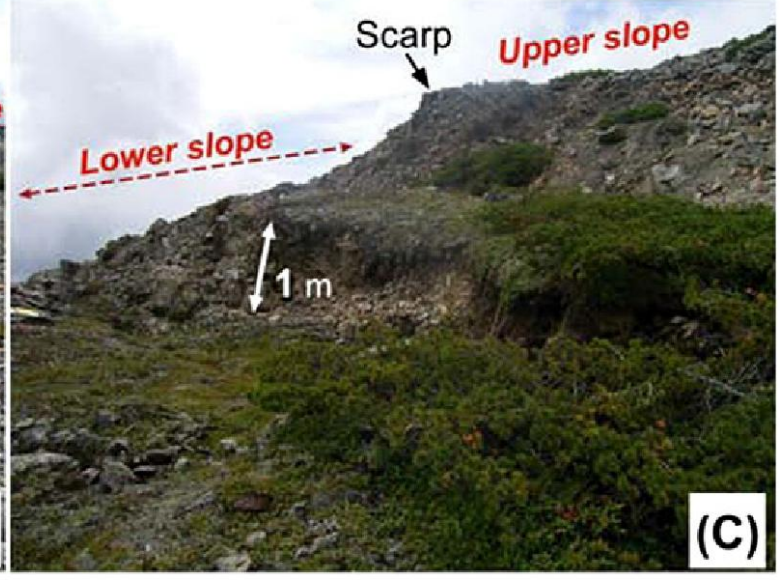

(b)

Figure 2.26. a) Scarp formed after the failure of 2004 , b) overview of the monitored area (from Nishii and Matsouka, 2010).

A significant seasonal difference was observed. From October to June the observed displacements were small (approximately $1 \mathrm{~mm} /$ day), while from June to October the observed displacements increased to approximately 10mm/day (Nishii and Matsouka, 2010). Also, more movement was observed in the lower slope than the upper slope for the same periods. Nishii and 
Matsouka (2010) concluded that the lack of liquid water filtrating into the bedrock in the winter resulted in low movements. On the other hand, water filtration into the bedrock during the summer months due to snowmelt and rainfall lead to the landslide.

\subsection{Other Non-Remote Sensing Techniques used for Landslide Monitoring}

Historically, landslides have been monitored and studied using non-remote sensing techniques such as time domain reflectometry (TDR) and inclinometers. TDR technology has been used in geotechnical engineering for over 20 years (Dennis et al., 2006); however, a complete understanding of this technique has not yet been achieved. According to Stark and Choi (2008), inclinometers have been used for slope monitoring since the 1950s; making this technique a standard, field proven, method for earth displacement measurements, and shear plane depth determination.

A TDR system uses reflected energy to determine the location (depth) of anomalies in the ground, hence, why some people state this technique is similar to RADAR systems. However, unlike RADAR systems in which the energy is emitted into and received from the atmosphere, TDR systems consist of energy traveling through a coaxial cable. The end of the cable is anchored within a borehole, ensuring the length of the cable crosses the location of interest, and the borehole is grouted to provide direct contact with the soil mass surrounding it. The TDR operates by sending a voltage pulse to the coaxial cable. Every time an anomaly in the cable is encounter a portion of the voltage is reflected back to the TDR tester (or reader) device. Anomalies are typically associated with distortions in the cable caused by movements within the slope or earthen mass. A change in the resistivity of the cable, at the locations of the anomalies, is recorded using the TDR tester box. Since the velocity of the pulse and the travel time to the anomaly are known, distances to the different anomalies in the cable are computed. The size of 
the anomaly encountered in the cable (and the resulting permanent deformation of the cable at the location of interest) is also inferred by the magnitude of the reflected signal (Anderson et al., 1996).

Inclinometers provide a reliable and direct method to measure the movement of slope or earthen masses. A casing (usually plastic) is installed in a previously drilled borehole, and secured with grout. The grout provides intimate contact between the surrounding soil or rock strata and the casing. Deformations on the casing caused by the earth movements are measured using a portable traversing probe. Profiles of the casing lined borehole are obtained from subsequent investigations by drawing the probe from the bottom to the top of the casing. Typically the testing procedure is repeated for each profile (probe drawn up from the bottom two times) with the instrument rotated 180 degrees between each test to determine the profile. Inclinometers provide movements relative to two axis usually known as the A-A axis (primary axis) and B-B axis (secondary axis, rotated 90 degrees from the primary axis).

Researchers have compared TDR and inclinometer systems while monitoring the same site. Two case histories highlighting the use of TDR and slope inclinometers are presented in Sections 2.6.1 and 2.6.2. Dowding and Connor (2010) and Dennis et al. (2006) discuss the uses of each (TDR and slope inclinometer) for monitoring of slopes associated with mining applications, landfill applications, and roadway applications.

\subsubsection{Dowding and Connor (2000)}

Dowding and Conner (2000) used TDRs and inclinometers to monitor an oil sand strip mine highwall slope, a landfill slope, road distress, and an abutment embankment at various sites. TDR and inclinometer instrumentation were installed at each of the sites and monitored for a given period of time (the increment of time was not discussed for each of the cases). A brief description of each of the cases is provided below. 
A multimillion dollar dragline used at a strip mine was in jeopardy of being undermined by slope instability associated with numerous thin clay layers within the oil sand (Dowding and Connor, 2000). TDR coaxial cables and inclinometers were installed (10 meters apart for one another) at three different locations surrounding the dragline. The anomalies detected using the TDR method occurred at depths where movements were also detected using the inclinometer method. In order to quantify the amount $\left(1 \mathrm{mrho}=1 / 1000^{\text {th }}\right.$ of the launched voltage $)$ of the voltage of the pulse that was reflected by the anomaly, the voltages obtained were correlated to the displacements measured by the inclinometers. It was determined that $0.2 \mathrm{mrho}$ in the TDR corresponded to $1 \mathrm{~mm}$ of deformation in the inclinometer (Dowding and Connor, 2000).

As compared with the strip mine implementation, a smaller diameter borehole and a lower strength grout were used to enhance the sensitivity of the TDR for the landfill application. It was determined that $7.7 \mathrm{mrho}$ in the TDR corresponded to $1 \mathrm{~mm}$ of deformation in the inclinometer (Dowding and Connor, 2000). Therefore, more sensitivity was observed because larger quantities of the signal were returned to the TDR readout device.

For the third case (road distress) the sensitivity obtained from the TDR as compared with the inclinometers was $5 \mathrm{mrho} / \mathrm{mm}$. During the monitoring of this site the ability of TDR to extend the life of an inclinometer's casing was demonstrated. After almost a year after installation, the casing had deflected sufficiently at the shearing plane which prevented the inclinometer probe from passing through the casing. Subsequently, the casings were retrofitted with grouted coaxial cables allowing monitoring via the use of TDR after inclinometer casings ceased to function properly.

Very high sensitivities were obtained in the fourth case (abutment embankment), on the order of $105-145 \mathrm{mrho} / \mathrm{mm}$. In this project site the TDR reflections were exactly at the soil-fill or 
change of rock (strata) interfaces. The authors postulated that the highly localized shear developed in these locations deforms metallic coaxial cable easily (Dowding and Connor, 2000). TDR waveforms compared to inclinometer profiles installed in the vicinity for different cases of this study are shown in Figure 2.27 and Figure 2.28.

Dowding and Conner (2000) concluded that inclinometers probes are sensitive to gradual changes in the inclination of the inclinometer, while, highly localized shear (rock joints failure) deforms metallic coaxial cables very easily. The ratio of hole-diameter to cable-diameter should be kept as low as possible to assure that the grout fractures with low displacements. Finally, the grout strength must be large enough to deform the cable, but must be weak enough to fracture without exceeding the bearing capacity of the surrounding soil (Dowding and Connor, 2000).

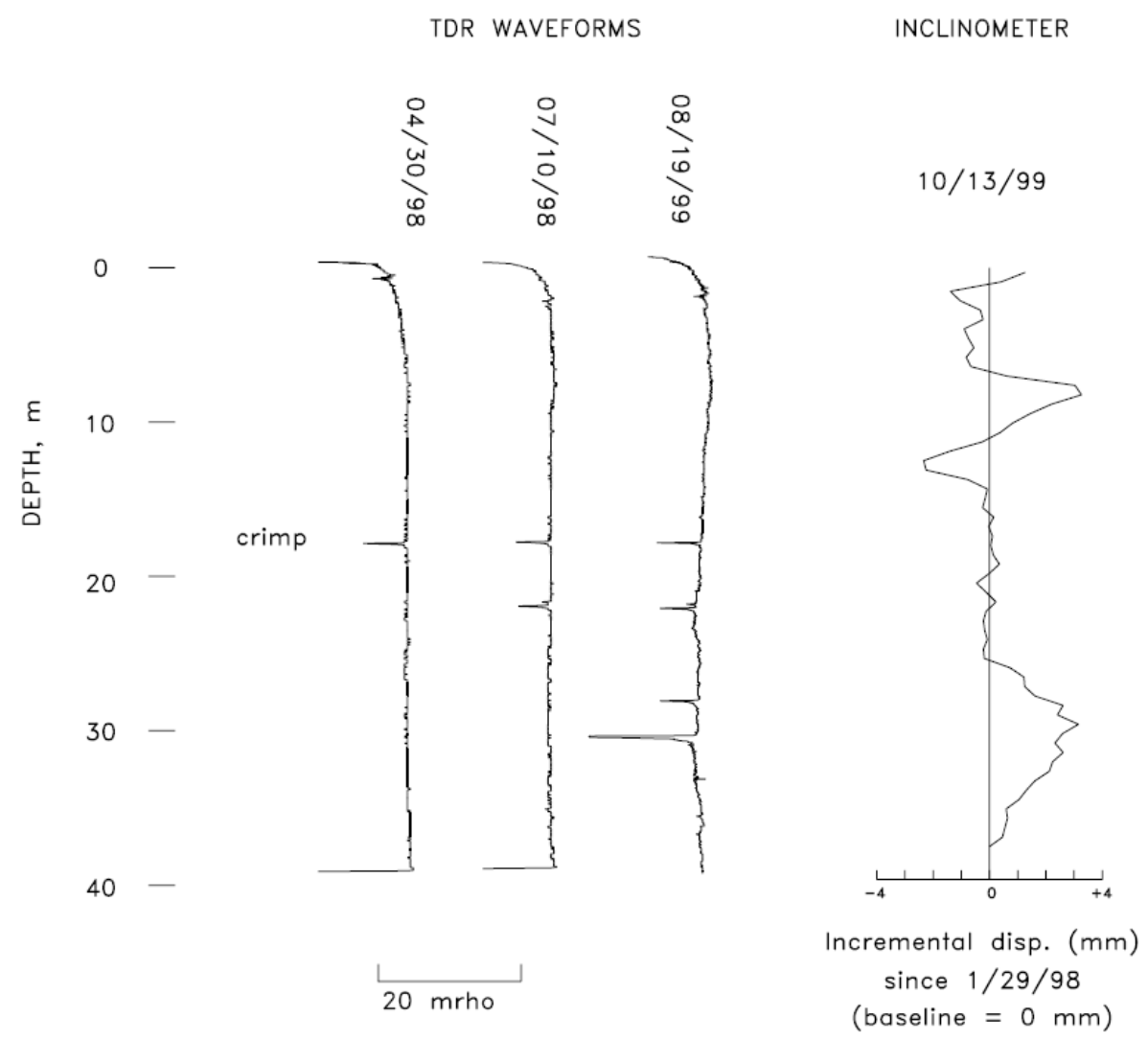

Figure 2.27. TDR waveforms and inclinometer profile against depth for case 1 (from Dowding and Connor, 2000). 


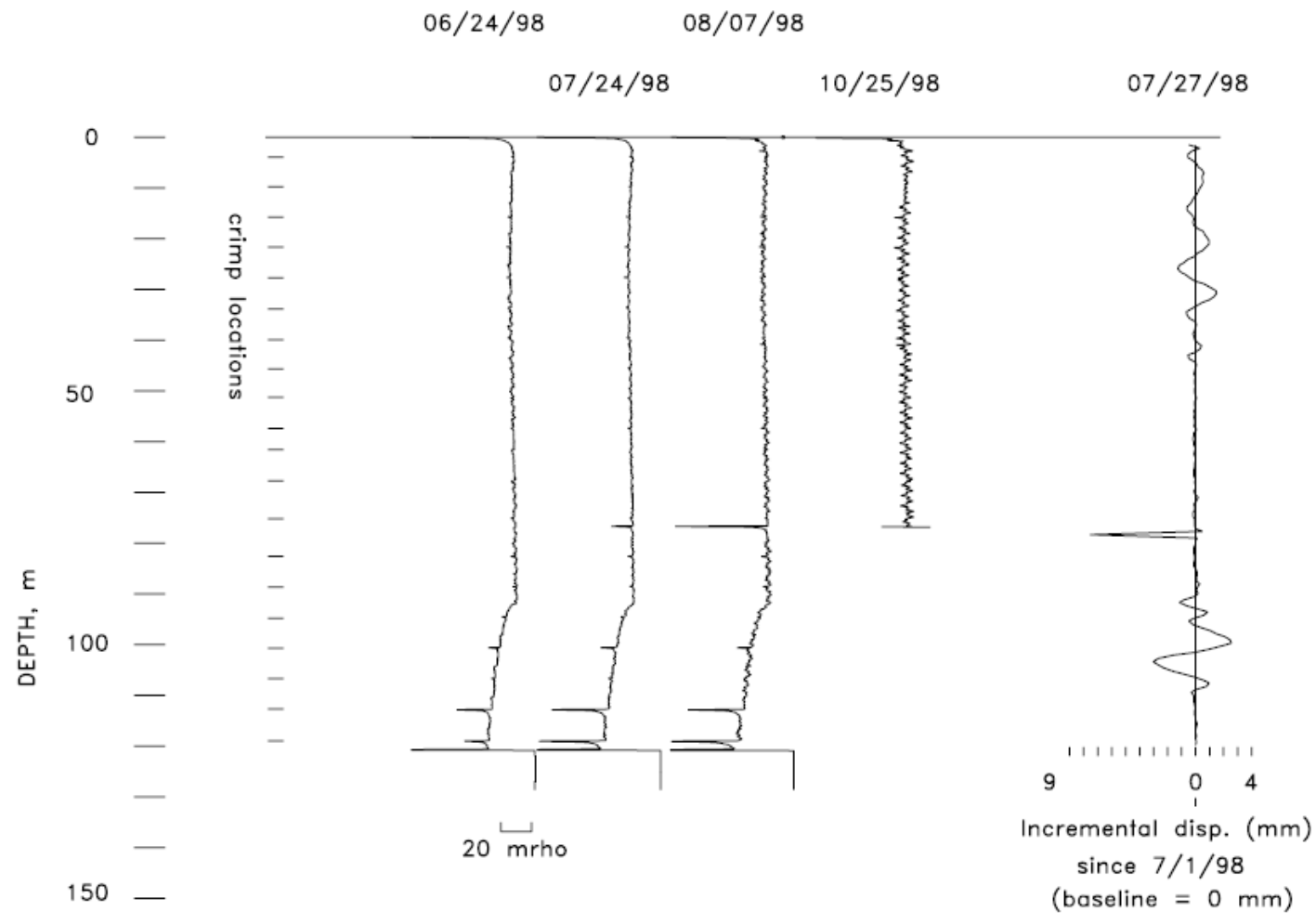

Figure 2.28. TDR waveforms compared to inclinometer profile for case 3 (from Dowding and Connor, 2000).

\subsubsection{Dennis et al. (2006)}

Inclinometers, TDR systems, and piezometers were used to monitor slopes failures in the state of Arkansas (Dennis et al., 2006). Four project sites in the Ozark Plateau were selected. Two sites consisted of cut slopes along Interstate Highway 540 (I-540) in the section between Fayetteville and Forth Smith, one site consisted of a cut slope on Interstate Highway 40 (I-40), and the one site consisted of a fill slope on United States Highway US-167 (Dennis et al., 2006).

The purpose of this study was not only to determine if TDR could be used as a reliable method for slope monitoring, but to determine the necessary threshold required by TDR systems to record movements. Laboratories studies were conducted to determine the most cost effective 
cable type to be used in TDR applications. After one year of monitoring in the first project site along I-540 no reflected pulses were observed. However, $4.5 \mathrm{~mm}$ of displacement was observed in the inclinometer data that was installed four meters away from the various TDRs (comprised of different coaxial cable types). The researchers hypothesized that the grouted boreholes reinforced the coaxial cable, preventing movement of the cables. The other project sites showed movements at the same depths where anomalies were noticed in the TDR data. A cross section of the US-167 project site is presented Figure 2.29. The displacements graphs recorded by the one of the inclinometers and one of the TDRs for the I-540 site are presented in Figure 2.30 and Figure 2.31, respectively.

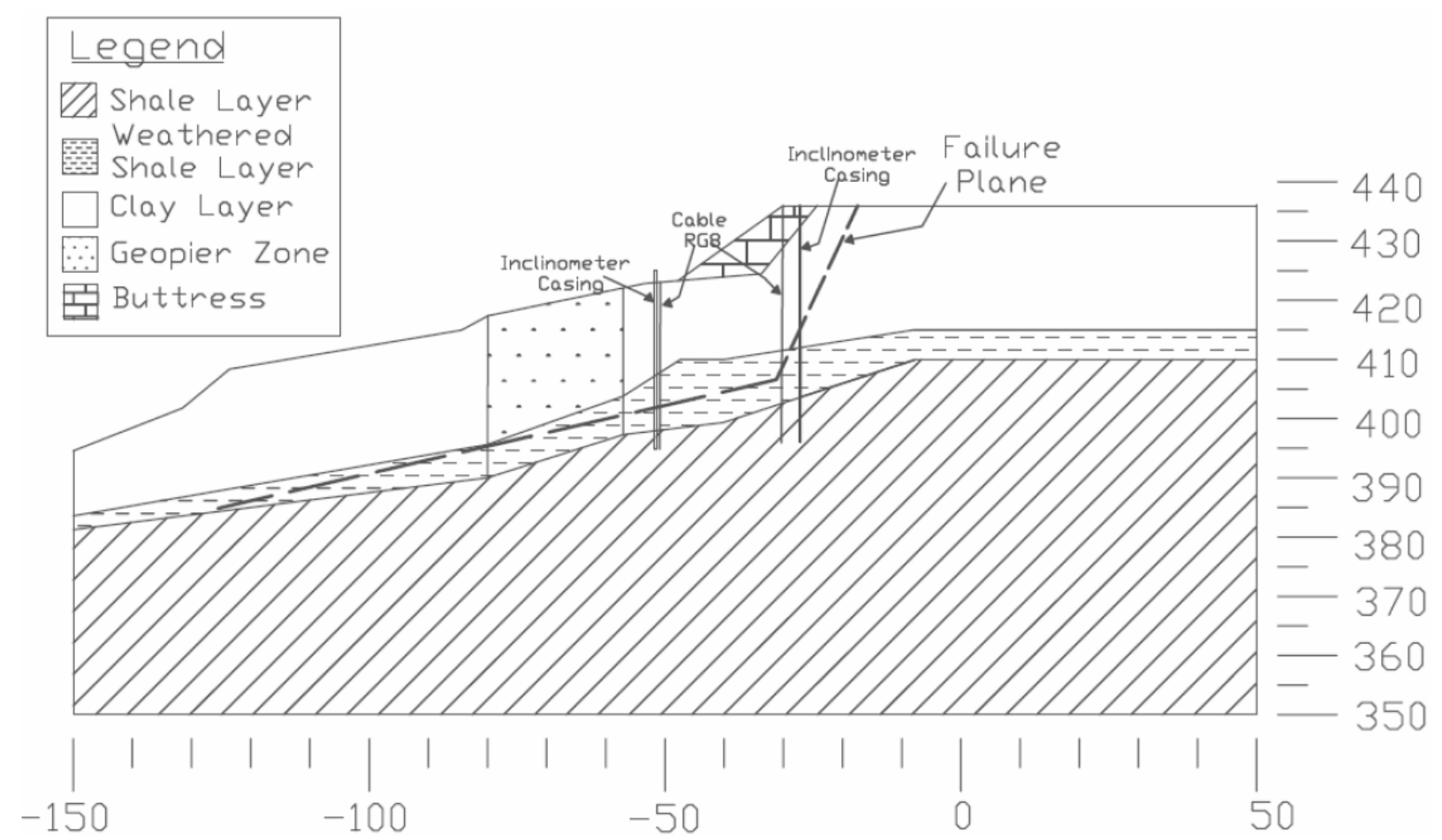

Figure 2.29. Cross-section of the test area along Highway 167 with instrumentation used (from Dennis et al., 2006). 
Batesville Upper A-Axis

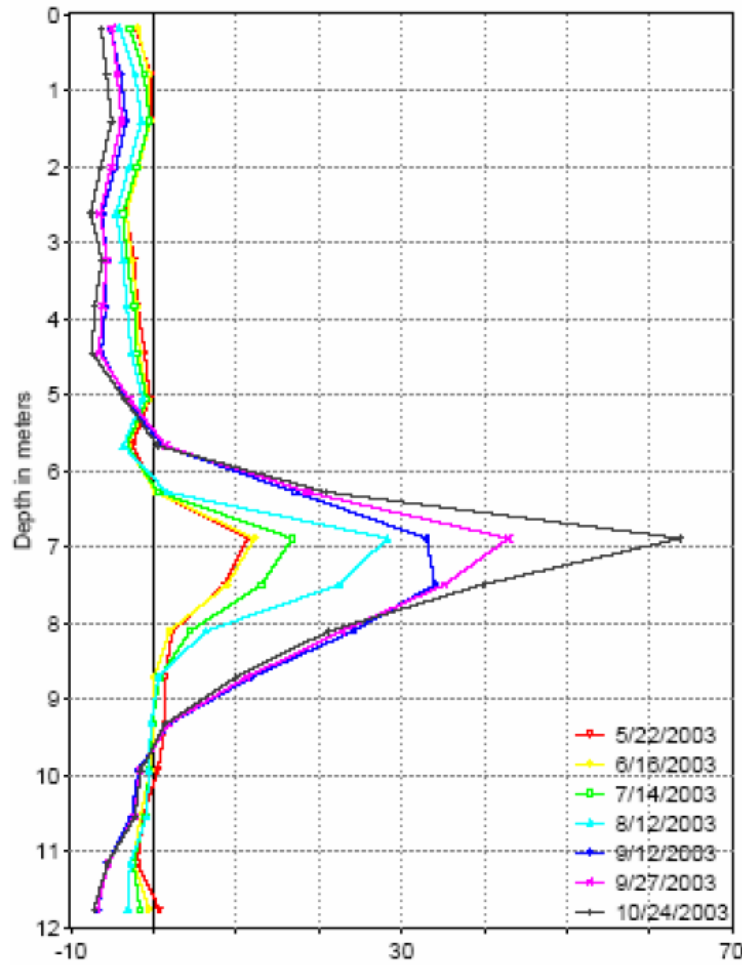

Batesville Upper B-Axis

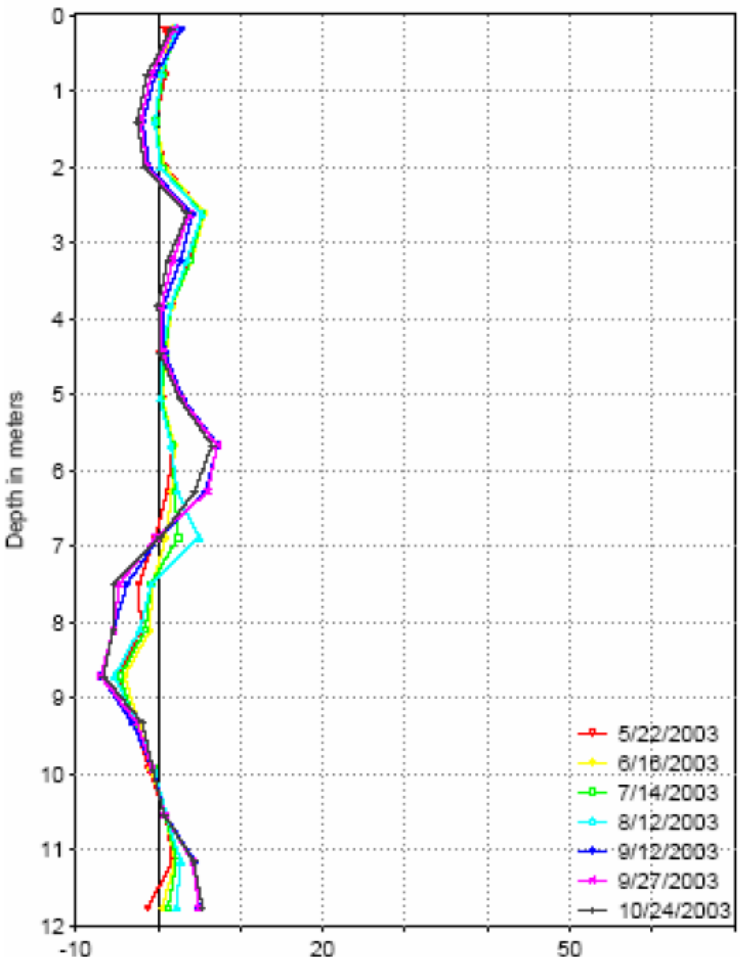

Figure 2.30. Inclinometers displacements obtained by the inclinometers on the Highway 167 project site (from Dennis et al., 2006).

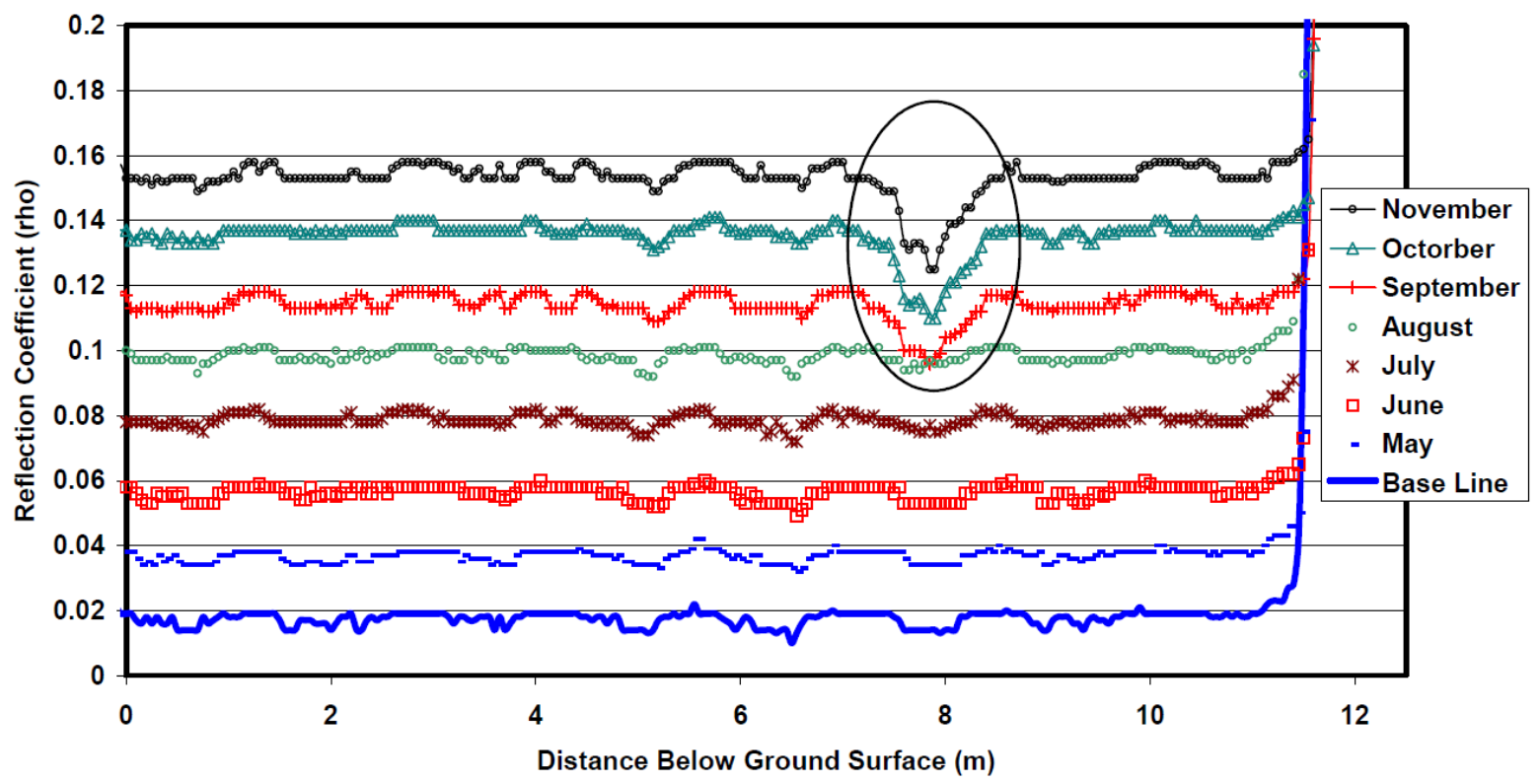

Figure 2.31. Monitoring results obtained by TDR on the Highway 167 project site (from Dennis et al., 2006). 
The conclusions drawn by Dennis et al. (2006) regarding this research project included that great consideration must be taken when installing TDR cables so the grout columns do not reinforce the shallow failures slopes. Furthermore, the grout strength and cable type are key factors when considering TDR as a slope monitoring technique. Additionally, TDR systems provide a less expensive way to monitor slopes than inclinometers. More specifically, the data obtained using TDRs systems is recorded and stored using a data collector. Therefore, the data was retrieved remotely using a modem. The laboratory and field studies showed strong correlation between deformation and reflected energy, but the correlation varied across the project sites (Dennis et al., 2006).

\subsection{Conclusion}

An overview of remote sensing was presented in Section 2.2. Specifically, advantages and disadvantages of common remote sensing techniques (Total Station, LIDAR, RADAR) were presented. The limitations of satellite and aerial remote sensing for geotechnical engineering applications were also briefly discussed. Furthermore, the need for ground based sensors (LIDAR and RADAR) was presented.

Each of the methods (RADAR documented in Section 2.3, LIDAR documented in Section 2.4, Total Station documented in Section 2.5, and Slope Inclinometers documented in Section 2.6) employed for this research project (AHTD TRC-1102) were also presented with accompanying case histories; the case histories were included to document the use of the respective devices for landslide monitoring.

As remote sensing techniques become more available, economical, and accurate the use of remote sensing devices to determine displacement rates, extents and behavior of a landslide and other geotechnical engineering applications is becoming more common. When used in 
conjunction with proven and new in-situ techniques such as inclinometers and TDRs systems (which although accurate can be expensive to install and maintain) a complete knowledge of the sliding mass is obtained. Furthermore, using a combination of remote and non-remote sensing techniques is ideal to obtain precise, rapid, economical, and accurate results for a given project. 


\section{Chapter 3. Project Sites}

\subsection{Introduction}

As previously mentioned in Chapter 1, slope failures at two separate sites were investigated during the course of this project research. The two sites were located along US Interstate Highways near the towns of Chester, Arkansas and Malvern, Arkansas. The Chester site was selected because of its close proximity to the University of Arkansas, while the Malvern site was selected because of research conducted at the site by prior investigations. Furthermore, AHTD personnel have conducted subsurface investigations at both sites.

The landslide in Malvern has been active for more than 20 years, and has been monitored previously by personnel from the Arkansas Highway and Transportation Department (AHTD) and the University of Arkansas. The stratigraphy of each of the sites is based on the information obtained from the previous investigations. In addition to the stratigraphy, the location, geology, and history of both the Chester and Malvern sites are presented in this chapter.

\subsection{Calibration Site - Chester, Arkansas}

The Chester site was selected due to the proximity of the site to the University of Arkansas and was used to calibrate all the remote sensing techniques as well as develop the testing methodologies employed during this research project (AHTD TRC-1102). Therefore, the Chester, Arkansas, site was referred to as the calibration site. Information about the calibration site including: the location, history, proposed purpose, geology, three dimensional topographic model, geotechnical engineering parameters and slope stability model are discussed in this Section. 


\subsubsection{Calibration Site Information}

The location, history, proposed purpose, geology, and geotechnical engineering parameters of the site provide information about why this site was chosen as the calibration site. Further information about each of these topics are found in the Subsections of this Section. Of particular importance are the site location, site history, and proposed purpose, as these are the factors which contributed to the selection of the calibration site near Chester, Arkansas.

\subsubsection{Location of the Calibration Site}

The slide occurring near Chester, Arkansas on Interstate 540, near Log Mile 36.4 (Figure 3.1) is approximately 2.5 miles north of the town center of Chester, Arkansas. The site is located approximately 36 miles from the University of Arkansas Bell Engineering building, five miles south of the Bobby Hopper tunnel. The driving time from the University to this project site was approximately 30 minutes.

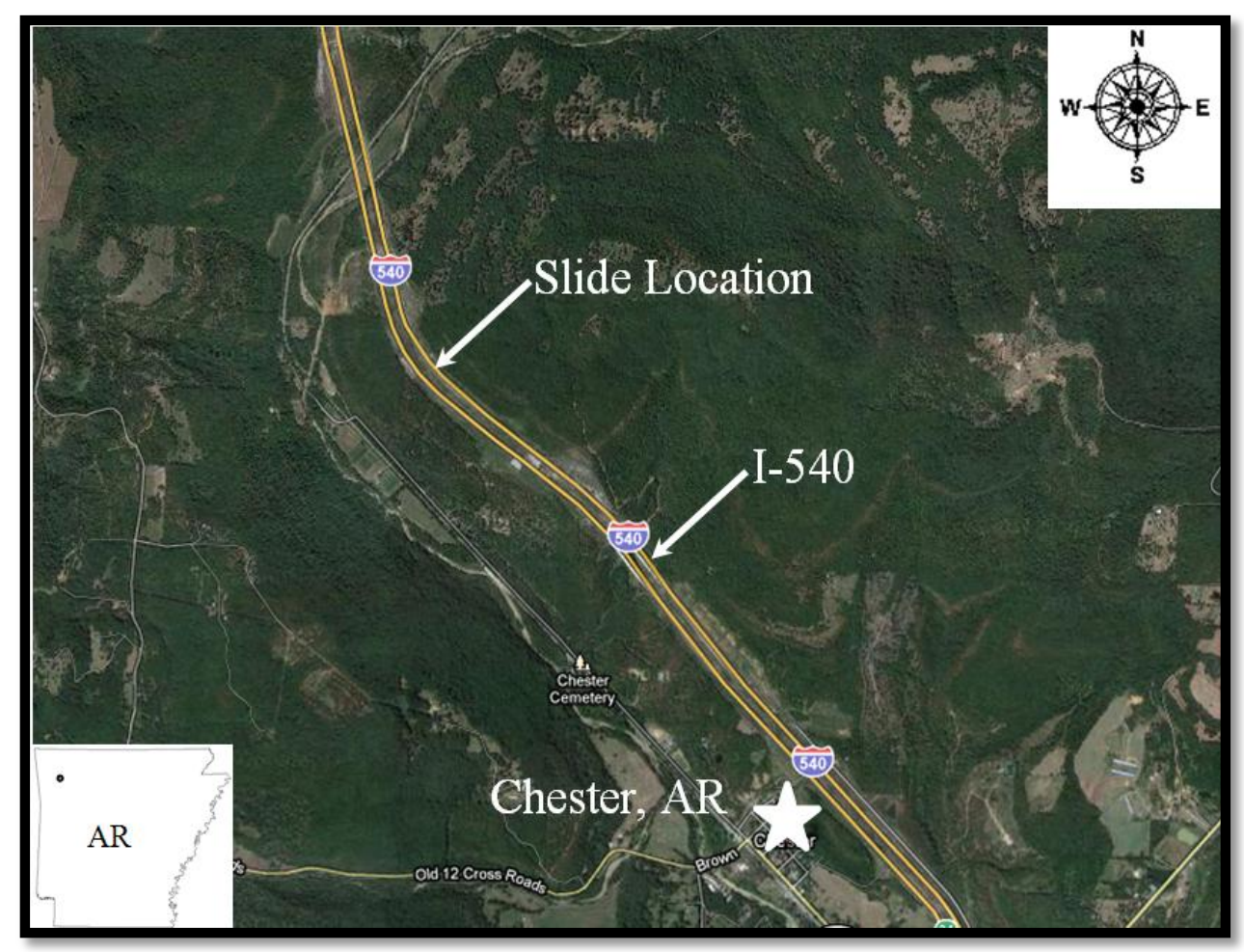

Figure 3.1. Location of calibration site along Interstate 540, near Log Mile 36.4 North of Chester, AR (Google Maps, 2011). 
The location of the calibration site was ideal for research operations due to the lack of population in the area where the slide is located; however, the slope failure is located in the median of I-540, a major transportation artery in Northwest Arkansas. The surface extents of the study area was approximately 550 feet long (in the direction of the roadway) and extend from the west shoulder of the northbound lanes to the east shoulder of the southbound lanes (transverse to the roadway). A picture of the site, as obtained from the west shoulder of the southbound lane of I-540, is presented in Figure 3.2.

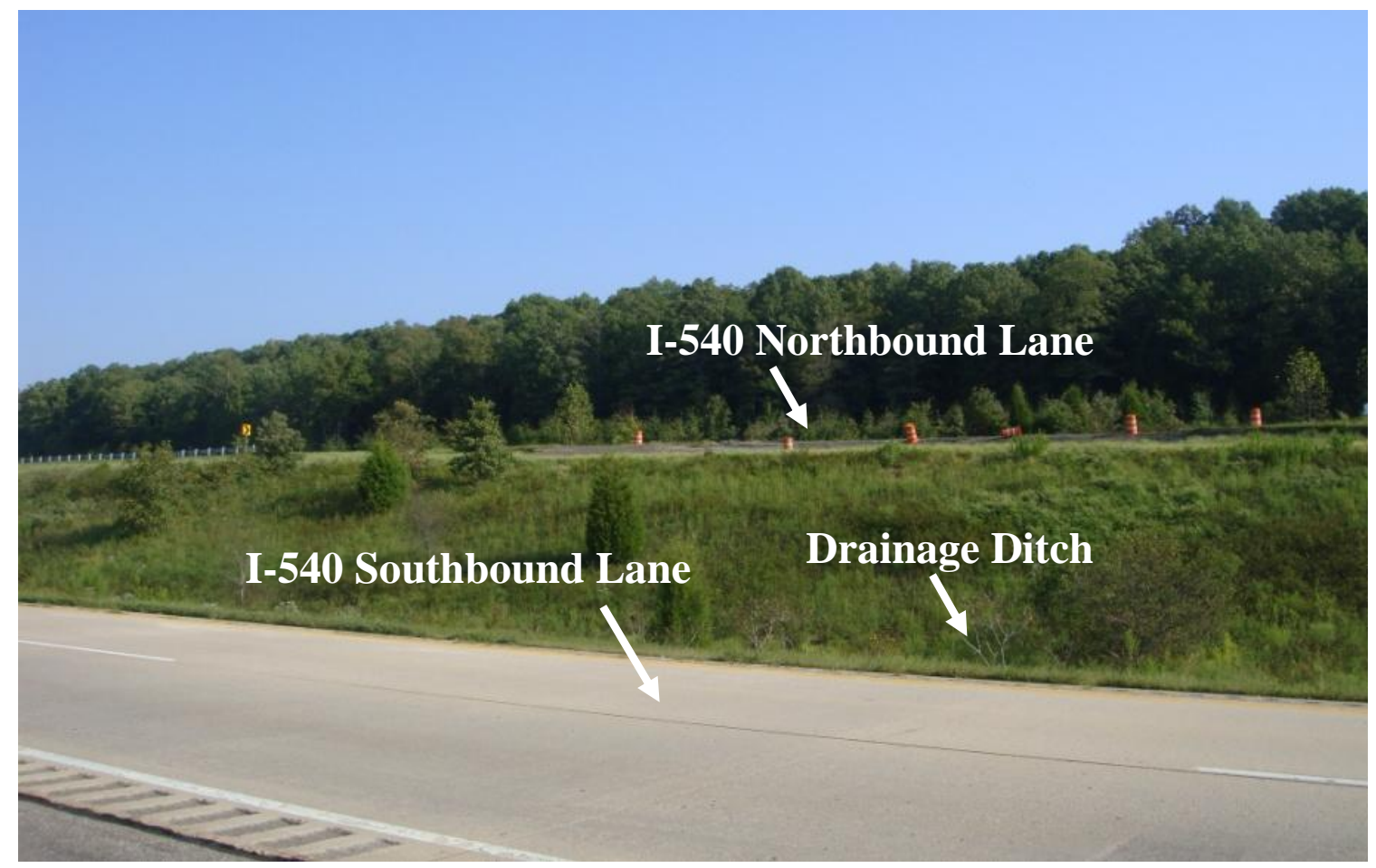

Figure 3.2. Photograph obtained while looking northeast across southbound lane of I-540 at calibration site near Chester, Arkansas.

\subsubsection{History of the Calibration Site}

The section of I-540 near Chester, AR has been known for its high quantity of slope failures along both sides of the Interstate. In fact, the AHTD spent up to 42 million dollars on post construction repairs of landslides in this area before 2006 (Dennis et al, 2006). The geology 
of the area (as discussed in Section 3.2.1.4) and the relatively steep topography (as discussed in Section 3.2.2) contribute to large numbers of unstable slopes.

A geotechnical investigation conducted by AHTD in May 2010 was documented in an AHTD report in August of that year (AHTD, 2010) which summarized the findings of the investigation and suggested remediation techniques. Specifically, a rock buttress was suggested to repair of the slope failure. However, only partial reparation of the slope was performed on this site prior to the completion of this research project (TRC-1102). Photographs of the site looking north towards the main scarp during the geotechnical investigation conducted in May 2010, and a picture of the same scarp in September 2010 (during the initial visit to the site by UofA personnel) are presented in Figure 3.3 and Figure 3.4, respectively. The 18-inches of vertical movement causing the head scarp and a tension crack located in the median, as observed during the September 2010 visit, are shown in Figure 3.5.

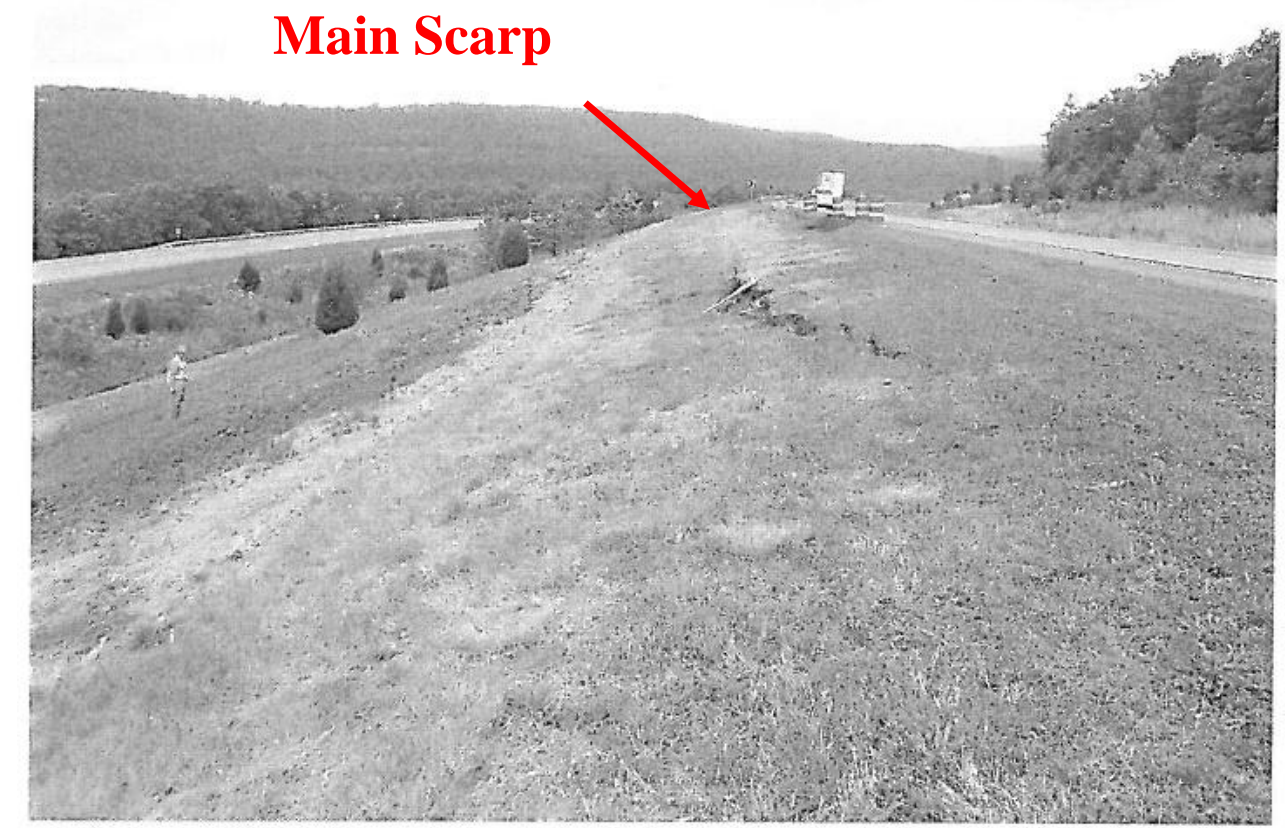

Figure 3.3. Looking north to the main scarp at the calibration site near Chester, Arkansas in May 2010 (from AHTD, 2010). 


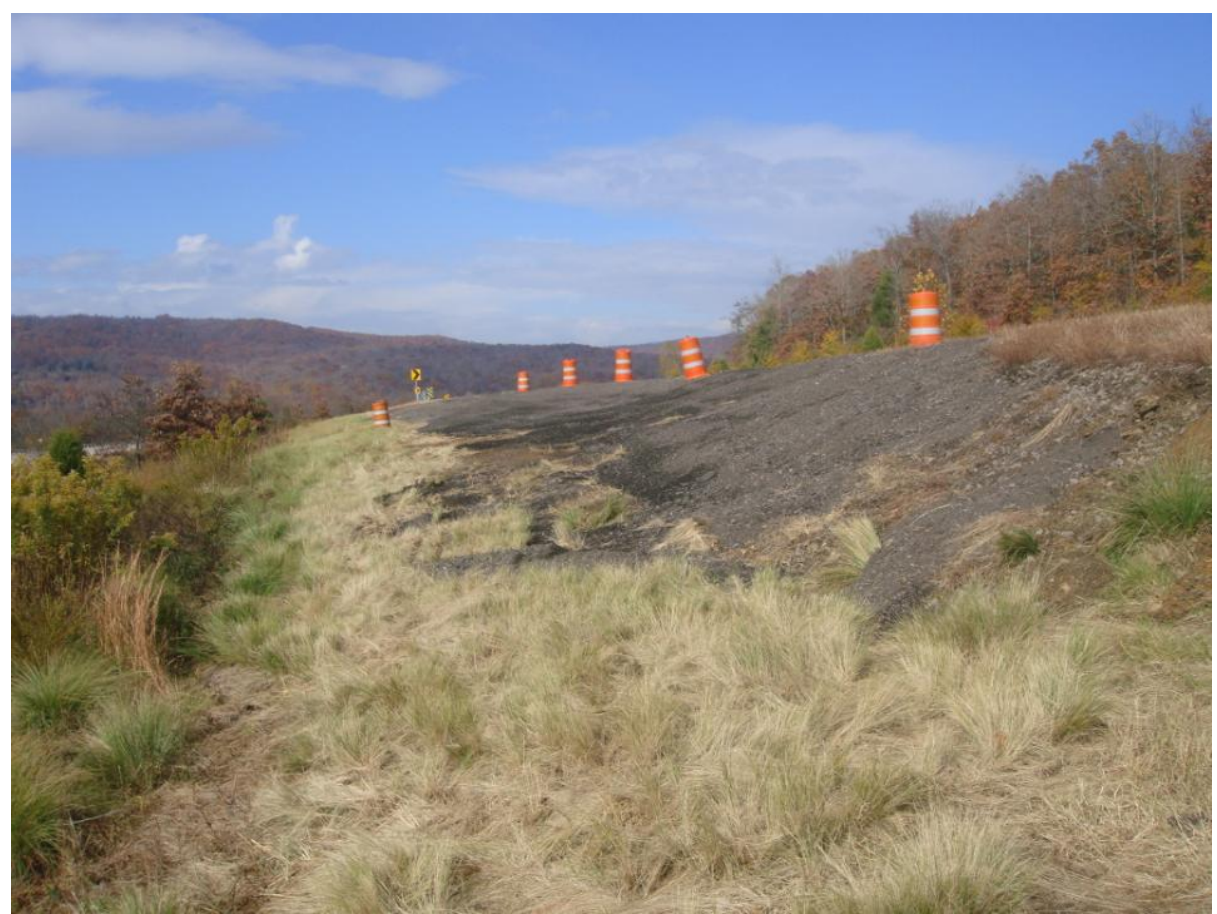

Figure 3.4. Looking southeast to the main scarp at the calibration site near Chester, Arkansas.

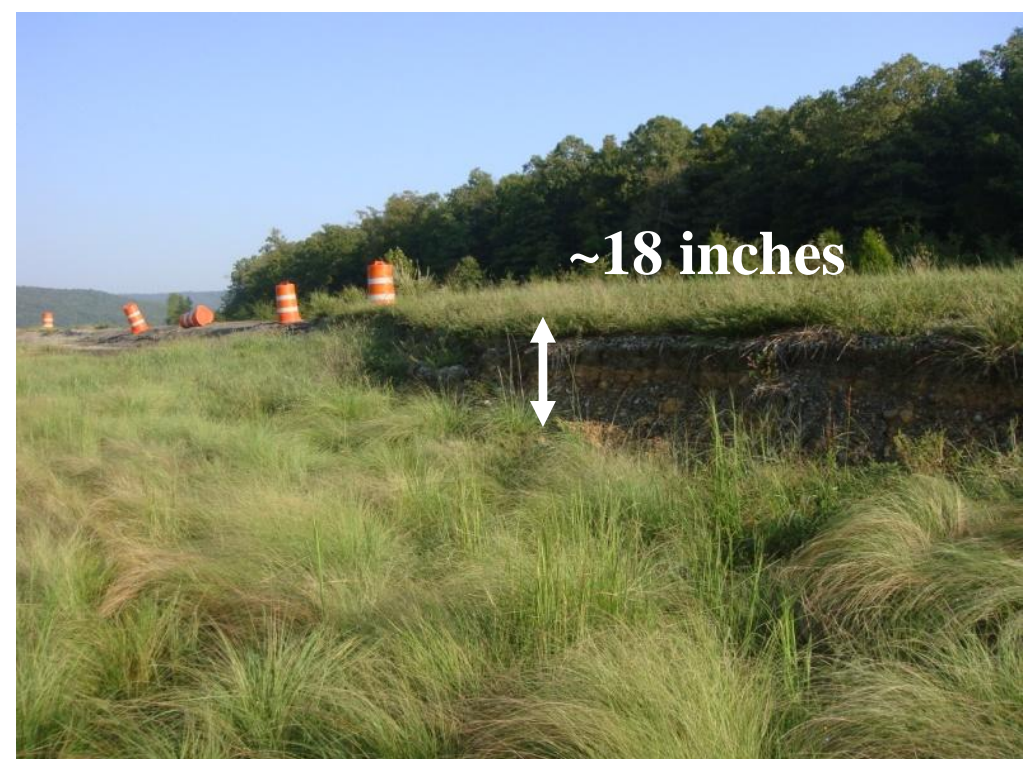

(a)

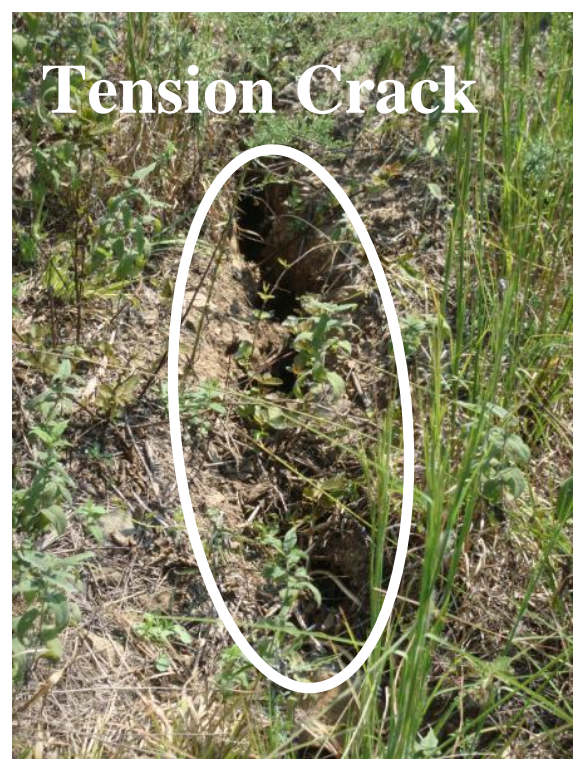

(b)

Figure 3.5. a) Looking north, the main scarp at the calibration site located in Chester, Arkansas, and b) tension crack observed in the median of I-540.

A separation of approximately five inch was observed, during the September 2010 site visit, between the west shoulder of the northbound and the northbound lane (Figure 3.6). The vegetation in the site consisted of blackberry plants, grass, small pine trees and some bushes. It 
was anticipated that seasonal vegetative effects as well as highway maintenance operations (i.e. mowing) were capable of significantly distorting the remotely sensed displacement measurements (as discussed in Chapter 5).

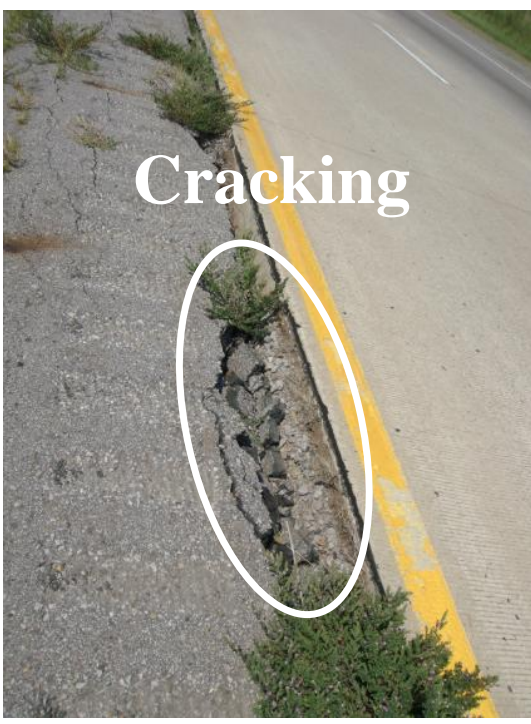

(a)

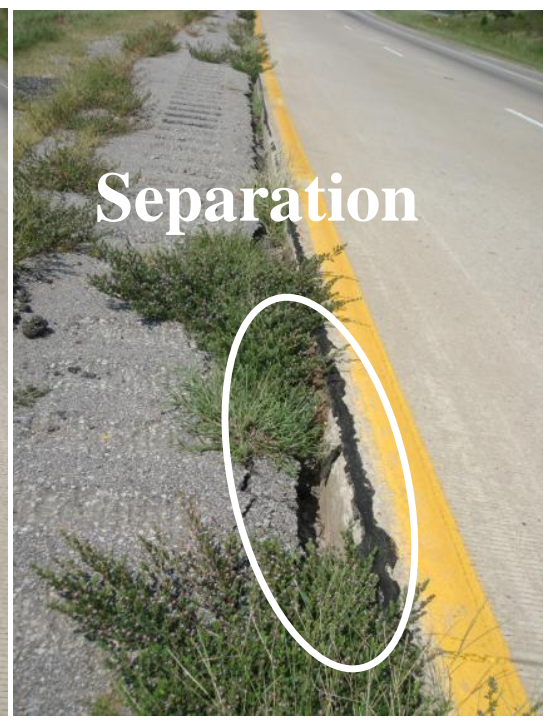

(b)

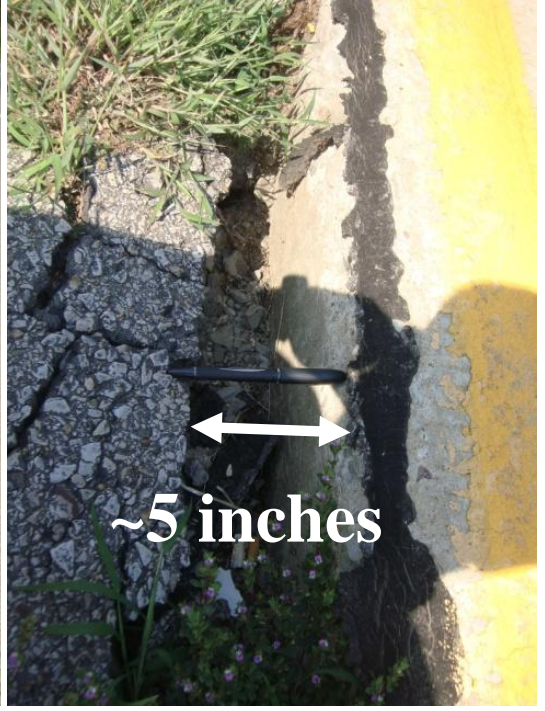

(c)

Figure 3.6. a) Cracking in the edge of northbound lane, b) separation between the shoulder and the road on the I-540 northbound lane, and c) separation of approximately 5 inches observed during September 2010.

The typical highest average monthly precipitation (6 inches) for this site occurs during April and the typical highest average monthly snowfall (2.5 inches) occurs during February (National Oceanic and Atmospheric Administration, 2012). It was anticipated that increased rates of ground movement were associated with periods of increased precipitation or after large storm events. Conversely, lower displacement rates were anticipated to occur during the summer months (May to August) where precipitation is considerably lower. Due to the proximity to the drainage ditch, the water table was expected to be near the surface which may have contributed to the instability of the site.

Except for the roadway and the associated right of way, there were no other significant urban or industrial developments in the proximity of the site. This section of the Interstate is highly used by commercial truck traffic (e.g. 80,000-lb gross weight vehicles) as it is a major 
transportation road between the northwest section of the state and major cities as Forth Smith and Little Rock. In addition, this section is highly used by other traffic carrying passengers and cargo between Northwest Arkansas (Fayetteville, Bentonville, Springdale, and Rogers) and the Fort Smith/Little Rock regions. The external loads applied daily by this traffic were anticipated to have aided in the failure of the slope. A picture of traffic in the northbound lane of I-540 next to the partially repaired main scarp is shown in Figure 3.7.

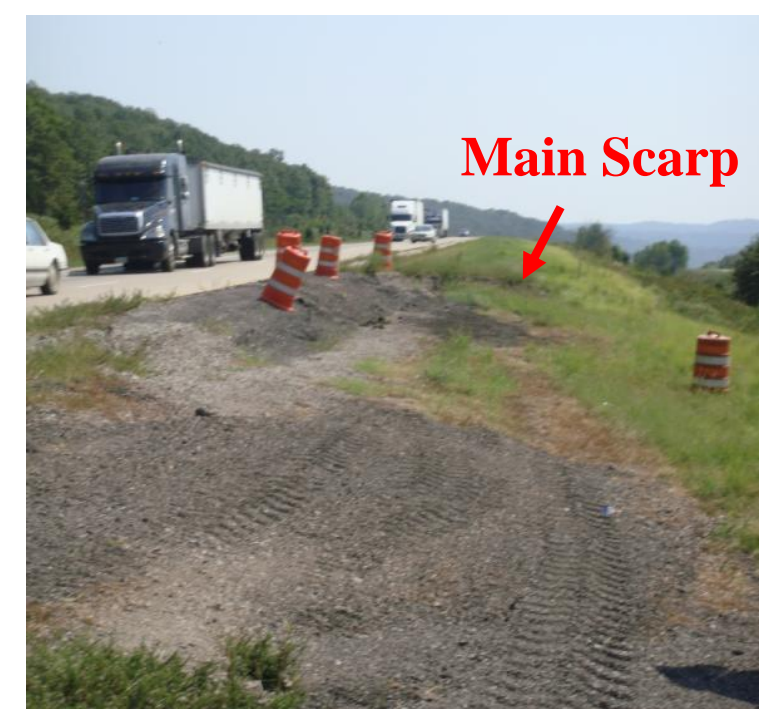

Figure 3.7. Traffic passing next to the main scarp in calibration site near Chester, Arkansas.

\subsubsection{Purpose of Calibration Site}

The primary purpose of the calibration site was to obtain accurate and useful data about the slope movement and to provide familiarization with the remote sensing equipment and testing methodologies. Specifically, data from this site was used in determining the optimum methods for data reduction, evaluation, and visualization. In general, the site was relatively open and contained minimal trees and other large obstruction in the area of interest. The lack of heavy vegetative cover was anticipated to increase the accuracy of the remote sensing methods (which may require complex data reduction to remove vegetation effects as discussed previously in 
Chapter 2). The open areas allowed for testing the RADAR and for reducing the obtained data without increasing the level of difficulty caused by vegetation.

This site was also used to develop the testing procedure and methodology to be employed for subsequent GPRI-II acquisitions. The calibration site was measured bi-weekly (every other week) and after major weather events (in order to detect any movements caused by precipitation). The large amount of data gathered allowed for a more complete verification of measurements; ensuring the interferograms were coherently paired to enable easier processing of the differential interferograms (as described in Coffman, 2010).

High traffic volume (as discussed in Section 3.2.1.2) was the only anticipated drawback. Traffic may cause interfere within the images obtained with the LIDAR or RADAR systems. Site visits to this site were planned during low traffic hours to increase image quality and for safety reasons. Due to the proximity of the site to the road, all UofA personnel were required to wear safety vests when working on site. Signs were also placed in the shoulders of the lanes (approximately 500 feet away) when work was being performed to advise drivers of the presence of individuals close to the shoulders.

\subsubsection{Geology of the Calibration Site}

In order to provide a more complete understanding of the underlying slope failure mechanics as well as the potential vertical extents of the movement, the geology of the site was investigated. In addition to on-site testing (described in detail in subsequent sections) information was obtained from available literature, specifically from geological and soil maps. Based on the geological maps of the region, the site bedrock is sandstone of the Atoka formation (part of the Pennsylvania group). Although the primary rock type of the Atoka formation is shale, sandstone is the secondary rock type. Other rock types that may be present in this formation are siltstone, limestone, and conglomerates (USGS, 2011). A section of the USGS 
geologic map pertaining to the Chester site in Crawford County, Arkansas is presented in Figure 3.8.

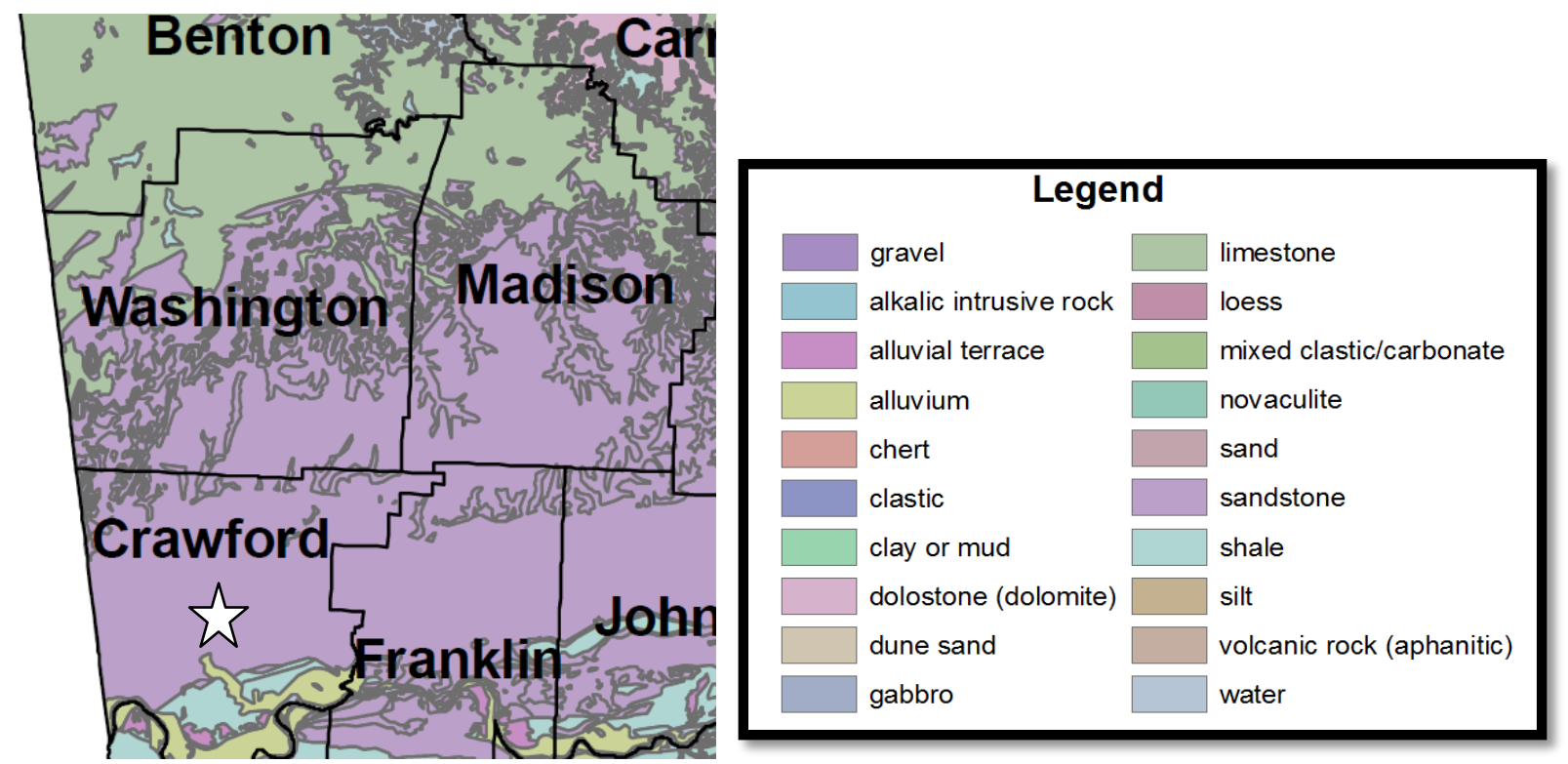

Figure 3.8. Map of the bedrock geology near the calibration site (indicated by white star) along Interstate 540, near Log Mile 36.4 near Chester, Arkansas (USGS, 2011).

On May $10^{\text {th }}$ through May $19^{\text {th }} 2010$, AHTD conducted a subsurface exploration at the calibration site in Chester, Arkansas. The geotechnical investigation consisted of eight borings along the slope failure. The borings were located as follows: two borings east of the I-540 northbound lanes; three borings west of the I-540 northbound lanes along the top portion of the failure; and three borings west of the I-540 northbound lanes along the length of the toe of the slope failure (AHTD, 2010). From the subsurface investigation the site was determined to consist of a top layer (15 to 31 feet) of colluvial clay overburden with sand and sandstones fragments, a 5 to 20 feet thick layer of highly weathered soft shale, and a foundation layer of weathered to slightly weathered shale with sandstone seams to a depth of 62 feet (AHTD, 2010). Artesian conditions were encountered at the bottom of the slope failure. The high water pressures acting against the soil are believed to have contributed to the failure of this site. 


\subsubsection{Three Dimensional Topographic Model}

In order to develop a three dimensional topographic model of the site, a survey was performed during the first two visits to the calibration site near Chester, Arkansas (in September 2010). Data were collected using a total station and the data were then transferred to AutoCAD Civil 3D 2010 (AutoCAD, 2010) to develop a three-dimensional (3D) model. The threedimensional (3D) model provided the geometry (and cross-sectional) information required for a slope stability analysis of the failure (as discussed in Section 3.2.3).

\subsubsection{Point Cloud Acquisition}

A topographic survey was performed using: a Nikon DTM-520 total station, a Leica tripod, a Carlson Explorer 600+ data collector, a Sokkia prism pole with bipod legs, and a Optima 30mm offset prism (Figure 3.9). During the survey, important features of the site such as: the ditch, the edge of the lanes, tension cracks, guard rails, and the main scarp were identified. Random topographic points were also acquired using a 25 foot square grid. A flat shoe was placed on the end of the prism pole to collect the points marking the ditch, tension cracks, guard rails, main scarp, and topography points, while a pointed shoe was used to collect the points marking the edge of the lanes (Figure 3.9). Extra data was collected for the main scarp, where more than 15 points were acquired, to increase the spatial resolution of the model at this location. Photographs of researchers from the University of Arkansas (UofA) preparing the total station for data collection and acquiring data with the total station are presented in Figure 3.10. 


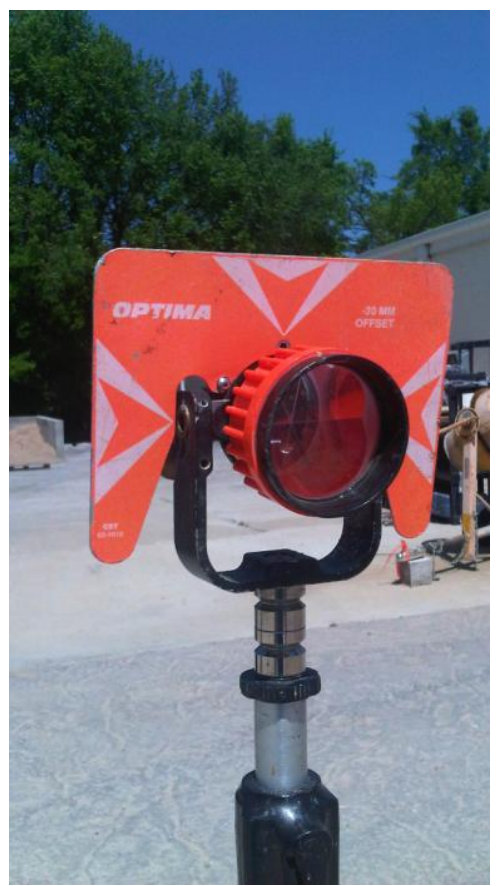

(a)

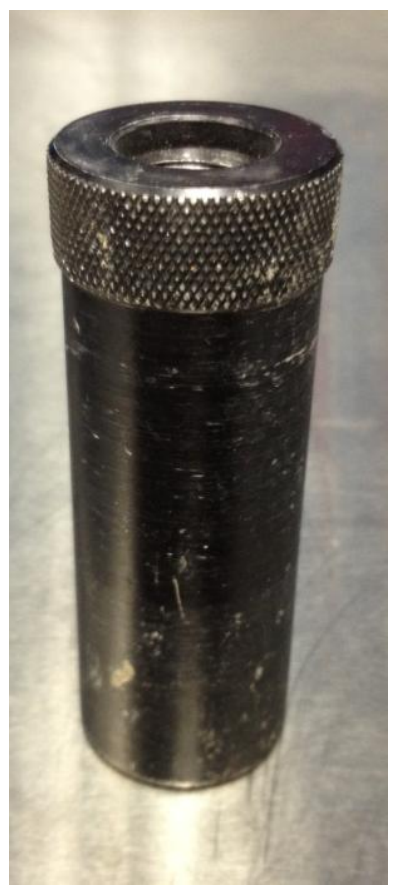

(b)

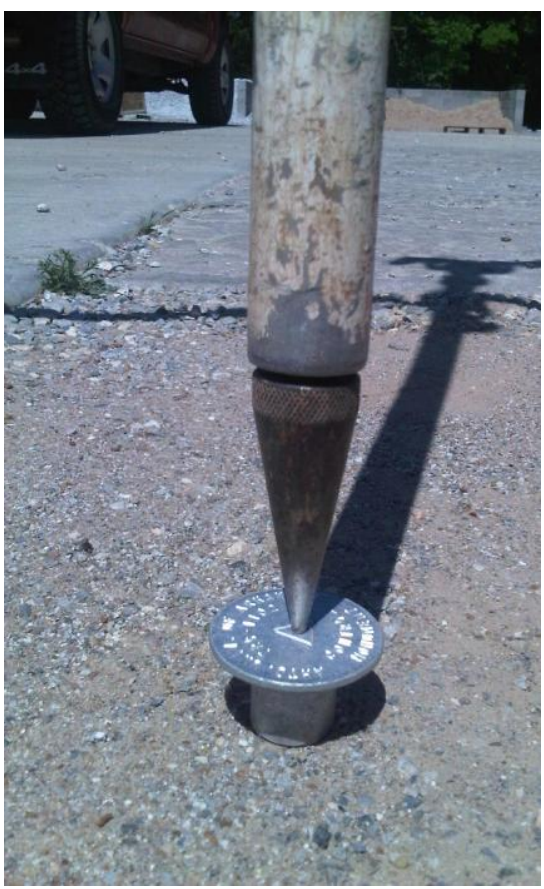

(c)

Figure 3.9. a) Optima 30mm prism, b) flat shoe for prism pole, and c) pointed shoe on the prim pole.

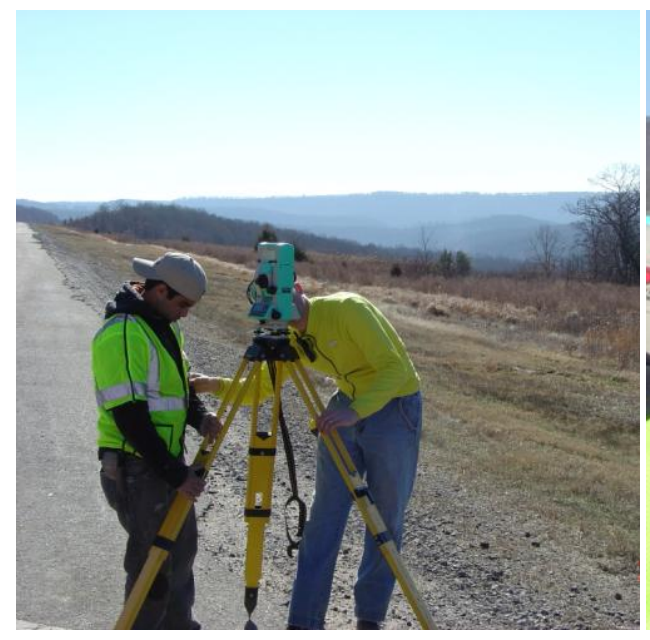

(a)

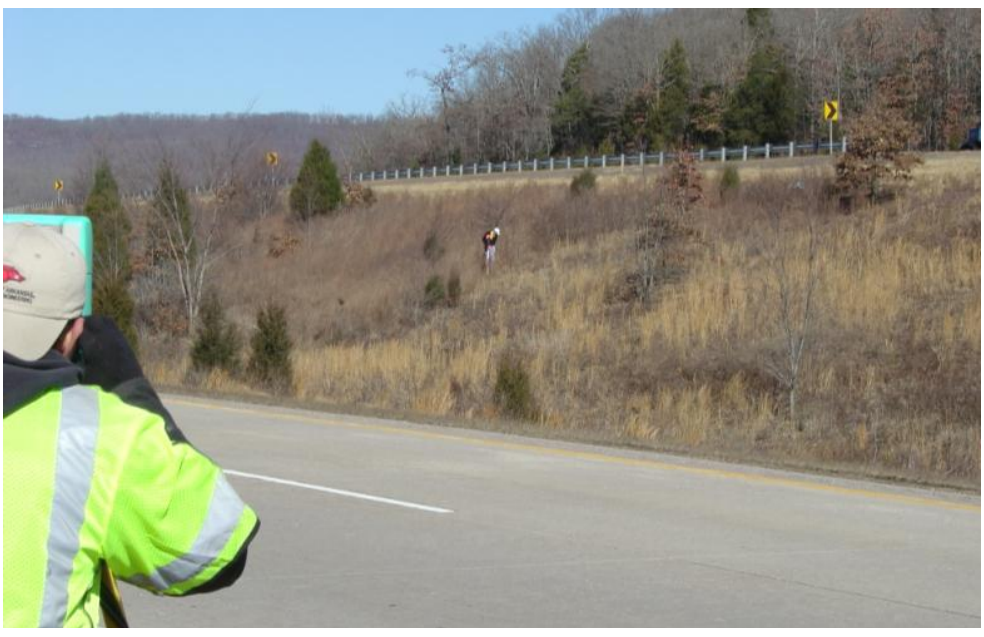

(b)

Figure 3.10. Researchers from the UofA a) preparing the total station for data acquisition, and b) acquiring topographic data at the calibration site near Chester, Arkansas.

\subsubsection{Model Creation}

After the topographic points were acquired in the field, they were exported from the data collector to an Excel spreadsheet (as described in Section 5.2.1). The spreadsheet was then saved as a Comma Separated Values (.csv) file. The CSV file was imported into AutoCAD Civil 3D 
(AutoCAD, 2010). A three-dimensional surface was created using all the acquired points by following the methods described in the step by step procedure in Appendix Error! Reference source not found.. Breaklines were added into the model (at locations of high and low points) to prevent interpolation between disparate topographic features such as: the lanes, the ditch, and the main scarp. The developed 3D topographic model for the Chester site is shown in Figure 3.11. A two-dimensional cross-section obtained from the 3D model is presented in Figure 3.12.

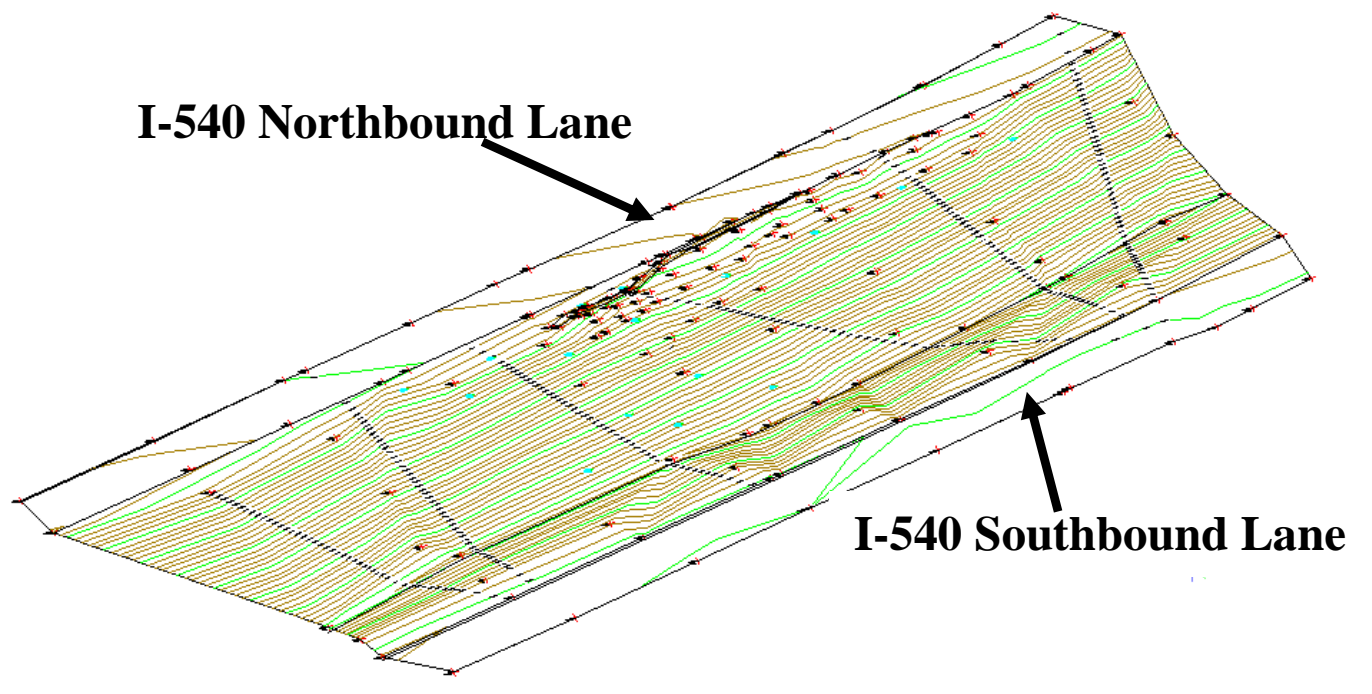

Figure 3.11. Screenshot of the 3D model created for the calibration site (AutoCAD, 2011).

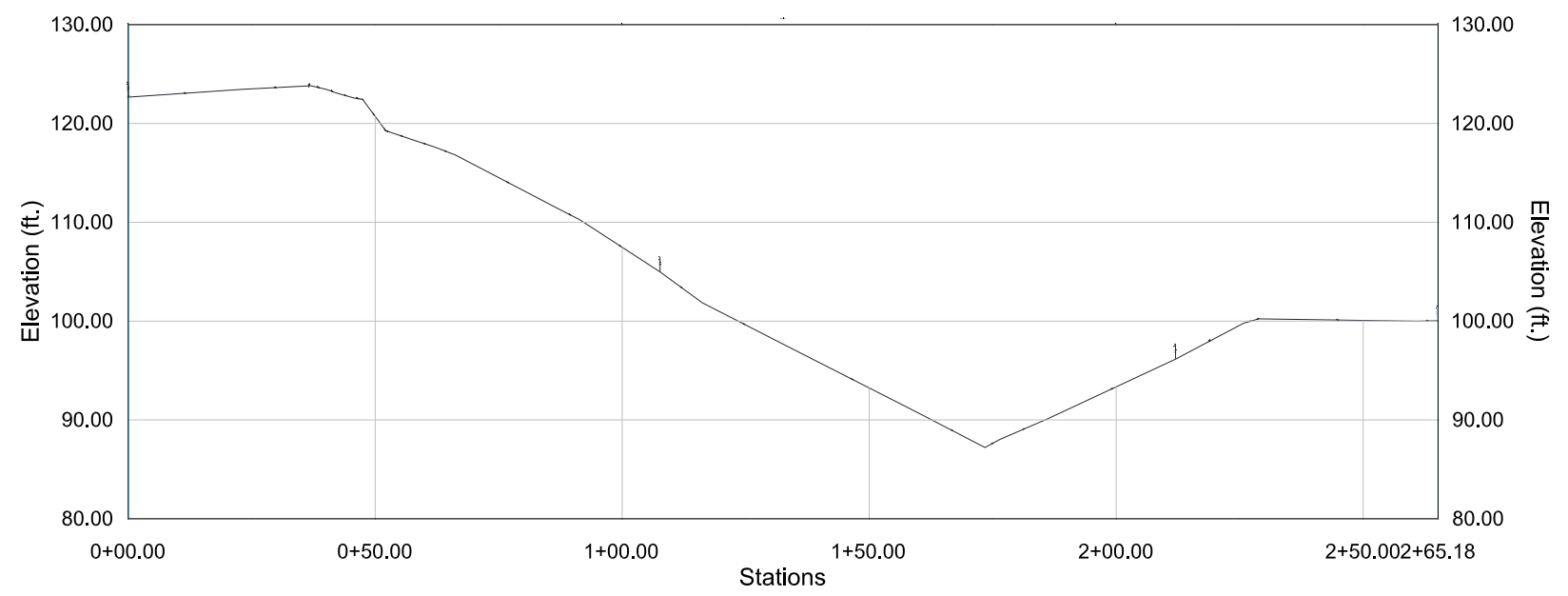

Figure 3.12. Typical 2D cross-section extracted from the 3D model (AutoCAD, 2011). 


\subsubsection{Site Slope Stability Model for the Calibration Site (Chester, Arkansas)}

An initial slope stability analysis was performed using SLIDE® 5.04 (SLIDE, 2010) software program. The geometry used in the slope stability analysis was obtained from the threedimensional topographic model developed in AutoCAD Civil 3D® (AutoCAD, 2010). A crosssection starting at the East outside shoulder of the I-540 northbound lane, passing through the main scarp and ending at the West outside should of I-540 southbound lane.

The soil properties parameters and layers introduced in the model were obtained from the subsurface exploration conducted by AHTD on the validation site prior to this research project (AHTD TRC-1102). Three correlations from SPT N-value to undrianed shear strength $\left(\mathrm{S}_{\mathrm{u}}\right)$ found in the literature were used to develop three different slope stability models. The undrained shear parameters assigned to each soil layer were obtained using the three different correlations developed by different authors. The field $\mathrm{N}$-values were corrected to $\mathrm{N}_{60}$ values using specific correction factors (AHTD, 2007) for the AHTD drill trucks. The correction to $\mathrm{N}_{60}$ values was performed for completeness purposes since the correlations used for the analysis required uncorrected values $\mathrm{N}$-values.

The AHTD correlation (Schubel, 2011), is defined in Equation 3.1, was used by AHTD on the daily basis. A second correlation, Terzaghi correlation (Equation 3.2), developed by Terzaghi and Peck (1967) was used for one of the models. The third correlation, UARK correlation (Equation 3.3), was developed by researchers at the University of Arkansas for Northwest Arkansas soils (Ritchey, 1999). The UAK correlation was developed by performing back analysis of failed slopes in the NWA area and correlated to uncorrected blow count $(\mathrm{N}$ value). Therefore, the analysis determined the residual undrained shear strength of the soil. The undrained shear strength values used to develop UARK correlation are presented in Figure 3.13. 
The soil parameters use for the initial slope stability analysis at the calibration site are summarize in Table 3.1.

$$
\begin{array}{ll}
S_{u}=\mathbb{N} \text {-value }(25) & \text { (Schubel, 2011) } \\
S_{u}=\mathbb{N} \text {-value }(20- & \text { (Terzaghi and Peck, 1967) } \\
S_{u}=\mathbb{N} \text {-value } \quad & \text { (Ritchey, 1999) }
\end{array}
$$

Equation 3.1

Equation 3.2

Equation 3.3

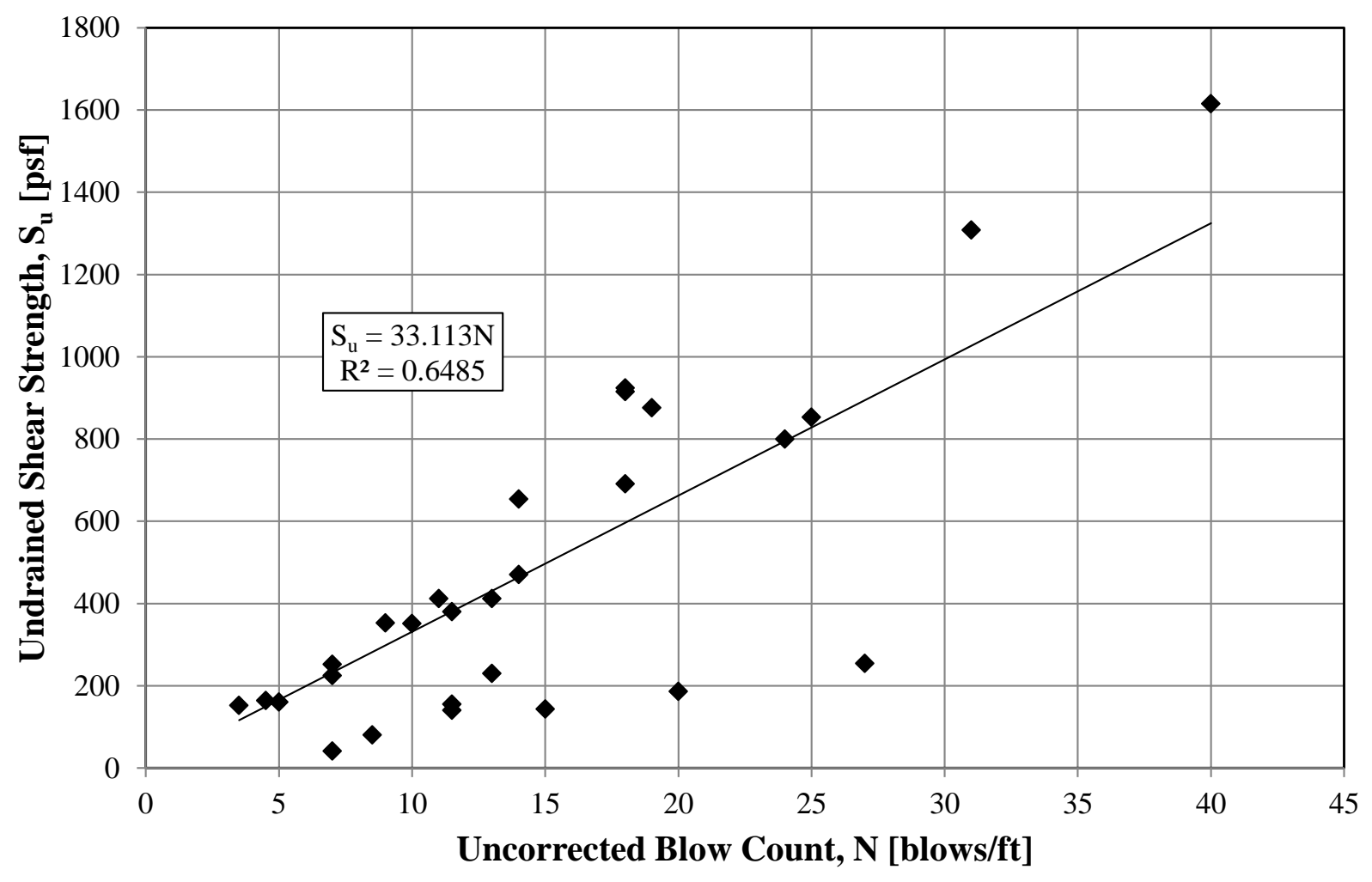

Figure 3.13. Values used to develop the UARK correlation for NWA soils (Ritchey, 1999). 
Table 3.1. Summary of soil parameters used in the slope stability analysis for calibration site

\begin{tabular}{|c|c|c|c|c|c|c|c|c|}
\hline \multirow[t]{2}{*}{ Borehole } & \multirow[t]{2}{*}{ Depth (ft) } & \multirow[t]{2}{*}{ Description } & \multirow[t]{2}{*}{$\mathrm{N}$-Value } & \multirow{2}{*}{$\begin{array}{c}\mathrm{N}_{60} \\
\mathrm{CF}=\mathbf{1 . 2 9}\end{array}$} & \multirow{2}{*}{$\begin{array}{c}\text { Unit } \\
\text { Weight } \\
\text { (pcf) }\end{array}$} & \multirow{2}{*}{\begin{tabular}{|c|}
$\begin{array}{c}\text { Undrained } \\
\text { Strength }\left(S_{\mathbf{u}}\right) \\
(\mathbf{p s f})\end{array}$ \\
AHTD $(125 * \mathbf{N})$
\end{tabular}} & \multirow{2}{*}{$\begin{array}{c}\begin{array}{c}\text { Undrained } \\
\text { Strength }\left(S_{\mathbf{u}}\right) \\
(p s f)\end{array} \\
\text { UARK }(33 * N)\end{array}$} & \multirow{2}{*}{\begin{tabular}{|c|}
$\begin{array}{c}\text { Undrained } \\
\text { Strength }\left(S_{\mathbf{u}}\right) \\
(\mathbf{p s f})\end{array}$ \\
Terzaghi \\
$(120 * N)$ \\
\end{tabular}} \\
\hline & & & & & & & & \\
\hline B-1 & $0.0-9.5$ & Clay w/ Sand & 9 & 12 & 90.0 & 1125.0 & 297.0 & 1080.0 \\
\hline B-1 & $9.5-32.0$ & Clay w/ Gravel & 10 & 13 & 110.0 & 1250.0 & 330.0 & 1200.0 \\
\hline B-1 & $32.0-54.5$ & Shale & - & - & - & & & \\
\hline B-3 & $0.0-24.0$ & Clay w/ Gravel & 8 & 10 & 110.0 & 1000.0 & 264.0 & 960.0 \\
\hline B-3 & $24.0-45.0$ & \begin{tabular}{|c|}
$\begin{array}{c}\text { Weathered } \\
\text { Shale }\end{array}$ \\
\end{tabular} & 23 & 30 & 115.0 & 2875.0 & 759.0 & 2760.0 \\
\hline B-3 & $45.0-62.0$ & Shale & - & - & - & & & \\
\hline B-6 & $0.0-15.0$ & Clay w/ Gravel & 13 & 17 & 110.0 & 1625.0 & 429.0 & 1560.0 \\
\hline B-6 & $15.0-26.0$ & $\begin{array}{c}\text { Weathered } \\
\text { Shale }\end{array}$ & 30 & 39 & 115.0 & 3750.0 & 990.0 & 3600.0 \\
\hline B-6 & $26.0-44.0$ & Shale & - & - & - & & & \\
\hline
\end{tabular}

\subsection{Validation Site - Malvern, Arkansas}

The Malvern site was selected because of the known movement and the amount of historic data collected at the site. The site has been monitored since Information about the validation site including: the location, history, proposed purpose, geology, three dimensional topographic model, geotechnical engineering parameters and slope stability model are discussed in this Section.

At the validation site located near Malvern, Arkansas, the sliding mass extends under Interstate 30, under Highway 84 (to the north of Intersate-30), and Haltom Road (to the south of Interstate-30). The zone of earth movement at the validation site is approximately 1100 feet wide (oriented parallel to the roadway). The continuing movement (lateral and downward) of the slide requires frequent maintenance to re-level and patch the displacement across the lanes. The potential negative impacts from this slope failure are significantly greater than at the calibration site due to the size of the slide and the quantity of traffic. Because of the ongoing movement at this site since the completion of construction, a documented history exists for this site. 


\subsubsection{Validation Site Information}

The location, history, proposed purpose, geology, and geotechnical engineering parameters of the site provide information about why this site was chosen as the validation site. Further information about each of these topics are found in the Subsections of this Section. Of particular importance are the site location, site history, and proposed purpose, as these are the factors which contributed to the selection of the validation site near Malvern, Arkansas.

\subsubsection{Location of the Validation Site}

The validation site is located near Malvern, Arkansas, in the county of Hot Springs, Arkansas. Specifically, the landslide is located approximately four (4) miles southwest of Malvern at mile marker 95.7 on Interstate I-30 (Figure 3.14). The site is approximately 226 miles (approximately three hours and half) from the UofA.

The landslide at this site had previously unknown extents, but its effects were noticeable along the whole site. The site is composed of private land on a hill side, a two lane highway (Highway 84), a median between Highway 84 and the interstate (Interstate 30), a median between the westbound and eastbound lanes of I-30, a median between I-30 and Haltom Road, Halton Road, and a strip of vegetation between Halton Road and the Ouachita River. The Ouachita River is believed to contribute to the instability of the site by removing the toe of the landslide. Photographs of the site, taken by UofA personnel during the site visit in December 2010, are presented in Figure 3.15. 


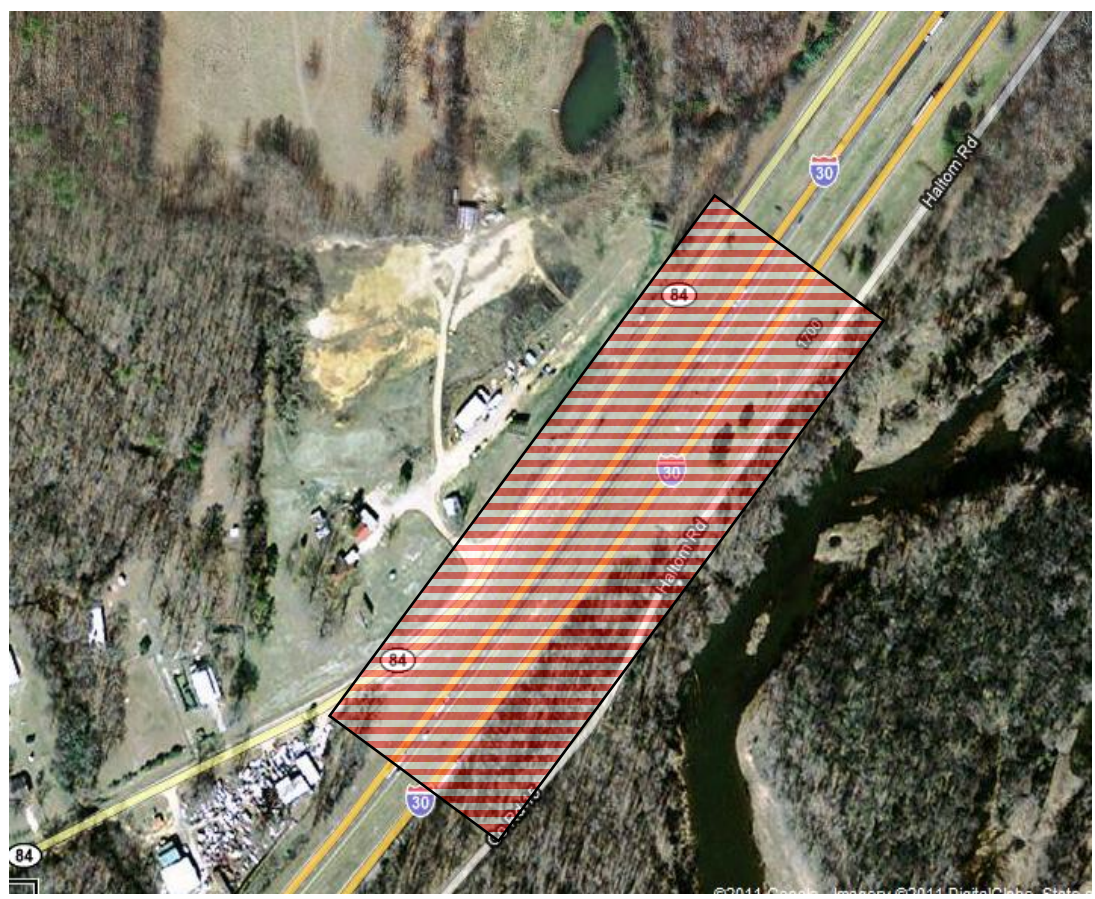

Figure 3.14. Location of project site located at Log Mile 95.7 on Interstate 30 near Malvern, Arkansas. Anticipated slide area shaded in red (Google Maps, 2011).

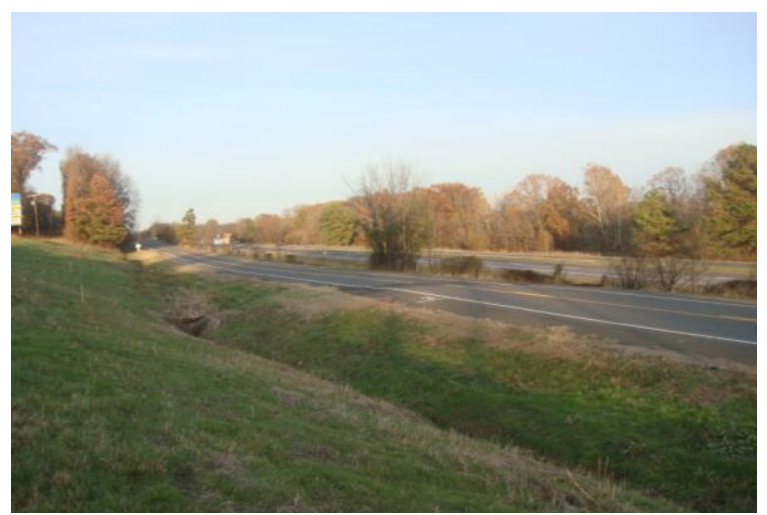

(a)

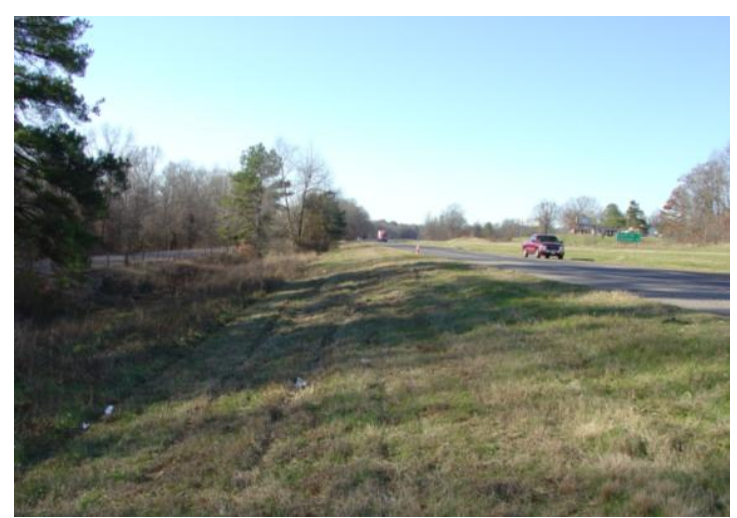

(b)

Figure 3.15. a) Looking southwest from the hillside between Highway 84 and I-30, and b) looking west towards I-30 at the validation site near Malvern, Arkansas in December 2010.

\subsubsection{History of the Validation Site}

For more than 20 years, a large sliding mass (approximately 1100 feet wide) located southwest of Malvern, Arkansas has moved slowly to the southeast in the direction of the Ouachita River. Prior to this research project (AHTD TRC-1102), the Malvern site was investigated by AHTD personnel; AHTD personnel also installed instrumentation consisting of 
piezometers and inclinometers. Three inclinometers and eight open-well piezometers (Figure 3.16) were installed between October 2004 and February 2006 (Westerman, 2006).

The water table was considered as one of the factors that initiated and enabled the slope failure; therefore the piezometers were installed at different locations within the slide to monitor the depth of the ground water table. Because the influence of the ground water table was considered as a critical component of the slope instability, different methods to reduce the pore water pressures in the aquifer were recommended. Inclinometers were installed on the site forming a cross-section from north to south. In 2006, based on the results from the inclinometer data, the sliding plane was reported to be 73 feet below the median of the ditch flow line (Westerman, 2006). A summary of the instrumentation installed between 2004 and 2006 is presented in Table 3.2 and Table 3.3.

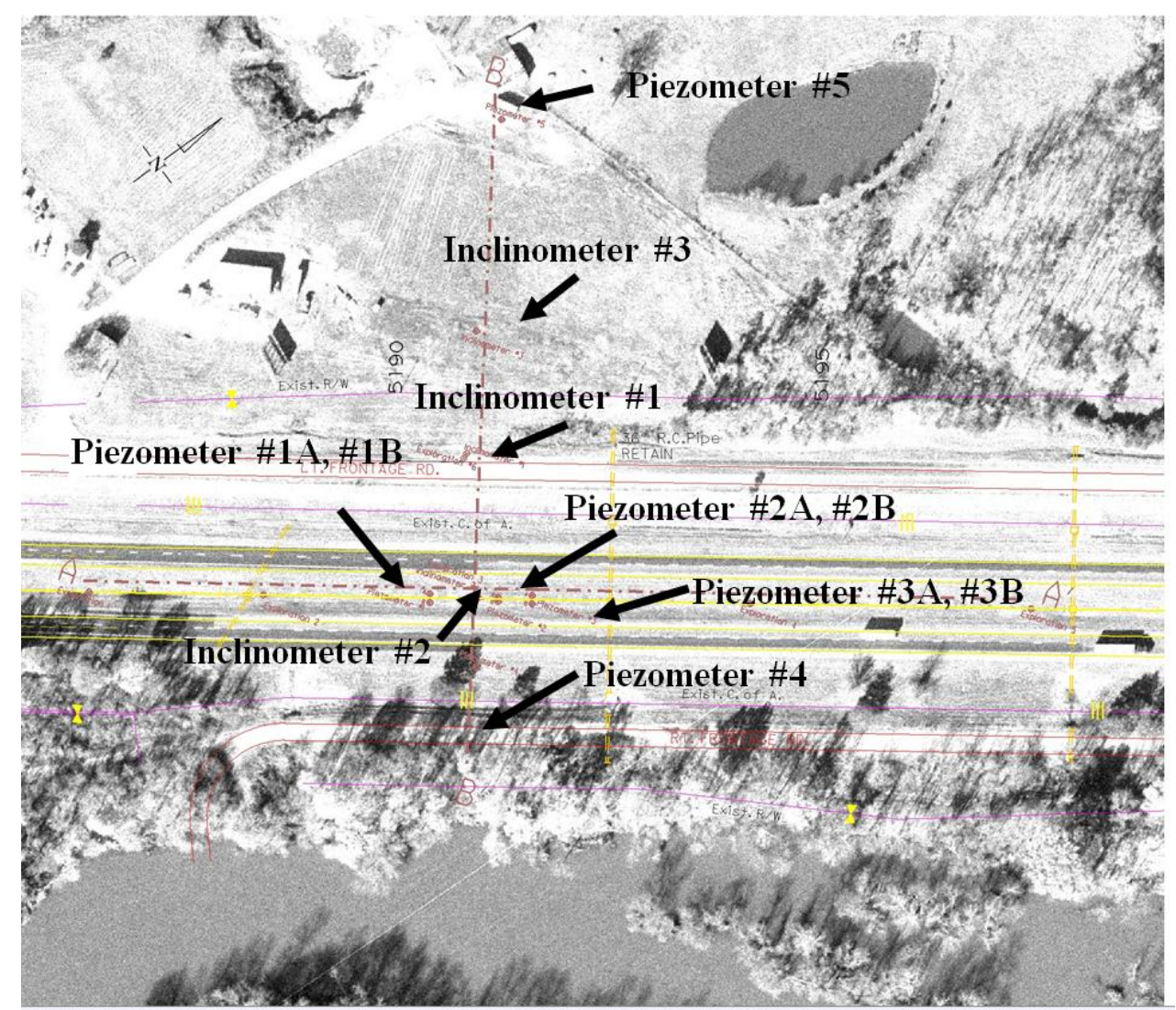

Figure 3.16. Position of inclinometers and piezometers installed between 2004 and 2006 in validation site near Malvern, Arkansas (modified from Westerman, 2006). 
Table 3.2. Location and depth of piezometers installed at the validation site between 2004 and 2006 (modified from Westerman, 2006).

\begin{tabular}{|c|c|c|}
\hline Well & Location & Depth \\
\hline Piezometer \#1A & Median - I 30 & $100 \mathrm{Ft}$ \\
\hline Piezometer \#1B & Median - I 30 & $100 \mathrm{Ft}$ \\
\hline Piezometer \#2A & Median - I 30 & $100 \mathrm{Ft}$ \\
\hline Piezometer \#2B & Median - I 30 & $60 \mathrm{Ft}$ \\
\hline Piezometer \#3A & Median - I 30 & $60 \mathrm{Ft}$ \\
\hline Piezometer \#3B & Median - I 30 & $20 \mathrm{Ft}$ \\
\hline Piezometer \#4 & S. of I-30 (Between I30 and ROW fence) & $100 \mathrm{Ft}$ \\
\hline Piezometer \#5 & Top of Hill North of Hwy 84 & $100 \mathrm{Ft}$ \\
\hline
\end{tabular}

Table 3.3. Location, depth, installation date, and observed cumulative movement of validation site inclinometers at the validation site 2004 and 2006 (from Westerman, 2006).

\begin{tabular}{|c|c|c|c|c|}
\hline Inclinometer & Location & $\begin{array}{c}\text { Depth of } \\
\text { Slip } \\
\text { Plane }\end{array}$ & $\begin{array}{c}\text { Initial } \\
\text { Reading } \\
\text { Date }\end{array}$ & $\begin{array}{c}\text { Cumulative } \\
\text { Movement Since } \\
\text { Installation }\end{array}$ \\
\hline$\# 1$ & Ditch on N. Slide of Hwy 84 & $52 \mathrm{ft}$. & $4 / 5 / 2004$ & $1.60 \mathrm{in}$. \\
\hline$\# 2$ & Median - I 30 & $73 \mathrm{ft}$. & $7 / 7 / 2004$ & $1.45 \mathrm{in}$. \\
\hline$\# 3$ & Bench North of Hwy 84 & $34 \mathrm{ft}$. & $5 / 6 / 2005$ & $0.04 \mathrm{in}$. \\
\hline
\end{tabular}

While the previously installed in-situ instrumentation was useful in developing an understanding of the slope failure geometry and historical conditions, by the time this research project began, the on-site instrumentation (piezometer and inclinometer casing) had suffered extensive damage and was no longer useful. Therefore, a new set of inclinometers and piezometers were required to be installed and monitored (as presented in Section Chapter 4).

During the first visit to the validation site by UofA personnel December 2010, several tension cracks were observed along the shoulders and in the roadway lanes; however, a visible main scarp was not detected at this site. Images of observed tension cracking are presented in Figure 3.17 and Figure 3.18 


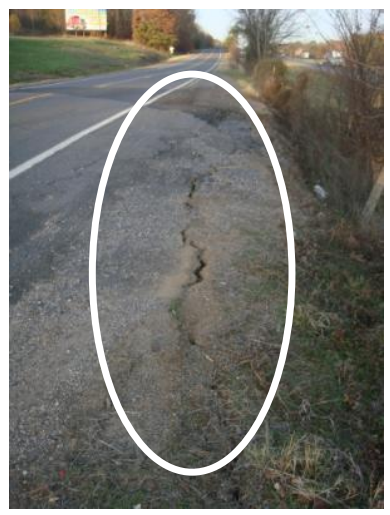

(a)

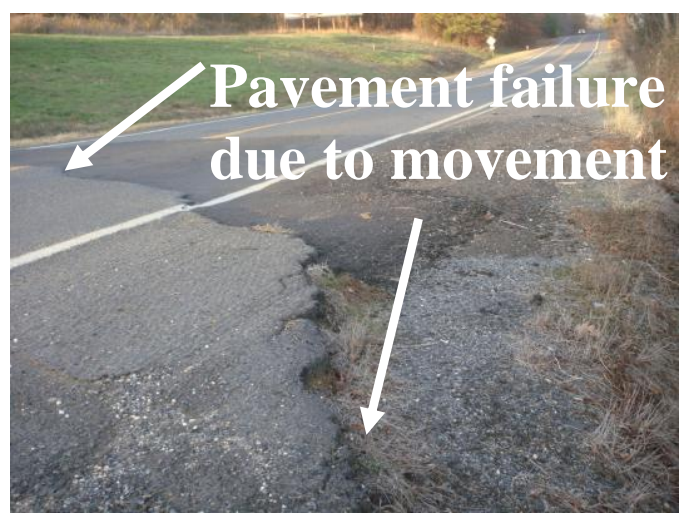

(b)

Figure 3.17. a) Tension cracking in the shoulder of the eastbound lane of Highway 84, and b) lane cracking and settlement failure in Highway 84.

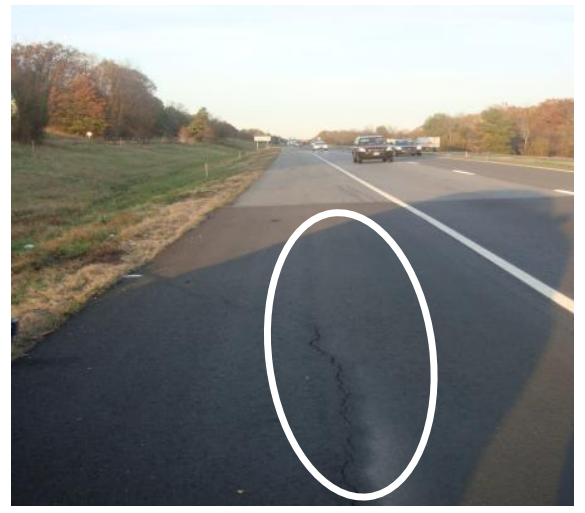

(a)

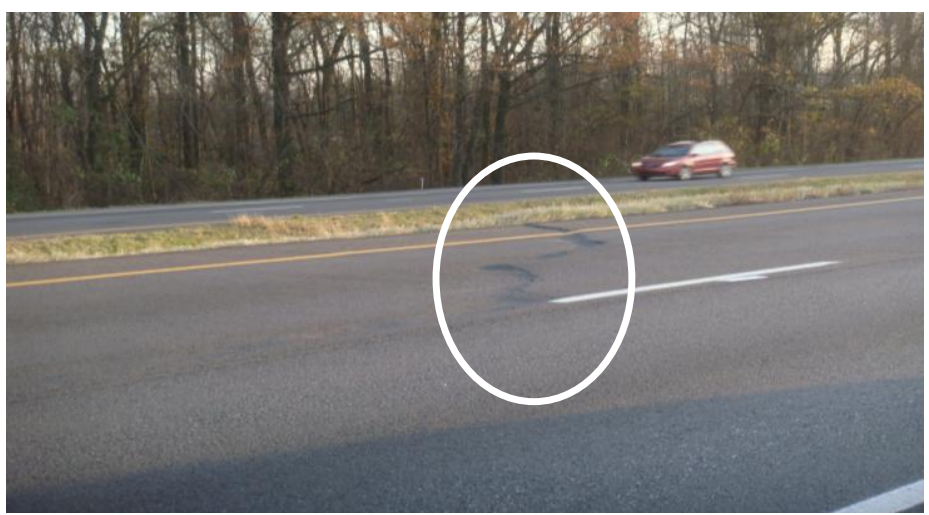

(b)

Figure 3.18. a) Crack observed in the shoulder of the westbound lane of I-30, and b) crack in the westbound lane of I-30 in December 2010.

Vegetative cover at site was primarily composed of grass or turf. However, trees were present in certain sections of the site. The main disadvantage of this site was the presence of wire fence lines within the median between Highway 84 and I-30, and in the median between I-30 and Haltom Road. A house and storage building were also present on the hillside to the north of Highway 84. These fences, house and storage building were expected to cause distortion within the images acquired using LIDAR and RADAR if they were in the line-of-sight between the sensor and the target.

The site is located in an area where the highest average monthly precipitation (6 inches) occurs during October; the highest average monthly snowfall (2.5 inches) occurs during the 
month of February (National Oceanic and Atmospheric Administrators, 2012). During periods of high rainfall (October) the water table at the site rises; also, during period of high rainfall the flow of the river increases. The elevated ground water table and the increase in the flow rate of the river are considered to contribute to the instability of slope at this site. Specifically, the rainfall increased the pore pressures, and the river cuts away the bank at the toe of the slope, resulting in a reduction of the resisting forces.

\subsubsection{Purpose of the Validation Site}

The primary purpose of the validation site was to obtain accurate and useful data about the slope movement and to ensure familiarization with the remote sensing equipment and testing methodologies. This site was also used to validate the remote sensing data acquisition techniques that were developed at the calibration site. The calibration site was measured monthly and after major weather events (in order to detect any movements caused by precipitation).

The site is located along the Interstate in area that usually experiences high traffic volumes. Safety signs were placed along the shoulders of I-30 during every site visit because of the proximity of UofA researchers to the different lanes. As described in Section 3.2.1.3 (for the Chester site), all UofA personnel were required to wear safety vests when working on site. Typical RADAR acquisitions were collected during the early morning hours (0200- 0500 hours) to collect data when traffic was minimal.

\subsubsection{Geology of the Validation Site}

The underlying site geology consists of two main geological formations, the Cenozoic sediment of the Gulf Coastal Plain which overlies the Paleozoic rocks (Stanley Group and Arkansas Novaculite) of the Ouachita Mountains. The Midway Group is the principal representation of the Cenozoic unit. The Midway Group, is composed of calcareous shale, 
arenaceous limestone, calcareous glauconitic sandstone, conglomerate, and a light to very dark bluish-gray clay shale (Figure 3.19).

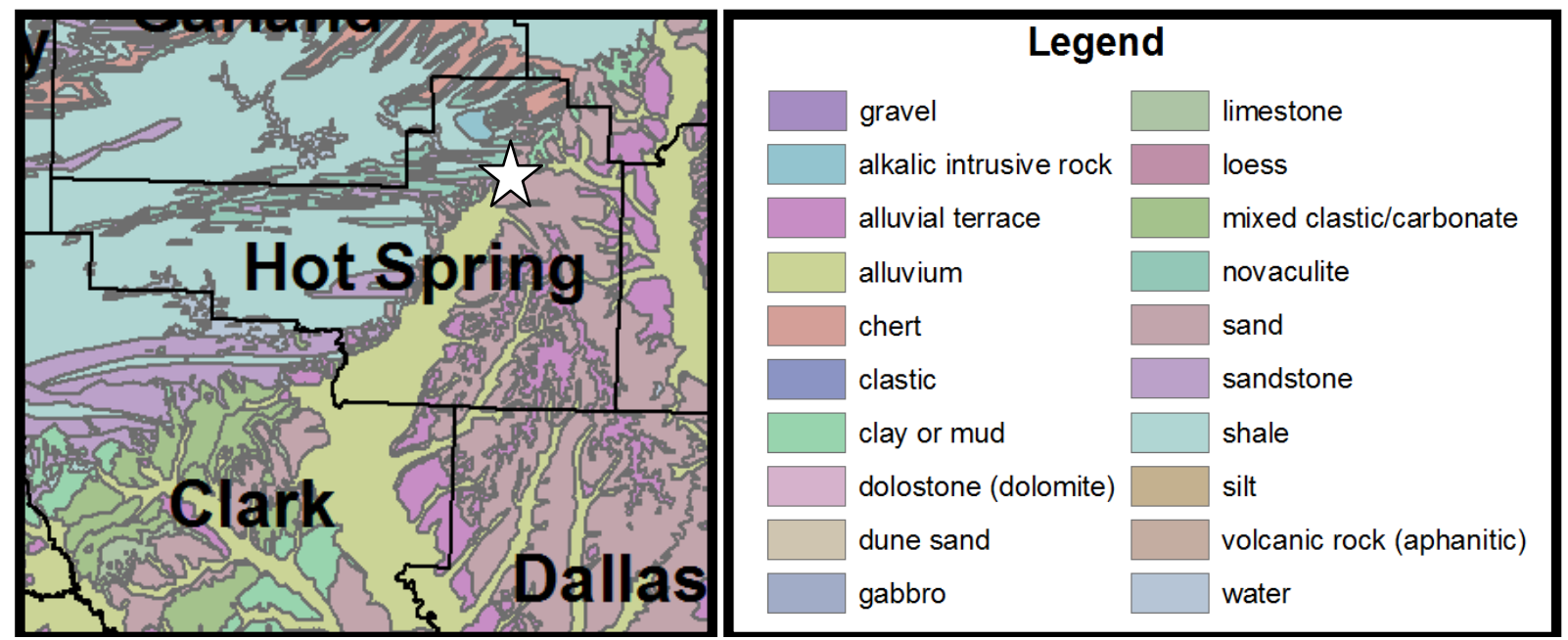

Figure 3.19. Geology map of validation site along Interstate 540, near Log Mile 36.4 at Chester, AR

Prior to the commencement of the AHTD TRC-1102 research project, AHTD personnel conducted several geotechnical explorations at this site (as discussed in Section 3.3.1.2). The site explorations, conducted to determine the soil and rock stratigraphy at the site as well as to install monitoring instrumentation, were conducted in May 2004, October 2005, and February 2006 (Westerman, 2006). From these explorations it was determined that the geology of the site south of I-30 consisted of terraced alluvial deposits of clay, sand, and gravel to about a depth of 20.5 to 34.5 feet. The Midway Group, primarily composed of claystone, was below the terraced deposits from depths of 34.5 feet to 70 feet; the Stanley Group sandstone was below the Midway Group from depths of 70 feet to 79.5 feet below the ground surface (Westerman, 2006). North of I-30 the geology consisted of 20 feet of a mixed clay and sand, underlain by a thick layer of Midway Group clay with limestone fragments until a depth of 55 feet. Layers of Novaculite, weathered limestone and shale with clay, were encountered from depths of 55 feet to 72 feet. The geology of the site is depicted in Figure 3.20. 


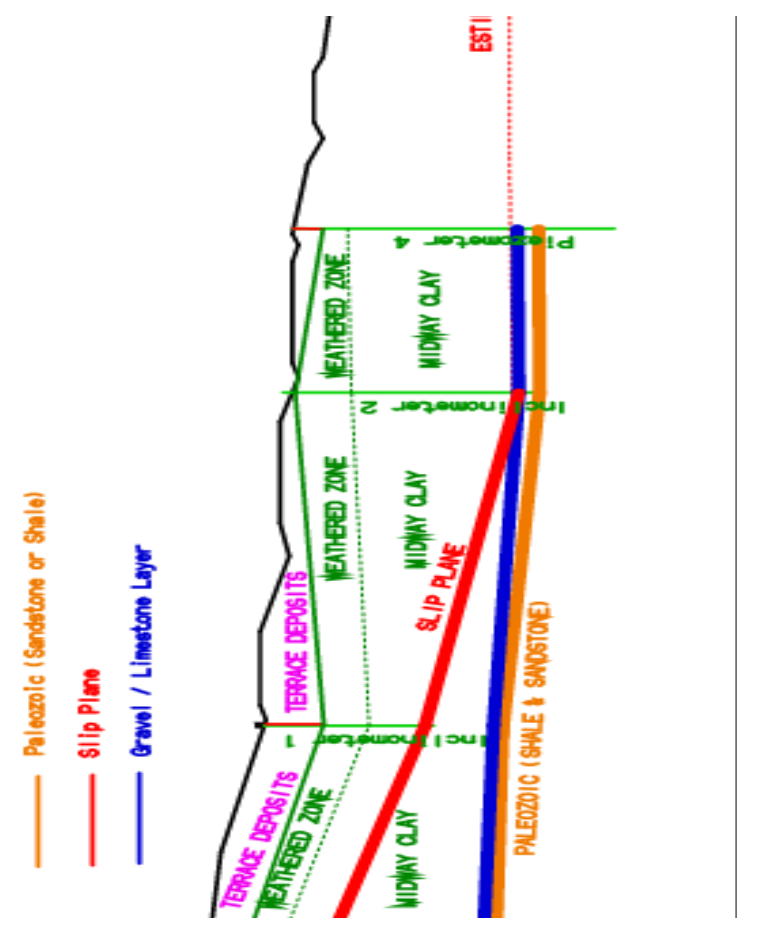

Figure 3.20. Validation site statigraphy and underlying geology near Malvern, Arkansas (from Westerman, 2006).

\subsubsection{Three Dimensional Topographic Model}

In order to develop a three dimensional topographic model of the site, a survey was performed during the first two visits to the validation site near Malvern, Arkansas (in December 2010). Following the same procedure described in Section 3.2.2, data were collected using a total station and the data were then transferred to AutoCAD Civil 3D 2010 (AutoCAD, 2010) to develop a three-dimensional (3D) model. The three-dimensional (3D) model provided the geometry (and cross-sectional) information required for a slope stability analysis of the failure (as discussed in Section 3.3.3).

\subsubsection{Point Cloud Acquisition}

A topographic survey was performed using the same equipment used at the calibration site (as described in Section 3.2.2.1) including: a Nikon DTM-520 total station, a Leica tripod, a Carlson Explorer 600+ data collector, a Sokkia prism pole with bipod legs, and a Optima 30mm 
offset prism. During the survey, important features of the site such as: the ditch, the edge of the lanes, and the tension cracks were identified. Random topographic points were also acquired using a 50 foot square grid. Photographs of researchers from the University of Arkansas (UofA) preparing the total station for data collection and acquiring data with the total station are presented in Figure 3.21.

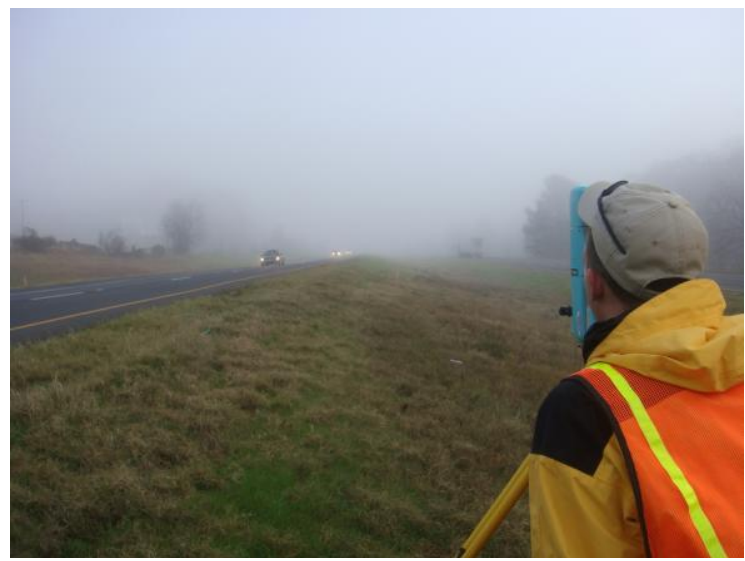

(a)

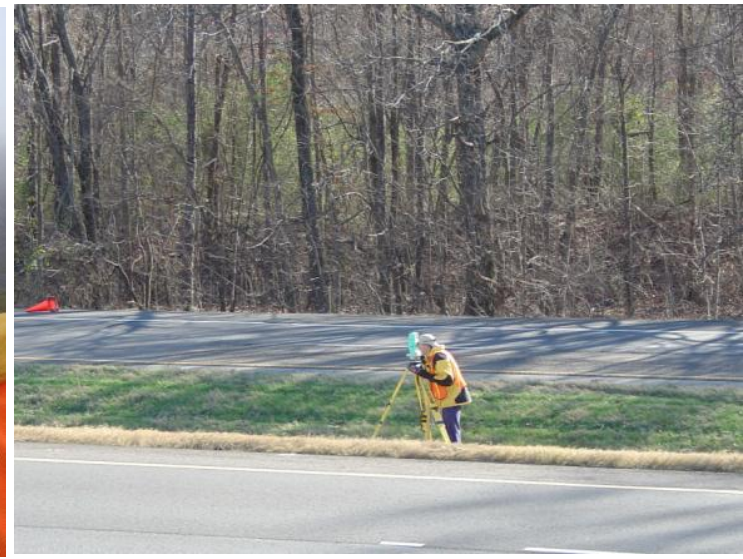

(b)

Figure 3.21.a) University personnel acquiring points for topographic model, b) looking South to the total station set up point in validation site near Malvern, Arkansas.

\subsubsection{Model Creation}

As described in Section 3.3.2.2, after the topographic points were acquired in the field, they were exported from the data collector to an Excel spreadsheet (as described in Section 5.2.1). The spreadsheet was then saved as a Comma Separated Values (.csv) file. The CSV file was imported into AutoCAD Civil 3D ${ }^{\circledR} 2010$ (AutoCAD, 2010). A three-dimensional surface was created using all the acquired points by following the methods described in the step by step procedure in Appendix Error! Reference source not found.. Breaklines were added into the model (at locations of high and low points) to prevent interpolation between disparate topographic features such as: the lanes, the ditch, and the tension cracks. The developed 3D 
topographic model for the Malvern site is shown in Figure 3.22. A two-dimensional crosssection obtained from the 3D model is presented in Figure 3.23.

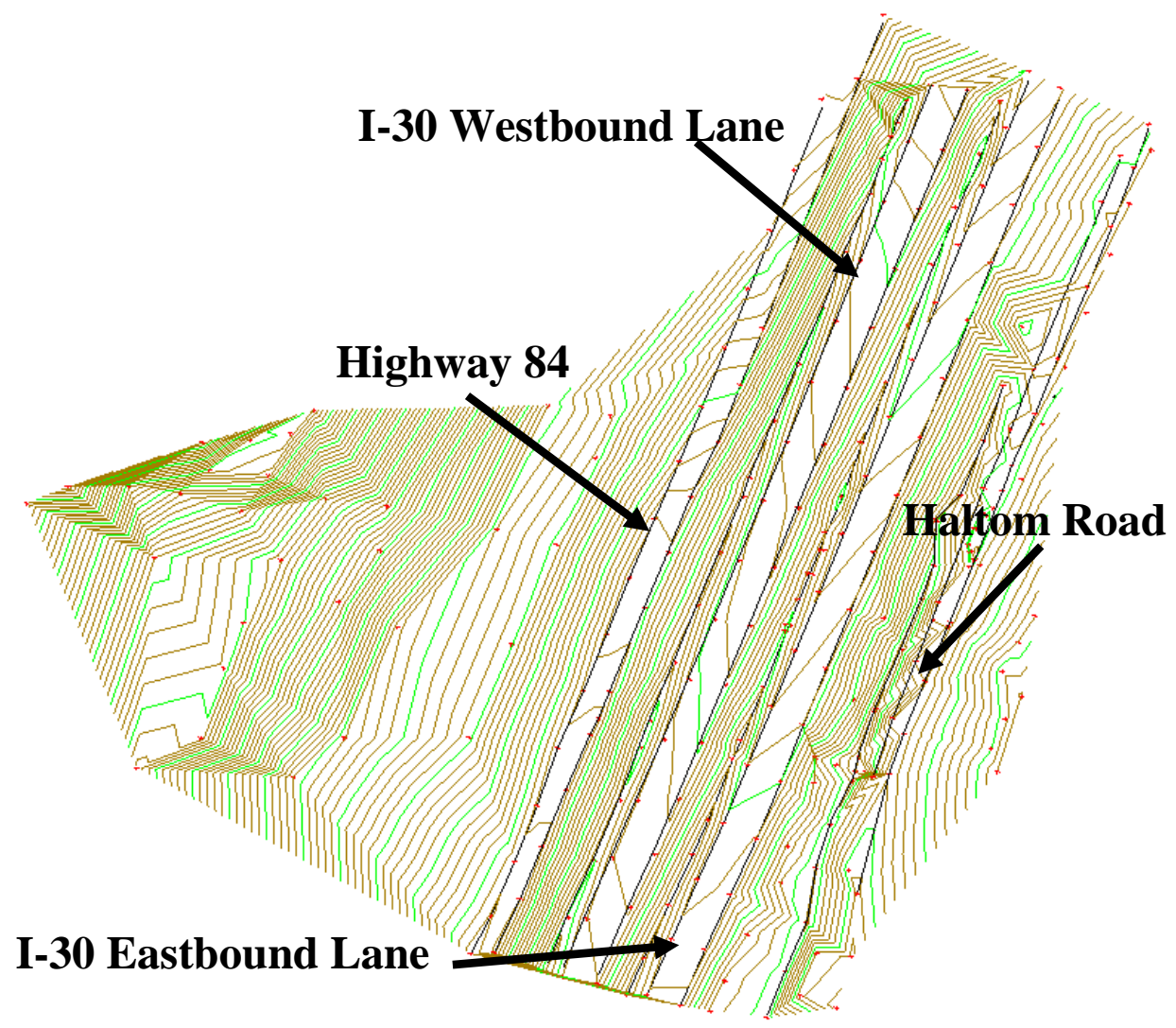

Figure 3.22. Topographic 3D model of the validation site near Malvern, Arkansas.

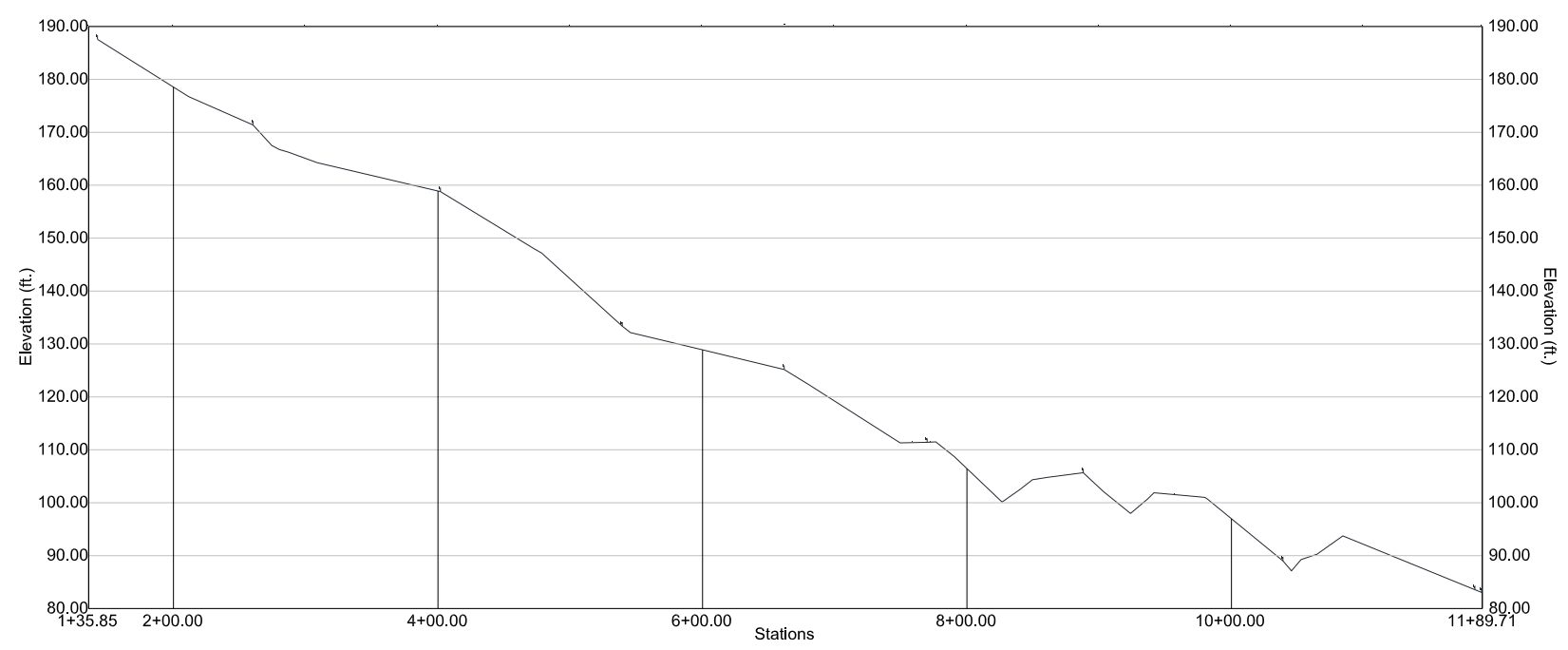


Figure 3.23. Profile view (vertical exaggeration $=4.0$ ) of the validation site near Malvern, Arkansas.

\subsubsection{Validation Site Slope Stability Model}

An initial slope stability analysis was performed using SLIDE® 5.04 (SLIDE, 2010) software program. The geometry and layers utilized in the initial slope stability model for the validation site was extracted from diagrams and boring logs found in the documentation (Westerman, 2006) of the site prior to AHTD TRC-1102 research project. As previously discussed in Section 3.2.3, three different slope stability models were developed using the soil properties parameters obtained by using the AHTD correlation, Terzaghi correlation, and UARK correlation. Three distinct soil layers were obtained using the boring log information of two boreholes (inclinometers) located at both sides (North and South) of the site. The undrained strength values were correlated from SPT N-values found in the boring logs. The parameters introduced in the initial slope stability analysis are summarized in Table 3.4.

Table 3.4. Summary of soil parameters utilized of the initial slope stability analysis for the validation site.

\begin{tabular}{|c|c|c|c|c|c|c|c|c|c|}
\hline \multirow[t]{2}{*}{ Borehole } & \multirow[t]{2}{*}{ Depth (ft) } & \multirow[t]{2}{*}{ Description } & \multirow{2}{*}{$\begin{array}{c}\text { USCS } \\
\text { Classification }\end{array}$} & \multirow[t]{2}{*}{ N-Value } & \multirow[t]{2}{*}{$\mathbf{N}_{60}$} & \multirow{2}{*}{$\begin{array}{c}\text { Unit } \\
\text { Weight } \\
\text { (pcf) }\end{array}$} & $\begin{array}{c}\text { Undrained } \\
\text { Strength (Su) } \\
\text { (psf) }\end{array}$ & $\begin{array}{c}\text { Undrained } \\
\text { Strength (Su) } \\
\text { (psf) }\end{array}$ & $\begin{array}{c}\text { Undrained } \\
\text { Strength (Su) } \\
\text { (psf) }\end{array}$ \\
\hline & & & & & & & AHTD $(125 * N)$ & UARK $(33 * \mathbf{N})$ & $\begin{array}{l}\text { Terzaghi } \\
(120 * \mathbf{N})\end{array}$ \\
\hline INC1 & $0.0-23.5$ & Clay w/ Gravel & $\mathrm{CL}$ & 12 & 16 & 90.0 & 1500.0 & 396.0 & 1440.0 \\
\hline INC1 & $23.5-54.5$ & Clay & $\mathrm{CL}$ & 11 & 15 & 110.0 & 1375.0 & 363.0 & 1320.0 \\
\hline INC2 & $0.0-20.0$ & Silty Clay & $\overline{C L}$ & 10 & 13 & 110.0 & 1250.0 & 330.0 & 1200.0 \\
\hline INC2 & $20.0-74.0$ & Clay & $\mathrm{CL}$ & 15 & 20 & 115.0 & 1875.0 & 495.0 & 1800.0 \\
\hline INC2 & $74.0-81.0$ & Limestome & - & - & - & - & & - & \\
\hline
\end{tabular}

\subsection{Conclusion}

A description of the two project sites studied during this research investigation (AHTD TRC-1102) was provided in this chapter. Details about the site information for each site, including: location, history, purpose, geology and geotechnical engineering parameters were discussed. A complete understanding of the calibration site at Chester and the validation site at 
Malvern, both in the state of Arkansas, was required to fully understand the behavior of the slope failures.

The calibration site at Chester, Arkansas was characterized for having a distinct main scarp in the median of the I-540 lanes. This site is also located in a more desolated area, while the validation site at Malvern, Arkansas does not contain a distinct scarp and is located in a populated area. Both slope failures are affecting major Interstates in the state of Arkansas. The geology of the sites was complex, and composed mainly of firm to stiff soils (Chester) or weathered rocks (Malvern). The history of the site including the work performed by AHTD personnel prior to this research project: geotechnical investigations, site inspections, monitoring details, and remediation suggestions were also discussed.

A three-dimensional (3D) model was created for each site (from preliminary data collected using the total station) to obtain the geometry of the slope failure. Descriptions about how the models were created using the point cloud acquisition and 3D surface modeling software (Cyclone and AutoCAD Civil 3D) were discussed. Specifically, a description about how the cross-sections obtained from these 3-D models were used in slope stability analyses was presented. Descriptions of how some of the data reported in this chapter were collected (total station data, geotechnical parameters) are provided in the next chapter (in Sections 4.3 and 4.6). Descriptions of how the surfaces that were discussed in this chapter were created are discussed in Chapter 5, while a step-by-step procedure to create the surfaces is presented in Section Error! Reference source not found. in Appendix Error! Reference source not found.and the slope stability results (which incorporate the surface cross-section) are presented in Section 6.4. 


\section{Chapter 4. Field Instrumentation and Data Acquisition}

\subsection{Introduction}

The equipment utilized (RADAR, LIDAR, Total Station, and soil sample testing and collection equipment) and the permanent instrumentation installed (surveying monuments, slope inclinometers, vibrating wire piezometers) for this research project (TRC-1102) are discussed in this chapter. A general description of each type of equipment and each of the devices installed at the sites are presented. A discussion explaining of how the equipment was deployed in the field for data acquisition at each of the different sites is offered. Procedures followed during monitoring of the landslides during site visits, installation descriptions for devices, and the geotechnical investigation plan are all explained in this chapter.

\subsection{Sites Instrumentation}

This research project (AHTD TRC-1102), required for each project site to be subjected to an intensive instrumentation program in order to generate accurate results. The site instrumentation at each project site (calibration and validation) generated a significant portion of the results obtained during this project. While each site was extensively monitored and instrumented, most of the employed field instrumentation was not highly complex. Project instrumentation utilized during this research project consisted of surveying monuments, slope inclinometers, vibrating wire piezometers, control benchmarks and concrete footings. As previously described in Chapter 3, two project sites were studied over the course of the AHTD TRC-1102 research project.

The first task performed in the field was to analyze each site to determine appropriate locations for the surveying control monuments (total station control/backsight control), and to 
establish the required surveying control. After each site was surveyed using a total station to obtain the topography of the area, three-dimensional models of each site were created (as presented previously in Section 3.2.2 and Section 3.3.2). The Digital Elevation Model (DEM) created was used to determine appropriate locations for survey monuments over which equipment would be placed (Total Station, RADAR, and LIDAR). Drawing upon the surface model, lath stakes were used to mark the locations where the surveying monuments were installed in the ground.

Wooden 36-inch long, two-inch wide, lath stakes were used in both sites to mark the location at which survey monuments were to be installed. Each survey monument consisted of a 2.5-inch diameter aluminum monument placed on a 24 -inch long, $1 / 2$-inch diameter (U.S. No. 4) rebar encased in 18-inches of concrete (the installation procedures of the monuments are discussed in Sections 4.2.1 and 4.2.2). Locations for the monuments were carefully selected because the observed ground displacements obtained from total station measurements were directly affected by the location and installation of the surveying monuments. Locations of special interest were adjacent to the main scarp and visible tension cracks around the slide area. Sufficient width and breadth of the instrumented area to capture ground movement along the length of the assumed moving mass was attempted. A picture of the main scarp at calibration site near Chester, Arkansas with the lath stakes in place is presented in Figure 4.1.

Temporary and permanent instrumentation were used during this research project. Temporary instrumentation was composed of: a LIDAR (Leica C-10) and targets, total station (Nikon DTM-520) and a prism reflector, and a RADAR (GPRI-II). Permanent instrumentation installed in the sites included: survey monuments, piezometers, and slope inclinometers. 
However, piezometers and inclinometers were only installed at the validation site near Malvern, Arkansas.

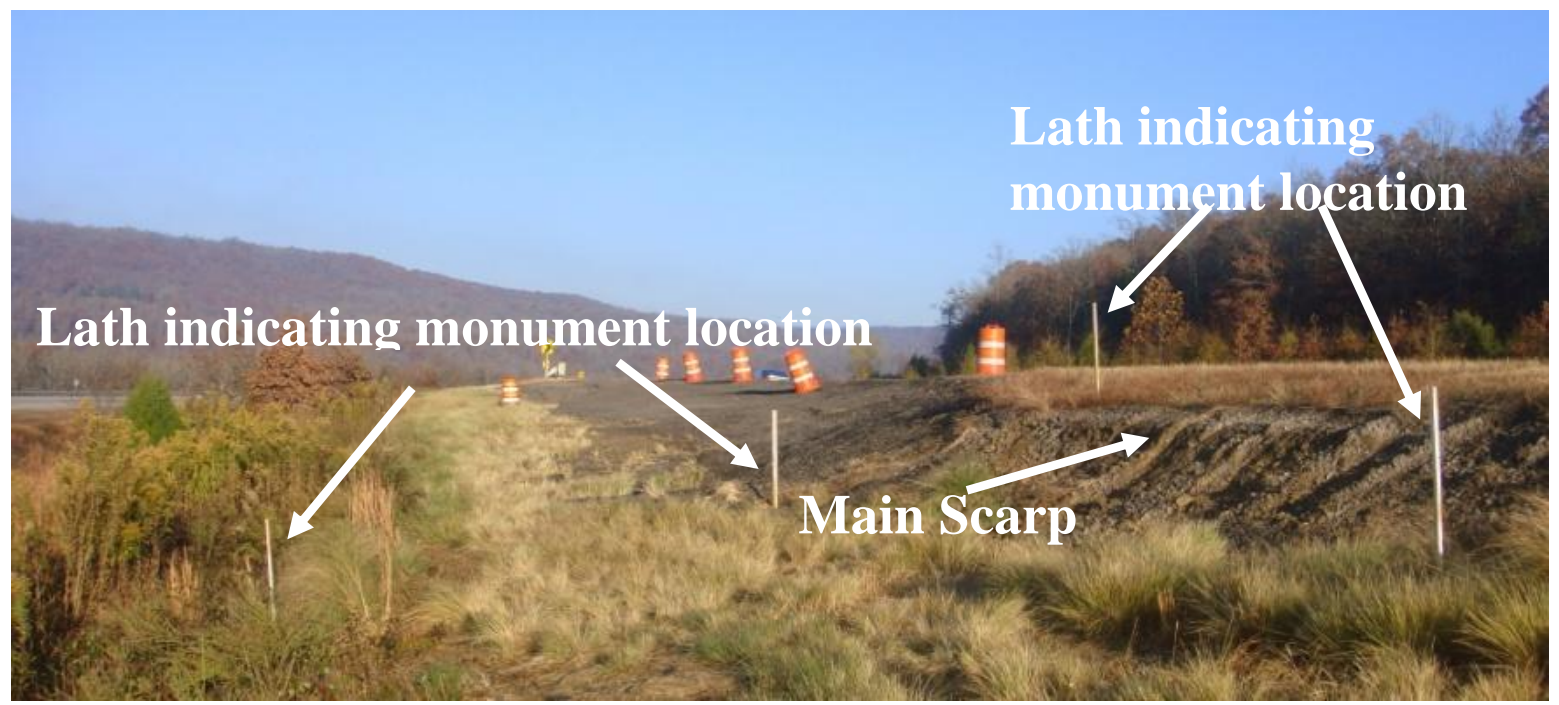

Figure 4.1. View of main scarp at the (calibration site) looking North from the median of I540 near Chester, Arkansas.

\subsubsection{Instrumentation at Calibration Site (Chester, Arkansas)}

The validation site was instrumented with a total of 29 surveying monuments spaced along the approximately 500 feet long moving mass. Sixteen of the monuments were installed on November $19^{\text {th }}, 2010$, while the other thirteen monuments were installed on November 24th, 2010. Two (2) of the 29 surveying monuments were placed to the West of the I-540 Northbound lanes, where it was assumed minimal movements would be observed (to serve as control reference points). The remaining 27 monuments were placed in the median of I-540, to the East of the I-540 northbound roadway. The monuments were placed in three approximately parallel lines. The first line was located at the bottom of the median (close to the ditch), the second line was located approximately half way up the slope of the median; and the third line was located at the top of the median, east of the I-540 northbound roadway (Figure 4.2 and Figure 4.3). 


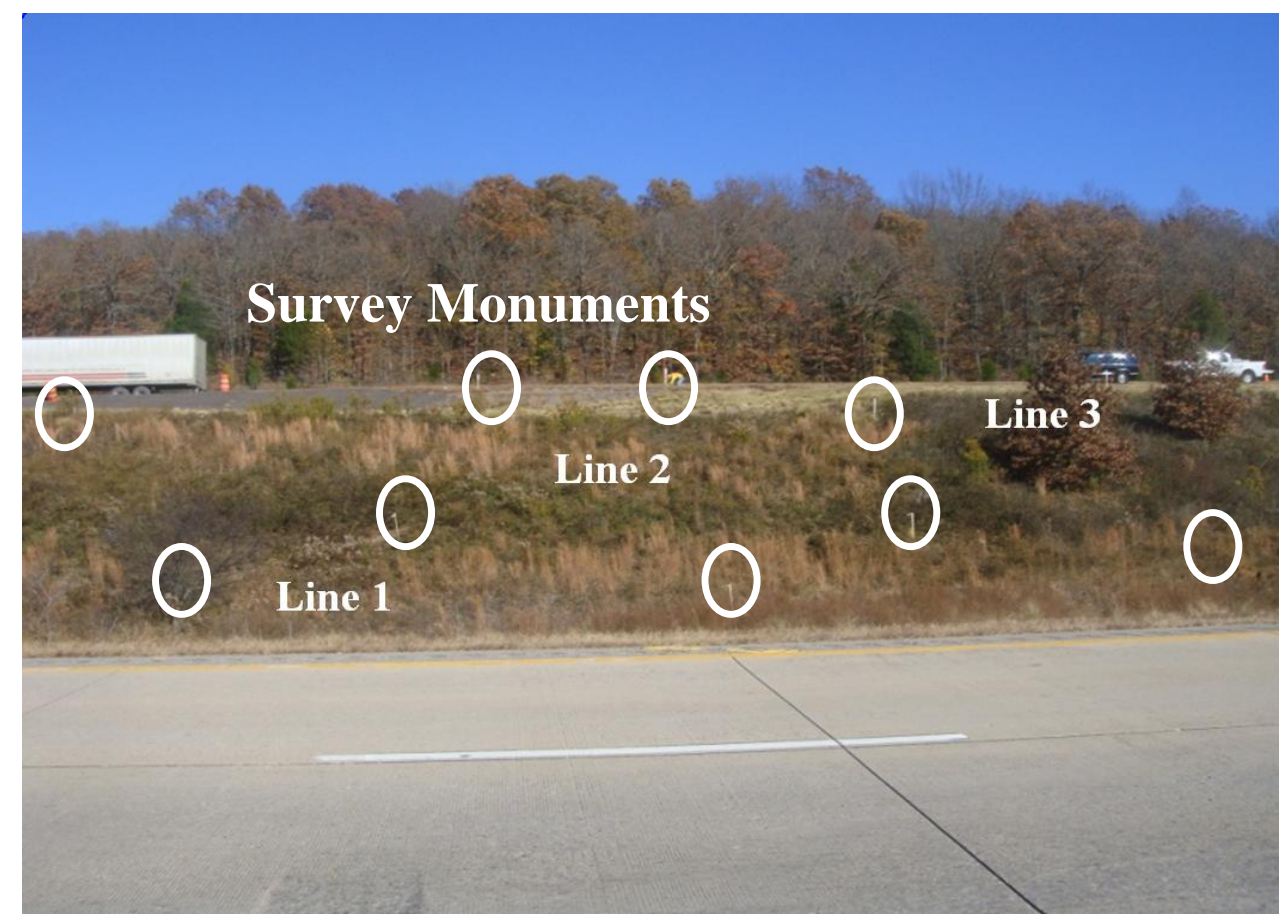

Figure 4.2. Relative positioning of survey monument lines at the calibration site (Chester, Arkansas) looking east from the Southbound lane of I-540.

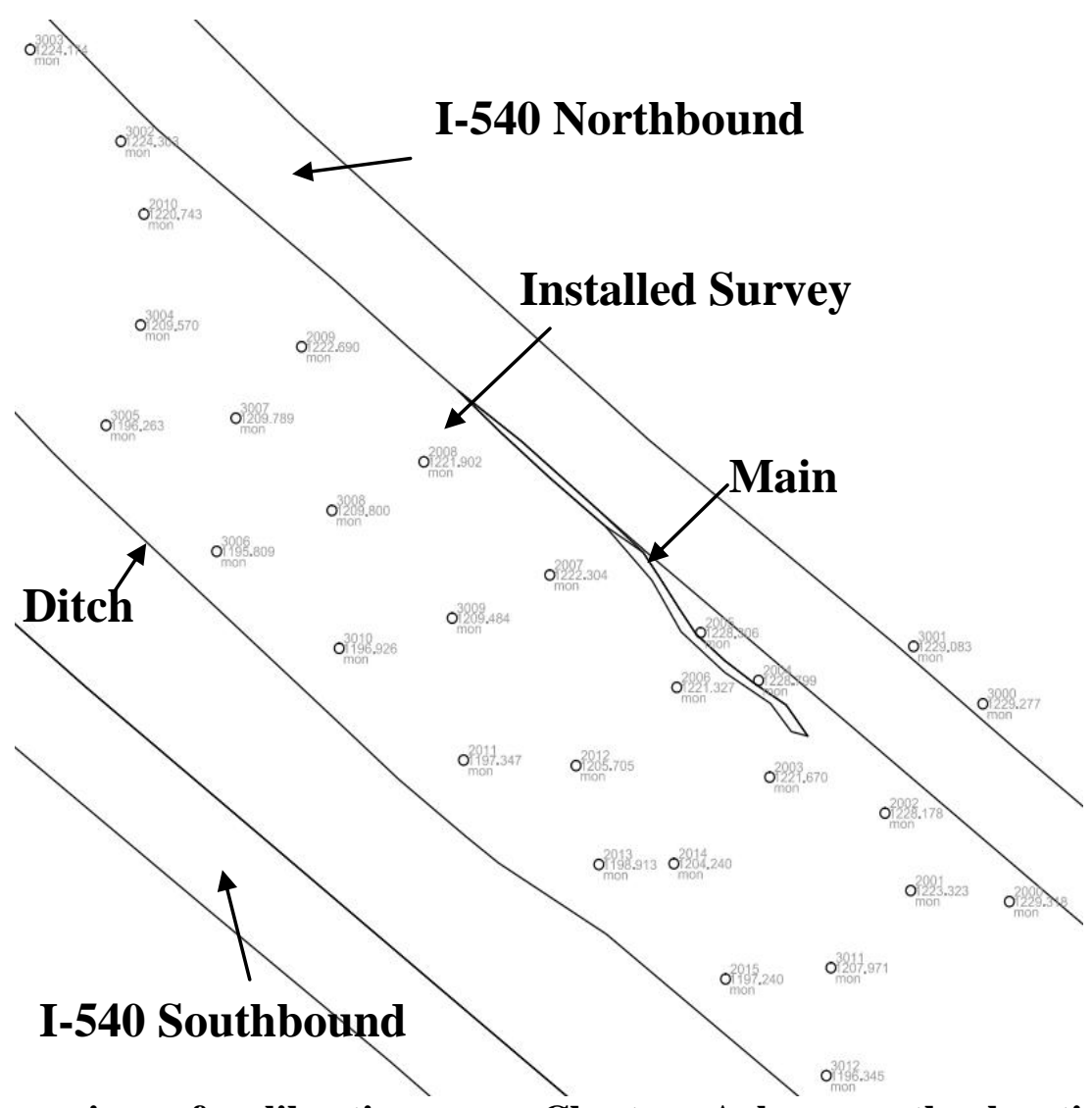

Figure 4.3. Plan view of calibration near Chester, Arkansas; the locations of survey monuments are illustrated. 
The monuments were positioned approximately 50 feet apart in a staggered or zigzag pattern between lines to provide sufficient coverage. Monuments were placed in the ground by augering a four-inch diameter hole to a minimum of depth of 18 inches below the ground surface using a hand auger. After the hole was excavated, a 24-inch long, 1/2 inch diameter (No. \#4) rebar was inserted in the middle of the hole. The bars were driven until the top of the aluminum monuments were level with the ground surface; the annulus space was then immediately filled with fast-set Quickcrete ${ }^{\circledR}$ and hydrated with water (Figure 4.4). The aluminum monument was not flush-set with the Quickcrete to allow for a RADAR target to be attached to the monument.

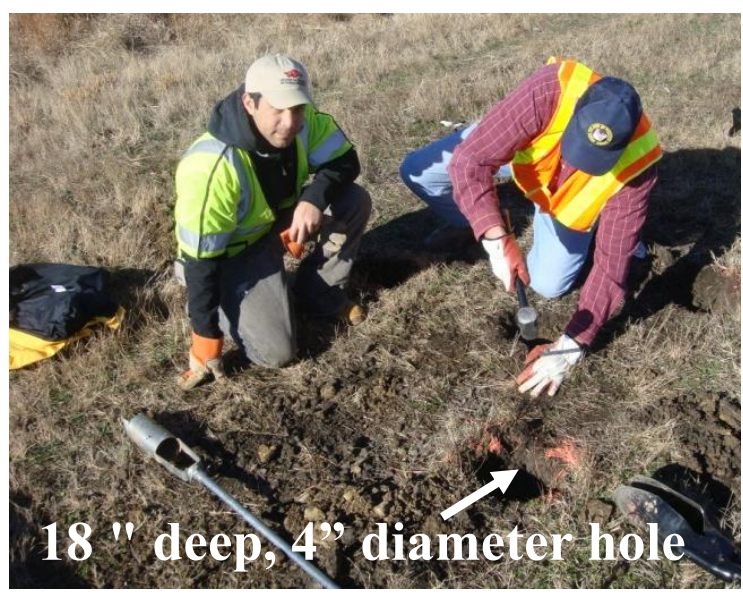

(a)

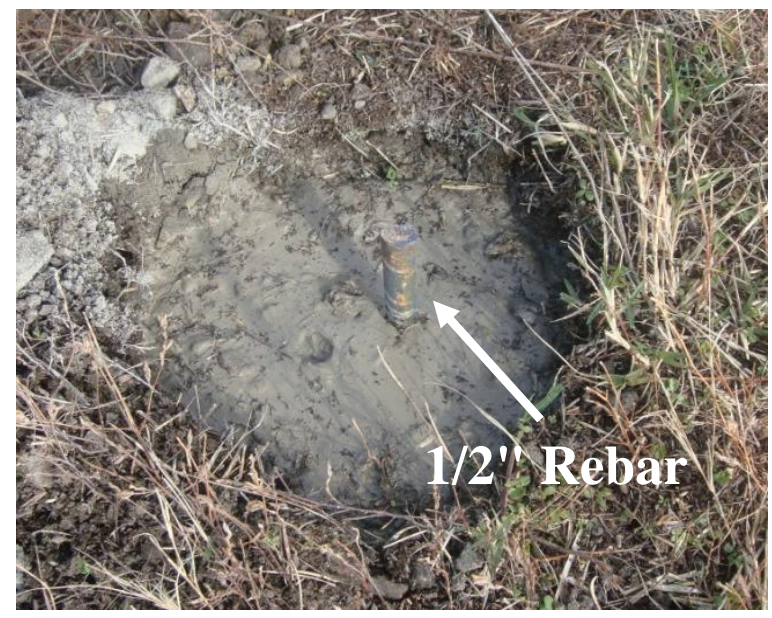

(c)

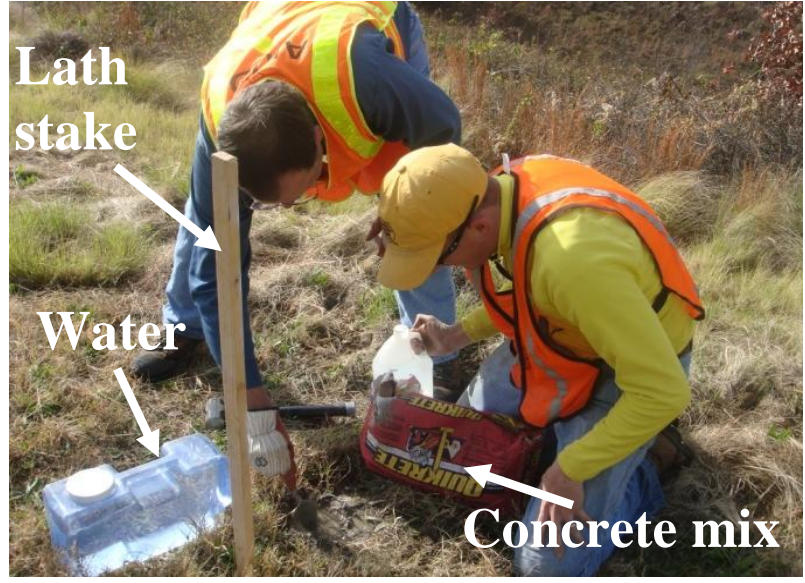

(b)

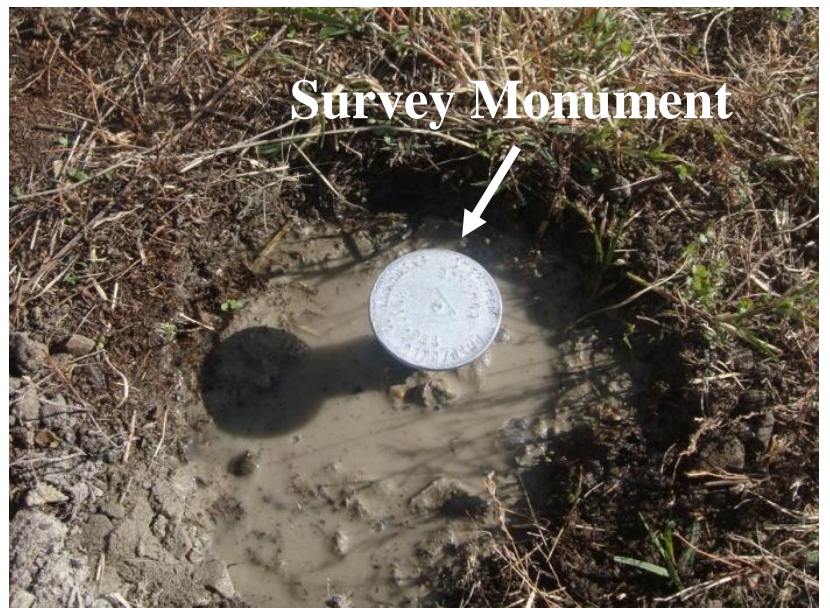

(d)

Figure 4.4. a) Hole augured for monument installation, b) placing Quickcrete ${ }^{\circledR}$ in the hole, c) steel bar placed in the ground, and d) survey monument installed. 


\subsubsection{Instrumentation at Validation Site (Malvern, AR)}

The Malvern site was instrumented with 53 survey monuments using the same procedures used at the Chester site (as described in Section 4.2.1). Forty-one monuments were installed on December $3^{\text {rd }}, 2010$ and twelve monuments were installed on January $6^{\text {th }}, 2011$. The monuments (Figure 4.5 and Figure 4.6) were installed in five lines (Figure 4.7) along the interstate (East-West direction). From North to South, the first line (6 monuments) was located north of the Highway 84; the next two lines were installed in a staggered (zigzag) pattern, and were located in the median between Highway 84 and the Westbound lane of I-30 (22 monuments); the next line (where the total station benchmark [Point 1000] was located) was in the median between the I-30 lanes (12 monuments); the fifth line was located just South of the I30 Eastbound lane (12 monuments, these were the monuments installed on January $6^{\text {th }}$ ).

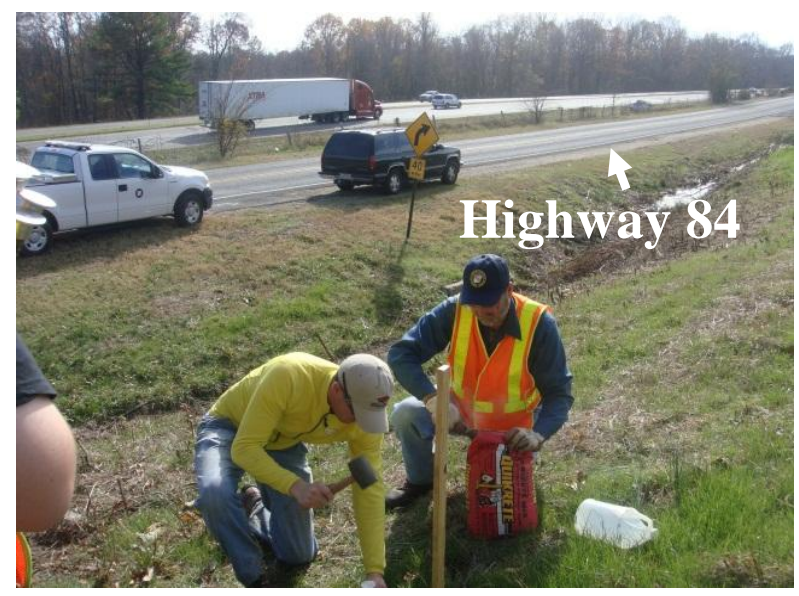

(a)

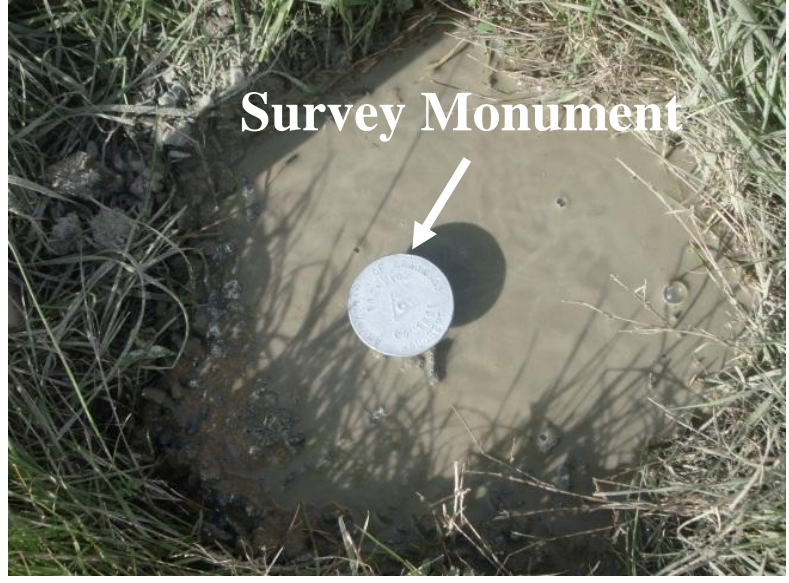

(b)

Figure 4.5. a) Installation of survey monument in the ground by UofA and AHTD personnel, and b) survey monument installed in the ground using Quickcrete ${ }^{\circledR}$. 


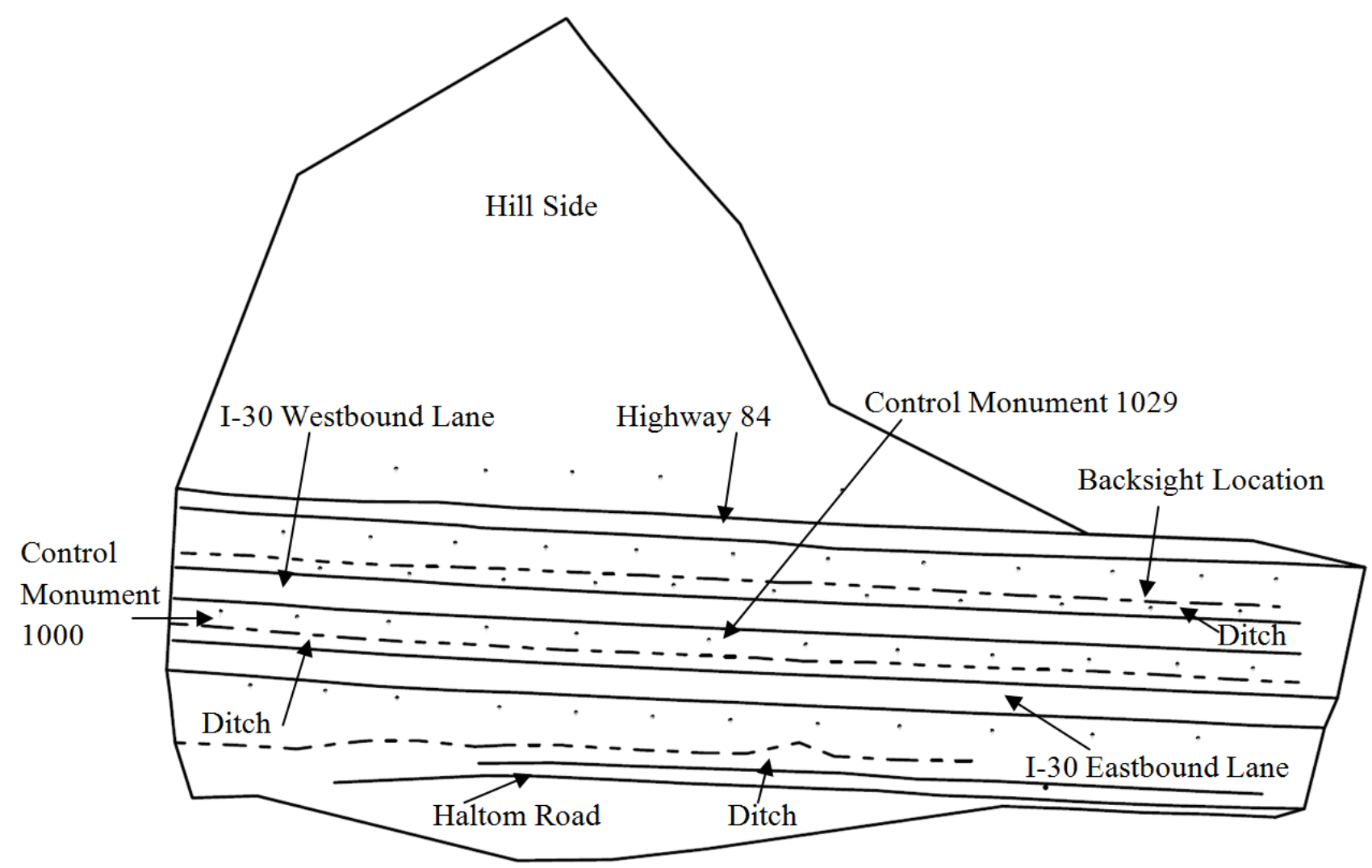

Figure 4.6. Plan view of survey monument positions installed in validation site near Malvern, Arkansas.

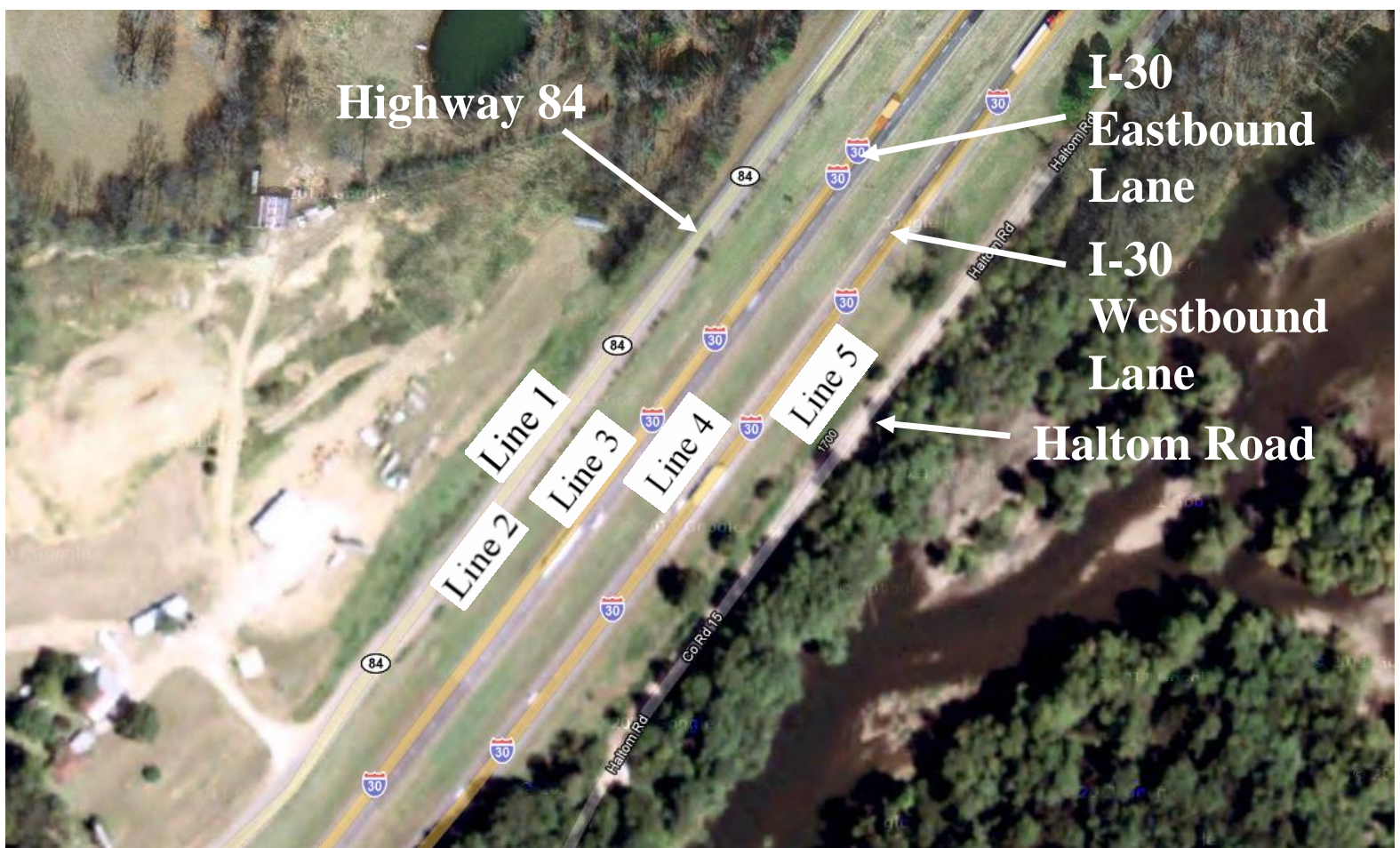

Figure 4.7. Alignments of installed survey monuments at the validation site near Malvern, Arkansas (modified Google Maps, 2011). 


\subsection{Total Station Data Acquisition}

One of the methods utilized for monitoring of the landslides located at the calibration and validation sites was performed using a total station. As previously discussed in Section 3.2.1.1, a Nikon DTM-520 total station mounted on a Leica tripod (Figure 4.8) was utilized for the entirety of this research project (AHTD TRC-1102). According to the Nikon Instruction Manual (2011), the maximum distance measurement using a single prism under ideal normal atmospheric conditions (ordinary haze with visibility greater than $12.5 \mathrm{miles}$ ) is $5,300 \mathrm{ft}(1,600 \mathrm{~m})$, with an accuracy of $\pm(2+2 \mathrm{ppm} x$ distance [D] $\mathrm{mm}$. Furthermore, the maximum distance range under ideal good atmospheric conditions (no haze with visibility over $25 \mathrm{miles} / 40 \mathrm{~km}$ ), using a single prism is 6,600ft $(2,000 \mathrm{~m})$ (Nikon Instruction Manual, 2011). A single Optima 30mm-offset prism mounted on a Sokkia prism pole with bipod legs was utilized as a target (Figure 4.10).

A Carlson Explorer 600+ (Figure 4.9) data collector was connected to the Nikon DTM520 to control the total station and to store the data that was collected by the total station. The data collector provided a simple method to manage the data and transfer the points coordinates to a computer for further analysis using various software programs. A picture of the total station and data collector used during the AHTD TRC-1102 research project is presented in Figure 4.9. 


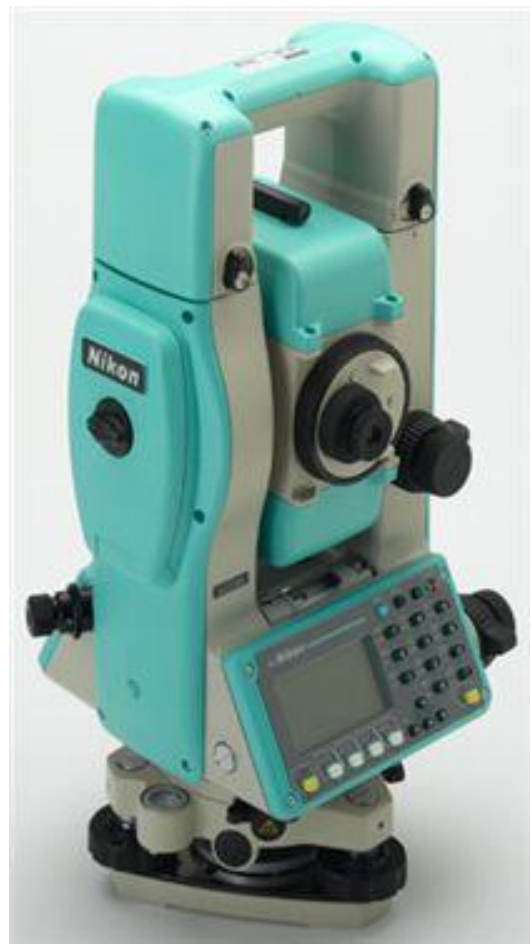

(a)

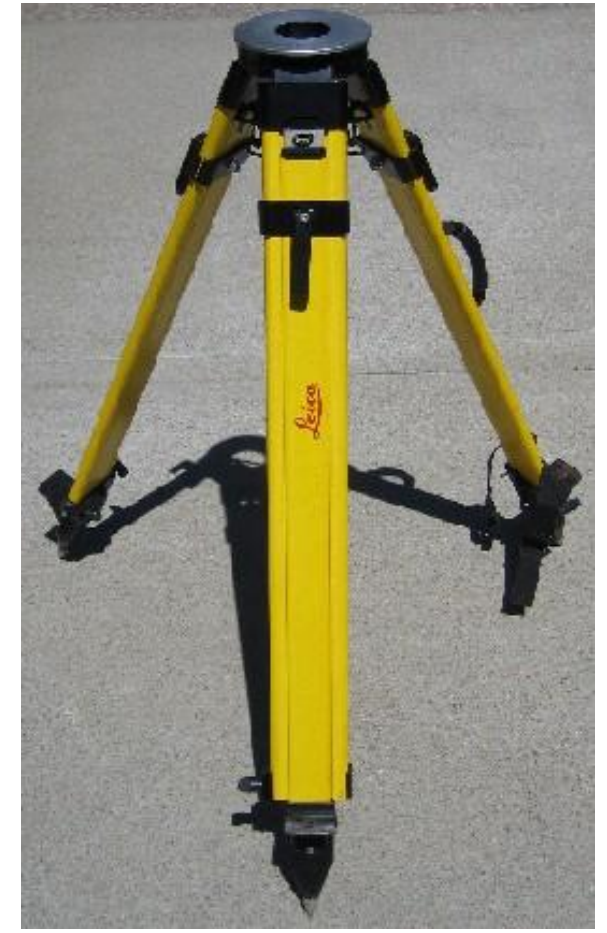

(b)

Figure 4.8. a) Nikon DTM-520 (Nikon Positioning Website, 2012), and b) Leica total station tripod utilized during this project.

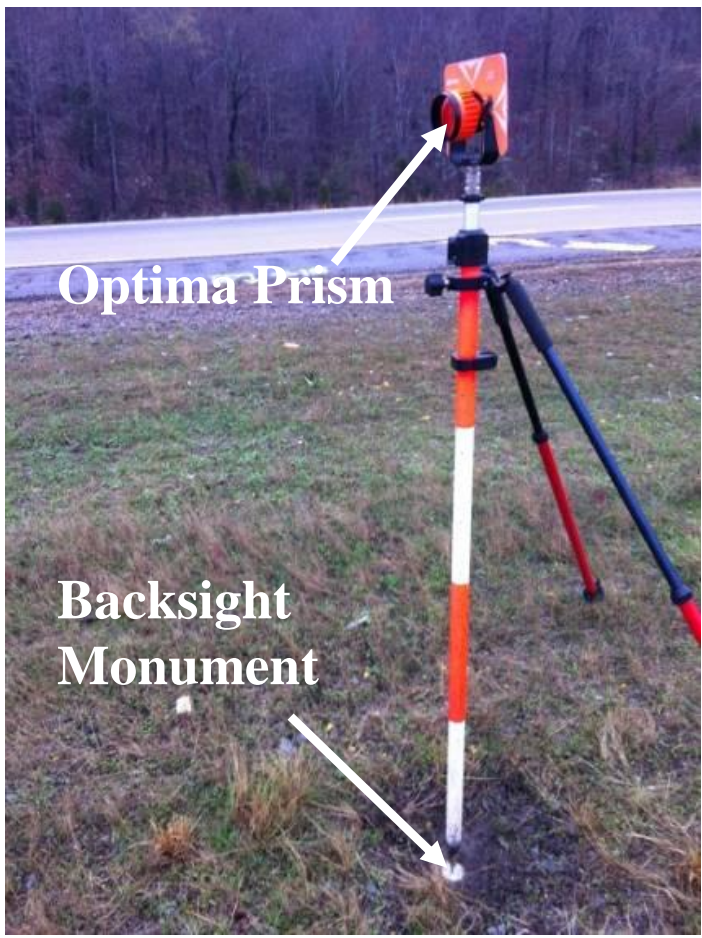

(a)

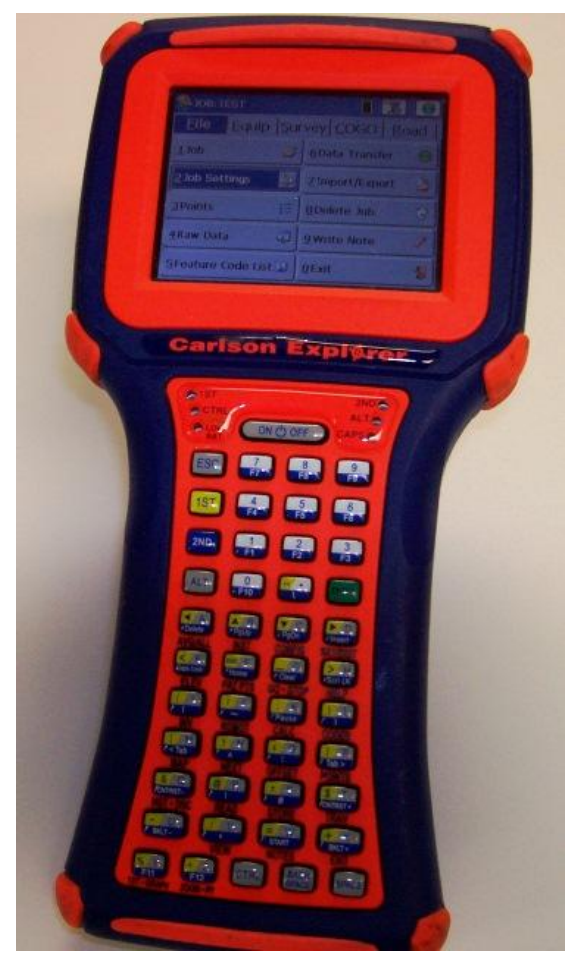

(b)

Figure 4.9. a) 30mm Optima prism with bipod legs on a Sokkia prism pole with bipod legs, and b) Carlson Explorer 600+ data collector. 


\subsubsection{Setup Procedure and Image Acquisition}

A standardized procedure for deploying the total station was followed for all site visits, at each of the sites. Prior to data acquisition, the total station was mounted on a tripod and aligned to the center of the control point using the optical plummet located on the side of the total station. The legs of the tripod were adjusted to allow for the operator to look through the eye piece (Figure 4.10). Once the tripod legs were firmly secured into the ground, the legs heights were adjusted to level the tripod and total station using the bullseye level bubble on the tribrach of the total station. After the total station and tripod were level (based on the bullseye bubble) the knobs of the tripods legs were secured to prevent movement. Small movements for final adjustments of the bubble were performed using the leveling screws on the tribrach. For final leveling, the spirit level (located on the total station) was leveled screws. Two level screws were used at the same time by performing inside or outside rotation, the third screw was rotated by itself after rotating the total station ninety degrees within the tribrach. After a careful inspection of the total station position, horizontality and verticality, the height of the total station was measured using the centimeters scale of a tape measure. 


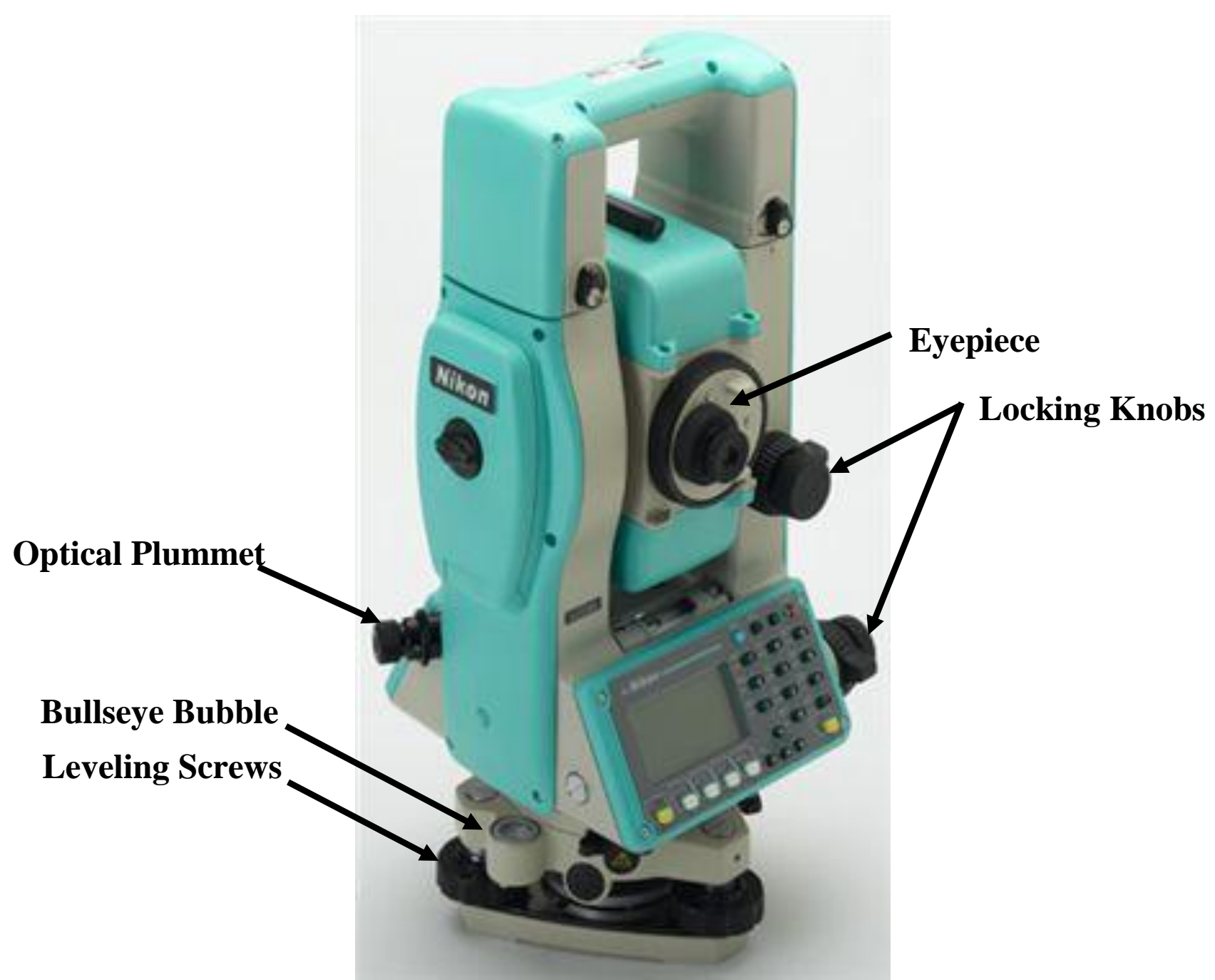

Figure 4.10. Nikon DTM-520 (Nikon Positioning Website, 2012).

The backsight equipment, consisting of a 30-mm offset Optima prism mounted on a Sokkia prism pole with bipod legs, (presented previously in Figure 4.9) was measured by placing a prism target at the backsight control point and measuring the angle and distance between the total station and backsight. The differences (or deltas) in distance and elevation between the total station and backsight for successive visits to the sites were computed by the data collector. The deltas obtained in most of the site visit were typically on the order of one hundredth of a foot (0.01ft), however; the deltas were limited to two hundredths of a foot $(0.02 \mathrm{ft})$ maximum. The 
deltas obtained during each visit were recorded to be taken into account when calculating displacements of the landslide.

Total station data acquisition consisted of collecting single point measurements at each of the individual survey monuments, at each site as discussed in the following two sub-sections. The coordinates collected $(\mathrm{x}, \mathrm{y}, \mathrm{z})$ for each point were stored in the data collector during each visit and were transferred to a computer following each visit. The data reduction procedures, for the total station data, followed during the AHTD TRC-1102 research project are discussed in Section 5.2.

\subsubsection{Total Station Data Acquisition at the Calibration Site (Chester, Arkansas)}

The total station (TS) was centered over the benchmark (indicated by a driven nail) in the West asphalt shoulder of the Southbound lane of I-540. The backsight (BS) point was located approximately 200 feet North of the total station benchmark, located in the West asphalt shoulder of the Southbound lane of I-540. A photograph of the total station equipment deployed at the calibration site is presented in Figure 4.11.

The total station benchmark was intentionally located in the approximate center (relative to the North-South extent) of all the instrumented area. An initial survey after the monuments were placed in the ground was performed and was used as a basis for comparison for all the following observations. A list of the dates of the observations, and the corresponding deltas (as discussed previously in Section 4.3.1) are presented in Table 4.1. 


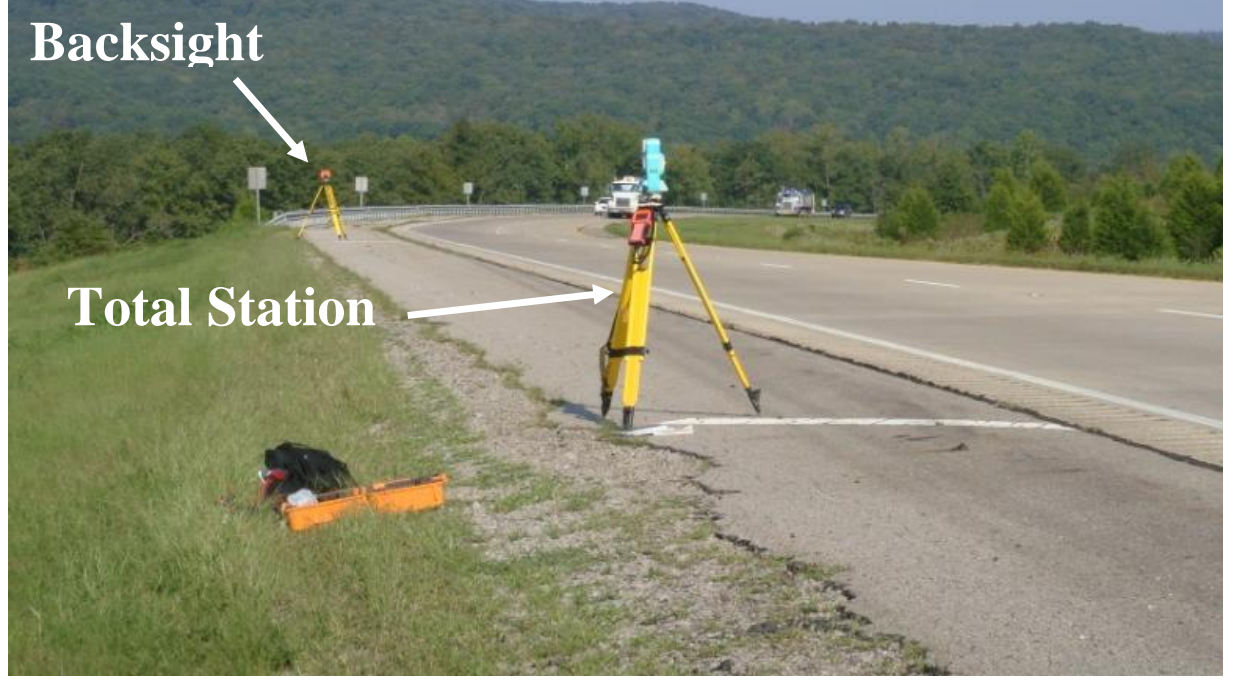

Figure 4.11. Total station setup and backsight at the calibration site near Chester, Arkansas.

Table 4.1. Dates, corresponding deltas, and comments for the calibration site acquisition located near Chester, AR.

\begin{tabular}{|c|c|c|c|c|c|}
\hline \multicolumn{6}{|c|}{ Total Station - Nikon DTM520 } \\
\hline \multirow{2}{*}{ Date } & \multicolumn{3}{|c|}{ Deltas } & \multirow{2}{*}{ Check \# } & \multirow{2}{*}{ Comment } \\
\hline & Angle & Distance (ft.) & Elevation (ft.) & & \\
\hline $11 / 24 / 2010$ & 0 & -0.013 & 0.024 & Check 1 & 13 monuments \& 4 laths placed \\
\hline $12 / 5 / 2010$ & - & - & - & - & Comunication error with data collector \\
\hline $1 / 5 / 2011$ & 0 & -0.007 & 0.034 & Check 2 & Dr. Coffman and Matthew Blanchard \\
\hline $1 / 25 / 2011$ & 0 & -0.007 & 0.012 & Check 3 & Points ID 5000 and above \\
\hline $2 / 22 / 2011$ & 0 & -0.012 & 0.029 & Check 4 & Points ID 6000 and above \\
\hline $3 / 8 / 2011$ & 0 & -0.014 & 0.018 & Check 5 & Points ID 6100 and above \\
\hline $3 / 26 / 2011$ & 0 & -0.016 & 0.029 & Check 6 & Points ID 6200 and above \\
\hline $4 / 5 / 2011$ & 0 & -0.013 & 0.014 & Check 7 & Points ID 6300 and above \\
\hline $4 / 19 / 2011$ & 0 & -0.013 & 0.019 & Check 8 & Points ID 6400 and above \\
\hline $5 / 16 / 2011$ & 0 & 0.104 & 0.019 & Check 9 & $\begin{array}{c}\text { BS level bubble broke. } \\
\text { Points ID } 6500 \text { and above }\end{array}$ \\
\hline $5 / 31 / 2011$ & 0 & -0.01 & 0.014 & Check 10 & Points ID 6600 and above \\
\hline $6 / 20 / 2011$ & 0 & -0.015 & 0.021 & Check 11 & Points ID 6700 and above \\
\hline $7 / 9 / 2011$ & 0 & -0.016 & 0.014 & Check 12 & Points ID 6800 and above \\
\hline $8 / 12 / 2011$ & 0 & -0.018 & 0.01 & Check 13 & Points ID 6900 and above \\
\hline $9 / 2 / 2011$ & 0 & -0.015 & 0.004 & Check 14 & Points ID 7000 and above \\
\hline $11 / 5 / 2011$ & 0 & -0.01 & -0.016 & Check 15 & Points ID 7100 and above \\
\hline 12/19/2011 & 0 & -0.006 & 0.005 & Check 16 & Points ID 7200 and above \\
\hline $2 / 3 / 2012$ & 0 & -0.011 & -0.004 & Check 17 & Points ID 7300 and above \\
\hline
\end{tabular}




\subsubsection{Total Station Data Acquisition at the Validation Site (Malvern, Arkansas)}

The validation site was visited approximately once a month (Table 4.2) for a total station survey, and GPRI-II (RADAR) and LIDAR data acquisitions (the procedures for the RADAR and LIDAR acquisitions will be discussed in Sections 4.4 and 4.5, respectively). The same procedures described in Section 4.3.1.1 for the calibration site were followed for the validation site. Two viewpoints were required, on occasion, for total station surveys due to the size of the validation site. The first viewpoint was from Survey Monument 1000 in the median of Interstate 30 (Line 4) and the other viewpoint was from Survey Monument 1029 in the same line.

Table 4.2. Dates, corresponding deltas, and comments for the calibration site acquisition located near Malvern, AR.

\begin{tabular}{|c|c|c|c|c|c|}
\hline \multicolumn{7}{|c|}{ Total Station - Nikon DTM520 } \\
\hline \multirow{2}{*}{ Date } & \multicolumn{3}{|c|}{ Deltas } & \multirow{2}{*}{ Check \# } & Comment \\
\cline { 2 - 5 } & Angle & Distance & Elevation & & Points ID 2000 and above \\
\hline $1 / 6 / 2011$ & 0 & 0.007 & 0.044 & Check 1 & Points ID 3000 and above \\
\hline $3 / 5 / 2011$ & 0 & -0.024 & -0.021 & Check 2 & Points ID3100 and above \\
\hline $3 / 6 / 2011$ & 0 & -0.029 & 0.025 & Check $2 \mathrm{~b}$ & Points ID 3200 and above \\
\hline $3 / 25 / 2011$ & 0 & -0.016 & 0.007 & Check 3 & Points ID 3300 and above \\
\hline $3 / 26 / 2011$ & 0 & -0.022 & 0.027 & Check 3b & Points ID 3400 and above \\
\hline $5 / 3 / 2011$ & 0 & -0.017 & 0.018 & Check 4 & Points ID 3500 and above \\
\hline $6 / 1 / 2011$ & 0 & -0.02 & 0.047 & Check 5 & Points ID 3600 and above \\
\hline $9 / 5 / 2011$ & 0 & -0.002 & -0.004 & Check 6 & Points ID 3700 and above \\
\hline $10 / 11 / 2011$ & 0 & -0.002 & 0.004 & Check 7 & Points ID 3800 and above \\
\hline $12 / 20 / 2011$ & 0 & -0.015 & 0.009 & Check 8 & Points ID 3900 and above \\
\hline $2 / 10 / 2012$ & 0 & -0.017 & 0.001 & Check 9 & \\
\hline
\end{tabular}

The first surveying monument installed, Survey Monument 1000 (Figure 4.11), was the first monument, West to East, in Line 4 and was selected because all of the other monuments were viewable from this location (as shown previously in Figure 4.6 and Figure 4.7). The downside of this location was that, because it was located on the end of Line 4, the distance to the other monuments increased until it reached the monuments at the other end of the sliding mass where the long surveying distances and minimal angular rotation (approximately 1350ft and three degrees of rotation) may have significantly impacted the measured displacement. In 
order to reduce the distance between the total station and these monuments, Survey Monument 1029 , located in the middle of Line 4, was selected as another total station viewpoint. From this monument most of the surveying monuments were visible (although one was located behind a traffic sign). Because Survey Monument 1029 was located in the middle of the monitoring mass, all the distances were reduced and the angular rotation to the other monuments was increased (Figure 4.6). The downside of using Survey Monument 1029 an observation point was that it was located in the middle of the moving mass; therefore, Survey Monument 1029 may have also been moving with the landslide. Data acquisition from Survey Monument 1029 was not continued after three trials due to time constrain during site visits, and because no significant benefits were observed when analyzing the data.

Instead of acquiring data from multiple observation points, beginning in September 2011 a double angle procedure, was implemented (for the calibration and validation sites), from one observation point. The double angle method consists measuring each point location by observing the backsight from both the direct and reverse positions on the total station and averaging the measured angles and distances. This features (available in the total station settings menu) allowed for a more robust method for data acquisition. A 30 second (30") maximum difference in angular rotation between the direct and reverse observations was allowed between the direct and reverse reading. The method was performed at the calibration and validation site for the remainder of the research project (AHTD TRC-1102). 


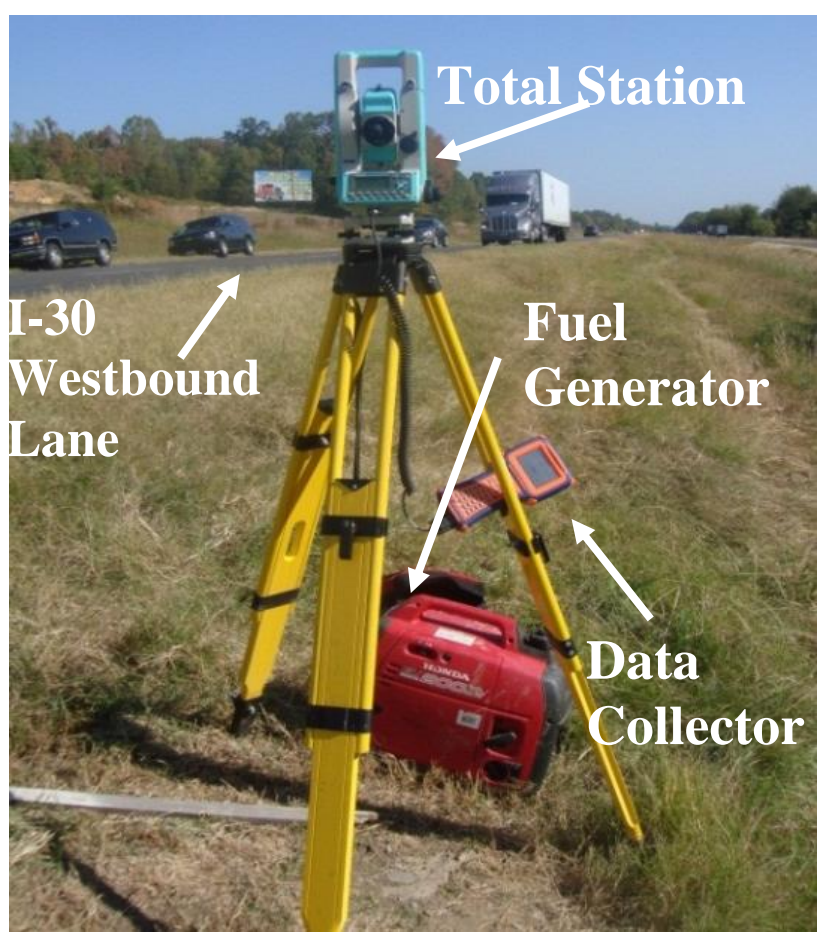

Figure 4.12. Total station deployed at Survey Monument 1000 in Line 4 of the monuments at the validation site.

\subsubsection{Limitations of the Total Station}

Due to the size of the calibration site, only one total station control point was necessary and it was located outside of the moving mass at the site. Conversely, the size of the validation site forced using Survey Monument 1000 (which was assumed to be outside the moving mass), and Survey Monument 1029 (which was known to be approximately in the center of the landslide) as observation points. The two viewpoints were required due to the large distances between Survey Monument 1000 and the points on the other side of the landslide. The topography of the site and other site features did not allow for a better total station viewpoint outside the moving mass, from which all of the monuments could be monitored.

\subsection{RADAR Data Acquisition}

Monitoring of the landslides located at the calibration and validation sites was conducted using a ground based RADAR GPRI-II. As previously mentioned in Section 2.3.1.1, GAMMA 
Remote Sensing recently developed and built a ground based portable RADAR interferometer referred to as a Gamma Portable RADAR Interferometer (GPRI-II). This portable RADAR, unlike previous terrestrial RADAR instruments from other manufactures, does not use aperture synthesis to obtain good azimuth resolution and is fully mobile. The instrument utilizes realaperture antennas, with two emitter antennas and one receiver antenna (Figure 4.13), operating at a frequency of $17.2 \mathrm{GHz}$. The relatively high frequency utilized by this device allows the user to obtain high azimuth resolution $(1 \mathrm{~m})$ and sensitivity to motion $(<1 \mathrm{~cm})$. Minimal deployment effort was required and individual measurements were obtained in less than 36 seconds, with 360 degrees of field view and 0.1 to 4 kilometers operational distance (GAMMA Remote Sensing, 2011).

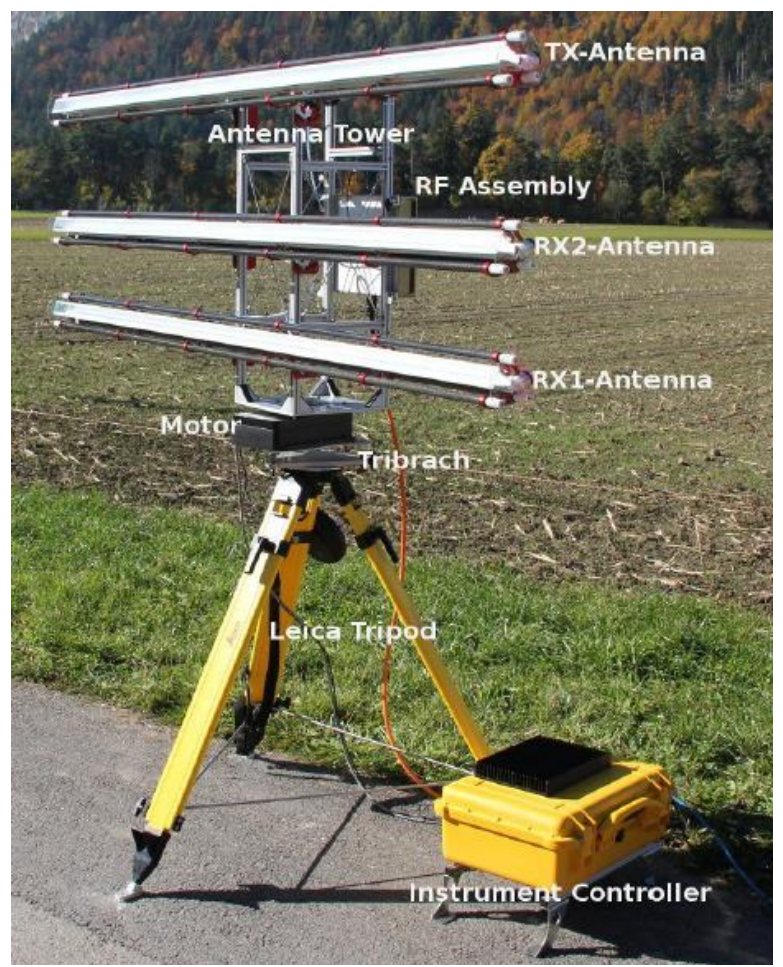

Figure 4.13. GPRI-II features (from GAMMA Remote Sensing AG, 2011). 


\subsubsection{RADAR Setup Procedure}

Concrete footings (Figure 4.14) were constructed or stable rock outcrops or asphalt roadways at the site were used to anchor the GPRI-II when acquiring data, and to ensure that the GPRI-II equipment was properly located for subsequent observations. The tripod for the GPRI-II has three steel rods midway up the tripod, between the legs of the tripod to provide enhanced stability for the equipment and a bubble level in the base of the tripod to ensure horizontality (Figure 4.14).

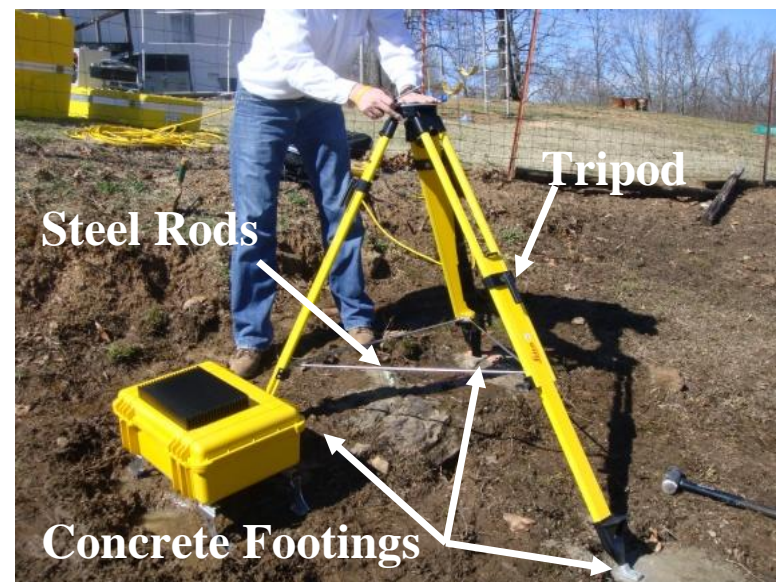

(a)

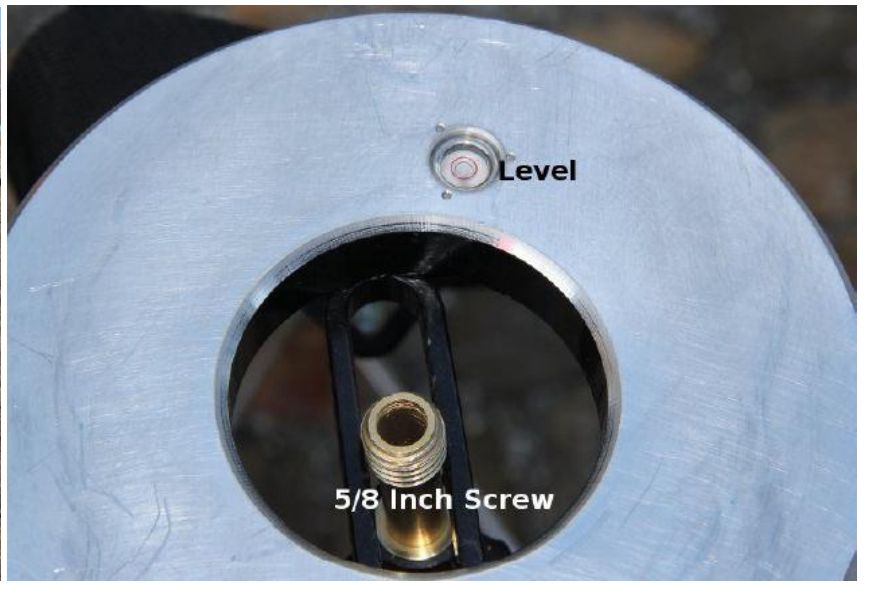

(b)

Figure 4.14. a) tripod for GPRI-II anchored to footings, b) tripod's bubble level (from GAMMA Remote Sensing AG, 2011).

The setup for the GPRI-II was performed by first anchoring the tripod to the concrete footings and then leveling the tripod. To ensure that the RADAR was at the same elevation for every acquisition the length of each of the legs of the tripod was measured and recorded on the first site visit to each viewpoint. The same lengths were used, thereafter, for every deployment of the GPRI-II (Figure 4.15). Next, the stepper-controlled motor and the adjustable mounting bracket (tribrach) were placed top of the tripod and secured using the $5 / 8$ inch screw (shown previously in Figure 4.14); to level the tribrach the two side screws and the center bubble were used (Figure 4.15). 
The antenna tower was then positioned on the baseplate on top of the stepper-controlled motor and four screws were used to secure the tower to the motor. After confirming that the bass was level and all the screws were secure, the radio frequency (RF) assembly box was mounted to the back of the antenna tower. The antenna holders were then set to the required elevation angle (Figure 4.15) required for each viewpoint, and the three antennas (one emitter and two receivers) were mounted to the tower and antenna cables and GPS cable were connected to the RF box (each antenna was placed in the same location [top, middle, or bottom] for each survey). All of the cables from the RADAR components (two cables for stepper motor controller, one cable for RF assembly, one cable for the power) were connected to the GPRI-II computer (or field computer), an Ethernet cable was used to control the GPRI-II using a laptop with a Linux interface (using the Gamma Remote Sensing proprietary software).

After all of the equipment was assembled and connected, the tripod set screw was untightened and the assembly was slid along the tripod/tribrach interface to ensure the assembly was precisely located over the survey monument. At the same time, a variable power telescopic sight was used to ensure the antennas were facing and aligned with a predetermined, site specific benchmarks (e.g., fence posts). For each site the aforementioned benchmarks were selected away from the moving mass, to ensure that the same starting angle was utilized for all observations (Figure 4.15). Following sliding the and rotating the assembly, the tripod set screw was retightened to ensure proper position. 


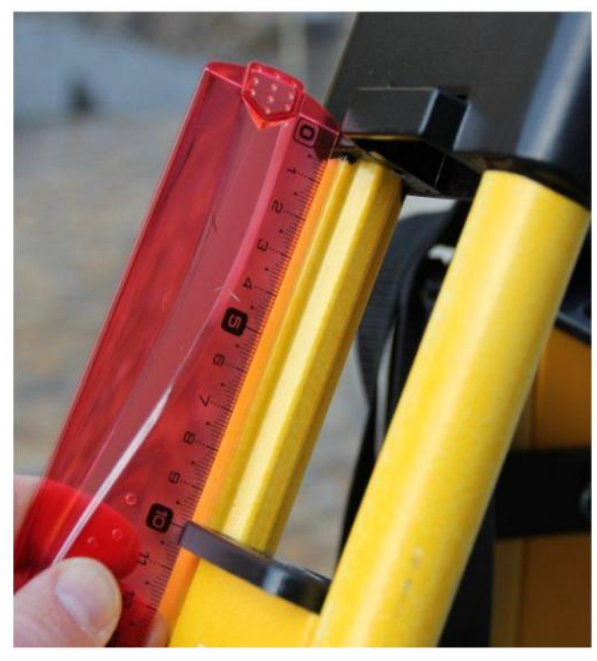

(a)

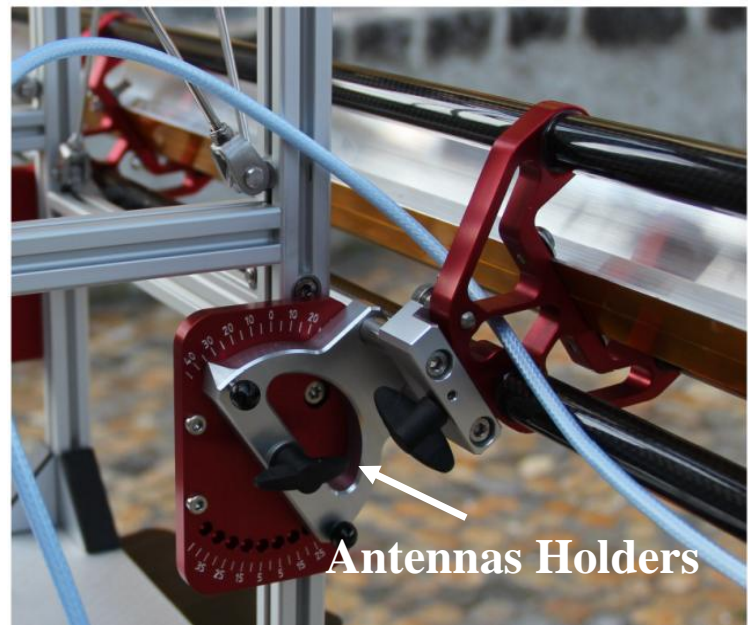

(c)

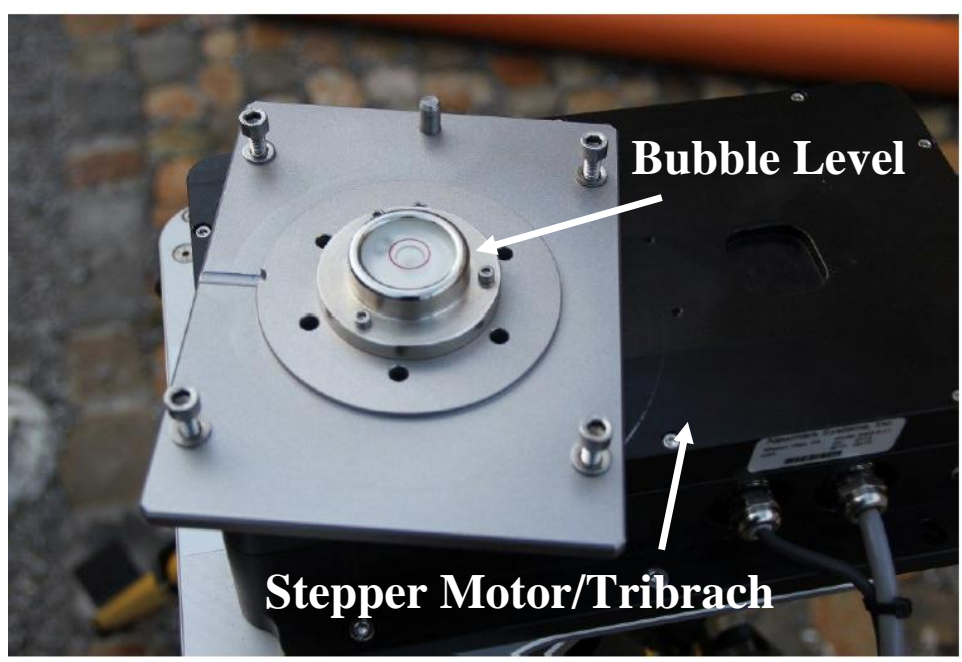

(b)

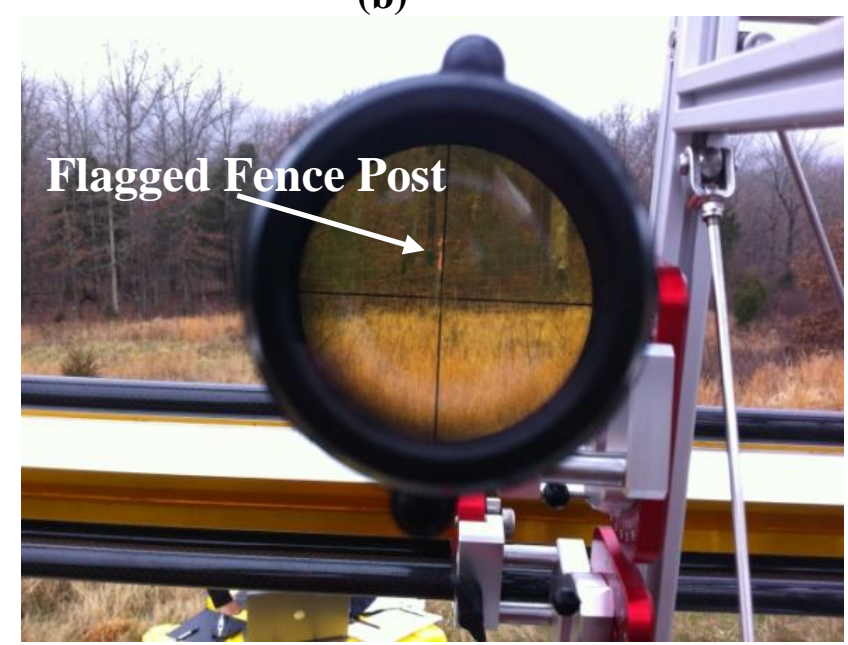

(d)

Figure 4.15. a) Measurement of tripod leg, b) motor bubble level, c) antenna holder with elevation angles, and d) scope mounted on GPRI-II frame used for alignment (a, b, and c from GAMMA Remote Sensing AG, 2011).

\subsubsection{RADAR Setup Procedure at the Calibration Site (Chester, Arkansas)}

RADAR acquisitions were conducted biweekly at the Chester site (Table 4.3 and Appendix Error! Reference source not found.). The viewpoint locations for RADAR image acquisition were selected according to the specifications for the GPRI-II and for the geography of the area. In order to identify if the observation distance between the RADAR equipment and the targeted area had a significant impact on the observed ground movement; two RADAR viewpoints have been selected per site location. For the validation site, one RADAR viewpoint 
was located near the asphalt shoulder of the I-540 Southbound lane and the other was located approximately 6500 feet $(2.0 \mathrm{~km})$ West of the slide area. The corresponding observation points are hereinafter referred to as the southbound viewpoint and the overlook viewpoint, respectively, and the relative locations of each are presented in Figure 4.16. Photographs of the GPRI-II deployed at each site are shown in Figure 4.17.

Table 4.3. Observation schedule for the calibration site near Chester, Arkansas.

\begin{tabular}{|c|c|c|c|}
\hline Date & Site & Viewpoint & $\begin{array}{c}\text { Number of Images } \\
\text { Acquired }\end{array}$ \\
\hline $02 / 22 / 11$ & Calibration & Southbound & 5 \\
\hline 03/08/11 & Calibration & Southbound & 12 \\
\hline $03 / 26 / 11$ & Calibration & Southbound & 6 \\
\hline $04 / 05 / 11$ & Calibration & Southbound & 6 \\
\hline $04 / 09 / 11$ & Calibration & Southbound & 6 \\
\hline $04 / 19 / 11$ & Calibration & Southbound & 6 \\
\hline 05/16/11 & Calibration & Southbound & 6 \\
\hline $05 / 31 / 11$ & Calibration & Southbound & 6 \\
\hline $06 / 20 / 11$ & Calibration & Southbound & 6 \\
\hline $07 / 09 / 11$ & Calibration & Southbound & 6 \\
\hline $08 / 12 / 11$ & Calibration & Southbound & 6 \\
\hline 09/04/11 & Calibration & Southbound & 11 \\
\hline $11 / 05 / 11$ & Calibration & Southbound & 9 \\
\hline $12 / 19 / 11$ & Calibration & Southbound & 9 \\
\hline $02 / 04 / 12$ & Calibration & Southbound & 9 \\
\hline $02 / 26 / 12$ & Calibration & Southbound & 9 \\
\hline \multicolumn{3}{|c|}{ Total } & 118 \\
\hline $03 / 01 / 11$ & Calibration & Overlook & 6 \\
\hline $03 / 08 / 11$ & Calibration & Overlook & 6 \\
\hline $04 / 05 / 11$ & Calibration & Overlook & 6 \\
\hline $04 / 19 / 11$ & Calibration & Overlook & 6 \\
\hline $05 / 16 / 11$ & Calibration & Overlook & 6 \\
\hline $05 / 31 / 11$ & Calibration & Overlook & 6 \\
\hline $06 / 20 / 11$ & Calibration & Overlook & 6 \\
\hline $07 / 02 / 11$ & Calibration & Overlook & 7 \\
\hline $08 / 12 / 11$ & Calibration & Overlook & 7 \\
\hline $09 / 04 / 11$ & Calibration & Overlook & 10 \\
\hline $11 / 05 / 11$ & Calibration & Overlook & 11 \\
\hline $12 / 19 / 11$ & Calibration & Overlook & 10 \\
\hline $01 / 06 / 12$ & Calibration & Overlook & 18 \\
\hline $02 / 04 / 12$ & Calibration & Overlook & 9 \\
\hline $02 / 26 / 12$ & Calibration & Overlook & 9 \\
\hline \multicolumn{3}{|c|}{ Total } & 123 \\
\hline \multicolumn{3}{|c|}{ Total Both Viewpoints } & 241 \\
\hline
\end{tabular}




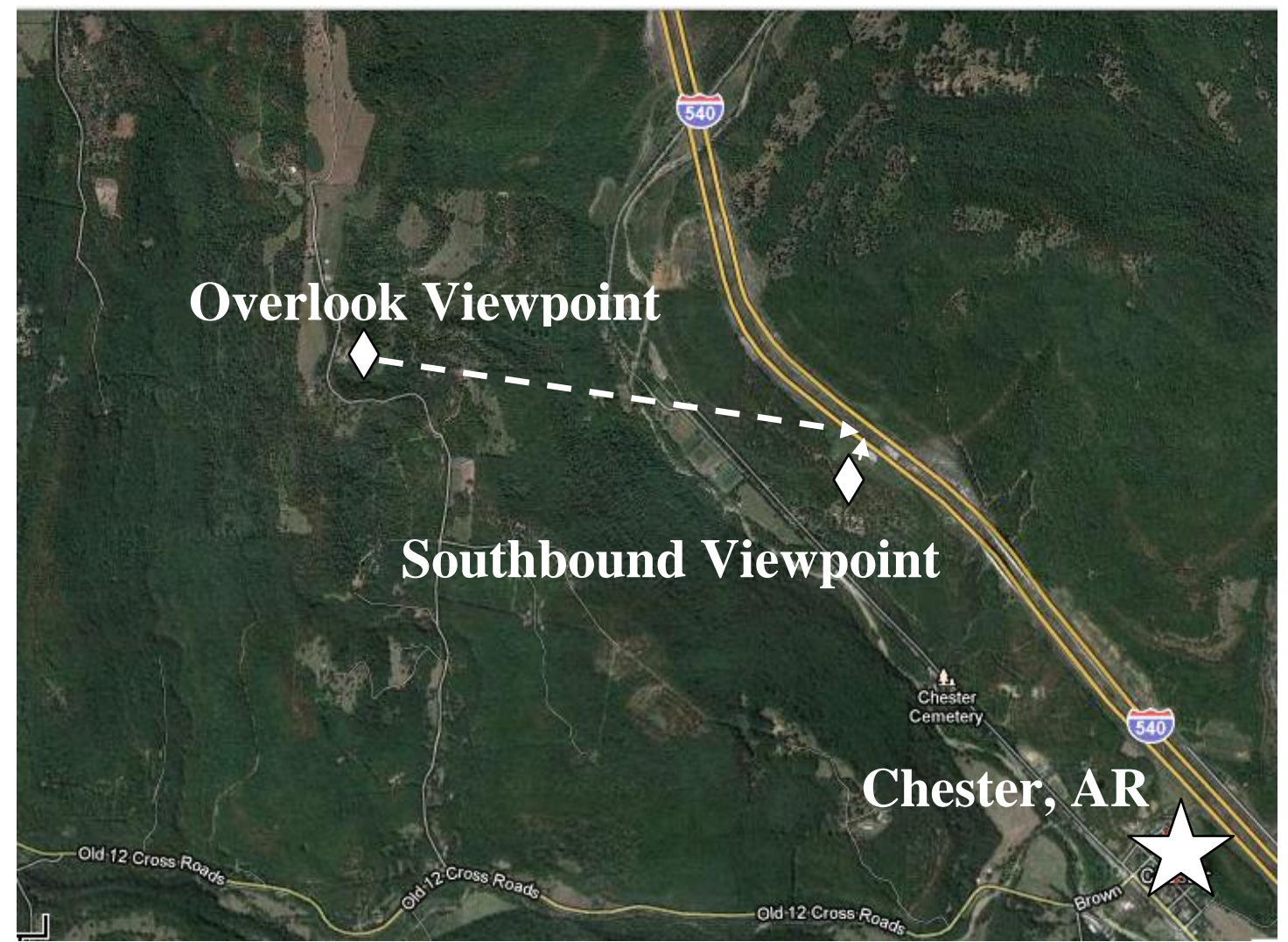

Figure 4.16. RADAR viewpoints locations at look directions at the calibration site near Chester, Arkansas (modified from Google Maps, 2011).

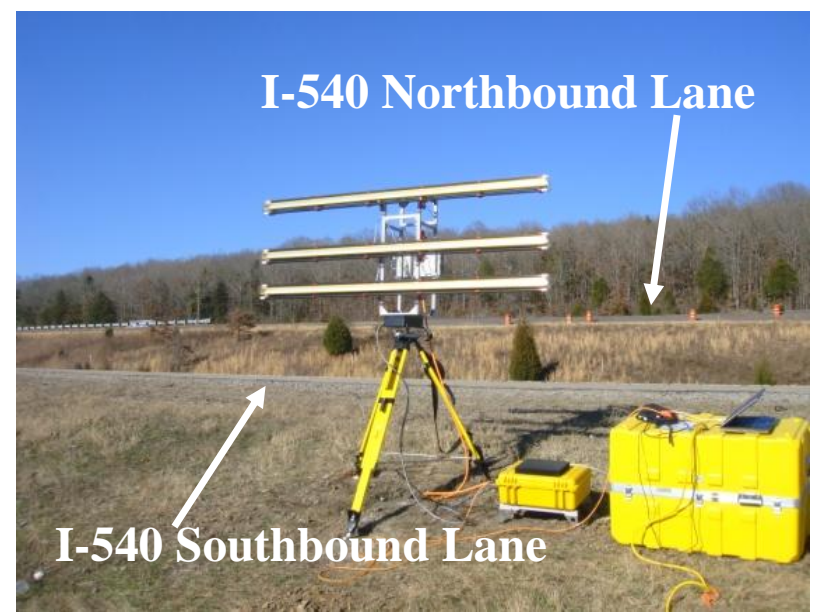

(a)

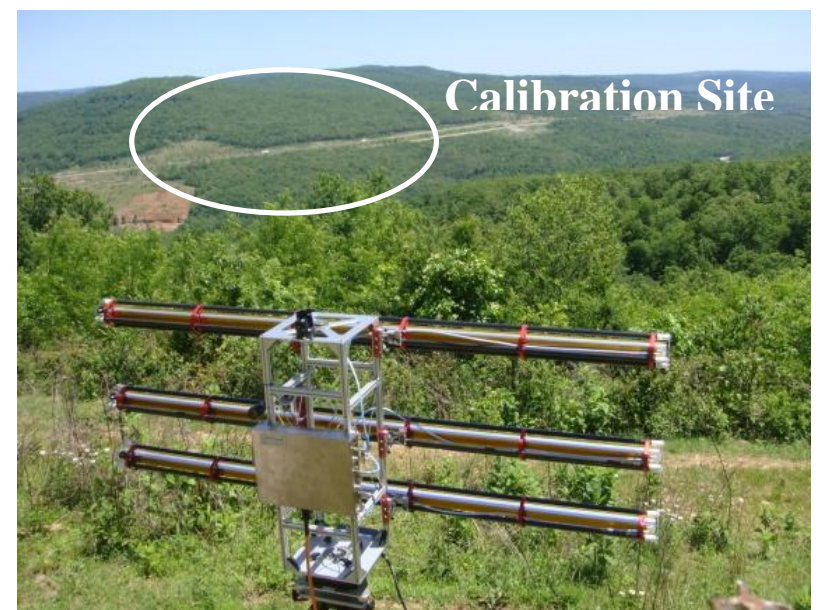

(b)

Figure 4.17. a) Southbound viewpoint, and b) Overlook viewpoint.

\subsection{Southbound Viewpoint at the Calibration Site (Chester, Arkansas)}

The Southbound viewpoint at the calibration site is located approximately 15 feet West of the Southbound shoulder of I-540. This location allowed for collection of RADAR data from 
with a short field of view (i.e. the RADAR was close to the sliding mass [approximately 100 feet]). As shown previously in Figure 4.16, the RADAR benchmark was placed due West of the center of the main scarp. Four concrete footings were utilized to deploy the GPRI-II at this viewpoint (Figure 4.18). Three concrete footings were used to secure the tripod legs to the ground using anchors, while the fourth concrete footing contained survey monument and served to align the RADAR in the same position during each visit. The setup procedure described in Section 4.4.1 was followed during each visit. Before acquiring images at the Southbound viewpoint, the GPRI-II was aligned to $4^{\text {th }}$ fence wire (marked with surveying flagging) using the scope of the RADAR.

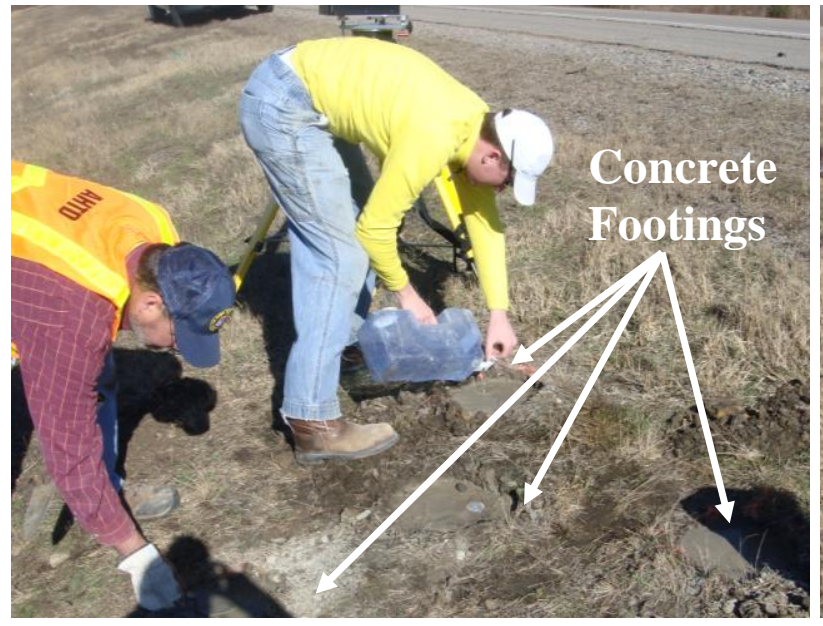

(a)

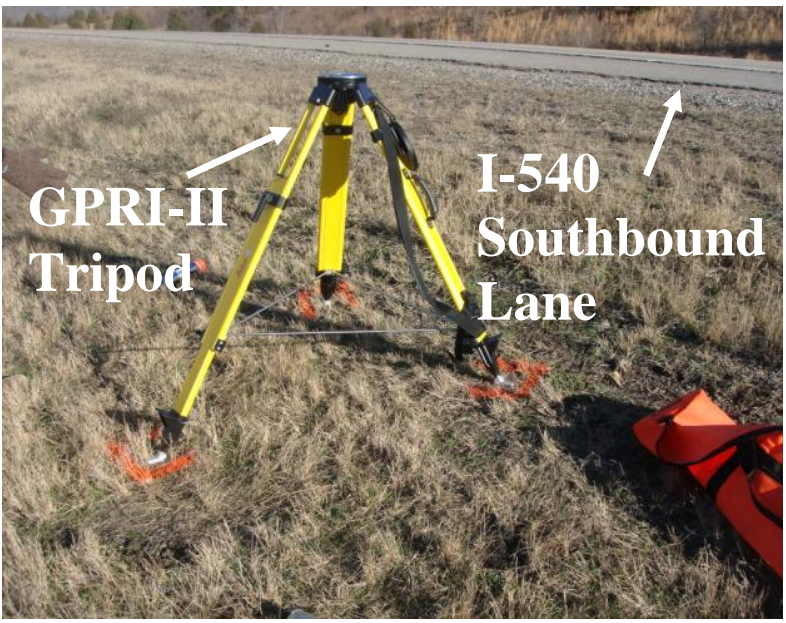

(b)

Figure 4.18. a) Placing concrete footings for GPRI-II at the Southbound viewpoint at the calibration site, and b) tripod of GPRI-II anchored at the Southbound viewpoint near Chester, Arkansas.

\subsection{Overlook Viewpoint at the Calibration Site (Chester, Arkansas)}

The Overlook viewpoint was selected based on the viewing geometry from this location. As shown previously in Figure 4.16, the Overlook viewpoint was located on a hillside located approximately $2 \mathrm{~km}$ West of the calibration site. The distance from the site and the higher topographic elevation of the Overlook viewpoint, as compared with the sliding surface, permitted a panoramic view of the whole site. Only one concrete footing was place in the ground at the 
overlook viewpoint (supporting the downhill leg of the tripod). The other two tripod legs were anchored to surficial rock at the Overlook location. The GPRI-II was centered over a PK nail installed in the rock. The setup procedure described in Section 4.4.1 was followed during each visit to the site. The GPRI-II was aligned (using the scope) to a fence post before acquiring data in the overlook viewpoint near Chester, Arkansas. Photographs of the deployment of the GPRI-II at the Overlook viewpoint site near Chester, Arkansas are shown in Figure 4.19.

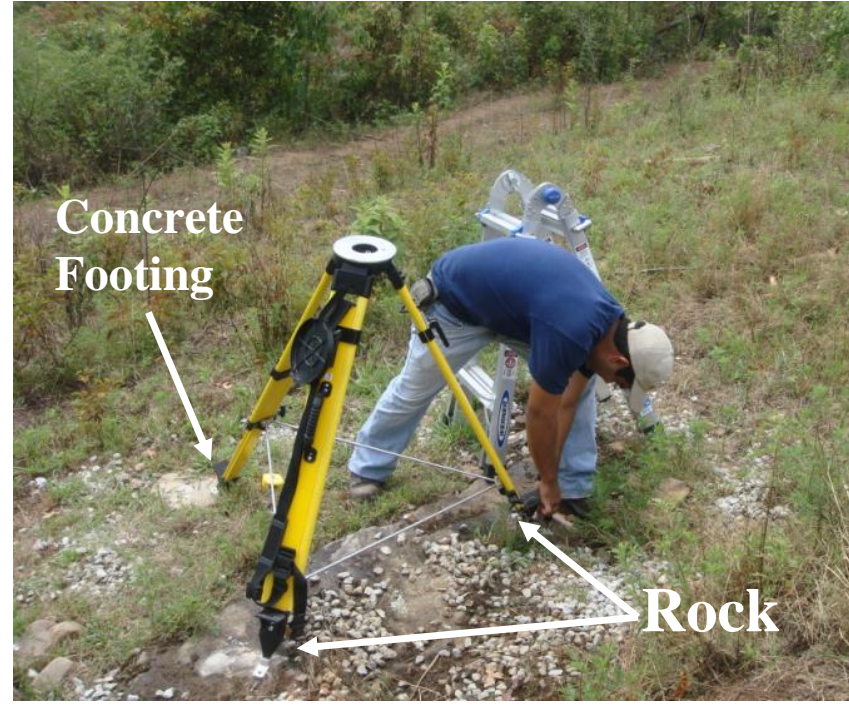

(a)

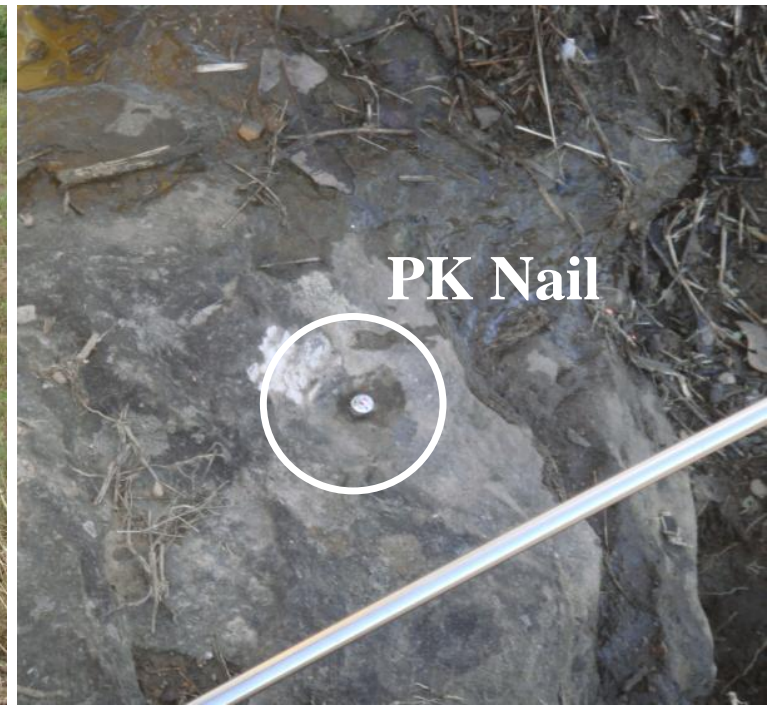

(b)

Figure 4.19. a) Anchoring tripod to rock at the Overlook viewpoint, and b) PK nail in rock used to center the GPRI-II at the Overlook viewpoint near Chester, Arkansas.

\subsubsection{RADAR Setup Procedure at the Validation Site (Malvern, Arkansas)}

Two viewpoints for were selected for RADAR acquisition at the validation site; each viewpoint contained a different viewing geometry of the slide area. One viewpoint was located on the shoulder of Halton Road and was referred as the Northeast (NE) viewpoint. The other viewpoint was situated on a survey monument that is parallel with of Line 2 (as shown previously in Figure 4.6), and is referred to as the Southwest (SW) viewpoint. In Figure 4.20, the locations and looking direction of both observation points are overlaid on an aerial image of the Malvern site. To prevent distortion in the RADAR images due to the high amount of traffic on I- 
30 (especially from semi-trucks), data was collected performed in the early morning hours (0000 hours-0600 hours). The location of the two viewpoints in the validation site near Malvern, Arkansas is illustrated in Figure 4.20. Additional information regarding data acquisition form the two different viewpoints at validation site near Malvern, Arkansas is discussed in the following subsections. Photographs from the two viewpoints are shown in Figure 4.21. A total of nine RADA visits were conducted to the validation site (Table 4.4).

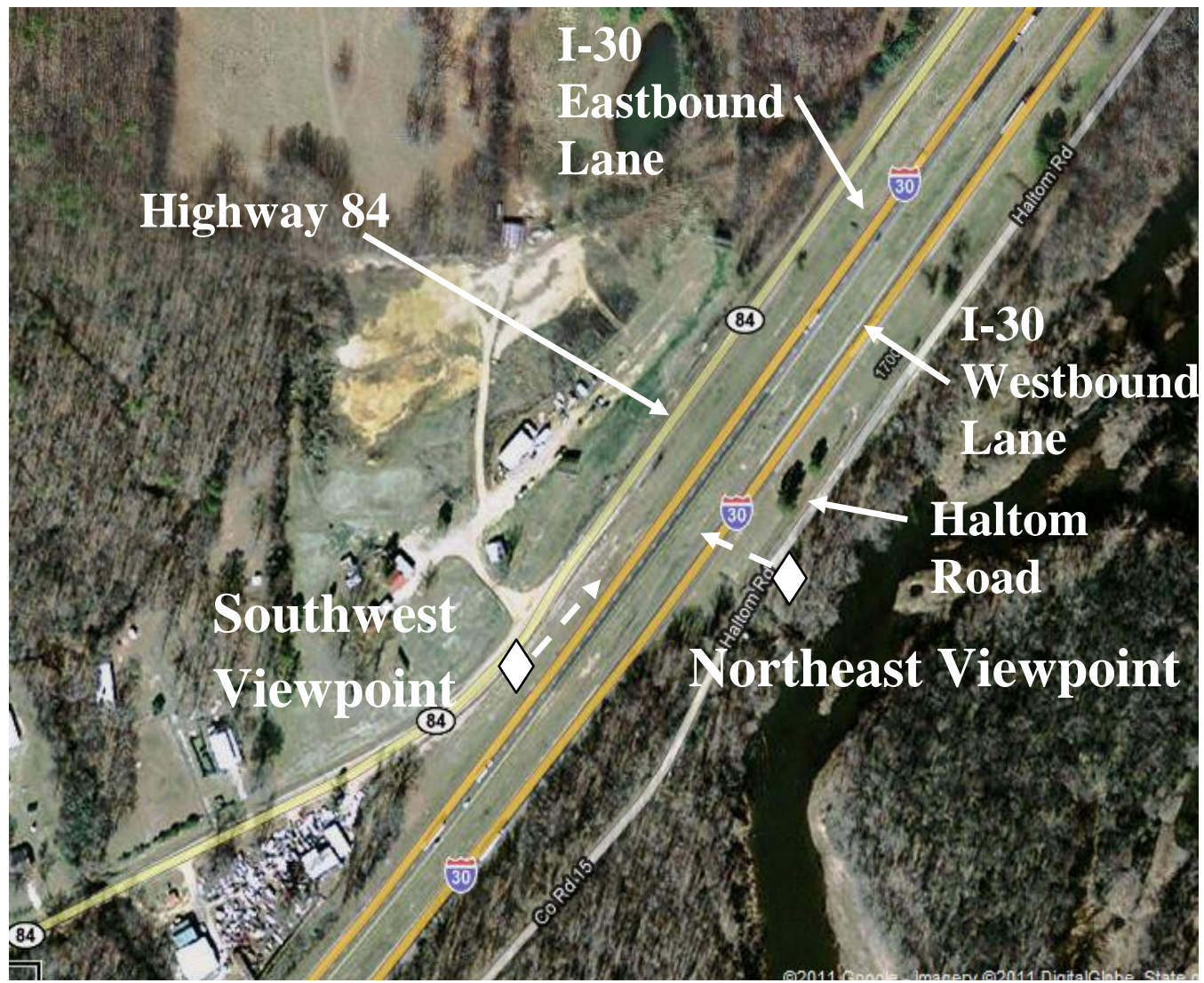

Figure 4.20. Location of the locations of the GPRI-II at the validation site near Malvern, Arkansas (modified from Google Maps, 2011). 


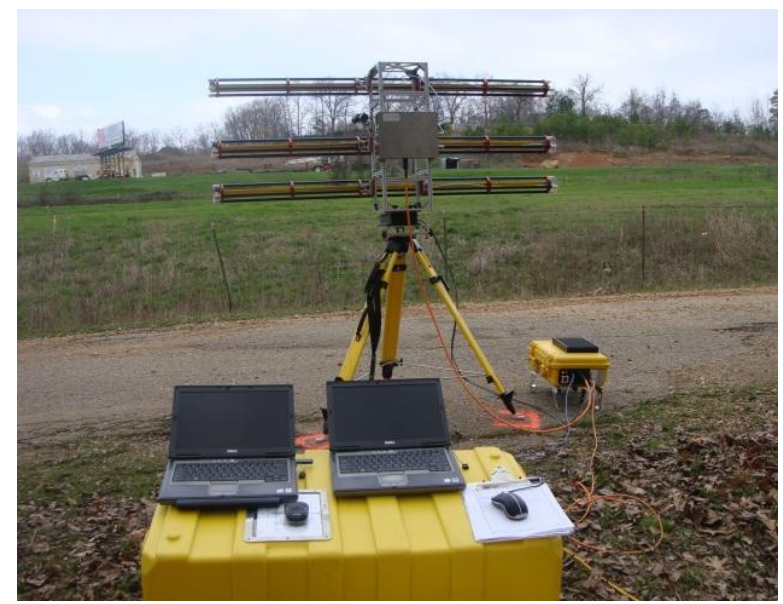

(a)

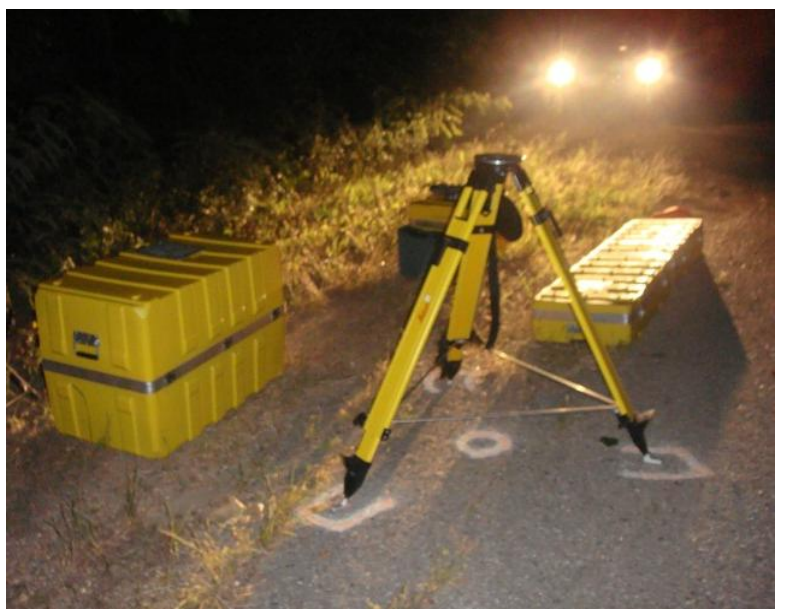

(c)

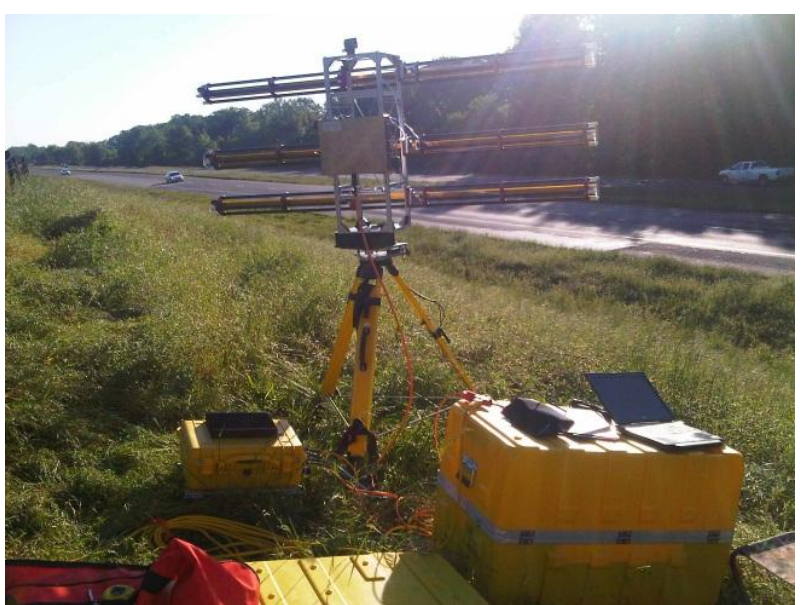

(b)

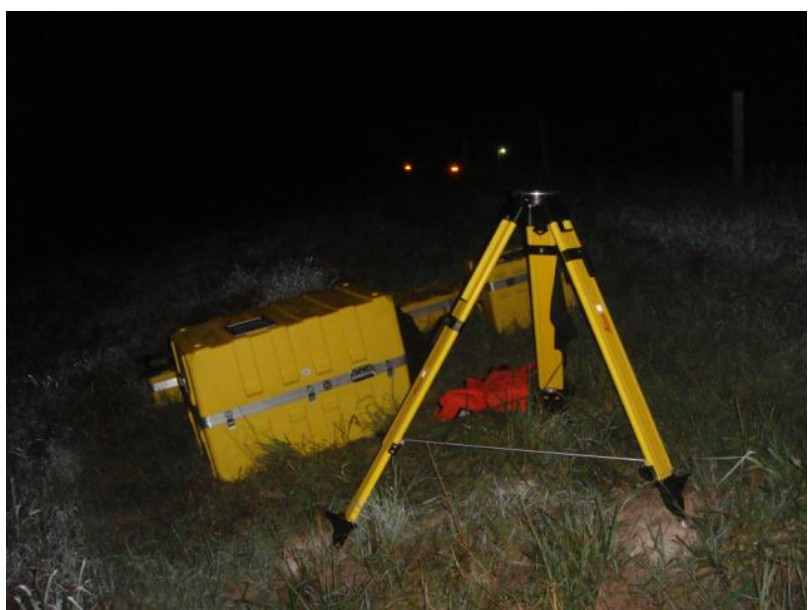

(d)

Figure 4.21. a) GPRI-II scanning at the NE viewpoint, b) GPRI-II scanning at the SW viewpoint. c) deployment of the GPRI-II at night at the NE viewpoint, and d) nighttime RADAR deployment at the SW viewpoint. 
Table 4.4. Observation schedule for the calibration site near Chester, Arkansas.

\begin{tabular}{|c|c|c|c|}
\hline Date & Site & Viewpoint & $\begin{array}{c}\text { Number of Images } \\
\text { Acquired }\end{array}$ \\
\hline $3 / 5 / 2011$ & Validation & NE & 7 \\
\hline $3 / 25 / 2011$ & Validation & NE & 9 \\
\hline $3 / 26 / 2011$ & Validation & NE & 6 \\
\hline $5 / 3 / 2011$ & Validation & NE & 6 \\
\hline $6 / 2 / 2011$ & Validation & NE & 6 \\
\hline $7 / 12 / 2011$ & Validation & NE & 6 \\
\hline $9 / 5 / 2011$ & Validation & NE & 10 \\
\hline $10 / 12 / 2011$ & Validation & NE & 10 \\
\hline $11 / 9 / 2011$ & Validation & NE & 10 \\
\hline $12 / 20 / 2011$ & Validation & NE & 9 \\
\hline $2 / 10 / 2012$ & Validation & NE & 9 \\
\hline $3 / 6 / 2011$ & Validation & NE & 7 \\
\hline \multicolumn{3}{|c|}{ Total } & $\mathbf{9 5}$ \\
\hline $3 / 26 / 2011$ & Validation & SW & 7 \\
\hline $5 / 3 / 2011$ & Validation & SW & 7 \\
\hline $6 / 2 / 2011$ & Validation & SW & 7 \\
\hline $7 / 12 / 2011$ & Validation & SW & 7 \\
\hline $9 / 5 / 2011$ & Validation & SW & 11 \\
\hline $10 / 12 / 2011$ & Validation & SW & 10 \\
\hline $11 / 9 / 2011$ & Validation & SW & 10 \\
\hline $12 / 20 / 2011$ & Validation & SW & 10 \\
\hline $2 / 10 / 2012$ & Validation & SW & 9 \\
\hline \multicolumn{3}{|c|}{ Total } & $\mathbf{7 8}$ \\
\hline \multicolumn{2}{|c|}{ Total Both Viewpoints } & $\mathbf{1 7 3}$ \\
\hline
\end{tabular}

\subsection{Northeast Viewpoint at the Validation Site (Malvern, Arkansas)}

The Northeast viewpoint was located approximately five feet south of the centerline of Harmon road. At this viewpoint the GPRI-II was anchored to road pavement (asphalt) and the device was centered over a screw placed in the asphalt. This viewpoint was located near the center of the sliding mass, but the ground elevation was lower than the I-84 and I-30 roadway. The fence lines separating Haltom Road and Highway 84 from I-30 were expected to cause partial saturation of the images. The scope of the GPRI-II was utilized to align the RADAR to the Southeast corner of a storage facility to the north of the sliding mass before acquiring data. Photographs obtained from the Northeast viewpoint at the validation site are presented in Figure 4.22 . 


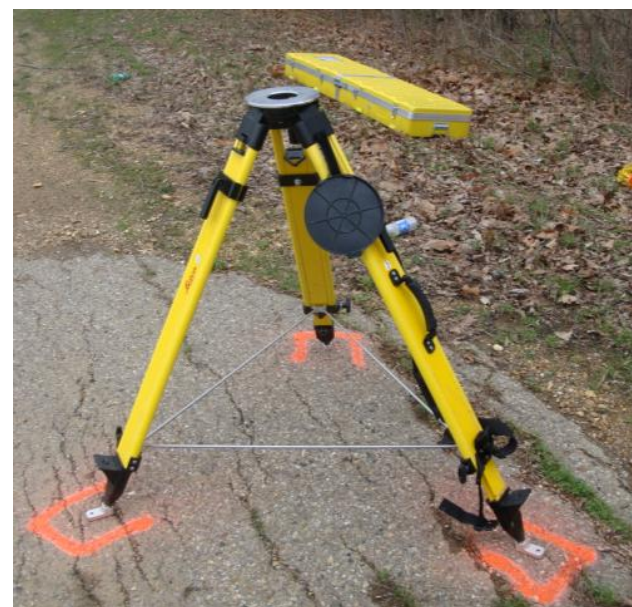

(a)

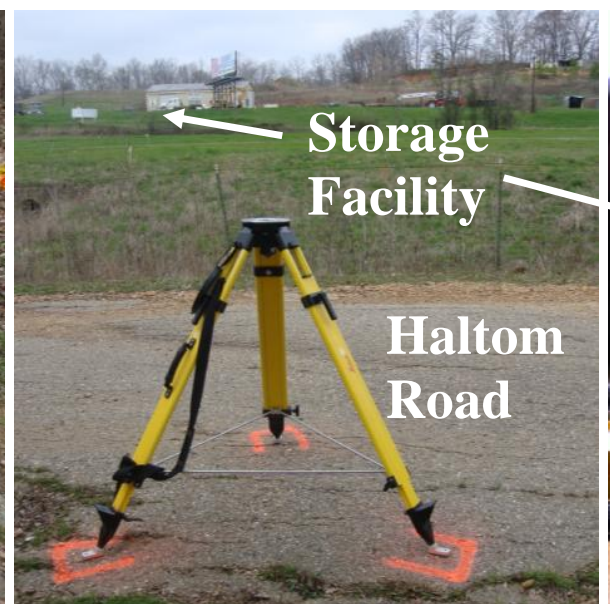

(b)

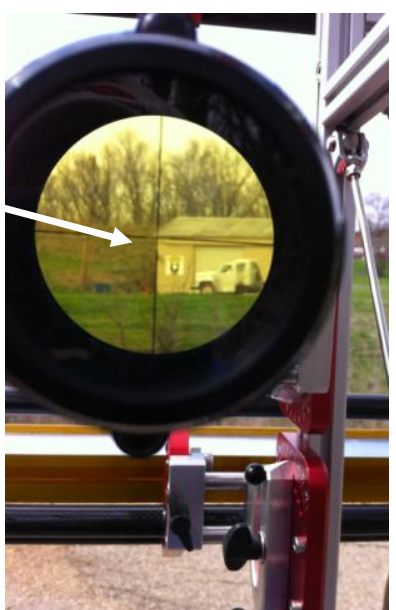

(c)

Figure 4.22. a) Tripod of the GPRI-II anchored to the asphalt pavement in northeast viewpoint, b) location of northeast viewpoint in validation site near Malvern, Arkansas, and c) scope aligned to corner of storage facility before image acquisition.

\subsection{Southeast Viewpoint at the Validation Site (Malvern, Arkansas)}

The GPRI-II was anchored to concrete footings (Figure 4.23), which were constructed following the procedures described previously in Section 4.4.1.1.1. Four concrete footings were constructed; three of the footings were used for the legs of the tripod one footing contained a surveying monument, over which the GPRI-II was centered. The Southwest viewpoint was located in the median between Highway 84 and the Westbound lane of I-30. The topographic elevation of the southwest viewpoint was higher than the majority of the validation site. A wire fence line was located immediately to the North of the Southwest viewpoint ad may have cause saturation within the image. Photographs of the deployment of the GPRI-II at the SW viewpoint at the validation site are presented in Figure 4.23. 


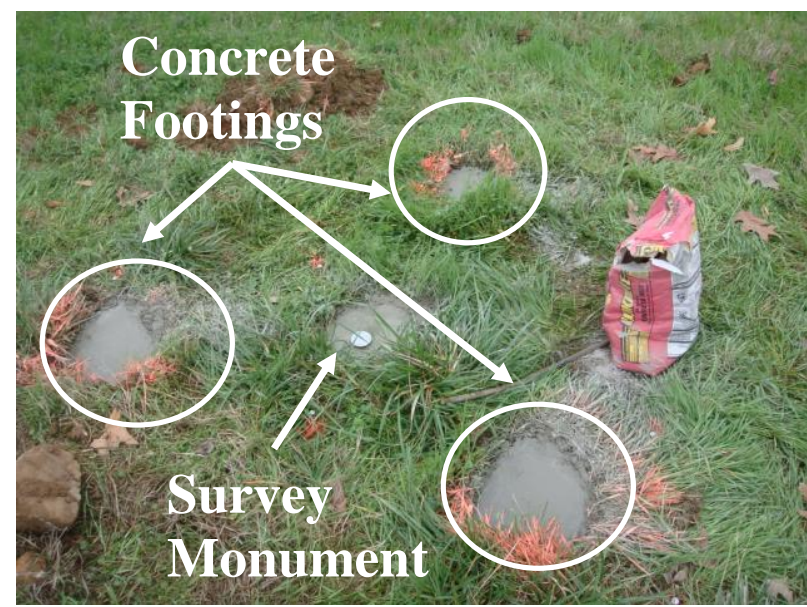

(a)

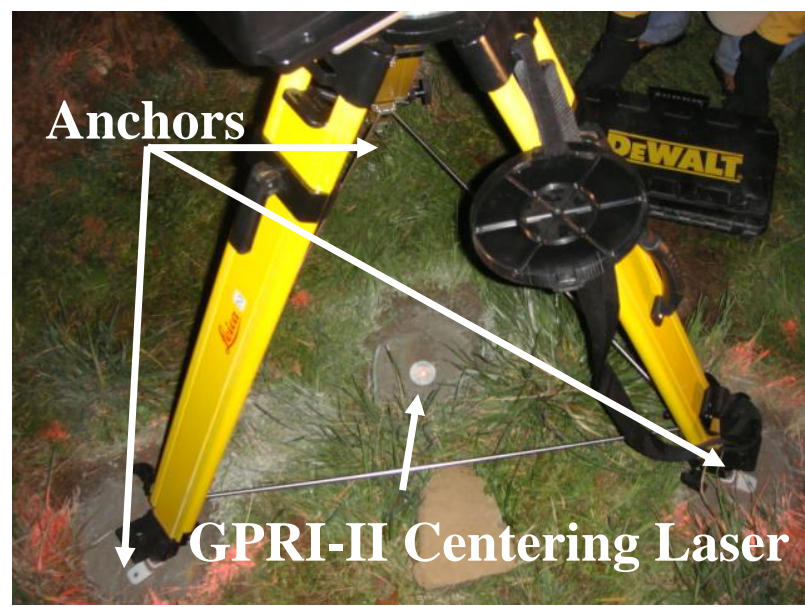

(b)

Figure 4.23. a) Concrete footings placed at the southwest viewpoint in validation site, and b) looking east from the southwest viewpoint.

\subsubsection{RADAR Image Collection}

RADAR images were collected using the GPRI-II by scanning the assumed extents of each sliding area. The start and end angles for each scan depended on the viewing geometry from each viewpoint at each site. A parameter file was developed for each site containing information about the GPRI-II instrument. The factors, within the parameter file, that varied from each viewpoint included: the starting angle, the ending angle, the antenna elevation angle, the chirp length, and the angular speed. A short description of each factor is provided below.

- Start angle: The initial absolute angle at the start of the scan, measured from the zero (or homerun) position of the RADAR at setup.

- End angle: The final absolute angle at the end of the scan, measured form the zero (or homerun) position of the RADAR at setup.

- Elevation angle: The vertical angle (as measured from the horizontal) of the GPRI-II antennas ranging from 0 to 45 degrees (up or down) in five degree increments.. 
- Chirp: Determines the characteristics of the pulse generated. The distance to the area of interests is the driving factor for this feature. Linear FM pulses (over the 900-1100 MHz frequency range) are generated by the chirp generator module (GAMMA Remote Sensing AG, 2011).

- Angular rotation speed: The velocity of the scan, while rotating from the start angle to the end angle. Higher velocity leads to less backscatter energy captured by the receiver antennas. Therefore, lower velocities were used at the overlook viewpoint due to the distance to the landslide.

All factors mentioned above influenced the images collected during all of the site visits. Unique parameter configurations permitted collections of the best possible images of the slide area at each site. The configurations used for each viewpoint are presented in the following Sections.

Important parameters were recorded before image acquisition during every site visit. The parameters include: weather conditions, time, GPS coordinate, Chirp Generator Assembly (CHUPA) status, and the Temperature, Stepper, Computer Controller board (TSCC) status. The CHUPA and TSCC status defined the temperature and voltages of the two hardware components. Monitoring and recording these parameters during every site visit, helped identify if a parameter was outside of the normal range of values before acquiring data. As previously explained in Section 2.3, the large microwaves wavelength generated by the GPRI-II allowed for data acquisition during a wide range of weather conditions (rain showers and fog). A picture of the GPRI-II acquiring data during rain showers and fog conditions is presented in Figure 4.24. Although all of the GPRI-II components are water proof, the laptop which serves as a terminal to control the field computer is not waterproof, thereby necessitating a cover. 


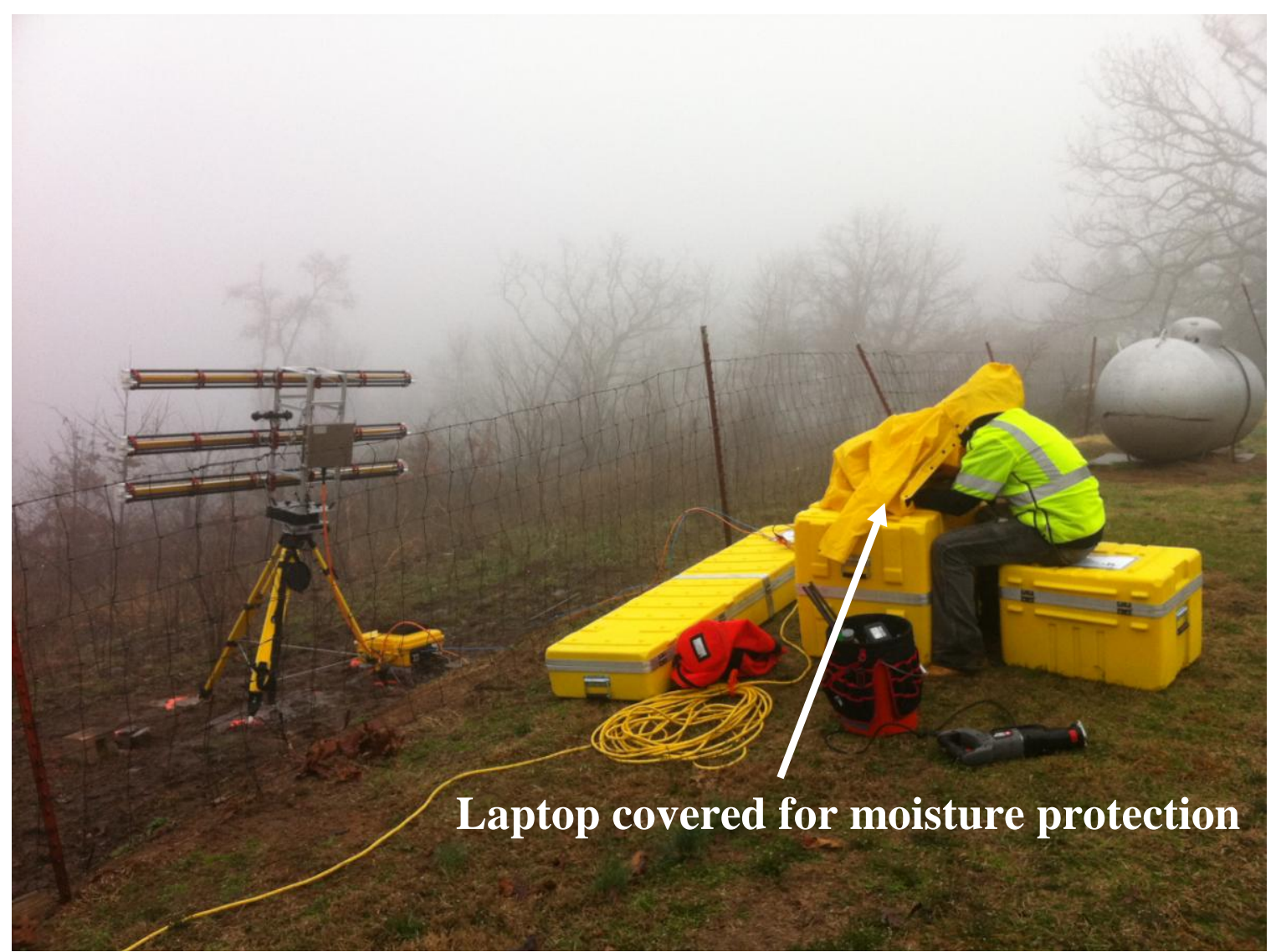

Figure 4.24. GPRI-II acquiring data during fog in overlook viewpoint (calibration site) near Chester, Arkansas.

\subsubsection{RADAR Data Acquisition at the Calibration Site (Chester, Arkansas)}

Data acquisition at the calibration site in Chester, Arkansas varied significantly from the two viewpoints. The distance and elevation differences of the two viewpoints to the moving mass forced changes to the important features in the image acquisition process such as velocity, chirp length, and antenna elevation. Numerous (typically $>6$ ) images were acquired with the GPIR-II during each site visit to allow for stacking to increase the coherence of the data. Caution was employed to acquire data during low traffic hours.

\subsection{Southbound Viewpoint at the Calibration Site (Chester, Arkansas)}

Due to the proximity to the I-540 Southbound lane, image acquisitions were performed during open windows within the traffic traveling in the Southbound lane. Images at this 
viewpoint were acquired using two different chirp lengths (500ms and $250 \mathrm{~ms})$. Two images were acquired with the 500 chirp and at least five images were acquired with the 250 chirp per visit to this viewpoint. During the first two visit, images were acquired using an Intermediate Frequency Amplifier/Mixer Assembly (IMA) attenuation of 26 (four [4] images total) and 28 (one [1] image total); an IMA attenuation value of 32 was utilized for all other images after the first two site visits. The values used during data acquisition at the Southbound viewpoint are summarized in Table 4.5. Photographs of the GPRI-II acquiring data are illustrated in Figure 4.25.

Table 4.5. Values utilized for data acquisition in southbound viewpoint near Chester, Arkansas.

\begin{tabular}{|l|l|}
\hline RF_center_freq: & $1.720000 \mathrm{e}+10$ \\
\hline IMA_atten_dB: & 32 \\
\hline CHP_freq_min: & $100.0 \mathrm{e} 6$ \\
\hline CHP_freq_max: & $300.0 \mathrm{e} 6$ \\
\hline CHP_num_samp: & 1564 \\
\hline TX_power: & on \\
\hline STP_antenna_start: & 120 \\
\hline STP_antenna_end: & 240 \\
\hline STP_gear_ratio: & 72 \\
\hline STP_rotation_speed: & 10.0 \\
\hline ADC_capture_time: & 1.0 \\
\hline ADC_sample_rate: & $6.25000 \mathrm{e}+06$ \\
\hline antenna_elevation: & 10 \\
\hline
\end{tabular}

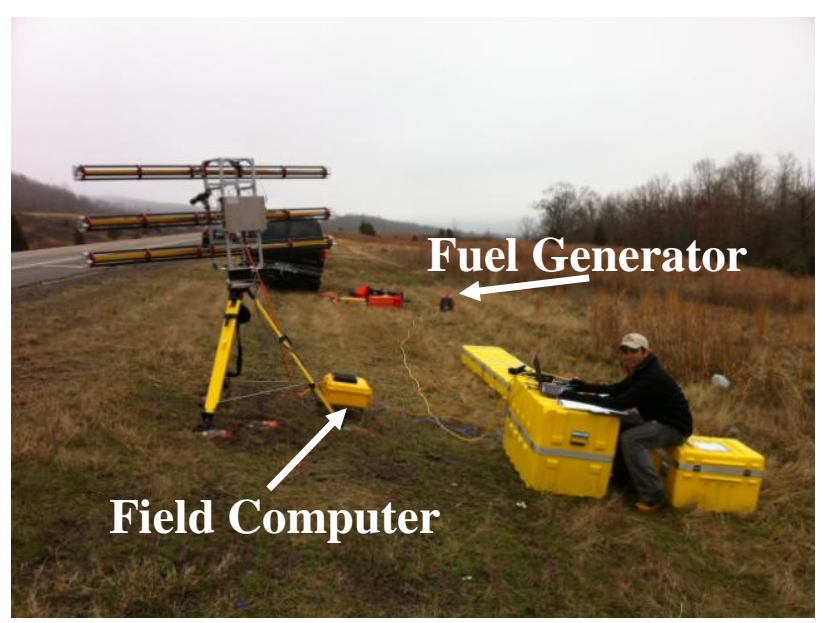

(a)

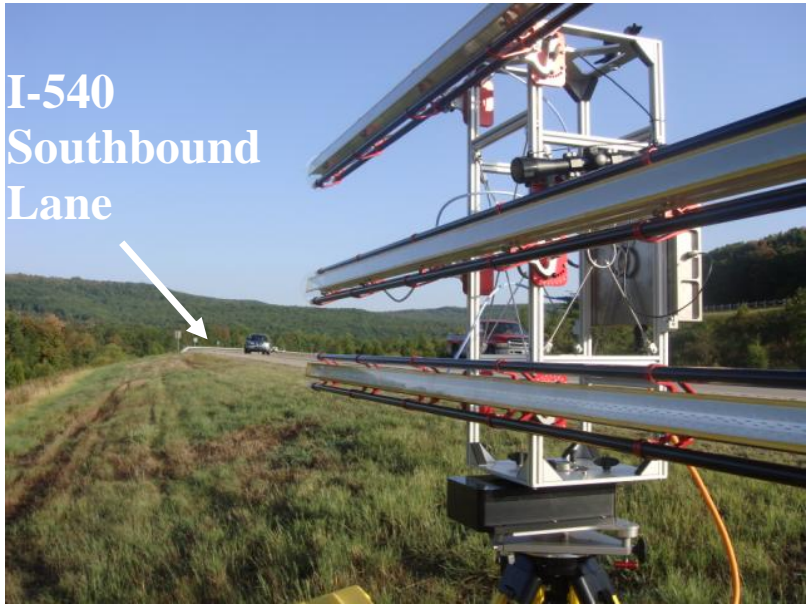

(b)

Figure 4.25. a) Photograph of GPRI-II acquiring images at the Southbound viewpoint, and b) waiting for a window in the traffic flow to acquire images at the Southbound viewpoint. 


\subsection{Overlook Viewpoint at the Calibration Site (Chester Arkansas)}

Traffic was not an issue while acquiring data from the outlook viewpoint because of the distance and elevation difference between the observation point and the sliding mass. A lower angular speed (5 degrees per second) was utilized at this viewpoint to obtain additional backscatter return to the sensor. At least seven images were acquired per site visit at this viewpoint (Figure 4.26) using the $2 \mathrm{~ms}$ chirp length. The values used during data acquisition at the Overlook viewpoint are summarized in Table 4.6. The viewing geometry of the GPRI-II from the overlook viewpoint is presented in Figure 4.26.

Table 4.6. Values utilized for data acquisition in overlook viewpoint near Chester, Arkansas.

\begin{tabular}{|l|l|}
\hline RF_center_freq: & $1.720000 \mathrm{e}+10$ \\
\hline IMA_atten_dB: & 28 \\
\hline CHP_freq_min: & $100.0 \mathrm{e} 6$ \\
\hline CHP_freq_max: & $300.0 \mathrm{e} 6$ \\
\hline CHP_num_samp: & 12500 \\
\hline TX_power: & on \\
\hline STP_antenna_start: & -70 \\
\hline STP_antenna_end: & 10 \\
\hline STP_gear_ratio: & 72 \\
\hline STP_rotation_speed: & 5.0 \\
\hline ADC_capture_time: & 1.0 \\
\hline ADC_sample_rate: & $6.25000 \mathrm{e}+06$ \\
\hline antenna_elevation: & -5 \\
\hline
\end{tabular}

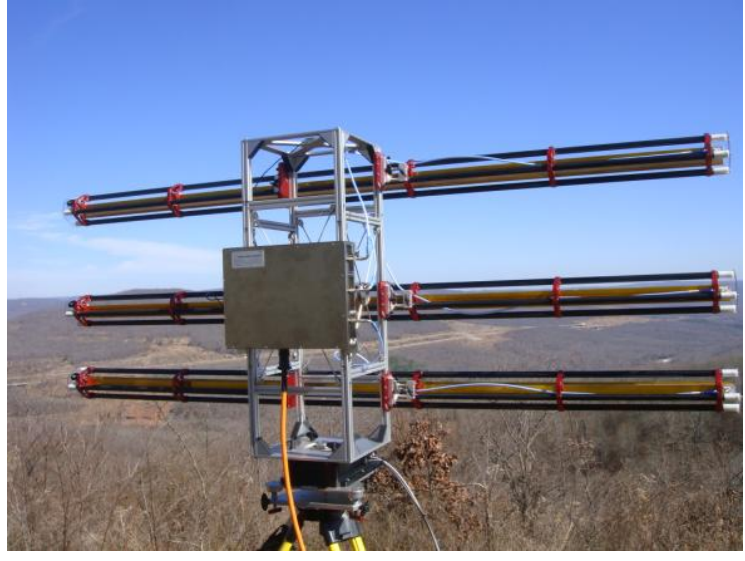

(a)

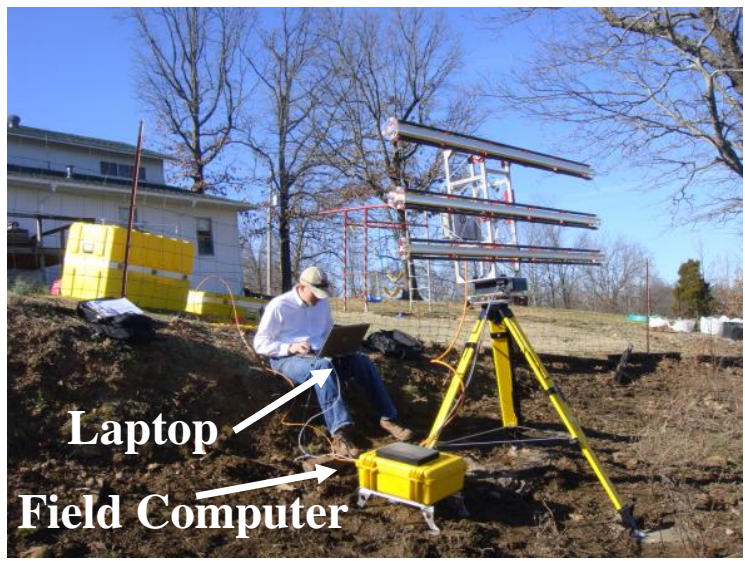

(b)

Figure 4.26. a) Viewing geometry of the GPRI-II at overlook viewpoint, and b) University researcher acquiring data with GPRI-II. 


\subsubsection{RADAR Data Acquisition at the Validation Site (Malvern, Arkansas)}

The different viewing geometries of the two viewpoints at the validation site dictated the values used for data acquisition. The line-of-sight for the northeast (NE) viewpoint was parallel line-of-sight to the direction of motion of the moving mass; the line-of-sight from the southwest (SW) viewpoint was perpendicular to the direction of motion of the landslide. Based on the proximity of the viewpoints to cars and wire fences, saturation of portions of the images was anticipated; however, these were the best possible viewing locations. Because the two viewpoints were located close to the lanes, data acquisition at the validation site took place during the late hours of the night or early hours of the morning to avoid traffic.

\subsection{Northeast Viewpoint at the Validation Site (Malvern, Arkansas)}

A minimum of nine images were acquired per visit to this viewpoint using a 250ms chirp length. The NE viewpoint location allowed for image acquisition at the center of the sliding mass, the images were acquired so that the line of sight was parallel to the direction of movement. A wire fence in front of the GPRI-II was expected to cause saturation of the images. The values used during image acquisition at the NE viewpoint are summarized in Table 4.7. Photographs of the GPRI-II acquiring images at the NE viewpoint are presented in Figure 4.27.

Table 4.7. Summarized values utilized in the NE viewpoint near Malvern, Arkansas

\begin{tabular}{|l|l|}
\hline RF_center_freq: & $1.720000 \mathrm{e}+10$ \\
\hline IMA_atten_dB: & 36 \\
\hline CHP_freq_min: & $100.0 \mathrm{e} 6$ \\
\hline CHP_freq_max: & $300.0 \mathrm{e} 6$ \\
\hline CHP_num_samp: & 12500 \\
\hline TX_power: & on \\
\hline STP_antenna_start: & -65 \\
\hline STP_antenna_end: & 85 \\
\hline STP_gear_ratio: & 72 \\
\hline STP_rotation_speed: & 5.0 \\
\hline ADC_capture_time: & 1.0 \\
\hline ADC_sample_rate: & $6.25000 \mathrm{e}+06$ \\
\hline antenna_elevation: & 0 \\
\hline
\end{tabular}




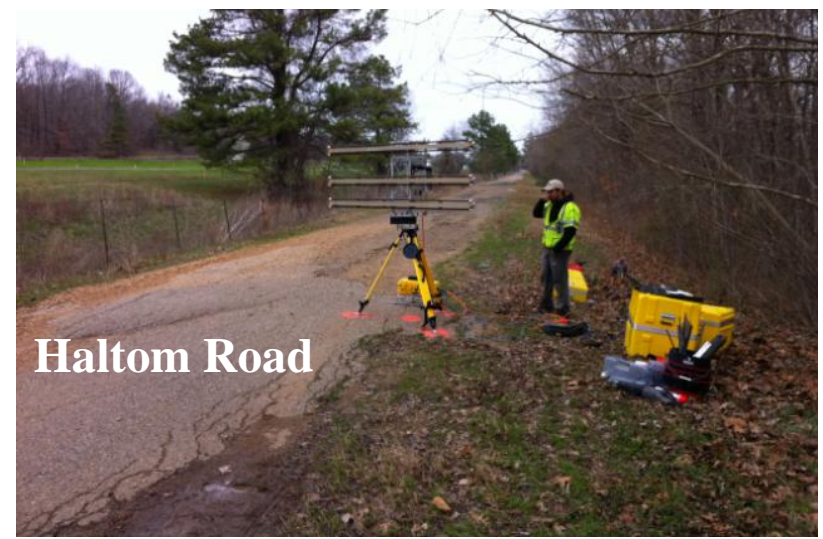

(a)

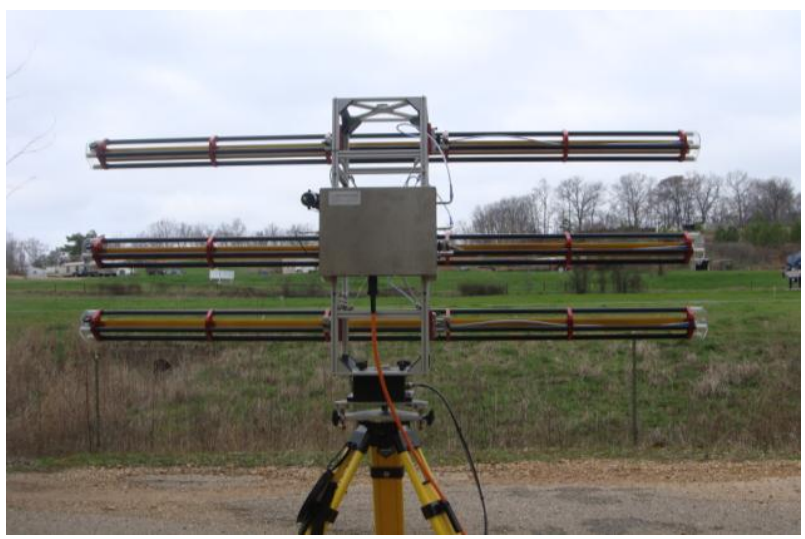

(b)

Figure 4.27. a) GPRI-II acquiring data at the NE viewpoint, and b) viewing geometry of the GPRI-II at the NE in validation site.

\subsection{Southwest Viewpoint at the Validation Site (Malvern, Arkansas)}

The location of the Southwest viewpoint permitted data collection from the Western boundary of the validation site. A minimum of nine images were acquired per visit to this viewpoint using a 500ms chirp length. A wire fence in to the north of the GPRI-II was expected to cause saturation of the left part of the images (towards the Highway 84). The values used during image acquisition at the NE viewpoint are summarized in Table 4.8. Figure of the GPRIII acquiring images at the NE viewpoint are presented in Figure 4.28.

Table 4.8. Summary of values utilized during GPRI-II data acquisition near SW viewpoint in Malvern, Arkansas.

\begin{tabular}{|l|l|}
\hline RF_center_freq: & $1.720000 \mathrm{e}+10$ \\
\hline IMA_atten_dB: & 32 \\
\hline CHP_freq_min: & $100.0 \mathrm{e} 6$ \\
\hline CHP_freq_max: & $300.0 \mathrm{e} 6$ \\
\hline CHP_num_samp: & 1564 \\
\hline TX_power: & on \\
\hline STP_antenna_start: & 120 \\
\hline STP_antenna_end: & 240 \\
\hline STP_gear_ratio: & 72 \\
\hline STP_rotation_speed: & 10.0 \\
\hline ADC_capture_time: & 1.0 \\
\hline ADC_sample_rate: & $6.25000 \mathrm{e}+06$ \\
\hline antenna_elevation: & -5.0 \\
\hline
\end{tabular}




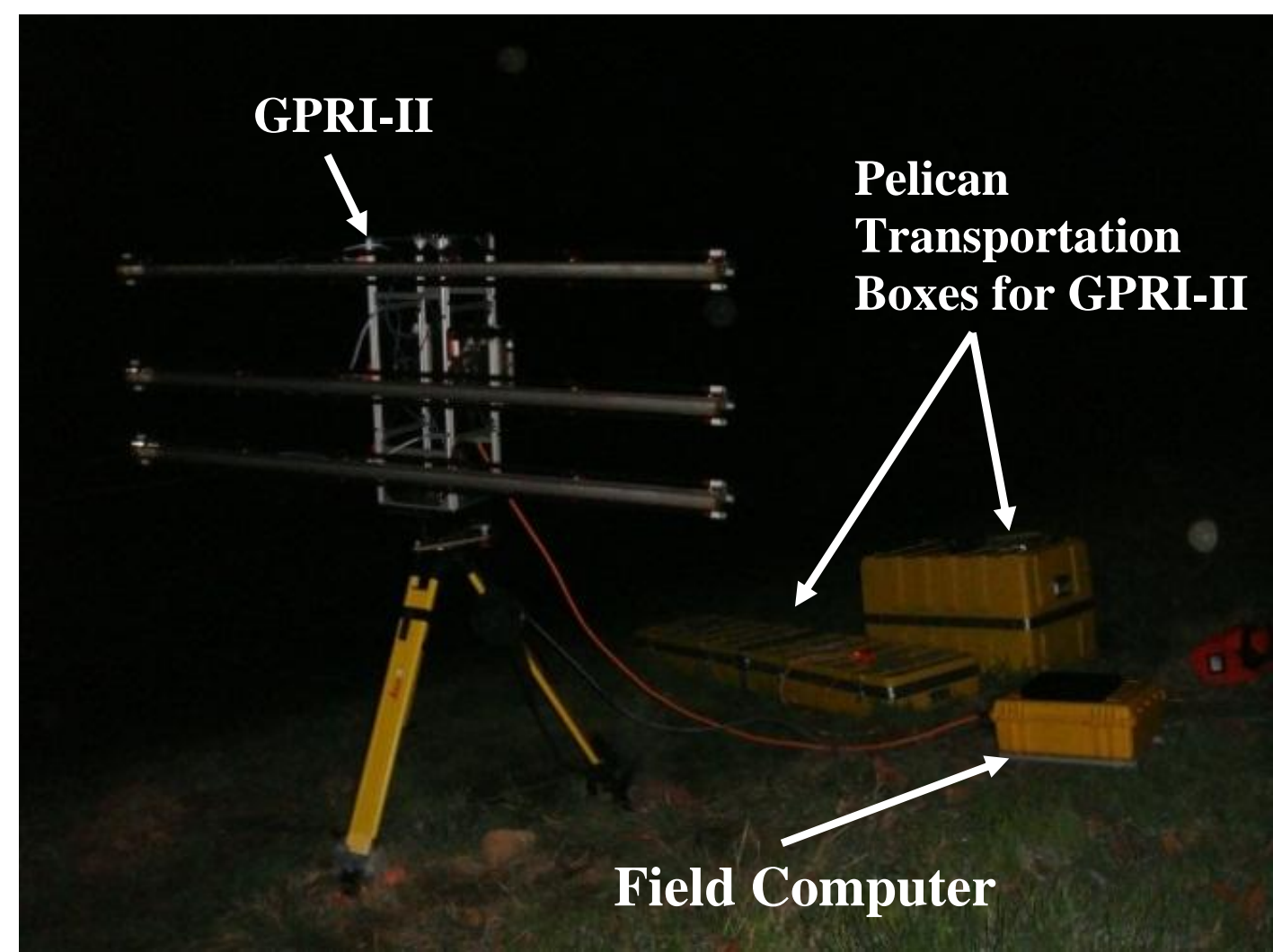

Figure 4.28. GPRI-II ready for data acquisition (at night) from the SW viewpoint near Malvern, Arkansas.

\subsubsection{Limitations of the RADAR}

Limitations of the GPRI-II were noticed during setup and data acquisition at the different sites. The topography at both sites prohibited better locations for image acquisition. Although, the locations selected on each of the sites were the ones that provided the best viewing geometry of the moving mass; a more perpendicular (to the direction of motion) line-of-sight would have aided image acquisition and data reduction (as discussed in Section 5.3).

Some of the concrete anchors failed with use and time, forcing the researchers to use sand bags to provide additional stability to the tripod. Waiting for traffic to clear the field of view caused time delays while completing acquisitions with the GPRI-II. Wire fences caused partial saturation of the image. 


\subsection{LIDAR Data Acquisition}

Monitoring of the landslides, located in the calibration and validation sites was conducted, by AHTD personnel once a month using a ground based LIDAR provided by the AHTD. As previously mentioned in Section 2.4, ground based LIDAR equipment has been used for landslide monitoring during the last decade because of the high accuracy and high portability. The LIDAR used in this research project was a Leica C-10. According to the (Leica, 2011), the maximum range of this instrument is $984 \mathrm{ft}$. (300 m.) at $90 \%$ albedo, with a resolution of $7 \mathrm{~mm}$ (Gaussian-based) and wavelength of $532 \mathrm{~nm}$. A 360 degree scans was performed at viewpoint at each location using the LIDAR. Targets were utilized to located control points, or benchmarks, to tie the scans to geographical coordinates.

The setup of the LIDAR consisted of aligning the scanner, centered over one of the control survey monuments within or along the extents of the moving mass. The heights of the LIDAR and targets were recorded during each site visit. Two occupation points were utilized at the calibration site; four occupation points were utilized at the validation site.

\subsubsection{LIDAR Setup Procedures}

LIDAR setup and data acquisition were performed by personnel from the AHTD. Targets were placed at the same location (above the same monuments) during every site visit to unify the different point clouds acquired and to aid in registering the data at each respective site. The setup and data collection procedures for each of the sites are presented in the following Sections.

\subsubsection{LIDAR Setup Procedures at the Calibration Site (Chester, Arkansas)}

Two LIDAR viewpoints were required at the validation site due to the size of the moving mass. The first LIDAR viewpoint was located in the median between Northbound and Southbound lanes of I-540, above a survey control monument (Point 2012). The second LIDAR viewpoint was located approximately 12 feet west from the southbound lane shoulder of I-540 
(same point used by GPRI-II). The two LIDAR viewpoints are illustrated in the photographs in Figure 4.29.

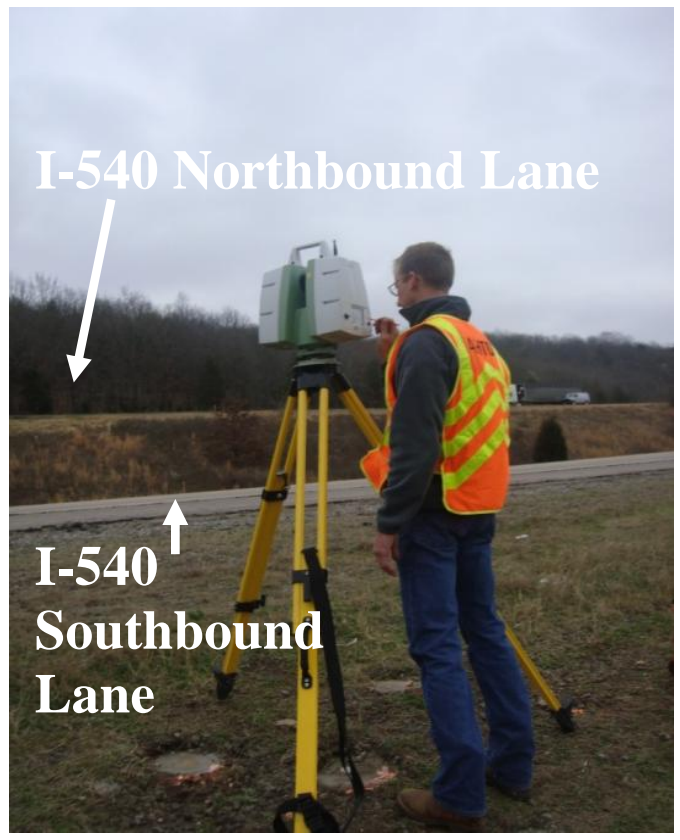

(a)

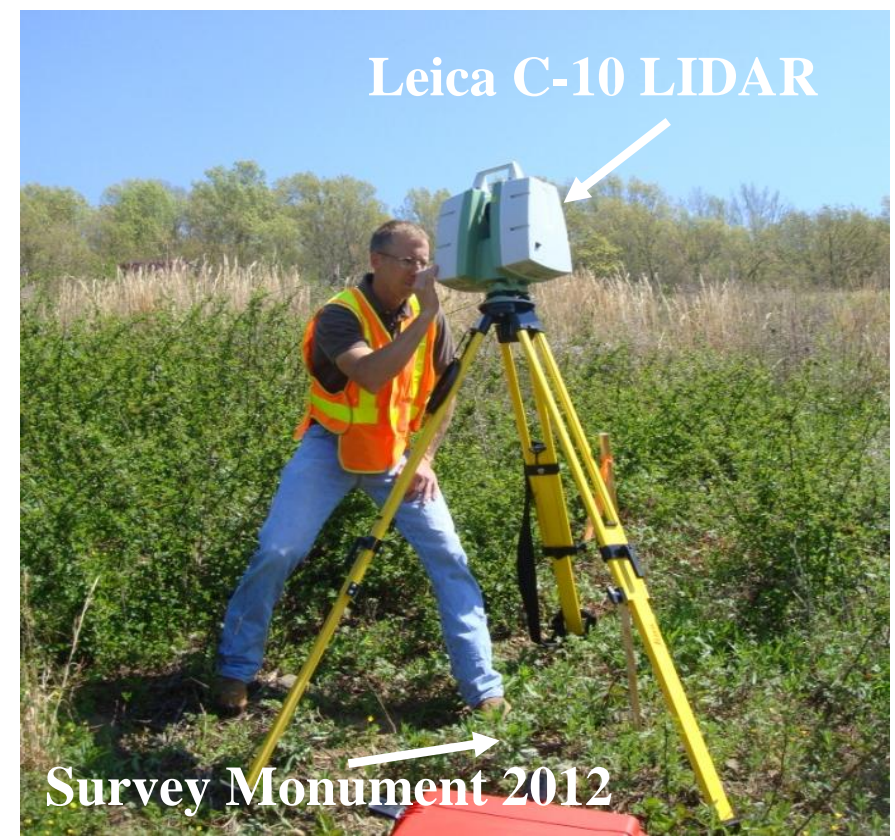

(b)

Figure 4.29. a) RADAR and LIDAR Southbound viewpoint, and b) LIDAR deployed at Point 2010.

\subsubsection{LIDAR Setup Procedures at the Validation Site (Malvern, Arkansas)}

At the Malvern site, two of four LIDAR occupation locations coincided with the RADAR acquisition locations (NE and SW viewpoints). Due to the range limitation of the LIDAR, three other locations were selected along the I-30 Westbound lane to capture the full extent of the sliding mass. Photographs of the LIDAR, deployed at the two coinciding RADAR viewpoints, are shown Figure 4.30. The LIDAR data was obtained by AHTD personnel using the same methodology applied in the validation site. At each observation point, 360 degree scans were collected. 


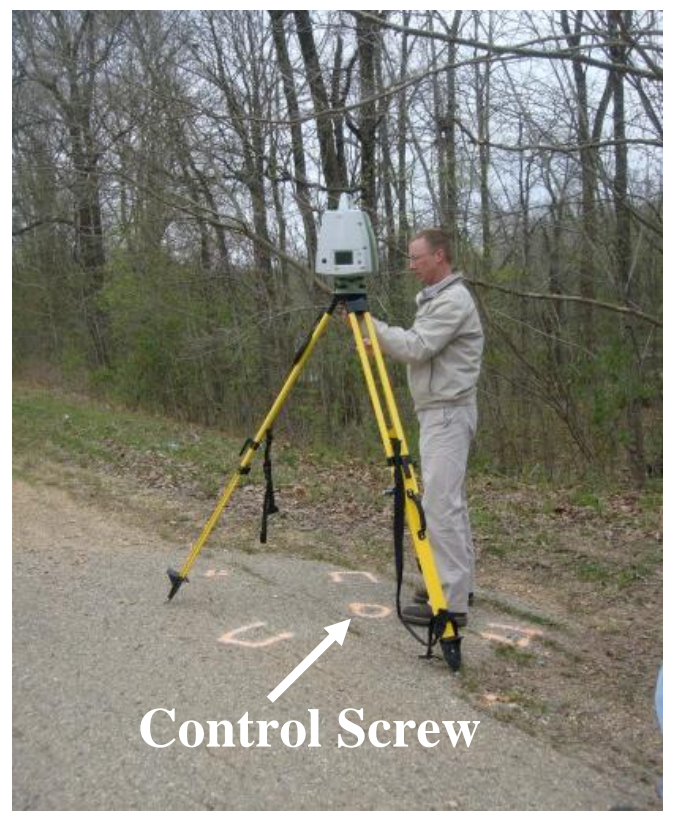

(a)

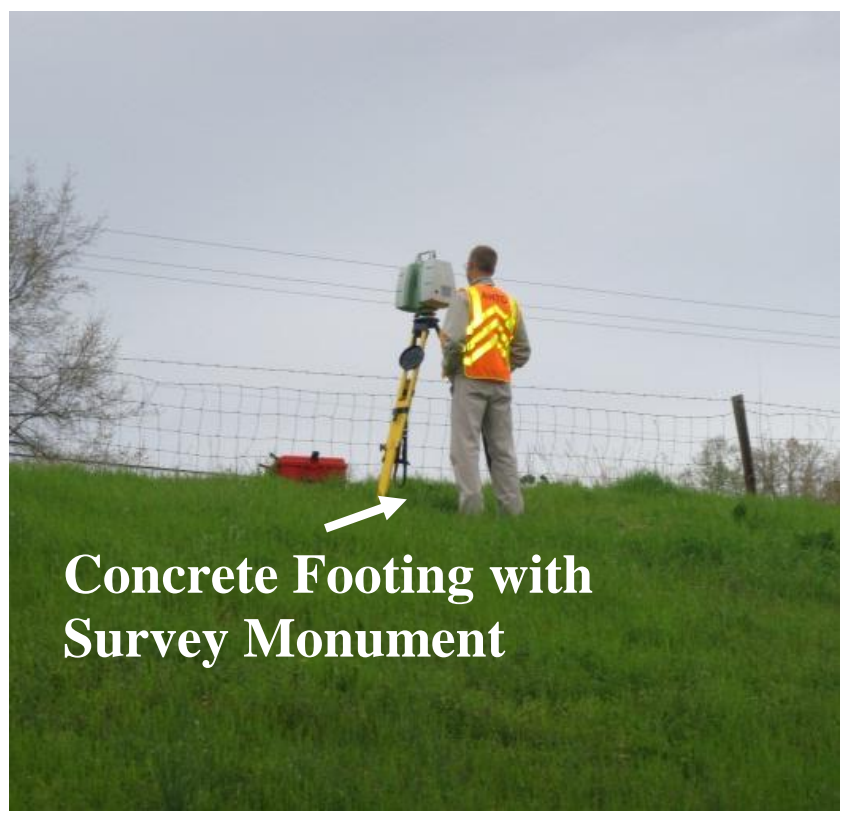

(b)

Figure 4.30. a) LIDAR being deployed at the NE viewpoint, and b) LIDAR acquiring data at the $S W$ viewpoint.

\subsubsection{LIDAR Point Cloud Acquisition}

Collecting LIDAR point clouds consisted of acquiring the coordinates and intensity $(\mathrm{x}, \mathrm{y}$, $\mathrm{z}$, i) of millions of points around each study area. As previously mentioned, LIDAR data acquisitions were performed monthly by the AHTD personnel. The LIDAR data acquisitions were performed during good weather conditions because laser light scanners are more susceptible to atmosphere and weather effects (water molecules), as discussed in Section 2.2. The duration of each individual 360 degree scan lasted approximately 25 minutes. Details of LIDAR point cloud acquisition at each site are presented in the following subsections.

\subsubsection{LIDAR Data Acquisition at Calibration Site (Chester, Arkansas)}

LIDAR scans were performed once a month, by AHTD personnel, at the calibration site near Chester, Arkansas (Table 4.9). Three targets were deployed with the LIDAR instrument. The targets were used to locate control points within the point cloud, to tie the scans together, and to tie the scans to geographical coordinates (Figure 4.31). 
Table 4.9. Observations schedule for LIDAR data acquisition at the calibration site near Chester, Arkansas.

\begin{tabular}{|c|c|}
\hline \multicolumn{2}{|c|}{ LIDAR Site Visits } \\
\hline Date & Comment \\
\hline $03 / 17 / 11$ & Leica C-10 \\
\hline $4 / 132011$ & Leica C-10 \\
\hline $5 / 172011$ & Leica C-10 \\
\hline $06 / 08 / 11$ & Leica C-10 \\
\hline $07 / 13 / 11$ & Leica C-10 \\
\hline $08 / 11 / 11$ & Leica C-10 \\
\hline $10 / 06 / 11$ & Leica C-10 \\
\hline $01 / 09 / 12$ & Leica C-10 \\
\hline
\end{tabular}

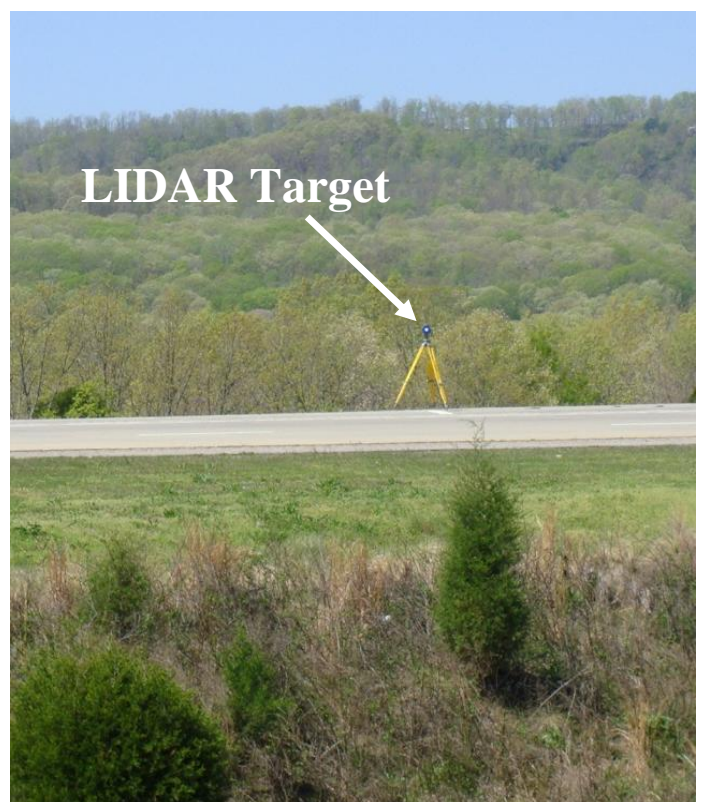

Figure 4.31. LIDAR target positioned at the Southbound Total Station viewpoint at the calibration site near Chester, Arkansas.

\subsubsection{LIDAR Data Acquisition at Validation Site (Malvern, Arkansas)}

LIDAR scans were also completed at the validation site once per month by AHTD personnel. The observation dates are summarized in Table 4.10. Data acquisitions were performed during the day, therefore interference from some traffic was expected to be in the point clouds, and was observed in the point clouds but was removed the methods discussed in 
Section 5.4.2. As with the calibration site, targets were also positioned on known survey monuments along the site to link each scan to state coordinates during the data reduction process.

Table 4.10. Observation schedule for LIDAR data acquisition at validation site near Malvern, Arkansas.

\begin{tabular}{|c|c|}
\hline \multicolumn{2}{|c|}{ LIDAR Site Visits } \\
\hline Date & Comment \\
\hline $05 / 03 / 11$ & Leica C-10 \\
\hline $05 / 27 / 11$ & Leica C-10 \\
\hline $06 / 27 / 11$ & Leica C-10 \\
\hline $08 / 01 / 11$ & Leica C-10 \\
\hline $10 / 26 / 11$ & Leica C-10 \\
\hline $12 / 02 / 11$ & Leica C-10 \\
\hline $12 / 29 / 11$ & Leica C-10 \\
\hline
\end{tabular}

\subsubsection{Limitations of LIDAR}

Although terrestrial LIDAR served as a great tool for rapid monitoring of the landslides during this research project (AHTD TRC-1102), some limitations were encountered while using this scanner. Specifically, a clear line-of-sight to the object of is needed to obtain data. Shadows caused by trees and structures (cars, signs, etc.) prevented data acquisition in certain locations. Seasonal effects also caused problems with vegetation (growth and cutting/mowing), moisture and ponded water. The LIDAR could not be used during poor weather conditions due to the short wavelength used by the scanner, and no data was collected from the ditches in which water was ponded.

\subsection{Geotechnical Investigation}

A geotechnical investigation was performed at this site during July 17 to July 21, 2011. The geotechnical investigation lasted 8 days; the work was performed Monday through Thursday during those two weeks. The subsurface investigation was performed by AHTD personnel with AHTD equipment, under the supervision of personnel from the University of Arkansas. The original investigation plan consisted of 6 boreholes all of them to 100 feet of depth and two CPT 
tests (conducted by personnel from the Missouri Department of Transportation [MODOT] with MODOT equipment).

\subsubsection{Drilling Method}

The drilling methods employed for this site were planned based on the site reconnaissance and anticipated subsurface conditions. The final drilling method depended on equipment availability and Arkansas Highway and Transportation Department (AHTD) scheduling. The rotary wash drilling method was utilized for the geotechnical investigation associated with this project (AHTD TRC-1102). The sides of the borehole were supported with drilling fluid/mud during drilling operations. The AHTD drilling truck and practices used to drill all of the borings are displayed in the photographs in Figure 4.32.

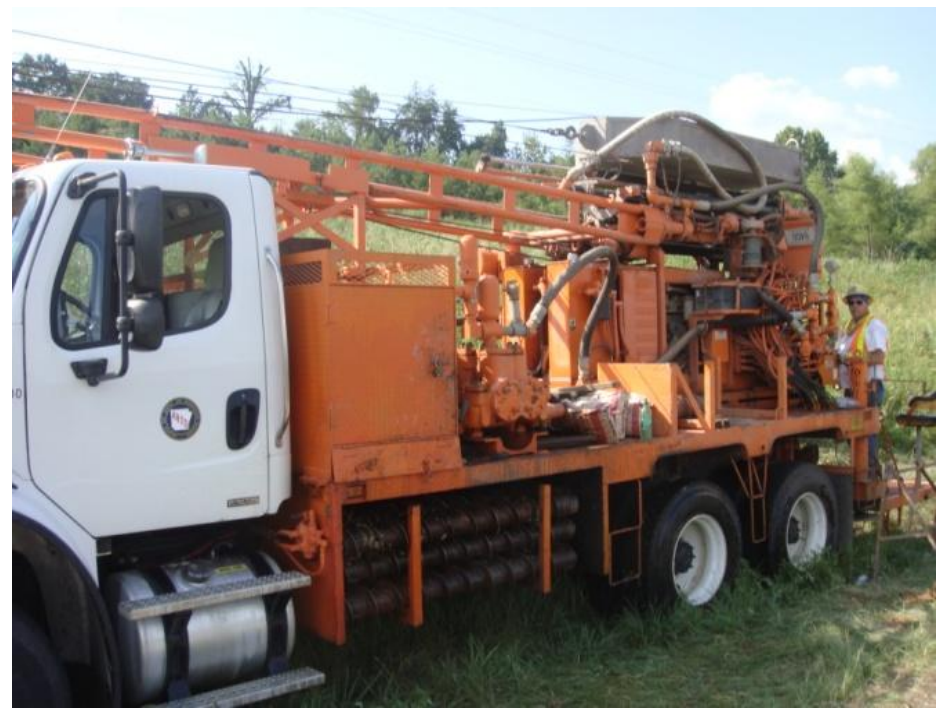

(a)

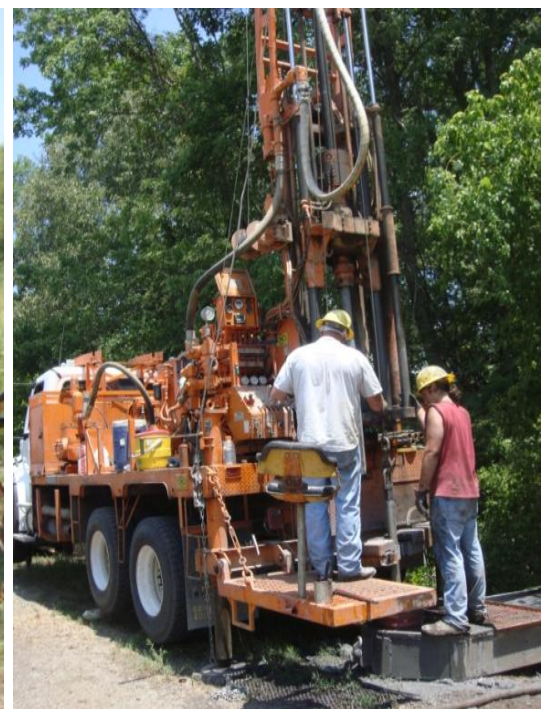

(b)

Figure 4.32. (a) AHTD drill truck used for geotechnical exploration, (b) view of AHTD rotary wash method used for sample collection near Malvern, Arkansas.

\subsubsection{Sampling Method}

Alternating Shelby Tube (ST) and Standard Penetration Test (SPT) samples were collected on alternating 5 foot intervals to a depth of 65 feet. Continuous ST sampling was conducted from a depth of 65 feet to a depth of 75 feet below the ground surface. This sampling 
program was intended to allow for sampling of the material at the sliding interface (as identified previously from inclinometers data collected at the site, and described previously in Section 3.2.3). After 75 feet the sampling procedure consisted of alternating ST and SPT every 5 feet. When a Shelby tube cannot be pushed or became bent, an SPT test was conducted; upon refusal of the SPT rock coring was conducted until the final depth of the borehole.

Due to time constraints and safety concerns, Borehole B-5 (Figure 4.33) located in the median of I-30 was canceled, and was not drilled. Therefore only 5 boreholes were successfully sampled and drilled to depths of 100 feet. Four inclinometers and one nested piezometer were installed in the five boreholes several months after drilling and sampling were completed (as discussed in Section 4.6.3). This borehole layout configuration allowed the creation of two different cross-sections for analysis. A summary of the number of samples obtained after geotechnical investigation is presented in Table 4.11.

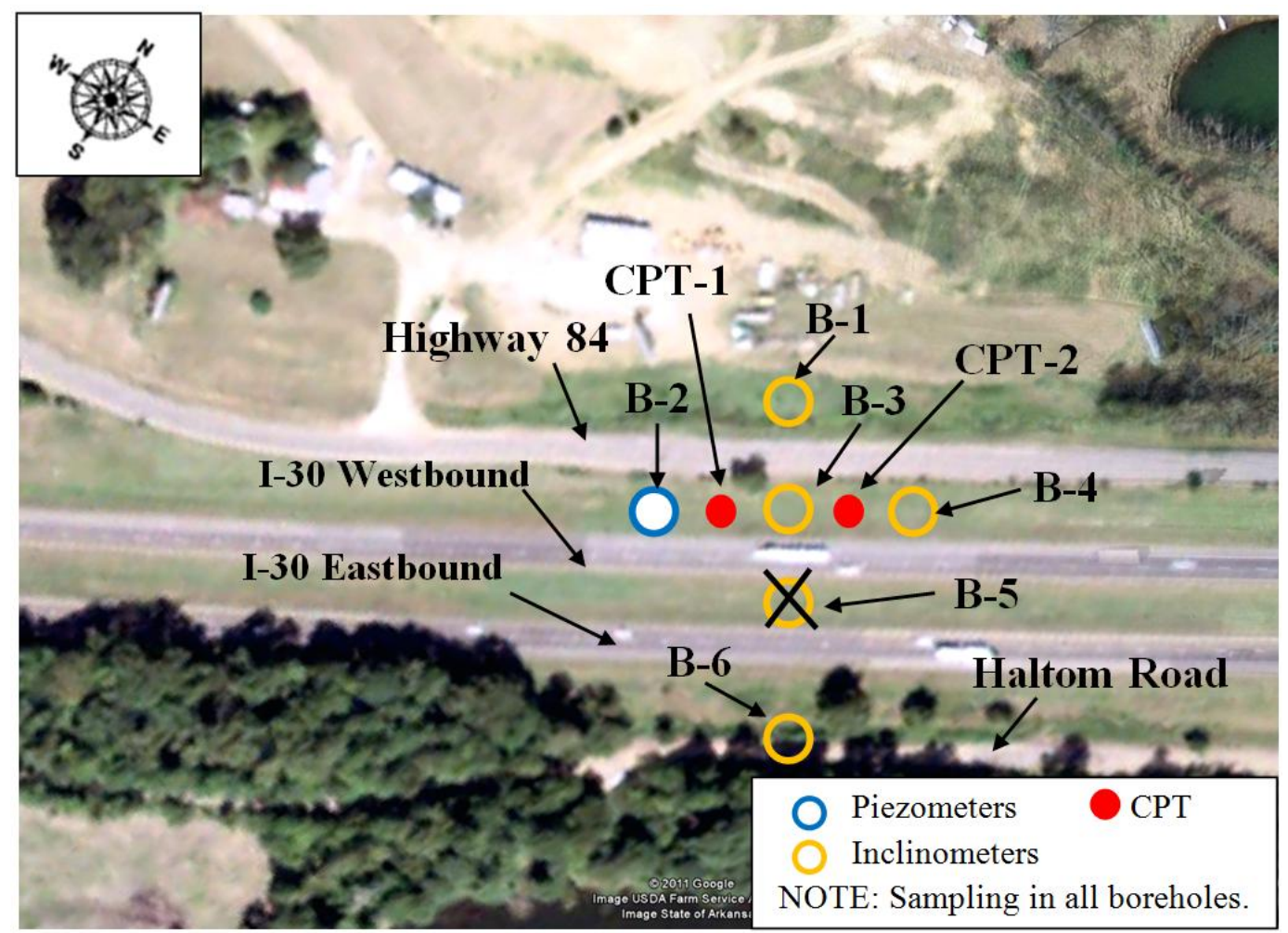

Figure 4.33. Geotechnical investigation borehole locations at the validation site (modified from Google Maps, 2011). 
Table 4.11. Summary of samples from geotechnical exploration.

\begin{tabular}{|c|c|c|c|}
\hline Sample Type & ST & SPT & Core \\
\hline B-1 & 9 & 7 & 3 \\
\hline B-2 & 10 & 7 & 4 \\
\hline B-3 & 8 & 9 & 3 \\
\hline B-4 & 7 & 13 & 0 \\
\hline B-6 & 7 & 7 & 5 \\
\hline TOTAL & $\mathbf{4 1}$ & $\mathbf{4 3}$ & $\mathbf{1 5}$ \\
\hline
\end{tabular}

Samples recovered during the geotechnical exploration were handled, transported, and tested by personnel from the UofA. After the amount of soil recovery was measured for each tube pocket penetrometer, torvane, and strength index tests were performed in the field to the soil in the bottom end of every ST after it was pulled from the borehole and removed from the sampling line. Index properties (as obtained from the penetrometer and torvane) were used to size the load frames used for triaxial testing of the clay samples recovered (Figure 4.34). After these tests were conducted on the end of each tube, the moisture content was acquired for the soil that was removed from the bottom two inches of the soil sample at end of the tube. The twoinches of air space created at the bottom of the tube allowed for sufficient space for the bottom gasket. A gasket was also placed in the top of the tube, hot wax was poured on top of both gaskets (top and bottom), and a plastic cap was attached to both ends in order to preserve the moisture inside the tube.

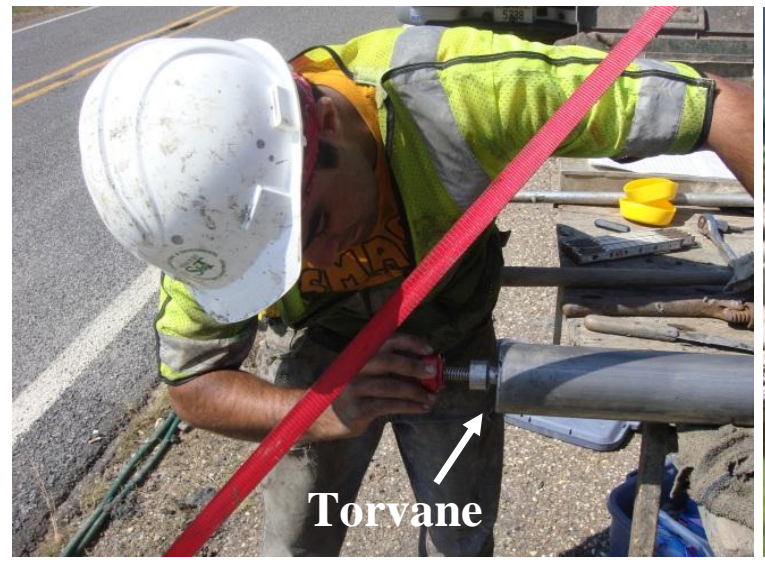

(a)

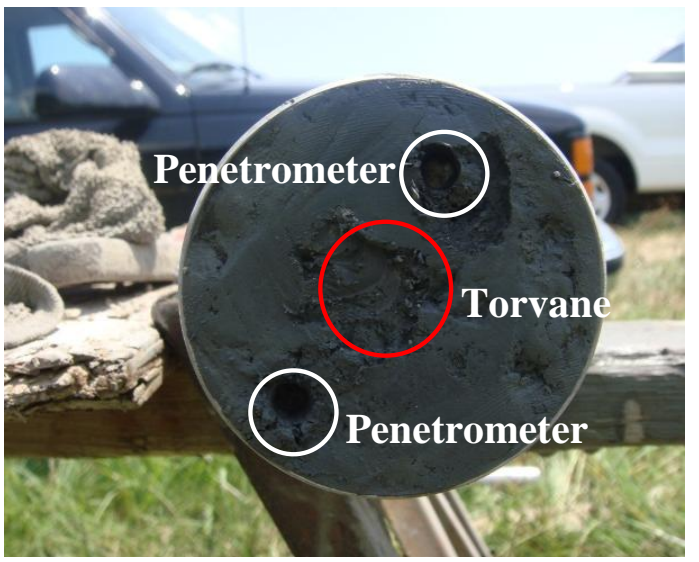

(b)

Figure 4.34. a) Torvane test being performed on a tube, b) index test locations. 
Shelby tubes and bag samples (obtained from the SPT tests) were transported back to the soils lab at the UofA using a wooden box designed to prevent disturbance to the samples during transport (ASTM D4220, 2007). Unconsolidated undrained (UU) tests (ASTM D2850, 2007) were performed on undisturbed samples (ST tubes). Index testing (atterberg limits, moisture content, unit weight) was also conducted on the UU samples. Soil from the bag samples (disturbed samples obtained from the SPT tests) were used to classify the soil.

Rock coring was necessary in all of the boreholes except for Borehole B4. Rock quality designation (RQD) was measured in the field for all of the rock core runs. The rock samples were placed on core boxes and transported to the laboratory for strength testing (Figure 4.35).

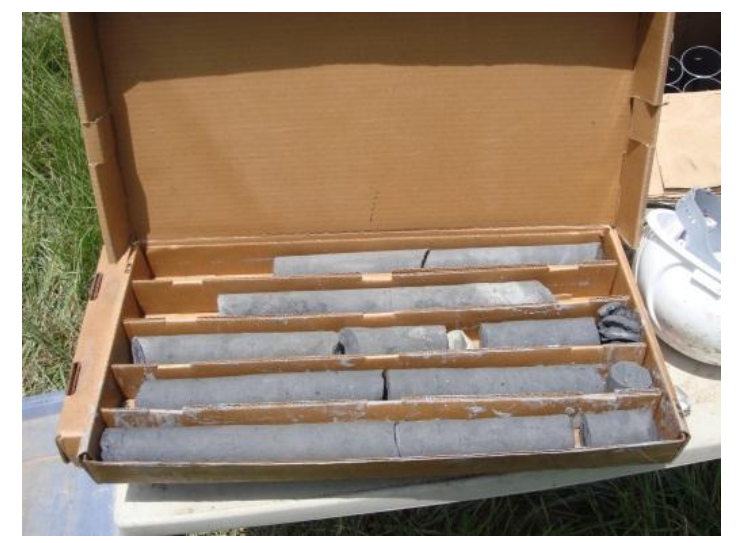

Figure 4.35. Core rock sample box from sampling operations at validation site in Malvern, Arkansas.

\subsubsection{In-situ Equipment}

Four inclinometers and one vibrating wire piezometer were installed at the validation site in Malvern, Arkansas. The in-situ instrumentation was installed during the first two weeks of October, 2011. The inclinometers and vibrating wire piezometer were installed by AHTD personnel under the direct supervision of UofA personnel. The details of the installation and monitoring of the in-situ instrumentation are provided in the following subsections. 


\subsubsection{Installation of In-situ Equipment}

Two months after the geotechnical exploration was conducted, the site was instrumented with four inclinometers (B-1, B-3, B4, B-6) and one vibrating piezometer (B-2). The boreholes were reopened by reaming the holes to a depth of 102 feet (to allow for the grouting connection located at depth at the end of the casing). No samples were obtained during this instrumentation and monitoring phase of the filed work. Ten-foot sections of 3.34-inch diameter Slope Indicator inclinometer casing were joined together and installed in the ground. A grout cement mix (consisting of one 94 pound bag of Portland cement, a 50 pound bag of bentonite, and 70 gallons of water) was used to secure the inclinometers in the borehole. The ground cement mix was pumped to the bottom of the inclinometer casing (and delivered to and through the one-way check valve) using a 1.5-inch diameter tremie (consisting of eleven 1.5-inch diameter Schedule 40 PVC pipes coupled together with a screw on connection at the bottom that was attached to the check valve). A summary of the inclinometer installation details is presented in Table 4.12, and the installation process for the inclinometers is illustrated in the photographs in Figure 4.36.

Table 4.12. Summary of inclinometer installation details.

\begin{tabular}{|l|c|c|c|c|}
\hline \multicolumn{1}{|c|}{ Borehole } & B1 & B3 & B4 & B6 \\
\hline Hole Depth (ft.) & 100 & 100 & 102 & 100 \\
\hline Casing Length (ft.) & 100 & 100 & 105 & 85 \\
\hline Casing Stick out (ft.) & 1.25 & 2 & 4.5 & 1.12 \\
\hline Comments: & None & $\begin{array}{c}\text { Steel pipe } \\
\text { connected to the } \\
\text { one way valve } \\
\text { (inside of the } \\
\text { casing was } \\
\text { removed). }\end{array}$ & None & $\begin{array}{c}\text { Refusal reached when } \\
\text { pushing down casing at } \\
\text { approximately 80 feet, } \\
\text { even though the hole was } \\
\text { 100 feet deep. }\end{array}$ \\
\hline
\end{tabular}




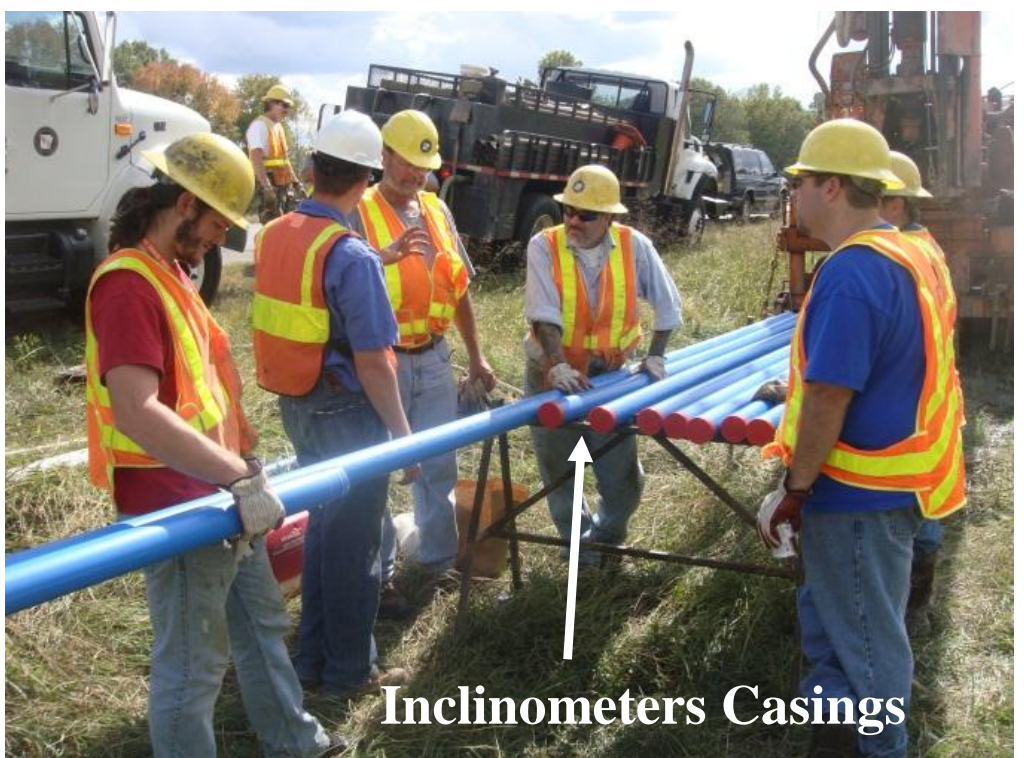

(a)

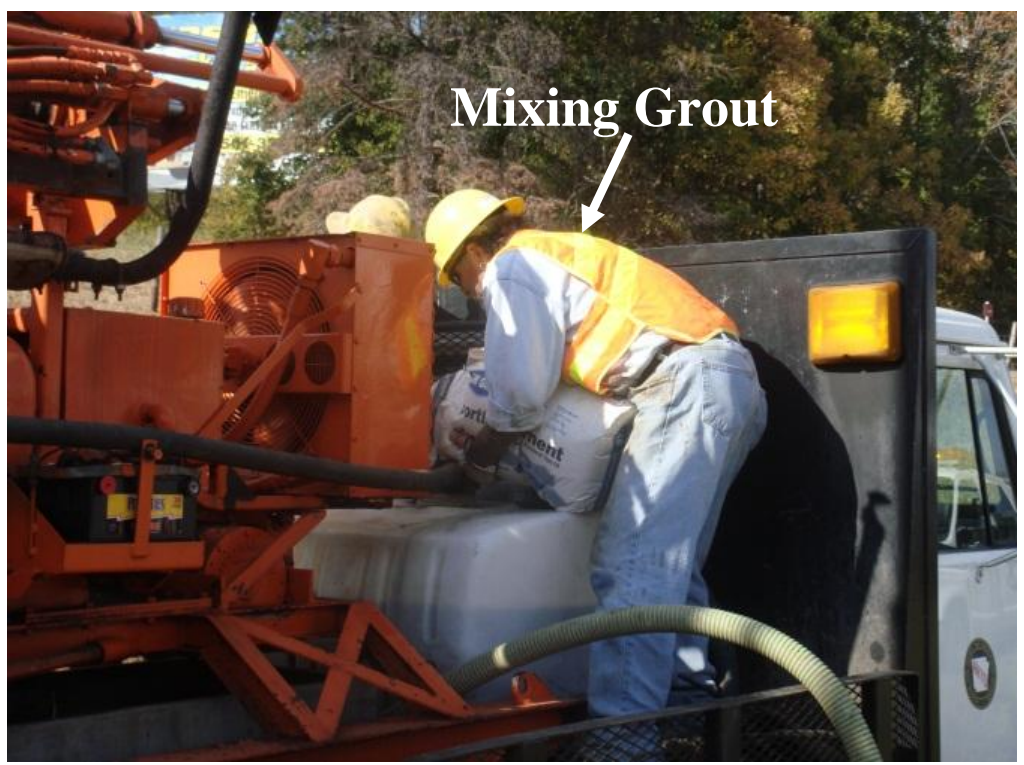

(c)

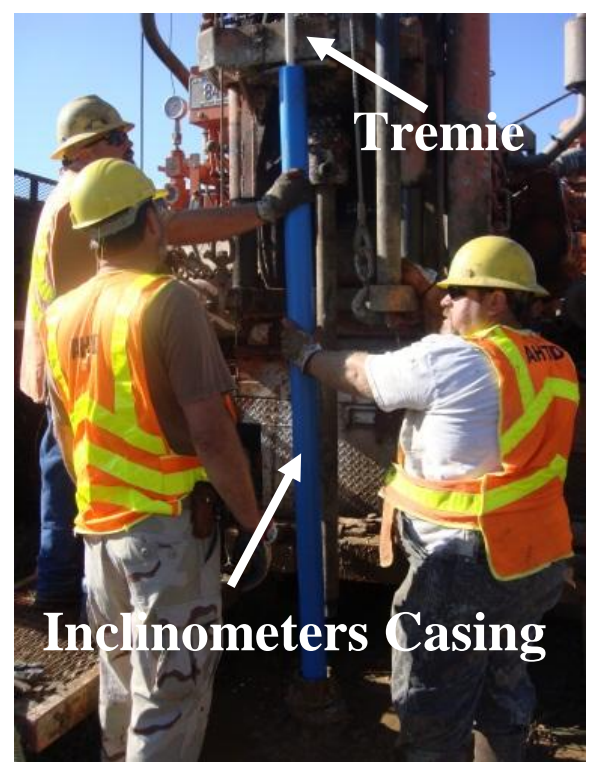

(b)

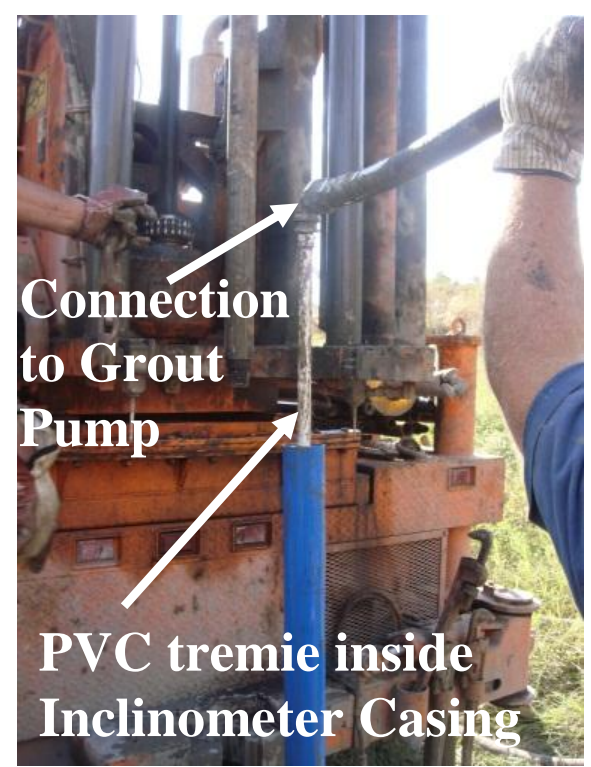

(d)

Figure 4.36. a) Sections of inclinometer casing, b) installation of inclinometer casing, c) preparing grout mix, and d) grout connection between tremie and grout pump.

A nested vibrating piezometer was installed in borehole B-2 to determine the pore water pressure fluctuation with time. The nested piezometer consists of 5 vibrating wire sensors at different depths. The transducers were placed at the following depths: 16, 37, 58, 79, and 100 feet. Implementation of the vibrating piezometer is illustrated in Figure 4.37. Pictures of the installed vibrating wire piezometer and inclinometer in the ground are shown in Figure 4.38. 


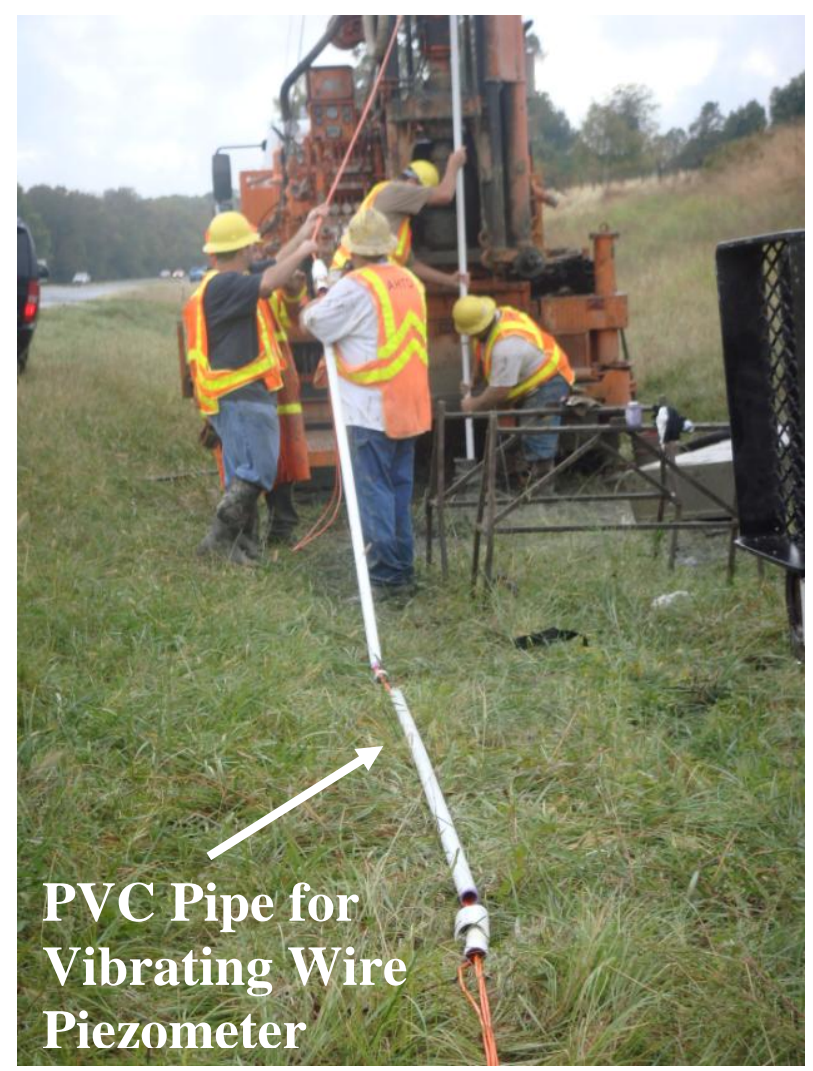

(a)

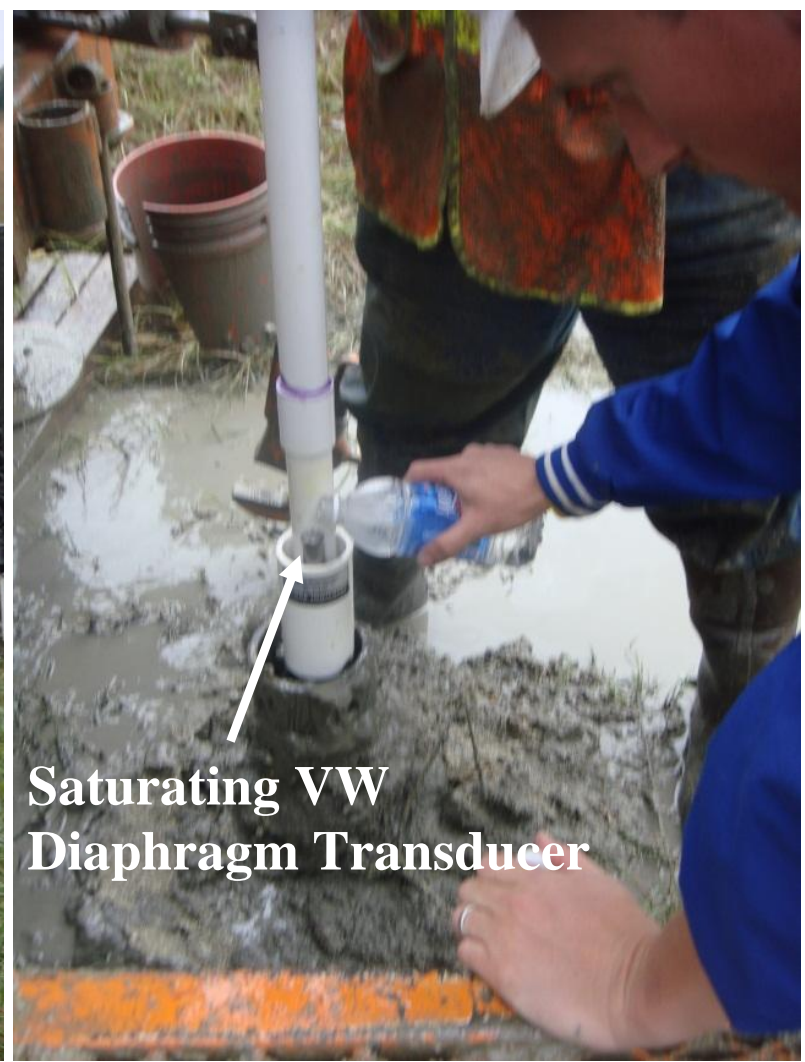

(b)

Figure 4.37. a) AHTD personnel installing nested vibrating wire piezometer in borehole B2 , and b) saturating transducers prior to placement in the hole.

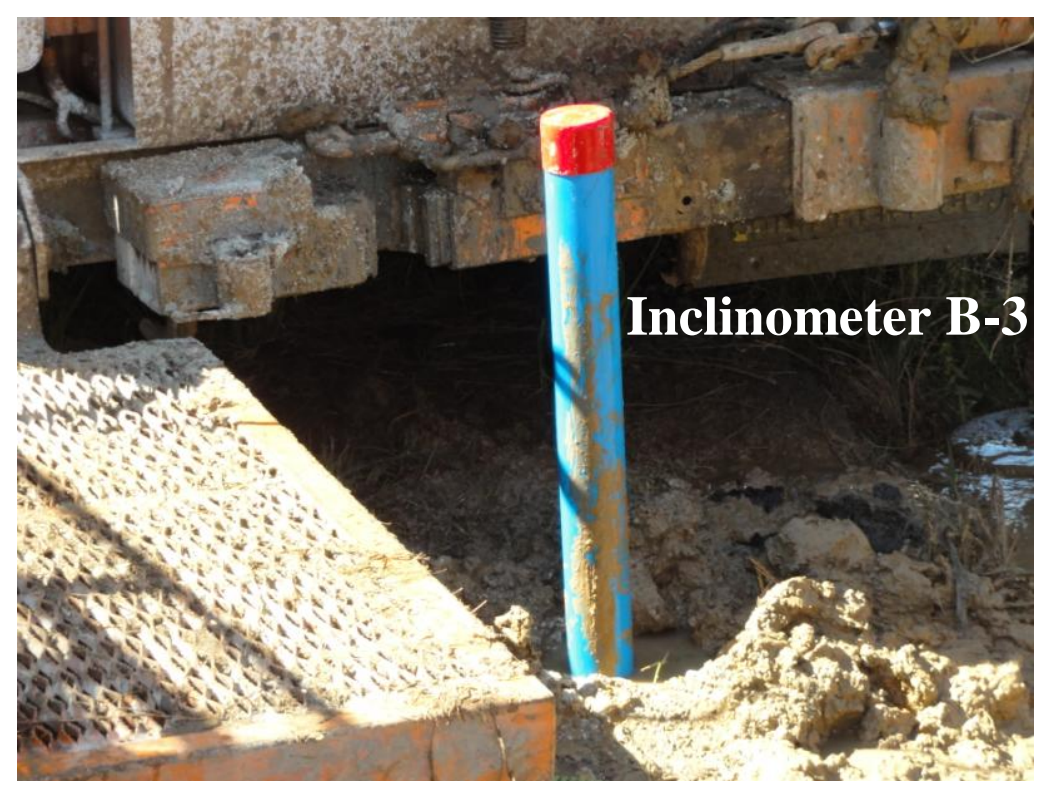

(a)

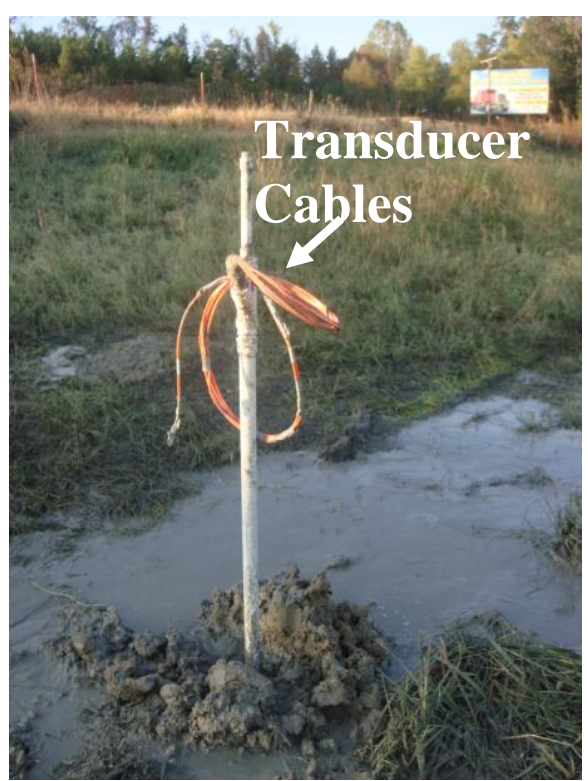

(b)

Figure 4.38. a) Post-installation view of Inclinometer B-3, and b) nested vibrating wire piezometer installed in B-2. 


\subsubsection{Monitoring of In-situ Equipment}

Data was collected once per month using the in-situ equipment and slope inclinometer and vibrating wire piezometer tools and readout boxes. The readings were obtained in conjunction with the total station surveys and RADAR surveys at the validation site near Malvern, Arkansas. The inclinometers were monitor by lowering a probe to the bottom of the inclinometer casing (Figure 4.39). The probe was inserted to the bottom of the hole and then the probe was removed, stopping every two feet to obtain a reading using the readout box that was connected to the probe. This procedure was repeated twice, once to obtain the $\mathrm{A}_{0}$ measurements (the receiver was placed in the casing such that the upper most wheel was facing North) and again to obtain the $A_{180}$ measurements (the receiver was placed in the casing such that the upper most wheel was facing South). During both acquisition trips up the hole, the probe measured the casing profile in two directions (North-South and West-East). The inclinometer profiles obtained during each site visit were compared to the first profile (obtained on October 13, 2011) to determine the cumulative deformation. All data was collected and stored in a Slope Inclinometer data collector box. The methods used to reduce the data collected using the Slope Inclinometer are presented in Section 5.5.1.

The nested vibrating wire piezometer was also monitored to obtain the pore water pressure at five different depths. Pore water pressure was considered as a major contributor to the slide (Westerman, 2006), therefore monitoring of the pore water pressure was investigated during this project (AHTD TRC-1102). A correlation between large values of pore pressure and large values of displacement was expected to be observed for site visits following strong rain events or high river levels. Data were collected by communicating with the sensors using a data readout box by connecting the data readout box with the wires at the ground surface Figure 4.40. 


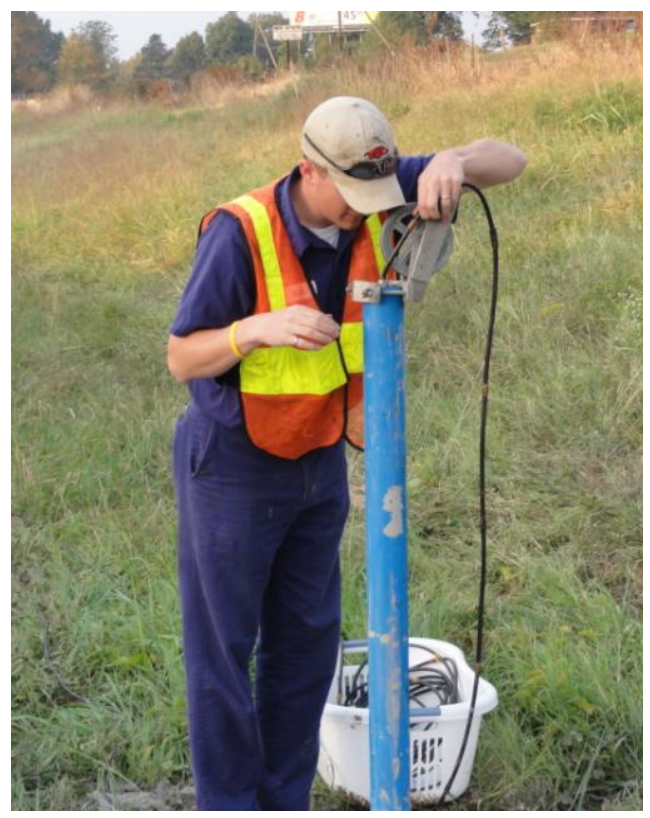

(a)

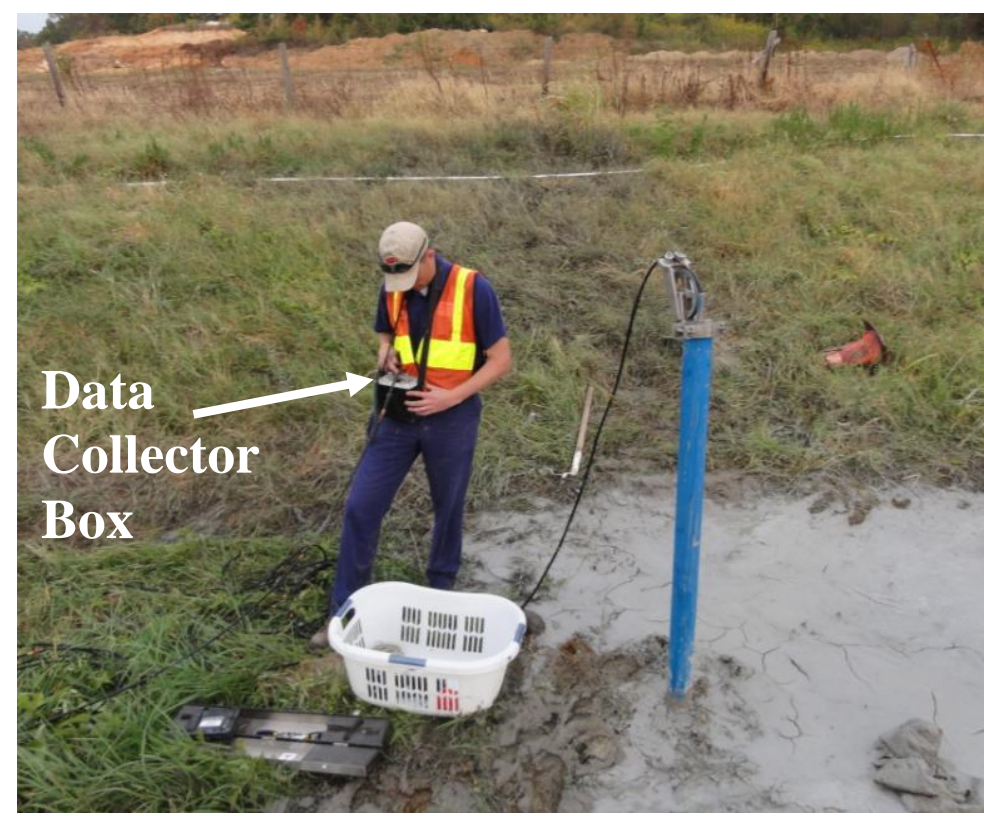

(b)

Figure 4.39. a) Lowering probe into inclinometer casing at B-4, and b) recording slope inclinometer data using the readout box.

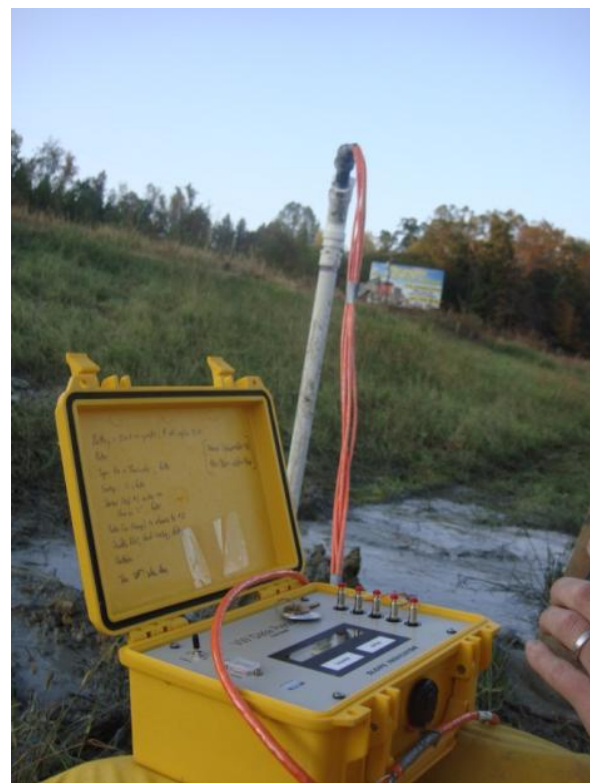

(a)

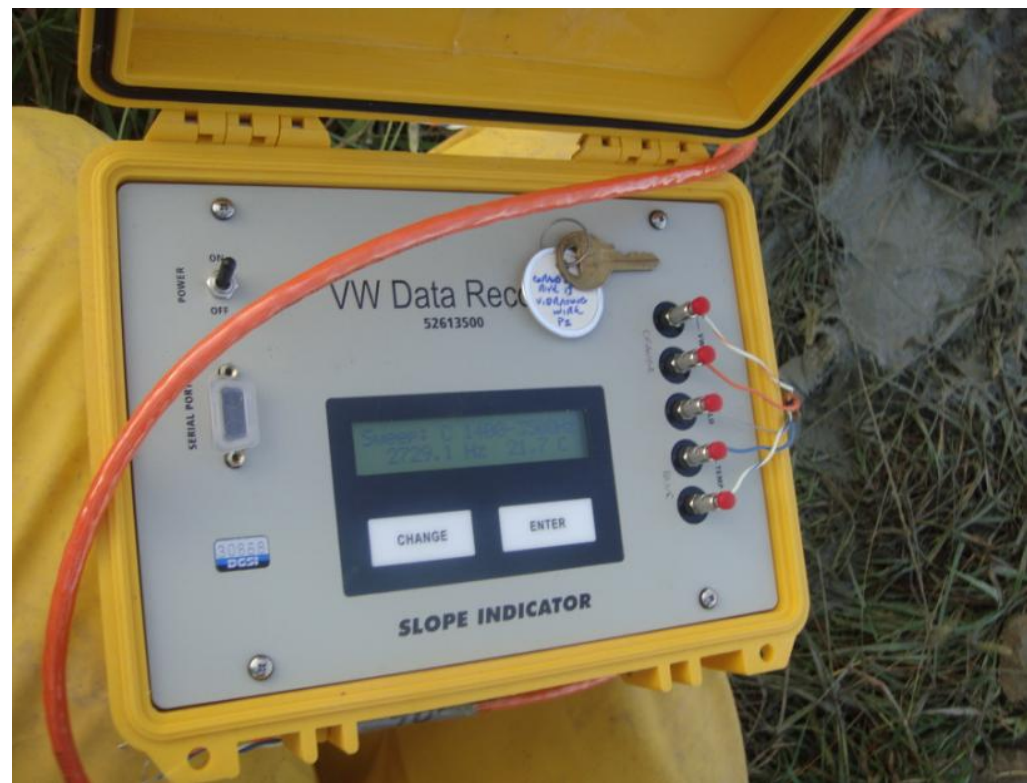

(b)

Figure 4.40. a) Obtaining readings of the different pore pressure transducers installed at different depths, and b) vibrating wire piezometer data readout box.

\subsubsection{Cone Penetrometer Testing (CPT)}

Two CPT tests were conducted by the Missouri Department of Transportation (MoDOT) at the validation site near Malvern, Arkansas. The CPT tests were performed in between the two 
of the boreholes location to allow for comparison of the results. Specifically, as shown previously in Figure 4.33, both CPT tests were conducted between Eastbound lane of Highway 84 and the Westbound lane of Interstate I-30 in between boring B-2 and B-3 (CPT-1), an in between borings B3-and B-4 (CPT-2). During both CPT tests the cone was pushed to refusal. Refusal was reached at 48.8 feet below ground surface for CPT- 1 and at approximately 12.5 feet below ground surface for CPT-2. Photographs of the CPT rig conducting the tests at the validation site near Malvern, Arkansas are shown is Figure 4.41.

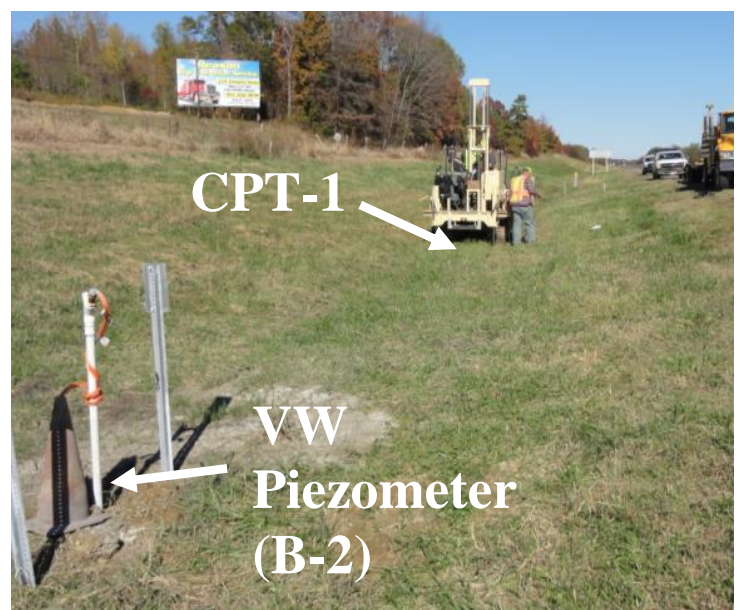

(a)

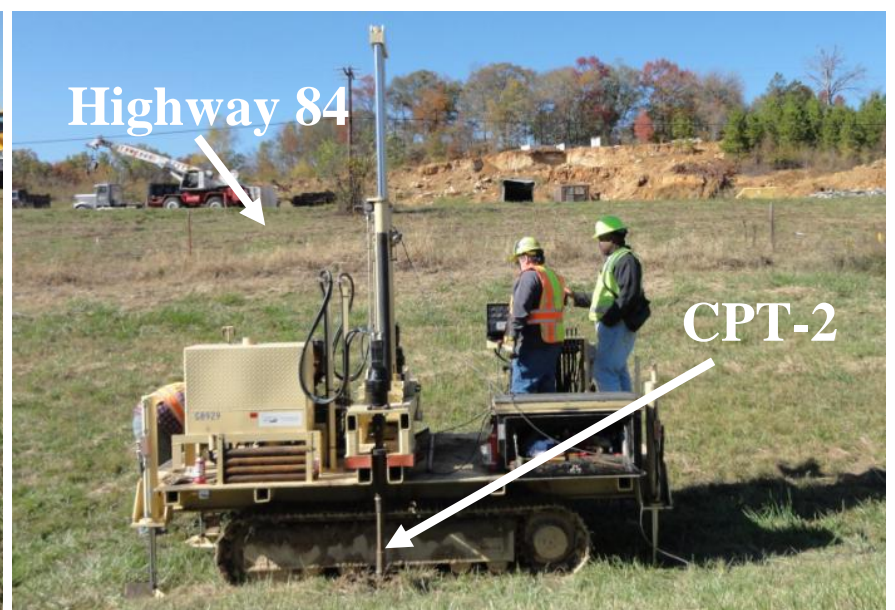

(b)

Figure 4.41. a) Cone penetrometer test being performed at the CPT-1 location, and b) cone penetrometer rig conducting the test at CPT-2 location.

\subsection{Laboratory Testing}

The methods and procedures followed for the laboratory testing conducted in the samples obtained during the geotechnical exploration. Unconsolidated Undrained (UU) tests were performed in the samples from Shelby extracted from the Shelby tubes. The unit weights were calculated from the dimensions measured of each sample prior to UU test. The results of the laboratory testing are presented in Section 6.3. The American Standard Methods (ATSM) followed on each of the different tests are presented in the following sub sections. 


\subsubsection{Water Content and Index Properties}

Field moisture content was obtained from every sample obtained during the geotechnical investigation according to ASTM D2216 (2007). The water content test were performed by recording the wet weight of a moisture sample from the bottom part of a Shelby tube sample or a portion of a Standard Penetration Test (SPT) sample. In order to obtain the weight of the moisture can, an AHTD maintenance facility in the proximity to the site was used by the researches to set up a balance and used as storage for the soil samples. Samples were sampled out of the ground and immediately taken to the facility, minimizing heat exposure and loss of moisture. After water content sample was extracted from the tubes, caskets and wax were used to seal the tubes. Moisture content was also obtained from UU samples after were tested in the laboratory. A figure of the AHTD facility used for storage and weight measurements is presented in Figure 4.42.

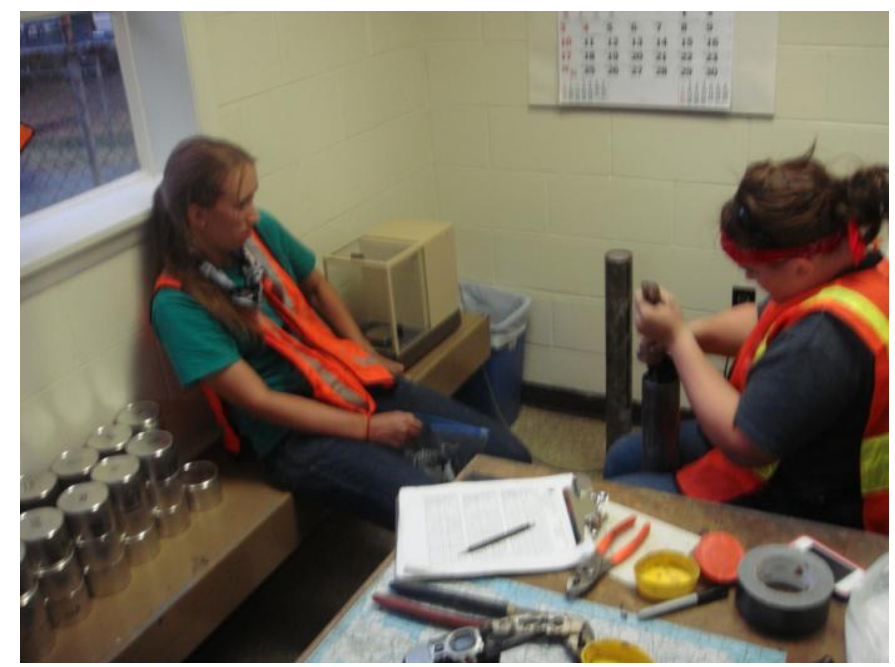

Figure 4.42. Moisture contents being obtained at a facility nearby the validation site.

Atterberg limits were conducted on all Shelby tubes samples to obtain the index properties of the soil. Liquid limit and plastic limit test were conducted on UU specimens following the ASTM D4318 "Standard Test Method for Liquid Limit, Plastic Limit, and Plasticity Index of Soils" (ASTM D4318, 2008). 


\subsubsection{Soil Sample Extraction}

First, one inch was cut from the bottom of each Shelby tube sample to discard the soil disturbed by the water content and strength index test conducted in the field during sampling operations. Six inches length specimens were cut from the Shelby tube sample, the rest of the Shelby tube was securely wrap with plastic paper and covered with plastic caps to prevent he change in moisture content. The soil specimens were retrieved form the tube by splitting the tube specimens. A Dewalt circular hand saw was used first to cut and initial seam along the tube, and once the seam was close to the thickness of the tube a Dremel tool was used to carefully finish splitting he tube without disturbing the soil specimen. The procedure for UU test specimen extraction is presented in Figure 4.43 and Figure 4.44.

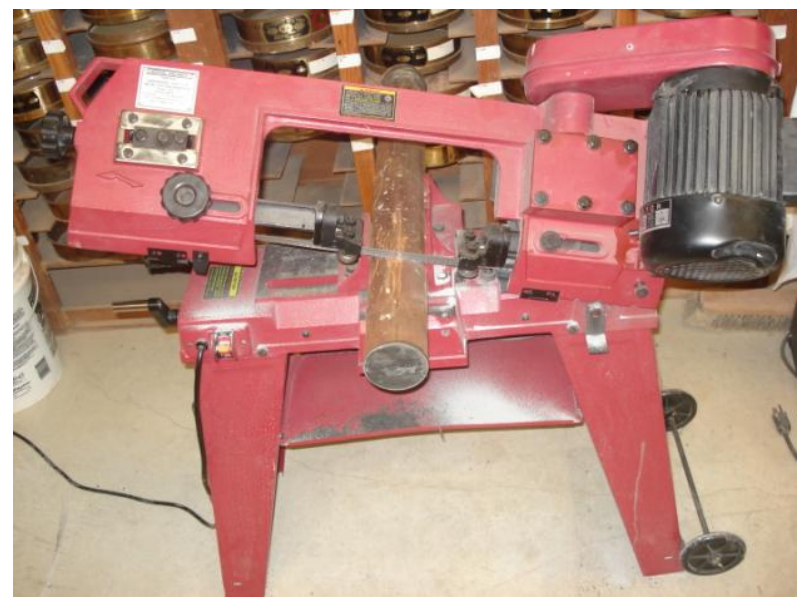

(a)

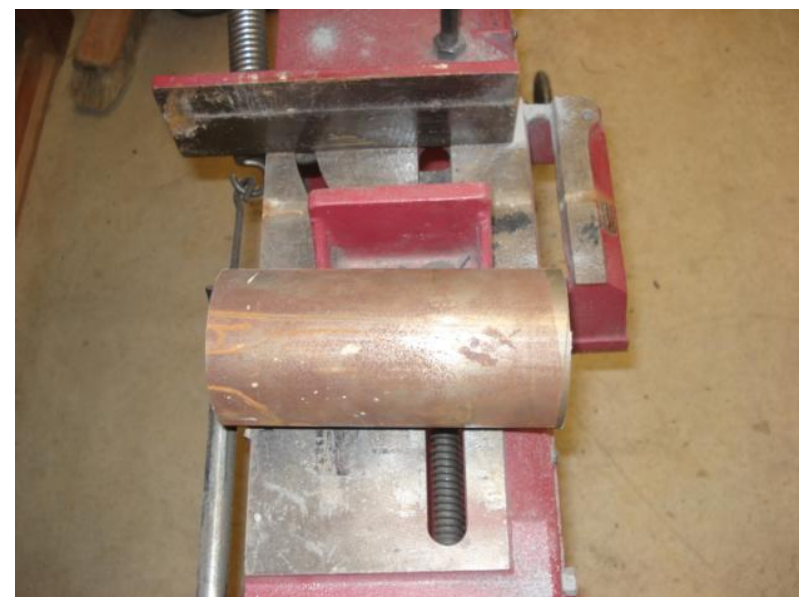

(b)

Figure 4.43. a) Central Machinery band saw cutting Shelby tube sample for UU test, and b) six inches Shelby tube specimen for $\mathrm{UU}$ test. 


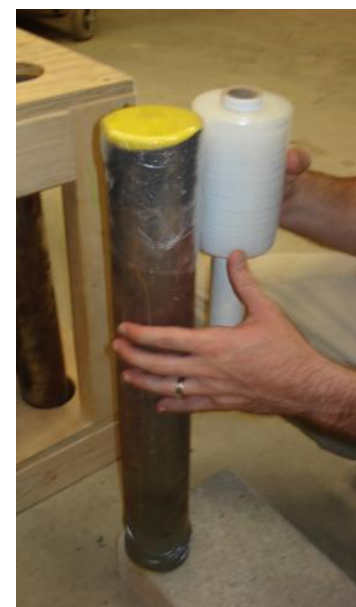

(a)

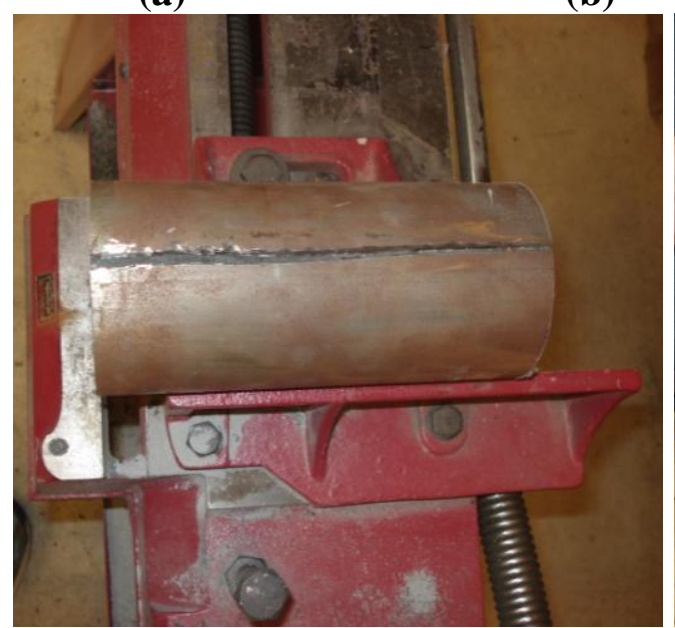

(d)

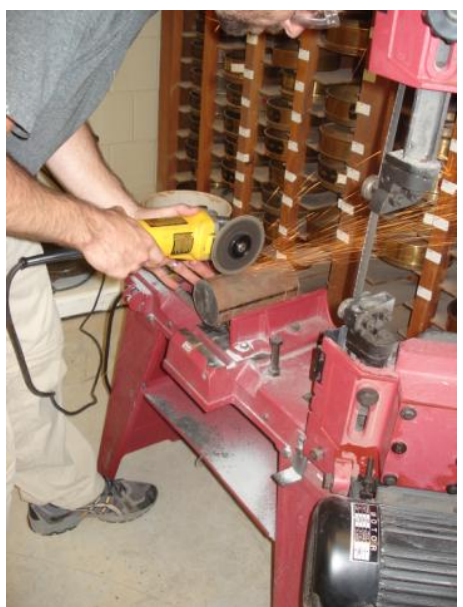

(b)

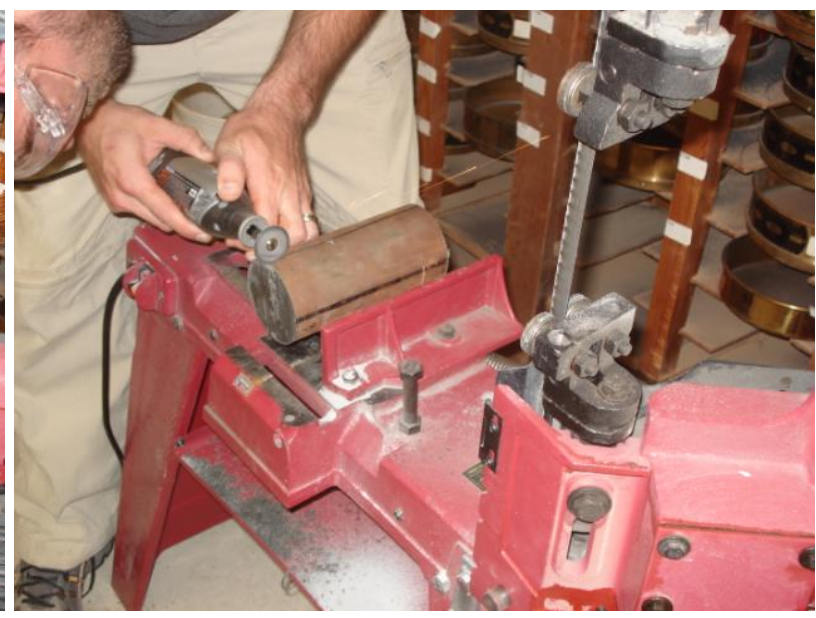

(c)

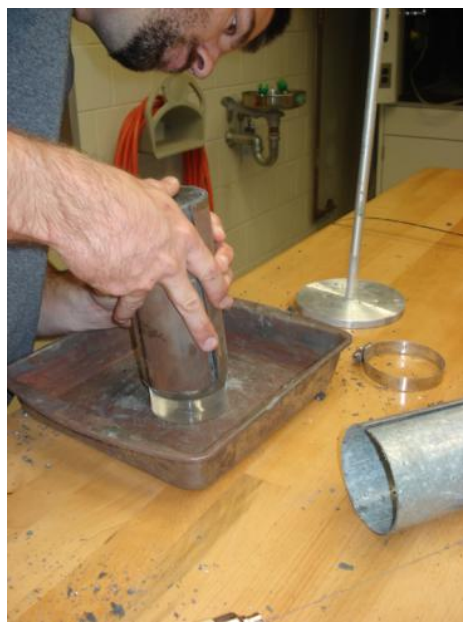

(e)

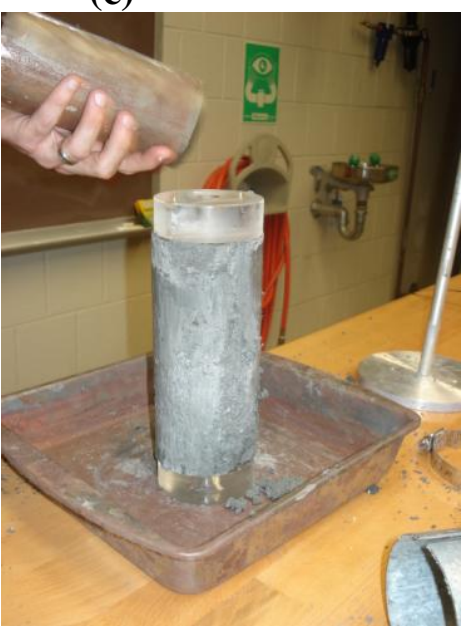

(f)

Figure 4.44. a) Shelby tube sample wrapped to prevent moisture change, b) circular hand saw used to start splitting the Shelby tubes specimen, c) final cuts with the Dremel before splitting the Shelby tube specimen, d) Shelby tube specimen with seam parallel to tube, e) retrieving soil specimen for $U U$ test, and f) $U U$ test specimen after Shelby tube extraction.

\subsubsection{Unit Weight Calculations}

Unit weights were obtained by measuring the dimensions of the UU soil specimens and weighting each sample (Figure 4.45). After obtaining the water content of the UU soil specimens, phase diagrams were calculated, and void ratios were obtained. 


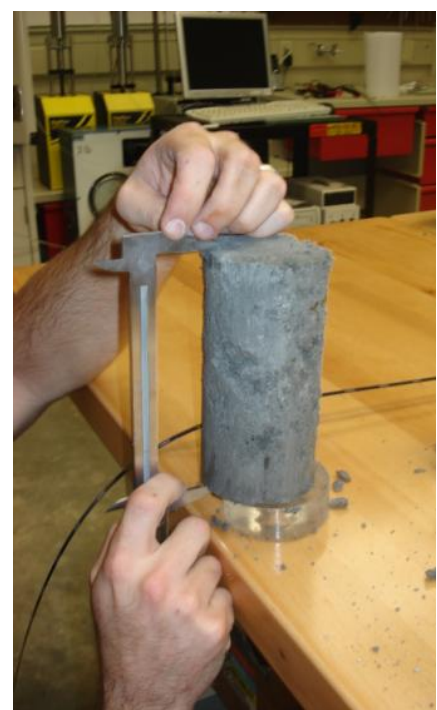

(a)

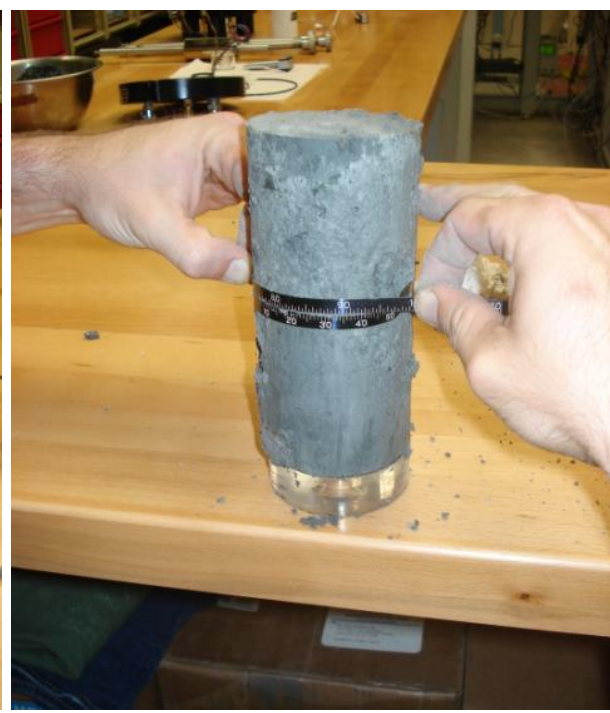

(b)

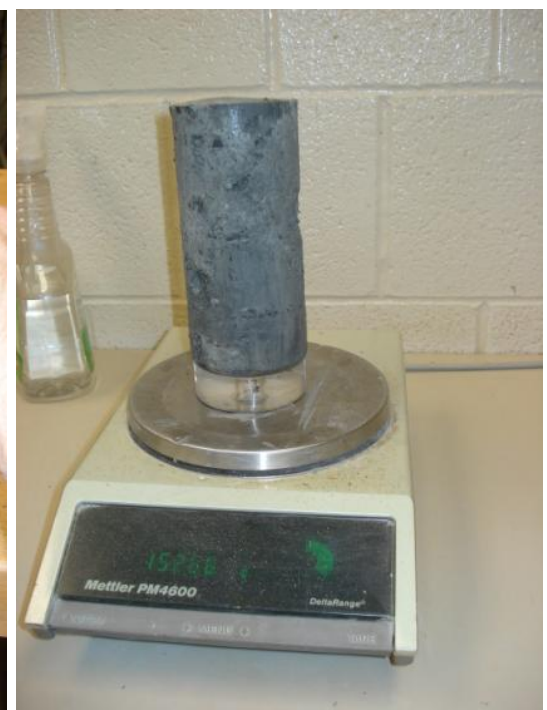

(c)

Figure 4.45. a) Height measurement of $U U$ test soil specimen, b) measuring diameter of $U U$ soil specimen using Pi tape, and c) scale utilized to obtain weight of the soil specimen.

\subsubsection{Unconsolidated Undrained (UU) Triaxial Test}

Unconsolidated Undrained triaxial tests (commonly known in the industry as UU test) were performed in the clay samples obtained from the Shelby tubes recovered at the validation site near Malvern, Arkansas. The tests were conducted by University researchers in the Graduate Soils Laboratory of the University of Arkansas in Fayetteville, Arkansas. The UU specimens were six inches in length obtained by cutting the Shelby tubes samples using a Central Machinery vertical/horizontal band saw.

The unconsolidated undrained test is a wide spread, relatively easy and not expensive test to obtain an overall idea of the strength of the soil sample in undrained conditions. The UU tests were performed in accordance with (ASTM D2850, 2007). The UU apparatus utilized to perform the different tests was manufacturer by GeoTac, GeoJac load frame, sensors and DigiFlow pump. A deviation from the standard was that the piston friction was measured at the beginning of the test by leaving a small gap between the piston and the top cap of the specimen. Before placing the soil specimens in the UU triaxial cell, the soil specimens were carefully leveled using a wire 
knife. An even distribution of stress is required when performing any type of triaxial testing to obtain the most accurate results when testing. Unit weights of each specimen were measured prior UU triaxial test, as discussed in Section 6.3.2. Membrane was used to prevent water contamination and conserve the moisture of the soil specimen. To prevent the loss of water and pressure O-rings are used to seal the triaxial cell. A UU test specimen being placed in the UU triaxial cell is presented in Figure 4.46.

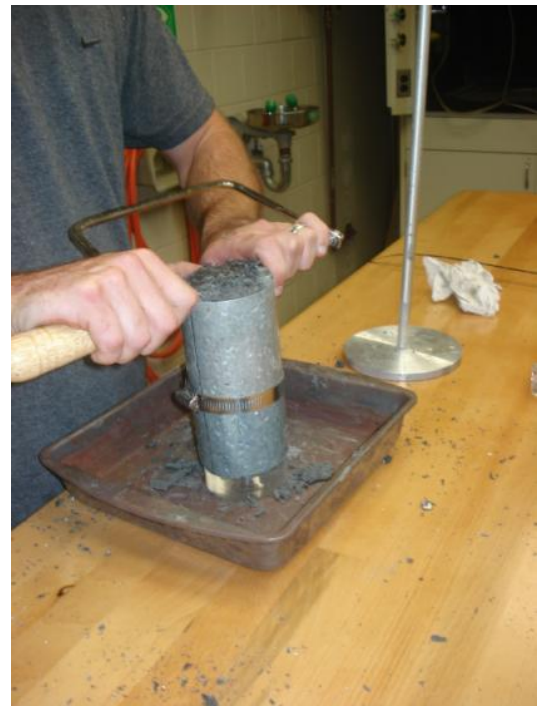

(a)

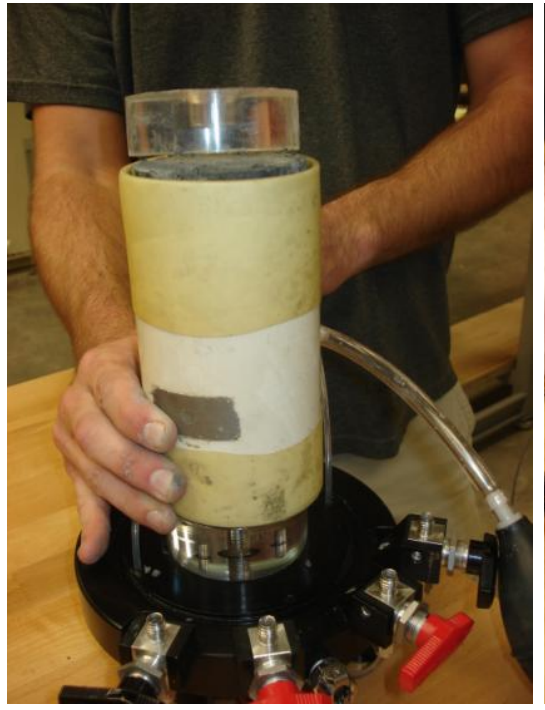

(b)

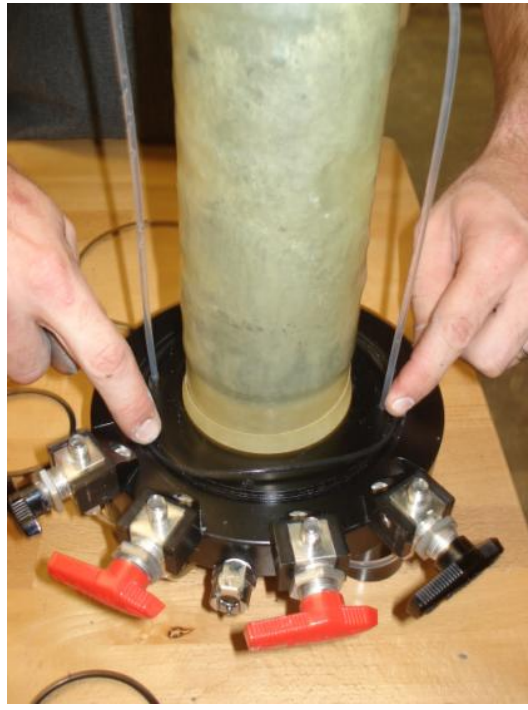

(c)

Figure 4.46. a) Soil specimen being level to prevent concentration of stresses, b) placing membrane around the sample, and c) securing o-ring to seal the UU triaxial cell.

The soil specimens were tested to a confining stress following a correlation of one pound squared inch (psi) per foot of depth. For example, a specimen obtained from a depth of 20ft. was tested at a pressure of 20psi. The UU tests were conducted until an axial strain of $15 \%$ was reached as per (ASTM D2850, 2007). The testing equipment and a specimen during UU test is presented in Figure 4.47. Moisture contents were obtained from each specimen after the each UU test was conducted (Figure 4.48); the moisture contents obtained were compared to the field moisture contents performed during the geotechnical exploration as discussed in Section 6.3.1. 


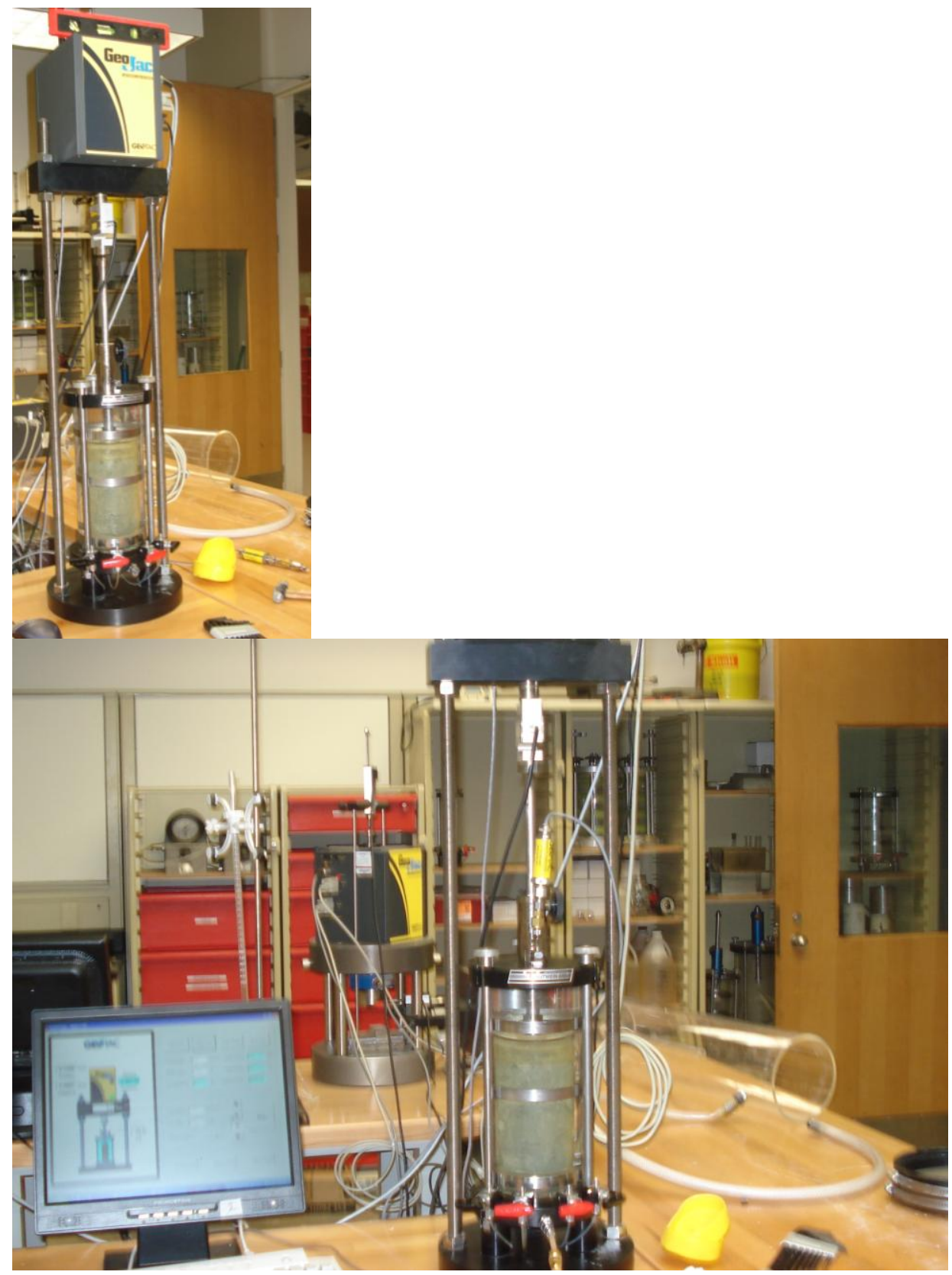

(a)

(b)

Figure 4.47. a) UU triaxial apparatus, and b) UU test being conducted in a soil specimen obtained from validation site near Malvern, Arkansas. 


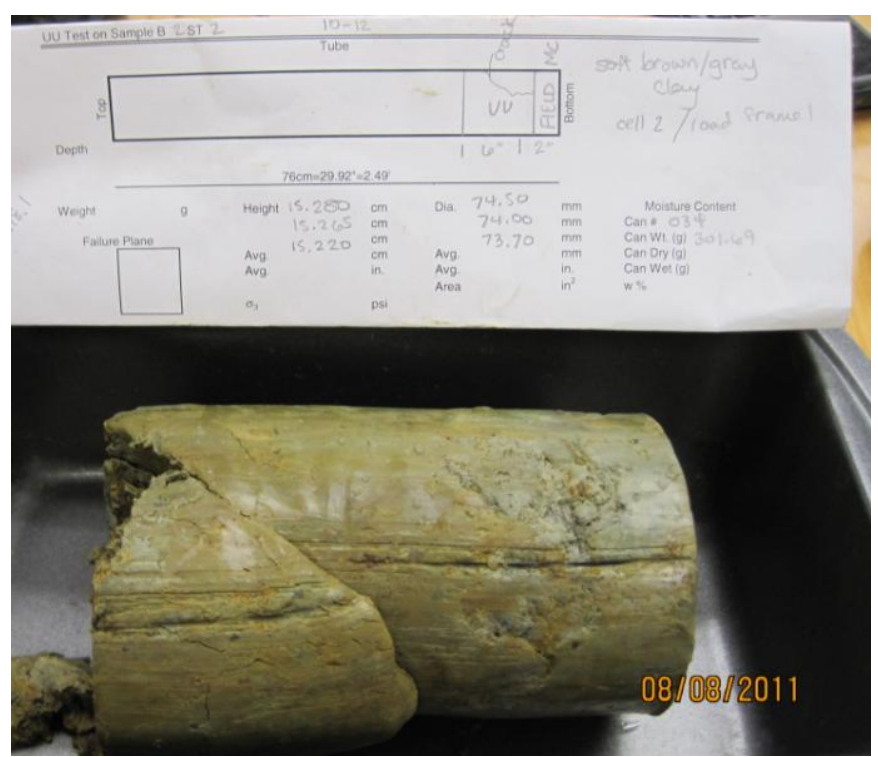

Figure 4.48. Soil specimen B-2 ST2 after UU triaxial test, sample ready for post-test moisture content.

Rock samples obtained from core samples were tested using the same UU equipment configuration. The core sampler was approximately 2.0in diameter, therefore, the rock samples were cut to approximately 4.0in in height to obtain a 2:1 ratio. This ratio prevented buckling of the sample during testing which will result in false strength values. A wet saw was used to cut the different rock samples (limestone, shale, sandstone), and then the rock specimens were grinded to obtained a level endings to avoid any concentration of stresses which may lead to low strength values. The rock samples that did not failed using the 10 kips load frame were subjected to Unconfined Compression (UC) in a concrete frame. A photograph of a rock sample being cut using a wet saw for UU and UC tests is presented in Figure 4.49. 


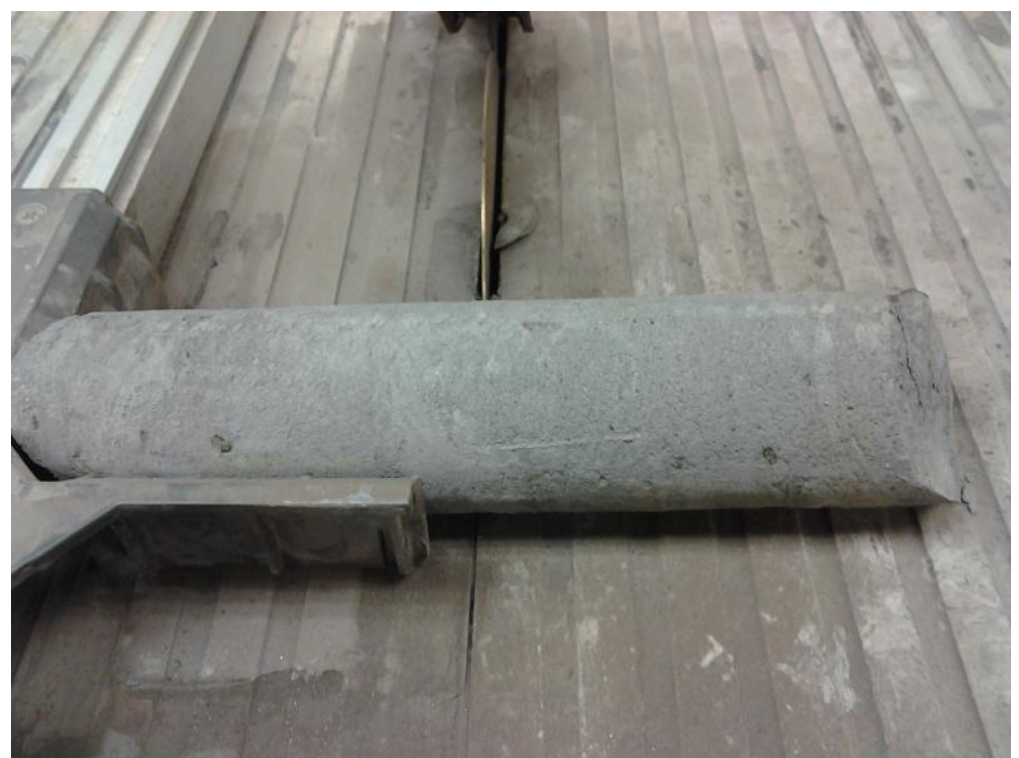

(a)

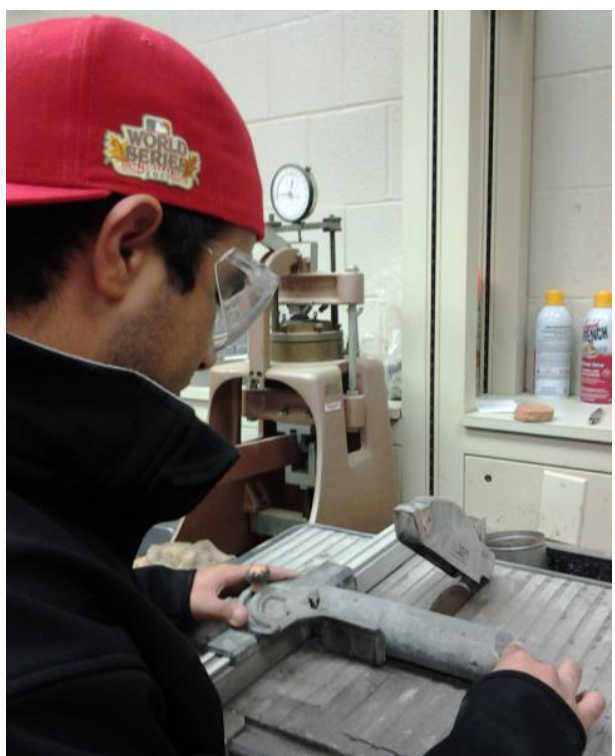

(b)

Figure 4.49. a) Rock sample obtained from coring operations at validation site, and b) wet saw used to cut rock samples.

\subsection{Conclusion}

The site instrumentation utilized during this project research (AHTD TRC-1102) was described in this chapter. Methods and procedures followed during installation and monitoring of the instrumentation (temporary and permanent) at the calibration and validation sites were presented. Temporary instrumentation included the Total Station, LIDAR, GPRI-II and targets associated with these devices. Permanent instrumentation included survey monuments, piezometers and slope inclinometers.

The geotechnical exploration conducted at the validation site was also discussed including: how the samples were obtained, how the samples were transported, and how the samples obtained were tested in the laboratory. Monitoring using the Total Station and GPRI-II was conducted on a bi-weekly basis at the calibration site; while monitoring using the Total Station, GPRI-II, Slope Inclinometers, and Nested Piezometer was conducted on a monthly basis at the validation site. LIDAR site visits were conducted by AHTD personnel on a monthly basis. 


\section{Chapter 5. Data Reduction and Interpretation}

\subsection{Introduction}

The methodologies and procedures used to analyze, process, and interpret the data generated by the various instruments (described in Chapter 4) used in this research project (AHTD TRC-1102) are described in this chapter. For the purposes of this document the data, as recorded and exported from the various instruments, is referred to as raw data prior to filtering, processing, or other manipulations. The process by which the raw data was ingested, processed, displayed and interpreted is hereinafter referred to as the data reduction process. Several software programs (Microsoft Excel®, AutoCAD Civil 3D $®$, LAStool@, DigiPro, Gamma Remote Sensing, Cyclone) were utilized during data reduction. The data reduction procedures consisted of several steps that allowed for the raw data to be displayed for analysis and varied depending on the instrumentation utilized in the field. The data reduction processing performed, after data was collected in the field, using the: Total Station (Section 5.2), GPRI-II (Section 5.3), LIDAR (Section 5.4), and in-situ instrumentation (Section 5.5) is discussed in the following sections.

\subsection{Total Station Data Reduction}

The Total Station was used to generate a three dimensional point cloud of the area of interest using traditional surveying techniques as described in Section 4.3. The details of the data reduction process for the data acquired using Total Station are explained the subsequent subsections. The data reduction procedure was the same for the calibration and validation sites.

\subsubsection{Procedure}

After site visits were performed at the different sites (calibration and validation), the data that was stored in the Total Station were exported from the onboard memory of the Carlson 600+ to a computer. The initial step in the data reduction process involved exporting the total station 
data for each site to a text file. The export option in the Carlson 600+ was used to export the raw data from each site visit to a corresponding text file, listing each individual survey point using the following structure: point ID, $x, y, z$, description). After the text file was created the Active Microsoft ${ }^{\circ}$ Sync 4.5 software program (Microsoft Active Sync, 2011) was used to transfer the file to either a laptop or desktop computer via a serial cable connection. The Active Sync 4.5 program was obtained for download through the Microsoft download center (Microsoft Website, 2011). Following download of the data to the computer, computer processing of the raw data commenced.

\subsubsection{Analysis}

The total station data was analyzed using the Microsoft Excel® (Microsoft Excel, 2011) and AutoCAD Civil 3D® (Autodesk, 2011) software programs. Both programs permitted the analysis of large amounts of data in a user friendly and graphical interface. Microsoft Excel® was used to view and analyze the data in spreadsheet (tabular) form, while AutoCAD Civil 3D® permitted the analysis of the data in a graphical form. The primary objective of the Total Station data reduction process for this research project (AHTD TRC-1102) was to determine the rate and amount of movement of the surveyed points.

The movement of each surveyed monument was computed in Microsoft Excel@. AutoCAD Civil $3 \mathrm{D} ®$ was used to visualize the points and compute displacements (previously discussed in Section 3.2.2 and Section 3.3.2, respectively). The total station data analyses were conducted differently for the two sites (calibration and validation). The calibration site was smaller and observation from only one Total Station control point was necessary for data acquisition. As further discussed later in Section 6.6.1.1 it was believed that error was observed at the validation site related to the turning of the total station. However, due to the size of the validation site and line-of-sight limitations for the total station; data analysis methods were 
attempted to reduce the encountered error. As discussed previously in Section 4.3.1.2, a second total station setup was selected in the middle section of the assumed moving mass. Also, two analysis methods were employed during the data processing phase were attempted to reduce the error; the methods are herein defined as the angles method, and the tangent method. These two methods were performed using both the Microsoft Excel® and AutoCAD Civil 3D® software programs. The procedures undertaken for data analysis are explained in the following subsections.

\subsubsection{Microsoft Excel $®$}

The coordinates of the points located in text files, corresponding to each visit, were imported into Microsoft Excel® using the built-in import tool. The displacements were measured by comparing the initial position of each monument (from the initial site survey) to the position of the monument as observed in subsequent site visit (hereinafter referred to as checks). The displacements and elevation differences for the check in at both project sites (Chester and Malvern) were computed using Microsoft Excel® by subtracting the initial surveyed coordinates $(\mathrm{x}, \mathrm{y}$, and $\mathrm{z}$ ) from the surveyed coordinates measured during each subsequent check. An example of this calculation for the Check 12 data on the first four survey monuments is presented in Table 5.1.

Table 5.1. Summary of displacements (horizontal) and elevation differences for the four first monuments after Check 12 at the calibration site near Malvern, AR.

\begin{tabular}{|c|c|c|c|c|c|c|c|c|c|c|c|}
\hline \multicolumn{12}{|c|}{ Calibration Site - Chestr, Arkansas } \\
\hline \multicolumn{5}{|c|}{ Initial Monuments } & \multicolumn{5}{|c|}{ Check 12- 07/09/2011 } & \multicolumn{2}{|l|}{ Results } \\
\hline ID\# & $\mathbf{N}$ & $\mathbf{E}$ & $\mathbf{Z}$ & Description & ID\# & $\mathbf{N}$ & $\mathbf{E}$ & $\mathbf{Z}$ & Description & $\Delta$ displacement & $\Delta$ elev \\
\hline 2000 & 5176.42 & 5207.14 & 123.471 & Mon & 6814 & 5176.4 & 5207.12 & 123.52 & Check12 & 0.029 & 0.049 \\
\hline 2001 & 5161.39 & 5167.59 & 117.476 & Mon & 6815 & 5161.35 & 5167.58 & 117.516 & Check12 & 0.045 & 0.040 \\
\hline 2002 & 5184.34 & 5143.74 & 122.331 & Mon & 6817 & 5184.31 & 5143.75 & 122.385 & Check12 & 0.038 & 0.054 \\
\hline 2003 & 5175.12 & 5093.35 & 115.823 & Mon & 6816 & 5175 & 5093.3 & 115.75 & Check12 & 0.127 & -0.073 \\
\hline
\end{tabular}


The angles method was performed while analyzing the data from the validation site. The monuments to the North and South of Control Monument 1000 were evaluated separately using the angles data analysis method. The computed North to South (or vise versa) distance and East to West (or vise versa) from Control Monument 1000 control point to each monument were the cathetus and the direct distance to the point was the hypotenuse of the right triangle formed. The turning angles were then computed for each point using trigonometric identities and the hypotenuse/cathetus values (Figure 5.1). The points at which Northern displacement occurred had a different trend than the points that showed a Southern displacement. Two trendlines were calculated using Microsoft Excel® from the two groups of points (Figure 5.2). A correction angle value was then obtained for each point by using the trendline formula and the distance to the point. After the correction angle was applied to each monument all additional data reduction analysis was carried out using AutoCAD Civil 3D® software program discussed below.

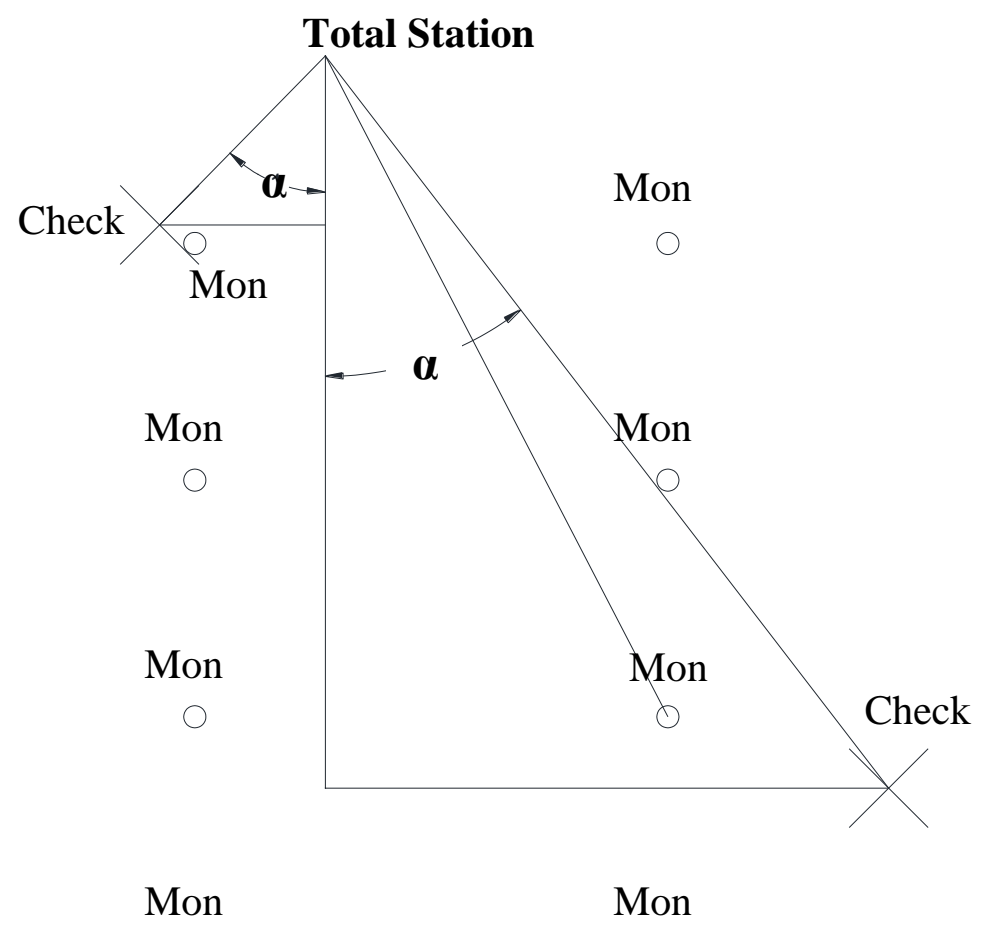

Figure 5.1. Diagram with an illustration of the procedures followed for the angle method. 


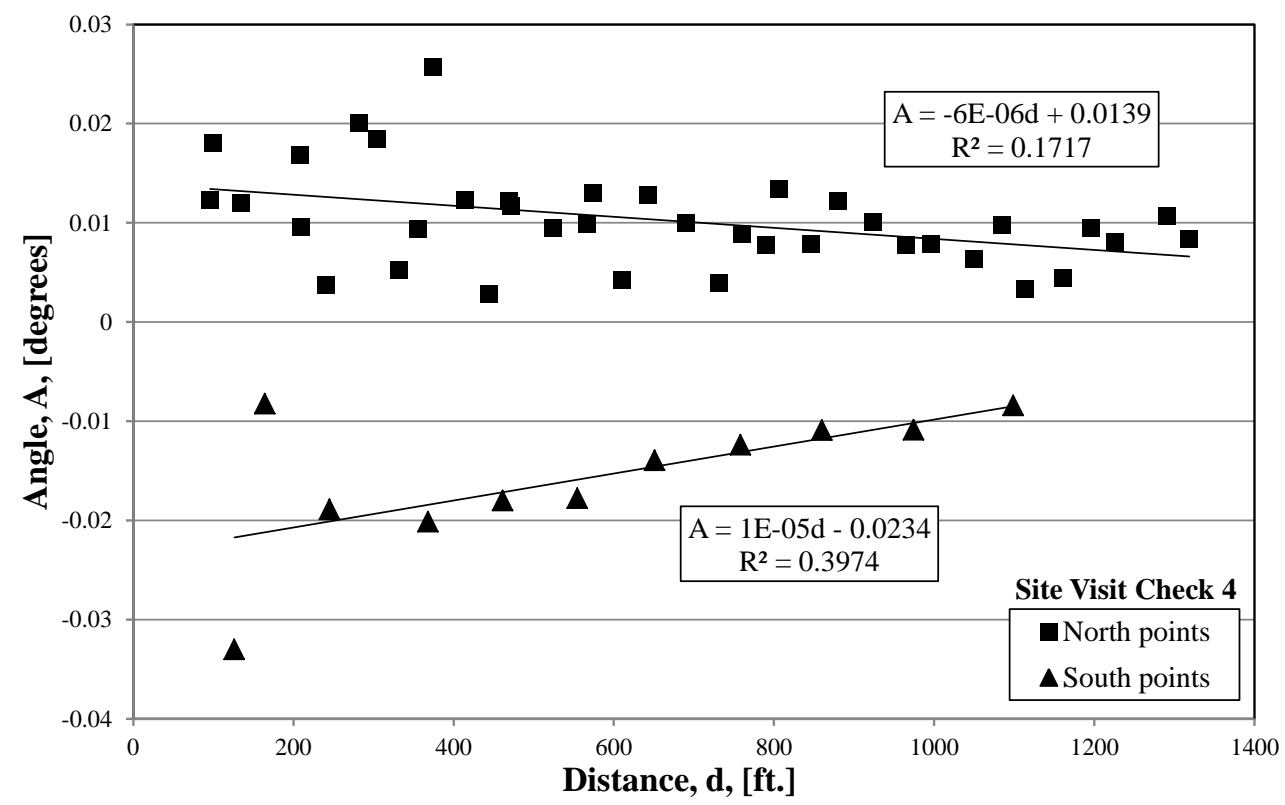

Figure 5.2. Graph obtained from Microsoft Excel® after the angles method was performed for Check 4 site visit at the validation site in Malvern, Arkansas.

\subsubsection{AutoCAD Civil $3 D \circledR$}

The recorded data collected during each site visit were imported into one AutoCAD Civil $3 \mathrm{D} ®$ file per site. Displacement vectors (arrows) were drawn between the initial location of each monument location to the location of the survey monument observed during each of the subsequent Checks. This procedure was followed for both the validation and calibration sites.

After the angle correction had been calculated using angles method (using Microsoft Excel®, as described previously in Section 5.2.2.1), the angles from the total station to the different survey monuments were adjusted or rotated in the AutoCAD Civil 3D® drawing by the angle correction value. The angle correction was performed by drawing a line from the total station point to the survey monument point and using the "rotate" function in AutoCAD Civil $3 \mathrm{D} \circledast$ to rotate the line by the angle correction value found with the Microsoft Excel ${ }^{\circledR}$ graphs.

The second data correction technique utilized for the validation site near Malvern, Arkansas was the tangent method. This method was performed entirely using the AutoCAD Civil 3D software program. The tangent method consisted of importing the raw survey monuments 
positions, acquired from total station control point 1000 and control point 1029 (Figure 4.6) into AutoCAD Civil 3D®. The survey monuments position were not the same when acquired from control point 1000 or control point 1029 , even though, they were acquired within small time window (hours) difference. Therefore any large difference observed between the positions of a survey point acquired form control point 1000 and control point 1029 would be the effect of measurement error and not actual landslide displacement. In order to mitigate this error the tangent method was to find an average survey point position (Check) taking into to account the data acquired form the two control points (control point 1000 and control point 1029). A circle was drawn in AutoCAD Civil $3 \mathrm{D} \AA$ from the control point 1000 to each of the survey monuments. A second circle was then drawn from the total station control point 1029 to each of the survey monuments. Where the two circles (drawn from different total station control points) were tangent to each other, that point was selected as the true or corrected survey monument location for that site visit. An illustration of the tangent method concept is presented in Figure 5.3 .

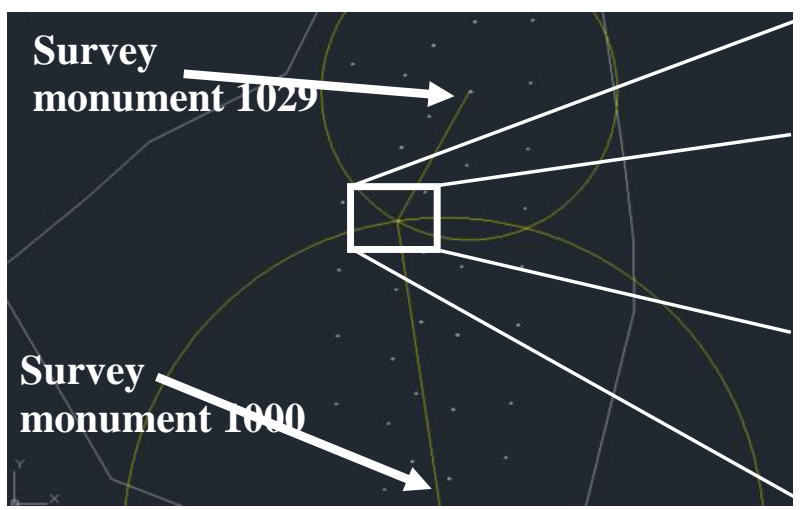

(a)

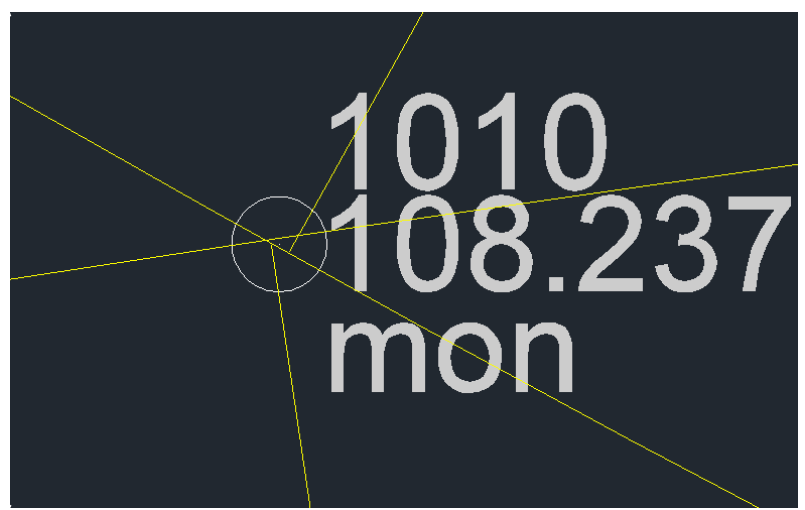

(b)

Figure 5.3. a) Plan view of the validation site while tangent method was attempted, and b) zoomed view of the intersection between the two circles developed during the tangent method using AutoCAD Civil 3D®. 


\subsection{RADAR Data Reduction}

The data reduction process for the GPRI-II RADAR images was primarily conducted using the Gamma Remote Sensing software operating in a Linux environment (Ubuntu, 2011). Data reduction for the RADAR images was a multiple step process consisting of processing the raw data to create interferograms. The interferograms between data acquired in different dates allowed for measurement of displacements. A complete step-by-step of the procedure followed for data acquisition and data reduction is presented in Appendix Error! Reference source not

\section{found..}

\subsubsection{Procedure}

The data reduction process for RADAR was initialized by transferring the raw data acquired in the field from the GPRI-II field computer to a drive used for data storage and processing. The raw data was utilized to create Single Look Complex (SLC) files where the phase and amplitude of the raw data was retained. At this point, Multi Look Intensity (MLI) images were created for visualization of the scans acquired in the field. Before MLI could be opened using an image software, the MLI files had to be converted to a raster image file format. Due to the angular acquisition of the GPRI-II the MLI raster images were in polar coordinates. Although, images in polar coordinates allowed for a detail inspection of the images acquired form the RADAR perspective, the MLI raster files were converted to rectangular coordinates. Raster images files allowed easier location and positioning of objects in the field (ditches, structures, lanes etc.). The MLI files were only use for visualization purposes, SLC files were used for all the data reduction process. Examples of the MLI files obtained for each viewpoint in the two sites are presented in Section 6.6.1.3 and 6.6.2.3.

Although final interferograms were not created and are not presented in this thesis document, the initial procedure to obtain interferograms was conducted with promising results. 
The procedure followed to see some initial interferograms was initialized by resampling all the images for one site visit and for all the site visits to a "master" image geometry. This process is known as single geometry, where the master image was picked to be one of the first image acquired during the first acquisition day at each viewpoint. Then, offset were calculated for each individual image separately. The comparison of points was set to be performed in a 200x200 samples area. Once the offset were created, the Signal to Noise Ratio (SNR) was manually set to a threshold of 3.0. The SNR threshold value was selected to provide a good alignment of the images with a good quantity of samples. After the images were analyze separately, the images were resampled to the master image geometry or "alignment them on top of each other."

A second spectrum comparison was conducted to increase the co-registration of the images. New images were not created during this phase of the data reduction. Conversely, the surfaces in comparison were subtracted and the distances were put it in a table. Wrapped interferograms were then created with the information contained in the table created in the last step. The interferograms were filtered to fine the correct cycle and to do not allow phase degradation. After filtering, interferograms were unwrapped to allow the phase to continue for more than one cycle.

Raster image files were created from the interferograms for visualization purposes. Again, interferograms raster images were created first in polar coordinates and then converted to rectangular coordinates. Temporal analysis can be conducted by analyzing the displacements obtained in the interferograms with time. Results for the interferograms obtained are not presented in this thesis document, but the procedure utilized serves as a good starting point when computing interferograms for this application. 


\subsubsection{Linux Commands}

As previously stated, the data reduction process for GPRI-II was performed using a Linux (Ubuntu [2011]) operating system. The majority programs or scripts utilized during this project research (AHTD TRC-1102) were developed by GAMMA Remote Sensing. The Linux commands utilized during the RADAR data reduction process are summarized in Table 5.1. A sample of all the Linux commands utilized for each of the sites is presented in Appendix Error!

\section{Reference source not found.}

Table 5.2. Summary of relevant data reduction Linux commands.

\begin{tabular}{|l|l|}
\hline \multicolumn{1}{|c|}{ ginux Command } & \multicolumn{1}{c|}{ Description } \\
\hline gpri2_proc_all.pl & Creates SLC files from the specified raw data folder \\
\hline mk_mli_all & Creates MLI files from the specified SLC folder \\
\hline rast pwr & Creates a raster image file form the specified MLI files \\
\hline pol2rec & $\begin{array}{l}\text { Converts the MLI in polar coordinates to a MLI file in } \\
\text { rectangular coordinates }\end{array}$ \\
\hline offse pwd & Compares the spectrum of the points \\
\hline offset fit & Allows to see and specify SNR \\
\hline INTERF & Resamples SLC files to masters geometry \\
\hline FILTER & Finds correct cycle in the wrapped interferogram \\
\hline UNWRAPPER & Allows to continue the phase of an interferogram \\
\hline
\end{tabular}

\subsection{LIDAR Data Reduction}

The data reduction and analysis process for LIDAR was composed of an initial Cyclone ${ }^{\circledR}$ phase (Section 5.4.2.1), LAStools phase (Section 5.4.2.2), and an AutoCAD® phase (Section 5.4.2.3). The raw data was imported in Cyclone ${ }^{\circledR}$ for an initial analysis, then the registered scan data was imported into LAStools $\odot$ and AutoCAD® for the creation and comparison of surfaces. Elevation changes ( $\mathrm{z}$ direction) were obtained from the comparison of surfaces form different site visits. The procedure followed in all the phases of the LIDAR data reduction is presented in the following subsections. 


\subsubsection{Procedure}

The initial step in the data reduction of the LIDAR data was to open the raw data using the Leica Geosystems Cyclone® (Leica Geosystems, 2010) software program. The Cyclone® software program is specifically designed to handle the large ( 20 million point $)$ point clouds obtained using terrestrial LIDAR scanners. After importation of each individual scan, the registration and unification of the different scans for the same site visit was performed in Cyclone®. To obtain the accurate measurements of ground surface displacement two methods were developed, the polylines method and the bare earth correction method. After the ground information was isolated from the rest of the data acquired (vegetation, structures, cars etc.), only the data of interest was imported into AutoCAD Civil®. Surfaces were created from the ground data obtained during each site visit to the two sites. Surfaces were compared using the AutoCAD Civil 3D® software program to obtained elevation changes between site visits.

\subsubsection{Analysis}

The analysis of the LIDAR data acquired during each visit to the calibration and validation site was performed with the objective of obtain displacements of the landslide. The displacements rates were expected to show progressive movement of the sliding mass with time. Vegetation removal was a key part of while analyzing the LIDAR data in order to reduce error induced by vegetation growth and highway maintenance (mowing). A filtering process was necessary to obtain accurate results. The polyline method was developed and used first, until the bare earth correction method; a more robust procedure was implemented. The procedure developed and followed using the different software programs is discussed in the following subsections. 


\subsubsection{Cyclone ${ }^{\circledR}$}

Several LIDAR scans were acquired per site visit at each of the sites studied in this research project (AHTD TRC-1102). For the calibration site near Chester, Arkansas two scans (from different viewpoints) were performed per site visit, as explained in Section 4.3.1.1. Four scans were required to cover the extension of the slide at the validation site near Malvern, Arkansas. The LIDAR scans from the same site visit were registered and unified, using the LIDAR targets, to obtain a single point cloud with all the data. A database containing the raw data acquired with the LIDAR C-10 in the field was registered and unified using Leica Cyclone® software program by AHTD personnel. The Cyclone ${ }^{\circledR}$ databases containing the registered and unified point clouds were uploaded to AHTD's file transfer protocol (ftp) site (//ftp www.arkansashighways.com/outgoing/surveys/data/trc1102) by AHTD personnel for further analysis by University of Arkansas researchers. Proper registration and unification of the point clouds in each database was verified by visual inspection using the Cyclone ${ }^{\circledR}$. The three

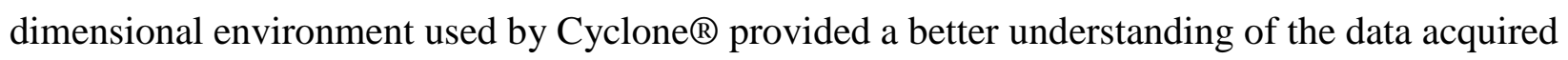
during each site visit.

The first procedure attempted for vegetation removal was the polylines method. The polylines method was a manual attempt to filter and remove vegetative effects. The polylines method consisted in dividing the extension of the sliding mass in the point cloud for a given site visit into different cross-sections (5 meters apart). Once in cross-section view, the lowest points were manually selected by visual inspection. The selected points were assumed to be the returns from the ground at the site. Polylines were created form the selected points on each crosssection. After all the polylines were created from each cross-section, the final outcome was a set of polylines that followed the assumed ground topography. Views after the polyline method was conducted at the validation site in Malvern, Arkansas are presented in Figure 5.4. 


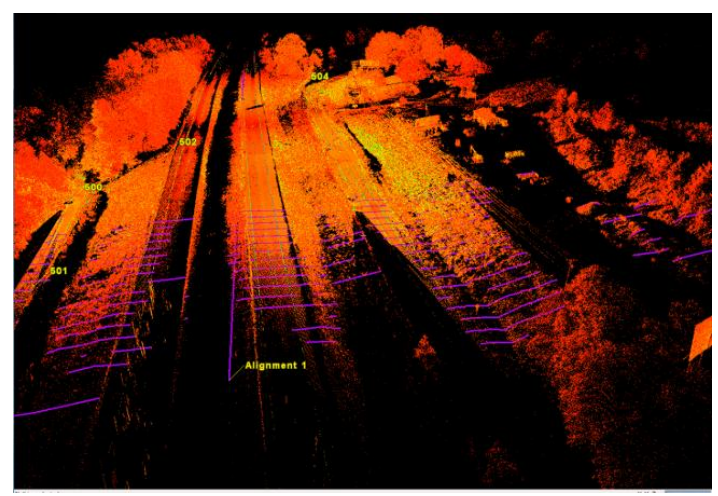

(a)

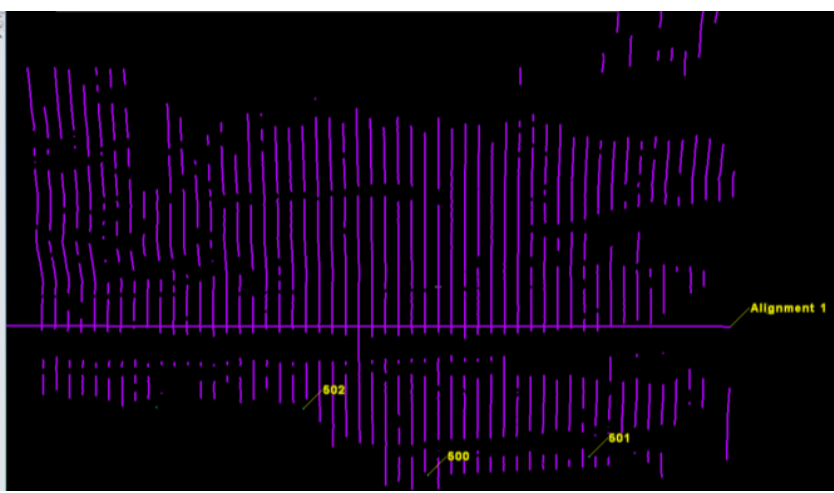

(b)

Figure 5.4. a) Cyclone ${ }^{\circledR}$ screenshot after polyline method was finished, and b) plan view of the ground polylines at validation site in Malvern, Arkansas [in color].

Once the ground polylines were obtained using the Cyclone® software program, only the polylines were exported as a AutoCAD® DXF format. The polyline method allowed for a manual removal of vegetation and other features encountered that were not of the interest of this research project. One expected drawback of the polyline method was the processing time required for one site. The calibration site required, on average, a minimum of three hours to perform of the polylines method. Due to the large physical extends of the validation site required a minimum of five hours were required to perform the polyline method. An inherent drawback of the polylines method was the spacing between polylines (five meters). More spacing between polylines resulted in less data for surface creation, but the less space in between polylines resulted in an significantly increased of data processing time. Researchers attempted to find a suitable balance between spatial resolution and required processing time. Another method for vegetation removal was developed and applied during the analysis of his research project.

The bare earth correction method was an automated, mathematical method for vegetation removal that was employed to create the surfaces. While this method was capable of providing much more data (millions of points) due to the limitations of the AutoCAD software filtering was employed to reduce the number of points. The use of the automated bare earth correction 
time resulted in a reduced processing time. For the bare earth correction method the previously described registered and unified Cyclone ${ }^{\circledR}$ databases created by AHTD personnel were used. An initial inspection was performed in the Cyclone ${ }^{\circledR}$ software program. The unified and registered point clouds were exported as a PTS format (Leica ASCII Unordered Interchange Format). The bare earth correction was a more automated procedure that required less data processing by the operator, hence, the main advantage of this method. The next step on the bare earth correction method had to be performed using the LAStools@ software program.

\subsubsection{LAStools@}

The next step in the bare earth correction method was to use LAStools@ software program to perform the removal of vegetation for each point cloud. The procedure followed was found in the literature by Crosby and Oskin (2011) from a Southern California Earthquake Center (SCEC) LIDAR short course. Specifically, the following LAStools software features were employed:

- LASground.exe: classification of points,

- LASthin.exe: filtering the classified point clouds,

- LASinfo.exe": used to record data about individual LAStools operations, LASsplit.exe: used to split the .las files into smaller segments for processing,

- LASmerge.exe: used to integrate processed files,

- txt2las.exe: convert .pts files to .las, and

- las2txt.exe: convert .las files to .txt for import to AutoCAD Civil 3D®.

As exported from Cyclone (in .pts format) each individual point cloud contained millions of points. LAStools $\bigcirc$ was used to perform both vegetation removal and reduce the amount of points to a practicable size. The LASground tool was used to classify all points in the point cloud 
as either ground or non-ground points (Figure 5.5). Classification was accomplished by imposing a three foot by three foot ( $3 \mathrm{ft} \times 3 \mathrm{ft}$ ) grid spacing on the point cloud. Extreme high or low points were excluded from the processing. The lowest point in each grid spacing was used to create a TIN surface. Each additional point was then iteratively compared to the TIN surface to refine the estimation of the ground surface.

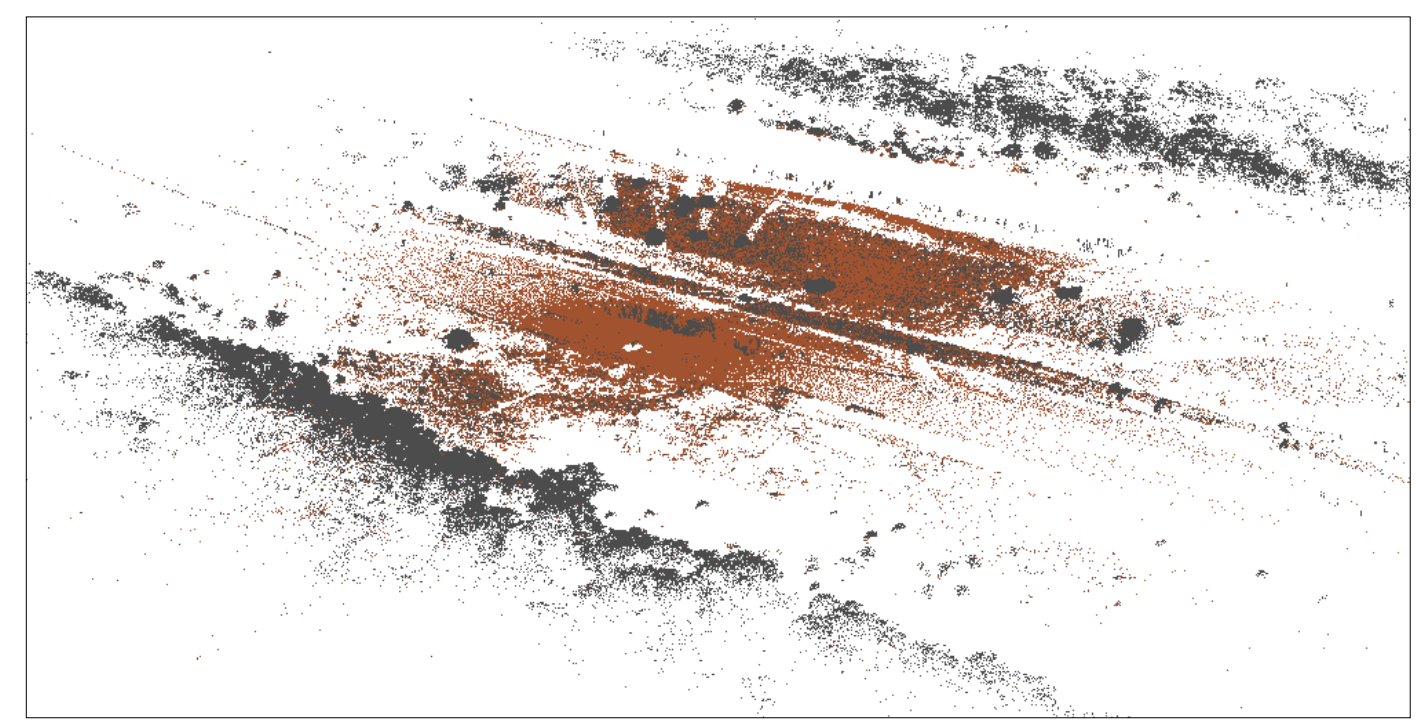

Figure 5.5. Classified point cloud as a non-vegetative layer and a vegetation layer.

The selected ground points were compared to the surrounding in the same grid ( $3 \mathrm{ft} . \mathrm{x}$ 3ft.), if the points were higher (elevation) than the ground points by 0.5 feet or 6 in the points were grouped as vegetation layer. All points classified as vegetation were then filtered out of the point cloud using the LASthin tool. A picture of the non-vegetative layer or ground points used for further analysis is presented in Figure 5.6. The size of the points clouds had to be reduced for practical handling with AutoCAD Civil 3D® software program. Further reduction or thinning of the point clouds was accomplished by dividing the point clouds containing the non-vegetation layers into three by three feet in calibration site (ten by ten for validation site) grids and selecting only the lowest (elevation) point in each grid. The final outcome of the bare earth process was a smaller point cloud (thousands instead of millions of points) containing only ground surface 
points. The ground surface points then were converted to text file containing the coordinates $(\mathrm{x}, \mathrm{y}, \mathrm{z})$ of each point for the final analysis in AutoCAD Civil 3D® software.

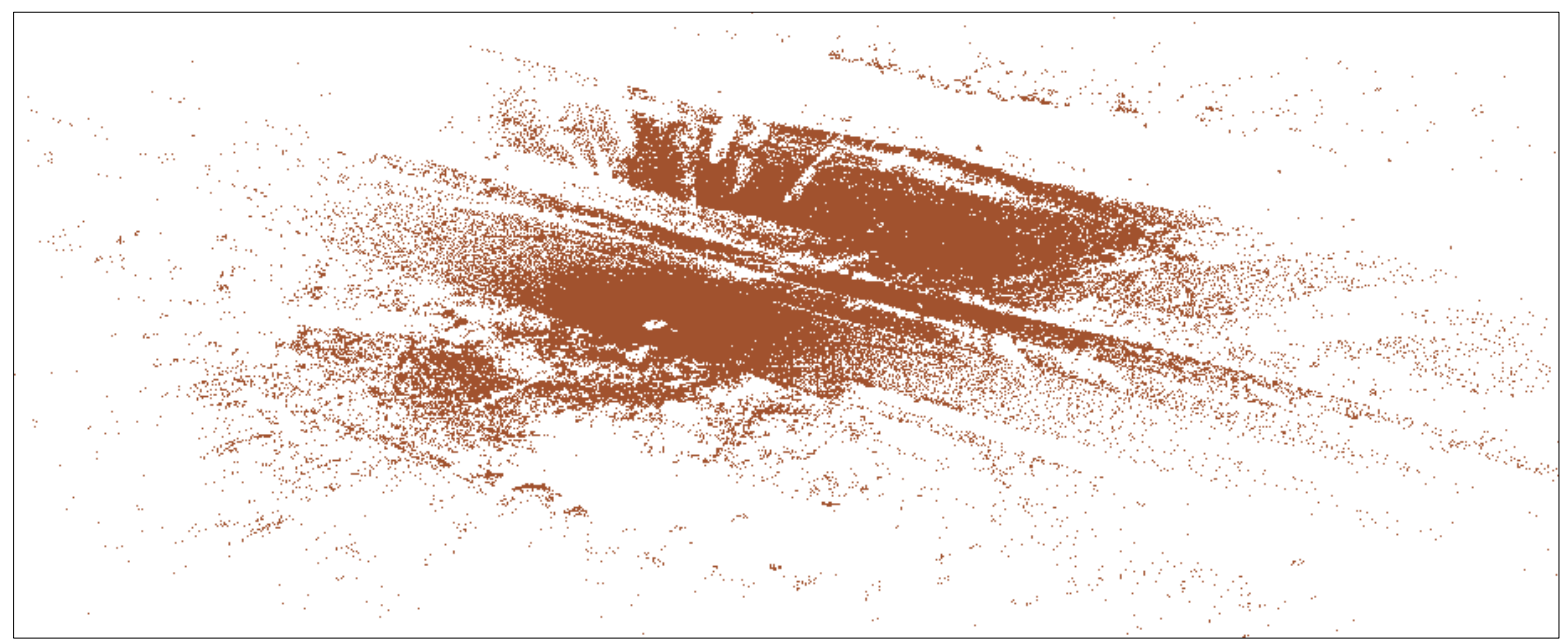

Figure 5.6. Point cloud after bare earth correction method.

\subsubsection{AutoCAD Civil 3D®}

The exported DXF files containing the ground polylines from Cyclone ${ }^{\circledR}$ had to be converted to DWG files, in order to be imported into AutoCAD Civil 3D®. Consequently, the ground polylines (DXF files) obtained via polyline mehod were first imported into the AutoCAD® software in order to convert the files from DXF to DWG format file. A step by step procedure for the conversion from DXF to DWG is presented in (Appendix Error! Reference source not found.)

The DWG file containing the ground polylines were then imported into AutoCAD Civil $3 \mathrm{D} \circledast$ to develop surfaces for each site visit. The surfaces were developed by interpolating between the ground polylines obtained after the polyline method performed in Cyclone ${ }^{\circledR}$. Once the created surface had been created for each site visit, the elevation difference between site visits were obtained by creating a volume surface. Volume surfaces are surfaces created in between the site visit surfaces in comparison. Volume surfaces are calculated from the volume 
between two surfaces (i.e. the initial measurement and subsequent measurements).Volume surfaces allowed the researchers to identify and quantize downward and upward movement of the surface in comparison by color intervals. User defined movement intervals were selected and colors were assigned to each interval in order to develop a movement ( $\mathrm{z}$ direction) color map of the site in AutoCAD Civil 3D® software program.

\subsection{In-situ Instrumentation Data Reduction}

The in-situ instrumentation installed at the validation site near Malvern, Arkansas was described in Section 4.6.3.1 Chapter 4. The data reduction or processing of the instrumentation consisted of transferring the recorded field data (voltages) measured using the inclinometers to a laptop or desktop computer. Data processing for inclinometers and vibrating wire piezometer was performed using Microsoft Excel®. Transfer of the raw data from the field recording devices was accomplished using several software programs (DataMate Manager (DMM)®, Microsoft Access®, and DigiPro®).

\subsubsection{Inclinometers Data Reduction}

The raw data collected in the field during the monthly site visits to the validation site were transferred from the slope inclinometer data collector box to a computer using a serial cable. The program utilized to retrieve the slope inclinometer data from the data collector box was DateMate Manager (DMM). DMM software was supplied by the manufacture of the Digitilt DataMate inclinometers and obtained via the Slope Indicator website (DataMate Manager Manual, 2011).

After data retrieval and transfer, the data sets were accessed using the Microsoft Access ${ }^{\circledR}$ software program. Data sets for each inclinometer on each site visit were subsequently imported (using copy and paste) into Microsoft Excel®. Once in Microsoft Excel, an average reading or "combined reading" $(\mathrm{CR})$ was calculated from the two readings obtained $\left(\mathrm{A}_{0}\right.$ and $\left.\mathrm{A}_{180}\right)$ per 
measurement direction (A-A' and B-B') using Equation 5.1 (Slope Indicator, 2001). Displacements were calculated by converting the readings from voltages to engineering units using the conversions formulas (Equation 5.2) and factors were given in the slope inclinometer manual (Slope Indicator, 2001). The data was also analyzed graphically using plots of inclinometer's casing deformation with depth developed using Microsoft Excel®. Additionally graphical representation of the data was obtained using the DigiPro® graphical software, provided by Slope Indicator. This software allowed for plotting the raw data immediately after retrieving it with DMM. The DigiPro® software offered limited plotting options and scales. Due to the limitation of the software the program was only used to validate the data plotted in Microsoft Excel®.

$$
\begin{aligned}
& C R=\frac{\left(\left(A_{0} \text { Re ading }\right)-\left(A_{180} \text { Re ading }\right)\right.}{2} \quad \text { (Slope Indicator, 2001) } \\
& \text { Displacement }=\frac{(4 i n) C R_{\text {current }}-C R_{\text {initial }}}{\text { ( } 0,000)} \quad \text { (Slope Indicator, 2001) }
\end{aligned}
$$

Equation 5.1

Equation 5.2

\subsubsection{Wire Piezometer Data Reduction}

The data reduction for the vibrating wire piezometer installed at the validation site in Malvern, Arkansas during the geotechnical investigation in October 2011 was performed using a data recovery box and Microsoft Excel®. Measurements were obtained from the vibrating wire piezometer on each site visit using the data recovery box. The voltages of every sensor in the vibrating wire piezometer were measured with the data recovery box and manually transcribed into a field data sheet. The recorded voltage and temperature values were converted to pressure units using Microsoft Excel® software program. The conversion factors and formulas utilize for the conversion were obtained from the vibrating wire piezometer user manual (Slope Indicator, 2008). Graphs of hydraulic pressure with depth were also developed using Microsoft Excel® 
software program. The ground water table depth on each visit was calculated using the pressure values obtained with the vibrating wire piezometer.

\subsection{Conclusion}

The data reduction methodologies employed in this research project (AHTD TRC-1102) were developed to ingest, process, and interpret the data collected from the various instruments. Each monitoring system required a separate procedure for data processing. The various software programs utilized for the data reduction are described in the different sections of this chapter. Due to the size of the validation site in Malvern, Arkansas, a turning error was observed in the total station data. Methods attempted to eliminate or reduce the error caused by the reading distances were described. Several methods were developed to attempt to remove some observed error in the total station data. The two methods endeavored during total station data reduction included angles method and tangent circles method. In order to generate an accurate measurement of the ground surface displacement it was necessary to develop a method to remove vegetative effects from the LIDAR data at both the calibration and validation sites. Two different methods were attempted for vegetation removal (polylines method and bare earth correction method) and the procedures undertaken for each method were presented in this chapter.

An overview of the procedure employed was discussed for each step of the data reduction process. The data reduction processes discussed in this chapter included the procedures developed for the remote sensing (total station, RADAR and LIDAR) as well as the in-situ instrumentation (inclinometers and vibrating wire piezometer) installed at the validation site. 


\section{Chapter 6. Results and Discussion}

\subsection{Introduction}

The results obtained during the AHTD TRC-1102 research project are presented in this chapter. Additionally, where possible any inferences or implications of these results are discussed. The findings of this research project have been categorized and are presented in independent sections of this chapter. These categories include samples recovered during geotechnical investigation, field strength index values (penetrometer, torvane), laboratory testing results (plasticity index properties and unconsolidated undrained test [UU]), and results from the three remote sensing techniques used to monitor the two sites (total station, LIDAR, and RADAR).

\subsection{Subsurface Exploration Results at the Validation Site (Malvern, Arkansas)}

The validation site subsurface exploration consisted of five subsurface borings (Boreholes-1, Boreholes-2, Boreholes-3, Boreholes-4, and Boreholes-6) taken to a depth of 100 feet below the ground surface. The site stratigraphy of observed at each boring is presented on the following sections. Material descriptions and properties were based on the borehole logs made on site and the strength index values obtained from field testing (pocket penotrometer and torvane). The sampling procedure employed at this site was previously discussed on Chapter 4. The North-South cross-section of the subsurface profile at the validation site obtained from the geotechnical investigation is presented in Figure 6.1. The findings and results of each individual boring are presented and discussed in the following sections. 


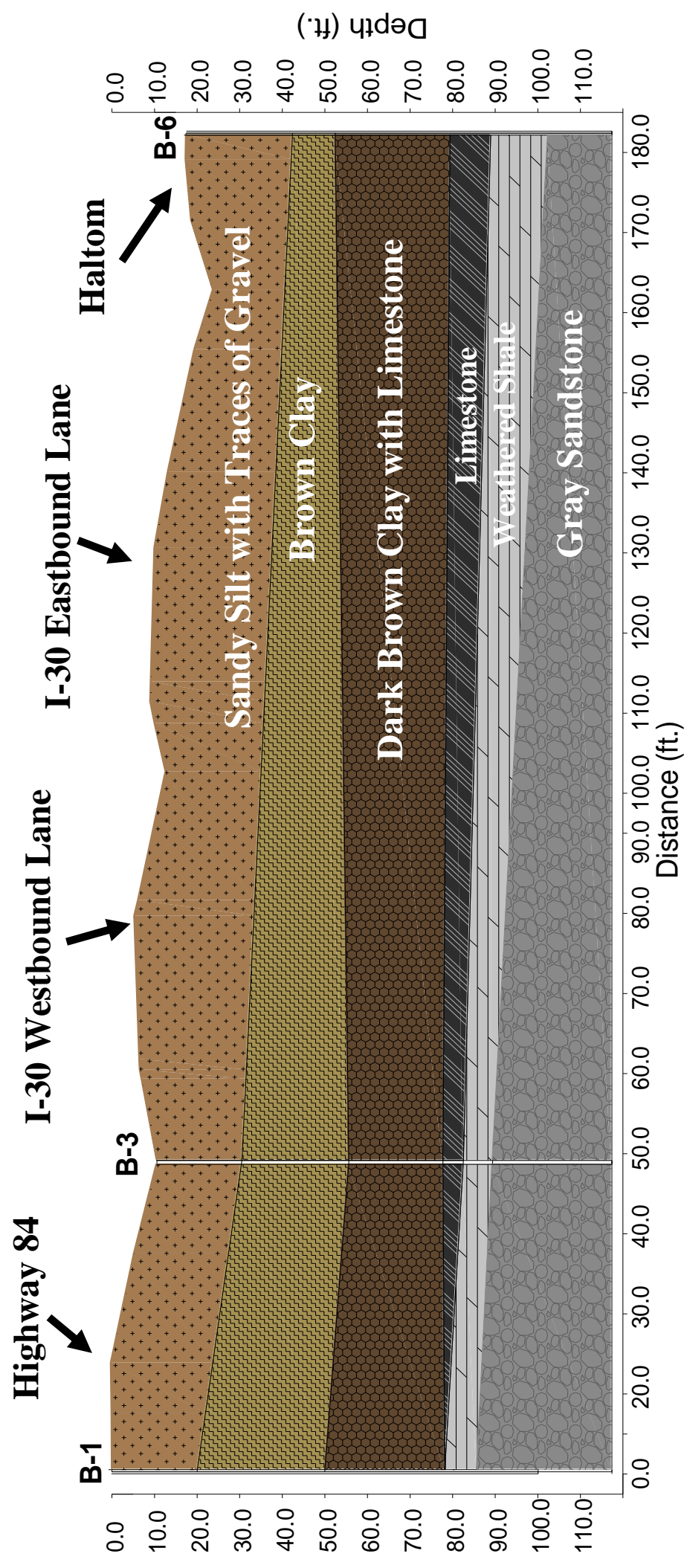

(t) पाdә0

Figure 6.1. Soil strata cross-section containing boreholes B-1, B-3 and B-6 in validation site near Malvern, Arkansas. 


\subsubsection{Borehole-1}

The first 20 feet were augured, from the cuttings the soil consisted of stiff brown clay with pea gravel inclusions. Drill crew changed to rotary wash at approximately 20 feet depth. Underlying this layer was a dark brown-gray clay extending to a depth of 75 feet. The browngray clay layer was observed to exhibit increasing strength with depth. Layers of limestone of approximately 1 foot thick were encountered in the brown-gray clay layer at depths of 48 feet and 68 feet. Between 75 feet and 80 feet hard layers of limestone and claystone were encountered. SPT refusal was recorded at 80 feet. A thick layer of dark gray shale towards the top and sandstone towards the bottom was encountered from 80 feet to a depth of 100 feet with rock quality designations ranging (RQD) from $99 \%$ on top to $55 \%$ in the bottom. Views of sampling operation at B-1 are illustrated in Figure 6.2. The boring logs for Borehole-4 (B-1) are presented in Appendix Error! Reference source not found.

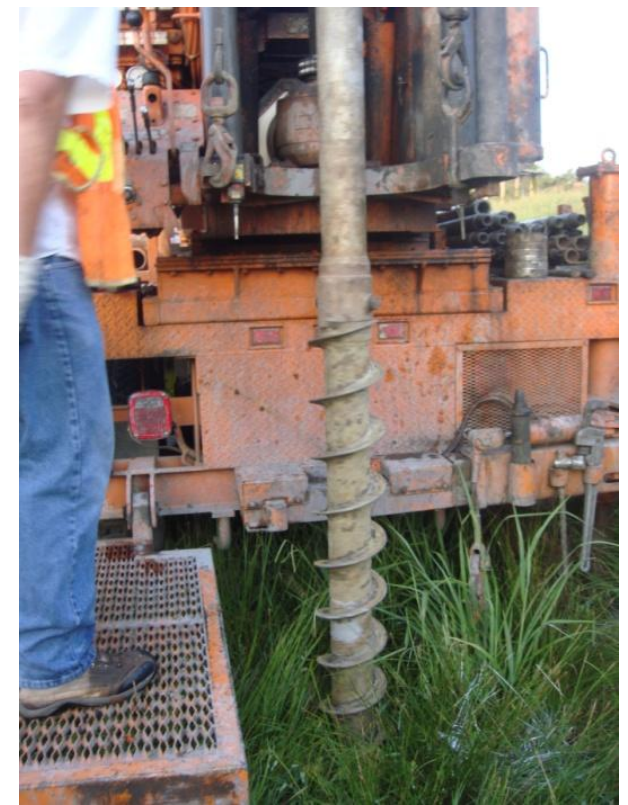

(a)

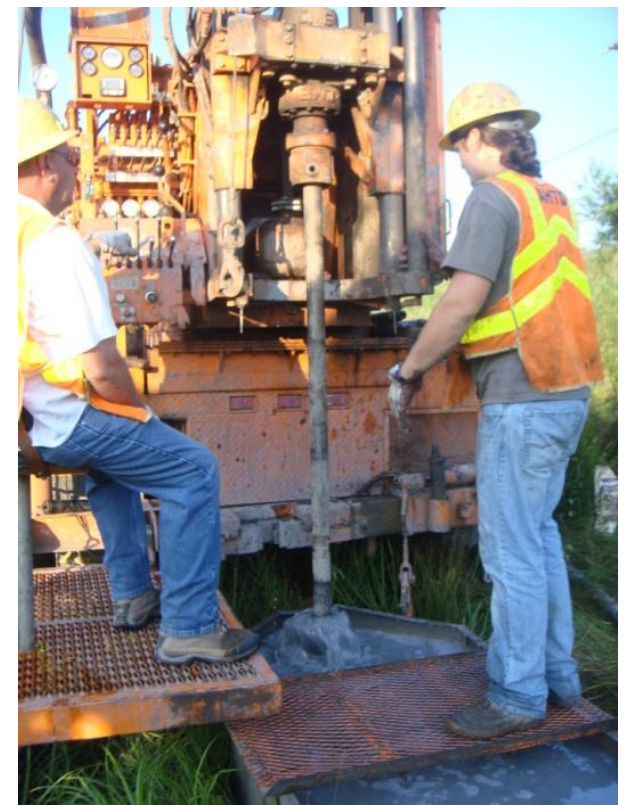

(b)

Figure 6.2. a) Auguring first 20 feet at B-1, and b) rotary wash method being performed at B-1. 


\subsubsection{Borehole-2}

Borehole drilled between two days 07-18-2011 to 07-19-2011. At this location a layer of molted brown-gray clay was encountered until a depth of 25 feet. Rotary wash method was started at approximately 18 feet below ground surface. A 1.5 foot thick layer of limestone of was encountered at 25 feet, underlain by a thick layer of blocky hard dark clay to a depth of 40 feet. Between depth of 40 feet and 60 feet a second (softener) brown-grey clay layer with traces of limestone was encountered. From 60 feet to 68 feet a hard dark clay layer was reached. SPT refusal was occurred at a depth of 68 feet, and coring was immediately started on 5 feet intervals from a depth of 68 feet. Weathered shale layer was encountered to a depth of 78 feet. A 20 feet layer of sandstone was encountered until a depth of 98 feet with RQD ranging from $75 \%$ to $92 \%$. Rock sample box obtained and end hole conditions presented on Figure 6.3. The boring logs for Borehole-2 (B-2) are presented in Appendix Error! Reference source not found.

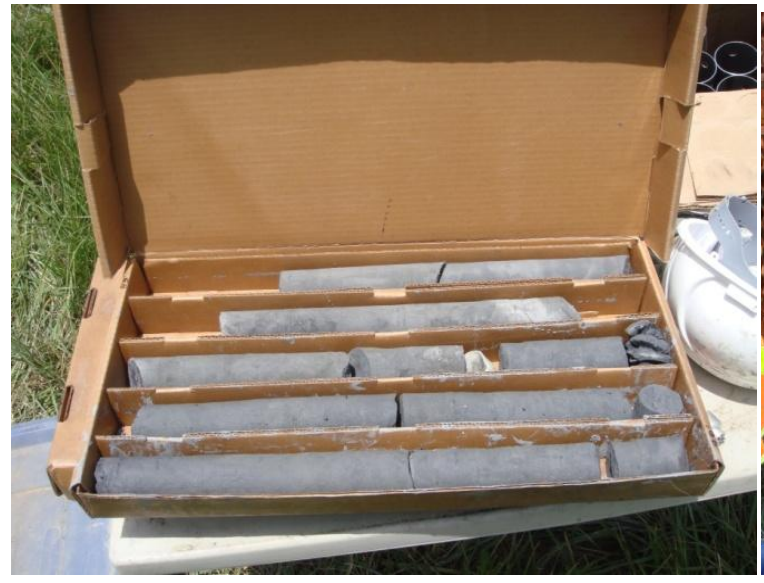

(a)

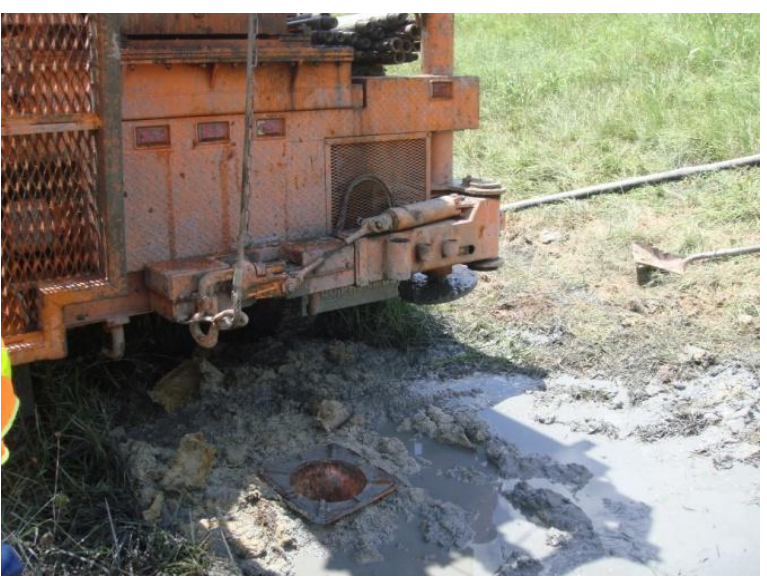

(b)

Figure 6.3. a) Rock sample obtained coring at B-2 (validation site), and b) post-drilling conditions at B-2

\subsubsection{Borehole-3}

Borehole drilled between two days 07-13-2011 to 07-14-2011. The initial 20 feet consisted of a layer of gray clay with sand in the first 5 feet and with traces of silt towards the 
bottom of the layer. Approximately below 20 feet a thin layer of limestone was noticed. Drill crew changed to rotary wash at approximately 22 feet below ground surface. A thick layer of dark very stiff to hard clay with traces of gravel and limestone was encountered to a depth of 67 feet. Below 67 feet a layer of weathered claystone was observed until 71.5 feet where SPT refusal was reached. Coring was started at approximately 71.5 feet. A layer of claystone was encountered from 71.5 feet to 100 feet depth with RQD of $17.5 \%, 68 \%$ and $90 \%$. A photograph of drilling operations while taking place at B-6 and measuring RQD of a rock sample is presented in Figure 6.4. The boring logs for Borehole-4 (B-4) are presented in Appendix Error! Reference source not found.

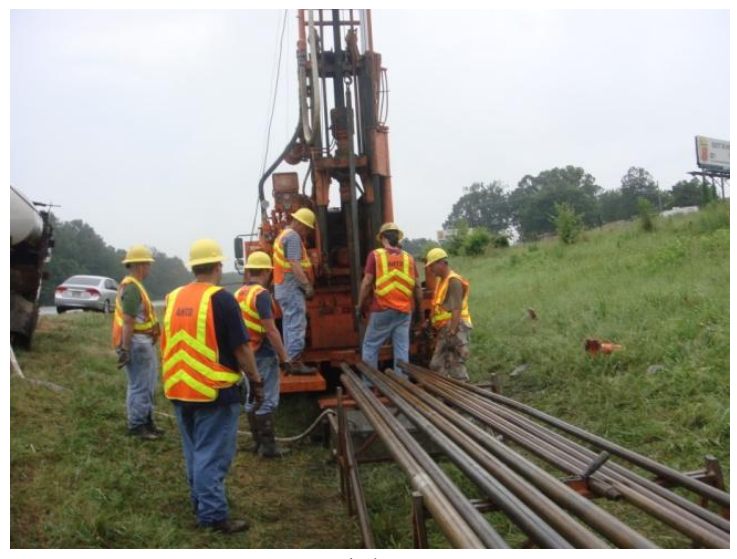

(a)

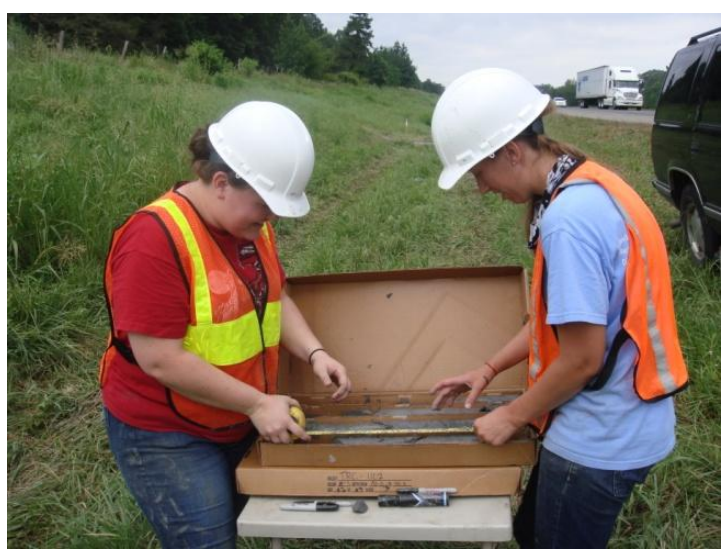

(b)

Figure 6.4. a) Drilling operations at B-3, and b) measuring RQD of rock sample obtained from B-3.

\subsubsection{Borehole-4}

Borehole drilled between two days 07-11-2011 to 07-12-2011. Drill crew changed to rotary wash at approximately 6.5 feet below ground surface. A uniform layer of brown to gray clay with traces of gravel was encountered at this location until a depth of 45 feet. Between 45 feet to 75 feet gray clay with some limestone layers were observed. Below 75 feet SPT refusal was reached, but coring was performed. A layer of weathered to more competent sandstone was encountered to from 75 feet to a depth of 91 feet, underlain by 9 feet of weathered shale and hard 
sandstone to a depth of 100 feet below ground surface. A photograph of the pre-drill conditions at B-4 and researchers performing torvane test at the end of a Shelby tube sample are presented in Figure 6.5. The boring logs for Borehole-4 (B-4) are presented Error! Reference source not

\section{found.}

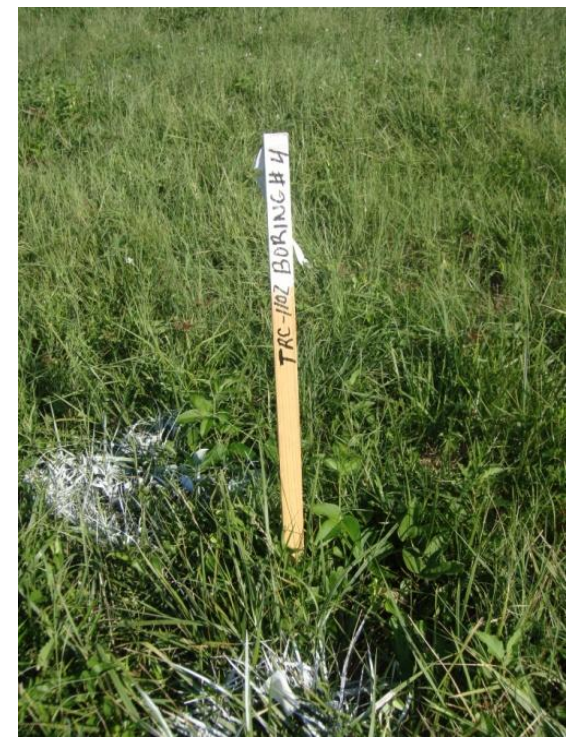

(a)

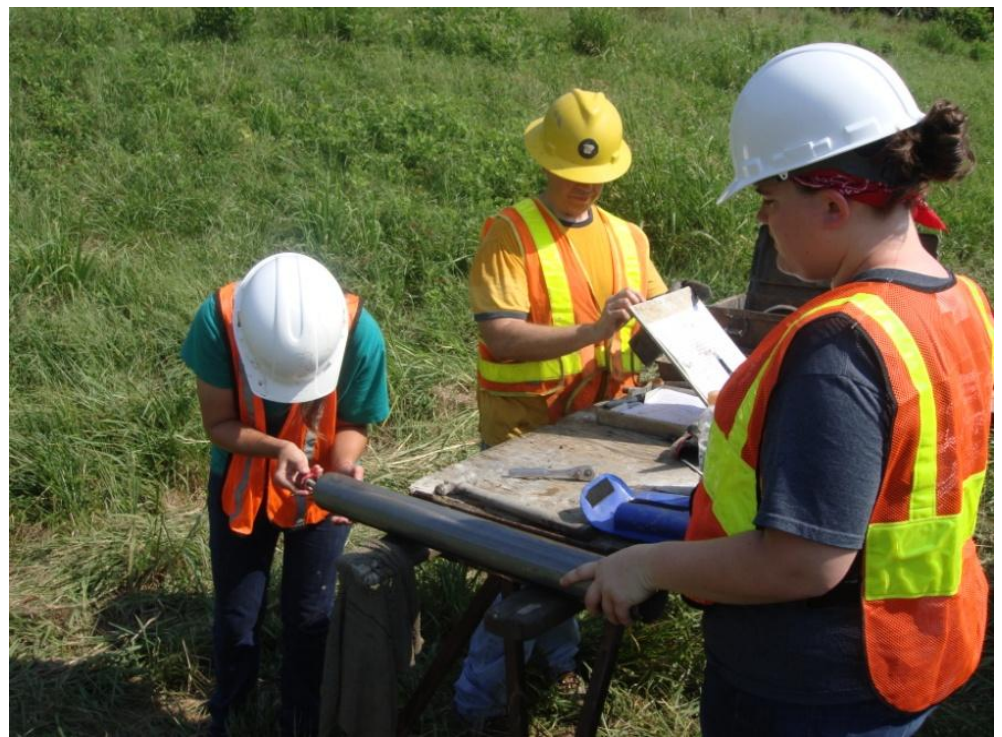

(b)

Figure 6.5. a) Pre-drilling conditions at B-4, and b) torvane test being performed in Shelby tube soil sample.

\subsubsection{Borehole-6}

Borehole drilled between two days 07-19-2011 to 07-20-2011. Rotary wash method started at 15 feet below ground surface. The first 6 feet consisted of brown clayey sand (probably road fill), underlain by a layer of dark gray clay to a depth of 41.5 feet below ground surface. A two foot thick layer of gray fine sand with clay was logged at 45 feet. From a depth of 47 feet to 60 a dark gray clay layer was observed. Coring was started at 61 feet. Between a depth of 61 feet and 67 feet a layer of limestone with clay intrusions and a RQD of 23\% was found. From 67 feet depth to approximately 75 feet a layer of conglomeratic limestone with dipping bedding angles (indicating the failure surface intersecting this boring at this depth) and some sandstone with an RQD of $50 \%$ was encountered. Below 75 feet (until borehole termination at 100 feet) a 
thin layer of shale was observed underlain by a thick layer of sandstone with RQD values ranging from $38 \%$ to $83 \%$ until a depth of 100 feet below ground surface. A photograph of the B-6 location and a rock sample obtained from B-6 are presented in Figure 6.6. The boring logs for Borehole-4 (B-4) are presented in Appendix Error! Reference source not found..

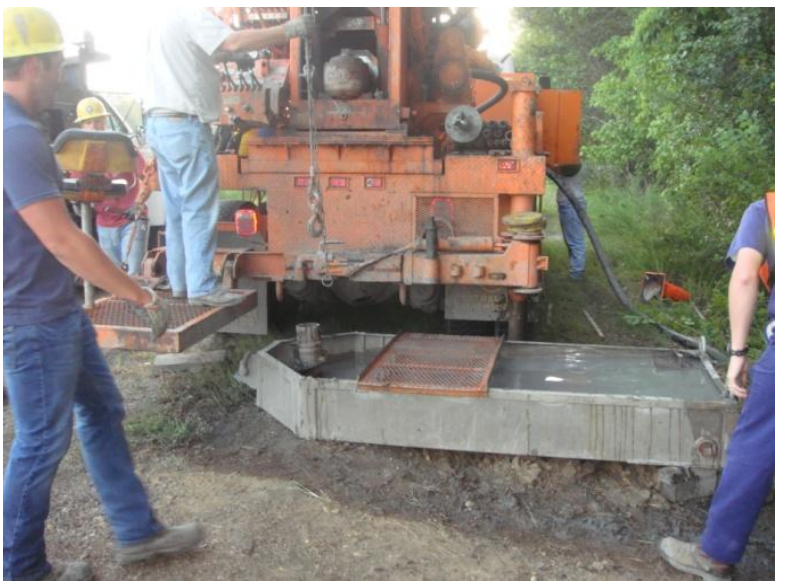

(a)

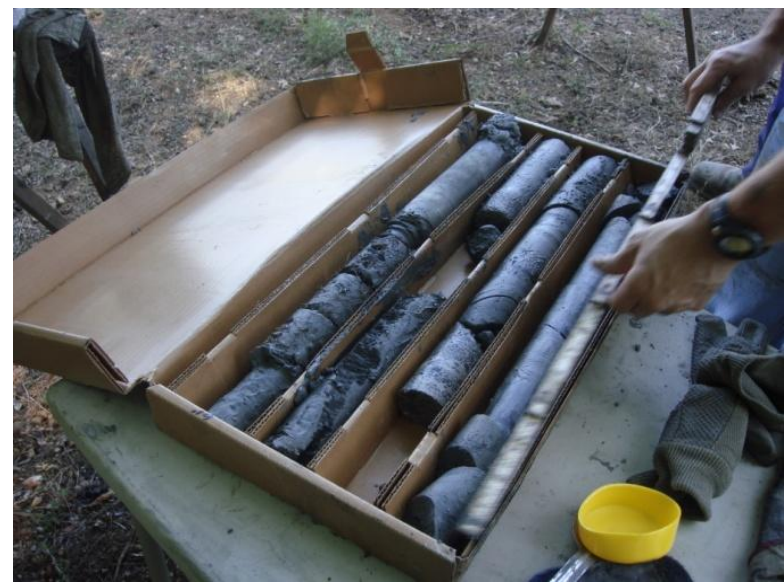

(b)

Figure 6.6. a) Changing to rotary wash method at B-6, and b) rock sample obtained from B-6.

\subsection{Laboratory Testing Results}

The laboratory testing for this project consisted on index properties (Atterberg Lmimits) for soil classification, field water content, and unconsolidated undrained (UU) tests. The index strength properties (torvane, penetrometer) obtained in the field served as guidelines to size the load cells used for the UU tests. All tests (field and lab) were performed by researchers from the University of Arkansas. Results from the different test performed are presented in the following sections.

\subsubsection{Moisture Content and Index Properties}

Water contents obtained after the UU samples were tested varied (dryer) from the field moisture contents obtained while sampling (Figure 6.8). The variance in moisture contents is attributable to several factors including: loss in moisture in the Shelby tubes in transportation and storage between sampling and laboratory testing. Another potential factor which may have 
artificially increased the measured field water content is the presence of drilling fluid used during the rotary wash method.

As previously discussed in Section 4.7.1, Atterberg limits were conducted on all Shelby tube samples to obtain the index properties of the soil. Liquid limit and plastic limit test were conducted on UU specimens. The majority of the recovered samples were classified as either a high plasticity silt $(\mathrm{MH})$ or a high plasticity clay $(\mathrm{CH})$. The results of Atterberg limit testing for all of the samples recovered from the validation site (Malvern, Arkansas) are presented in Figure 6.7 .

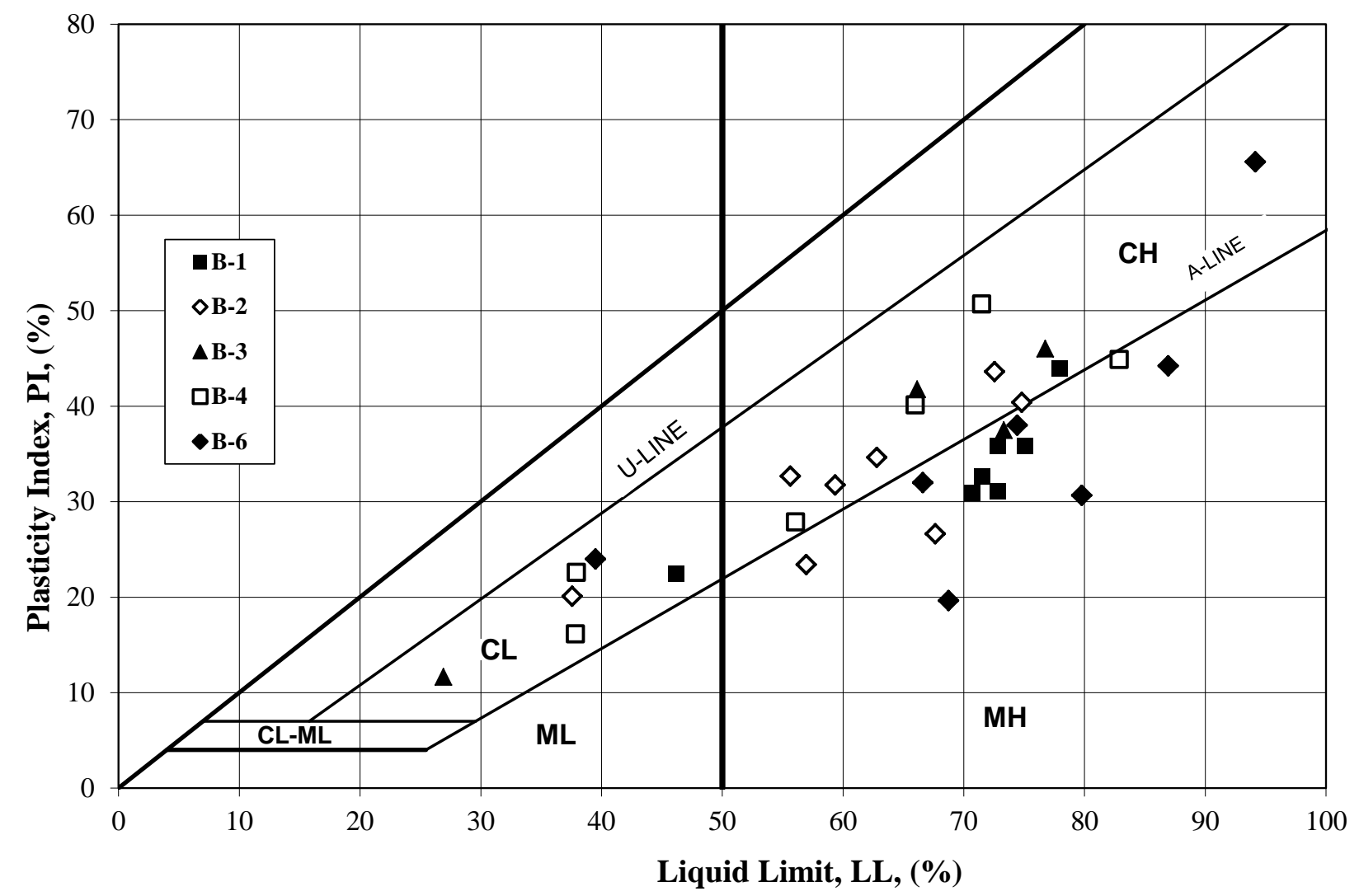

Figure 6.7. Soil index properties for recovered samples from the validation site as determined by Atterberg Limit tests. 


\subsubsection{Unit Weights}

The unit weights were measured from each of the UU soil specimen as discussed previously in Section 4.7.3. The unit weights for soils in this site ranged from 108 pcf to 125 pcf. For the rock samples (limestone, sandstone) the unit weights ranged from 125 pcf to 159 pcf.

The measured sample unit weights were used in conjunction with the results of the Plastic Limit testing to determine soil stratification and layer boundaries. The in-situ water contents were closer to the Plastic Limit (PL) than to the Liquid Limit (LL). The water content (field and lab), Atterberg limits, void ratio, and unit weights for validation site samples was compiled. The average or design values were selected and presented in Figure 6.8. All the values obtained are also plotted by hole and presented in Appendix Error! Reference source not found.. 


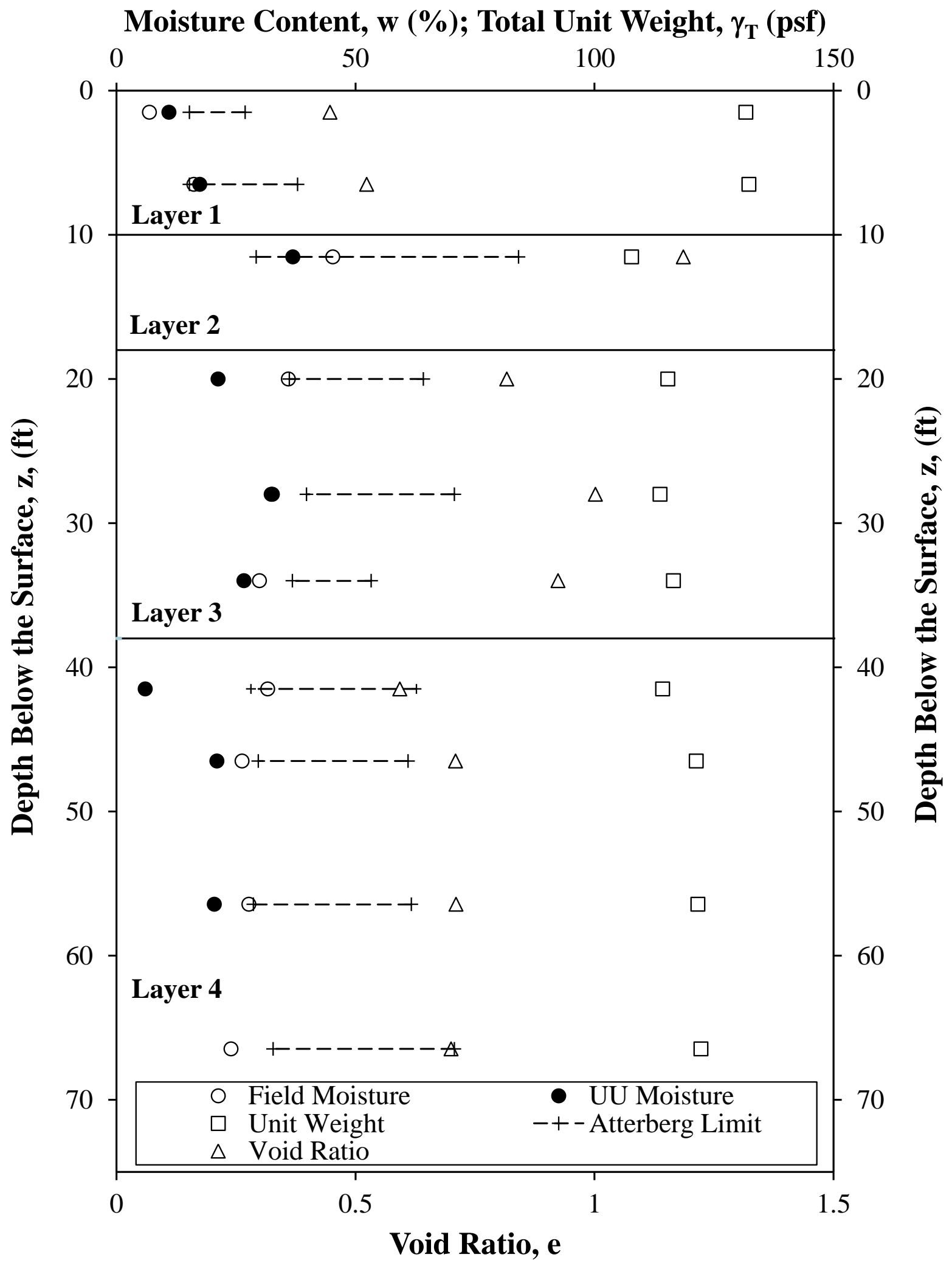

Figure 6.8. Design moisture content, unit weight and Atterberg Limits profile. 


\subsubsection{Unconsolidated Undrained (UU) Triaxial Test}

Unconsolidated Undrained triaxial (UU) tests were performed on the clay samples obtained from the Shelby tubes recovered at the validation site. The UU tests were performed in accordance with (ASTM D2850, 2007) as previously described in Section 6.3.2. A deviation from ASTM D2850 was the measurement of the piston friction force at the beginning of the test by leaving a small gap between the piston and the top cap of the specimen

Softening behavior was observed in all the specimens during UU testing was performed. The maximum undrained shear strength values obtained varied with the depth of the sample, moisture content and soil type. For each test important parameters such as: the Peak Principal Stress Difference (PPSD), the peak maximum undrained shear stress (q), the axial strain at PPSD, the axial strain at 50 percent PPSD, and the residual undrained shear stress at 12.5 percent axial strain were calculated. Reduced results from the UU testing conducted during this research project are attached as Table C.4.1 located in Appendix Error! Reference source not found.. A distinct loss shear strength was observed between the peak undrained shear stress values and the residual undrained shear stress values for most of the specimens recovered at a depth greater than 61 feet. Normalized stress-strain curves were developed for each UU test. The curves allowed to determine if any errors with piston, sensors, pressure transducers etc. were encountered during each UU test. A normalized stress-strain graph for the B-2 specimens between $51.5 \mathrm{ft}$. to $67.5 \mathrm{ft}$. is presented in Figure 6.9. The rest of the graph for the rest UU test conducted in specimens from validation site are presented in Appendix Error! Reference source not found.. 


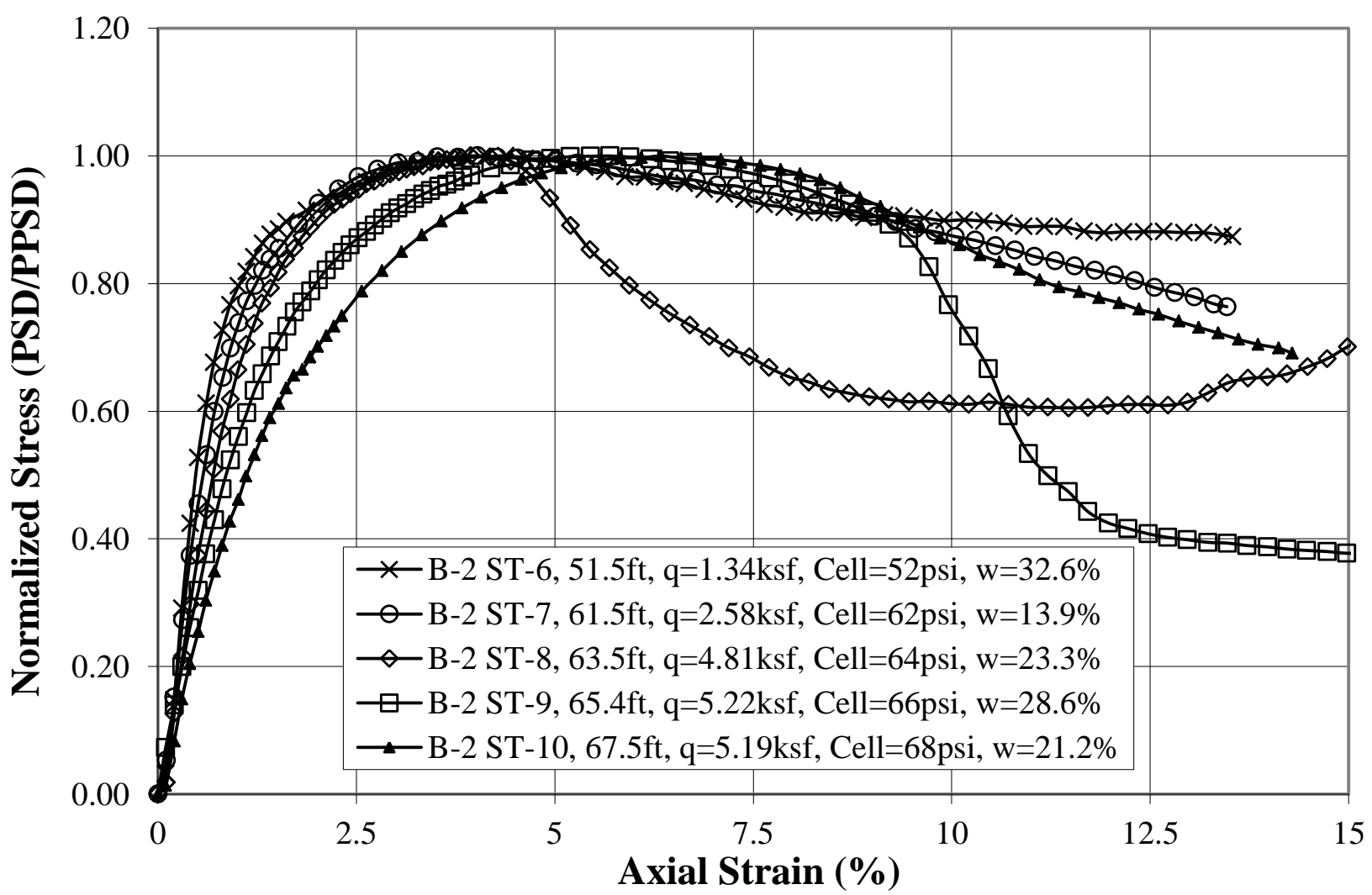

Figure 6.9. Normalized stress-strain graph of UU test for B-2 specimens at validation site.

The maximum undrained shear stress values and residual stress values obtained from the UU tests, and the strength index values (penetrometer/torvane) where compared. The penetrometer and torvane results were obtained in the field during the geotechnical exploration (Section 4.6.2). Penetrometer and torvane values were measured in tons per square feet (tsf) and converted to kips per square feet (ksf) to compare with the values of undrained shear strength $\left(\mathrm{S}_{\mathrm{u}}\right)$ obtained from UU test. The penetrometer values measured were unconfined compression values and therefore the measured value had to be divided by two in order to obtain undrained shear strength. Conversely, the values measured with the torvane were undrained shear strength values that had to be multiply by the shoe factor (2.5).

The unconsolidated undrained (UU) parameters resulted in higher undrained shear strength than the values obtained by penetrometer and torvane. In general, torvane values resulted in the lowest undrained shear strength values. The calculated values for strength as 
obtained using laboratory and field testing as well as correlations between standard penetration test results and undrained shear strength (as described later in 6.4) are presented in Table 6.5.

Four distinct soil layers with different strength ranges were observed from the calculated design strength profile. The increase in undrained shear strength in the first layer is attributable to effective overconsolidation in this layer caused by desiccation. An increased in undrained shear strength with depth was observed for the different layers in the profile (below the desiccation zone). However, some outliers that did not follow the trend were observed. It is hypothesized that these outlying measured strength values are caused by either sample disturbance or laboratory error in the UU testing. The design strength profile for the validation site near Malvern, Arkansas is presented in Figure 6.10. All the individual strength profiles for all the boring holes are presented in Appendix Error! Reference source not found.. 


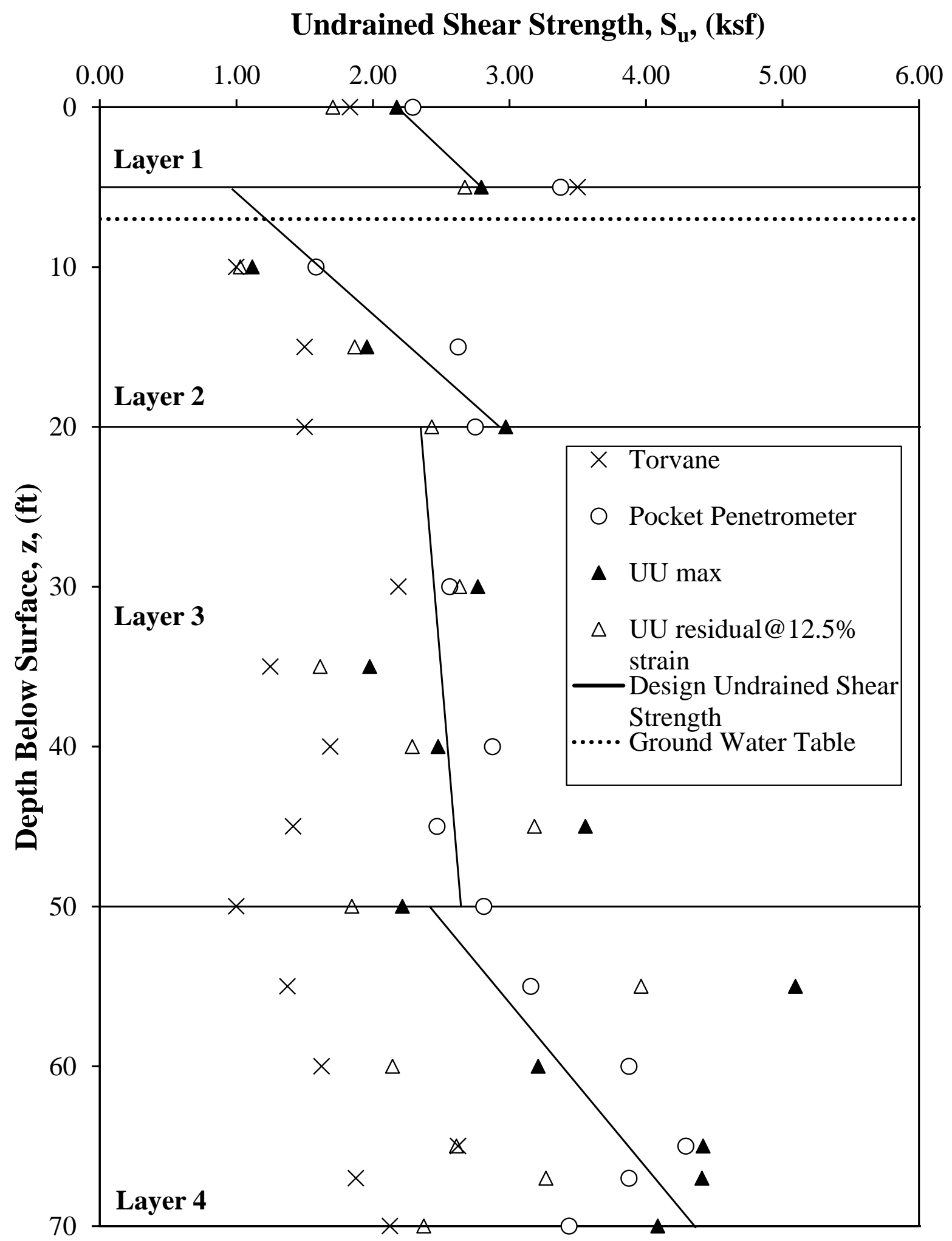

Figure 6.10. Design strength profile for validation site near Malvern, Arkansas. 
The results of the rock samples tested allowed the detection of a hard layer of limestone at approximately $68 \mathrm{ft}$ to $72 \mathrm{ft}$ on top of a weathered shale layer. The strength values obtained ranged from $14 \mathrm{ksf}$ to $211 \mathrm{ksf}$. A sandstone layer was observed at depths greater than 90 feet in all the boreholes sampled. A summary of the results after testing of the rock samples are summarized in Table 6.1. Four rock samples of the hard limestone were tested for Unconfined Compression (UC). The results of the unconfined compression test are tabulate in Table 6.2.

Table 6.1. Summary of rock sample tested in confined compression test.

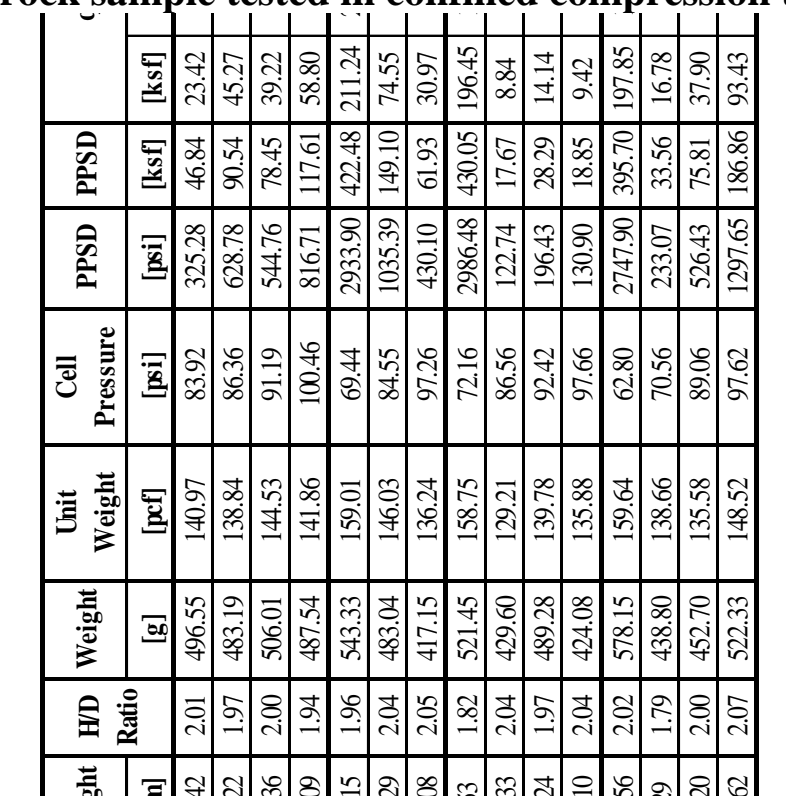

Table 6.2. Summary of unconfined compression test results performed in rock samples.

\begin{tabular}{|c|c|c|c|}
\hline Borehole & Depth (ft.) & Pressure (psi) & Force (lb) \\
\hline B2 & 69 & 4894 & 15380 \\
\hline B2 & 72 & 3612 & 11350 \\
\hline B3 & 72 & 3770 & 11840 \\
\hline B6 & 100 & 2515 & 7900 \\
\hline
\end{tabular}

\subsection{Preliminary Slope Stability Analyses}

The SLIDE v5.044 software (Slide, 2010) was used to model and analysis the stability of both the calibration and validation sites. Both slope stability analyses were conducted as per the procedure and parameters previously described in Section 3.2.3. For both sites the slope stability was evaluated using Bishop's simplified method and Janbu's method (Slide 2010). The analyses 
were configured to perform 2000 iterations, a tolerance of 0.05 and the number of slices was set to 100 .

For the calibration site, the slope stability analysis of the calibration was performed using historical data (Westerman, 2006) since no additional geotechnical exploration was conducted at this site during this research project. Conversely, two slope stability analyses were performed at the validation site near Malvern, Arkansas. An initial slope stability analysis was performed using the historical data (diagrams and boring log information) previously described in Section 3.2.3. Following the completion of the geotechnical investigation at the validation site (as part of the scope of this project), the additional data was used to construct a refined slope stability analysis. The results of each slope stability simulation are presented in the following sections.

\subsubsection{Preliminary Slope Stability Analysis at the Calibration Site (Chester, Arkansas)}

Three separate correlations between standard penetration test (SPT) results and undrained shear strength $\left(\mathrm{S}_{\mathrm{u}}\right)$ as proposed by UARK (Ritchey, 1999), AHTD (Schubel, 2011), and Terzaghi (Terzaghi and Peck, 1967) were used in the slope stability analyses conducted at the calibration site. The minimum factors of safety (FS) that resulted from the slope stability analysis using the three SPT-S $\mathrm{u}_{\mathrm{u}}$ correlation methods are summarized in Table 6.3. The UARK correlation resulted in the lowest factor of safety, a factor of safety of 1.003 The factor of safety (1.003) provided by this model indicates that this slope was at, or near, failure conditions and that therefore movement was expected to occur. The movement observed at the site provides justification for this back-analysis of the slope. The AHTD correlation and Terzaghi correlation resulted in calculated factors of safety of 3.384 and 3.352, respectively. These factors of safety are sufficiently high to indicate that the slope would experience no movement. Therefore, the movement observed at the site supports for the use of the UARK correlation at this site. The superior shear strength prediction of the UARK correlation was anticipated since the UARK 
correlation was developed from back analysis of slope failures occurring in local (Northwest Arkansas) soil types and topographical and climatological conditions. Following the observation of a main failure scarp at the calibration site during site visits the slope stability model was recalculated using failure slices coinciding with the observed feature. Slope stability analysis performed using the refined failure geometry generated a minimum factors of safety of 1.319 and 1.511. The results of the SLIDE v. 5.044 (2010) limit equilibrium slope stability analysis are displayed in Figure 6.11.

Table 6.3. Summary of factors of safety obtained using different SPT-S $\mathrm{S}_{\mathrm{u}}$ correlation methods for calibration site

\begin{tabular}{|c|c|}
\hline Correlation Method & Factor of Safety (FS) \\
\hline UARK & 1.003 \\
\hline Terzaghi & 3.352 \\
\hline AHTD & 3.384 \\
\hline
\end{tabular}

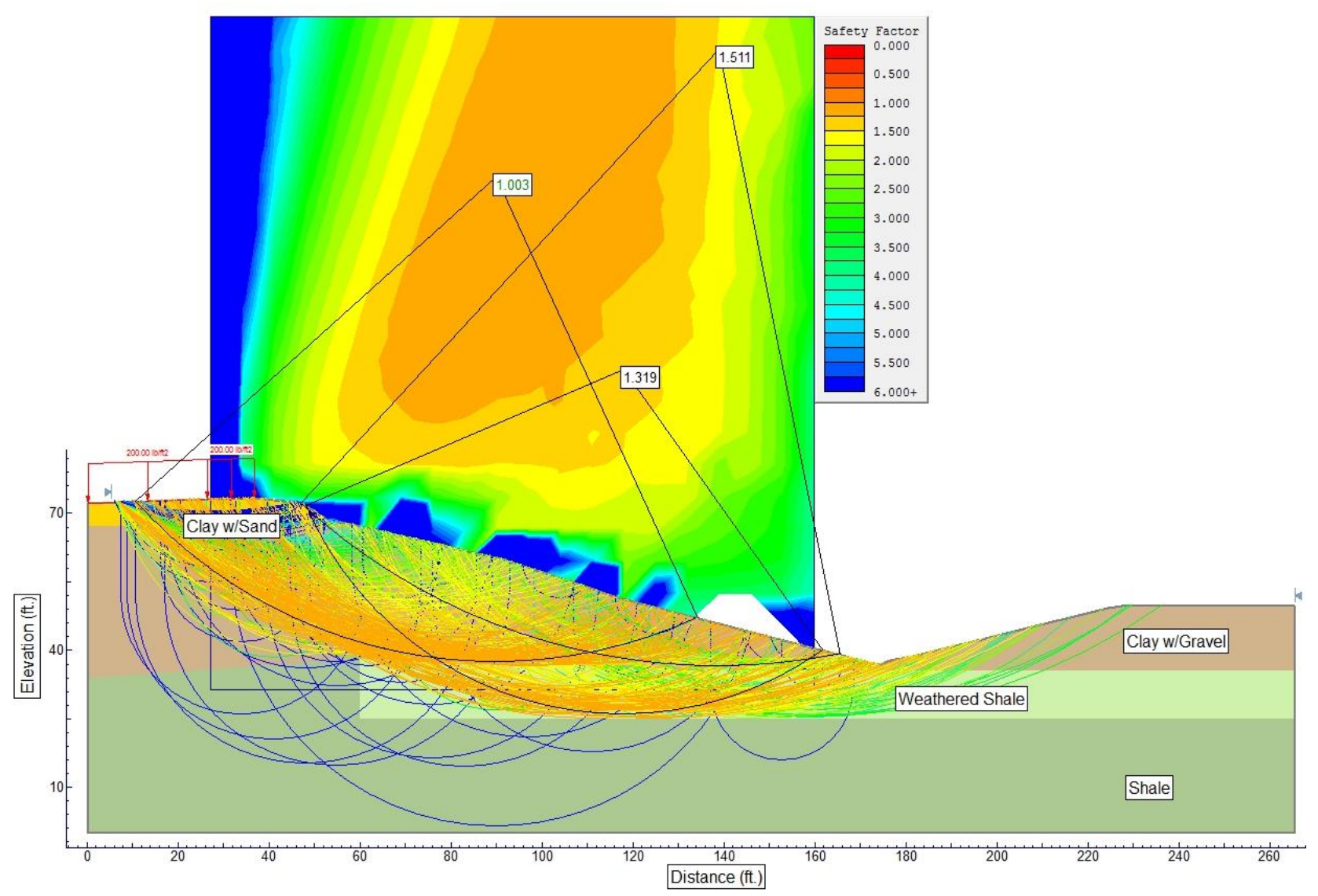

Figure 6.11. Slope stability analysis using the UARK correlation for the calibration site. 


\subsubsection{Preliminary Slope Stability Analysis at the Validation Site (Malvern, Arkansas)}

As previously discussed in Section 3.3.3, the initial slope stability analysis for the validation site was performed using the geometry of diagrams found in the documentation and the boring log information from subsurface explorations performed prior this research project (AHTD TRC-1102). The soil parameters used for the initial slope stability analysis are summarized in Table 3.4. The FS obtained from the initial slope stability analysis (using the UARK, AHTD, and Terzaghi correlations) for validation site are summarized in Table 6.4. The FS obtained using the UARK correlation was unreasonably low at 0.378. This value is significantly lower than the FS obtained using the AHTD and Terzaghi correlations (1.373 and 1.30, respectively). Therefore, it is implied that the UARK correlation is only applicable for slope failures in NWA. The output images for the limit equilibrium slope stability analysis are presented in Appedix. As previously discussed, a more refined slope stability analysis was performed using data obtained during the subsequent geotechnical investigation at the validation site.

Table 6.4. Summary of results for the preliminary slope stability analysis of the validation site.

\begin{tabular}{|c|c|}
\hline Correlation Method & Factor of Safety (FS) \\
\hline Terzaghi & 1.373 \\
\hline AHTD & 1.430 \\
\hline UARK & 0.378 \\
\hline
\end{tabular}

\subsection{Refined Slope Stability Analysis at the Validation Site (Malvern, Arkansas)}

The results from the slope stability analysis preformed for the validation site is presented in this section. The slope stability analyses were performed using Slide v. 5.044 (2010). The methods selected to perform the slopes stability analysis were Bishop's simplified method and Janbu's simplified method (SLIDE, 2010). As for the preliminary slope analysis the three SPT- 
to- $\mathrm{S}_{\mathrm{u}}$ correlations (UARK, AHTD, Terzaghi) were employed in addition to the laboratory determined shear strength data.

A more refined slope stability analysis was performed using the results of field and laboratory testing. The undrained shear strength $\left(\mathrm{S}_{\mathrm{u}}\right)$ of the clay layers correlated using the three SPT-S $\mathrm{u}_{\mathrm{u}}$ correlations (UARK, AHTD, Terzahi) were also compared to the undrained shear strength (maximum and residual) obtained from UU test in the laboratory. The parameters utilized in the refined slope stability analysis are summarized in Table 6.5.

The geometry utilized in the slope stability model was obtained from the topographic three-dimensional model developed in AutoCAD Civil 3D® (AutoCAD, 2010). Specifically, a cross-section from the North side of the model (hillside) to the South of Highway 84 was selected and imported into the slope stability model. The soil layers were classified after the soil exploration performed in October 2010.

Table 6.5. Summary of soil parameters used in the refined slope stability analysis at the validation site near Malvern, Arkansas. 


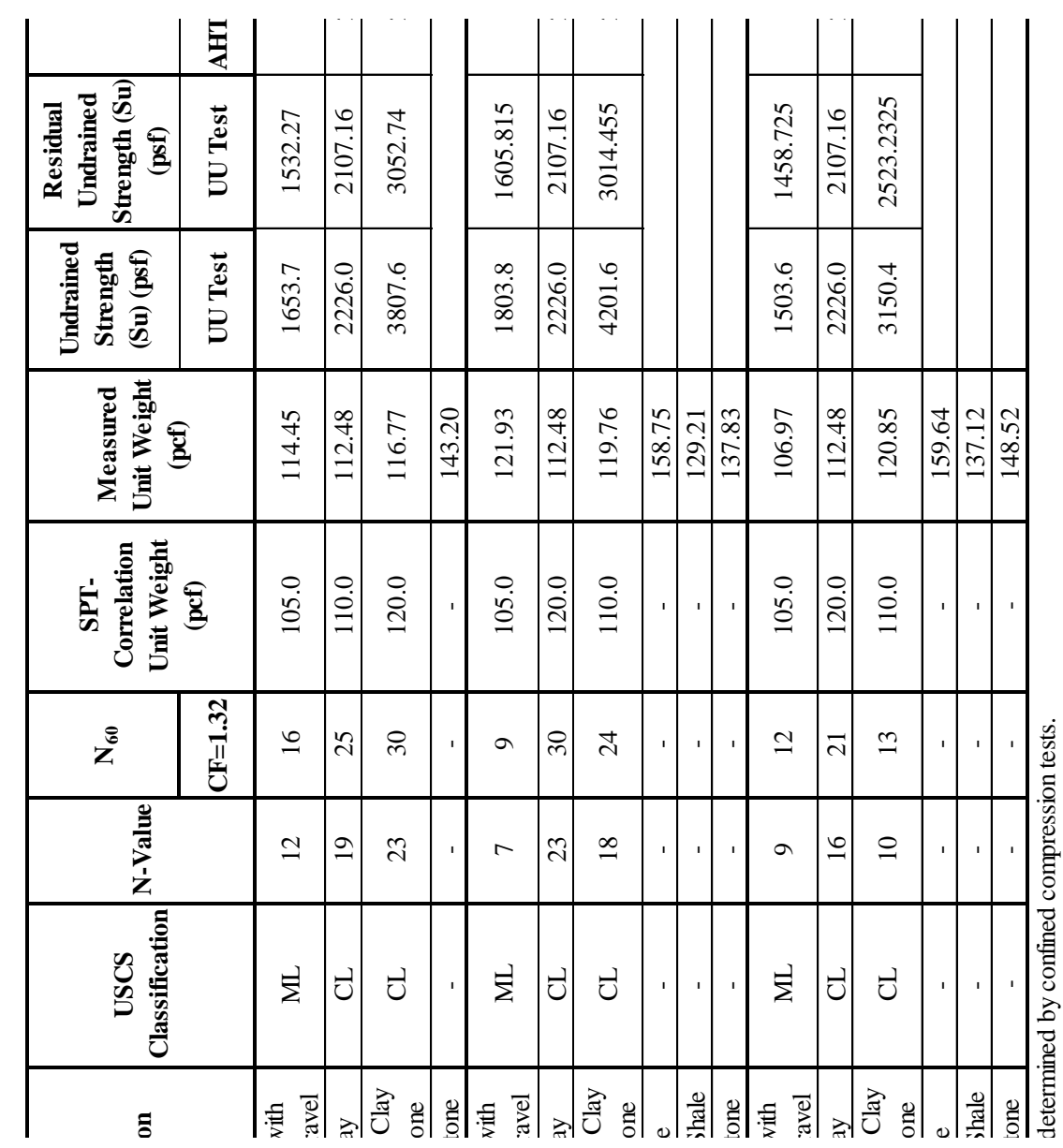

The UARK correlation resulted in the lowest FS of 0.679. The highest FS was obtained from the UU test peak shear strength parameters. The factors of safety obtained after the refined slope stability analysis at the validation site are summarized in Table 6.6. The results of the SLIDE v. 5.044 (2010) limit equilibrium slope stability analysis using the UU test residual parameters is displayed in Figure 6.12. The limit equilibrium slope stability analyses for the other parameters are presented in Appendix Error! Reference source not found..

Table 6.6. Summary of factors of safety obtained after refined slope stability analysis for the validation site.

\begin{tabular}{|c|c|}
\hline Correlation Method & Factor of Safety (FS) \\
\hline UARK & 0.679 \\
\hline Terzaghi & 2.479 \\
\hline AHTD & 2.674 \\
\hline UU TEST-residual & 2.931 \\
\hline
\end{tabular}




\begin{tabular}{|l|l|}
\hline UU TEST-max & 6.672 \\
\hline
\end{tabular}




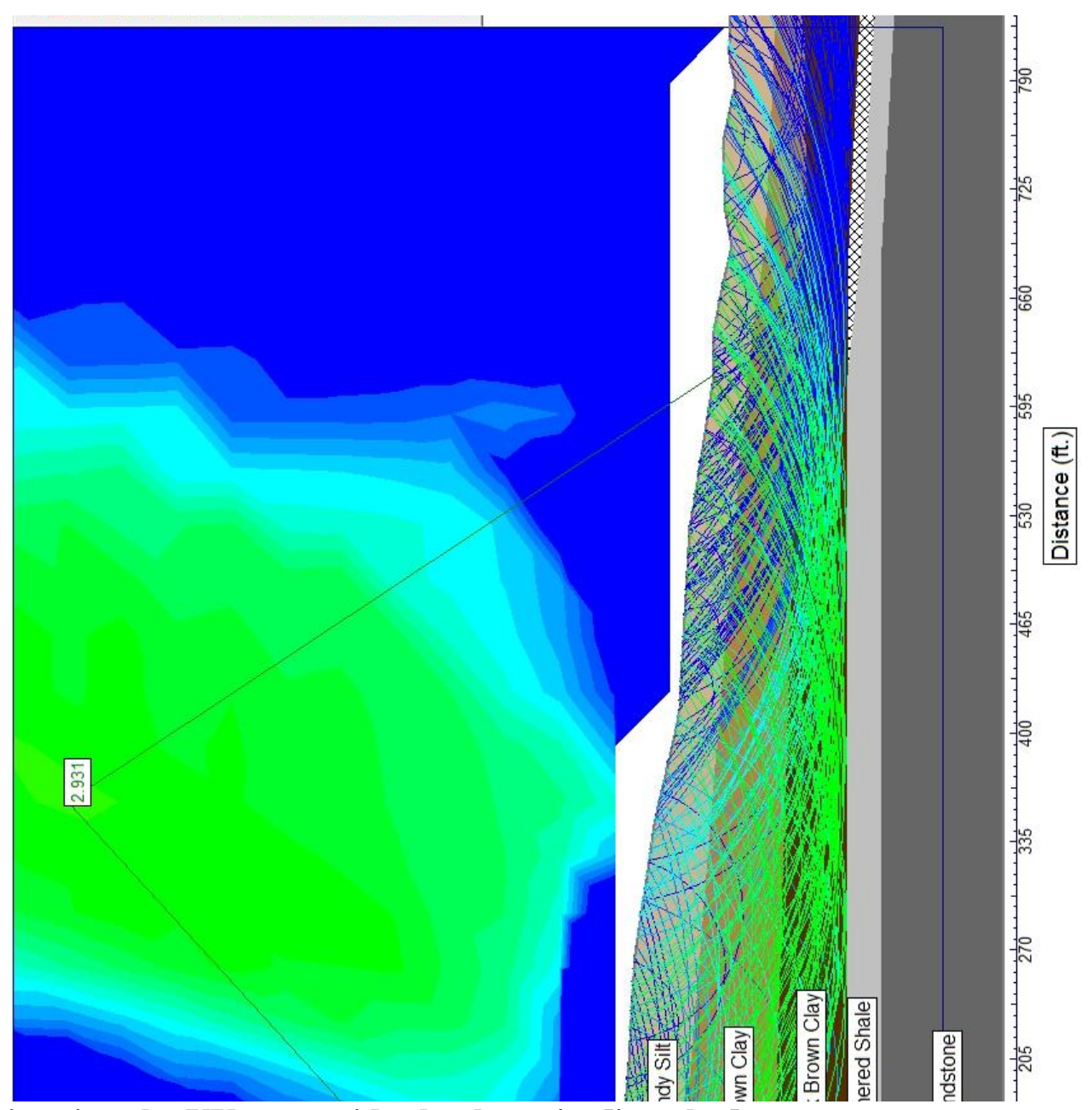

Figure 6.12. Slope stability analysis using the UU test residual values site [in color].

\subsection{Monitoring Results}

The results of the remote sensing and in-situ (validation site only) monitoring programs for the two project sites studied for AHTD TRC-1102 are discussed in this section. The results obtained for each site, calibration and validation, with the various remote and non-remote sensing systems are presented in Section 6.6.1 and Section 6.6.2, respectively. Furthermore, the results from total station, LIDAR, RADAR (GPRI-II), inclinometers, and piezometers are compared and discussed in Section 6.7.

\subsubsection{Monitoring Results at the Calibration Site (Chester, Arkansas)}

The results from the monitoring program at the calibration site described in Chapter 4 are presented in the following subsections. The results were obtained and calculated following the 
steps and procedures discussed in Chapter 5. The monitoring methods used at the calibration site near Chester, Arkansas were total station, LIDAR and RADAR (GPRI-II).

\subsubsection{Total Station}

Site visits to the calibration site subsequent to the installation of the 29 survey monuments $(11 / 24 / 2010)$ were referred as checks. A total of 17 checks were conducted to the calibration site near Chester, Arkansas. As previously explained in Section 4.3.1.1, a total station device was used to monitor the displacement of each of the 29 survey monuments. The checks were performed during a 15 months period from November 2010 (Check 1) to February 2012 (Check 17). Total station measured displacements and elevation changes of each individual survey monument installed. Check arrows were scaled to allow the analysis and facilitate the visibility. Displacements to the West represented downhill movements. A diagram of Check 15 at the calibration site is presented in Figure 6.13. 


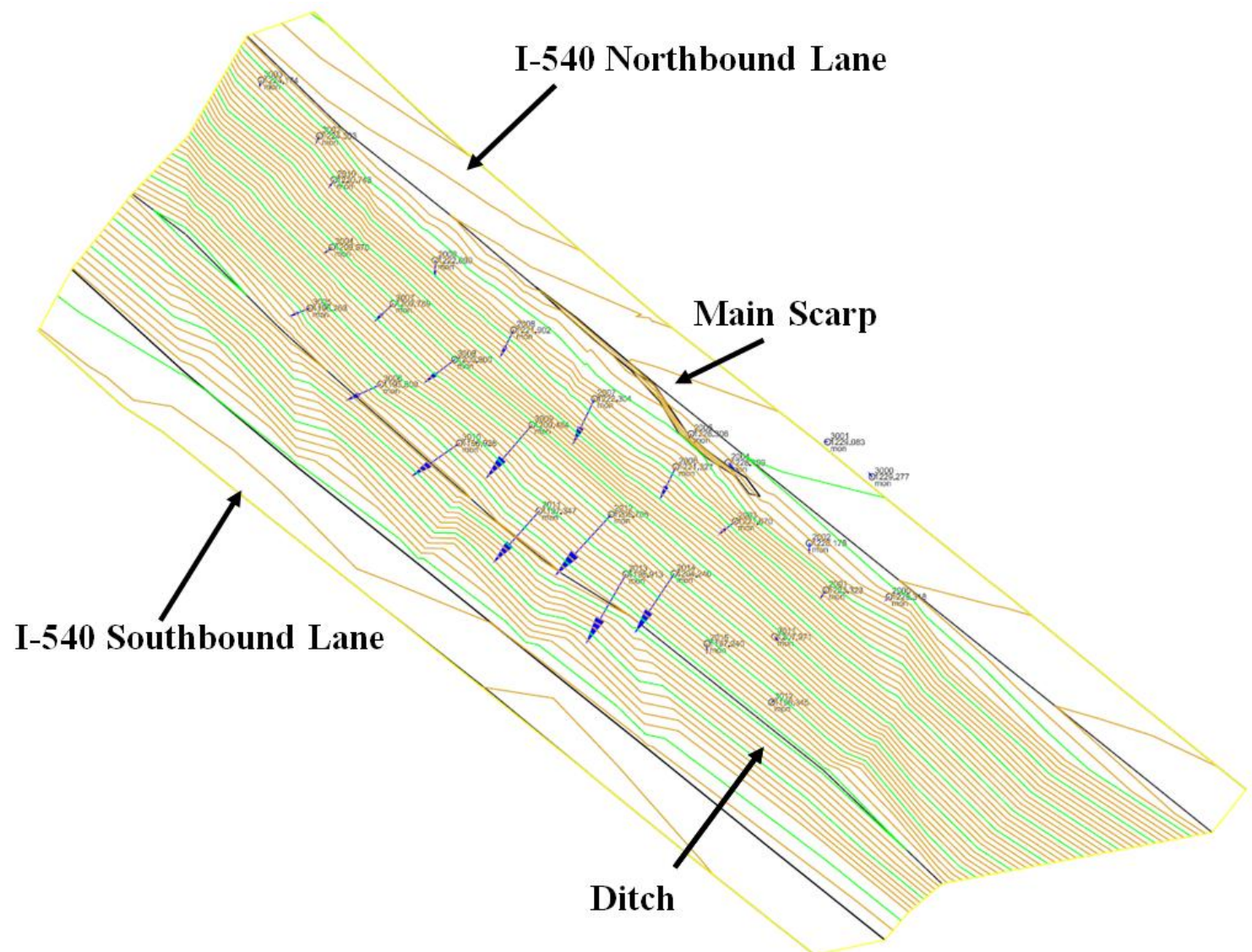

Figure 6.13. Plan view of total station Check 15 at calibration site near Chester, Arkansas.

During the first eight Checks (from 11/24/2010 to 4/19/2012) performed with the total station the displacements measured did not pass the deltas measured for those visits. Therefore, real movement of the survey monuments was not quantified by the total station during that time. Beginning on Check $9(5 / 16 / 2011)$ the displacements measured for the majority of the survey monuments installed at the calibration site increased considerably. The larger displacements (in both the horizontal and vertical directions) were observed on and after May 2011 (Check 9) corresponding to the large amounts of precipitation experienced between the months of April and May of 2011.The precipitation and runoff water saturated the soil in the slope failure, and the increased hydrostatic pore pressures caused a reduction in effective stress and induced/accelerated the displacement of the moving mass. The precipitation data for the 15 
month period between October, 2010 and January, 2012 obtained from the National Oceanic \& Atmospheric Administration (2012) is summarized in Table 6.7. The maximum horizontal displacements and maximum elevation differences observed using the total station for each of he site visit were plotted with the precipitation data. The horizontal displacements, elevation differences versus time including precipitation data are presented in Figure 6.14 and Figure 6.15, respectively.

Table 6.7. Summary of precipitation data for October 2010 to January, 2012 at calibration site near Chester, Arkansas (from National Oceanic and Atmospheric Administration, 2012).

\begin{tabular}{|c|c|c|}
\hline \multirow{2}{*}{ Date } & \multicolumn{2}{|c|}{ Precipitation (in.) } \\
\cline { 2 - 3 } & Total Monthly Precipitation & $\begin{array}{c}\text { Extreme Maximum Daily } \\
\text { Precipitation }\end{array}$ \\
\hline October 2010 & 1.71 & 0.75 \\
\hline November 2010 & 3.28 & 0.74 \\
\hline December 2010 & 1.34 & 0.68 \\
\hline January 2011 & 0.58 & 0.20 \\
\hline February 2011 & 3.44 & 0.96 \\
\hline March 2011 & 1.40 & 0.80 \\
\hline April 2011 & 12.01 & 3.51 \\
\hline May 2011 & 10.80 & 2.81 \\
\hline June 2011 & 1.66 & 0.79 \\
\hline July 2011 & 1.21 & 0.76 \\
\hline August 2011 & 6.79 & 1.70 \\
\hline September 2011 & 2.81 & 1.09 \\
\hline October 2011 & 5.44 & 2.78 \\
\hline November 2011 & 9.16 & 2.57 \\
\hline December 2011 & 4.09 & 1.31 \\
\hline January 2012 & 4.85 & 2.53 \\
\hline
\end{tabular}




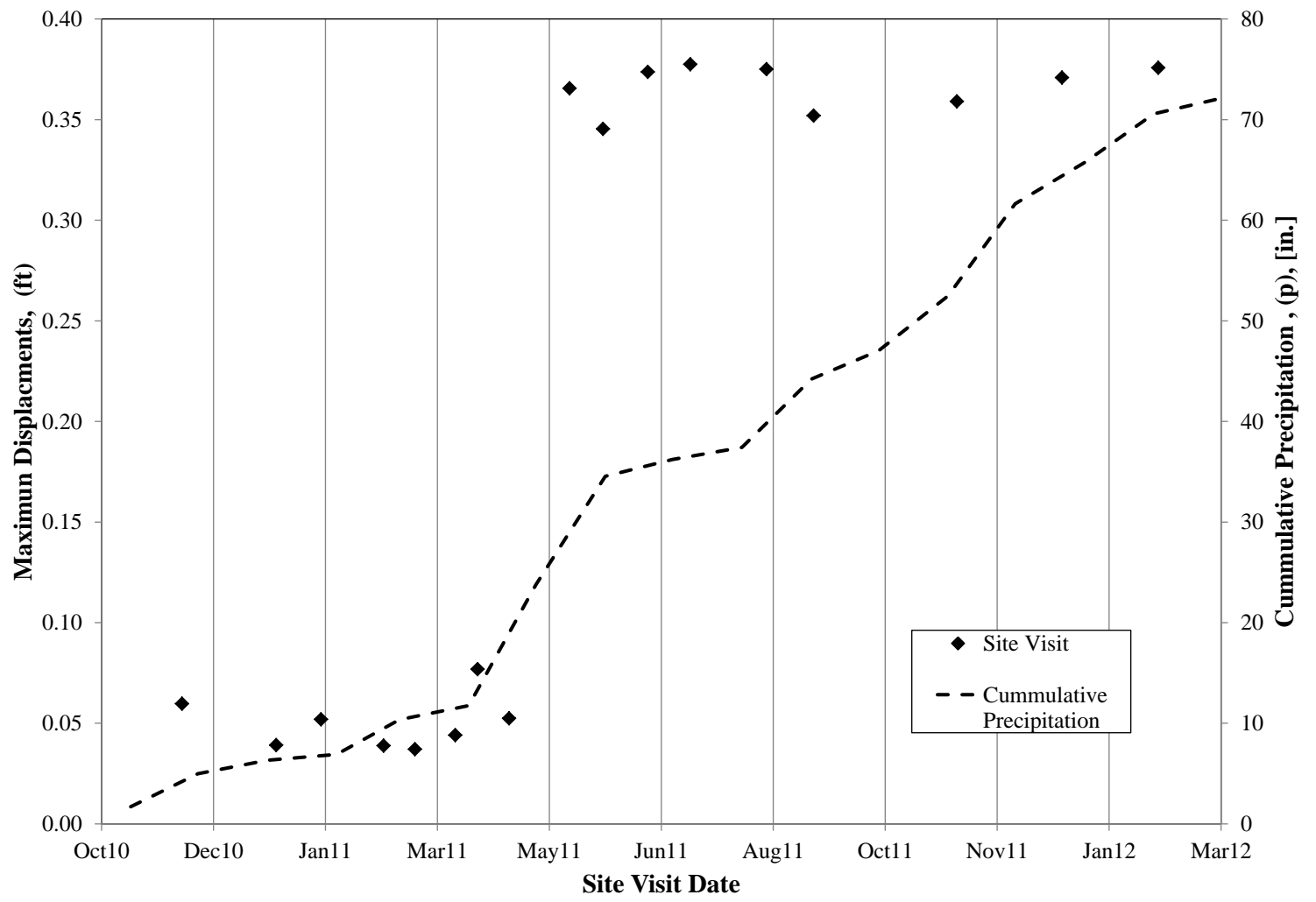

Figure 6.14. Horizontal displacements measured and precipitation data for calibration site.

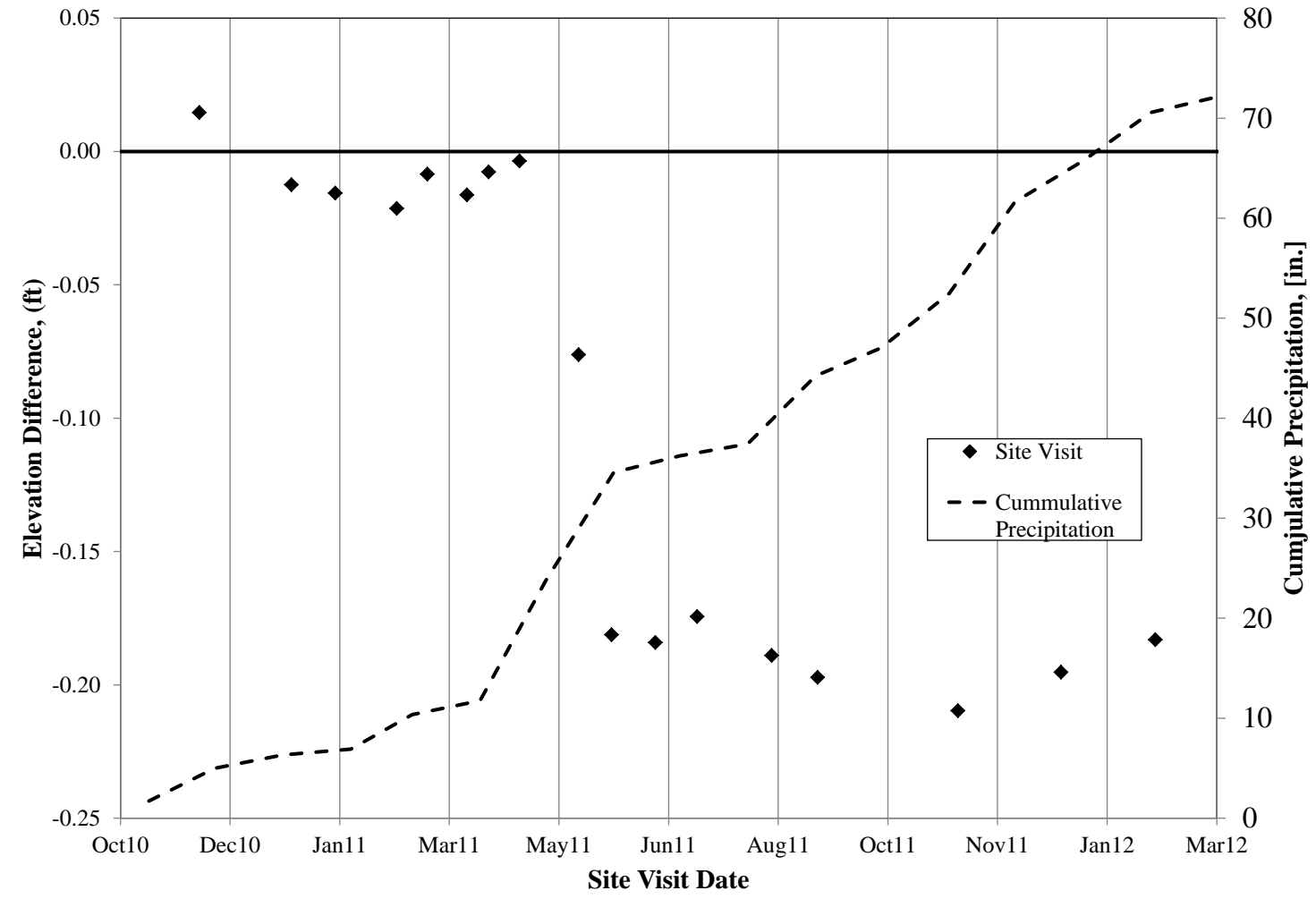

Figure 6.15. Elevation differences measured and precipitation data for calibration site. 
The displacements obtained after Check 9 revealed that the majority of the monuments were moving East to West (downhill) in a progressive trend with time. The two control monuments installed in the North side of I-540 northbound lane showed movements smaller than the surveying error for each site visit and are therefore assumed to be static (stationary). The maximum displacements and elevation differences of a single survey monument during one Check; as well as the minimum displacements and elevation differences of a single survey monument are summarized in Table 6.8. After Check 10 the maximum displacements observed occurred at survey monument 2012, which was located in the center of line two (below the main scarp). In the same manner, the minimum elevation differences (down movement) observed after Check 10 occurred at survey monument 2006, which is located in line 3 next to the main scarp.

Displacement rates for individual survey monuments were calculated using the time (days) between site visits (checks), and the monuments that showed the greatest movements. An average displacement rate of 0.11 inches per day was calculated. The average elevation difference (downwards vertical displacement) rate for the calibration site monuments was calculated to be 0.05 inches per day. The horizontal displacement rates calculated were higher than the elevation differences rates. The displacements obtained after for periods between Check 1 to Check 4 and Check 12 to Check 17 are presented in Figure 6.16. and Figure 6.17., respectively. 
Table 6.8. Summary of maximum and minimum displacements and elevation differences for calibration site.

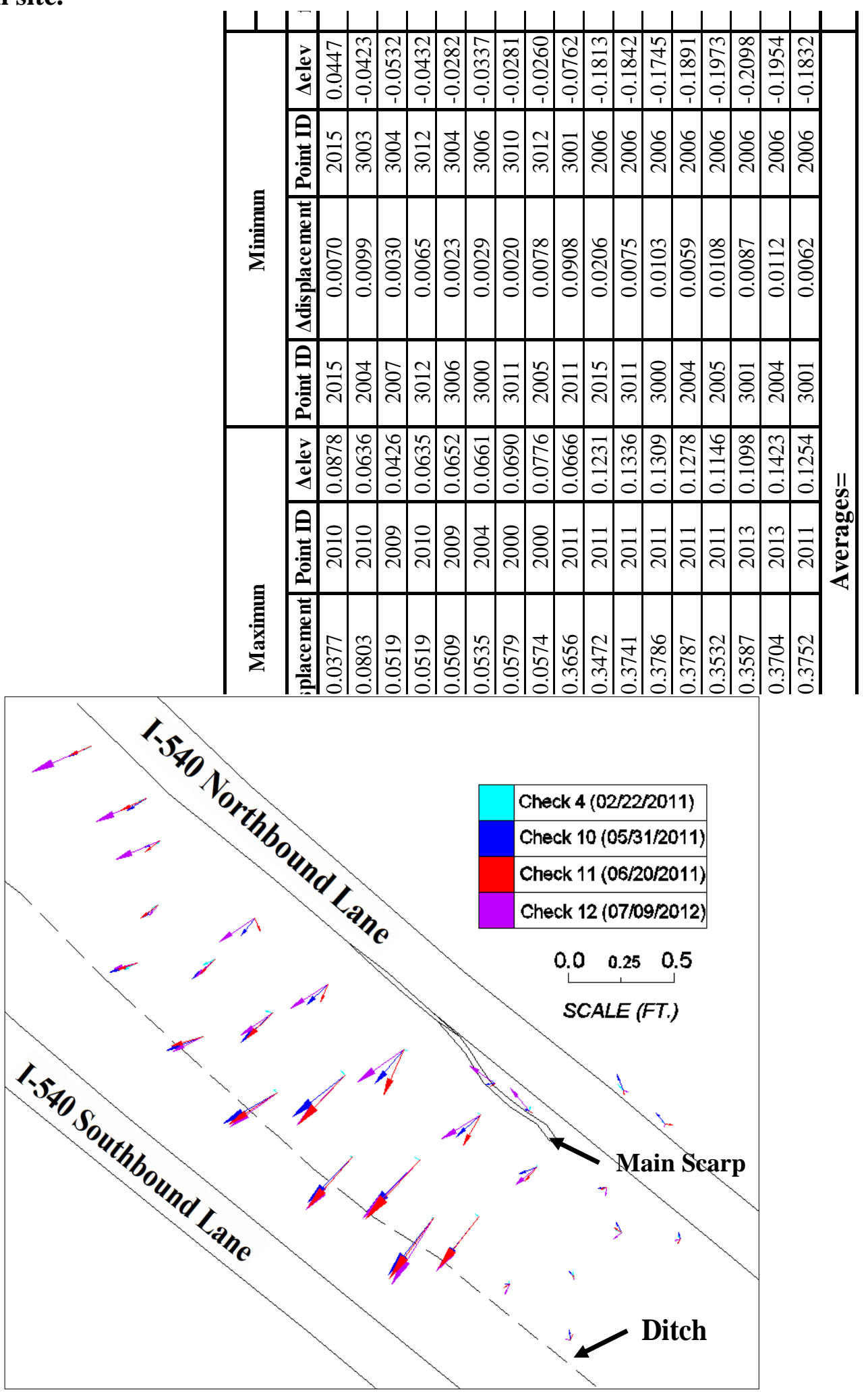

Figure 6.16. Displacements after four Checks performed at the calibration site [in color]. 


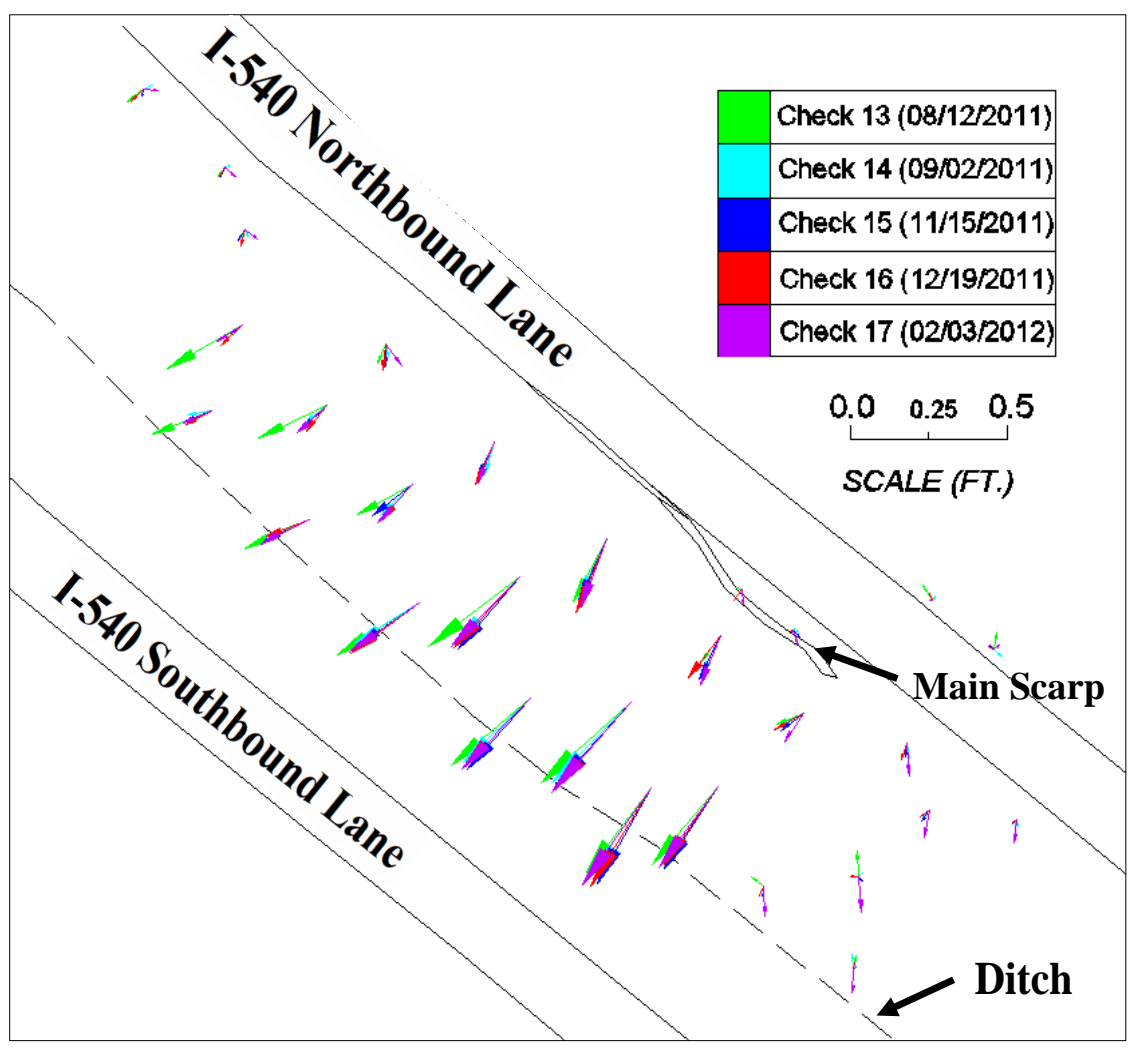

Figure 6.17. Displacements of the last five Checks conducted at calibration site [in color]. The displacements rates calculated for the calibration site near Chester, Arkansas showed

a correlation to the period of heavy rain observed during the monitoring period. Larger displacement and elevation difference rates were observed for the period when the slope was saturated due to precipitation. The maximum displacements rates were observed during the months of March, April, and May of 2011. The maximum displacement rates calculated and elevation differences were plotted with cumulative precipitation and are presented in Figure 6.18 and Figure 6.19, respectively. 


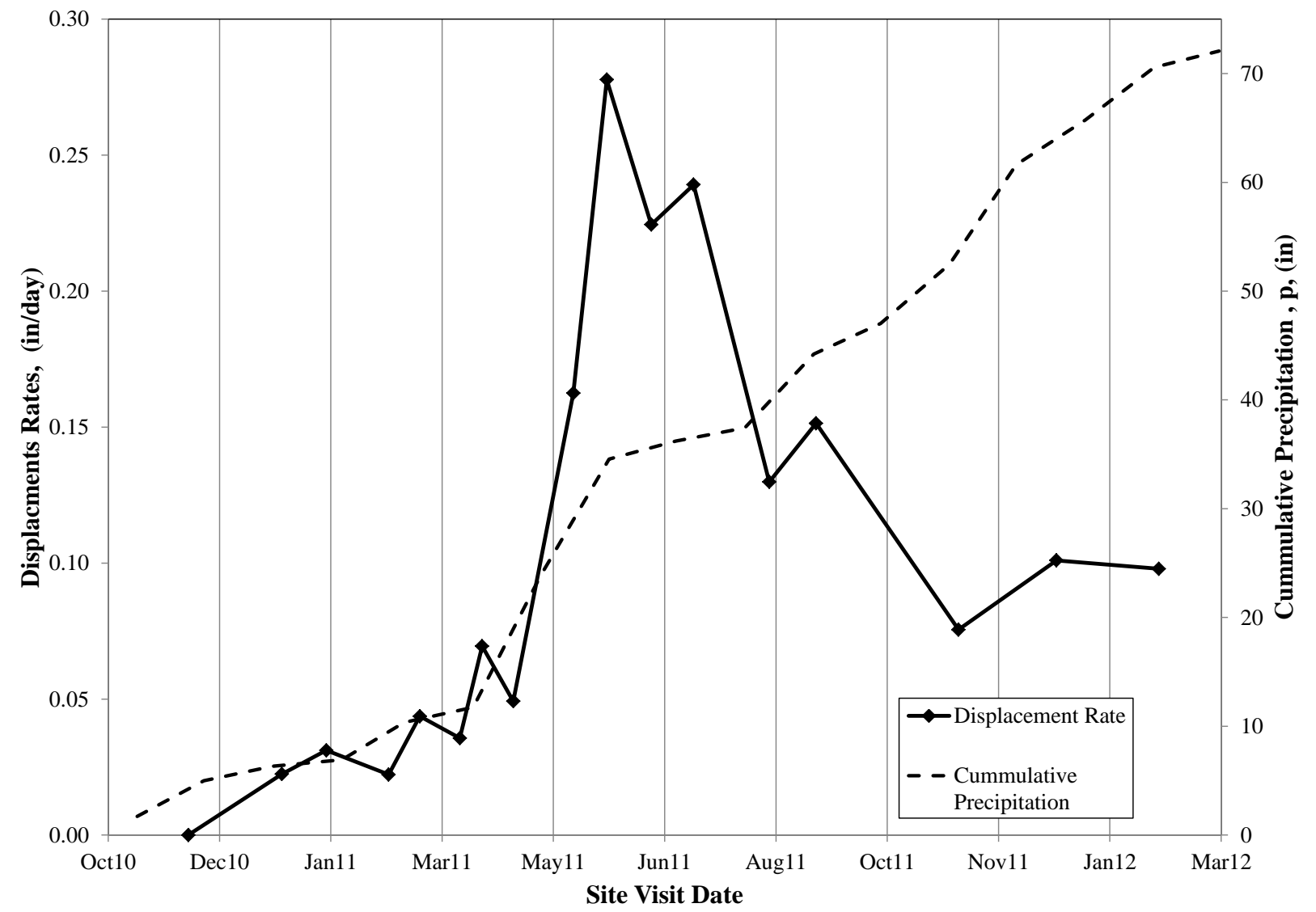

Figure 6.18. Maximum displacement rates (horizontal) and cumulative precipitation data with time for calibration site near Chester, Arkansas. 


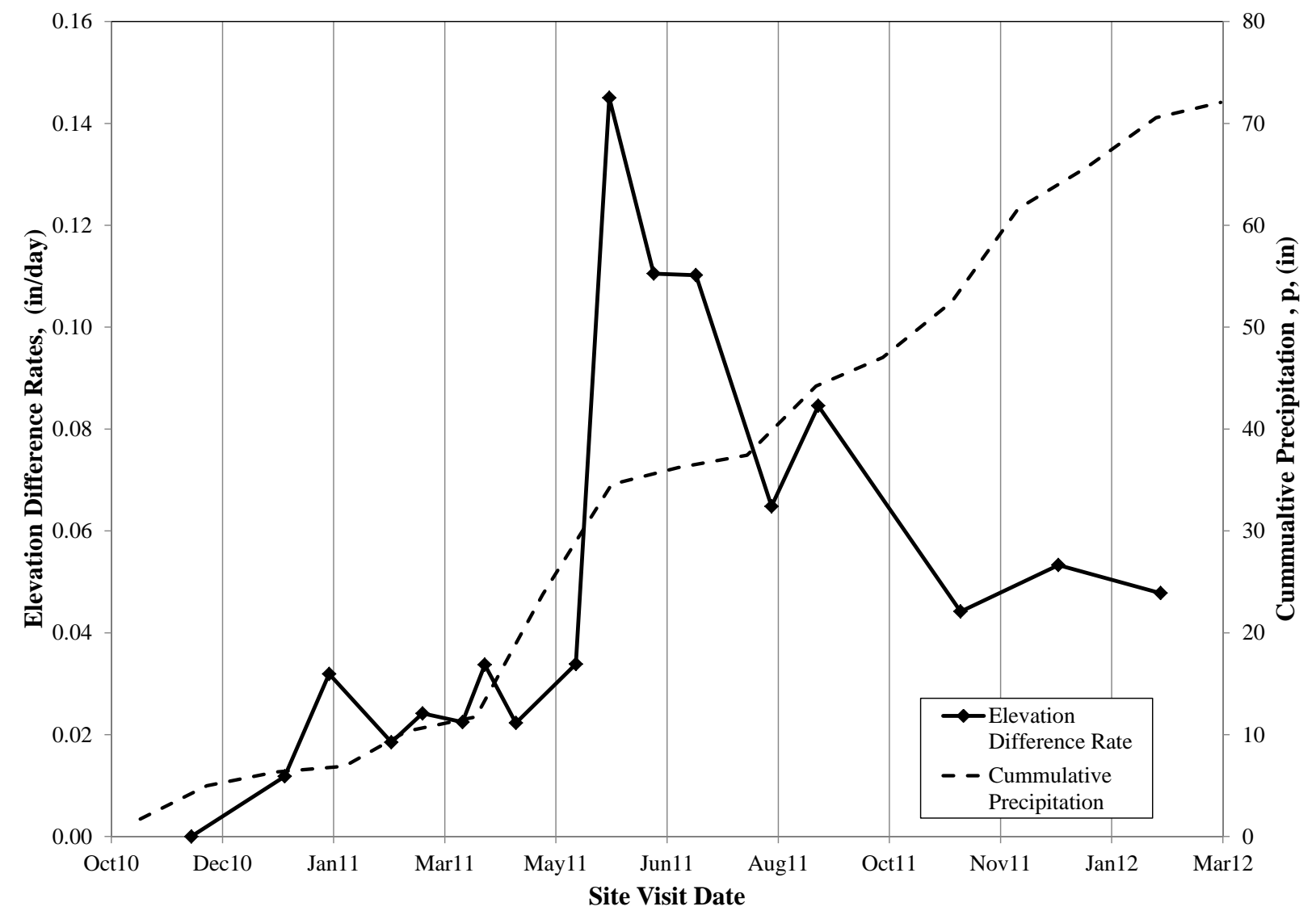

Figure 6.19. Elevation differences rates (vertical) and cumulative precipitation data with time for calibration site near Chester, Arkansas.

Due to the single point measurements obtained with total station, movements of an area of the landslide were not captured. Displacements areas for different parts of the moving mass were developed using a tributary area for each survey monument. The survey monuments that showed the largest displacements (horizontal) were located in the center of the landslide area under the main scarp. Survey monuments that experienced low or none displacements values were observed at the North and South sides of the moving mass.

Three distinct displacement areas were delineated to characterize the moving mass as presented in Figure 6.20. The red zone was the area where the largest horizontal displacements were observed; the monuments bounded by orange zone had moderate horizontal displacements. Large movements of the survey monuments were expected to occur in the area below the main 
scarp which is in agreement with the observed movements. The yellow zones were established where the monuments experiences zero (between the deltas) or low displacements.

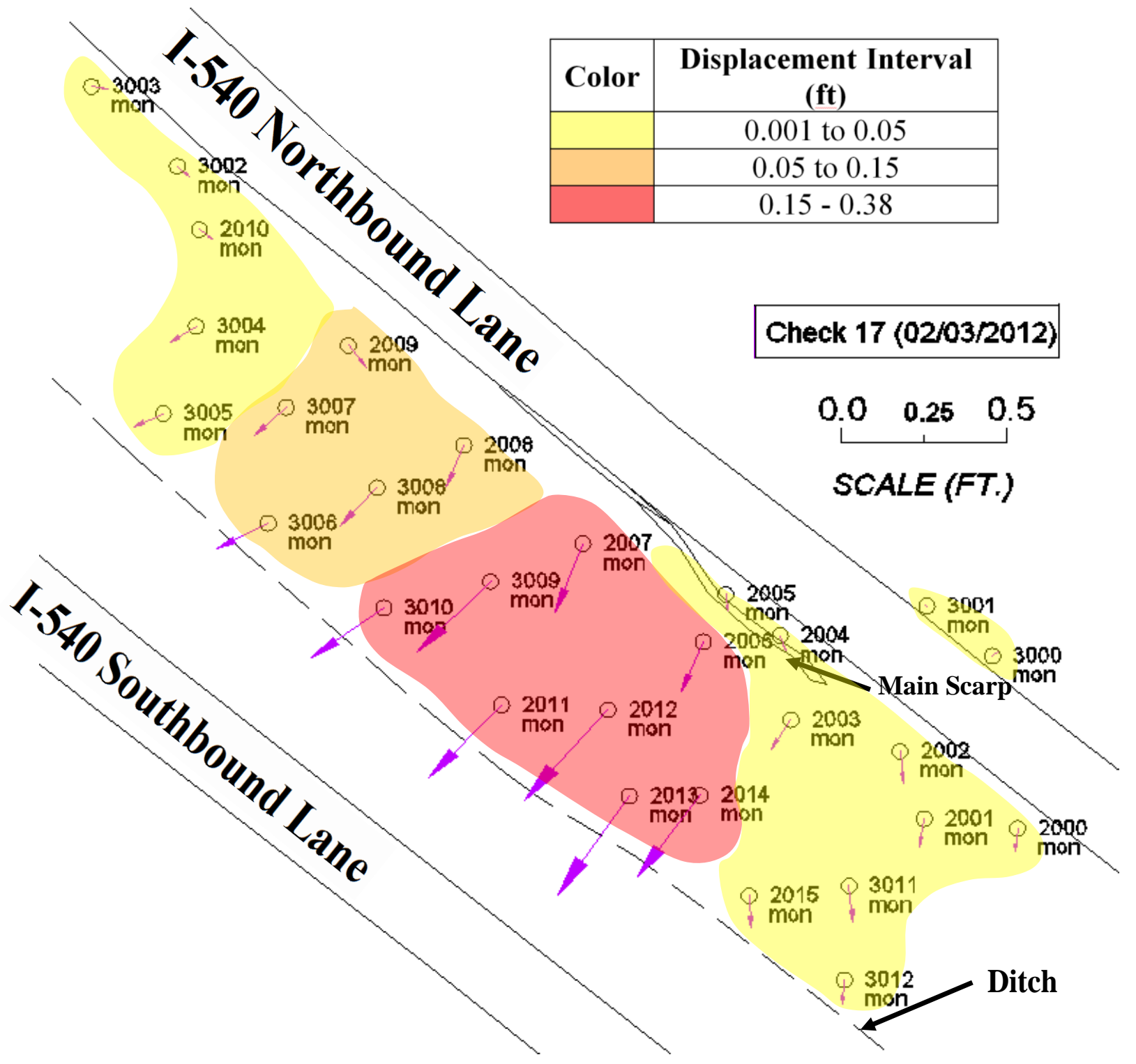

Figure 6.20. Displacement areas for the calibration site; red zone represents largest movements, orange zone represents medium movements, and yellow areas low to zero movement [in color].

Similarly, four distinct zones were delineated to characterize the vertical movement of the slide after analyzing the elevation differences measured on each survey monument during the Checks. Vertical displacements were grouped in different intervals depending of the amount and 
direction of movement experienced. A rotational behavior was observed in the landslide at the calibration site near Chester, Arkansas. Downward movements were observed in the survey monuments installed at the head area of the slide and uplift movements were measured in the monuments installed at the toe of the sliding mass. A picture illustrating the four different sections of elevation difference is presented in Figure 6.21.

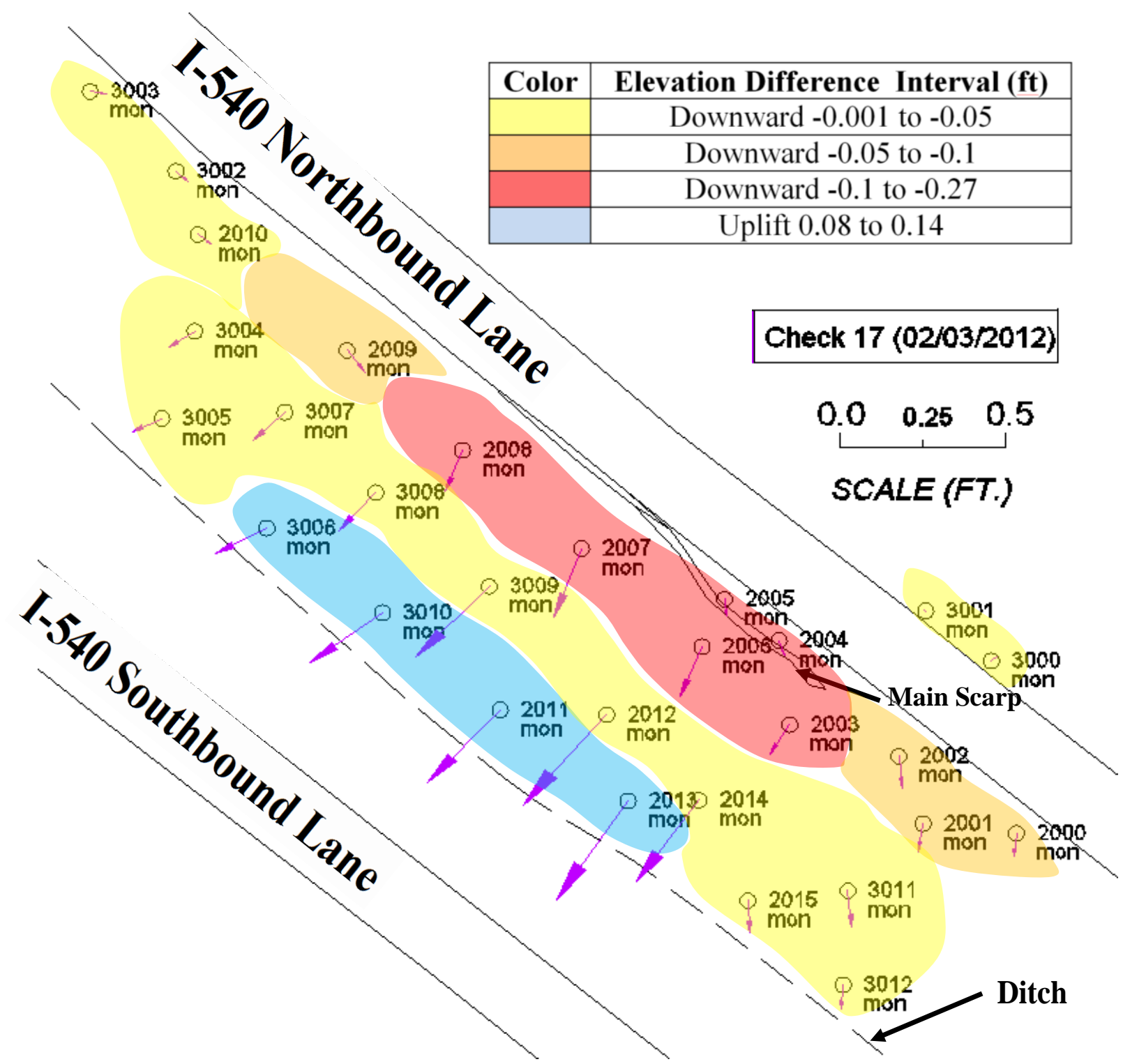

Figure 6.21. Zones of vertical movements for the calibration site; red zone represents largest down movements, orange zone represents down medium movements, yellow areas low to zero down movement, and blue areas represent uplift movement [in color]. 


\subsubsection{LIDAR}

The slope failure at the calibration site near Chester, Arkansas was monitored over 10 months period, from March 2011 to January 2011. The calibration site was visited in eight occasions for data acquisition using a LIDAR Leica C-10 laser scanner, as described in Section 4.5.1.1. The data acquired on each site visit was processed to develop a ground surface (Section 5.4.1) which were; subsequently compared to detect the movements of the sliding mass.

Eight surfaces were created from the LIDAR data acquired at the calibration site. The first image recorded (March $17^{\text {th }}, 2011$ ) was used as a "master" image to provide a reference for all subsequent images. However, some of the subsequent scans were compared to other images (not the master) to resolve any movements over specific periods. Elevation differences (vertical direction) between the surfaces in comparison were the final output of the analysis. As previously discussed in Section 5.4.2, two methods were attempted for vegetation correction, the polylines method and the bare earth correction method. A picture illustrating the raw data and an example of the volume surfaces using developed the two methods is presented in Figure 6.22.

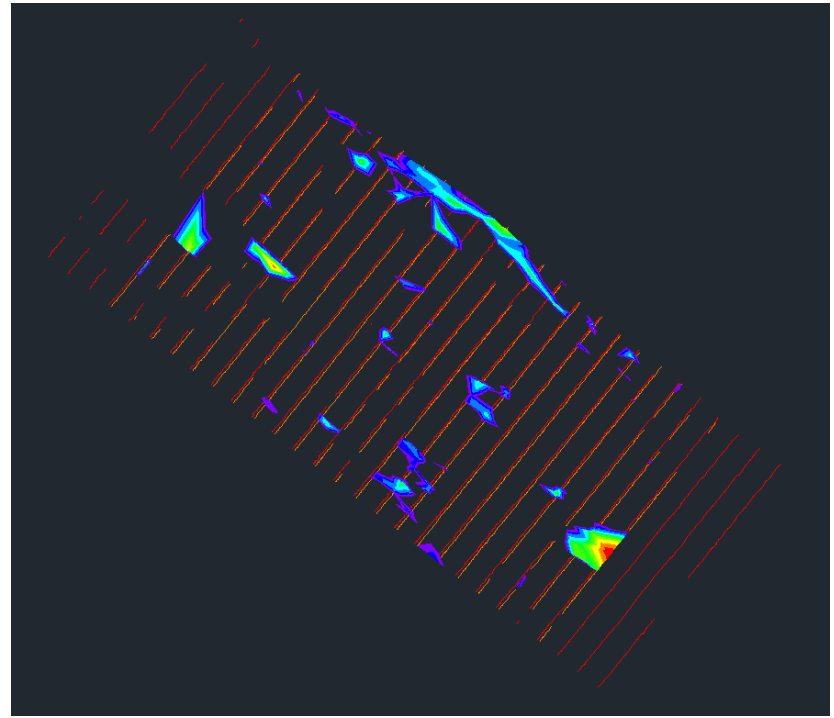

(a)

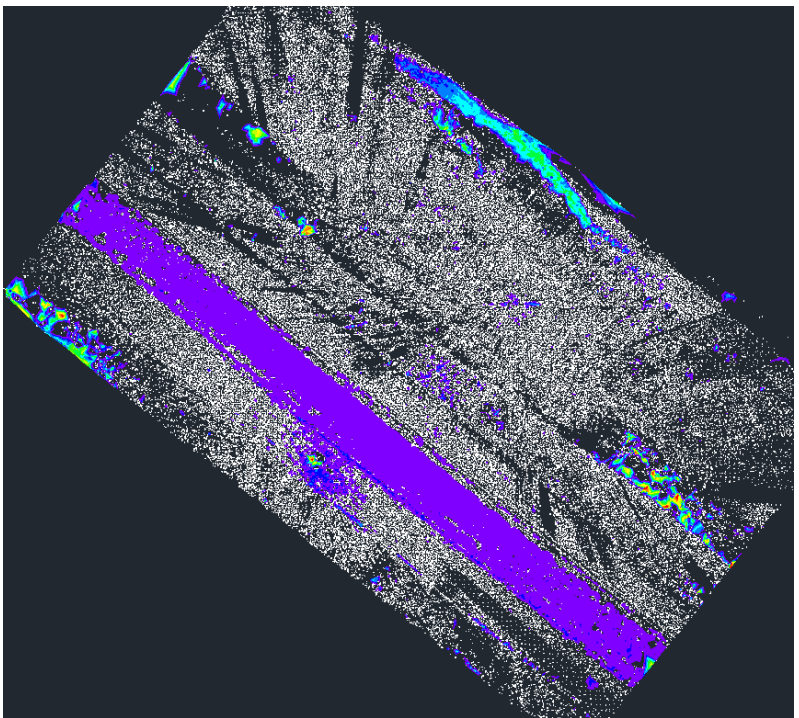

(b)

Figure 6.22. a) Surface developed using polylines method, and b) Surface developed using bare earth correction method [in color]. 
The main scarp at the calibration site was detected through the comparison of surfaces after LIDAR data acquisition. Direction of movement in the horizontal direction was not captured by the methods employed in this research project to process the LIDAR data. The use of volume surfaces to detect the change in slope as a function of time allowed for the extraction of vertical deformation measurements only. All the volume surfaces created using the polyline and bare earth correction methods are presented in Appendix Error! Reference source not

\section{found.}

Progressive downward movement of the main scarp was observed for the first three LIDAR site visits to validation site (March $17^{\text {th }}, 2011$ through June $8^{\text {th }}, 2011$ ). Data recorded after the June $8^{\text {th }}, 2011$ scan show an anomalous upwards movement over a section of the main scarp. It is believed that this measurement does not represent physical upwards movement of the slope in this location but instead is attributable to vegetative shadowing (disrupting line of sight [LOS] between sensor and the target area) from a nearby bush. A maximum downward displacement of approximately 0.5 feet was observed in the main scarp when comparing the surfaces from March $17^{\text {th }}, 2011$ to June $8^{\text {th }} 2011$ after LIDAR data reduction using both of the aforementioned vegetation removal methods. All the volume surfaces created using the polyline and bare earth correction methods are presented in Appendix Error! Reference source not

\section{found..}

While the polylines method did not accurately detect the main scarp at the calibration site it also resulted in large, false elevation changes. False movement zones (noise zones) were caused by the AutoCAD software interpolating between points in the data. There was a noticeable paucity of data points acquired proximal to the drainage ditch, this resulted in a large area of the image where polylines could not be created. Possible factors which prevented data 
capture in this region are water pending or by shadowing by topographic features at this site (no LOS between sensor and the bottom of the ditch). Since the polylines method used the implicit assumption that the lowest point at each position along the cross-section represented the ground surface it is possible that some vegetation effect could still be present (e.g. if the LASER pulse did not penetrate through to the ground surface). A picture of the volume surface created from site visits March 17t, 2011 and June $8^{\text {th }}, 2011$ at the calibration site near Chester, Arkansas is presented in Figure 6.23. Progressive downward movement of the main scarp between LIDAR site visits 05/17/11 and 06/27/11 is presented in Figure 6.23.

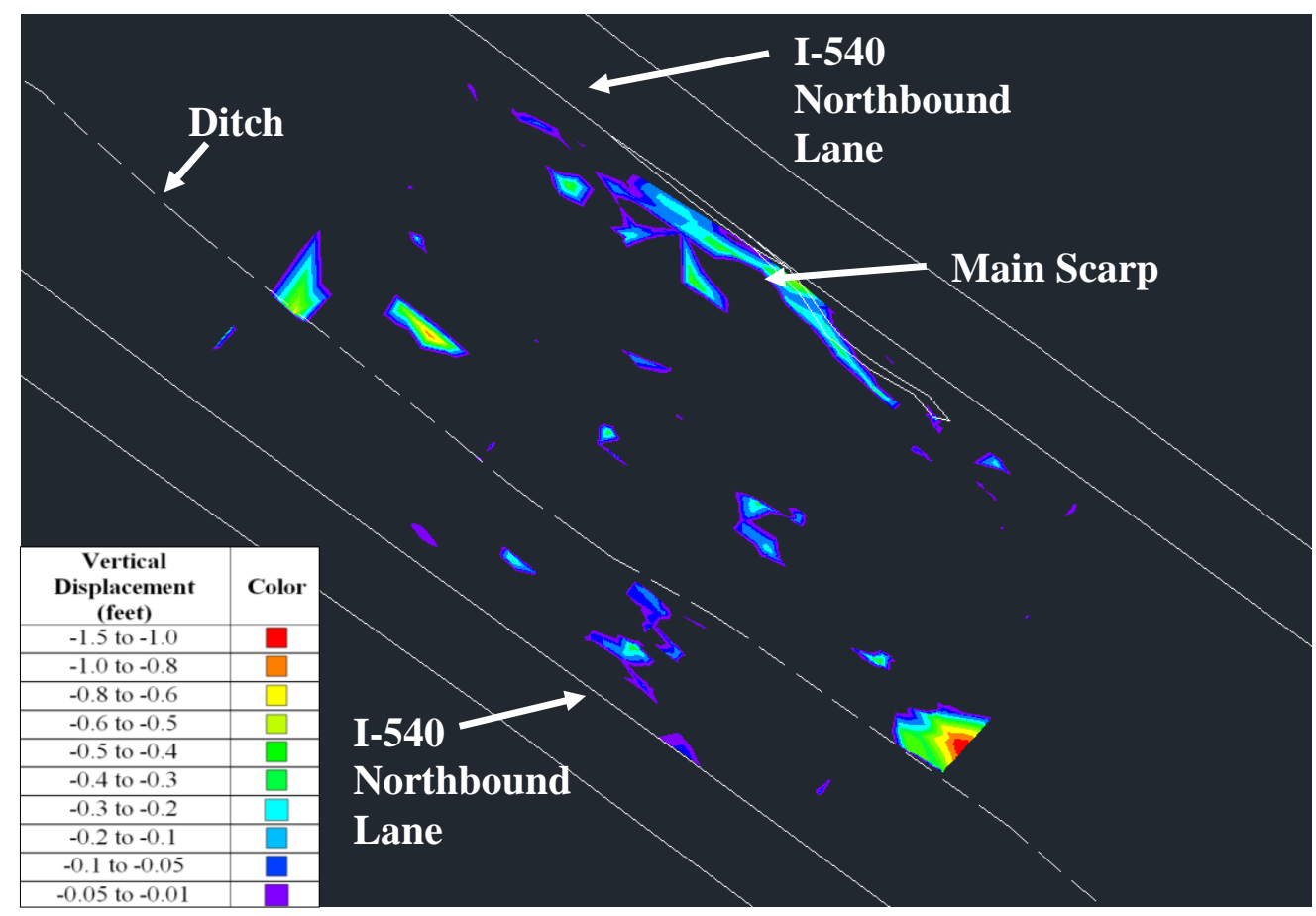

(a)
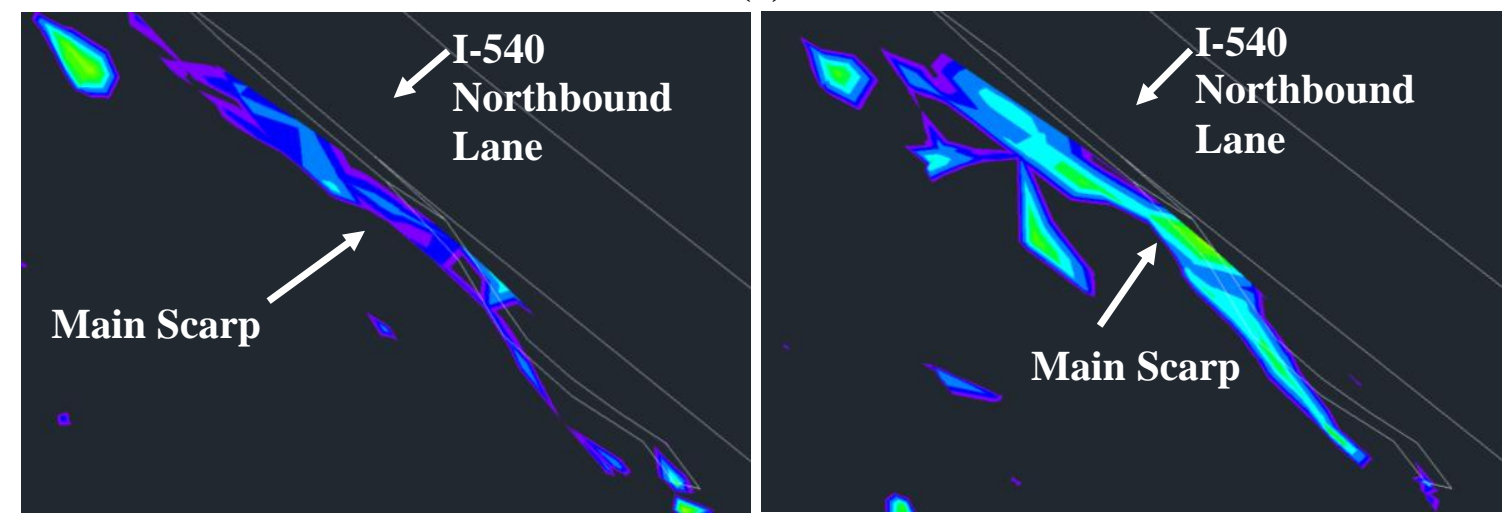
(b)

Figure 6.23 a) Volume surface 03/17/11-06/08/11 (obtained using polylines method) where maximum elevation difference on the main scarp was observed, and b) zoomed view to the main scarp where progressive movement was observed from 05/17/11 to 06/08/11 [in color].

The accuracy of the polylines method could be increased by decreasing the spacing between polylines and therefore increasing the density of the data. This would also mitigate the effects of interpolation across regions of little or no data. No movements was detected in the either the northbound or southbound lanes of I-540. The location of the main scarp obtained using the polylines method data matched the location of the main scarp obtained with the total station during the topography surveys.

The second method preformed for the removal of vegetation during the LIDAR data processing was the bare earth correction method as described in Section 5.4.2.2. Similarly to the polylines method the numerical bare earth correction method allowed for the detection and identification of the main scarp. The effects of "vegetation noise" were reduced relative to the polylines method by the use of a more rigorous numerical algorithm. However, the numerical bare earth correction also indicated false movements caused by the vegetation shadowing (i.e. where the vegetation blocked the LOS between the sensor and the ground surface) and the presence of ponded water.

Negative (downward) displacements were detected in the Southbound lane of I-540. The downward movements observed in the I-540 Southbound lane resulted of the expansion and contraction of the concrete pavement. The main scarp location using the bare earth method also matched the location obtained with the total station. The volume surface obtained using the bare earth correction method for the site visits between March $17^{\text {th }}, 2011$ and June $6^{\text {th }}, 2011$ is presented in Figure 6.24. Progressive movement of the main scarp during the May $17^{\text {th }}, 2011$ surface and the June $8^{\text {th }}, 2011$ surface are illustrated in Figure 6.24. 


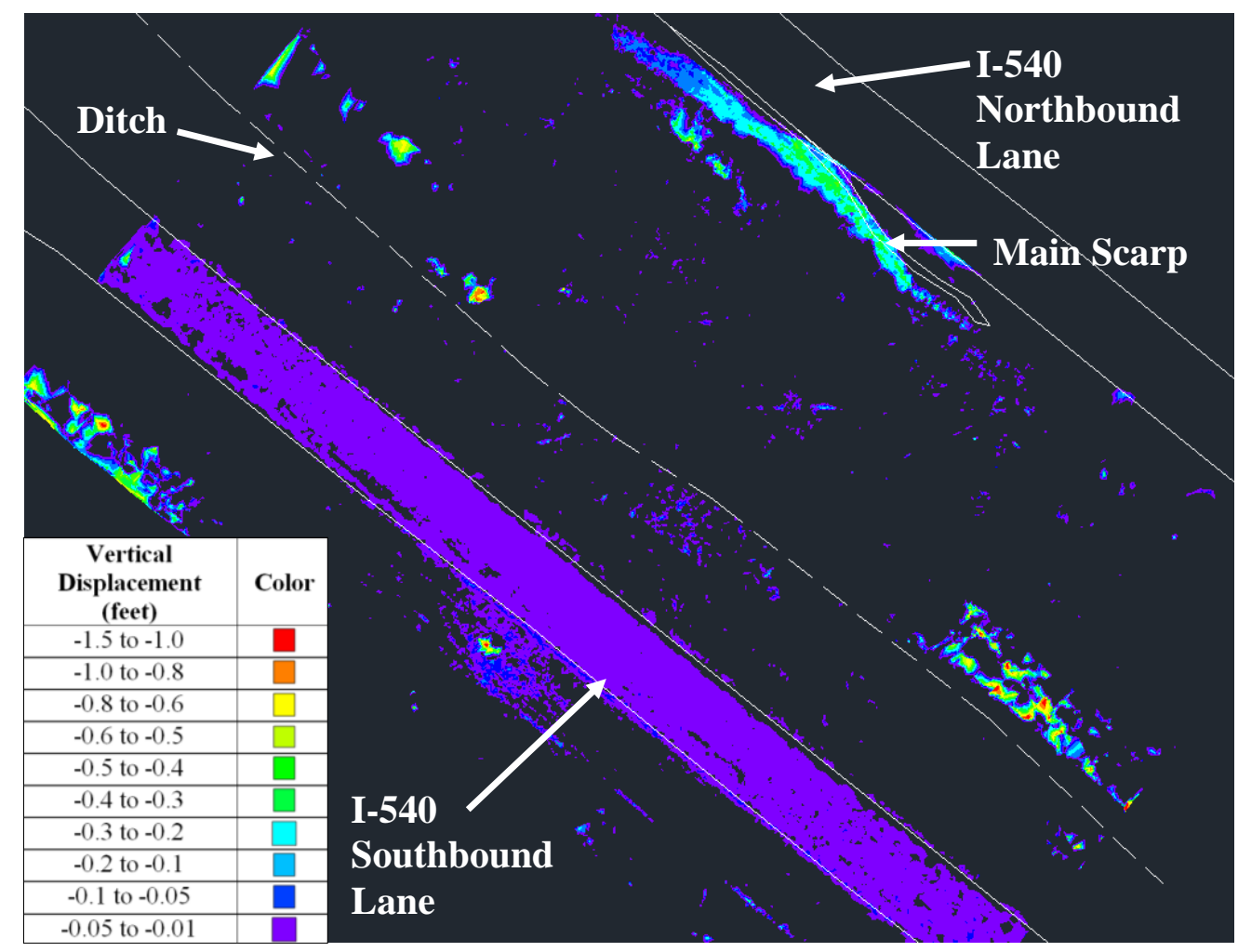

(a)

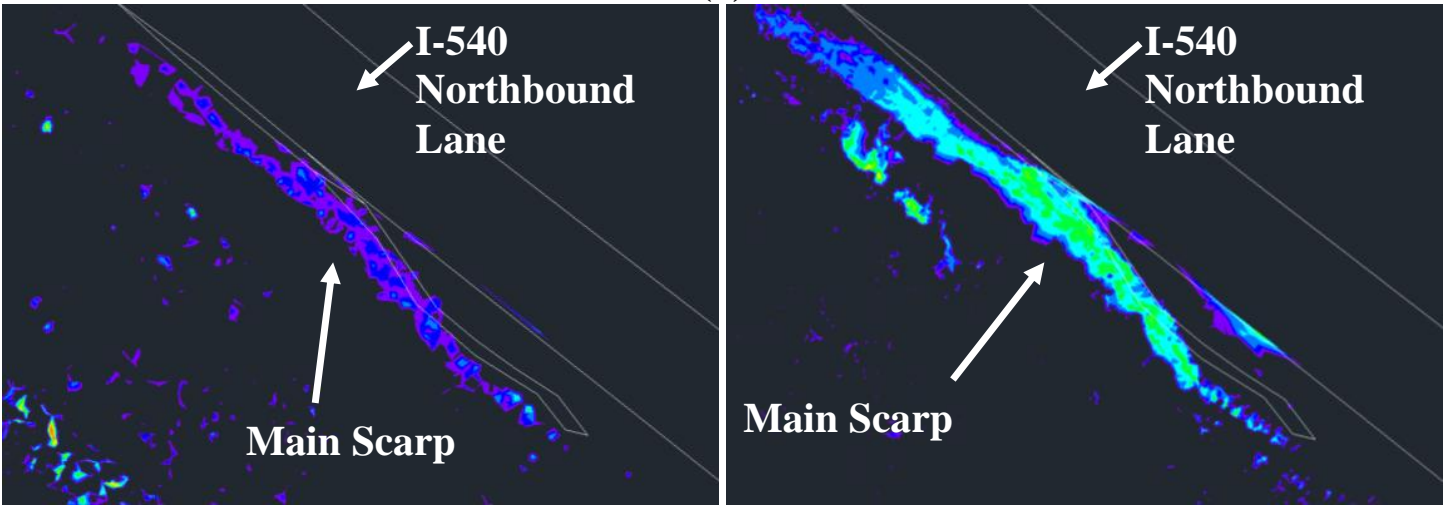

(b)

Figure 6.24. a) Volume surface 03/17/11-06/08/11 (obtained using bare earth correction method) where maximum elevation difference on the main scarp was observed, and b) zoomed view to the main scarp where progressive movement was observed from $05 / 17 / 11$ to $06 / 08 / 11$ [in color].

\subsubsection{GPRI-II}

The results of the monitoring program using RADAR (GPRI-II) at the calibration site near Chester, Arkansas are presented in this section. As previously discussed in Section 5.3, the first result from the RADAR data processing were MLI (Multi Look Intensity) images. The MLI, 
first obtained in polar coordinates, allowed for inspection of the data acquired in the field. The MLI were converted to rectangular coordinates in order for an easier interpretation of the features obtained in the image.

For the southbound viewpoint, images were acquired using two different chip settings (Section 4.4.2.1.1); the images acquired using the 500ms chirp were not centered due to the larger range covered. Conversely, images obtained using the $250 \mathrm{~ms}$ permitted a closer and better interpretation. In fact, due to the RADAR data acquisition proximity to the site; a lower chirp would have produced better MLI images, but the system allowed for $250 \mathrm{~ms}$ to be the lowest chirp possible. The I-540 Northbound and Southbound, the ditch and the terrain North of I-540 Northbound lane are appreciated in the MLI produced. Some saturation is observed in the images due to the traffic of vehicles along the I-540 lanes. The MLI obtained after the initial processing of the RADAR (GPRI-II) data for the calibration site using the 500ms and 250ms are shown in Figure 6.25 and Figure 6.26, respectively.

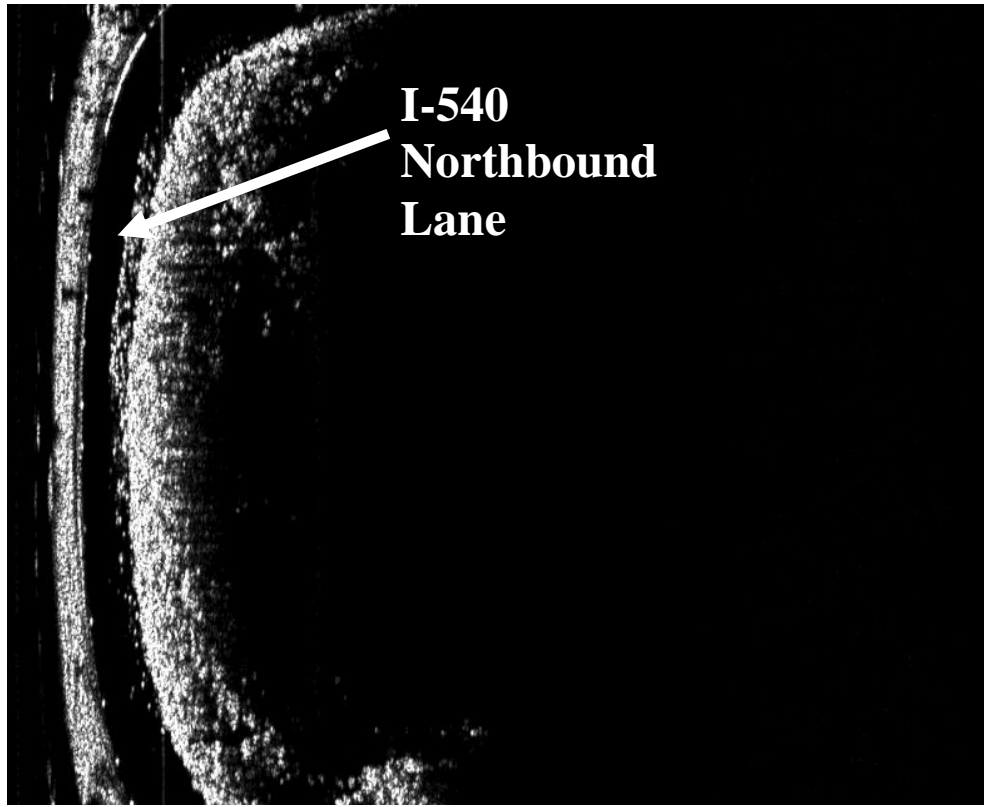

(a)

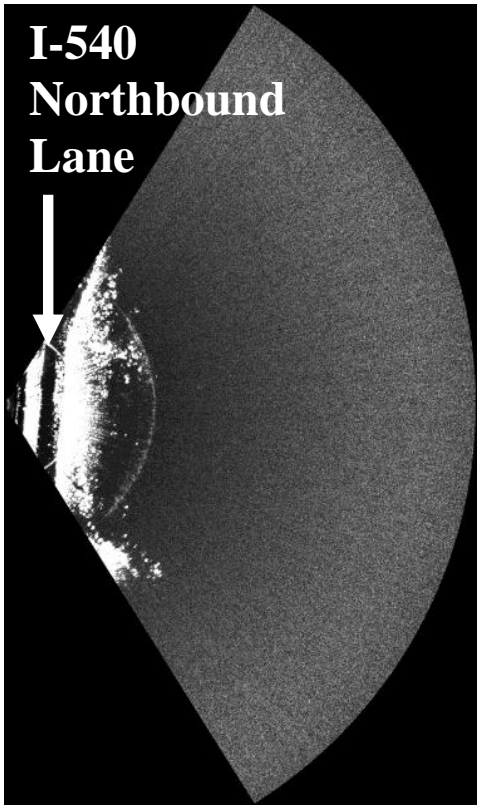

(b)

Figure 6.25. a) MLI RADAR image obained from southbound viewpoint in polar corrdinates using 500ms chirp, and b) MLI RADAR image obained from southbound viewpoint in rectangular corrdinates using 500ms chirp. 


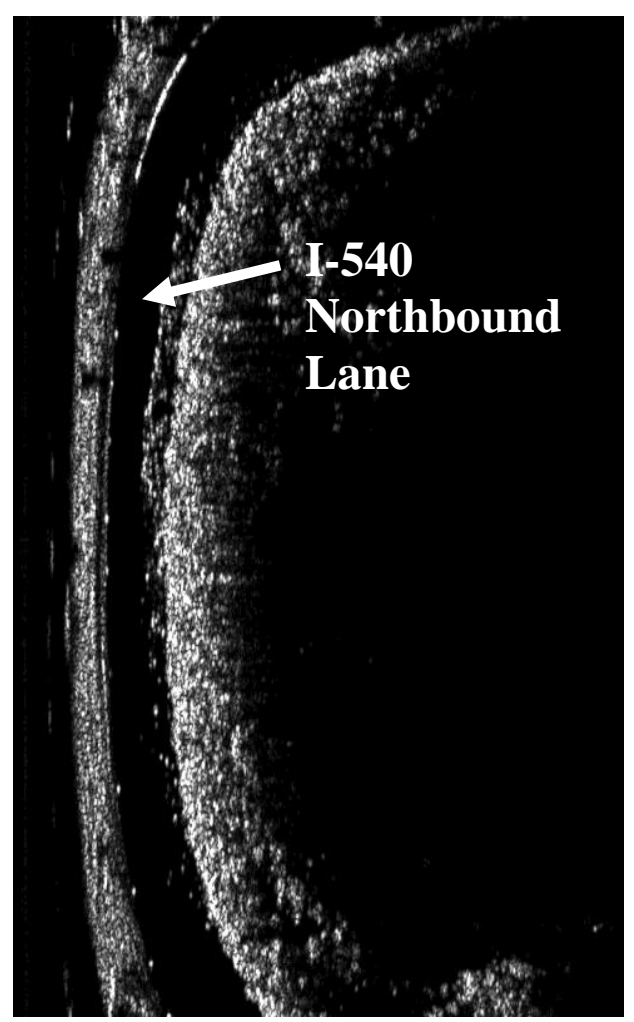

(a)

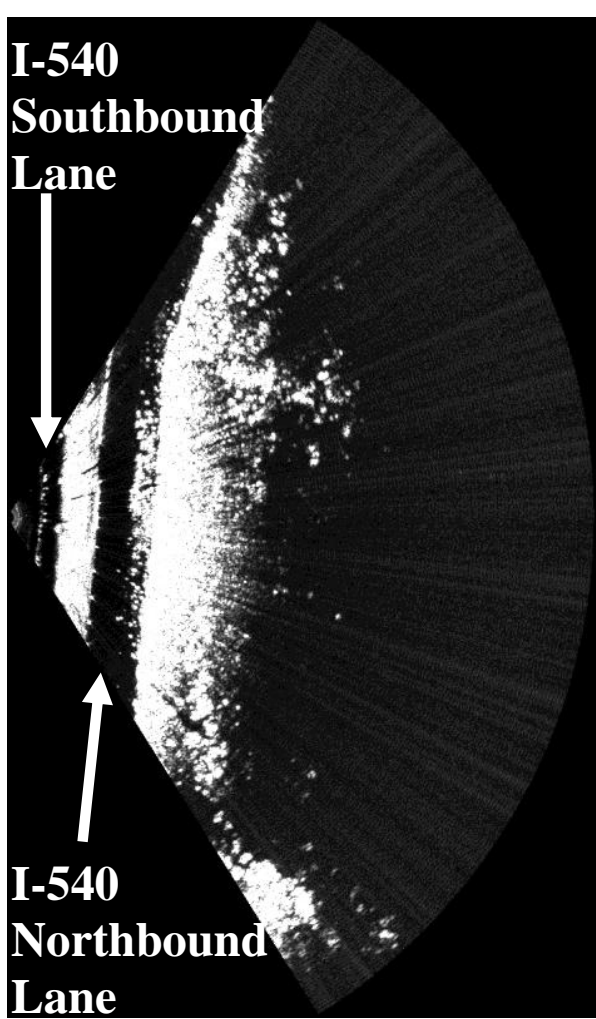

(b)

Figure 6.26. a) MLI RADAR image obained from southbound viewpoint in polar corrdinates using 250ms chirp, and b) MLI RADAR image obained from southbound viewpoint in rectangular corrdinates using 250ms chirp.

As presented earlier, the GPRI-II image acquisition at the calibration site were performed from two different viewpoints. The second viewpoint, overlook, was located approximately $2 \mathrm{~km}$ away from the calibration site. The different viewing geometry of this viewpoint resulted in images that covered a broader area due to the distance, elevation, and chirp (4ms) utilized. The MLI RADAR images obtained from the overlook viewpoint covered the site, the mountain (where the site is located), bridge and surroundings among other features. Saturation of the images was not observed in the images acquired from the overlook viewpoint due to the distance to the calibration site. A RADAR shadow, created by the topography of the mountain itself, was observed in the image. The MLI RADAR images obtained from the overlook viewpoint in polar and rectangular coordinates are presented in Figure 6.27 and Figure 6.28, respectively. 


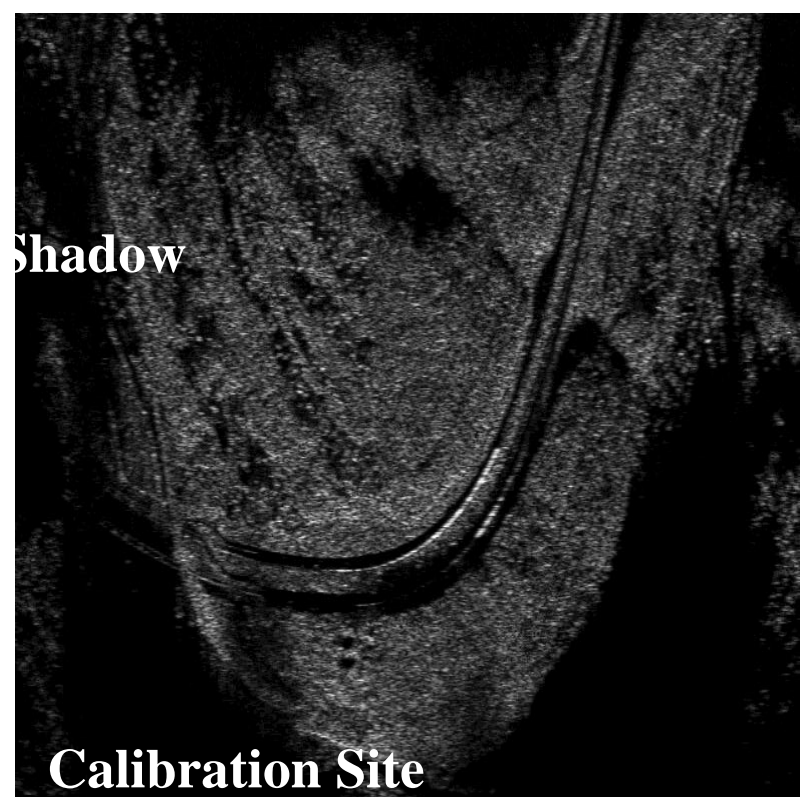

Figure 6.27. MLI RADAR image obained from rverlook viewpoint in polar corrdinates using 4ms chirp. 


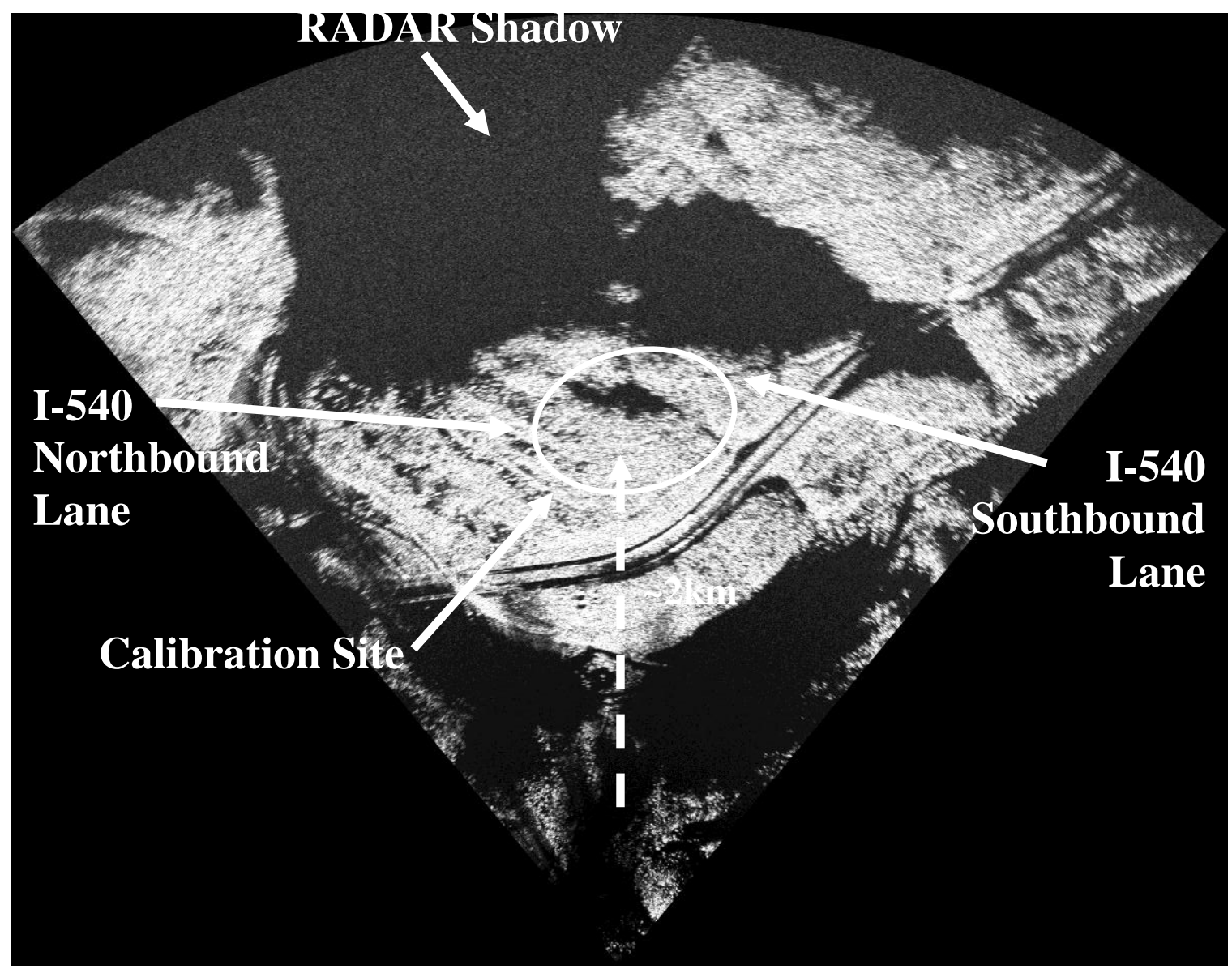

Figure 6.28. MLI RADAR image obained from overlook viewpoint in polar corrdinates using $4 \mathrm{~ms}$ chirp.

\subsubsection{Monitoring Results at the Validation Site (Malvern, Arkansas)}

The results from the monitoring program at the Malvern, Arkansas validation site of the TRC-1102 research project are presented in this section. The validation site was monitored through the use of both temporary (remote) sensing techniques and permanently installed in-situ instrumentation. Remote and non-remote sensing systems utilized at this site were a total station, 
LIDAR, RADAR (GPRI-II) and inclinometers. A comparison of the measured data obtained from the aforementioned instrumentation is presented in Section 6.7.1.

\subsubsection{Total Station}

A total station was used to monitor the displacement of 53 survey monuments were installed at the validation site on January $6^{\text {th }}, 2011$. Each subsequent site visit is referred to as a check A total of nine checks were performed to the validation site. The checks were performed over the 13 month period between January 2011 and February 2012. As explained in Section 5.2.2, the displacements measured at each survey monuments were visualized by creating displacement vectors at each point. Displacement vectors were scaled to enhance visibility of the displacements. Elevation differences in the vertical direction were measured and recorded for each survey monument installed at the validation site. A diagram of the surface of the validation site with Check 8 and Check 9 is presented in Figure 6.29.

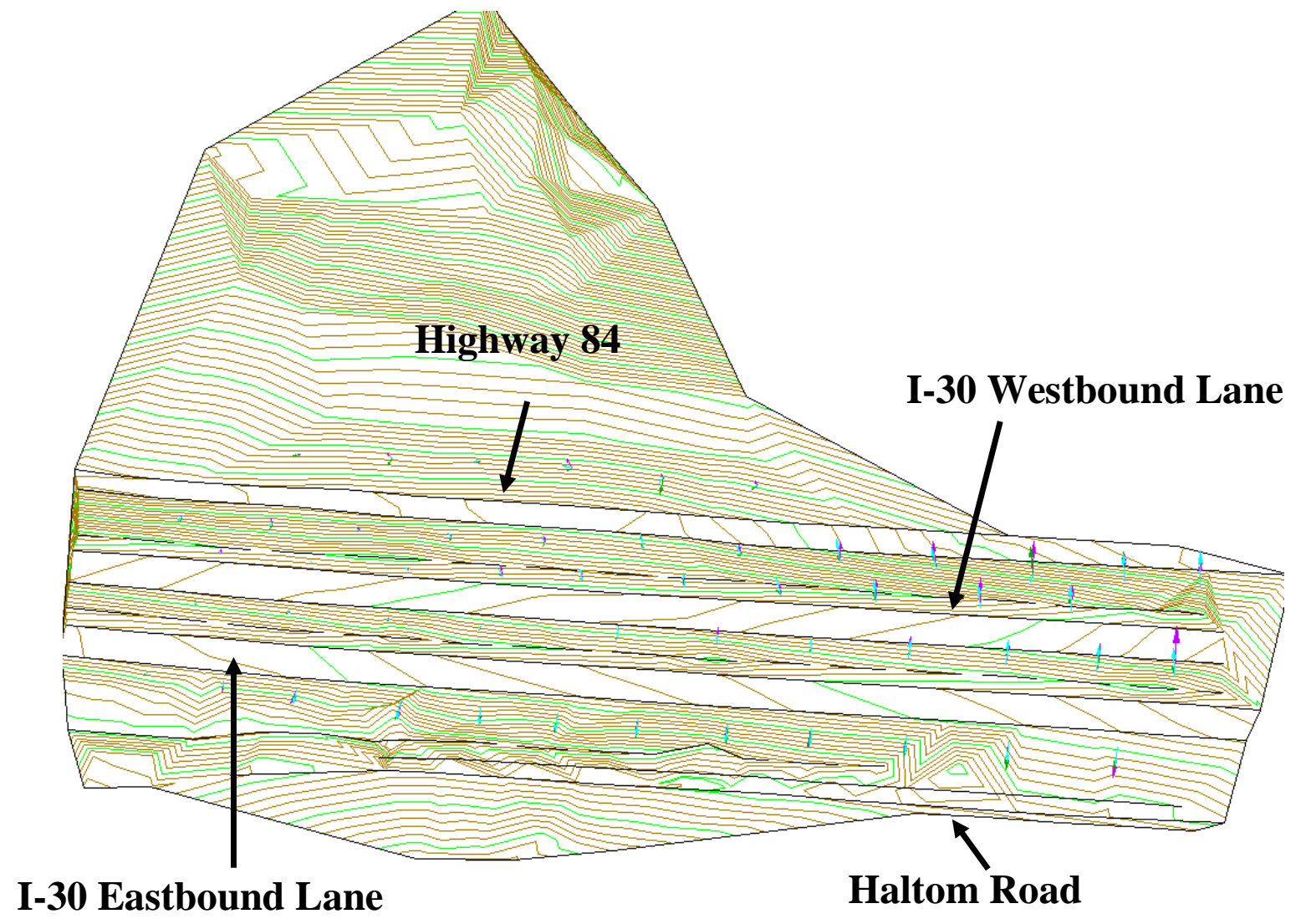


Figure 6.29. Recorded displacement (at the monuments) and digital elevation model of the validation site obtained using the total station.

The large (relative to the calibration site) physical extents of the validation site were a factor contributing to errors in the data collected with total station. The displacement arrows obtained increased linearly with the distance to the total station. A turning trend was also observed for the displacement arrows after each check. Low displacements were measured in the survey monuments close to the total station, while large displacements were obtained for survey monuments on the other side of the moving mass. Displacements over a half foot were obtained for Check 1 in some monuments located on the other side of the moving mass, while, it was determined (by inspection) that the survey monuments did not experienced large movements at the time. Displacements arrows pointing North (uphill) were obtained for the survey monuments located on the other side from the total station. This in contradicted by the physical evidence of the landslide failure mode which is moving south towards the river. Therefore, the displacements obtained with the total station for the majority of survey monuments were believed to not be a measurement of physical displacement of the survey monuments and instead represent instrument error. The viewing geometry of the total station, parallel to the landslide, was believed to influence the results obtained.

The maximum horizontal displacements and vertical (downwards) displacement differences obtained for each site visit (check) were plotted with the precipitation data obtained for the validation site area. At this site no correlation was observed between the displacements recorded and the precipitation during the checks. The large displacements and elevation differences obtained were caused by instrument error compounded by the distance between the total station and the reflector. The weather data for the validation site near Malvern, Arkansas is summarized in Summary of precipitation data for validation site near Malvern, Arkansas 
(modified from National Oceanic and Atmospheric Administration, 2012).. The maximum displacements and elevation differences plotted with cumulative are presented in Figure 6.30 and Figure 6.31, respectively.

Table 6.9. Summary of precipitation data for validation site near Malvern, Arkansas (modified from National Oceanic and Atmospheric Administration, 2012).

\begin{tabular}{|c|c|c|}
\hline \multirow{2}{*}{ Date } & \multicolumn{2}{|c|}{ Precipitation (in.) } \\
\cline { 2 - 3 } & Total Monthly Precipitation & $\begin{array}{c}\text { Extreme Maximum Daily } \\
\text { Precipitation }\end{array}$ \\
\hline October 2010 & 1.94 & 0.93 \\
\hline November 2010 & 5.79 & 1.65 \\
\hline December 2010 & 2.55 & 1.23 \\
\hline January 2011 & 2.04 & 0.80 \\
\hline February 2011 & 4.24 & 1.06 \\
\hline March 2011 & 3.40 & 1.64 \\
\hline April 2011 & 7.67 & 3.05 \\
\hline May 2011 & 8.89 & 3.00 \\
\hline June 2011 & 2.32 & 2.32 \\
\hline July 2011 & 2.52 & 1.52 \\
\hline August 2011 & 5.17 & 1.68 \\
\hline September 2011 & 0.93 & 0.35 \\
\hline October 2011 & 3.05 & 1.85 \\
\hline November 2011 & 10.02 & 4.59 \\
\hline December 2011 & 7.50 & 2.45 \\
\hline January 2012 & 2.68 & 0.68 \\
\hline
\end{tabular}




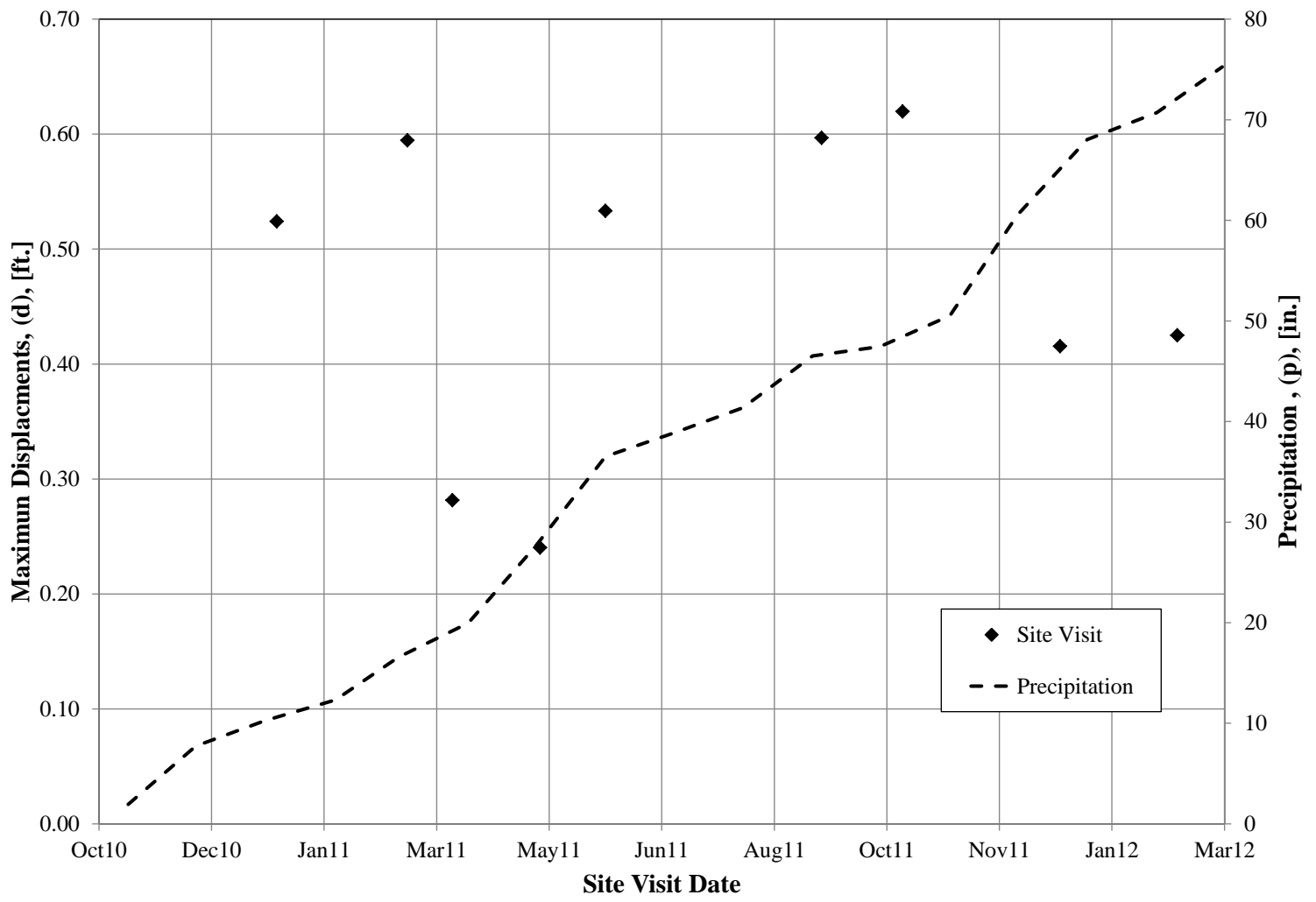

Figure 6.30. Horizontal displacements measured and precipitation data for validation site.

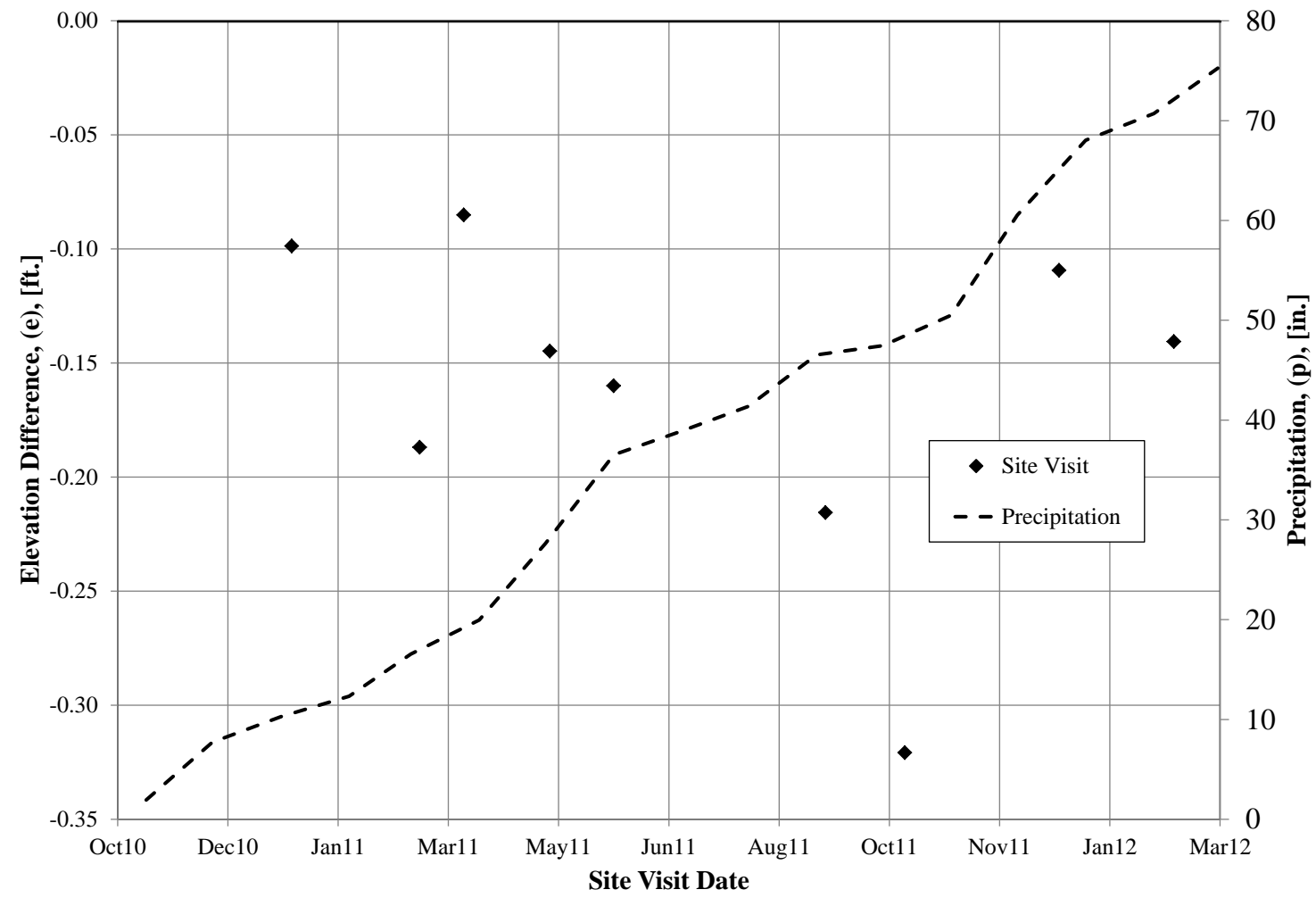

Figure 6.31. Elevation differences measured and precipitation data for validation site. 
The maximum displacements obtained during each visit for all the checks were recorded at monuments 1023,1024 or 2050 . These survey monuments are located in the opposite end of the site approximately 1330 feet away from the total station control point. Displacements to the South (downhill toward the river) were recorded for the majority of the site visits for survey monuments installed in Line 5 (south of the I-30 eastbound lane). Negative elevation differences corresponded to downward movement of the survey monuments. A summary of the maximum and minimum horizontal displacements and elevation change recorded for each check at the validation site is presented in Table 6.10. the measured displacement vectors for each survey monument at the validation site obtained using the total station are presented in Figure 6.32 and Figure 6.33 for Checks1-4 and Checks 6-9, respectively.

Table 6.10. Summary of maximum and minimum displacements and elevation differences for validation site.

\begin{tabular}{|c|c|c|c|c|c|c|c|c|c|}
\cline { 3 - 10 } \multicolumn{2}{c|}{} & \multicolumn{4}{c|}{ Maximun } & \multicolumn{4}{c|}{ Minimun } \\
\hline Date & Check \# & Poinr ID & $\Delta$ displacement & Point ID & $\Delta$ elev & Point ID & $\Delta$ displace ment & Point ID & $\Delta$ elev \\
\hline $1 / 6 / 2011$ & Check 1 & 1023 & 0.5240 & 1002 & 0.0534 & 1003 & 0.0204 & 1025 & -0.0987 \\
\hline $3 / 5 / 2011$ & Check 2 & 1026 & 0.5945 & 1035 & 0.0946 & 1003 & 0.0178 & 1021 & -0.1869 \\
\hline $3 / 25 / 2011$ & Check 3 & 1023 & 0.2816 & 2050 & 0.1201 & 1034 & 0.0030 & 1037 & -0.0851 \\
\hline $5 / 3 / 2011$ & Check 4 & 1024 & 0.2403 & 1004 & 0.0836 & 1005 & 0.0155 & 1017 & -0.1448 \\
\hline $6 / 1 / 2011$ & Check 5 & 1024 & 0.5332 & 1035 & 0.0887 & 1034 & 0.0198 & 1037 & -0.1600 \\
\hline $9 / 5 / 2011$ & Check 6 & 2050 & 0.5967 & 1035 & 0.0906 & 1017 & 0.0097 & 1025 & -0.2156 \\
\hline $10 / 11 / 2011$ & Check 7 & 1024 & 0.6197 & 1003 & 0.0435 & 1034 & 0.0058 & 1025 & -0.3208 \\
\hline $12 / 20 / 2011$ & Check 8 & 1023 & 0.4154 & 1022 & 0.1081 & 1034 & 0.0079 & 1021 & -0.1094 \\
\hline $2 / 10 / 2012$ & Check 9 & 1023 & 0.4250 & 1035 & 0.1478 & 2039 & 0.0088 & 1025 & -0.1406 \\
\hline
\end{tabular}

The moving mass was delineated by grouping the survey monuments with recorded displacements close to the same magnitude. A progressive "displacement" of the survey monuments was observed as the distance from the reflector increased. As previously described, the as accuracy of the measured displacement was negatively impacted by the several factors including the large distance between the sensor and the target reflector and a parallel viewing 
geometry to the moving mass. The plan view of the relative movement of different regions at the validation site is presented in Figure 6.34.

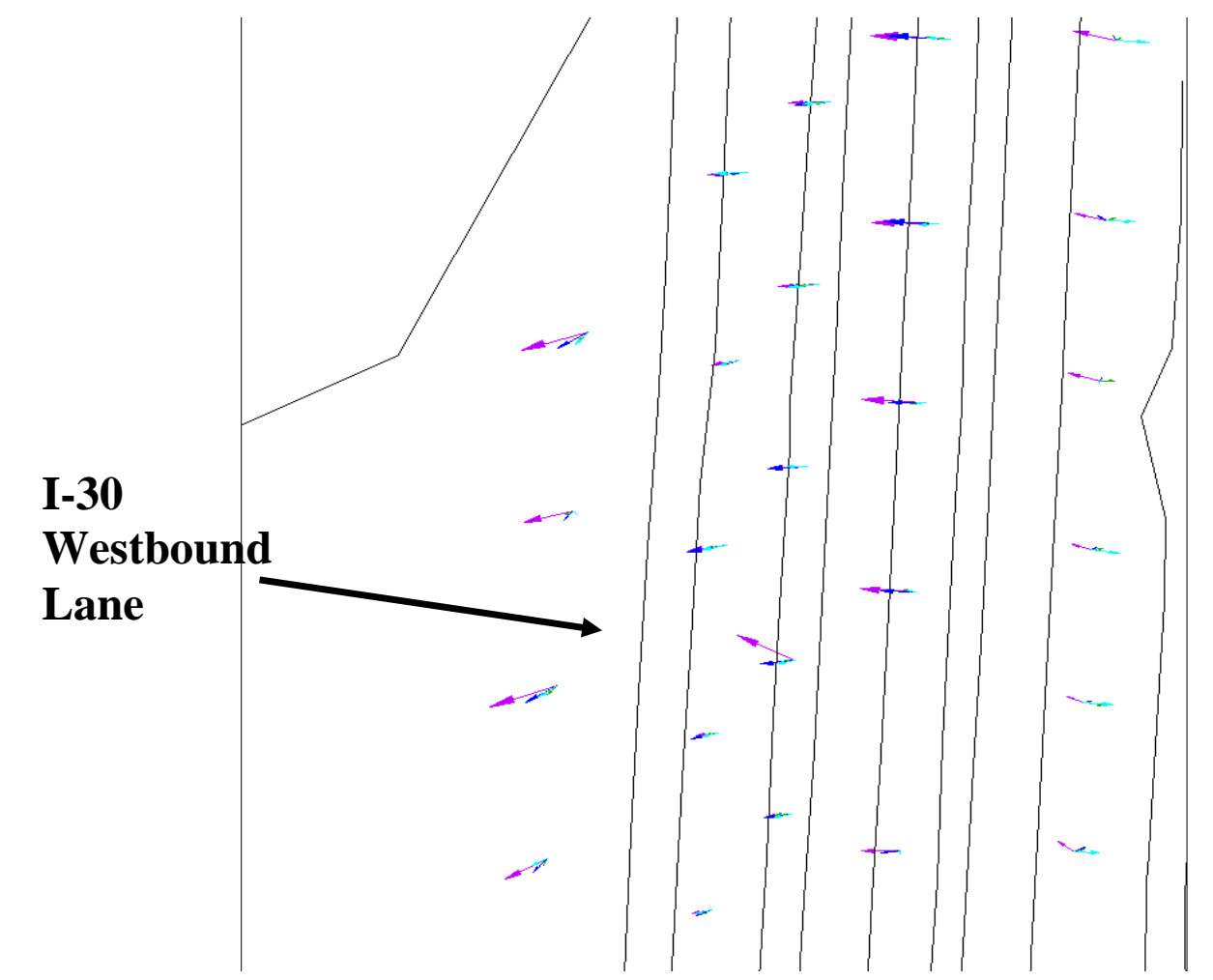

Figure 6.32. Displacements Piferded on four checks on validation site [in color].

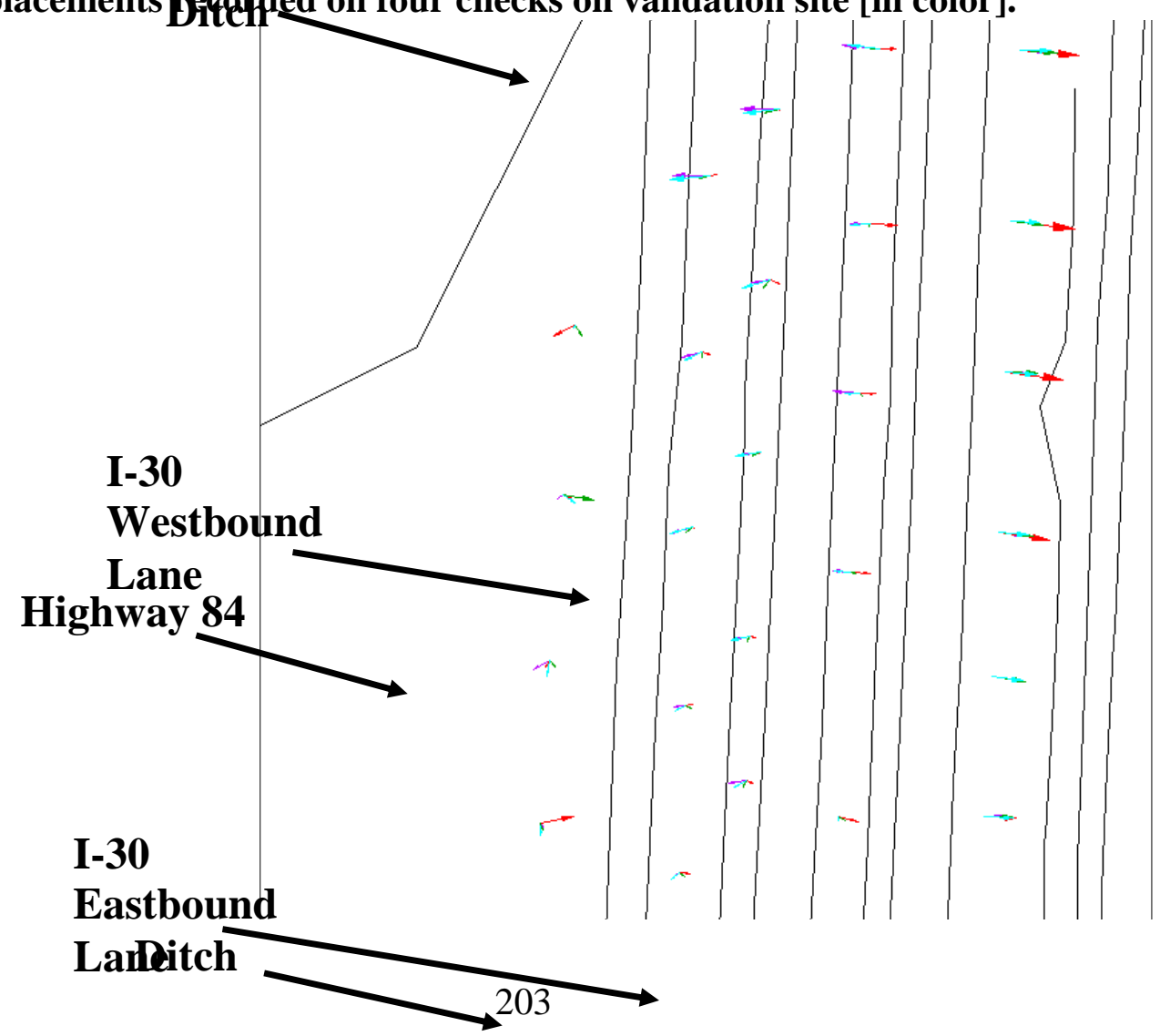


Figure 6.33. Displacements recorded on the last four checks on validation site [in color].

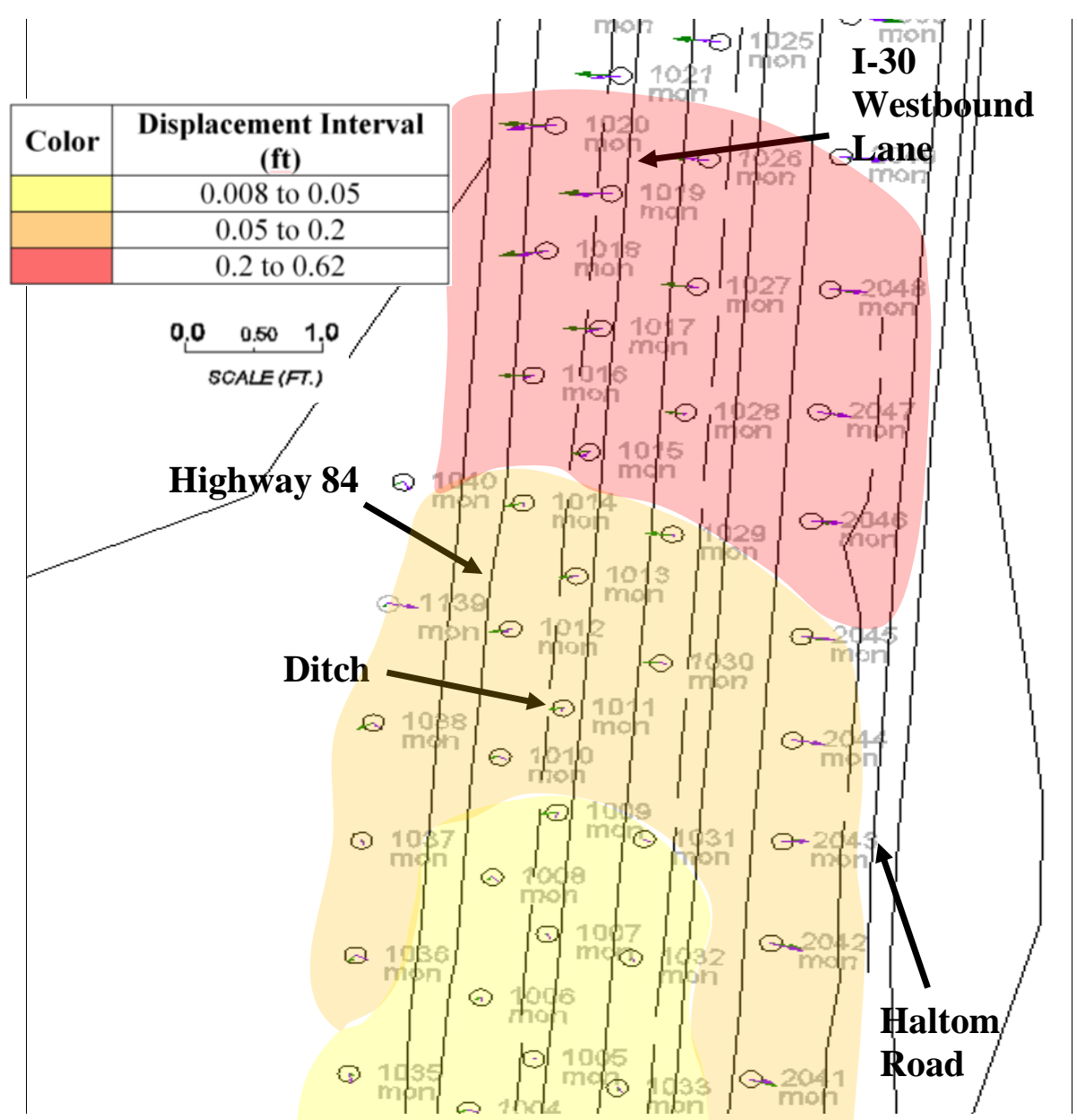

Figure 6.34. Movement areas based on survey monument displacements obtain with total station at validation site [in color].

Due to the large errors in the total station, displacement rates were not calculated for the validation site monuments. As explained in Section 5.2.2, two methods were developed to reduce the error caused by the large distances when acquiring data with the total station. Prior to the implementation of the error correction method the displacement vector $\begin{aligned} & \text { Eastbound } \\ & \text { Latained from the survey }\end{aligned}$ monument 1029 displayed a linear increase in measured displacement with distance away from the sensor. Turning error was also observed to increase with the distance to the total station. The angle method attempted to correct the error method but however provided little to no mitigation of the turning error observed in the total station measurements. The displacements recorded from 
survey point 1000, and the displacement acquired from survey monument 1029 did not match in either quantity or direction for the majority of the survey points on each check. The second correction method developed, the tangent circles method, was implemented for two different site checks. The time difference between data acquisition from each survey monument (1000 and 1029) was approximately three hours.

Errors were encountered when using the tangent circles method for survey monuments with parallel lines of site or were located equidistant from the two total station control points. The corrected displacement at these survey monuments indicated movements in excess of what was observed in the field. It was concluded that the method did not provide any enhancement of the data and therefore discontinued. Due to the large errors encountered, the lack of a suitable correction method and time constraints during site visits to the validation site, acquisitions from the survey monument 1029 were discontinued. A picture comparing the data acquired from survey monument 1000 and survey monument 1029 with the total station for Check 3 and Check $3 \mathrm{~b}$ is presented in Figure 6.35. 


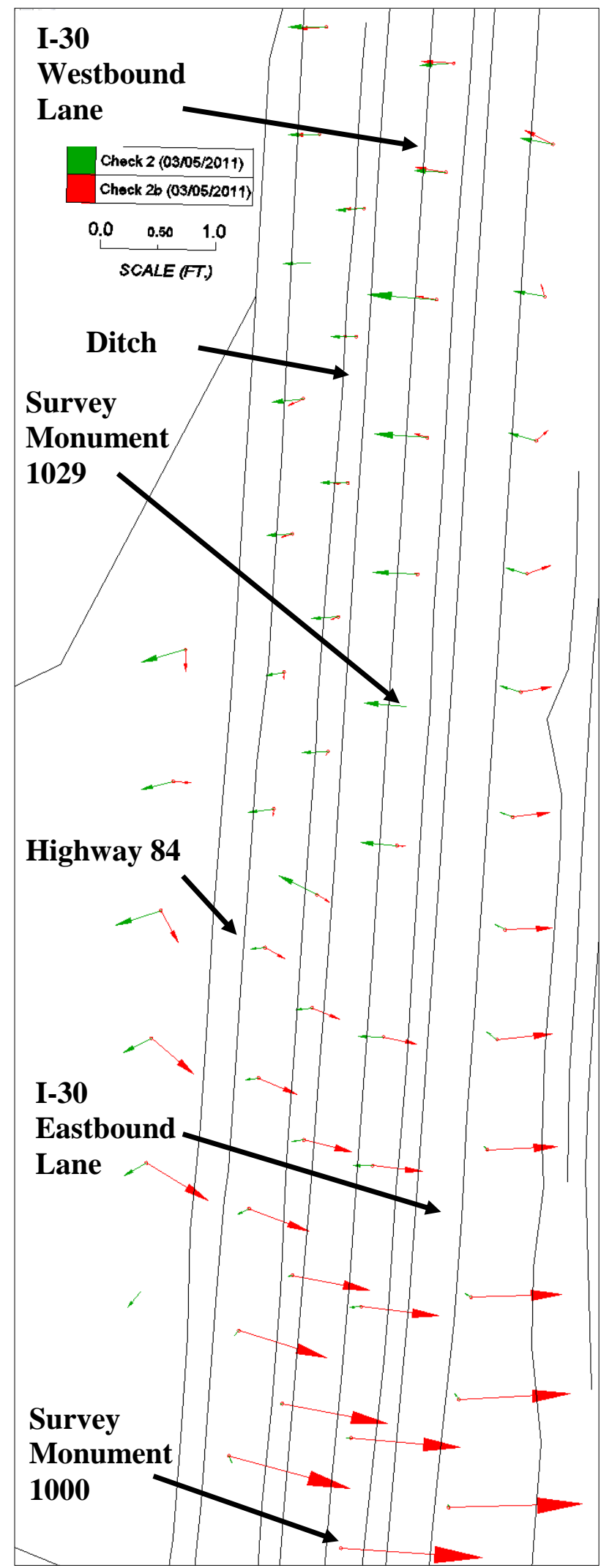

I-30

Westbound

Lane

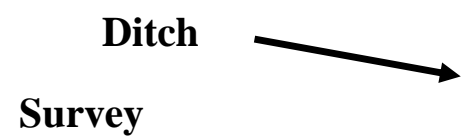

Monument

1029

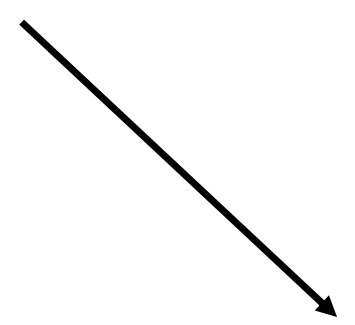

Highway 84

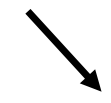

I-30

Eastbound

Lane

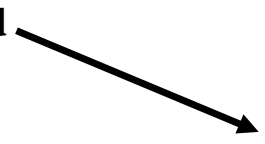

Survey

Monument

1000

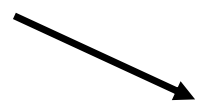




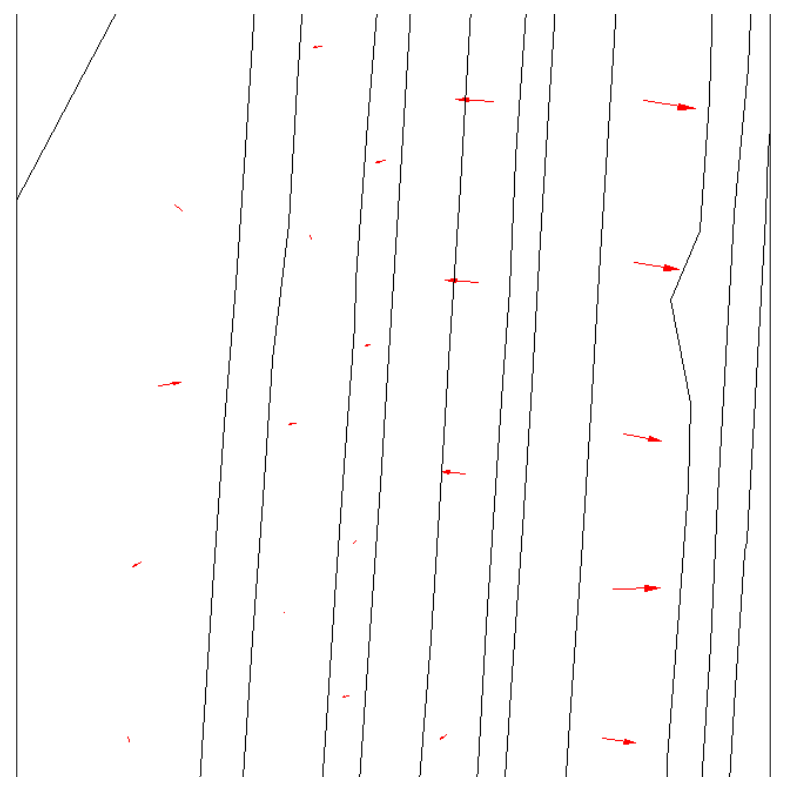

Figure 6.35. Comparison of displacements obtained from control point 1000 and control point 1029 for validation site near Malvern, Arkansas.

\subsubsection{LIDAR}

The LIDAR data acquired was analyzed following the procedure discussed in Section 5.4, to locate the boundaries and displacement rates of the moving mass located near Malvern, Arkansas. As performed with the calibration site (Section 6.6.1.2), the polylines method and bare earth correction methods were performed to delete the vegetation before creating the surfaces. Negative elevation differences were obtained by comparing surfaces form different site visits. A main scarp was not observed at the validation site, and progressive downward movement was just observed in a portion of the hillside North of Highway 84. Small or no movement was observed around the structure (house) and drive way north of Highway 84 . The ditch in the median of I-30 lanes created a shadow that prohibited the acquisition of data at this location.

Movements of the landslide located at the validation site were not fully detected using LIDAR. The size, complexity and topography of the site prevented a clear detection of the moving mass. Four LIDAR scans were required to cover the extensions of the validation site. Even though, the different scans for each site visit were registered and unified. The variability in the sensor setup may introduce some noise to the final images. After analyzing the data from the 
monitoring devices utilized at the validation site it was concluded that the four LIDAR scans locations were inside the moving mass. Therefore, the LIDAR movements obtained were not relative to a fix point resulting in the poor correlation observed. The images obtained for the 050311-122911 comparison using the polylines and bare earth correction methods are presented in Figure 6.36 and Figure 6.37, respectively. Progressive downward elevation different of the validation site in a time spam of six months is shown in Figure 6.38.

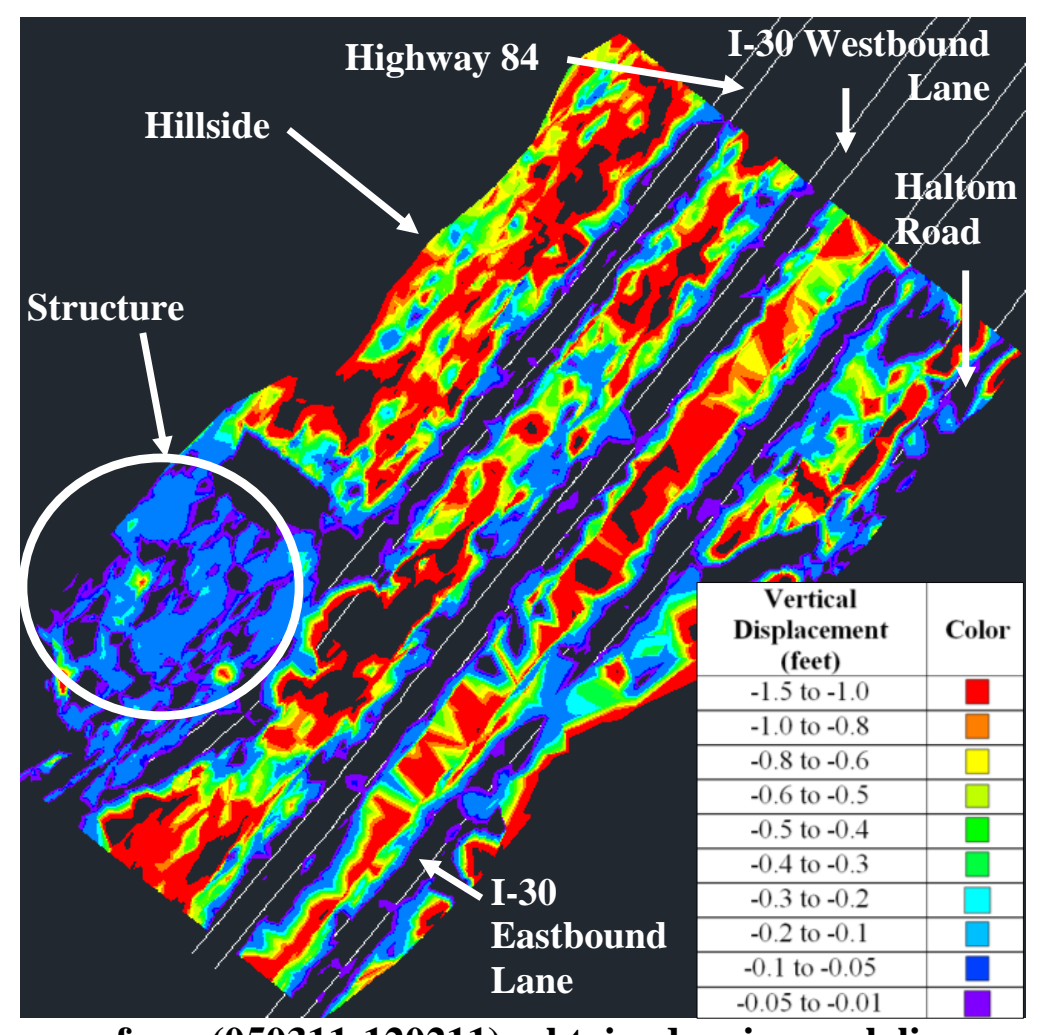

Figure 6.36. Volume surface (050311-120211) obtained using polylines method at the validation site [in color]. 


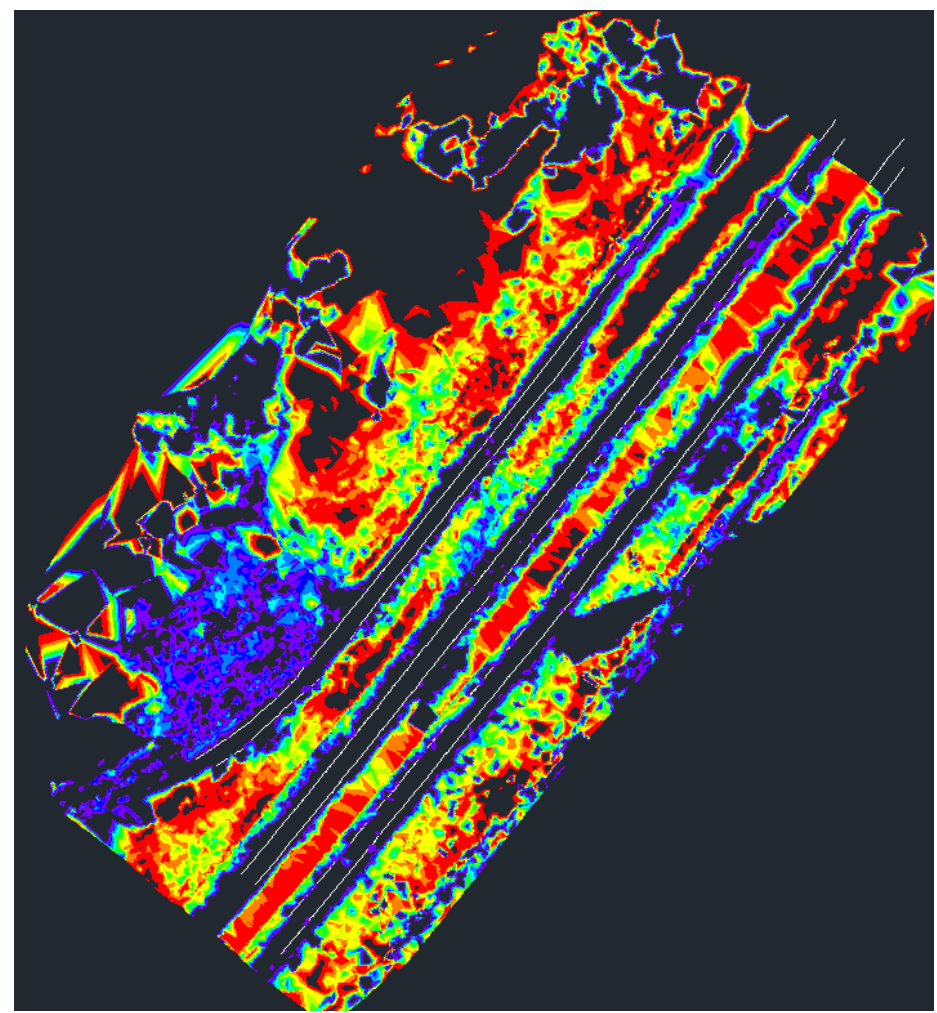

Figure 6.37. Volume surface (050311-120211) obtained using bare earth correction method at the validation site [in color]

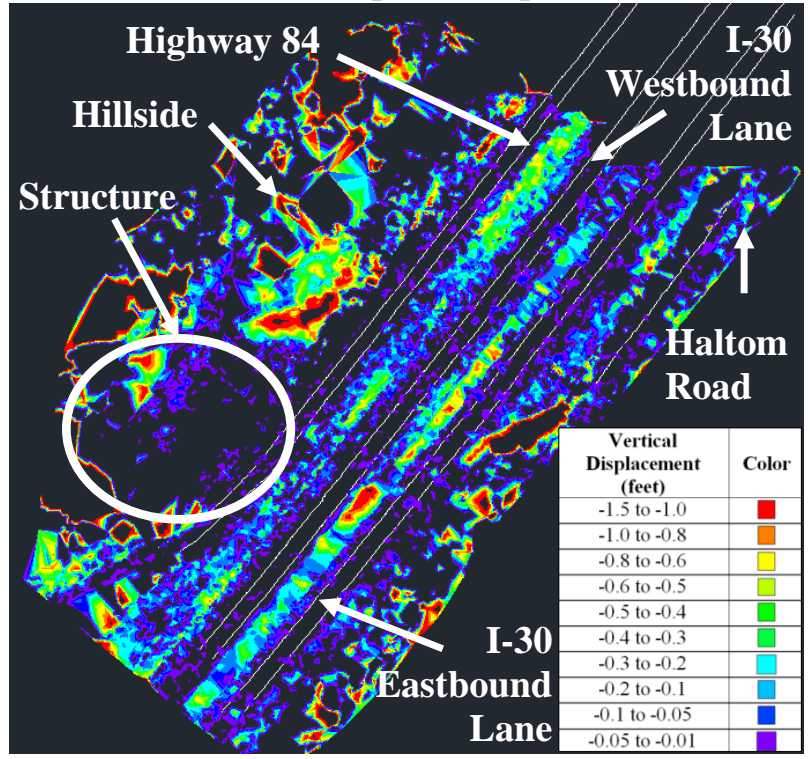

(a)

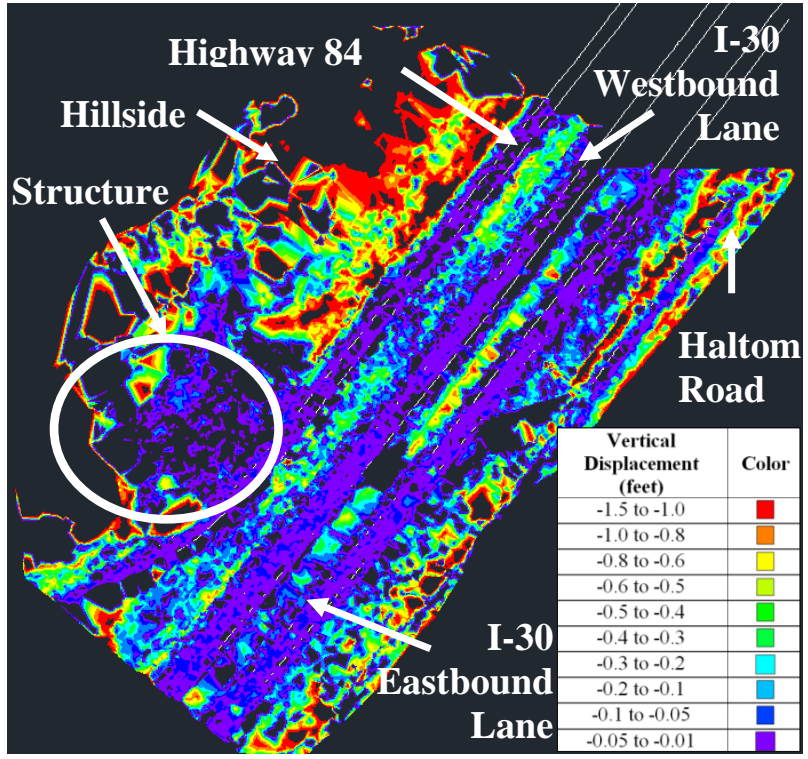

(b)

Figure 6.38. a) Volume surface (062711-080111) using bare earth correction method, and b) volume surface (062711-120211) using bare earth correction method [in color]. 


\subsubsection{GPRI-II}

The results obtained from the data acquired in the field at the validation site near Malvern, Arkansas are presented in this chapter. As previously discussed in Section 5.3, the first result obtained while processing the data acquired using the GPRI-II were MLI images. The MLI images obtained for the Northeast viewpoint at the validation site allowed for an analysis of the landslide in a parallel (to the moving mass) viewing geometry, while, MLI images obtained from the Southwest viewpoint provided a perpendicular (to the moving mass) viewing geometry to the moving mass.

The MLI obtained from the Northeast RADAR viewpoint (polar and rectangular) allowed the inspection of the entire site, a fence located in front of the sensor and traffic in the I-30 lanes caused saturation of the images. The images covered the hillside to the North of Highway 84 where the toe of the landslide is believed to be located. The MLI image for the March 3, 2011 visit, which was used as master, is presented in Figure 6.39. 


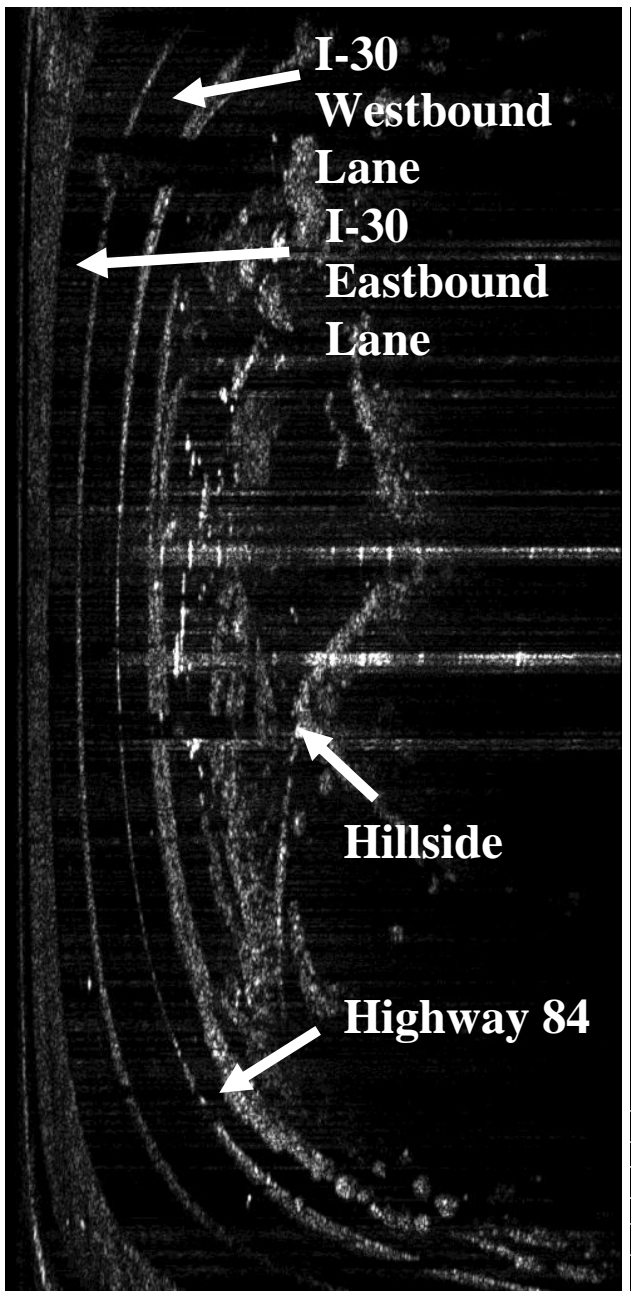

(a)

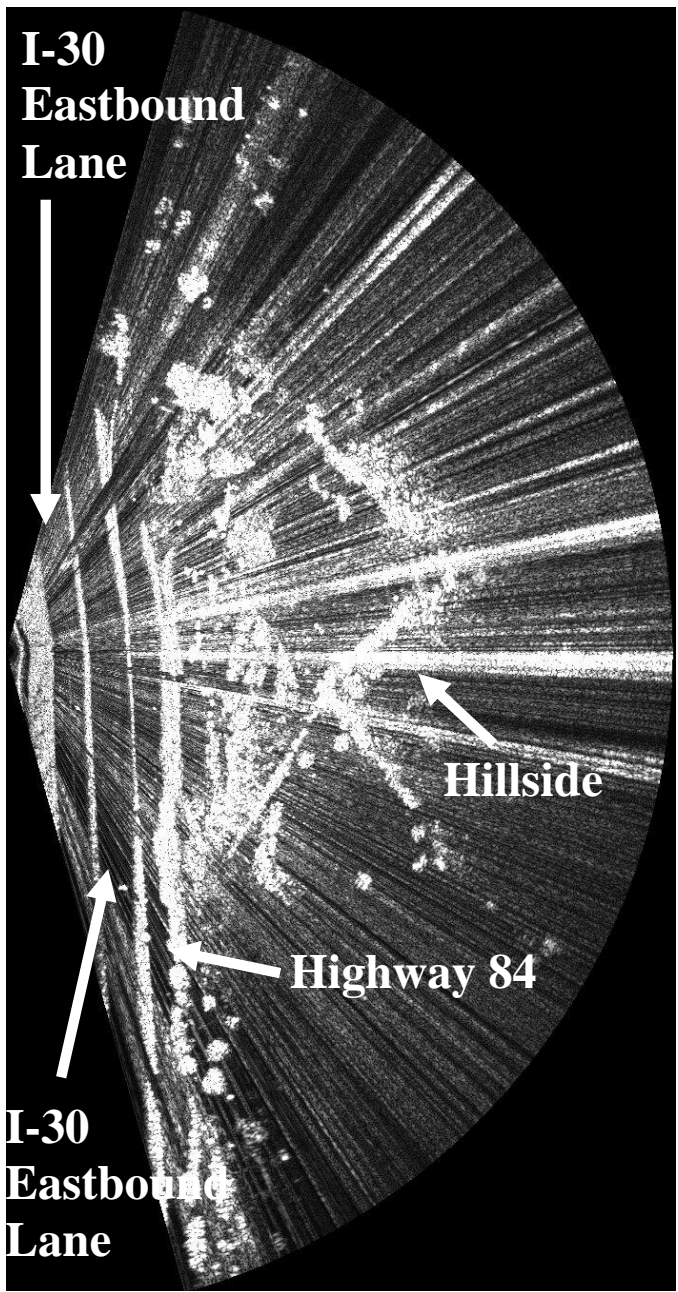

(b)

Figure 6.39. a) MLI RADAR image obained from Northeast viewpoint in polar corrdinates using 250ms chirp, and b) MLI RADAR image obained from Northeast viewpoint in polar corrdinates using $250 \mathrm{~ms}$ chirp.

The hillside, both I-30 lanes, Highway 84, and the structures located North of Highway 84, are among the features observed in the MLI obtained from the southbound viewpoint at the validation site near Malvern, Arkansas. A fence located in the median between Highway 84 and the I-30 Westbound lane and the traffic encountered during site visits caused some saturation of the image. As observed form the MLI images obtained after processing of the raw data acquired at the Southwest viewpoint covered more lateral area of the landslide, than the data acquired form the Northeast viewpoint. The MLI image (polar and rectangular) for the Southwest viewpoint is presented in Figure 6.40. 


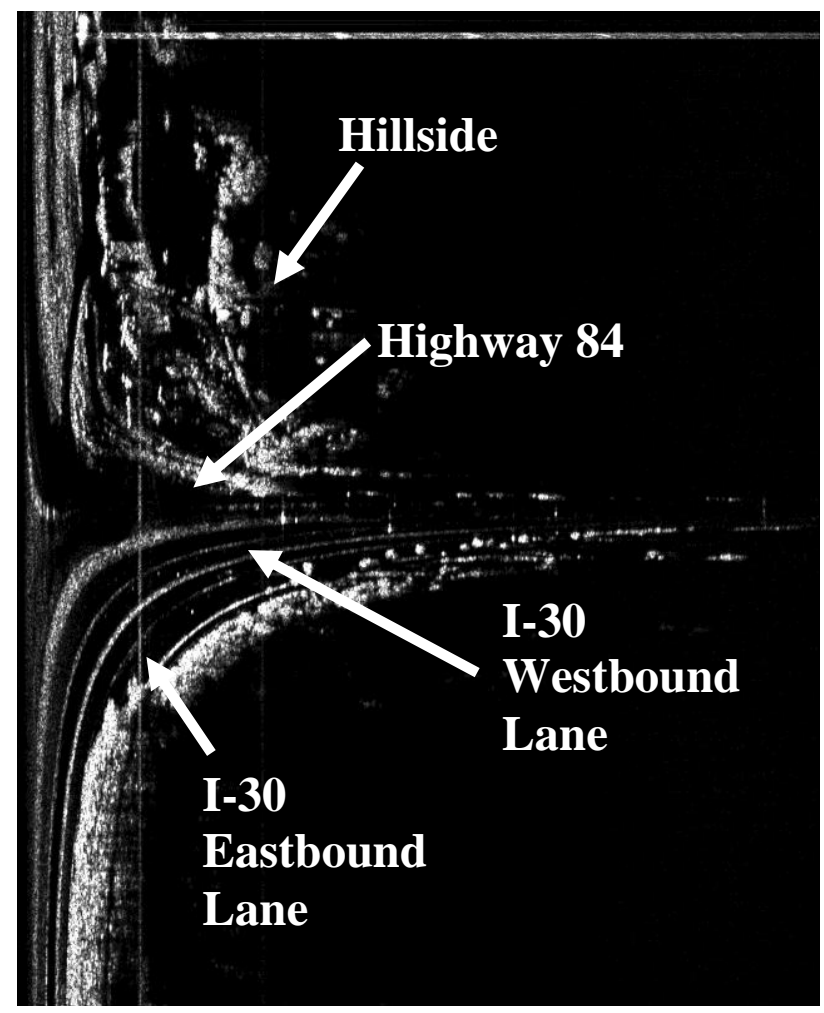

(a)

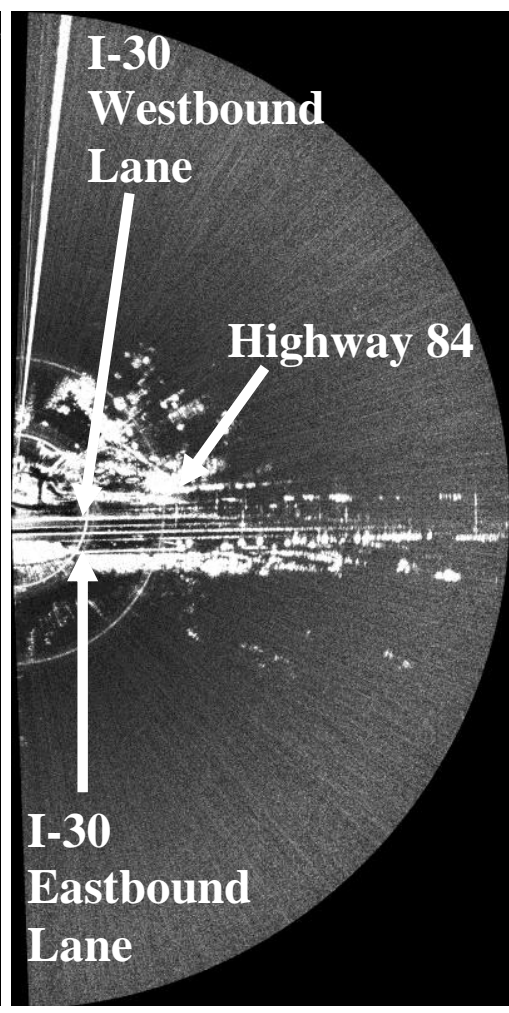

(b)

Figure 6.40. MLI RADAR image obained from Southwest viewpoint in polar corrdinates using 500ms chirp, and b) MLI RADAR image obained from Southwest viewpoint in polar corrdinates using 500ms chirp.

\subsubsection{Non-remote Sensing Techniques}

The validation site was monitored using permanently installed in-situ instrumentation for a period of approximately four months from October 2011 to February 2012. Four slope inclinometers and one vibrating wire piezometer were installed at the validation site. Displacements of the landslide were measured from the deformation of the inclinometer casing caused by stress applied by the moving mass. The vibrating wire piezometer provided a recording of the ground water table (GWT) depth for the last four site visits to the validation site. The inclinometers and vibrating wire piezometer results are presented in the following subsections. 


\subsection{Inclinometers}

The inclinometers installed in the validation site were used to generate two different cross-sections. Inclinometers installed at boreholes B-1, B-3, and B-6 formed a North-South cross-section (Figure 6.1); whereas inclinometers at B-3 and B-4 formed an East-West crosssection. The data obtained from the inclinometers installed at the validation site is summarized in table. The sliding failure depth measured by inclinometer casing installed at the B-1 (located north of Highway 84) was approximately 51.5 feet below the ground surface. There was 10.5 foot elevation difference between the ground surface at the B-1 location and the ground surface at the B-3 location between Highway 84 and I-30 Westbound lane. The depth of the sliding surface recorded at the B-3 location was approximately 64 feet below the ground surface. Plots of displacement versus depth for the slope inclinometers installed at the B-1 and B-3 locations containing the readings acquired during last for visits are presented in Figure 6.41.

The slope inclinometer installed at the B-4 location, between Highway 84 and I-30 Westbound lane, recorded the sliding surface at a depth of approximately 60 feet. The sliding surface was measured at approximately 60 feet below the ground surface at the B-6 location. There was an elevation difference of approximately 7.5 feet between the ground surface at B-6 and the ground surface at B-3. The profiles graphs for slope inclinometers located at B-4 and B-6 are presented in Figure 6.42.

The slope inclinometers allowed for the observation and measurement of ground movement at different depths along the validation site. The sliding surface was interpolated from the three inclinometers at B-1, B-3 and B-6. The inclinometer data coupled with the site stratigraphy observed during the subsurface investigation indicate that the failure surface is located within the limestone-weathered shale layer. The sliding surface appears to angle upwards 
at both ends of the cross-section studied. A diagram of the sliding surface is presented in Figure 6.43.

Table 6.11. Summary of results for inclinometers installed at validation site.

\begin{tabular}{|c|c|c|c|c|c|c|c|}
\hline \multirow{2}{*}{ Inclinometer } & \multirow{2}{*}{$\begin{array}{c}\begin{array}{c}\text { Depth to Slip } \\
\text { Plane }\end{array} \\
\text { ft. } \\
\end{array}$} & \multirow{2}{*}{ Date } & \multirow{2}{*}{$\begin{array}{c}\begin{array}{c}\text { Incremetal } \\
\text { Displacement }\end{array} \\
\text { inch } \\
\end{array}$} & \multirow{2}{*}{ Days } & \multicolumn{2}{|c|}{ Displacmeent Rates } & \multirow{2}{*}{$\begin{array}{l}\text { Average } \\
\text { inch/year }\end{array}$} \\
\hline & & & & & inch/day & inch/year & \\
\hline \multirow{3}{*}{ B-1 } & \multirow{3}{*}{51.5} & Nov. 8 & 0.0066 & 26 & 0.0003 & 0.093 & \multirow{3}{*}{0.13} \\
\hline & & Dec. 20 & 0.0189 & 68 & 0.0003 & 0.101 & \\
\hline & & Feb. 10 & 0.0687 & 120 & 0.0006 & 0.209 & \\
\hline \multirow{3}{*}{ B-3 } & \multirow{3}{*}{64} & Nov. 8 & 0.0012 & 26 & 0.0000 & 0.017 & \multirow{3}{*}{0.18} \\
\hline & & Dec. 20 & 0.0411 & 68 & 0.0006 & 0.221 & \\
\hline & & Feb. 10 & 0.1029 & 120 & 0.0009 & 0.313 & \\
\hline \multirow{3}{*}{ B-4 } & \multirow{3}{*}{60} & Nov. 8 & 0.0042 & 26 & 0.0002 & 0.059 & \multirow{3}{*}{0.13} \\
\hline & & Dec. 20 & 0.0246 & 68 & 0.0004 & 0.132 & \\
\hline & & Feb. 10 & 0.0687 & 120 & 0.0006 & 0.209 & \\
\hline \multirow{3}{*}{ B-6 } & \multirow{3}{*}{60} & Nov. 8 & 0.0021 & 26 & 0.0001 & 0.029 & \multirow{3}{*}{0.16} \\
\hline & & Dec. 20 & 0.0333 & 68 & 0.0005 & 0.179 & \\
\hline & & Feb. 10 & 0.0864 & 120 & 0.0007 & 0.263 & \\
\hline
\end{tabular}




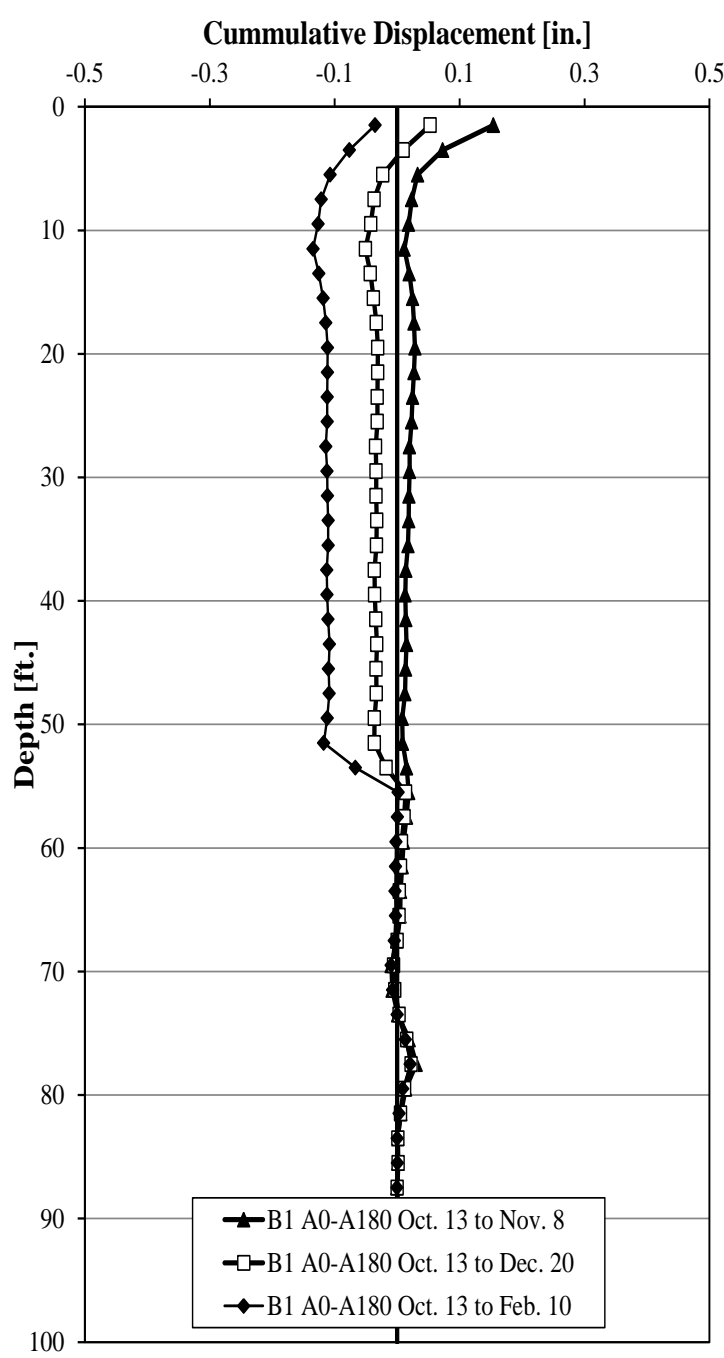

(a)

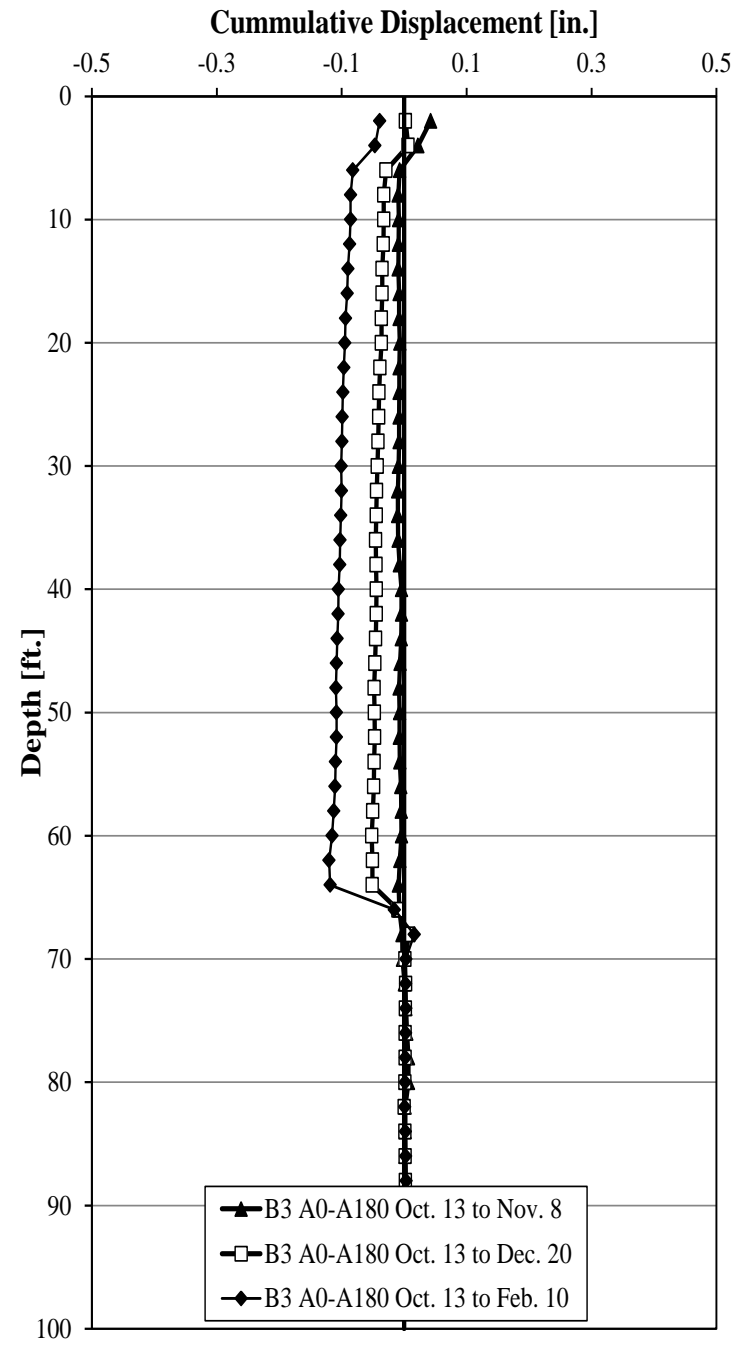

(b)

Figure 6.41. Profile of the slope inclinometer installed at B-1 location for the site visits to the validation site, and b) Profile of the slope inclinometers casing installed at the B-3 location for the site visits to the validation site. 


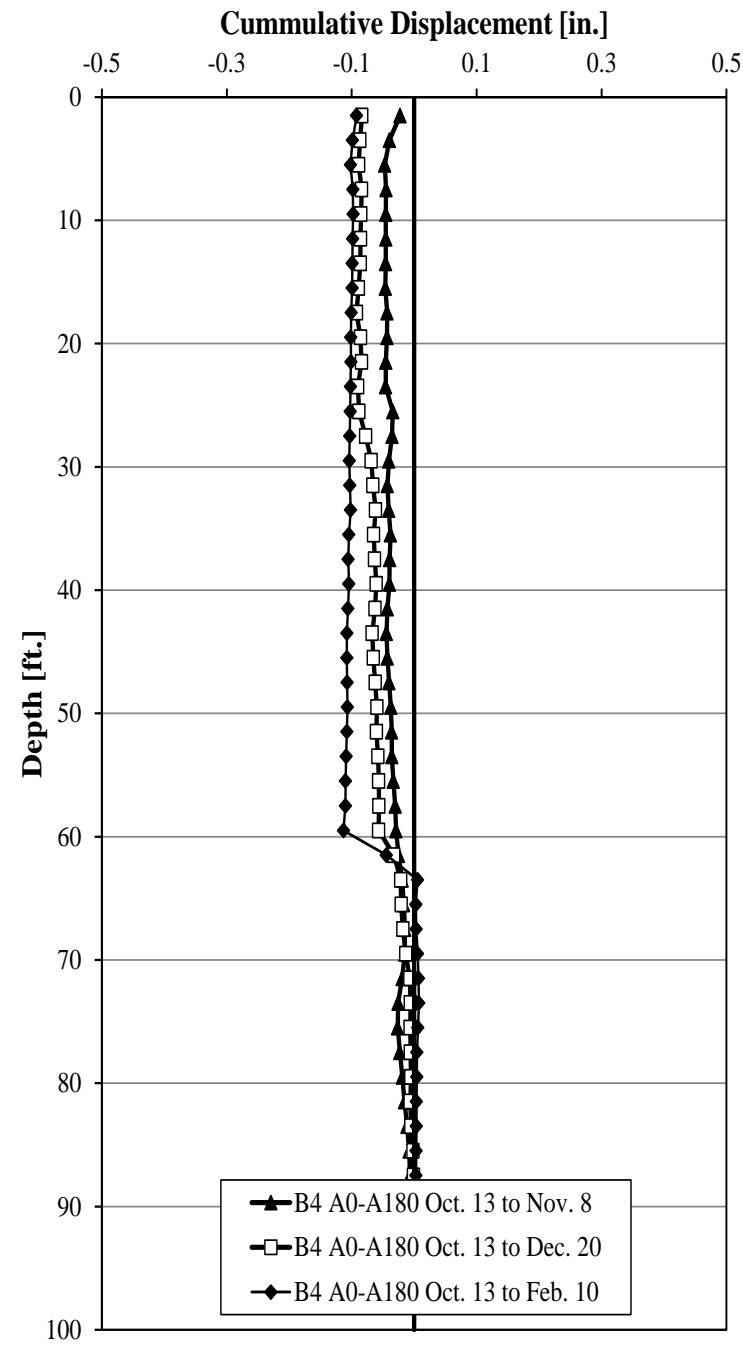

(a)

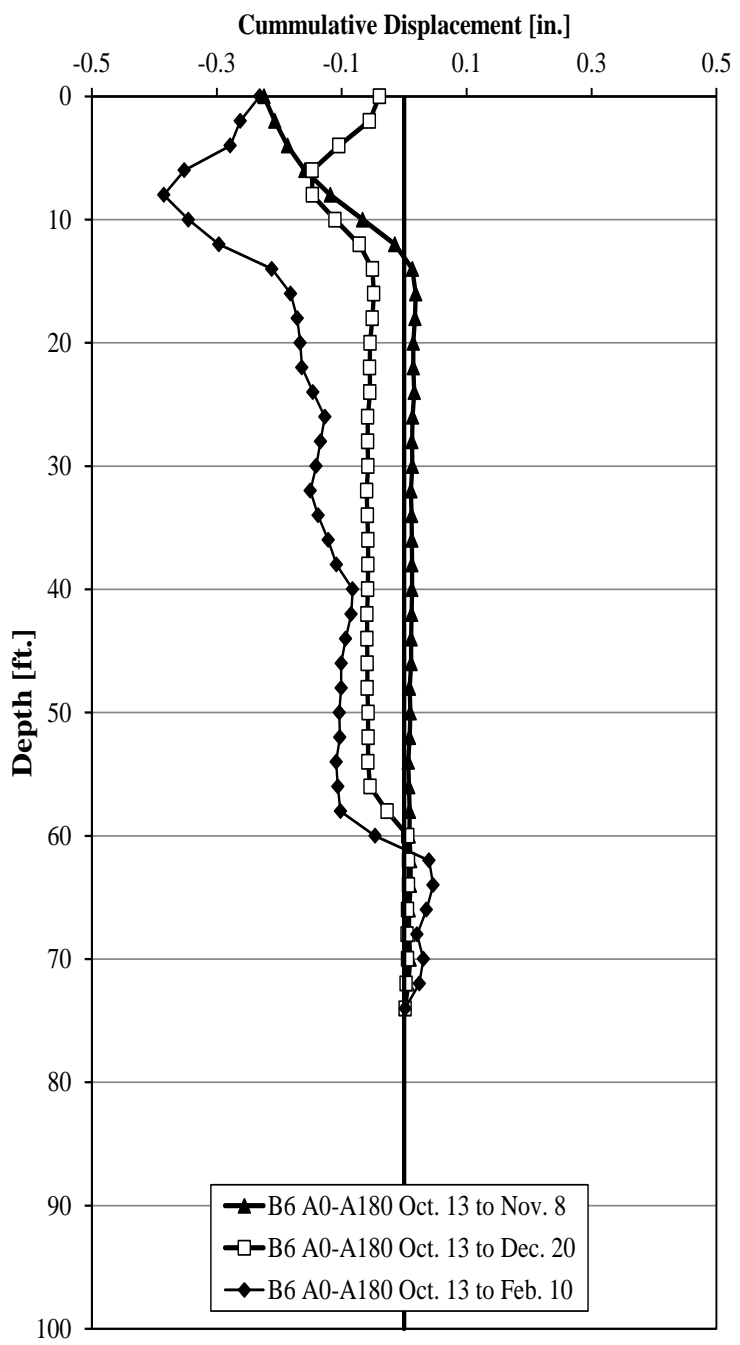

(b)

Figure 6.42. Profile of the slope inclinometer installed at B-4 location for the site visits to the validation site, and b) Profile of the slope inclinometers casing installed at the B-6 location for the site visits to the validation site. 


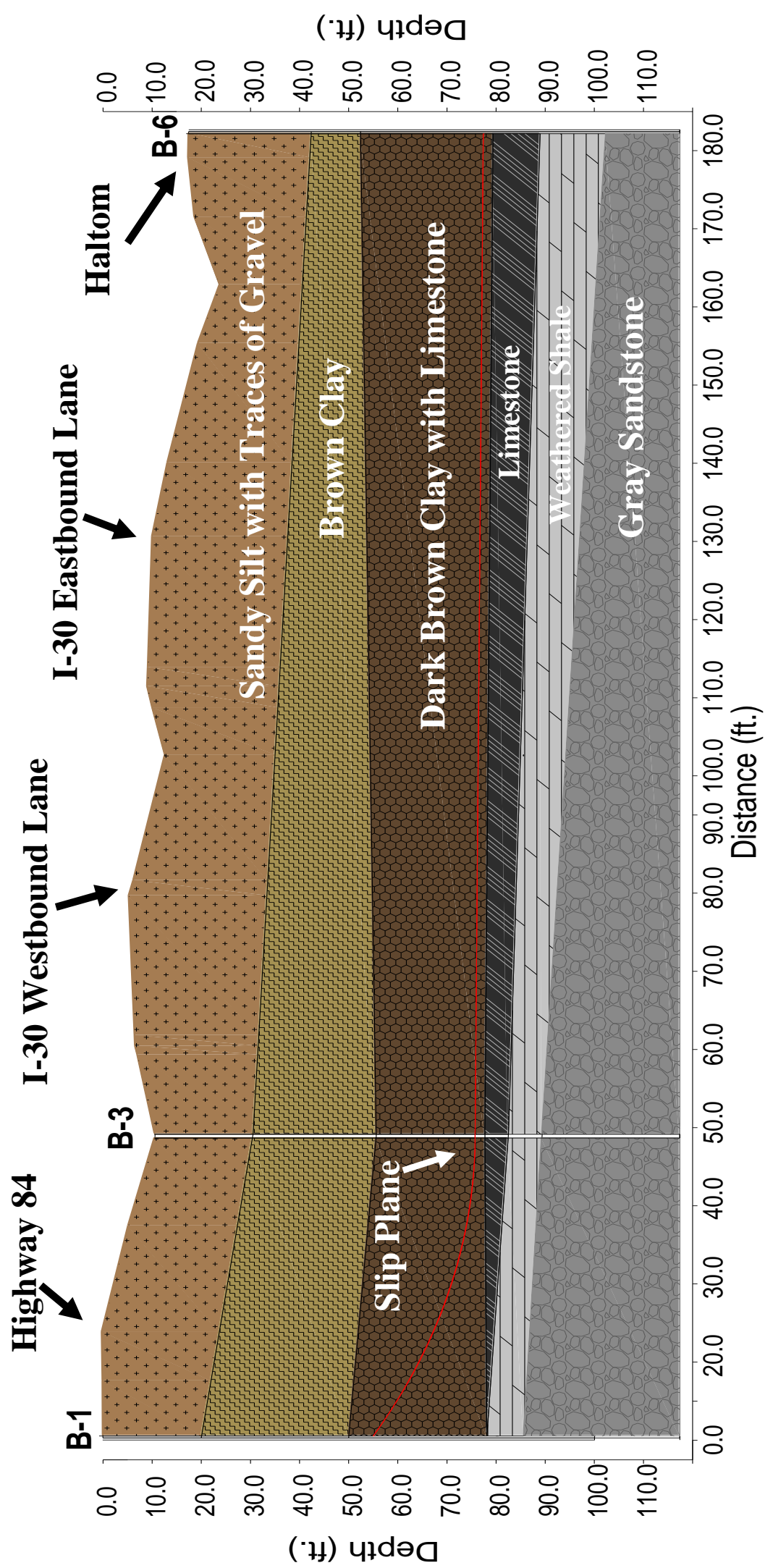

Figure 6.43. Sliding surface as recorded by slope inclinometers installed at validation site [in color]. 


\subsection{Vibrating Wire Piezometer}

The nested vibrating wire piezometer (VWP) was installed at boreholes (B-2), in the median between Highway 84 and the westbound lane of I-30 (Section 4.6.3). The vibrating wire piezometer was monitored over four months period between October 2011 and January 2012. Data was acquired during the last five site visits to the validation site near Malvern, Arkansas.

Pressure changes at the slip surface (measured with inclinometers) were not observed with the nested vibrating wire piezometer installed at B-2. However, artesian conditions could have affected the measurements obtained. The ground water table (GWT) depth was inferred from the pressures measured by the transducer sensors (installed at different depths) during the different visits. The GWT was consistently (except for the last site visit) located an approximate depth of 7.3 feet below the ground surface (Table 6.12). The GWT depth measured with the nested vibrating wire piezometer coincided with the change in strata as indicated by a change in plastic index (PI) during the subsurface investigation at the same location (Figure 6.44). During the last site visit to the site (February 2, 2012), the calculated GWT was at a depth of approximately 2 feet (Table 6.12). The increased elevation of the GWT correlated with and was causative of the increase in displacements rates measured by the inclinometers, as discussed in Section 6.6.2.4.1. A profile of the pressure obtained using the vibrating wire piezometer installed at the validation site is presented in Figure 6.44. 
Table 6.12. Summary of data and results obtained from the nested VWP.

\begin{tabular}{|c|c|c|c|c|c|c|c|c|c|c|c|c|c|c|c|c|c|c|c|c|c|c|c|c|c|c|}
\hline 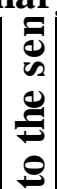 & | & $\begin{array}{l}0 \\
\\
-\end{array}$ & $\begin{array}{l}\stackrel{\Omega}{1} \\
\stackrel{+}{+}\end{array}$ & $\begin{array}{l}\infty \\
0 \\
\text { ஸे } \\
0\end{array}$ & $\begin{array}{l}2 \\
n \\
\infty \\
\infty\end{array}$ & $\begin{array}{l}\text { N่ } \\
\infty \\
0\end{array}$ & $\begin{array}{l}\stackrel{1}{\infty} \\
0 \\
0\end{array}$ & 年 & $\left|\begin{array}{l}\infty \\
a \\
\vdots \\
0 \\
n\end{array}\right|$ & $\left|\begin{array}{l}\hat{a} \\
\hat{\sigma}\end{array}\right|$ & | & $\mid \begin{array}{l}\stackrel{9}{二} \\
=\end{array}$ & $\left|\begin{array}{l}0 \\
0 \\
m\end{array}\right|$ & $\left|\begin{array}{l}\mathfrak{N} \\
\dot{0} \\
\dot{n}\end{array}\right|$ & $\left|\begin{array}{l}\hat{\sigma} \\
\hat{\sigma} \\
\sigma\end{array}\right|$ & $\left|\begin{array}{l}a \\
\text { ma. } \\
\hat{a}\end{array}\right|$ & $\begin{array}{c}\text { 이 } \\
\stackrel{1}{-}\end{array}$ & \begin{tabular}{|l|}
$\nexists$ \\
$\dot{d}$ \\
$\dot{n}$
\end{tabular} & $\mid \begin{array}{l}\vec{y} \\
\dot{\forall}\end{array}$ & $\mid \begin{array}{c}\vec{m} \\
m \\
n\end{array}$ & $\left|\begin{array}{c}\hat{\jmath} \\
\dot{+} \\
\text { | }\end{array}\right|$ & 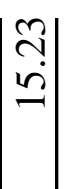 & $\begin{array}{l}n \\
\tilde{n} \\
m\end{array}$ & $\left|\begin{array}{l}n \\
n \\
n \\
n \\
n\end{array}\right|$ & \begin{tabular}{l}
\multirow{n}{*}{} \\
$\stackrel{2}{*}$
\end{tabular} & 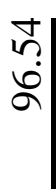 \\
\hline 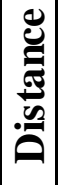 &.$\dot{0}$ & 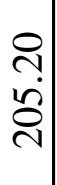 & $\begin{array}{l}\bar{n} \\
\cdots \\
\infty \\
+\end{array}$ & $\begin{array}{c}\sim \\
\text { N } \\
\sim\end{array}$ & 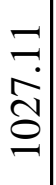 & 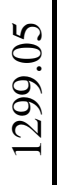 & 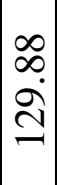 & $\begin{array}{l}n \\
n \\
\infty \\
\infty \\
n\end{array}$ & 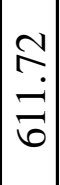 & $\mid \begin{array}{l}m \\
\hat{2} \\
\tilde{\infty} \\
\infty\end{array}$ & $\mid \begin{array}{l}\circ \\
\infty \\
8 \\
8 \\
\varnothing\end{array}$ & $\begin{array}{l}\vec{n} \\
\dot{m} \\
\tilde{n}\end{array}$ & $\begin{array}{l}+ \\
\hat{\sigma} \\
m\end{array}$ & $\left|\begin{array}{l|}\infty \\
0 \\
0 \\
0 \\
0\end{array}\right|$ & $\left|\begin{array}{l}\infty \\
+ \\
\dot{f} \\
\infty \\
\infty\end{array}\right|$ & $\begin{array}{c}\bar{r} \\
\dot{+} \\
0 \\
0\end{array}$ & $\begin{array}{l}\infty \\
\infty \\
\dot{+} \\
\infty\end{array}$ & 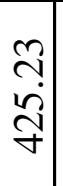 & 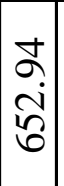 & $\mid \begin{array}{c}0 \\
0 \\
0 \\
\infty \\
\infty\end{array}$ & $\left|\begin{array}{l}0 \\
+ \\
\dot{0} \\
0 \\
=\end{array}\right|$ & $\begin{array}{l}\curvearrowright \\
\infty \\
\dot{\infty} \\
\infty\end{array}$ & $\begin{array}{l}n \\
\dot{m} \\
\dot{\sigma}\end{array}$ & $\left|\begin{array}{l}\nabla \\
0 \\
\dot{0} \\
0 \\
0\end{array}\right|$ & 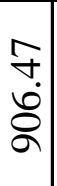 & \begin{tabular}{l}
$\infty$ \\
\multirow{+}{*}{} \\
$\infty$ \\
$\stackrel{n}{\beth}$ \\
$=$
\end{tabular} \\
\hline 电 & $\overline{2}$ & $\begin{array}{l}\vec{J} \\
-\end{array}$ & \begin{tabular}{l}
0 \\
\multirow{2}{*}{} \\
I.
\end{tabular} & 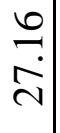 & $\begin{array}{l}2 \\
\hat{\theta} \\
\hat{n}\end{array}$ & $\begin{array}{l}\bar{\sigma} \\
\dot{0} \\
\dot{y}\end{array}$ & $\begin{array}{l}\hat{b} \\
\dot{+}\end{array}$ & $\begin{array}{l}\hat{\sigma} \\
\dot{\theta}\end{array}$ & $\left|\begin{array}{l}8 \\
0 \\
\dot{0} \\
\text { in }\end{array}\right|$ & $\mid \begin{array}{c}n \\
\tilde{n} \\
\stackrel{n}{2}\end{array}$ & $\begin{array}{l}a \\
\tilde{a} \\
\tilde{m}\end{array}$ & $\begin{array}{l}\mathscr{\infty} \\
\dot{+} \\
\dot{\gamma}\end{array}$ & $\begin{array}{l}N \\
\\
\end{array}$ & $\begin{array}{l}\infty \\
\sigma \\
\bar{\sim}\end{array}$ & $\begin{array}{c}\bar{Z} \\
\dot{n} \\
\tilde{n}\end{array}$ & $\begin{array}{c}n \\
\dot{a} \\
m\end{array}$ & $\begin{array}{l}\sigma \\
\dot{6}\end{array}$ & $\begin{array}{l}0 \\
n \\
n \\
n\end{array}$ & $\begin{array}{l}\infty \\
n \\
\\
\end{array}$ & $\mid \begin{array}{c}\infty \\
\stackrel{n}{n} \\
m\end{array}$ & $\left|\begin{array}{l}0 \\
\infty \\
0 \\
\dot{f}\end{array}\right|$ & $\begin{array}{l}0 \\
0 \\
0\end{array}$ & $\mid \begin{array}{l}n \\
n \\
n\end{array}$ & $\begin{array}{c}\tilde{O} \\
\dot{J} \\
\text {. }\end{array} \mid$ & $\begin{array}{c}m \\
\stackrel{n}{n}\end{array}$ & $\begin{array}{l}\infty \\
\infty \\
\dot{\nabla}\end{array}$ \\
\hline$\stackrel{\varrho}{2}$ & 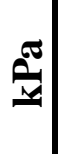 & $\frac{5}{n}$ & 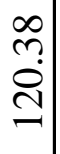 & 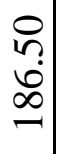 & $\begin{array}{l}\approx \\
\therefore \\
\therefore \\
\sim\end{array}$ & 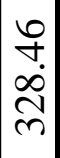 & $\begin{array}{l}\bar{n} \\
\tilde{n} \\
\tilde{n}\end{array}$ & 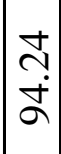 & $\begin{array}{l}6 \\
6 \\
\bar{n} \\
-\end{array}$ & 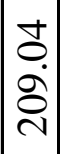 & $\begin{array}{l}n \\
\tilde{n} \\
\stackrel{n}{n}\end{array}$ & $\begin{array}{l}0 \\
+ \\
\dot{r} \\
m\end{array}$ & $\begin{array}{l}n \\
\dot{a} \\
\end{array}$ & 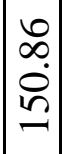 & $\left|\begin{array}{l}0 \\
0 \\
\infty \\
0 \\
0\end{array}\right|$ & 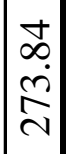 & $\begin{array}{l}\checkmark \\
0 \\
0 \\
+ \\
+\end{array}$ & $\left|\begin{array}{l}\infty \\
\infty \\
\dot{0} \\
0 \\
0\end{array}\right|$ & $\begin{array}{l}\infty \\
\dot{-1} \\
-\end{array}$ & $\mid \begin{array}{l}m \\
\frac{m}{2}\end{array}$ & $\left|\begin{array}{c}\bar{n} \\
n \\
\infty \\
\infty\end{array}\right|$ & $\begin{array}{l}\vec{n} \\
\tilde{y}\end{array}$ & $\left|\begin{array}{c}n \\
n \\
0 \\
0\end{array}\right|$ & $\left|\begin{array}{c}0 \\
0 \\
2 \\
0 \\
-0\end{array}\right|$ & 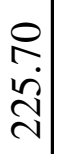 & $\begin{array}{l}\text { ๙ે. } \\
\text { ๙ิ }\end{array}$ \\
\hline 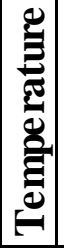 & 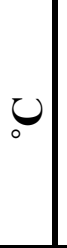 & $\dot{\grave{d}}$ & $\ddot{\grave{d}}$ & $\stackrel{\sim}{\sim}$ & 吕 & ڤે̀ & $\hat{a}$ & 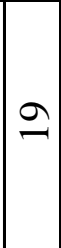 & $\left|\begin{array}{l}\infty \\
0 \\
0\end{array}\right|$ & $\begin{array}{l}0 \\
\infty \\
\infty\end{array}$ & $\begin{array}{l}n \\
\infty \\
\infty\end{array}$ & $\begin{array}{l}0 \\
0\end{array}$ & $\left|\begin{array}{l}0 \\
0 \\
2\end{array}\right|$ & $\mid \begin{array}{l}n \\
\infty \\
-1\end{array}$ & $\begin{array}{l}m \\
\infty\end{array}$ & 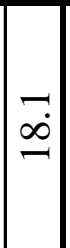 & $\stackrel{0}{a}$ & $\left|\begin{array}{c}0 \\
\infty \\
0\end{array}\right|$ & $\left|\begin{array}{l}n \\
\infty \\
0\end{array}\right|$ & $\begin{array}{l}N \\
\infty \\
\infty\end{array}$ & $\ddot{\infty}$ & $\ddot{2}$ & $a$ & $\underset{\infty}{\infty}$ & $\underset{\infty}{\infty}$ & $\underset{\infty}{\infty}$ \\
\hline 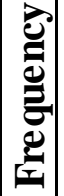 & $\underline{\mathbf{I}}$ & 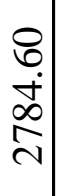 & 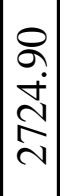 & $\left|\begin{array}{c}0 \\
0 \\
0 \\
\stackrel{0}{2} \\
\end{array}\right|$ & 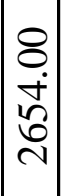 & $\mid \begin{array}{c}0 \\
\\
\hat{2} \\
2 \\
\end{array}$ & 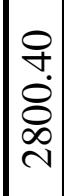 & $\mid$\begin{tabular}{l}
0 \\
$\infty$ \\
$\dot{0}$ \\
\multirow{+}{\pm}{} \\
\end{tabular} & 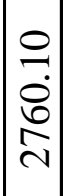 & 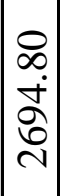 & 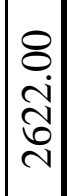 & 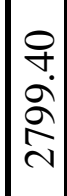 & 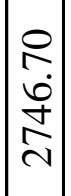 & 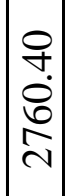 & 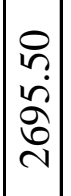 & 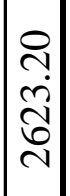 & $\begin{array}{l}0 \\
\curvearrowright \\
\infty \\
\infty \\
N \\
\sim\end{array} \mid$ & 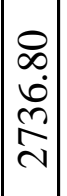 & $\left|\begin{array}{c}0 \\
\infty \\
0 \\
\\
\end{array}\right|$ & 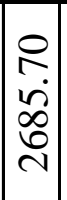 & 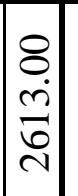 & $\begin{array}{l}8 \\
0 \\
\infty \\
N \\
N\end{array}$ & 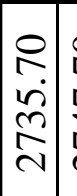 & 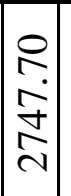 & 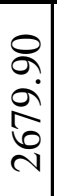 & 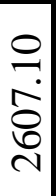 \\
\hline 들 & 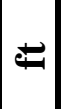 & $\underline{-}$ & $\tilde{n}$ & 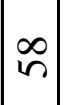 & 2 & 8 & 0 & $\hat{n}$ & $\stackrel{\infty}{\curvearrowleft}$ & 9 & 8 & 0 & $\hat{n}$ & $\mid \begin{array}{l}\infty \\
\wp\end{array}$ & 2 & @ & 0 & $n$ & $\mid \begin{array}{l}\infty \\
\curvearrowleft\end{array}$ & 2 & 8 & 0 & $\tilde{m}$ & 文 & 2 & 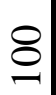 \\
\hline & & 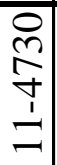 & 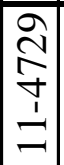 & 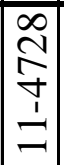 & 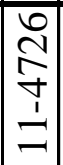 & \begin{tabular}{|c|}
$\stackrel{̃}{N}$ \\
$\stackrel{+}{+}$ \\
$\stackrel{1}{二}$
\end{tabular} & 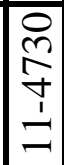 & 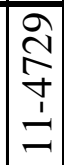 & 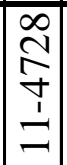 & 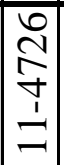 & \begin{tabular}{l}
$\tilde{N}$ \\
\multirow{J}{+}{} \\
I \\
\end{tabular} & 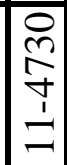 & 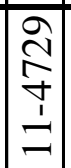 & \begin{tabular}{c}
$\infty$ \\
N \\
\multirow{J}{+}{} \\
$\vdots$ \\
$=$
\end{tabular} & 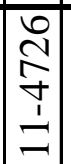 & 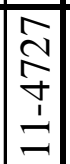 & \begin{tabular}{|c|} 
\\
$\stackrel{n}{0}$ \\
$\stackrel{f}{1}$ \\
1 \\
$=$
\end{tabular} & 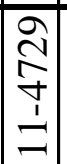 & 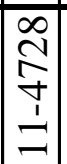 & 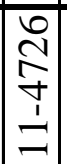 & \begin{tabular}{c}
$\widehat{N}$ \\
\multirow{\gamma}{*}{} \\
1 \\
$=$
\end{tabular} & 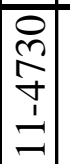 & 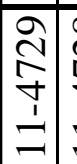 & 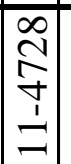 & \begin{tabular}{l}
$\stackrel{0}{ }$ \\
\multirow{N}{*}{} \\
$\stackrel{+}{+}$ \\
$\beth$
\end{tabular} & \begin{tabular}{l} 
N \\
\multirow{+}{*}{} \\
$\stackrel{1}{二}$
\end{tabular} \\
\hline
\end{tabular}




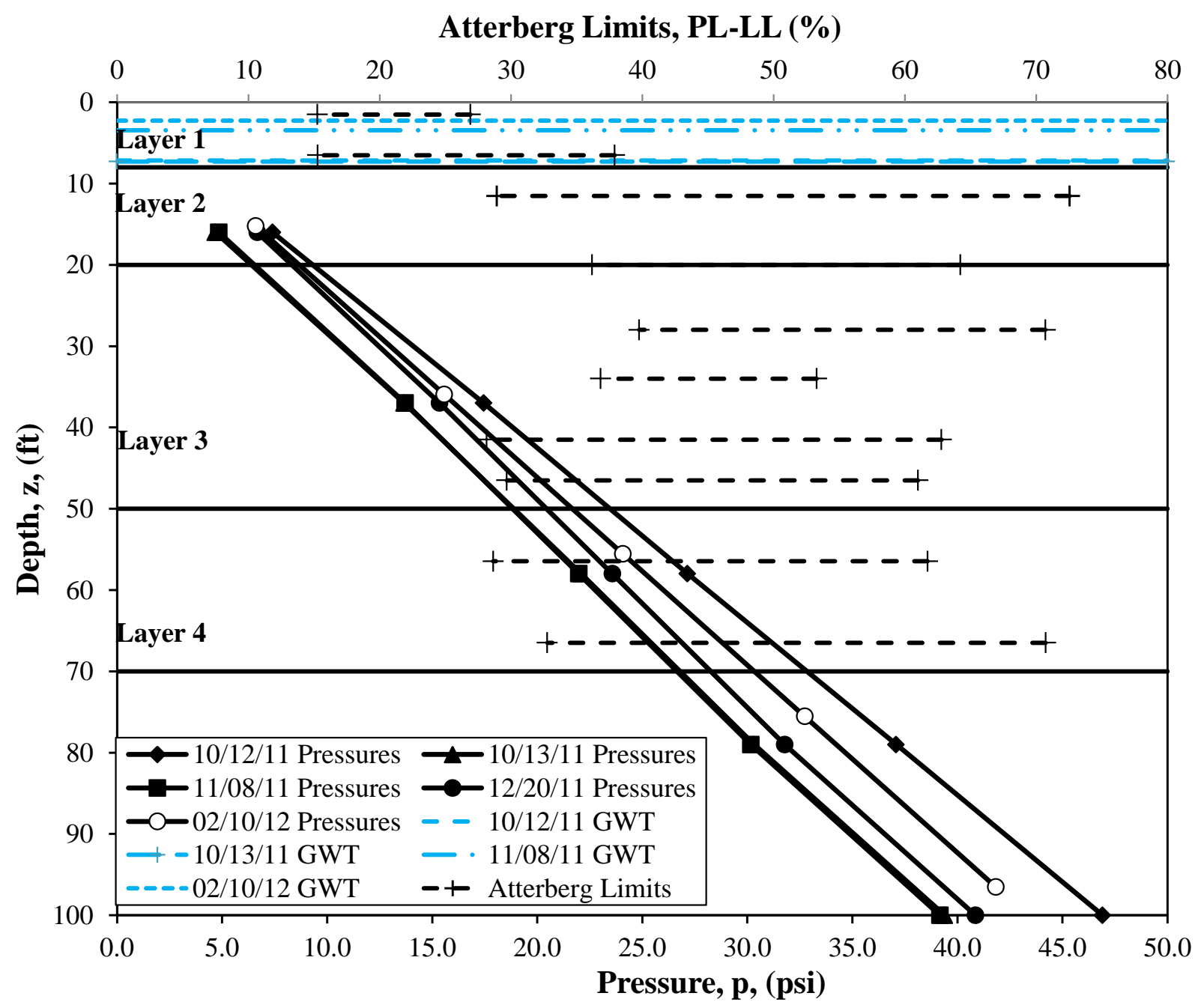

Figure 6.44. Pressure obtained from the nested vibrating wire piezometer [in color].

\subsection{Discussion of Results}

A discussion of results obtained from the geotechnical exploration, laboratory testing, and slope stability models is presented in this section. The results of the remote and non-remote sensing monitoring techniques implemented at the two sites, calibration and validation, for this research project (AHTD TRC-1102) are compared in the following subsections. As discussed in Section 6.2, Shelby tube samples, SPT samples, and core (rock) samples were obtained during the subsurface exploration and sampling operations conducted at the validation site in October 2011. The different soil and rock layers forming the stratigraphy at the validation site were 
determined through the subsurface exploration. Soil and rock samples acquired were tested in the University of Arkansas soils laboratory to characterize both, the material and strength properties of the samples. After index properties (Atterberg Limits), moisture contents (field and laboratory), unit weight, and void ratios were obtained a profile of the area was developed for a better interpretation of the soil layers. The soils in the validation site predominately classified as high plasticity silts and clays with typical PI above 55. The moisture contents obtained (field and moisture) were, in general, closer to the plastic limit than to the liquid limit of the individual soil layers suggesting that the material properties are subject to change depending on the hydraulic condition. A significant change in the Atterberg Limits and unit weights was obtained at a depth of approximately 7 feet depth which was indicative of the presence of the groundwater table. The location of the ground water table was further confirmed by the results obtained from the nested wire piezometer.

Despite the disparate nature of the tests the undrained shear strength (from UU testing) was compared to the strength index properties (field pocket penetrometer and torvane) after the requisite conversions were applied (as described in Section 6.3.3). Four distinct different layers were observed from the strength tenting and subsurface. The undrained shear strength was higher in the top five feet due to desiccation of this layer causing an increase in the effective overconsolidation ratio. Below the desiccation zone, a general increase in strength was observed among each individual soil layer. A significant loss in strength, after the peak strength of the sample was reached, was observed for all the samples below at 61 feet. The low residual strengths were considered to be a major factor in driving the sliding mechanism and continuing movement of the landslide at the validation site. The cone penetrometer testing (CPT) data provided higher undrained shear strengths when compared to the undrained strengths obtained 
from UU tests. This was partially due to the fluctuations of the water table from the time the geotechnical exploration was performed (summer), and when the CPT tests were performed (fall). The lower water table present in the fall caused an increase in effective stress due to reduction of the hydrostatic pressure resulting in a strength gain. However, both the CPT and UU testing show strength gains at the same depth.

Testing of rock samples and the RQD values obtained in the field provided an estimate of the quality of the rock layers. A hard limestone layer located above a weathered shale layer was observed from the results of confined compression testing conducted in the rock samples. The characterization of the material and strength properties of the soils found in the validation site provided critical information while analyzing the monitoring data performed at this site.

\subsubsection{Comparison of Monitoring Results at the Calibration Site (Chester, Arkansas)}

The results from the remote sensing monitoring program performed at the calibration site using the total station, LIDAR and RADAR systems were analyzed to determine the failure mode and displacement rates of the moving mass. The survey monuments monitored using the total station provided information in the horizontal and vertical planes from a specific single point in the sliding area, but did not provide an "area" measurement requiring interpolation of displacement between monuments.

A rotational failure mode for the landslide at the calibration site was detected by the movements measured using the total station. The largest negative elevation differences or downward movements were measured on the survey monuments installed on top of the slide proximal to the main scarp, while the largest uplift movements were recorded on the monuments installed at the toe of the slope failure. The LIDAR survey detected the location of the main scarp at the calibration site. The maximum negative elevation difference (downward movement) detected using LIDAR was the approximately same negative elevation difference measured 
using the total station. Downward movements in other areas, besides the main scarp, were not detected using LIDAR.

In the horizontal direction, the largest movements were obtained from the survey monuments located in the center of the monitored area and directly below the main scarp. The horizontal displacements measures decreased for the survey monuments located close to the boundaries of the monitored area. Therefore, interpolation between survey monuments was necessary to estimate the boundaries of the moving mass by total station data. Conversely, the methods utilized during this research project (AHTD TRC-1102) for LIDAR data reduction were incapable of detecting the horizontal movements or horizontal directions of the sliding mass. Individual targets would have to be installed to track individual points using LIDAR and determine horizontal displacement rates and directions.

The increased in pore water pressures caused by increased saturation (driven by precipitation) of the moving mass resulted in large displacements in both directions due to corresponding reduction in effective stress. In fact, the calculated maximum displacements rates in both, horizontal and elevation difference were measured using the total station after strong precipitation events. The largest downward elevation difference observed using LIDAR also correlated with a heavy rain period experienced near Chester, Arkansas between May and June 2011.

By comparison of the three different slope stability models generated for the calibration site, it was demonstrated that the Terzaghi (1967) and AHTD (2011) correlations overestimate the undrained shear strength relative to the SPT blow count for the soils in the Northwest Arkansas (NWA) region. The slope stability models for the calibration site were performed using the site geometry obtained from the topographic maps. Therefore, the properties assigned to the 
different soil layers were the driving factor for the failure in the model. The most reasonable factor of safety was obtained using the UARK correlation, which was expected since it was developed for the soils in the area (NWA). The result of the slope stability model at the validation site is validated by the movement observed during the site visits.

\subsubsection{Comparison of Monitoring Results at the Validation Site (Malvern, Arkansas)}

The larger physical extends of the moving mass at the validation sites caused significant difficulties in capturing accurate data through the monitoring program. The total station was unable to measure the real or true displacements of the survey monuments installed in the site. Even though, the distances to the survey monuments were within the published capabilities of the Nikon DTM-520 total station, large amounts of error were encountered when surveying long distances (above 800 feet) perpendicular to the direction of movement. False displacements were obtained as the distance of the survey monuments from the total station control point increased. A turning error was also observed when the total station data was reduced. Despite the development of two methods (the angle correction and tangent circles methods), no significant improvement in the data was noted after the implementation of a correction scheme. Additionally, the total station control points used (Point 1000 and 1029) were believed to be inside the extents of the moving mass, therefore the displacements measured were affected by the movement of the instrument.

Poor correlation of progressive movement was obtained from LIDAR results. The large amount of noise observed in the images was attributed to errors in the setup or registration of the four different scan locations. A main scarp, the extents of the moving mass, and/or the pavement cracks observed during site inspections were not detected by LIDAR at the validation site. The area close to the structure (house/driveway) North of Highway 84 showed little or no movements as expected. 
To date the most useful information about the movement of the landslide at the validation site near Malvern, Arkansas was obtained using the non-remote sensing techniques installed on site. The four inclinometers were able to detect movement and measure the depth to the slip surface of the slide. The slip surface depth obtained using the inclinometers matched the information provided from previous investigation and instrumentation installed in the validation site. The displacements rates computed from inclinometers data increased for the last visit, when an increase in the ground water table was measured using the vibrating wire piezometer installed at B-2. Translational landslide movement was determined to be the failure mode at the validation site near Malvern, Arkansas.

\subsection{Conclusion}

The results from the geotechnical exploration and monitoring program at the calibration and validation sites were presented and discussed in this chapter. The results of the temporary and permanent instrumentation used at each of the sites were presented in a tabular and graphical form. The monitoring techniques used on each site were compared to find the best technique that resulted in the best representation and provided the best quantification of the movements of the landslide.

The results from each of the sites studied during this research project (AHTD TRC-1102) were analyzed to determine the causes of the noise or errors obtained for the different techniques. The results of the preliminary and refined slope stability models were presented and compared. Three different correlations were utilized to calculate the undrained shear strength values form SPT data. A slope stability model using the undrained shear strength values obtained after laboratory testing of the Shelby tubes samples was presented. 


\section{Chapter 7. Conclusion and Recommendations}

\subsection{Introduction}

The conclusions derived from the results of this research project (AHTD TRC-1102) are summarized and presented in Section 7.2 of this chapter. Recommendations derived from the geotechnical exploration, monitoring program (total station, LIDAR and RADAR), and laboratory testing results are presented in Section 7.3. Ideas for other research opportunities, as developed while collecting and processing the data but were not further investigated because of time and budgetary constraints, need to be investigated to refine the use of remote sensing techniques for ground monitoring applications. Therefore, proposed research avenues with the potential to provide more accurate results for landslide monitoring using remote sensing techniques are discussed in Section 7.4.

\subsection{Conclusions}

The landslide near Malvern Arkansas (validation site) has being moving for more than 20 years and has been studied by several researchers prior to this research project (AHTD TRC1102). However, the failure mechanism of the landslide was not fully understood and physical extents of the moving mass were not identified prior to this research project. Conversely, a smaller slope failure at the calibration site near Chester, Arkansas was identified more recently. This landslide is located in an area that is known for slope failures attributed to the steep topography, the poor compaction of the constructed roadway embankments (cut and fill slopes), and the weak foundation soils. Because of the small size, limited history of slope movement, budget and time constrains, a full geotechnical exploration was not performed at the calibration site, but instead was performed at the validation site near Malvern, Arkansas. 
The geotechnical exploration conducted at the validation site consisted of drilling five boreholes (B-1, B-2, B-3, B-4, B-6) to a depth of 100 feet below the ground surface; four of which were instrumented with inclinometers (B-1, B-3, B-4, B-6) and the other with a nested vibrating wire piezometer (B-2). The soil stratigraphy encountered consisted of four soil layers and three distinct rock layers observed during sampling operations.

- The water content as obtained from samples measured in the field were higher than the water contents obtained after testing of the Unconsolidated Undrained (UU) samples. In general, the soils in the area (top four layers) classified as a $\mathrm{MH}$ to $\mathrm{CH}$ according to the Atterberg Limits results and Casagrande plasticity chart. Softening behavior of the clay samples was observed during the UU tests, and large undrained shear strength $\left(\mathrm{S}_{\mathrm{u}}\right)$ losses, were recorded for samples below 61 feet, which is close to the slip surface (as inferred from the inclinometer data). Four distinct soil layers were observed when plotting the strength data. Desiccation caused overconsolidation of the top layer resulting in higher undrained shear strengths.

The slope failure located at the calibration site near Chester, Arkansas affected the lanes of the Interstate 540 in the Northwest Arkansas (NWA) region. The failure was first observed by the Arkansas Highway and transportation Department (AHTD) in May 2010. Three remote sensing techniques (total station [Nikon DTM-520], LIDAR [Leica C-10], and RADAR [GPRIII]) were successfully implemented for monitoring over a 12 months period at the calibration site.

- The total station data acquisition point (parallel to the direction of movement) provided a reliable method to determine the movement of the survey monuments installed in the moving mass at the calibration site. The surveys were unable to determine the exact extents of the 
moving mass due to single point data acquisitions. Consequently, the moving mass boundaries were interpolated between the survey monuments that display large movements and the survey monuments where none or low movements were observed.

- Total station provided measurements in both, the horizontal and vertical directions. The high displacements rates calculated using total station data correlated to strong precipitation events experienced at the calibration site during May and June 2011.

- Two LIDAR scans setup locations were necessary to cover the extension of the site (approximately 550 feet wide). The slope failure was determined to be a rotational landslide as observed from analyzing the displacements obtained using the total station.

- The location (confirmed by visual inspection and total station) and vertical elevation differences of the main scarp were detected using LIDAR. The elevation differences of the monuments close to the main scarp (measured with the total station) matched the elevation differences obtained from the LIDAR data. However, trees, bushes, and topography of the project site caused shadows in certain spots of the calibration site during the spring season prohibiting LIDAR to acquire data in certain areas.

- A maximum elevation difference of 0.5 feet was detected in the main scarp at calibration site using LIDAR, before repairs were performed. The exact limits of the moving mass acting at the calibration site were not detected using LIDAR. The data reduction methods utilized in this research project (AHTD TRC-1102) for LIDAR data processing did not allow for the detection of horizontal movements.

- The UARK SPT-S $\mathrm{u}_{\mathrm{u}}$ correlation (Ritchey, 1999), among the other two correlations (AHTD [2011], Terzaghi [1967]) considered, was demonstrated to be the one that best fit the soils encountered in the Northwest Arkansas (NWA) area. A factor of safety of 1.003 for the 
validation site was obtained from the slope stability model using the UARK correlation. This supports the advantage in the use of locally developed correlations where available. The movements observed during the site visits to the calibration site validated the limit equilibrium model created in SLIDE v5.044 for the calibration site near Chester, Arkansas.

The landslide occurring at the validation site near Malvern Arkansas affected several lanes of a major Interstate (I-30), highway (HWY 84), and access road (Haltom Road) of the area. Remote and non-remote sensing techniques were utilized to monitor the movements of the landslide located at the validation site. The remote sensing techniques implemented were total station, LIDAR and RADAR. The non-remote sensing techniques consisted of inclinometers and a piezometer.

- The total station setup location (perpendicular to the direction of movement) did not allow for reliable total station data acquisition at the validation site near Malvern, Arkansas. A turning error and false displacements of the survey monuments, caused by the large survey distances, were encountered using the total station. The two methods attempted (angle correction and tangent circles) to decrease the distance error observed did not improved the total station results. Therefore, displacements rates from total station results were not calculated due to the large amount of displacement error observed.

- Four LIDAR setups were necessary to scan the extensions of the validation site (approximately 1100 feet wide). LIDAR detected downward elevation change in certain areas of the validation site. Other areas close to structures and lanes showed low to no movement. Two different methods (polylines method and bare earth correction method) were performed to remove the vegetation of both sites. 
- The depth of the failure surface as detected from the inclinometer data, matched the slip surface depth measured in investigations prior to this research project (AHTD TRC-1102). A translational failure mode was believed to be acting at the validation site. The failure surface was detected in the interface between the dark brown clay layer and the limestone layer at a depth of approximately 62 feet below the ground surface.

- The ground water table depth in the validation site was inferred from the pressures measured using the nested wire piezometer installed at B-2. No changes in pressure were measured at the depths where the transducers were installed (16ft, 37ft, $58 \mathrm{ft}, 79 \mathrm{ft}$, and $100 \mathrm{ft})$. The increased of the ground water table measured during the last visit (February $2^{\text {nd }}, 2012$ ) correlated to an increase in the displacement rates calculated from the inclinometers installed on site.

In general, each monitoring technique utilized during this research project (AHTD TRC1102) demonstrated advantages and disadvantages. Limitations encountered during the data acquisition phase of the systems impacted the results obtained for each of the sites. The data reduction processes utilized for each of the sites varied accordingly to the site specific features.

- The total station viewing geometry directly affected the data acquired. Total station required the installation of survey monuments in the ground for point acquisition. Therefore, data was only collected where survey monuments were installed. In order to increase the resolution more survey monuments had to be installed in the study area. Total station data acquisition required more time and labor than LIDAR and RADAR data acquisition.

- LIDAR scans covered larger areas in less time than the total station. Thousands of points were acquired on every LIDAR scan, in comparison to the single points acquired using total station. Targets are necessary to track or calculate displacements in the horizontal direction. 
The bare earth correction method utilized for LIDAR during this research project (AHTD TRC-1102) provided an automated and reliable method for vegetation removal. Data processing of LIDAR scans was more complex than the total station data reduction. Consequently, user training and application specific software programs are necessary for a LIDAR monitoring program.

- RADAR permitted the acquisition of data during a wide range of weather conditions, while, the LIDAR and total station systems were unable to acquired data during the same weather conditions. Portability of the scan enables data acquisition on remote areas with a long range (approximately 4 kilometers).

\subsection{Recommendations}

The three monitoring techniques may be used for landslide monitoring. Depending in the site specific features the use of one technique method may be preferentially indicated. Total station was found to provide reliable results for monitoring of relative small areas (up to 600 feet) where the amount of survey monuments required is not extensive. Conversely, when time and labor costs are of the driving concern, LIDAR and RADAR systems may provide a better method to efficiently monitor large areas with a reduced investments in manpower and scheduling.

The total station data reduction process is less computationally and intellectually demanding for the user, then the more advanced remote sensing techniques. Additionally, the total station data reduction can be performed in common datasheet programs without the usage of special software dedicated and potentially expensive software. Although, the data processing of LIDAR and RADAR is more complex, automations of certain procedures is possible. Also, the LIDAR and RADAR data reduction process allows for visualization of the data acquired. 
Three-dimensional visualization of the data (LIDAR) provides the opportunity for manual inspection and filtering of any erroneous data.

Collect Pitcher Barrel samples at the sliding surface in the Malvern site to conduct direct shear test because horizontal plane may control the failure mode. A good selection of the setup locations for data acquisition on any of the three systems studied (total station, LIDAR, and RADAR) is critical for accurate results. Deploy and install RADAR targets in the study area to increase the resolution of the system. The viewing geometries to the study area directly affected the data acquired during site visits. For example, it is recommended that a location parallel to the moving direction of the landslide is selected for total station data acquisition. RADAR and LIDAR data acquisition location must be far from any objects (signs, trees, bush, or structure) that will cause shadows in the study area. Vegetation removal is a key step when analyzing LIDAR and RADAR data for ground movement applications.

\subsection{Future Research}

This research project compared three different remote sensing techniques for monitoring of landslide along road lanes, an application where some of these techniques were not fully tested. Based in the field experience and results obtained during this project research (AHTD TRC-1102), further research is necessary in the following areas:

- quantification of vegetation effects by using a control study area, where no vegetation is present,

- analyzing the financial burdens associated with the purchasing, deployment, operation, and processing inherent to each systems to determine which systems provides the most cost-effective method for landslide monitoring, 
- determine the precision and accuracy for each independent sensor by measuring a well a site or object with known velocities,

- automate the LIDAR and RADAR data acquisition procedures to be performed remotely without a user operator; in order to serve as warning systems for landslide acting along populated areas, and

- study the other landslide failure modes such as: rock fall, debris to determine the reliability of the systems for those applications.

\subsection{Conclusion}

The final conclusions and recommendations of this research study (AHTD TRC-1102) were presented in this chapter. The conclusions were presented based on the results obtained from each of the sites studied (calibration and validation), and general conclusions obtained after handling of the different monitoring sensors. The data reduction procedures and selection of the setup locations for data acquisitions are key aspects when using total station, LIDAR and RADAR.

As with most research projects, new ideas were developed during the data acquisition, data reduction and analysis of results phases of this research project (AHTD TRC-1102). The areas and topics to be investigated next related to the findings of this study were presented in the future research section of this chapter. Further improvement of the advance remote sensing techniques (LIDAR and RADAR) will increase understanding of the public and set the state of the art for monitoring of unstable slopes using these techniques. 


\section{References}

American Society for Testing and Materials, (2007), "Standard Test Methods for Liquid Limit, Plastic Limit, and Plasticity Index of Soils" Annual Book of ASTM Standards, Designation D4220, Vol. 4.09, ASTM, West Conshohocken, PA.

American Society for Testing and Materials, (2007), "Standard Test Methods for Laboratory Determination of Water (moisture) Content of Soil and Rock by Mass" Annual Book of ASTM Standards, Designation D2216, Vol. 4.09, ASTM, West Conshohocken, PA.

American Society for Testing and Materials, (2007), "Standard Methods for UncosolidatedUndrained Triaxial Compression test on Cohesive Soils" Annual Book of ASTM Standards, Designation D2850, Vol. 4.09, ASTM, West Conshohocken, PA.

American Society for Testing and Materials, (2007), "Standard Practices for Preserving and Transporting Soil Samples" Annual Book of ASTM Standards, Designation D4220, Vol. 4.09, ASTM, West Conshohocken, PA.

Anderson, N., Gwinnup-Green, M., and Kane, W., (1996), "Monitoring of Embankments Stability Using Embedded Coaxial Cables," Proceedings, 1996 Annual Conference, Association of State Dam Safety Officials, Seattle, WA

Arkansas State Highway and Transportation Department (2007). "Standart Penetration Hammer Efficiency for N-Value Correction,” Project Number TRC-0701, November 2007.

Arkansas State Highway and Transportation Department (2010). "Geotechnical Report D04133," August 26.

AutoCAD. Version E. 115.0.0. 2011. 2010 AutoDesk, Inc.

Barla, G., Antolini, F., and Barla, M., (2010), "Monioring of the Baeuregard Landslide (Aosta Valley, Italy) using advanced and conventional techniques," Engineering Geology Journal, Sptwmber 2010.

Bitelli, G., Dubbini M., and Zanutta, A., (2004) "Terrestrial laser scanning and digital photogrametry Techniques to monitor landslide bodies," Proceedings of the XXth ISPRS congress, Instanbul, Turkey, Commision, V, WG V/2.

Bozzano, F., Mazzanti P., and Prestininzi, A. (2008), “A RADAR Platform for Continuous Monitoring of a Landslide Interacting with a Under-Construction Infrastructure," Italian Journal of Engineering Geology and Environmental, 2, pp 35-50.

Coffman, Richard A. (2009), "Processing of Synthetic Aperture RADAR Data as Applied to the Characterization of Localized Deformation Features," PhD. Dissertation, University of Missouri, Columbia, August. 
Coffman. Richard A. (2010), "Slope Stability Monitoring Using a Ground Based Portable RADAR Interferometer," AHTD Proposal, Little Rock, Arkansas.

Crosby, C., and Oskin, M., (2011), "LiDAR Classification," SCEC LiDAR Short Course: Imagining \& Analyzing Southern California's Active Faults with High-Resolution Lidar Topography," Power Point presentation, October 24-25, 2011.

Dallaire, E., (1974) "Electronic distance measuring revolution well under way," Civil Engineering 44 (10), pp 66-71

DataMate Manager Manual, (2011), "DMM for Windows," Durham Geo Slope Indicator, Washington, USA.

Dennis, N. D., Ooi, C. W., and Wong, V. H., (2006) "Estimating Movement of Shallow Slope Failures Using Time Domain Reflecometry," Proceedings TDR 2006, Purdue University, West Lafayette, USA, September 2006, Paper ID 41, 16p.

Dowding, C., O'Connor K., (2000) "Comparison of TDR and Inclinometers fo Slope Monitoring,” Geotech. Spec. Publ., 106, 80-90.

Duffell, C., Rudrum D., and Willis, M., (2005) "Detection of Slope Instability using 3D LIDAR Modeling," Proceedings of GeoCongress 2006, ASCE, USA, pp 1-5.

GAMMA Remote Sensing AG, (2011) "GAMMA Portable RADAR Interferometer II (GPRI-II) User Manual,” Worbstrasse 225 CH-3073 Guemligen, Switzerland, February.

GAMMA Remote Sensing AG, (2012), "Research \& Development/Microwave Hardware/GPRI," website viewed March 21, 2012, <http://www.gammars.ch/rud/microwave-hardware/gpri.html>.

Google Maps Website, (viewed August 2011), http://maps.google.com/.

GroundProbe, (2012), "Slope Stability RADAR (SSR) Online Brochure," website viewed March 21, 2012, < http://www.groundprobe.com/docs/ssr/GP\%20SSR\%20brochure.pdf>.

Griffiths, J., Stokes, M., and Thomas, R., (1999), “Landslides,” Taylor \& Francis, $1^{\text {st }}$ Edition.

Harries, N., Noon, D., and Prichett, H., (2009), "Slope Stability RADAR for Managing Rock Fall Risks in Open Cut Mines," Proceedings of the $3^{\text {rd }}$ Canus Rock Mechanics Symposium, Toronto, May

Harries, N., Noon, D., and Rowley, K. (2006) "Case studies of slope stability RADAR used in open cut mines" Stability of Rock Slopes in Open Pit Mining and Civil Engineering Situations, Johannesburg, SAIMM, Symposium Series S44, pp. 335-342. 
Heritage, G., Large A., (2009) "Laser scanning for the environmental sciences," WileyBlackwell, London.

Hertz, H., (1893), “Electric-Waves,” London:Dover.

Hisham, T., and Stark, T., (1998), "Undrained shear strength from cone penetrometer test," Geotechnical Site Characterization, Balkema, Rotterdam.

Ingegneria Dei Sistem Online Brochure, (2007), “IBI-L Case Study May 2007,” website viewed March 2, 2011, <http://microgeo.it/Interferometria/pdf/Monitoraggio-Frane.pdf>.

Ingegneria Dei Sistem Website, (2012), “IDS Australasia,” website viewed March 22, 2012, <http://www.idsaustralasia.com/announcements-1/ibis-l-release-x-band-sensor>.

Ingensand, H. (2006) "Metrological aspects in terrestrial laser-scanning technology," Proceedings of the $3^{\text {rd }}$ IAG $/ 12^{\text {th }}$ FIG Symposium, Baden, Autria.

Jaboyedoff, M., Oppikofer, T., Abellán, A., Derron M., Loye A., Metzger R., and Pedrazzini A., (2010), "Use of LIDAR in landslide investigations: a review," Natural Hazards Journal, 61, pp 5-28.

Jensen, J. R. 2007. Remote Sensing of The Environment: An Earth Resources Perspective. Prentice Hall, Upper Saddle River, NJ.

Jungner, Andreas, (2009), "Ground-Based Synthetic Aperture RADAR Data Processing for Deformation Measurement," Master's of Science Thesis in geodesy No. 3116, Division of Geodesy, Royal Intitute of Technology (KTH), 10044 Stockholm, Sweeden, May 2009.

Krabill, W., Collins J., Link L., Swift R., and Butler M., (1984) "Airborne laser topographic mapping results," Photogramm Eng. Remote Sensing 50, (6), pp 685-694.

Krabill, W., Thomas, R., Martin C., Swift R., and Frederick E., (1995), "Accuracy of airborne laser altimetry over Greenland ice sheet," International Journal of Remote Sensing, 16 (7), pp 1211-1222.

Leica Cyclone (2010), Version 7.1.1 Documentation, Leica.

Leica ScanStation C10 Brochure, (2011), "The All-in-One Laser Scanner for Any Application," Leica Geosystems AG, Heerbrugg, Switzerland.

Manetti, L., Steinmann, G., (2007) "3DeMoN ROBOVEC-integration of a new measuring instrument in an existing generic remote monitoring platform," Proceedings of $7^{\text {th }}$ Symposium on Field Measurements in Geomechanics, ASCE, Boston, MA, USA, pp 2427.

Maxwell, C. (1873), “A Treatise on Electricity and Magnetism,” The Clarendon Press, Oxford 
McHugh, E., Dwyer, J., Long, D., and Sabine, C., (2006) “Applications of Ground-Based RADAR to Mine Slope Monitoring," Report of Investigations 9666, Department of Health and Human Services-Centers for Disease Control and Prevention-National Institute for Occupational Safety and Health, Cincinnati, Ohio, April

Metzger, J., (2012) Personal Correspondance (e-mail) with Omar Conte, GeoProbe Pre-Sales Representative-North America. March 3, 2012.

Mora, P., Baldi, P.,Casula, G., Fabris, M., Ghriotti, M., Mazzioni, E., and Pesci, A. (2003), "Global Positioning Systems and Applications, Geomatica, Vol. 56 No. 1 pp. 21-33.

National Oceanic and Atmospheric Administration Website (2012), "National Weather Service Forecast Office Tulsa, Oklahoma," website viewed March 16, 2012 , $<$ http://www.nws.noaa.gov/climate/index.php?wfo=tsa>.

Nikon Instruction Manual, (2011), "Total station DTM-500 series," Nikon Corporation, Shinagawa-ku, Japan.

Nikon Positioning Website, (2012), "Surveying Products," website viewed February 2, 2012, < http://www.nikonpositioning.com/nivo_m.aspx>.

Nishii, R., and Matsouka, N., (2010), "Monioring rapid head scarp movment in an alpine rockslide,” Engineering Geology Journal, June 2010.

Noon, David (2012), Personal Correspondance (e-mail) with Omar Conte, March 25, 2012.

Ritchey, R.L. (1999). "Reliability Design Considerations and Procedure for Arkansas Slopes." M.S. Thesis. University of Arkansas, May.

Rudolf, H., Leva, D., Tarchi, D. and Sieber, A.J. (1999) “A mobile versatile SAR system,” Proc., IGRASS 1999, Hamburg, Germany, pp. 594-595.

Savvaidis, P., (2003), "Existing Landslide Monitoring Systems and Techniques," School of Rural and Surveying Engineering, The Aristotle University of Thessaloniki.

Schubel, A., (2011) Personal Correspondance (e-mail) with Dr. Richard Coffman, Arkansas Highway and Transportation Department Bridge Division. August 9, 2011.

Shan, J., Toth K. (2008) "Topographic laser ranging and scanning: principles and processing," CRC Press, Taylor \& Francis Group, LLC, UK.

Slide Version 5.044. Feb 2 2010. Rocscience Inc.

Slope Indicator, (2001), "Geo Slope Indicator Sample Chapter," Data Reduction and Error Correction Manual ,Durham Geo Slope Indicator, Washington, USA. 
Slope Indicator, (2008), "VW Piezometer," Vibrating Wire Piezomter Manual, Durham Geo Slope Indicator, Washington, USA.

Stark, T.D. and H. Choi, (2008), "Slope Inclinometers for Landslides," Landslides, Journal of the International Consortium on Landslides, Vol. 5 No. 3, September, 2008.

Sturzeneger, M., Stead, D., Froese, C., Moreno F., and Jaboyedouff, M., (2007), “Ground-based and airborne LiDAR for structure mapping of a large landslide: the Frank Slide IN: Ebehardt E, Stead D, Morrison T (eds) Rock mechanics: meetins society's challenges and demands. Taylor \& Francis, London, pp 925-932.

Teza, G., Pesci, A., Genevois, R., and Galgaro, A., (2008), "Characterization of landslide ground surface kinematics from terrestrial laser scanning and strain field computation," Geomorphology 97, pp 424-437.

Terzaghi, K., and Peck, R. B., (1967), "Soil Mechanics in Engineering Practice," Second Edition John Wiley and Sons, New York, pp. 729.

Ubuntu Version 11.1 February 2011.

United Survey Geological Survey Website, (2011), “Atoka Formation," website viewed February $\quad$ 10, 2012, <http://tin.er.usgs.gov/geology/state/sgmcunit.php?unit=OKPAat\%3B0>.

Valle d' Aosta Website, (2012), "Beauregard Dam," website viewed April 4, 2012 <http://www.regione.vda.it/turismo/prima_di_partire/informazioni/pagina_ricerche_e.asp?t ipo=scheda\&pk=611\&nomesch=sch_prodvda\&ts=prodvda $>$

Werner, C., Strozzi, T., Wiesmann, A., and Wegmuller, U., (2008), "Gamma's Portable RADAR Interferometer," Proc., $13^{\text {th }}$ FIG Symposium on Deformation Measurement and Analysis. Lisbon, May 12-15.

Werner, C., (2010), Personal Communication (e-mail) with Dr. Richard A.Coffman, March 10, 2010 .

Westerman, J., (2006) "I-30 Slide - Malvern: I-30 Section 21: Log Mile 95.7: Hot Spring County" Arkansas Highway and Transportation Department Memo to Robert Walters, February, 212006.

Wiesmann, A., Werner, C., Strozzi, T., and Wegmuller, U. (2008), "Measuring Deformation and Topography with a Portable RADAR Interferometer," Proc., $13^{\text {th }}$ FIG Symposium on Deformation Measurement and Analysis. Lisbon, May 12-15.

Wolf, Paul, (2002) "Surveying and Mapping:History, Current Status, and Future Projections," Journal of Surveying Engineering, Vol. 128, No. 3, pp. 79-107. 
